\title{
Development of High Energy Density Fuels From Mild Gasification of Coal
}

Final Report

Work Performed Under Contract No.: DE-AC21-88MC25020

For

U.S. Department of Energy

Office of Fossil Energy

Morgantown Energy Technology Center

P.O. Box 880

Morgantown, West Virginia 26507-0880

By
Lummus Crest, Inc.
1515 Broad Street

Bloomfield, New Jersey 07003

December 1991 


\section{TABLE OF CONTENTS}

Page No.

List of Figures

List of Tables

\subsection{EXECUTIVE SUMMARY}

1.1 Background \& DOE Perspective

1.2 Contract Objectives

1.3 Task Breakdown Structure

1.4 Feedstocks

1.5 High Energy Density Fuels (HEDF) 8

1.6 Process Screening Alternatives 9

1.7 Experimental Procedures 10

1.8 Summary of Results of COALITE Operations 11

1.9 Summary of Results of Colorado 12

\subsection{EXPERIMENTAL PROCEDURES}

2.1 Overview

2.2 Bench-Scale Fixed-Bed Hydrotreating Unit 22

2.3 Bench-Scale Fixed-Bed Hydrotreating Unit 23

2.4 Bench-Scale LC-Fining Unit

2.5 Continuous Bench Coking Unit 28

2.6 Laboratory Extraction Unit 30

2.7 4-in Batch Fractionation Unit 32

2.8 Equilibrium Flash Vaporization Pilot Unit 32

2.9 Laboratory Batch Distillation Pilot Unit 32

2.10 Clay Treating Units 32

2.11 Pilot Plant LC-Fining Unit 34

2.12 Pilot Plant Fixed-Bed Hydroprocessing Unit 34

2.13 Calculation Procedures and Anapessing Unit 36

2.13 Calculation Procedures and Analytical Methods 38 
3.1 COALITE Feedstock

3.2 Colorado Shale 0il Feedstock 51

4.0 SUMMARY OF SCREEENING PROGRAM OPERATIONS (TASK 3)

4.1 Cverview 81

4.2 COALITE Operations $\quad 81$

4.2.1 Feedstock Preparation 81

4.2.2 Virgin Distillate Hydrotreating Campaigns 82

4.2.3 Virgin Atmospheric Resid Cracking Campaigns 84

4.2.3.1 LC-Fining (Hydrocracking) 94

4.2.3.2 Delayed Coking 94

4.2.4 Cracked Distillate Hydrotreating Campaigns 100

4.2.4.1 Hydrotreating of LC-Finate 100

$\begin{array}{llll} & 4.2 .4 .2 & \text { Hydrotreating of Coker Distillates } & 100 \\ \text { 4.2.5 } & \text { Two-Step Selective Hydrocracking Campaigns } & 100\end{array}$

4.3 Colorado Shale Oil Operations 112

4.3.1 Feedstock Preparation 112

4.3.2 Virgin Distillate Hydrotreating Campaigns 112

4.3.3 Virgin Atmospheric Resid Cracking Campaigns 119

4.3.3.1 LC-Fining (Hydrocracking) 119

4.3.3.2 Delayed Coking 119

4.3.4 Cracked Distillate Hydrotreating Campaigns 119

4.3.4.1 Hydrotreating of LC-Finate 124

4.3.4.2 Hydrotreating of Coker Distillates 124

4.3.5 Two-Step Selective Hydrocracking Campaigns 124

4.3.6 Extraction Studies 134 


\section{TABLE OF CONTENTS}

Page No

5.0 SUMMARY OF RESULTS OF COALITE SCREENING OPERATIONS

138

5.1 Overview

5.2 Virgin Distillate Hydrotreating

138

5.3 Virgin Atmospheric Resid Cracking

5.3 .1

LC-Fining

5.3.2 Delayed Coking

181

181

181

5.4 Cracked Distillate Hydrotreating

5.4.1

Hydrotreating of LC-Finate Distillates

187

5.4.2 Hydrotreating of Coker Distillates

187

187

5.5 Two-Step Selective Hydrocracking of Vacuum Gas 0il (VGO) 200

5.5.1 Overview of Early Results

5.5.2 Subtask 3.1/3.2 Scope

200

203

5.5 .3

Subtask 3.1/3.2 Results

205

5.5.3.1 LC-Fining Studies 207

5.5.3.2 Fixed-Bed HDN Studies 208

5.5.3.3 Fixed-Bed Selective Hydrocracking Studies 208

5.5.3.4 Hydrotreating Studies 216

5.5.3.5 HEDF Finishing

6.0 SUMMARY OF RESULTS OF COLORADO SHALE OIL SCREENING OPERATIONS 222

6.1 Overview

6.2 Virgin Distillate Hydrotreating

6.3 Virgin Atmospheric Resid Cracking

6.4 Cracked Distillate Hydrotreating

6.5 Two-Step Selective Hydrotreating

6.6 Extraction Studies

259

262 
7.0 SUMMARY OF RESULTS OF PILOT PLANT SAMPLE PREPARATION (Task 5) 267

7.1 Overview

7.2 LC-Fining Operations 267

7.3 Fixed-Bed Hydrodenitrogenation Operations 268

7.4 Fixed-Bed Selective Hydrocracking 270

7.5 Post-Hydroprocessing Operations Operations 272

7.6 HEDF Assays 272

8.0 SUMMARY OF REFINERY UPGRADING ECONOMIC ASSESSMENT (Task 4) 281

8.1 Basis Of Linear Programming Model

8.2 Results of Linear Programming Model Studies

8.3 Economics Sensitivity Studies Model Studies 288

8.4 Conclusions and Recommendations 300

\subsection{REFERENCES}

10.0 INVENTION DISCLOSURES

11.0 ACKNOWLEDGEMENTS 


\section{LIST OF TABLES}

Table No.

Iitle

Page \#

1.8-1

1.8-2

2.11-1

3.1-1

3.1-2

3.1-3

3.2-1

4.2.1-1

4.2.2-1

4.2.2-2

4.2.2-3

4.2.2-4

4.2.2-5

4.2.2-6

4.2.3.1-1

4.2.3.1-2

4.2.3.1-3

4.2.3.2-1

4.2.3.2-2

4.2.4.1-1

4.2.4.1-2

4.2.4.1-3

4.2.4.2-1

4.2.4.2-2

4.2.5-1

4.2.5-2

4.2.5. -3

4.2.5-4

Task 3 Screening Program Results

Final COALITE HEDF Test Fuel Properties

Formulas for Selected Hydroprocess

Analyses of Narrow-Boiling COALIsing Parameters 40

G. .M.S. Analysis-Boiling COALITE Distillates

. Analys is of 200-550F COALITE

NMR Spectroscopy of 390-650F COALITE

Analyses of Narrow-Boiling Colorado Shale 0il Distillates

Hydrotreating Feedstock Analyses of Raw COALITE Mid-Distillate

Summary of Operating Conditions for Fixed-Bed COALITE Hydrotreating Tests (FB17A1-49)

Summary of Operating Conditions for Fixed-Bed COALITE Hydrotreating Tests(FB30-36)

Summary of Operating Conditions for Fixed-Bed COALITE Hydrotreating Tests(FB169-177)

Summary of Operating Conditions for Fixed-Bed COALITE Hydrotreating Tests (FB94-104)

Summary of Operating Conditions for Fixed-Bed COALITE Hydrotreating Tests (FB146-147)

Summary of Operating Conditions for Fixed-Bed COALITE Hydrotreating Tests (FB135-138)

46

48

58

71

83

85

89

90

91

92

93

Feedstock Assays for LC-Fining of COALITE Residua

Summary of Operating Conditions for LC-Fining Tests (BLCF86-101)

Summary of Operating Conditions for LC-Fining 97 Tests (BLCF90-95)

Assays of Delayed Coking COALITE Feedstocks

Summary of Operating Conditions for Delayed Coking of COALITE

Assays of COALITE Mid-distillate LC-Finate Feeds to Hydrotreating

Summary of Operating Conditions for Fixed-Bed Hydrotreating of Hydrocracked COALITE Distillate (FB44-105)

Summary of Operating Conditions for Fixed-Bed Hydrotreating of Hydrocracked COALITE Distillate (FB156-158)

Assays of COALITE Coker Mid-distillate Feeds to Hydrotreating

Summary of Operating Conditions for Fixed-Bed Hydrotreating of Thermally Processed COALITE Distillate (FB45-127)

Assays of COALITE VGO Feedstocks To Fixed- 108 Bed Hydrocracking

Summary of Operating Conditions for Fixed-Bed Hydrocracking of COALITE (FBHC1-17)

Summary of Operating Conditions for Fixed-Bed Hydrocracking of COALITE(FBHC18-27)

Assays of Selectively Hydrocracked COALITE MidDistillate Feed to Hydrotreating

98

99

101

102

103

104

105

109

110

111 


\section{LIST OF TABLES}

Table No.

Title

Page \#

4.3.1-1

4.3.2-1

$4.3 .2-2$

$4 \cdot 3 \cdot 2-3$

$4 \cdot 3 \cdot 3 \cdot 1-1$

4.3.3.1-2

$4 \cdot 3 \cdot 3 \cdot 2-1$

Assay of Raw Colorado Shale Oil Mid-Distillate

113 Feedstock to Hydrotreating

Summary of Operating Conditions for Fixed-Bed

114

Colorado Shale 0il Hydrotreating (FB106-130)

Summary of Operating Conditions for Fixed-Bed

117

Colorado Shale 0il Hydrotreating (FB148-155)

Summary of Operating Conditions for Fixed-Bed

Colorado Shale 0il Hydrotreating (FB159-164)

Summary of Operating Conditions for LC-Fining

of Colorado Shale 0il (BLCF89-1/89-5)

Summary of Operating Conditions for LC-Fining of Colorado Shale 0il (BLCF91-99)

\section{8}

120

121

Assay of Delayed Coking Colorado Shale 0ilDerived Feedstock

122

$4 \cdot 3 \cdot 3 \cdot 2-2$

Summary of Operating Conditions for Delayed Coking

123

4.3.4.1-1 of Colorado Shale 0il (CBC65-66)

Assay of Colorado Shale Oil LC-Finate Mid-

125

4.3.4.1-2

Distillate to Hydrotreating

Summary of Operating Conditions for Fixed-Bed Hydrotreating of Hydroprocessed Colorado Shale Oil Distillate (FB143-145)

$4 \cdot 3 \cdot 4 \cdot 2-1$

$4 \cdot 3 \cdot 4 \cdot 2-2$

Assay of Colorado Shale Oil Delayed Coker MidDistillate to Hydrotreating

Summary of Operating Conditions for Fixed-Bed Hydrotreating of Thermally Processed Colorado Shale 0il Distillate (FB131-134)

$4 \cdot 3 \cdot 5-1$

$4 \cdot 3 \cdot 5-2$

$4 \cdot 3 \cdot 5-3$

$4 \cdot 3 \cdot 5-4$

$4 \cdot 3 \cdot 5-5$

of Colorado Shale Oil VGO Feedstocks

To Fixed-Bed Hydrocracking

Summary of Operating Conditions for Fixed-Bed Colorado Shale 0il Hydrocracking(FBHC5-12)

Summary of Operating Conditions for Fixed-Bed Colorado Shale 0il Hydrocracking (FBHC28-35)

Summary of Operating Conditions for Fixed-Bed Hydrotreating of Hydroprocessed Colorado Shale 0il Distillate (FB186-187)

Summary of Operating Conditions for Fixed-Bed Hydrotreating of Hydrocracked Colorado Shale 0il Distillate (FB188-189)

$4 \cdot 3 \cdot 6-1$

$5.2 .1-1$

5.2.1-2

5.2.1-3A

5.2.1-3B

5.2.1-4A

5.2.1-4B

Results of Extraction of Hydrotreated Colorado 137

126

127

128

130

131

132

133

135 Shale 0ils

Key Specifications for Military Turbine Fuels 141

Assays of Distillate Hydrotreating Catalysts 143

Summary of Operating Results for Fixed-Bed 145 COALITE Hydrotreating (FB17Al-49)

Summary of Properties of Ful1-Range Hydrotreated

149 COALITE From Fixed-Bed Hydrotreating (FBI7Al-49)

Summary of Operating Results for Fixed-Bed COALITE Hydrotreating (FB30/36-2)

Summary of Properties of Ful1-Range Hydrotreated COALITE From Fixed-Bed Hydrotreating (FB30/36-2) 


\section{LIST OF TABLES}

Table No.

Title

Page \#

$5.2 .1-5 A$

Summary of Operating Results for Fixed-Bed

155

$5.2 .1-5 B$ COALITE Hydrotreating (FB169-177)

Summary of Properties of Full-Range Hydrotreated

156

$5.2 .1-6 A$ COALITE From Fixed-Bed Hydrotreating (FB169-77)

Summary of Operating Results for Fixed-Bed COALITE Hydrotreating (FB94-104)

$5.2 .1-6 B$

$5.2 .1-7 A$

$5.2 .1-7 B$

$5.2 .1-8 A$

$5.2 .1-8 B$

$5.3 .1-1$

$5.3 .1-2$

$5.3 .1-3$

$5.3 .1-4$

$5.4 .1-1 A$

Summary of Properties of Full-Range Hydrotreated COALITE From Fixed-Bed Hydrotreating (FB94-104)

Summary of Operating Results for Fixed-Bed COALITE Hydrotreating (FB146-47)

Summary of Properties of Ful1-Range Hydrotreated COALITE From Fixed-Bed Hydrotreating (FB146-47)

Summary of Operating Results for Fixed-Bed COALITE Hydrotreating (FB135-38)

Summary of Properties of Ful1-Range Hydrotreated COALITE From Fixed-Bed Hydrotreating (FB135-38)

157

158

159

160

161

162

Summary of Operating Conditions for LC-Fining of COALITE (BLCF86-1/90)

Summary of Operating Conditions for LC-Fining 184 of COALITE (BLCF92-101)

Summary of Properties of Fu11-Range LC-Finates 185 COALITE (BLCF86-90)

Summary of Properties of Ful1-Range LC-Finates 186 COALITE (BLCF92-101)

Summary of Operating Results for Fixed-Bed Hydrotreating of Hydrocracked COALITE Distillate (FB44-105)

$5.4 .1-1 B$

Summary of Properties of Full-Range Hydrotreated COALITE From Fixed-Bed Hydrocracking (FB44-105)

$5.4 .1-2 A$

Summary of Operating Results for Fixed-Bed Hydrotreating of Hydrocracked COALITE Distillate (FB156-158)

$5 \cdot 4 \cdot 1-2 B$

Summary of Properties of Ful1-Range Hydrotreated COALITE From Fixed-Bed Hydrocracking(FB156-58)

$5.4 .1-3 A$ ry of Operating Results for Fixed-Bed Hydrocracking of COALITE(FBHC1-17)

$5.4 .1-3 B$

$5.4 .1-4 A$

$5.4 .1-4 B$

$5.4 .1-5 A$

$5.4 .1-5 B$

$5.4 .2-1 A$ ary of Properties of Hydrocrackates From Fixed-Bed COALITE Hydrocracking (FBHC1-17)

Summary of Operating Results for Fixed-Bed Hydrocracking of COALITE(FBHC18-27)

Summary of Properties of Hydrocrackates From Fixed-Bed COALITE Hydrocracking(FBHC18-27)

Summary of Operating Results for Fixed-Bed Hydrotreating of Hydrocracked COALITE Distillate (FB165-168)

Summary of Properties of Full-Range Hydrotreated C(JALITE From Fixed-Bed Hydrocracking(FB165-68)

188

189

190

191

192

193

194

195

196

197

Summary of Operating Results for Fixed-Bed Hydrotreating of Thermally Processed COALITE (FB45/126/127) 


\section{LIST OF TABLES}

Table No.

5.4.2-1B

5.5-1

5.5.3.1-1

5.5.3.2-1

5.5.3.3-1

5.5.3.3-2

5.5.3.3-3

5.5.3.3-4

5.5.3.3-5

5.5.3.4-1

5.5.3.5-1

$6.2-1 A$

$6.2-1 B$

$6.2-2 A$

$6.2-2 B$

$6.2-3 A$

$6.2-3 B$

$6.2-4 A$

$6.2-4 B$

$6.2-5 A$

$6.2-5 B$

$6.2-6 A$

$6.2-6 B$

$6.3-1 A$

$6.3-1 B$
Title

Page \#

Summary of Properties of Full-Range Hydrotreated COALITE From Delayed Coking(FB45/126-7)

Comparison of COALITE-Derived HEDF Fuels Produced Via Two Hydroprocessing Schemes

Summary Results for LC-Fining Run 6LCF-11

Results of Fixed-Bed Hydrotreating of $975 \mathrm{~F}$ COALITE LC-Finate

Summary of Fixed-Bed Hydrocracking Run FBHC-37

Summary of Fixed-Bed Hydrocracking Run FBHC-38

Summary of Fixed-Bed Hydrocracking Run FBHC-39

Summary of Fixed-Bed Hydrocracking Run FBHC-40

Comparison of Run FBHC-40F with FBHC-41

Summary of Fixed-Bed Hydrotreating Run FB-214

COALITE Derived HEDF Fuel Properties for Subtask 3.2 Screening Program

Summary of Operating Results for Fixed-Bed Colorado Shale 0il Hydrotreating(FB148-64)

Summary of Properties of Full-Range Hydrotreated Colorado Shale 0il From FixedBed Hydrotreating (FB148-164)

Summary of Operating Results for Fixed-Bed Colorado Shale 0il Hydrotreating(FB106-130)

Summary of Properties of Fu11-Range Hydrotreated Colorado Shale 0il From FixedBed Hydrotreating (FB106-130)

Summary of Operating Results for Fixed-Bed Hydrotreating of Hydroprocessed Colorado Shale Oil Distillate(FB186-87)

Summary of Properties of Fixed-Bed Hydrotreated Products from Hydroprocessed Colorado Shale 0il Distillate(FB186-87)

Summary of Operating Results of Fixed-Bed Hydrotreated 235 Products from Hydroprocessed Colorado Shale 0il Dist,illate(FB143-45)

Summary of Properties of Fixed-Bed Hydrotreated Products from Hydroprocessed Colorado Shale 0il Distillate(FB143-145)

Summary of Operating Results for Fixed-Bed Colorado Shale 0il Hydrocracking (FBHC28-35)

Summary of Properties of Hydrocrackates from FixedBed Colorado Shale 0il Hydrocracking (FBHC28-35)

Summary of Operating Results for Fixed-Bed Colorado Shale 0il Hydrocracking(FBHC5-12)

Summary of Properties of Hydrocrackates from FixedBed Colorado Shale 0il Hydrocracking(FBHC5-12)

Summary of Operating Results for LC-Fining of

Summary of Properties of LC-Finates from Colorado Shale 0il(BLCF89-1/89-5) 


\section{LIST OF TABLES}

Table No.

Title

Page \#

$6.3-2 A$

Summary of Operating Results for LC-Fining of Colorado Shale 0il (BLCF91-99)

$6.3-2 B$

$6.3-3 A$

$6.3-3 B$

Summary of Properties of LC-Finates from Colorado Shale Oil (BLCF91-99)

Summary of Operating Results for Fixed-Bed Hydrotreating of Thermally Processed Colorado Shale 0il Distillate(FB131-134)

Summary of Properties of Hydrotreated Products from Fixed-Bed Hydrotreating of Thermally Processed

$6.4-1 A$ Colorado Shale 0il Distillates (FB131-34)

Summary of Operating Results for Fixed-Bed Hydrotreating of Hydrocracked Colorado

$6.4-1 B$ Shale 0 il Distillate(FB188-189)

Summary of Properties of Fixed-Bed Hydrotreated Products from Hydrocracked Colorado Shale 0il Distillate(FB188-189)

Results of Solvent Extraction of Hydrotreated Colcrado Shale 0ils

6.6-2

$7.2-1$

$7.3-1$

7.4.1

$7.5-1$

$7.5-2$

$7.5-3$

7.6-1

$8.1-1$

8.1-2

$8.1-3$

$8.2-1$

$8.2-2$

$8.2-3$

$8.2-4$

8.3-1

8.3-2

Lab Extraction Study Results

Run 6LCF-14 LC-Fining Production Run Sumary 266

Run Run-5 Fixed-Bed Hydrodenitrogenation Run Summary

Run 6LCF-16 Fixed-Bed Selective Hydrocracking 273 Run Summary

Summary of Patch Distillation of Selectively 275 Hydrocracked LC-Finate Gas 0ils

Summary of Opt imum Blending Study of HEDF Test 276 Fuel Cuts From Batch Fractionation

Summary of Bentonite Clay Treating of HEDF Test 277 Fuels

Summary of Final COALITE HEDF Test Fuel Properties 278

HEDF Specifications Used 282

Process Alternatives Included 283

Feedstock Cost/Co-Product Price Bases 284

Product Comparison with Specifications 291

Investment Summary - Maximum HEDF Jet Fuel 292

Baseline Cases Economic Breakdown Summary 293

Economic Summary 295

Sensitivity Cases Economic Summary 299

Product Comparison with Specifications 308 


\section{LIST OF FIGURES}

iiqure No.

Iitle

Page \#

$1.8-1$

$2.2-1$

Effect of $H$ Content \& API Gravity on Energy Density

18

Schematic Flow Diagram of Fixed-Bed Hydroprocessing

24

2.3-1

2.4-1

2.5-1

$2.7-1$

$3.1-1$

$3.1-2$

$3.1-3$

$3.1-4$

Pilot Unit

Schematic of Bench-Scale Fixed-Bed Hydrocracking Unit

Schematic of Autoclave-Based LC-Fining Unit

29

Schematic of Continuous Bench Coking Unit

31

Schematic of Four-in Batch Fractionation Unit

33

Consolidated ASTM D86/D1160 Distillations of Dewatered 44

COALITE

ASTM Distillations of Synfuel Feedstocks

Wt\% Distillate Yield As a Function of VABP of Cut

45

$\mathrm{H} / \mathrm{C}$ Atomic Ratio of COALITE Distillate Cuts As A

Function of VABP of Cut

$3.1-5$

API Gravity of COALITE Distillates As A Function of VABP of Cut

$3.1-6$

$3.1-7$

$3.1-8$

$3.1-9$

$3.1-10$

$3.1-11$

$3.1-12$

Nitrogen Content As A Function of VABP of Cut

Wt\% Oxygen Content As A Function of VABP of Cut

Wt\% Sulfur Content As A Function of VABP of Cut

PONA Analysis of Selected COALITE Distillates As A Function of VABP of Cut

Hydrogen Distribution by HNMR Spectroscopy As A Function of VABP of cut

Calculated Carbon Distributions From HNMR As A Function of VABP of cut

H/C Ratios From HNMR Spectroscopy As A Function of VABP of cut

$3.1-13$

$3.1-14$

$3.1-15$

$3.1-16$

$3.1-17$

$3.1-18$

Bromine No As A Function of VABP of Cut 62

47

52

53

54

55

56

57

59

60

Refractive Index O20C As A Function of VABP of Cut 63

API Gravity As A Function of Refractive Index 64

$\mathrm{H} / \mathrm{C}$ Atomic Ratio As A Function of Refractive Index 65

Hydrogen Aromaticity As A Function of Refractive $\quad 66$ Index of Distillate Cuts

Carbon Aromaticity As A Function of Refractive $\quad 67$

$3.2-1$ Index of Distillate Cuts

Consolidated ASTM Distillation of Raw Colorado Shale $\quad 69$ 0 il Feedstock

$3.2-2$

$3.2-3$

ASTM Distillations of Synfuel Feedstocks

70

H/C Atomic Ratio of Synfuel Distillates As a Function 72 of VABP

$3.2-4$

API Gravity of Synfuel Distillates As a Function of VABP

$3.2-5$

Nitrogen Content of Synfuel Distillates As a Function of VABP

$3.2-6$

$3.2-7$

$3.2-8$

Sulfur of Synfuel Distillates as a Function of 75 VABP

PONA Analysis of Synfuel Distillates as a Function of VABP

NMR Carbon Distribution for COALITE and Colorado

Shale 011 as a Function of Distillate VABP
Refractive Index of Synfuel Distillates as a Function

73

74 of VABP 


\section{LIST OF FIGURES}

Fiqure No.

3. $2-10$

4.2.5-1

4.3.5-1

5.2.1-1

5.2.1-2

5.2.1-3

5.2.1-4

5.2.1-5

5.2.1-6

5.2.1-7

5.2.1-8

5.2.1-9

5.2.1-10

5.2.1-11

5.2.1-12

5.2.1-13

5.2.1-14

5.2.1-15

5.2.1-16

5.2.1-17

5.2.4-1

5.2.4-2

5.2.4-3

$6.2-1$

$6.2-2$

$6.2-3$

6.2-4

Iitile

Fage \#

NMR Carbon Distribution for COALITE \& Colorado Shale 011 as a Function of Refractive Index

Hydrocracking/Hydrogenation Routes To HEDF

107

Processing Approaches to Colorado Shale Oil HEDF

129

Volumetric Heat Content vs Hydrogen Content of Model Compounds

Hydrotreating Severity vs VHLV for Hydrotreated COALITE Distillates

142

163

Hydrotreating Severity vs Hydrogen Content For COALITE Distillates Over K-550

Hydrotreating Severity vs FIA Aromatics For COALITE Distillates Over K-550

Hydrotreating Severity vs API Gravity For COALITE Distillates Over K-550

Hydrotreating Severity vs Aniline Pt For COALITE Distillates Over K-550

Hydrotreating Severity vs Cetane Index For COALITE Distillates Over K-550

Hydrotreating Severity vs Smoke Pt For COALITE Distillates Over K-550

164

165

166

167

168

169

Hydrotreating Severity vs Refractive Index For COALITE Distillates Over K-550

170

Effect of Aromatics on VLHV of Coal-Derived Diesel/Jet Fuels

171

Effect of Aromatics on Cetane Quality of CoalDerived Diesel Fuels

Effect of Aromatics on Smoke Point of CoalDerived Turbine Fuels

Predicted Net Heat of Combustion of COALITE vS R.I. and API Gravity

Distillate Hydrogen Content as a Function of R.I. of COALITE Distillates

172

173

174

175

Predicted API Gravity as a Function of R.I. of Hydrotreated COALITE

Watson $K$ Factor As a Function of R.I. of Hydrotreated COALITE

Smoke Pt and Luminometer No vs R.I. of COALITE

Relative Hydroprocessing Performance for 350-550F COALITE: Sp. Gr Reduction

Relative Hydroprocessing Performance for 350-550F COALITE: Aromatics Conversion

Relative Hydroprocessing Performance for 350-550F COALITE: Hydrogen Uptake

178

179

180

182

Hydrotreating Severity vS VHLV for COALITE \& Shale Derived Jet Fuels

Hydrotreating Severity vS FIA Aromatics for Coal \& Shale Derived Jet Fuels

Hydrotreating Severity vs Hydrogen Content for Coal \& Shale Derived Jet Fuels

Hydrotreating Severity vS API Gravity for

Coal \& Shale Derived Jet Fuels 


\section{LIST OF FIGURES}

Figure No.

Title

Page \#

$6.2-5$

Hydrotreating Severity vs Smoke Pt for

Coal \& Shale Derived Jet Fuels

Hydrotreating Severity vs Refractive Index for Coal \& Shale Derived Jet Fuels

Effect of Aromatics on VLHV of Coal \&

$6.2-8$ Shale Derived Jet Fuels

Effect of Aromatics on Smoke Pt of Coal \& Shale Derived Jet Fuels

$6.2-9$

API Gravity vs Refractive Index of Coal \& Shale Derived Distillates

$6.2-10$

Smoke Pt vs Refractive Index of Coal \& Shale Derived Jet Fuels

Distillate Hydrogen Content vs Refractive Index of Coal \& Shale Derived Jet Fuels

$6.6-1$

Extraction/Hydrogenation Route to HEDF From Colorado Shale 0il

8.1-1

$8.1-2$

$8.2-1$

$8.2-2$

$8.2-3$

8.2-4

8.3-1

8.3-2

8.3-3

8.3-4

8.3-5

8.3-6

Effect of Reactor Severity

Flash Point Prediction

Schematic of Maximum HEDF Jet Fuel

250

Schematic of $40 \%$ HEDF Jet Fuel

Feedstock Rate Effect on Profit

Effect of Feedstock Rate 040\% HEDF Yield \&

\$18/bbl Feed Cost

Effect of Heating Value Specification

251

263

286

287

289

294

297

298

HEDF Cost vs Heating Value

301

HEDF Cost Breakdown

302

303

Feedstock Rate Effect on Profit

304

Effect of Feedstock Rate C40\% HEDF Yield \& 306

$\$ 30 /$ bbl Feed Cost

Schematic of Maximum HEDF Jet Fuel -

307

No Specifications

8.3-7

Effect of HEDF Yield - 40 MBCD Cases

309

8.3-8

Effect of HEDF Yield - 40 \& 10 MBCD Cases Compared

310 


\subsection{EXECUTIVE SUMMARY}

\subsection{Background and DOE Perspective}

In April 1988, the Department of Energy (DOE) Morgantown Energy Technology Center (METC) issued a request for proposal (RFP) soliciting a research effort for the "Development of High Energy Density Fuels from Mild Gasification of Coal". ABB Lummus crest Inc. (then a subsidiary of Combustion Engineering Inc and currently a subsidiary of Asea Brown Boveri Inc.) and Amoco 0il Company (AOC) as key subcontractor successfully responded to the RFP and entered into a contract (No. DE-AC22-88MC25020) with the DOE on September 30, 1988.

The RFP was predicated on DOE's desire to enhance the development of advanced transportation fuels made from coal via a program to process mild coal gasification (MCG) liquids into high volumetric energy density (HEDF) test fuels. The desired product fuels were to be cost effectively manufactured, have high volumetric energy density, and be hydrocarbon-based for existing and prototype turbine and diesel engines. The sources for these special fuels consist of the abundant and secure indigenous energy resources of coal. Comparison studies were also to be made using other non-petroleum fuels such as shale oil and $\operatorname{tar}$ sands bitumen.

METC has concluded that MCG technology has the potential to simultaneously satisfy the transportation and power generation fuel needs in the most cost-effective manner. MCG is based on low temperature pyrolysis, a technique known to the coal community for over a century. Most past pyrolysis developments were aimed at maximizing the liquids yield which results in a low quality tarry product requiring significant and capital intensive upgrading.

By properly tailoring the pyrolysis severity to control the liquid yield-liquid quality relationship, it has been found that a higher quality distiliate-boiling liquid can be readily "skimmed" from the coal. The resultant liquids have a much higher $H / C$ ratio than conventional pyrolytic tars and therefore can be hydroprocessed at lower cost. These liquids are also extremely enriched in 1-, 2-, and 3-ring aromatics. The co-product char material can be used in place of coal as a pulverized fuel(pf) for power generation in a coal combustor. In this situation where the original coal has a high sulfur content, the MCG process can be practiced with a coal-lime mixture and the calcium values retained on the char can tie up the unconverted coal sulfur upon pf combustion of the char. Lime has also been shown to improve the yield and quality of the MCG liquids.

The development of advanced fuels will provide increased range of volume-limited aircraft/missiles/vehicles and possibly provide a better heat sink than existing liquid fuels for high-speed aircraft. These special fuels would also provide desired characteristics for aircraft/vehicle operations in extreme conditions. Development of these fuels would have civilian and military applications in turbine and/or diesel engines for extended range and uses in remote areas where fuel supply may be difficult to sustain. 
While little R\&D has been conducted on the treatment of coal-derived MCG liquids to produce advanced fuels, significant R\&D efforts have been carried out to produce specification fuels from shale oil and tar sands bitumen. The major technical challenge in this program is the development of effective methods for treating MCG liquids and in increasing volumetric energy density while still meeting the essential features of the operational fuel specifications.

Processing and upgrading methods are needed to produce good yields of advanced fuels while minimizing overall processing costs. Advanced test fuels of interest must be produced to meet operational requirements reflected in the $D O D$ fuel specifications but may vary in chemical composition so as to increase the volumetric energy density and/or reduce the processing severity.

\subsection{Contract Objectives}

The overall objective of the research effort is the determination of the minimum processing requirements to produce high energy density fuels (HEDF) having acceptable fuel specifications. The program encompasses assessing current technology capability; selecting acceptable processing and refining schemes; and generating samples of advanced test fuels.

The specific objectives are:

- Conduct a technical and economic assessment of promising processing and upgrading methods to convert raw products from mild coal gasification into advanced high volumetric energy density test fuels for aviation turbines and diesel engines;

$0 \quad$ Conduct screening tests of alternative processing methods; and

- Generate and deliver gallon-size test quantities of advanced fuels from mild coal gasification liquids and other sources.

\subsection{Task Breakdown Structure}

The Phase I Baseline Program is intended to explore the processing alternatives for producing advanced HEDF from two raw synfuel feedstocks, one from Mild Coal Gasification as exemplified by the COALITE process and one from Colorado shale oil. Eight key tasks were initially identified as follows:

Task I.D. No.

1

2

3

4

5

6

7

Task Definition

Planning and Environmental Permitting

Transporting and Storage of Raw Fuel Sources and Products

Screening of Processing and Upgrading Schemes Proposed Upgrading Schemes for Advanced Fuel Upgrading of Raw Oil into Advanced Fuel Packaging and Shipment of Advanced Fuels Updated Technical and Economic Assessment Final Report of Phase I Efforts 
Our overall approach to processing Mild Coal Gasification liquids and shale oils consists of integrated hydrofining technology using catalysts tailored to the heteroatom removal and ring hydrogenation functions. In order to perform the optimization of maximum yield of the desired HEDF products at minimal processing costs, there will have to be a tradeoff of product yield vs. hydrogen consumption requirements. Consideration will have to be given to the handing of the light end and the heavier end of the synfuel feedstocks which can not directly be incorporated into the desired mid-distillate advancec fuel products. Based on in-house hydroprocessing experience with these type of synfuel feedstocks together with Amoco's Refinery LPT model, preliminary flowschemes will be developed to serve as the basis for initiating the screening studies of Task 3 .

At this point in the project, one possible route might consist of distilling the volatile fraction from the synfuel feedstock. The purpose of this step is to remove water and certain materials such as pyridinics and light phenolics that are difficult and costly to catalytically upgrade especially with respect to hydrogen consumption requirements. The distillation cut point will have to be determined that will result in the preservation of certain Category II endothermic fuel precursors, e.g., toluene and xylenes.

The heavier end can be hydrocracked under recycle conditions to produce more cyclic (naphthenic or aromatic) material boiling in the required turbine or diesel fuel ranges specified in the MIL specs. The hydrocracking feed will have to be purified of heteroatom content in order to utilize the desirable active hydrocracking catalysts. Thus, there will be a tradeoff in heteroatom removal requirements $v s$. catalytic hydrocracking catalyst requirements. A goal will be to find hydrogenation/hydrocracking conditions that will result in extinction recycle of the heavier gas oil component of the synfuel feedstocks. The recycle cut point will have to be determined as one that maximizes the yield of the desired two- and single-ring aromatics but still allows for the attainment of the back-end volatility specs for the advanced turbine or diesel fuels.

\section{Task 1: Planning and Environmental Permitting}

The objective of this task is to prepare a project management plan for both the Phase I and Phase II tasks in sufficient detail to allow the DOE COTR to understand and ultimately monitor the Contractor's performance. This plan will contain the most current and accurate information and projections available to LCI as Contractor at the time of submission of the work plan.

of particular importance is the responsibility of the Contractor to obtain all required permits and to comply with all environmental regulations governing the operation of the Contractor's facility and its ability to process the synfuel feedstocks to be provided by DOE. 
The project management $p l a n$ will consist of the following items:

1. A detailed discussion of the technical approach to be used to achieve the contract objectives, specifics about test conditions, equipment configurations, feedstock specifications, calculation procedures, analytical procedures, reporting requirements and milestone/schedule plan;

2. A screening test $p l a n$ enumerating the currently preferred processing/upgrading schemes; the types of tests planned; and test parameters to be explored for the screening studies of Task 3;

3. Management reports including cumulative estimated costs and cumulative estimated manhours by month and by task as well as for the total contract effort;

4. A project work chart showing key personnel or key groups and their estimated percentage of time to be devoted to each task; and

5. A model subcontract proposed to be negotiated with Amoco 0 il Company.

By virtue of the exploratory nature of R\&D projects, it is probable that technical redirections might be in order as experimental data are collected during the course of the project. Contractor will submit appropriate work plan revisions, if deemed to be in the best interest of the overall program goals, to the DOE COTR for consideration and approval. Incorporation of such proposed revisions will not be implemented until prior written approval is granted by the DOE COTR.

The deliverables for this task will include:

1. A self-contained written report summarizing all of the work plan items; and

2. A briefing to be made to the DOE COTR on the details of the work plan.

\section{Task 2: Transporting/Storage of Raw Fuel Sources}

This task consists of the procurement of the MCG and shale-derived liquids; the storage of feeds and products at Contractor's test facility; and disposal of waste byproducts and unused feedstocks. The details are discussed in more detail below.

\section{Task 3: Screening of Processing/Upgrading Schemes}

The objectives of this task are to: 1) characterize the two synfuel feedstocks supplied by DOE with regard to their processability for conversion to advanced HEDF; and 2) perform laboratory screening tests of candidate processing methodologies. 
The deliverables for Task 3 will include:

- Delivery of samp?e quantities (ca. I Liter) of test HEDF to DOE and/or its designated contractors;

- A draft topical report on the experimental efforts including all analytical results, unit operating reports, material balances and data correlations, to be submitted within 30 days after completion of the screening tests;

o Briefings on the status of the screening studies outlining the progress and results of the work effort to the DOE COTR at METC;

- Hot line reports as required to report major breakthroughs or significant events.

\section{Task 4: Proposed Upgrading Schemes For Advanced Fuels}

In this task, Amoco as key subcontractor will develop preliminary designs and economic evaluations of commercial processing schemes to make the advanced HEDF from the MCG liquids and the Colorado shale oil based on the use of its Linear Programming Technology (LPT) models of refinery processing units. It is probable that the processes to make these fuels will also produce co-products including motor gasoline and aromatic petrochemicals and thus the economics will include feedstock cost considerations as well as co-product values.

The following deliverables will be provided:

- A draft topical report on the results of the processing and economics calculations including the economic analyses for producing the three categories of HEDF;

- Briefings on the status of the processing studies outlining the progress and results of the work effort to the COTR at METC.

\section{Task 5: Upgrading Raw 0il Into Advanced Fuel}

The objective of this task is to generate sufficient test quantities (ca. $100 \mathrm{gal}$ ) of two advanced fuels, one from Category I and one from either Category II or Category III fuels for the Mild Coal Gasification liquids and the Colorado shale oil. Processes that would minimize the overall cost of production in a full-scale commercial unit will be considered. Thus, approximately $400 \mathrm{gal}$ of advanced HEDF samples will be required.

The Task 4 topical report will identify the specific upgrading schemes and technical approaches to be used for the Task 5 pilot plant sample preparation efforts. Upon approval of this report by the DOE COTR, the Contractor will initiate the required tasks as follows:

1. Contractor will characterize the two candidate feedstocks and prepare them for processing in the bench-scale units. If it is 
determined from the Task 4 studies that an initial fixed-bed hydrotreating step will be required, then the feeds will be filtered or centrifuged to remove particulate (e.g., coal char fines or oil shale fines) matter. If it is determined from the Iask 4 studies that the initial step will be an expanded-bed (LC-Fining ${ }^{2}$ ) hydroprocessing operation then the filtration step will not be necessary as the LC-Finer ${ }^{\mathrm{m}}$ can tolerate solids. In either case, the LC-Fining ${ }^{\text {Sil Pilot }}$ Plant unit will be used, operated either cocurrent downflow for the fixed-bed hydrotreatment or cocurrent upflow for the expanded-bed hydroprocessing operation.

2. If the Task 4 studies indicate that the two-step, heteroatom removal-ring saturation process is the preferred mode, then the initial operation will be to process the first feedstock at the preferred catalytic hydrotreatment severity. The amount of feed to be processed will depend upon the projected ultimate yield of HEDF on feed. This value will be determined from the screening studies of Task 3 and the processing studies of Task 4 . Thus, if the ultimate yield of Category I HEDF for example is 60 liquid volume percent on feed, then 166.7-gal of feed would have to be processed. For safety margins related to pilot plant handling efficiencies, we would plan to process at least 250-300 gal. It might also turn out that during the first campaign to produce the required 100 gal of Category I advanced fuel, Category II or Category III fuel might be producad as a co-product. In this event, the second campaign to produce the Category II or Category III fuel could be shortened by the amount of that advanced fuel produced in the first campaign.

3. The unit will be operated on a 24-hour, 7-day per week basis until the total required feed batch has been processed. The upper limit on the throughput of this unit is about $6 \mathrm{gal} / \mathrm{hr}$. Thus, the minimum cycle for a pilot plant campaign will be 250-300 gal divided by 6 gal/hr or about 42 to 50 hours. The upper limit on the catalyst volume is about $1.4 \mathrm{gal}$ per reactor vessel or $2.8 \mathrm{gal}$ total volume which corresponds to a minimum space velocity of about 2.1 to $4.3 \mathrm{hr}^{-1}$ at the maximum throughput. Thus, if the processing space velocity requirements are lower, then the feed pump rate would have to be lowered and the time for completion of a campaign would be proportionately increased.

4. Two campaigns will be required for each HEDF fuel sample produced, one for the first-step heteroatom removal and one for the second-step ring saturation. Thus, eight pilot plant campaigns could be required for producing two advanced fuels for two synfuel feedstocks, assuming that the same processing scheme will be applicable to both synfuel feeds. The first four campaigns will carry out the catalytic hydrotreatment step with a single charge of preferred heteroatom removal catalyst. The unit would then be disassembled; the spent catalyst removed; the unit thoroughly purged and cleaned with solvent to remove residual heteroatoms; and a fresh charge of the preferred ring saturation catalyst would be installed.

5. The second-step operation may initially consist of a purge period to stabilize the catalyst and to provide a further purging of residual 
heteroatoms from the earlier cat hydrotreating campaigns. The unit would then be operated on a 24-hour, 7-day basis until the $100 \mathrm{gal}$ yield of the required advanced fuel sample is achieved. A post-hydrogenation distillation step will be required to fix all of the turbine fuel specs controlled by front-end and back-end volatility.

6. Analytical testing will be grouped into two categories: control analyses for monitoring the heteroatom removal and the ring saturation operations; and product specifications. The control analyses for the heteroatom removal operations will include ultimate analysis, specific gravity, FIA trace sulfur and nitrogen analyses, and simulated distillation. Control analyses for the ring saturation operations will include ultimate analysis, specific gravity, aniline point, diesel index, LHV, smoke point, and simulated distillation. Each of the four HEDF products will be completely analyzed for all of the relevant JP-4, 7, 8 and 10 specifications in addition to calorific value.

The deliverables for this task are:

- 400 gal (aggregate amount) of advanced fuels, one from Category I and one from Category II or III, for each of the two candidate synfuel feed's;

- A draft topical report describing the processing techniques, material balances, specification test results, engineering analyses and test reports;

- Briefings to the DOE COTR at METC to outline the progress and results of the Task 5 work effort;

- Hot line reports as required to report major breakthroughs or significant events.

\section{Task 6: Package and Shipment of Advanced Fuels}

The pilot plant upgrading operations will be structured such that 100 gallons of each of the required HEDF samples will be produced in one month intervals. Once the analytical workup confirms the final targetted specs, the sample will be shipped to DOE's designated site. In order to limit the storage time at the Contractor's site, we propose to ship each 100-gal sample separately. However, it might also be acceptable to await completion of more than one product sample in the event that the samples will be shipped to the same site. The COTR will be notified 30 days in advance of each shipment to allow for sufficient time to transmit the address of the receiving site. A Material Safety Data (MSD) sheet will be completed and sent with the sample shipment to the receiving location specified by the COTR.

The samples will be loaded into sealed, nitrogen-pressurized stainless steel drums using a sampling/valving system installed in the two drum bungs. This system will allow the maintenance of the nitrogen gas 
blanket while sampling the drum. This essentially eliminates the infusion of any air into the drum. The drums will be labeled with the proper UN number and appropriate reference sample number. Pressurizing will be maintained at 0.5 to 1 psig nitrogen. Directly after filling and pressurizing, the drums will be stored in a cold box which will be maintained at a temperature of no more than 35 to $40 \mathrm{~F}$. The drums will also be connected to a manifold to maintain the nitrogen pressure should there be any small gas ?eaks. The drums will be transferred to a dedicated refrigerated truck, maintained at or below 35 to $40 \mathrm{~F}$, during the loading and transporting.

\section{Task 7: Updated Technical and Economic Assessment}

In order to confirm the processing routes developed from the screening studies of Task 3, the pilot plant upgrading efforts of Task 5 were to be used to update the Task 4 results. Consideration was to be given to the scalability of the data between the bench-scale and pilot plant units and the subsequent scaleup to commercial units. The Task 5 data was to be incorporated into the LP model developed in Task 4 . The updated LPT model was to be used to generate final optimized processing schemes for the production of Category I, II, and III HEDF fuels. When the contract was modified to reflect the reduced DOE funding availability, this task was eliminated.

\section{Task 8: Final Phase I Report}

The objective of this task is to prepare a draft final technical report summarizing the results of all the efforts of the individual tasks in the Phase I program. The report will contain an executive summary highlighting the major project results, conclusions and recommendations and in particular, addressing the issues of a)ternative processing schemes, anticipated fuel performance characteristics and the conceptual economics of producing HEDF from mild coal gasification liquids. The draft report will be delivered two months prior to the contract completion and a revised final report after receipt of DOE's comments will be issued at contract completion.

\subsection{Feedstocks}

The two candidate synfuel feedstocks selected for the Phase I program by DOE consisted of a mild coal gasification liquid and a shale oil. The coal liquid consists of a nominal 160-1000F boiling range product from the British COALITE carbonization process. The COALITE process was developed in the early 1900's (1) based on the use of a vertical retort. A COALITE plant built in 1936 at the Bolsover Works of Coalite and Chemical Products Ltd is still in operation and the 1000-gal sample was procured and delivered to Lummus by United Coal Company Research Corporation of Bristol, VA. The COALITE was produced from a medium coking British coal and is expected to have properties similar to those of U.S. Eastern bituminous coals.

The shale oil is derived from Green River oil shale and was produced at the Unocal plant in Colorado. The 1000-gal sample was provided to Lummus by the Western Research Institute of Laramie, WY. 


\subsection{High Energy Density Fuels (HEDF)}

Conventional petroleum-based aviation turbine fuels (e.g., JP-4) generally contain about 20 volume percent aromatics (25\% max.) and $30 \%$ paraffinics with the balance being naphthenics. If these conventional fuels were severely hydrogenated to convert all the aromatics to naphthenes, the total saturated cyclic content would still only be about $70 \%$. In order to convert the paraffinic compounds, which characteristically have low energy density because of their high $\mathrm{H} / \mathrm{C}$ ratios and low specific gravities, to cycloparaffins would require cor. lex and expensive processing techniques such as isomerization and aromatization.

Naphthenic hydrocarbons having two or three rings represent the optimal density-calorific value relationship of any hydrocarbon fuel currently produced. Thee two-ring (and three-ring) saturates can be readily produced 'by hydrogenation of their unsaturated or aromatic precursors. Coal liquids produced by mild coal gasification are known to have in excess of $90-95 \% 2-r i n g$ and 3-ring polynuclear aromatics content. Thus, by hydroprocessing techniques to insure the integrity of 2- and 3-ring hydrogenated products, these mild gasification products can be converted to advanced high energy density fuels at high yields.

Three advanced HEDF types have been defined for this RFP as discussed below.

\section{Category I - Aviation Turbine Fuel}

This advanced fuel is defined as one having a Lower Heating Value (LHV) in excess of $130,000 \mathrm{Btu} / \mathrm{gal}$ and preferably on the order of 135,000 Btu/gal and having high thermal stability. For comparison, conventional JP-4 turbine fuel has an LHV of only $119,400 \mathrm{Btu} / \mathrm{gal}$ and typical kerosene has a value of about 123,000. Decalin, an unsubstituted 2-ring cycloparaffin, has an LHV of 135,400 Btu/gal and an alkylated decalin has an LHV of 134,950 Btu/gal. This Category I advanced fuel must conform to the operational requirements reflected in the DOD fuel specifications for JP-4 and JP-8 but with necessary chemical composition variations required to achieve the desired higher volumetric energy densities and/or to reduce the required processing severity.

\section{Category II - Endothermic Turbine Fuel}

This advanced fuel must have a high energy density value but also must have those properties to make it a satisfactory fuel for use in advanced hypersonic aircraft. At hypersonic speeds, significant thermal problems arise due to the effect of stagnation temperature, the latter being the resultant temperature due to the resistance of the air molecules impeding the motion of the vehicle. Heat can be removed by either a mechanical refrigeration system; a non-combustible coolant; or by the fuel itself, the latter being the most preferred. Three types of endothermic processes can be used depending upon fuel type: a) catalytic dehydrogenation of naphthenes; b) thermal cracking 
of various hydrocarbons; and c) depolymerization of polymers. All of these systems have varying heat sink limits and the prior R\&D reported in the literature has pinpointed the naphtha dehydrogenation route as a preferred endothermic mechanism. Typical compounds having good heat sinks include methylcyclohexane (MCH), methycyclopentane(MCP), decal in, dicyclohexyl, etc. Compounds of these types or their unsaturated precursors might exist in the Mild Coal Gasification liquids at some appreciable concentrations to result in the production of a reasonable yield of the Category II advanced fuel.

\section{Category III - High Energy Diesel Fuel}

This advanced fuel must meet DOD's diesel spec VV-F-800D(this spec supersedes the VV-F-800C spec shown in the RFP) and have an energy density comparable to that of the Category I turbine fuel thus allowing extended driving range for military vehicles such as tanks. This spec has no volumetric energy density limitation per se, but the Cetane No. spec can be effected by hydrocarbon type, in particular, aromatics, and the latter will affect the resultant energy density of the fuel. The three grades of VV-F-800D diesel fuel, namely, DF-A, $D F-1$ and DF-2 have varying operability characteristics pursuant to the climactic specification. Grade DF-A, Arctic grade, has the lowest viscosity requirement and distillation end point limit. Back-end diesel cut blending to achieve the desired high volumetric energy density will have to be balanced against front-end blending to insure that the Distillation End Point, Viscosity and Carbcr. Desidue specs are not violated.

\subsection{Process Screening Alternatives}

Our overall approach to processing Mild Coal Gasification liquids and shale oils consists of integrated hydrofining technology using catalysts tailored to the heteroatom removal and ring hydrogenation functions. In order to perform the optimization of maximum yield of the desired HEDF products at minimal processing costs, there will have to be a tradeoff of product yield vs. hydrogen consumption requirements. Consideration will have to be given to the handling of the light end and the heavier end of the synfuel feedstocks which can not completely be incorporated into the desired mid-distillate advanced fuel products. Based on in-house hydroprocessing experience with these type of synfuel feedstocks together with Amoco's Refinery LPT model, preliminary flowschemes were developed to serve as the basis for initiating the screening studies of Task 3.

The initial screening consisted of the catalytic two-step hydrotreatment, i.e., heteroatom removal followed by ring saturation, in a fixed-bed, downflow bench-scale unit. Tests were performed with selected distillate fractions of the feeds. The heavier fraction boiling above the aviation turbine fuel range was cracked either via thermal (e.g., coking); or hydrocracking (e.g., LC-Fining, VGO hydrocracking) technologies. 
A contract modification for extending the Task 3 screening studies was approved by DOE. The directive for this modification was to deemphasize the colorado shale oil feedstock (since the early screening data indicated that it did not have the high energy density potential as that of the MCG liquids) and to concentrate on the production of HEDF components via selective hydrocracking of the gas oil and resid components of the raw COALITE feedstock. An enhanced screening program was implemented to evaluate alternative catalysts for the selective hydrocrackini steps and to relate hydroprocessing severities to the thermal stabi:ity properties of the finished HEDF test fuels.

\subsection{Experimental Procedures}

The Task 3 Work Statement called for the screening of processing and upgrading schemes using laboratory-scale screening equipment while the Task 5 sample preparation program required the larger pilot plant-scale equipment. At LCI's Engineering Development Center (EDC), currently referred to as the Bloomfield Research \& Development Center (BRDC), process testing including screening and sample preparation artivities is carried out in either laboratory-scale, bench-top or pilot plant equipment. The processing and upgrading schemes for producing HEDF from synfuel feedstocks under the subject program include the following unit operations:

- Fixed-bed Distillate Hydrotreating

- Fixed-bed Distillate Hydrocracking

- Expanded-bed Resid Hydrocracking

- Delayed Coking

- Fractionation

- Solvent Extraction

o Clay Treating

The Task 3 screening of these process operations was carried out in the following test units:

1. Bench-Scale Fixed-Bed Hydrotreating Unit

2. Bench-Scale Fixed-Bed Hydrocracking Unit

3. Bench-Scale Expanded-Bed LC-Fining ${ }^{\mathrm{m}}$ Unit

4. Continuous Bench Coking Unit

5. Laboratory Extraction Unit

6. 4-in Batch Fractionation Unit

7. Equilibrium Flash Vaporization Pilot Unit

8. Laboratory Batch Distillation Units

9. Laboratory Clay Treating Unit 
The Task 5 sample preparation program was carried out in the following test units:

1. Pilot Plant LC-Fining ${ }^{\text {tm }}$ Unit

2. Pilot Plant Fixed-Bed Hydroprocessing Unit

3. Pilot Plant Clay Treating Unit

\subsection{Summary of Results of COALITE Operations}

The raw COALITE feedstock was fractionated in the 4-in Batch Distillation unit in four different campaigns. The initial fractionation, referred to as $C C-1$, resulted in the collection of sixteen successive distillate cuts and a vacuum resid fraction. The bulk of these materials was used for the analytical characterization tests (described in Section 3), the delayed coking evaluation of the $650 \mathrm{~F}+$ resid, and the LC-Fining evaluation of the $650 \mathrm{~F}+(343 \mathrm{C}+)$ resid.

Batch fractionation $\mathrm{CC}-2$ resulted in the collection of 24 distillate fractions and a $670 \mathrm{~F}+(354 \mathrm{C})$ resid fraction. Two composite blends for distillate hydrotreating were made: a nominal 350-650F (177-343C) blend of distillate fractions 5 through 22 to simulate a Category III boiling-range fuel; and a nominal 350-550F (177-288C) blend of distillate fractions 5 through 14 to simulate a Category I boiling-range fuel. Two additional blends were made with heavier end points (i.e., 750F and 820F) to determine whether the addition of the heavier gas oil components could increase energy densities above and beyond the $130,000 \mathrm{Btu} / \mathrm{gal}$ specification.

It should be kept in mind that the final Initial Boiling Point and End Point of the finished HEDF product is set in a post-hydrogenation topping and tailing operation. The nominal ranges of the feeds could not be fine-tuned in advance of and during the screening test work until sufficient information was acquired on the interaction of the process variables on all of the specified HEDF properties. Thus, the approach taken was to use the post-hydrogenation distillation operations to fine tune the critical distillation temperatures controlling the volatility (i.e., flash point spec) and the back-end viscosity/freeze point spec. Of course, in a commercial operation, the design of the fractionation systems would be optimized to reduce the cost of any unnecessary towers.

Six virgin distillate hydrotreating campaigns were made with the COALITE distillates to study the effects of catalyst type, distillate boiling range, single-stage vs two-stage, recycle of first-pass hydrotreated product and severity as controlled by space velocity, hydrogen partial pressure and reactor temperature. A total of 59 material balance tests were made of durations extending from 2-hours to 36-hours. The following table summarizes the salient features of each campaign and the summary table reference number. 
CAMPAIGN \# \# STAGES CATALYST TYPE FEED BOILING RANGE \#TESTS

$\begin{array}{rllcr}1 & 1 & K-550 & 350-650 \mathrm{~F} & 30 \\ 2 & 1 & K-550 & 350-550 \mathrm{~F} & 8 \\ 3 & 2 & K-550 / K-550 & 350-750 \mathrm{~F} ; 350-820 \mathrm{~F} & 8 \\ 4 & 2 & K-550 / \mathrm{K}-599 & 350-650 \mathrm{~F} & 7 \\ 5 & 1 & K-599 & 350-650 \mathrm{~F} & 2 \\ 6 & 1 & \text { Ca-doped K-550 } 350-650 \mathrm{~F} & 4\end{array}$

Campaign 5 was also used for the production of liter-size samples of finished HEDF samples required as a Task 3 deliverable. The specific objectives of each of these six campaigns are summarized below:

Campaign 1: Initial scans to evaluate the effects of space velocity, reaction temperature, hydrogen partial pressure and single-pass product recycle with a candidate NiWS hydrotreating catalyst in a single-stage reactor using the 350-650F COALITE distillate.

Campaign 2: Initial scans to evaluate the effects of space velocity, reaction temperature and single-pass product recycle with a candidate NiwS hydrotreating catalyst in a single-stage reactor using the 350-550F COALITE distillate.

Campaign 3: Initial scans to evaluate the effects of temperature and space velocity with higher end point COALITE distillates using a two-stage NiWS catalyst reaction system.

Campaign 4: Initial scans to evaluate the effects of temperature and space velocity with the 350-650F COALITE distillate in a two-stage reactor system comprising a NiwS catalyst in the first-stage and a high moly nickel catalyst in the second-stage reactor.

Campaign 5: Production run to produce liter size samples of HEDF materials in a single-stage reactor with the high moly nickel catalyst using the 350-650F COALITE distillate.

Campaign 6: Scans of the effects of temperature and space velocity with a calcium-doped NiWS catalyst using the $350-650 \mathrm{~F}$ COALITE distillate.

There is a considerable yield of atmospheric resid in the raw COALITE. HEDF products are end-point limited because of viscosity and freeze point specifications. Therefore, it is necessary to crack the heavier components to the mid-distillate range comprising the desired HEDF turbine fuel products. Three cracking methods were considered: 1) Resid hydrocracking using the LC-Fining process; 2) Delayed Coking; and 3) VGO fixed-bed hydrocracking.

LC-Fining ${ }^{\text {tm }}$ is a commercial technology for upgrading heavy oils. In the context of the COALITE HEDF application, LC-Fining thim has been used 
to hydrotreat long residues (ca., 300F+) and to hydrocrack the 650F+ $\left(343 C_{+}\right)$components into the HEDF boiling ranges. Three feedstocks were considered: 1) a virgin or raw $650 \mathrm{~F}+(343 \mathrm{C}+)$ atmospheric resid fraction of the raw COALITE; 2) a virgin 300F+ $(148 \mathrm{C}+)$ long resid fraction; and 3$)$ a hydrotreated $575 \mathrm{~F}+(301 \mathrm{C}+)$ atmospheric resid fraction. The objectives of these three campaigns were as follows:

0 Evaluate the first-pass reactivity of the virgin $650 \mathrm{~F}+$ atmospheric resid fraction towards hydrocracking and the production of hydrocracked HEDF-boiling range materials;

- Evaluate the hydrocracking reactivity of the first-pass unconverted $(575 \mathrm{~F}+)$ atmospheric resid recovered from the virgin $650 \mathrm{~F}+$ LC-Fining tests of the above campaigns; and

- Prepare hydrotreated gas oil (650-975F) for downstream selective fixed-bed hydrocracking campaigns by subjecting the $300 F+$ long resid to mild LC-Fining

Delayed Coking is another alternative technology for upgrading heavy oils to lighter products, such as HEDF materials. However, Delayed Coking is not as selective as hydrocracking and results in the production of a variety of byproducts, the predominant one being coke. On the other hand, Delayed Coking is much less capital intensive than hydrocracking and the differential HEDF yield losses are modulated by lower capital and operating costs.

Three Delayed Coking tests were made in the Continuous Bench Coker (CBC) unit, two with virgin C5OF+ atmospheric residua and one with a hydrotreated resid. Two delayed coking severities were investigated: a) 100 psig coke drum pressure; and b) 25 psig coke drum pressure, all other conditions kept constant.

The above two cracking operations, namely, LC-Fining ${ }^{\text {tm }}$ and Delayed Coking, are primarily conversion processes to produce HEDF precursor materials that boil within the HEDF boiling range. They therefore do not result in the production of finished HEDF products and a post-cracking hydrogenation operation is required for upgrading the cracked precursor materials. In a true commercial process, a fractionator would be installed between the cracking unit(s) with the cracked distillate fed continuously to the distillate hydrotreater and the heavier unconverted residuum being recycled back to the cracking unit. In this Task 3 screening program with the COALITE feedstock, the bench-scale cracking and hydrotreating units were not integrated and thus only first-pass crackates, either, delayed coker distillates or hydrocrackates (LC-Finates), were evaluated. Three distillate hydrotreating runs were made with delayed coker distillates and eleven distillate hydrotreating runs were made with LC-Finate (hydrocracked) distillates.

The objective of the eleven hydrotreating tests madw with the LC-Finate mid-distillates produced was to evaluate the effects of hydrocracked distillate end point, catalyst type, space velocity, reactor temperature, and single-stage vs two-stage distillate 
hydrotreating. The objective of the hydrotreating tests made with the coker mid-distillates was to evaluate the effects of coker severity, coker distillate end point, reactor temperature, and single-stage vs two-stage distillate hydrotreating.

During the early phases of the screening program, it was determined that the raw atmospheric resid fraction of COALITE was very reactive towards undesirable cracking and condensation reactions. Thus, it was postulated that a pretreatment based on hydrogenation would provide some degree of stabilization of reactive species and thereby allow better performance during subsequent cracking operations. Since the atmospheric COALITE resid contains some coal char particles, it was felt that hydrotreating in a fixed-bed unit would pose significant operability problems. The expanded-bed hydrocracking process of LC-Fining offers the capability to perform the hydrogen addition process in the presence of solids and other contaminants under commercially feasible conditions.

The two-step selective hydrocracking (TSSH) of COALITE consists of a hydrotreating pretreatment step using an LC-Fining reaction system followed by fractionation to recover a hydrotreated vacuum gas oil (HVGO) fraction and a hydrotreated middle distillate fraction, the latter of which can be directed to the HEDF pool. The HVGO fraction is then catalytically hydrocracked over a fixed-bed hydrocracking catalyst to convert the heavier gas oil-boiling species to HEDF precursors. The thus hydrocracked LC-Finate HVGO, is then subjected to distillate hydrotreating to produce the final HEDF product.

In the screening program, the fixed-bed hydrocracker and the hydrocracked distillate hydrotreater were not integrated and therefore hydrotreating of only the first-pass hydrocracked HVGO fraction was evaluated. Finally, in order to minimize fractionation equipment costs in a compercial plant, it was decided to perform the initial LC-Fining pretreatment step with a $300 \mathrm{~F}+$ atmospheric resid fraction rather than with a 650F+ atmospheric resid fraction. Two hydrocracking campaigns were made: 1) hydrocracking of virgin COALITE VGO; and 2) hydrocracking of hydrotreated LC-Finate VGO. The objective of these tests was to evaluate the effects of space velocity, reactor temperature and VGO feedstock type. All nineteen tests were made with a proprietary fixed-bed hydrocracking catalyst supplied by Amoco 0 il Company. The hydrocracied LC-Finate VGO was fractionated to recover a mid-distillate fraction for distillate hydrotreating.

A contract modification was approved by DOE to perform further screening studies of the two-stage selective hydrocracking route with the goal of exceeding the $130,000 \mathrm{Btu} / \mathrm{gal}$ energy density target of the finished HEDF test fuels. It was further expanded to also consider the impact of the energy density-JFTOT fuel stability relationships. A proprietary zeolitic hydrocracking catalyst from Zeolyst Enterprises was found to have dual functionality and be able to selectively hydrocrack VGO materials and saturate the cracked aromatic rings in the mid-distillate range simultaneously while generating a HEDF test fuel having a volumetric energy densities on the order of 133 $\mathrm{KBtu} / \mathrm{gal}$. Although this did not meet the revised target of 135,000 , it 
did exceed the original work statement target of 130,000 Btu/gal. Tables 1.8-1 and Figure 1.8-1 summarize the energy density achievements for the four Subtask 3.2 campaigns. Table 1.8-2 summarizes the properties of the gallon-size quantities of test fuels produced during the Task 5 sample preparation campaigns with the proprietary zeolitic selective hydrocracking catalyst. While the energy densities of the two test fuel samples did not achieve the maximum value demonstrated during the Subtask 3.2 screening studies (made with different hydrocracking/hydrotreating catalysts), fuel stability as measured by potentiai gum, accelerated storage stability and JFTOT tube deposit rating criteria, was excellent.

\subsection{Summary of Results of Colorado Shale 0il Operations}

Unlike the MCG liquids, the Colorado shale oil distillates are less concentrated in the cyclics and more concentrated in the aliphatic materials as seen in the table below:

\section{Colo. Shale 0il}

$\%$ olefins

\% Saturates (cyclictaliphaitic) \%Aromatics
39.9

32.9

27.2
COALITE

11.8

$<13.7$

$>74.5$

The COALITE olefins are primarily cyclic in structure, e.g., cyclooctene, cyclodecene, whereas the shale-derived olefins are primarily aliphatic, e.g., n-octene/iso-octene, $n$-decene/iso-decene. The saturates types, naphthenes vs. paraffins, for these raw synfuels were not readily differentiated by the sulfonation/R.I. procedure of the ASTM FIA analysis.

For the case of the Colorado shale oil, the raw 300-600F distillate had a volumetric heat content of only about $127 \mathrm{KBtu} / \mathrm{gal}$, some 3000 Btu/gal below the target. Upon hydrotreatment, the volumetric energy content decreases significantly away from the target. Thus, the K-550 NiWS and K-599 NiMo catalysts do not appear to have the right functionality to preserve and/or form the desirable cyclic structures. It may be possible to obviate this situation by extending the end point of the distillates beyond $600 \mathrm{~F}$ and the initial point beyond $300 \mathrm{~F}$ in order to increase the concentration of the denser 2- and 3-ring cyclics.

Two campaigns of resid hydrocracking via LC-Fining technology were made. One campaign of resid thermal cracking via delayed coking was completed. Oniy one test campaign was completed for the hydrotreating of cracked distillates. We previously found that volumetric energy densities of 300-600F raw Colorado shale oils after fixed-bed hydrotreating were limited to about $125,000 \mathrm{Btu} / \mathrm{gal}$. While this value is some $5000 \mathrm{Btu} / \mathrm{gal}$ below the spec, it still represents a $5000-10,000$ Btu/gal energy density premium above that of conventional jet fuels. Nevertheless, a campaign was initia ad with the heavy $(550 \mathrm{~F}+)$ Colorado shale oil fraction following parallel processing routes that successfully generated a $132,000+$ Btu/gal energy density HEDF from the $550 F+$ COALITE feedstock. 
TABLE $1.8-1$

COALITE DERIVED

HEDF PUEL PROPERTIES

TASK 3 SCREENING PROGRAM RESULTS

DESIGNATION

BOILING RANGE, DEG. F
FBHC-41

$3(x)-6(x)$
FB-214D

$300-610$
FB-214E

$300-620$
PB-214F

300-600

$\begin{array}{rrrr}0.856(1) & 0.8745 & 0.8571 & 0.8702 \\ 33.8 & 30.3 & 33.6 & 31.1\end{array}$

GRAVITY, SP. @60

GRAVITY, DEG. API

ELEMENTALS:

CARBON, WT.\%

HYDROGEN, WT.\%

NITROGEN, ppm

SLILFUR, ppm

VISCOSITY@-4F, cst.

FLASH POINT, DEG. $P$

FREEZE POINT, DEG. F

SMOKE POINT, $\mathrm{mm}$

ANILINE POINT, DEG. C

F.I.A.:

AROMATICS, VOL.\%

OLEFINS, VOL.\%

SATURATES, VOL\%

COPPER CORROSION,@212F

POTENTIAL GUM, mg/100ml

THERMAL STABILITY (JFTOT):

TUBE DEPOSIT RATING

TUBE DEPOSIT RATING, MAX.

DIFF. PRESS. MAX, $\mathrm{mm} \mathrm{Hg}$

$\begin{array}{rrrr}86.36 & 86.84 & 86.55 & 86.78 \\ 13.64 & 13.16 & 13.45 & 13.22 \\ <1 & <1 & <1 & <1 \\ 5 & 4 & 1 & <1\end{array}$

9.1

14.1

9.3

11.0

$>120$

$>145$

$>140$

$>150$

$<-50$

$<-50$

$<-50$

$<-50$

22

18

20

20

61.9

58.0

62.0

54.9

4.6

0.5

94.9

3.7

0.5

95.8

$3 A$

$1 \mathrm{~A}$

$1 \mathrm{~A}$

6.6

0.5

15.2

92.9

0.5

84.3

7.0

NA

7.4

16.4

1.4

$\begin{array}{rrrr}0 & 0 & 0 & 2 \\ 0.5 & 1.0 & 1.5 & 8.0 \\ 3.0 & 3.0 & 3.0 & 3.0\end{array}$

$\begin{array}{llll}130,860 & 133,992 & 131,622 & 132,901\end{array}$

ENERGY DENSITY, BTU/GAL 
FIGURE $1.8-1$

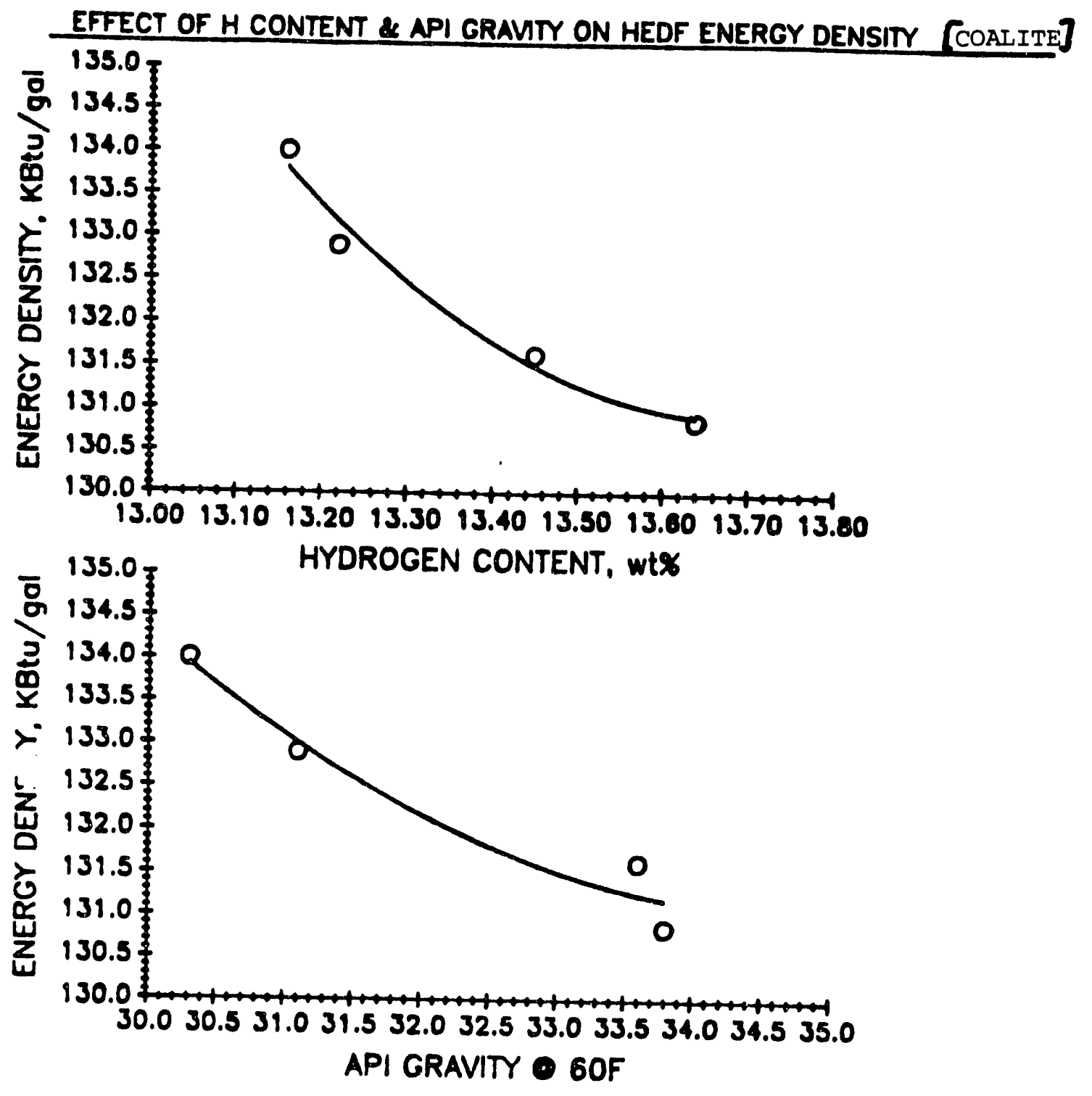


TABLE $1.8-2$

FINAL COALITE HEDF TEST FUEL PROPERTIES *

$=====$
DESIGNATION

= $=$ = $=$ = $=$ =

$===$
FBD-16

$====$

- - ב

GRAVITY, SP. @ 60/60

0.8591

33.2

FBD-17

GRAVITY, DEG. API

86.63

86.59

ELEMENTALS, WT.\%

CARBON

13.37

13.41

F.I.A., VOL.\%

AROMATICS

1.2

0.4

OLEFINS

0.3

0.7

SATURATES

98.5

98.9

FLASH POINT, DEG. F

130

125

FREEZE POINT, DEG. F

$<-76$

$<-76$

ANILINE POINT, DEG. C

60.8

64.4

SMOKE POINT, mm

VIScosity, cst@-4F

7.0

7.5

COPPER CORROSION, @212F

3A

$1 \mathrm{~A}$

POTENTIAL GUM, mg/100 ml

$<1$

$<1$

D2274 ACCEL. STORAGE STABILITY

(@95c, 16 Hr, 02), mg/100 ml

$<1$

$<1$

THERMAL STABILITY (JFTOT-D3241)

TUBE DEPOSIT VISUAL RATING(TDR)

0

0

TUBE DEPOSIT RATING MAX SPUN RATI

4.5

2.5

DIFFERENTIAL PRESSURE MAX., $\mathrm{mm} \mathrm{Hg}$

65

57

ENERGY DENSITY, BTU/GALLON

131,740

130,506

* WITHOUT ANTIOXIDANTS, ANTI-DEICING AGENTS, METAL DEACTIVATORS 
The selective hydrocracking route, as successfully implemented with the COALITE feedstock, basically consists of mild expanded-bed hydrofining (LC-Fining) of the $300 \mathrm{~F}+$ dewatered feed; fractionation to recover the 550-975F LC-Finate vacuum gas oil (VGO); selective hydrocracking of the VGO over the Amoco proprietary fixed-bed hydrocracking catalyst; and fixed-bed hydrogenation of the VGO hydrocrackate.

In the current campaign with the Colorado shale oil feedstock, the selective hydrocracking route followed the steps delineated below:

- The whole (IBP to end point), undewatered Colorado shale oil was subjected to the mild LC-Fining (test BLCF-102) step. The water collected in the LC-Finate product receivers was phase separated by decanting. The LC-Finate full-range product was fractionated to generate a 575-975F VGO fraction for downstream hydrocracking/hydrogenation.

- Since the nitrogen content of the LC-Finate VGO was still very high, ca., $15000 \mathrm{ppm}, \mathrm{a}$ subsequent fixed-bed hydrotreating (test FB-186/187) step using a NiW/NiMo two-stage catalyst system was used to reduce nitrogen content to $200 \mathrm{ppm}$.

- The thus hydrotreated LC-Finate VGO was then subjected to fixed-bed hydrocracking (test FBHC-32/35) over the Amoco proprietary hydrocracking catalyst. The resultant full-range hydrocrackate was then subjected to fixed-bed hydrotreating (FB-188/189) over a NiW/NiMo two-stage catalyst system without fractionating out the unconverted $575-975 \mathrm{~F}$ gas oil fraction.

- The hydrogenated hydrocrackate was fractionated to recover a 275-550F HEDF product that met flash point and freeze point specs.

The measured energy density of this latter product was still only about 125,000 Btu/gal, comparable to that generated when hydrotreating the raw 300-600F Colorado shale oil distillate. Thus, the selective hydrocracking of the $575 \mathrm{~F}+$ fraction of the Colorado shale oil did not improve energy density quality as was observed with the COALITE feedstock. Furthermore, the per pass conversions during the LC-Fining (BLCF-102) and the fixed-bed hydrocracking (FBHC-32/35) were very low indicating the relative refractory nature of the gas oil fraction of the Colorado shale oils.

The plan for the evaluation of the extraction/hydrogenation route consists of: a) collection of basic equilibrium solvent selectivity data for the two candidate solvents, namely, dimethylformamide (DMF) and tetraethylene glycol (TEG); b) analytical evaluation of the extracts and raffinates with respect to energy density improvements; and c) recommendations for preparation of bench-scale quantities of extracts for demonstration of the potential of fixed-bed hydrotreating (and hydrocracking) to upgrade extracted HEDF precursors to the $130,000 \mathrm{~min}$. Btu/gal energy density spec. 
The four feedstocks selected for the initial evaluation include:

$\begin{array}{ll}0 & \text { mildly LC-Fined vac gas oil (BLCF-102 product) } \\ 0 & \text { severely hydrotreated LC-Finate vac gas oil (FB-186/187) } \\ 0 & \text { selectively hydrocracked mid-distillate (FB-188/189) } \\ 0 & \text { hydrotreated raw mid-distillate (FB-130) }\end{array}$

The first two feedstocks represent the evaluation of heavier extracts boiling above the HEDF boiling range prior to hydrocracking. The latter two feedstocks to extraction represent HEDF products having nominal 125,000 Btu/gal energy densities.

The test equipment consists of a stirred, externally heated, glass extraction vessel. Testing consisted of three stages of contact using fresh solvent in each stage. Conditions held constant in these initial tests were as follows:

$$
\begin{array}{ll}
0 & \text { Nominal temperature of } 195 \mathrm{~F} \\
0 & \text { Atmospheric pressure } \\
0 & \text { Stirrer speed of } 5 \mathrm{rpm} \\
0 & 1 \text { hour extraction contact time per stage } \\
0 & \text { Fresh solvent to feed ratio of } 1.5 \mathrm{gm} / \mathrm{gm}
\end{array}
$$

Raffinate and solvent-rich extract phases were separated by decanting in a separatory funnel. The extract was separated from the solvent by introduction of water which dissolved the solvent and freed the hydrocarbon-rich extract. The two solvents selected were premised on separation from the extract by distillation. The initial testing indicated that the DMF solvent demonstrated a good degree of effectiveness in extracting some species from the heavier feedstock. The TEG solvent appeared to have no specificity for any of the components in the lighter distillate feedstock. Since the DMF solvent is soluble in water, it may be separated from the extract in a commercial-scale application by introduction of a third phase, namely, water or an aqueous-rich recycle stream, instead of distillation.

The DMF extraction of a hydrotreated 300-650F distillate can increase the energy density of the extract by some $2335 \mathrm{Btu} / \mathrm{gal}$ over that of the feed but at the expense of a reduction in the energy density of the raffinate. 


\subsection{EXPERIMENTAL PROCEDURES}

\subsection{Overview}

The Task 3 Work Statement called for the screening of processing and upgrading schemes using laboratory-scale screening equipment while the Task 5 sample preparation program required the larger pilot plant-scale equipment. At LCI's Engineering Development Center (EDC), currently referred to as the Bloomfield Research \& Dev opment Center ( $B R D C)$, process testing including screening and salure preparation activities is carried out in either laboratory-scale, bench-top or pilot plant equipment. The processing and upgrading schemes for producing HEDF from synfuel feedstocks under the subject program include the following unit operations:
- Fixed-bed Distillate Hydrotreating
- Fixed-bed Distillate Hydrocracking
- Expanded-bed Resid Hydrocracking
- Delayed Coking
- Fractionation
- Solvent Extraction
- Clay Treating

The Task 3 screening of these process operations was carried out in the following test units:

1. Bench-Scale Fixed-Bed Hydrotreating Unit

2. Bench-Scale Fixed-Bed Hydrocracking Unit

3. Bench-Scale Expanded-Bed LC-Fining Unit

4. Continuous Bench Coking Unit

5. Laboratory Extraction Unit

6. 4-in Batch Fractionation Unit

7. Equilibrium Flash Vaporization Pilot Unit

8. Laboratory Batch Distillation Units

9. Laboratory Clay Treating Unit

The Task 5 sample preparation program was carried out in the following test units:

1. Pilot Plant LC-Fining ${ }^{\text {tm }}$ Unit

2. Pilot Plant Fixed-Bed Hydroprocessing Unit

3. Pilot Plant Clay Treating Unit

The remainder of this section briefly describes the features of these process test units utilized in this contract. 


\subsection{Bench-Scale Fixed-Bed Hydrotreating Unit}

The Bench-Scale Fixed-Bed Hydrotreating Unit (see Figure 2.2-1) consists of a two-stage, close-coupled, fixed-bed reactor system equipped with high pressure liquid and gaseous (hydrogen) feed systems and a product recovery system. The reactors can be piped in series or in parallel with or without vapor/liquid separation between stages. The following describes each unit operating system.

$0 \quad$ Liquid Feed System

The oil feed is charged to a feed tank that is continuously stirred and circulated through a transfer line at about 5-10 psig back into the feed tank using a Tuthill lobe pump. A high pressure piston-type metering pump (Wallace-Tiernan) takes suction from the circulating loop and pumps the oil forward to the first stage reactor preheater. The feed rate is monitored by the rate of weight loss of the feed tank which is installed on a sensitive electronic weigh scale. Changes in the feed rate can be made by adjusting the plunger displacement on the Wallace-Tiernan pump.

$0 \quad$ Hydrogen Feed System

A continuous supply of hydrogen is available from high pressure hydrogen trailers. The hydrogen is regulated to a low pressure (ca., $100 \mathrm{psig}$ ) and then recompressed to about $2500 \mathrm{psig}$ with a diaphragm compressor. A high pressure piping manifold splits the compressed hydrogen and delivers it to the inlet of the preheater and the inlet of the fixed-bed reactors.

Each hydrogen filow is metered with a high pressure Brooks rotameter. The total hydrogen flow is also continuously metered by use of a precalibrated differential pressure monitor. System pressure is monitored at several locations including the discharge of the Wallace-Tiernan feed pump; inlet and outlet of the fixed-bed reactor; heavy oil product separator and the light oil receiver. System pressure is controlled by a diaphragm type back-pressure regulator.

\section{- Reaction Systems}

The preheater consists of a $0.245-i n$. inside diameter tube electrically heated with Calrod electric heaters providing for two separate controlled heating circuits. A separate transfer line heater controls the temperature of the stage I effluent. The fixed-bed reactors consist of a l-in. i.d. pipe having an internal volume of about 192-cc. Each reactor is immersed in a sand bath serving as the reactor heater. The bath can be fluidized in the event isothermal operation is desired. Each reactor is equipped with four internal thermocouples. A $25-c c$ layer of $3-\mathrm{mm}$ glass beads is positioned at the top of each catalyst bed. Each bed contains about 165-cc of catalyst.

- Product Collection System

The recovery system consists of four high pressure separators, each 


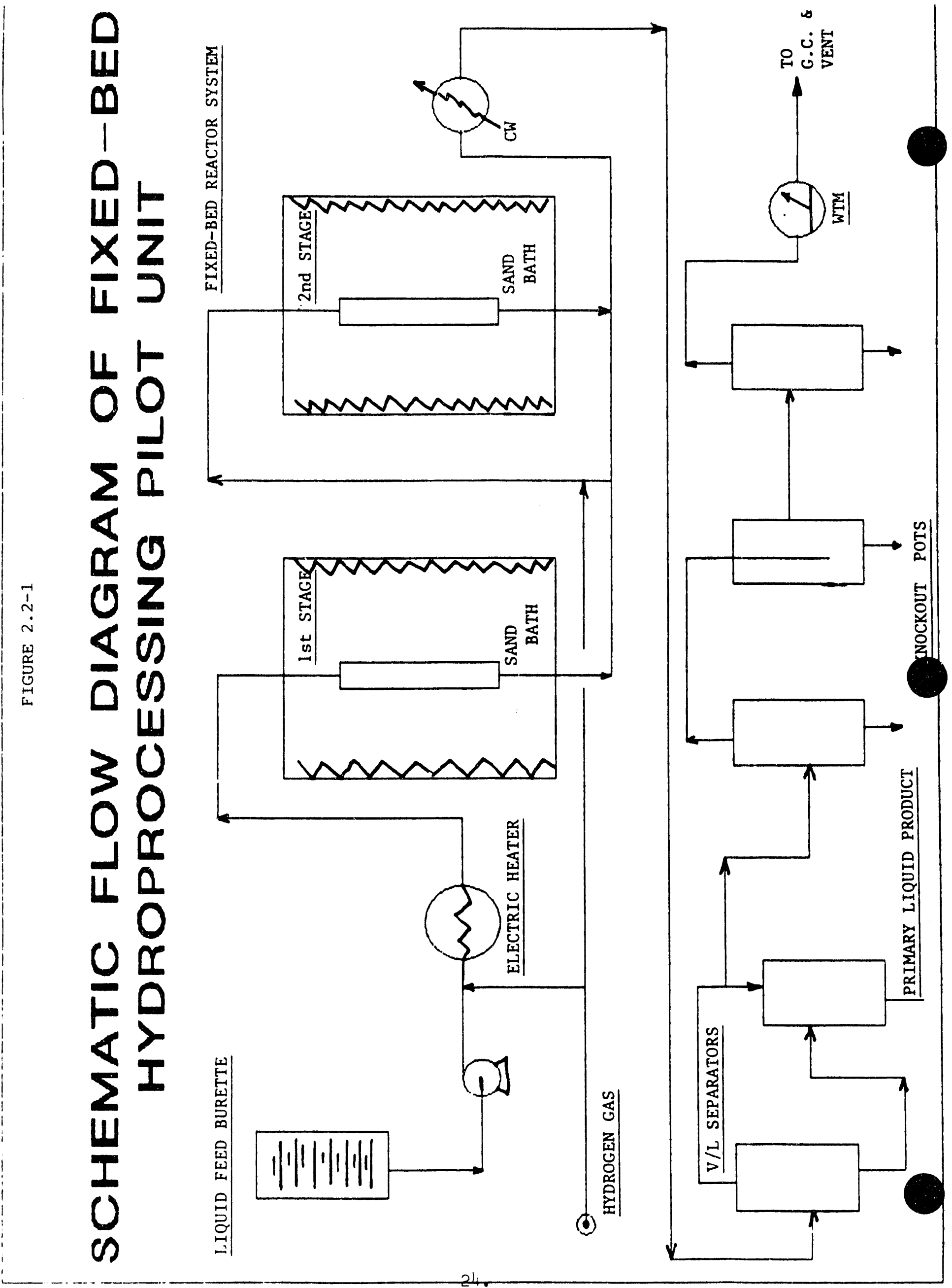


one operated at sequentially lower skin temperatures. In the first vessel, liquid products are separated from the uncondensed hydrocarbons and heteroatoms. This separator is steam traced and operated at system pressure. The resultant product is depressurized to ambient pressure, and then drained into an appropriate storage container.

The overhead vapor stream is further separated in three consecutive high pressure separators, and operated at sequentially lower temperatures. The pressure of the uncondensed vapors from the last separator is reduced to atmospheric, and cooled further in an ambient water-cooled condenser. Light uncondensed gases and hydrogen are then metered by a wet test meter and sampled for subsequent gas chromatographic analysis.

The basic operating procedure is summarized below:

1. The unit is pressurized with hydrogen and brought up to operating temperatures and flow rates using the oil feed. No external startup oil is required.

2. The unit is then lined out with the feed for a period of time to insure at least 95 percent displacement of the existing system inventory. At this point, a material balance period of 6 hour duration is initiated. Gas and liquid product samples are collected.

3. Operating conditions are then changed for the next test and the new line-out period is established prior to initiating a new material balance period.

\subsection{Bench-Scale Fixed-Bed Hydrocracking Unit}

The Bench-Scale Fixed-Bed Hydrocracking Unit (see Figure 2.3-1) consists of a single-stage, fixed-bed reactor system equipped with high pressure liquid and gaseous (hydrogen) feed systems and a product recovery system. The following describes each unit operating system.

\section{$0 \quad$ Liquid Feed System}

The liquid feed to the Bench-Scale Fixed-Bed Hydrocracker is generally a vacuum or atmospheric gas oil having a relatively high pour point. The feed system has been designed to provide heating to reduce feed viscosity and to provide circulation/agitation to prevent possible settling of contained solids (e.g., coal char fines as the case for COALITE feedstocks or oil shale fines as the case for Colorado shale oil feedstocks). The feed tank is continuously stirred and circulated through a transfer line at about 5-10 psig back into the feed tank using a Tuthill lobe pump. A high pressure piston-type metering pump (Wallace-Tiernan) takes suction from the circulating heavy oil loop and pumps the feed forward to the high pressure autoclave reaction system. The feed rate is monitored by the rate of weight loss of the feed tank which is installed on a sensitive electronic weigh scale. 

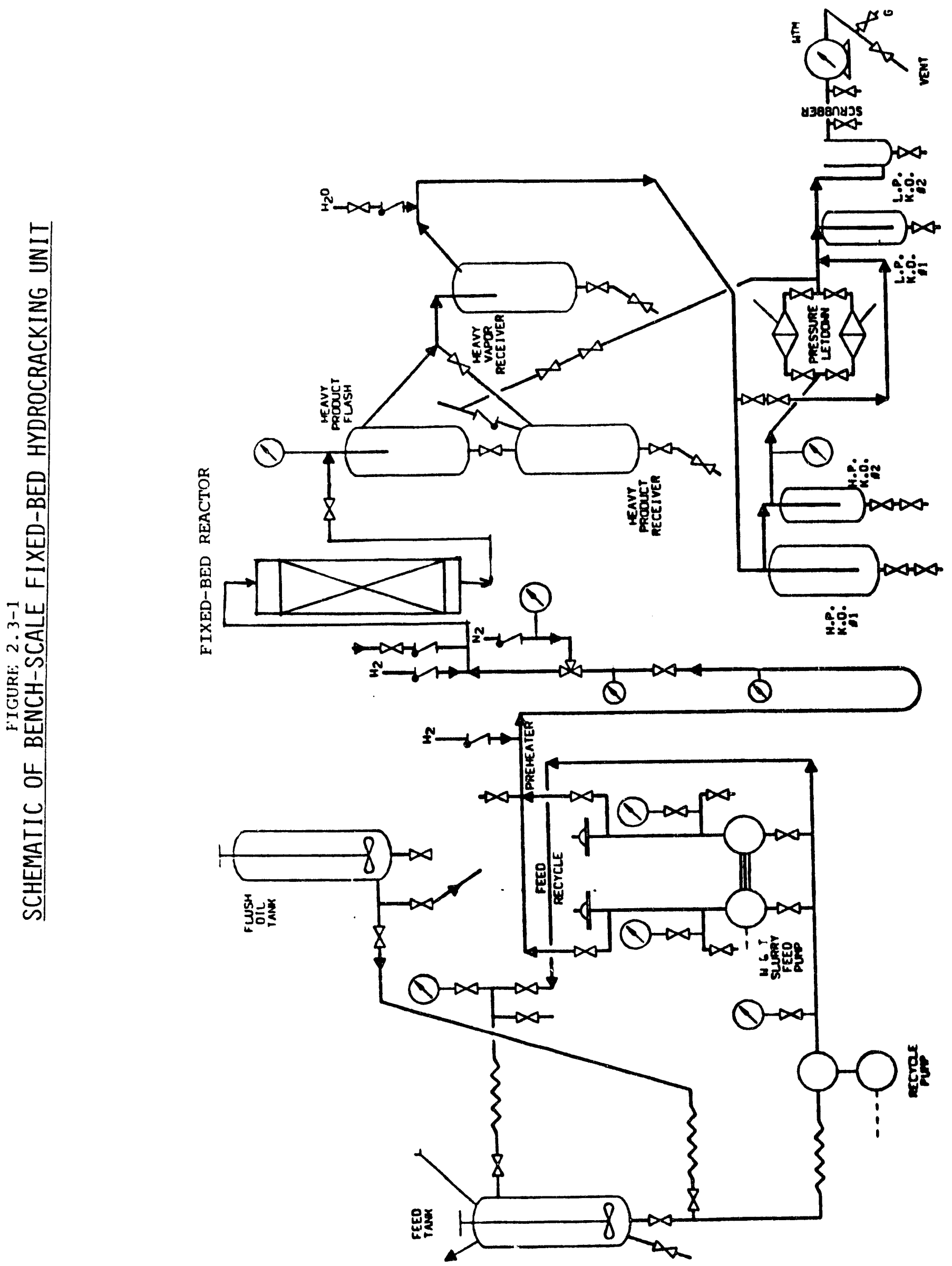
Changes in the feed rate can be made by adjusting the plunger displacement on the Wallace-Tiernan pump.

\section{$0 \quad$ Hydrogen Feed System}

A continuous supply of hydrogen is available from high pressure hydrogen trailers. The hydrogen is regulated to a low pressure (ca., $100 \mathrm{psig}$ ) and then recompressed to about $2500 \mathrm{psig}$ with a diaphragm compressor. A high pressure piping manifold splits the compressed hydrogen and delivers it to the inlet of the preheater, the inlet of the autoclave, and the drive assembly of the autoclave.

Each hydrogen flow is metered with a high pressure Brooks rotameter. The total hydrogen flow is also continuously metered by use of a precalibrated differential pressure monitor. System pressure is monitored at several locations including the discharge of the Wallace-Tiernan feed pump; outlet of the autoclave; heavy oil product separator and the light oil receiver. System pressure is controlled by a diaphragm type back-pressure regulator.

\section{- Reaction System}

The preheater consists of a $0.245-i n$. inside diameter tube electrically heated with Calrod electric heaters providing for two separate controlled heating circuits. The fixed-bed reactor consists of a l-in. i.d. pipe having an internal volume of about 192-cc. The reactor is wrapped with calrod electric heaters and an insulation laminate to provide some degree of adiabaticity. The reactor is equipped with four internal thermocouples. A 25-cc layer of 3-mm glass beads is positioned at the top of the catalyst bed which contains about $165-$ cc of catalyst.

\section{- Product Collection System}

The recovery system consists of four high pressure separators, each one operated at sequentially lower skin temperatures. In the first vessel, liquid products are separated from the uncondensed hydrocarbons and heteroatoms. This separator is steam traced and operated at system pressure. The resultant product is depressurized to ambient pressure, and then drained into an appropriate storage container.

The overhead vapor stream is further separated in three consecutive high pressure separators, and operated at sequentially lower temperatures. The pressure of the uncondensed vapors from the last separator is reduced to atmospheric, and cooled further in an ambient water-cooled condenser. Light uncondensed gases and hydrogen are then metered by a wet test meter and sampled for subsequent gas chromatographic analysis. 


\subsection{Bench-Scale LC-Fining ${ }^{\text {tm }}$ Unit}

As a co-licensor of the proprietary expanded-bed hydrocracking process known as LC-Finingsin, LCI has the responsibility of providing the process design package to LC-Fining ${ }^{2 m}$ licensees. In support of this effort, several LC-Fining ${ }^{S m}$ test units are available at the Bloomfield R\&D Center. The unit utilized in the Task 3 screening study is a continuous bench-scale system containing an autoclave reactor system to simulate the commercial expanded-bed reactors. Data from this unit can be readily utilized to develop the test conditions of the larger pilot plant reactor system planned for use in Task 5.

Figure 2.4-1 is a schematic of the autoclave-based LC-Finingsm bench-scale unit. The unit consists of a liquid feed system; a hydrogen feed system; a reaction system; and product collection system as described below.

\section{$0 \quad$ Liquid Feed System}

The liquid feed to the autoclave-based LC-Finer $5 \mathrm{Sm}$ is generally a vacuum or atmospheric resid having a relatively high pour point. The feed system has been designed to provide heating to reduce feed viscosity and to provide circulation/agitation to prevent possible settling of contained solids (e.g., coal char fines as the case for COALITE feedstocks or oil shale fines as the case for colorado shale oil feedstocks). The feed tank is continuously stirred and circulated through a transfer line at about 5-10 psig back into the feed tank using a Tuthil1 lobe pump. A high pressure piston-type metering pump (Wallace-Tiernan) takes suction from the circulating heavy oil loop and pumps the feed forward to the high pressure autoclave reaction system. The feed rate is monitored by the rate of weight loss of the feed tank which is installed on a sensitive electronic weigh scale. Changes in the feed rate can be made by adjusting the plunger displacement on the Wallace-Tiernan pump.

\section{- Hydrogen Feed System}

A continuous supply of hydrogen is available from high pressure hydrogen trailers. The hydrogen is regulated to a low pressure (ca., 100 psig) and then recompressed to about $2500 \mathrm{psig}$ with a diaphragm compressor. A high pressure piping menifold splits the compressed hydrogen and delivers it to the inlet of the preheater, the inlet of the autoclave, and the drive assembly of the autoclave.

Each hydrogen flow is metered with a high pressure Brooks rotameter. The total hydrogen flow is also continuously metered by use of a precalibrated differential pressure monitor. System pressure is monitored at several locations including the discharge of the Wallace-Tiernan feed pump; outlet of the autoclave; heavy oil product separator and the light oil receiver. System pressure is controlled by a diaphragm type back-pressure regulator. 


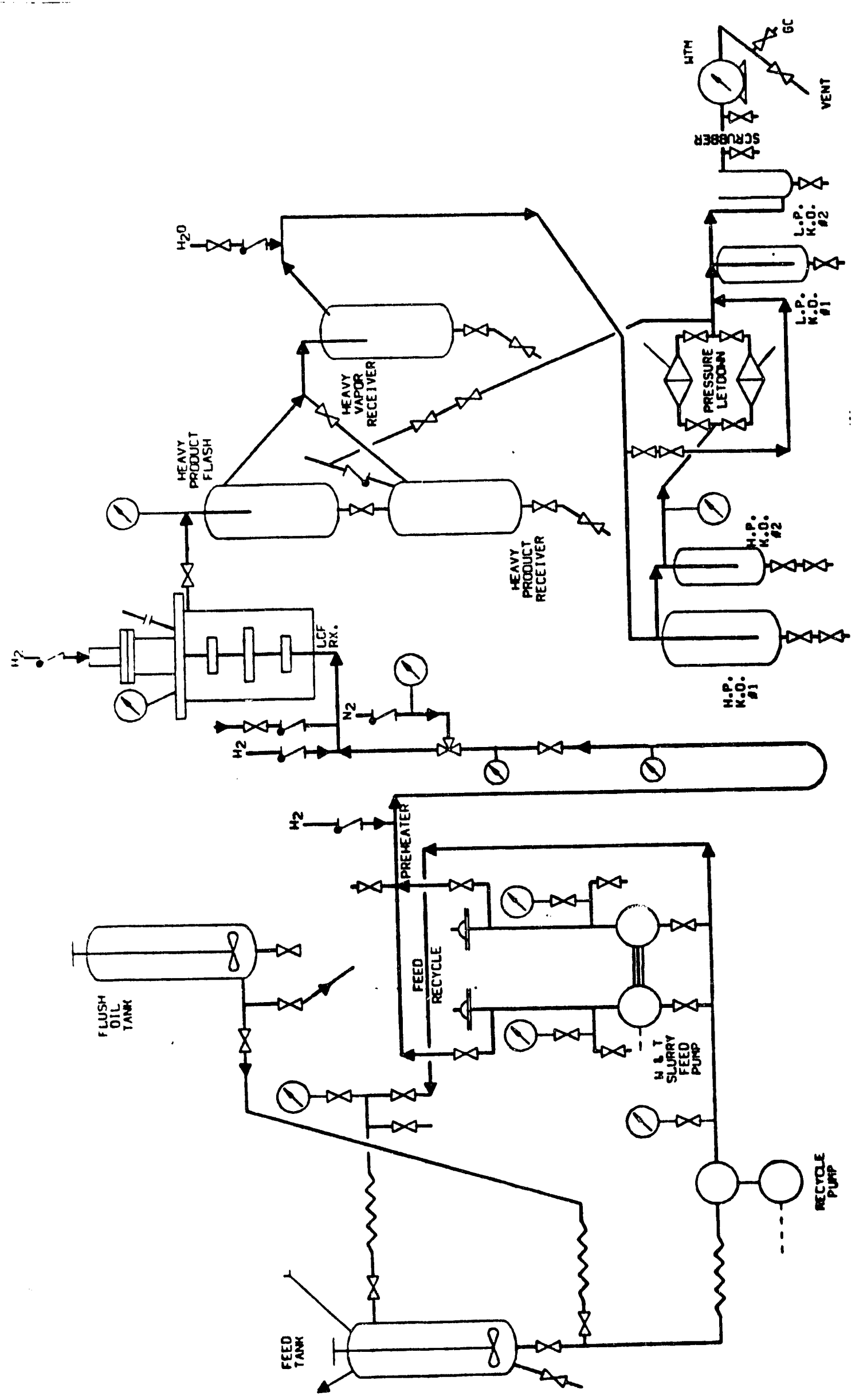


Two autoclave reaction systems are available: a $300 \mathrm{cc}$ stirred autoclave having a $240 \mathrm{cc}$ internal liquid volume; and a $1000 \mathrm{cc}$ stirred autoclave having an $800-c c$ volume. Preheated feed is fed directly to the inlet of the autoclave at the bottom and exits at the top of the autoclave. Two impellers each consisting of six-bladed turbines are attached to the stirrer shaft. Typical stirring speeds utilized in the screening program were 175-250 rpm. Use of more violent mixing could possibly result in excessive breakage of the catalyst extrudates. Temperature control was excellent with internal autoclave temperatures not varying by more than 3-4F from set point.

\section{- Product Collection System}

The recovery system consists of four high pressure separators, each one operated at sequentially lower skin temperatures. In the first vessel, liquid products are separated from the uncondensed hydrocarbons and heteroatoms. This separator is steam traced and operated at system pressure. The resultant product is depressurized to ambient pressure, and then drained into an appropriate storage container.

The overhead vapor stream is further separated in three consecutive high pressure separators, and operated at sequentially lower temperatures. The pressure of the uncondensed vapors from the last separator is reduced to atmospheric, and cooled further in an ambient water-cooled condenser. Light uncondensed gases and hydrogen are then metered by a wet test meter and sampled for subsequent gas chromatographic analysis.

\subsection{Continuous Bench Coking Unit}

LCI, as a licensor of commercial delayed coking technology, maintains several delayed coking test units at EDC. The Continuous Bench Coking (CBC) Unit, while somewhat smaller than the Delayed Coking Pilot Plant, matches commercial delayed coking operations with respect to coking time, heavy liquids recycle, coke drun temperature and coke drun pressure.

A schematic flow sheet of the CBC Unit is shown in Figure 2.5-1. The $C B C$ unit can be operated with fresh liquid feed rates from 400 to 1400 $\mathrm{gm} / \mathrm{hr}$ and with recycle/fresh feed ratios as desired, typically from 0 to $1.5 \mathrm{vol} / \mathrm{vol}$. Coke drum pressures up to $100 \mathrm{psig}$ and coking temperatures from about $800 \mathrm{~F}(426 \mathrm{C})$ to $1000 \mathrm{~F}(538 \mathrm{C})$ can be evaluated. The operating pressure and key temperatures are controlled automatically within a relatively narrow range. The coking cycle is generally conducted up to a 20-24 hour period amd depending upon the coke yield for a given feedstock, the coke drum can hold about 1300 to $4500 \mathrm{gm}$ of green coke product.

Fresh feed is pumped from the steam-heated feed tank and is joined with the heavy oil recycle stream. The combined streams flow through the preheater and through the heater coil. From the heater, the fresh 


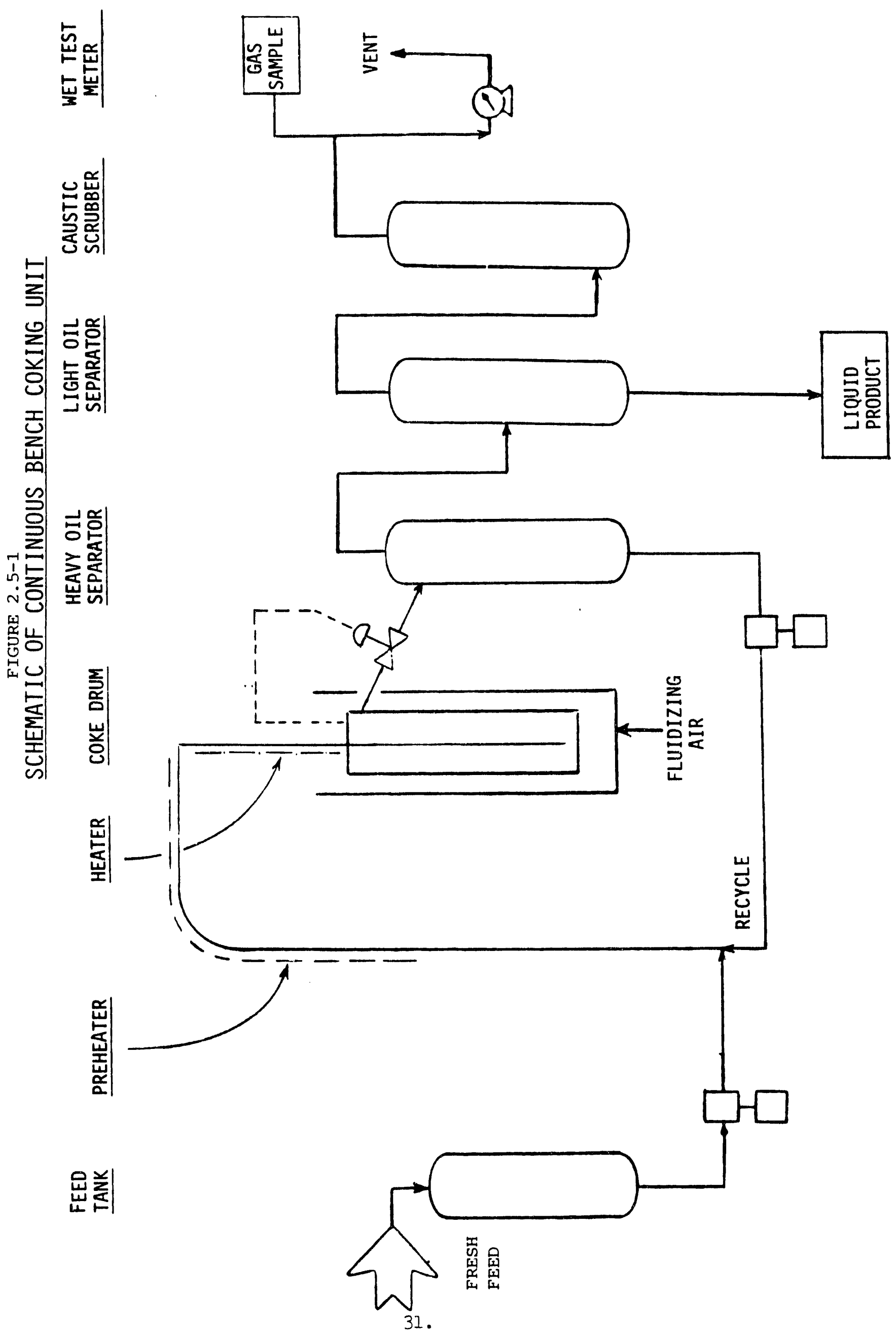


feed/recycle stream is fed to the coke drum. The devolatilized products from the coke drum flow through a pressure control valve and into the heavy oil separator. In this vessel, the recycle portion is condensed and pumped back to the inlet of the preheater. The coker "distillate" product is taken overhead into the light oil separator. The overhead vapor stream from this vessel is subsequently scrubbed in water and caustic scrubbers and then the non-condensibles are metered in a wet test meter.

\subsection{Laboratory Extraction Unit}

The initial approach to assessing the technical feasibility and amenability of the Colorado shale oil-derived products to HEDF energy density improvement consisted of equilibrium solubility studies in an ambient pressure glass contacting unit. The contactor consisted of a 1-L jacketed flask containing a glass stirring rod. Hot water is circulated through the jacket. Three stages of solvent contact were employed using the raffinate recovered from the preceeding stage in a subsequent extraction with fresh solvent. Contact time was maintained sufficiently to insure equilibrium. Shale oil-derived extracts were recovered from the separated solvents by water extraction.

\subsection{4-in Batch Fractionation Unit}

The 4-in Batch Fractionation Unit (see Figure 2.7-1) contains a 4-in diameter by $20-\mathrm{ft}$ SS column containing 20 SS decks of bubble caps, 2 bubble caps per deck equivalent to 8-10 theoretical plates; an automatic variable range reflux head; and an 85-gal reboiler. A vacuum system is capable of operation at reflux head pressures of $5-10 \mathrm{~mm} \mathrm{Hg}$ abs.

\subsection{Equilibrium Flash Vaporization Pilot Unit}

The Equilibrium Flash Vaporization pilot unit is a continuous system for performing single-stage equilibrium flash operations. The unit consists of an 8-in diameter by 14-in long flash chamber and can process 5-7 gal/hr of liquid feed to a 600F (315C) maximum temperature. At the operating vacuum 1 imits (ca., 3-4 $\mathrm{mm} \mathrm{Hg}$ abs), this temperature corresponds to a maximum atmospheric equivalent temperature of about $975 \mathrm{~F}(524 \mathrm{C})$. The unit is a true simple flash with essentially no reflux as the flash chamber walls are electrically heated to at or above the flash temperature.

\subsection{Laboratory Batch Distillation Units}

In the course of the screening work, it is necessary to tailor distillate product boiling ranges to meet certain jet/diesel fuel specs. As a result of the exploratory nature of the screening program, it is not always possible to prepare the hydroprocessing feedstocks to meet the exact boiling ranges of the final HEDF products. Therefore, there is a need for intermediate distillation for tailing front-end and back-end distillation temperatures. 


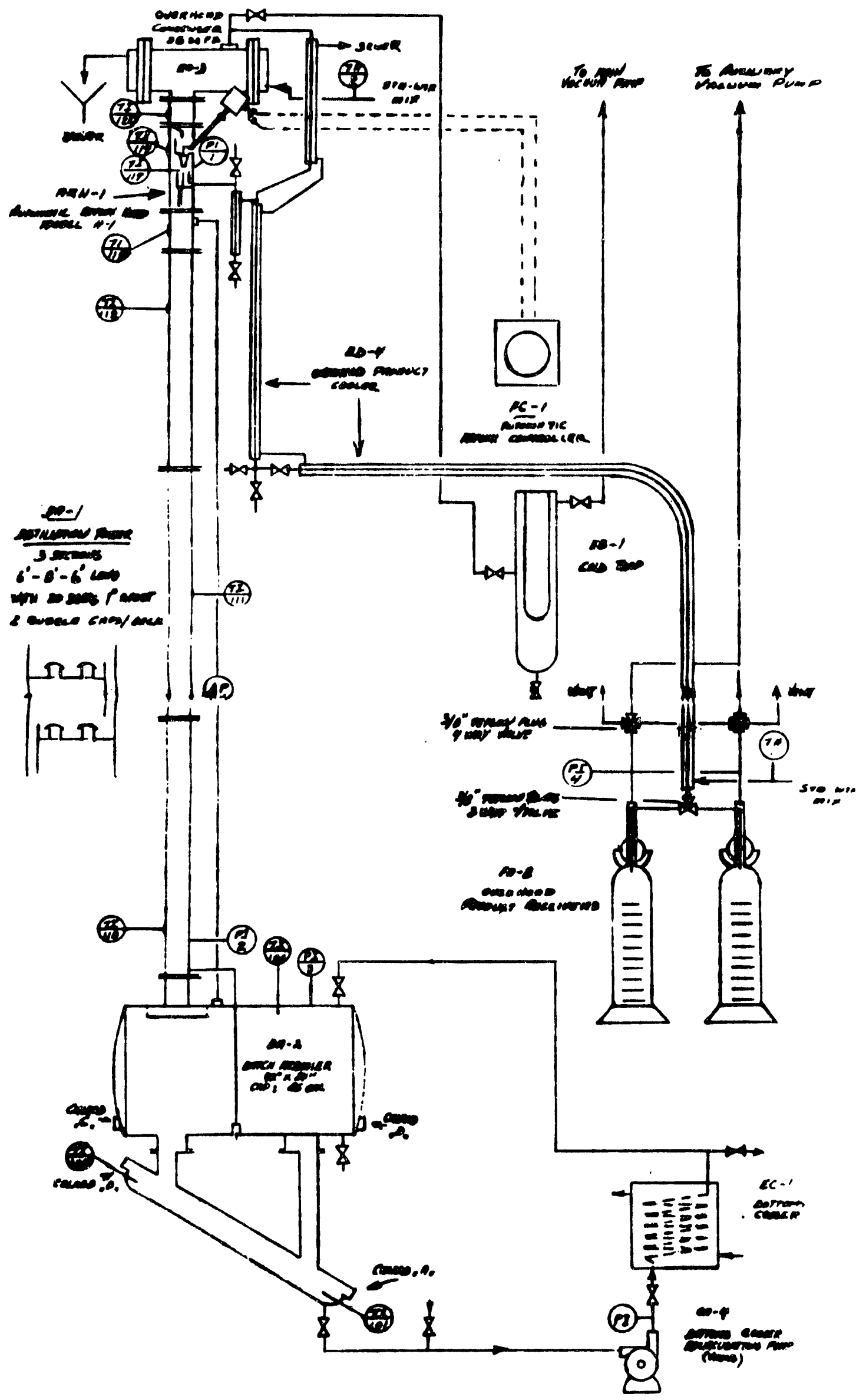

FIGURE 2.7-1

SCHEMATIC OF FOUR-IN BATCH FRACTIOMATION UNIT 
This work is facilitated in a variety of laboratory glass distillation columns. Two general types of distillation units were used: ASTM distillations and true boiling point distillations. The ASTM distillations were based on the use of either the D-86; D-1130 (Vac Engler); or modified D-1130 (Herzog) units. The true boiling distillation units consisted of either a 2-in diameter by 2-ft long glass column packed with 1/6-in Cannon stainless steel packing, or a 1 -in diameter by 18 -in long vacuum-jacketed Vigreaux column. Both units are equipped with variable reflux heads and a vacuum system capable of $1 \mathrm{~mm} \mathrm{Hg}$ abs pressure at the reflux head.

\subsection{Clay Treating Units}

Final purification of finished HEDF products is accomplished by clay treating. A simple laboratory glass column, 1-in diameter by 5 -ft long, was charged with adsorbent and feed was allowed to percolate through the column under gravity flow. A second pass can be used to obtain further reduction in trace impurities affecting color, corrosion and other jet fuel specifications. For the pilot plant sample preparation program, the clay treating for the nominal 50-gallons of HEDF product was carried out in a 2.5-in diameter column filled with $7-\mathrm{ft}$ of bentonite packing.

2.11 Pilot Plant LC-Fining ${ }^{\text {tm }}$ Unit

The pilot unit, equipped with two reactor stages, has a degree of flexibility and can be operated in alternative hydrogenation modes, fixed-bed upflow or downflow as well as expanded-bed. The following is a description of the major components of the pilot unit.

$0 \quad$ Feed Systems

The fresh oil feed is metered into the circulating reactor loop by a positive displacement pump. The oil feed rate is monitored by measuring the weight loss in a feed tank mounted on an electronic scale. The total hydrogen flow is measured using an orifice meter. The individual hydrogen flow rates to the LC-Fining reactor, instrument sensing lines, etc., are measured via high pressure rotameters. All of the "catalytic" hydrogen is introduced at the bottom of the reactor.

$0 \quad$ LC-Fining Expanded-Bed Reactor System

The LC-Fining reactor system (se Figure 2.11-1) consists of 1) a two-stage, expanded-bed in series reactor system; 2) a recycle surge bomb for each reactor stage; and 3) a duplex remote head recycle ("ebullating") pump. The liquid hourly space velocity is calculated based on either the total "thermal reactor" volume which includes the reactor, recycle lines and surge bomb, or on the settled-bed catalyst volume. The LC-Fining reactor and reactor loop are electrically heated with nine temperature controlled circuits for each reactor stage which insures essentially isothermal operation.

The internal recycle rate can be set to vary bed expansion from about 10 to $35 \%$ of settled bed height. The connecting line to the remote check valve assembly is purged intermittently with a small flow of gas oil from the stripping column. 


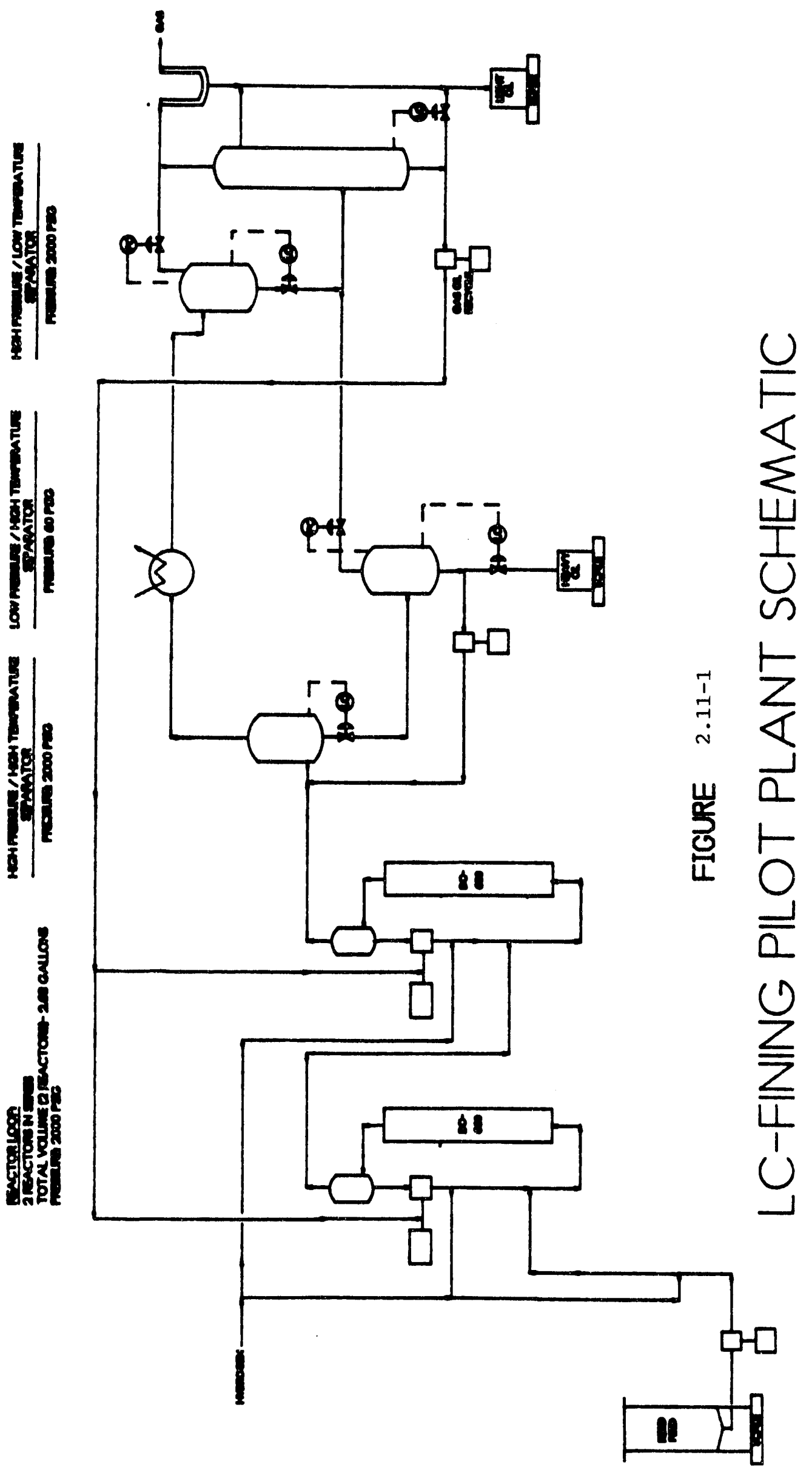

35. 
The net liquid and gas make from the LC-Fining reactor loop are separated in the high temperature/high pressure (HT-HP) separator. The light oil overhead from the HT-HP separator is condensed and collected in the low temperature/high pressure (LT-HP) separator where it is removed under level control. Quench water is introduced periodicalily upstream of the condenser to prevent the buildup of sulfides in the lines. The quench water is taken off in a decanter following the LT-HP level controller. The vapors from the LT-HP separator pass through the main pressure control valve which reduces the pressure to atmospheric. The low pressure gas is chilled, scrubbed, sampled, metered and vented. The hydrogen is not currently recycled in the pilot plant unit.

The heavy oil from the HT-HP separator is let down through the level control valve to the low pressure/high temperature (LP-HT) separator which is maintained at about 55 psig. The net flow of heavy oil through the recovery section is low. Heavy oil is recycled from the HT-LP separator back to the HT-HP separator to a) eliminate dead spots which may lead to overheating or undesirable phase separations; and $b$ ) increase the flow through the level control valve. A small quantity of stripping gas is introduced into the separator to remove a fraction of the gas oil from the heavy oil. The vapors from the HT-LP separator are let down to atmospheric pressure and stripped. The stripped gas oil, removed from the stripper by level control, is combined with stripper overhead product and the liquid from the cold trap to form the light oil product. The heavy oil is removed from the HT-LP separator by level control, collected and weighed on an electronic scale.

\section{- Sampling and Operating Procedure}

Daily operations are usually divided into twelve hour material balance test periods. Routine maintenance and changes in operating conditions are usually made during the day shift. The cold trap liquid is blended in with the light oil receiver liquid prior to analysis. The gas analysis is performed on a composite of equal volume hourly samples. The hydrogen consumption is calculated from the normalized feed and product elemental analyses. The yields of $\mathrm{H}_{2} \mathrm{~S}, \mathrm{NH}_{3}$ and $\mathrm{H}_{2} \mathrm{O}$ are usually obtained by difference from the elemental balances for sulfur, nitrogen and oxygen, respectively.

The operation of this hydroprocessing pilot plant can be tailored to the particular objectives of the program and deviations from the above might result when operating the unit under conditions that favor the production of HEDF's from MCG liquids and shale oils.

\subsection{Pilot Plant Fixed-Bed Hydroprocessing Unit}

The pilot plant fixed-bed hydrotreating unit consists of the pilot plant LC-Fining unit modified to operate in the fixed-bed downflow mode. Two reactors are available and the recycle pumps for expanding the catalyst beds are not energized. 
The fresh oil feed is metered into the top of the first reactor by a positive displacement pump. The oil feed rate is monitored by measuring the weight loss in a feed tank mounted on an electronic scale. The total hydrogen flow is measured using an orifice meter. The individual hydrogen flow rates to the fixed-bed reactors, instrument sensing lines, etc., are measured via high pressure rotameters. All of the "catalytic" or treat gas hydrogen is introduced at the top of the reactor.

\section{- Reactor System}

The reactor system consists of two 2.5 in i.d. fixed-bed reactors in series. The reactor and reactor loop are electrically heated with nine temperature controlled circuits for each reactor stage which insures essentially isothermal operation.

\section{- Product Recovery System}

The net liquid and gas make from the fixed-bed reactors are separated in the high temperature/high pressure (HT-HP) separator. The light oil overhead from the HT-HP separator is condensed and collected in the low temperature/high pressure (LT-HP) separator where it is removed under level control. Quench water is introduced periodically upstream of the condenser to prevent the buildup of sulfides in the lines. The quench water is taken off in a decanter following the LT-HP level controller. The vapors from the LT-HP separator pass through the main pressure control valve which reduces the pressure to atmospheric. The low pressure gas is chilled, scrubbed, sampled, metered and vented. The hydrogen is not currently recycled in the pilot plant unit.

The heavy oil from the HT-HP separator is let down through the level control valve to the low pressure/high temperature (LP-HT) separator which is maintained at about 55 psig. The net flow of heavy oil through the recovery section is low. Heavy oil is recycled from the HT-LP separator back to the HT-HP separator to a) eliminate dead spots which may lead to overheating or undesirable phase separations; and b) increase the flow through the level control valve. A small quantity of stripping gas is introduced into the separator to remove a fraction of the gas oil from the heavy oil. The vapors from the HT-LP separator are let down to atmospheric pressure and stripped. The stripped gas oil, removed from the stripper by level control, is combined with stripper overhead product and the liquid from the cold trap to form the light oil product. The heavy oil is removed from the HT-LP separator by level control, collected and weighed on an electronic scale.

\section{- Sampling and Operating Procedure}

Daily operations are usually divided into twelve hour material balance test periods. Routine maintenance and changes in operating conditions are usually made during the day shift. The cold trap liquid is blended in with the light oil receiver liquid prior to analysis. The gas 
analysis is performed on a composite of equal volume hourly samples. The hydrogen consumption is calculated from the normalized feed and product elemental analyses. The yields of $\mathrm{H}_{2} \mathrm{~S}, \mathrm{NH}_{3}$ and $\mathrm{H}_{2} \mathrm{O}$ are usually obtained by difference from the elemental balances for sulfur, nitrogen and oxygen, respectiveiy.

The operation of this hydroprocessing pilot plant can be tailored to the particular objectives of the program and deviations from the above might result when operating the unit under conditions that favor the production of HEDF's from MCG liquids and shale oils.

\subsection{Analytical Methods and Calculation Procedures}

The characterization tests consist of performing analytical assays of the COALITE liquids and the Colorado shale oil. Each feedstock was analyzed for the following minimal tests:

1. Elemental Analyses

2. Distillation

3. Specific Gravity

4. Hydrocarbon Type Anaiyses including \% Aromatics

5. Viscosity

6. Aniline Point

7. Bromine Number

8. Heating Value

9. Conradson Carbon Residue (CCR)

10. Solubility in heptane, toluene, quinoline

11. Pour Point

12. Flash Point

13. Diene Number

14. Accelerated Thermal Stability (D-2274)

15. Metals including arsenic

16. Basic Nitrogen

The feeds were also be fractionated into at least three cuts: an IBP-300 F naphtha; a 300-650 F mid-distillate; and a $650 \mathrm{~F}+$ residue. Several mid-distillate cuts were also taken with end-points varying about the nominal 650F value. The naphtha cuts were analyzed for:

1. Ultimate Analysis

2. Specific Gravity

3. Distillation

4. RI

5. Hydrocarbon Type Analysis

6. Flash Point

7. Octane Number

8. Bromine Number

9. Diene Number

10. Basic Nitrogen

The mid-distillate cuts were be analyzed for: 
1. Ultimate Analyses

2. Specific Gravity

3. Distillation

4. Hydrocarbon Type Analyses

5. Flash Point

6. Smoke Point

7. Cetane Number

8. Heating Value

9. ASTM D-873 Residue

10. Freeze Point

11. Basic Nitrogen

The resid cuts were analyzed for ultimate analysis, CCR content, specific gravity, solvent solubilities, distillation, viscosity, and metals content.

The finished HEDF materials were analyzed for the following properties:

1. Elemental Analyses

2. Specific Gravity

3. Heating Value

4. Distillation

5. Hydrocarbon Type Analysis

6. Flash Point

7. Smoke Point

8. Pour Point

9. Aniline Point

10. Stability

11. Cetane Number

12. D-873 Residue

13. Luminometer Number

14. Copper Corrosion

15. Viscosity

16. Color

17. Existent Gum

18. JFTOT

Intermediate HEDF products were also analyzed for selected properties, such as, specific gravity, heating value, hydrocarbon type analysis and elemental analysis.

The calculation procedures basically consist of determining performance criteria for hydroprocessing operations. These typically include percent removal of heteroatoms (hydrodesulfurization-HDS, hydrodenitrogenation-HDN, and hydrodeoxygenation-HDO); percent hydrocracking of $650 \mathrm{~F}+$ components; light gas yield; advanced HEDF yield; and hydrogen consumption. Other correlating parameters of importance include smoke point improvement; API gravity improvement; cetane number improvement; stability and viscosity improvement; percent aromatics reduction; kinetic activation energy and frequency factors. The formulas for some of these parameters are summarized in Table 2.11-1. 


\section{(1.) $650^{\circ} \mathrm{F}+$ Conversion}

This parameter represents the total conversion of the $650^{\circ} \mathrm{F}+$ fraction in the synfuel feedstocks to $650^{\circ} \mathrm{F}$ minus material (1iquid and gaseous products including $\mathrm{NH}_{3}, \mathrm{H}_{2} \mathrm{~S}, \mathrm{H}_{2} \mathrm{O}, \mathrm{CO}_{x}$, etc).

$650^{\circ} \mathrm{F}+$ Conversion $=$

$$
\frac{\left[\left(650^{\circ} \mathrm{F}+\text { in }\right)_{\text {Feed }}-\left(650^{\circ} \mathrm{F}+\text { out }\right)_{\text {TLP }}\right]}{\left(650^{\circ} \mathrm{F}+\text { in }\right)_{\text {Feed }}} \times 100
$$

\section{Gas Yield}

This is determined from wet gas test meter readings and gas analyses (corrected to a dry and $\mathrm{H}_{2}$ free basis).

Gas Yield =

$\left(\frac{S C F H \text { Dry GaS }}{379.5}\right) \times\left(\frac{100-H_{2} \text { Conc Dry Gas }}{100}\right) \times\left(\frac{\text { Mol. Wt. H Free Dry Gas }}{\text { Feed Rate, Ibs/hr }}\right)$

Net Distillate Make

Net Distillate Make, Net make of $\mathrm{C} 5-650^{\circ} \mathrm{F}$ in product 100 ibs $650^{\circ} \mathrm{Ft}$ in feed

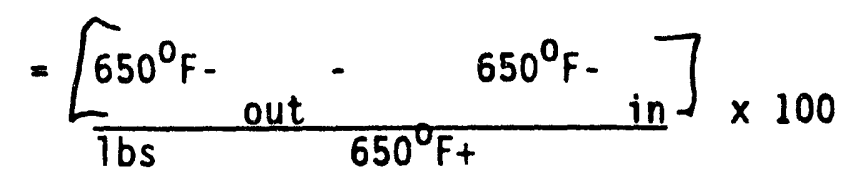

\section{(4.) Desulfurization}

The sulfur removal includes the sulfur converted to $\mathrm{H}_{2} \mathrm{~S}$ as well as any sulfur absorbed by the catalyst.

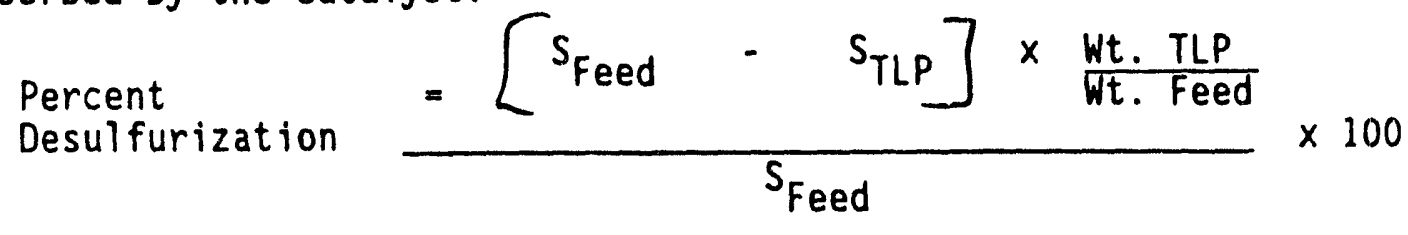




\section{(5.) Denitrogenation}

This parameter represents the percent nitrogen converted to $\mathrm{NH}_{3}$ during a material balance period.

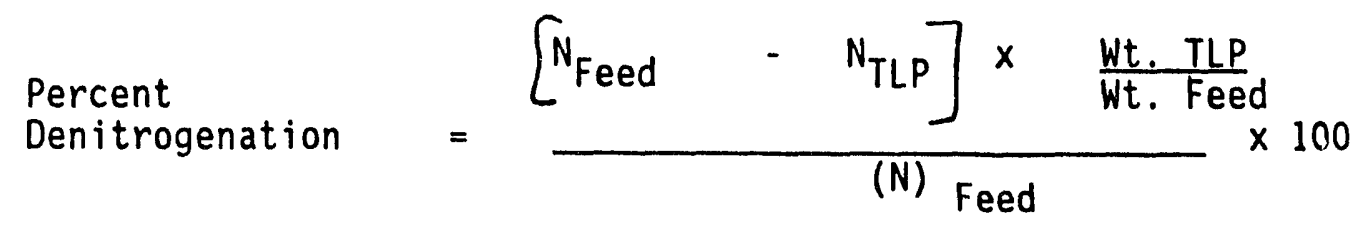

(6.) Deoxygenation

This parameter reprents the percent oxygen converted to $\mathrm{H}_{2} \mathrm{O}$ and $\mathrm{CO}_{x}$ during a material balance period.

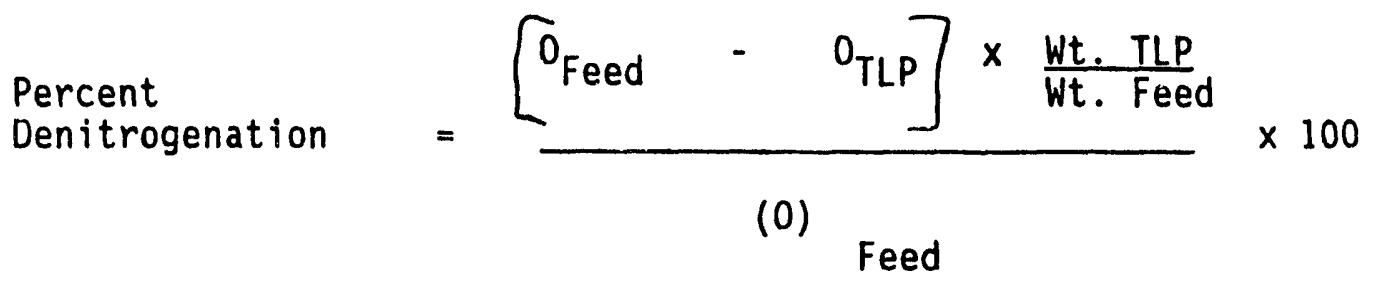


Data analysis consists of a combination of approaches. Trendwise correlations of hydroprocessing performance vs. operating conditions were generated from the test data. These are compared to correlations, both in-house as well as in the literature, for similar hydroprocessing operations with other synfuel feedstocks. Where applicable, pseudo-kinetics analyses were performed to help compare hydroprocessing performance for those cases where a constant set of base operating conditions is not readily available. 


\subsection{RAW SYNFUEL FEEDSTOCK ANALYSES}

\subsection{COALITE Feedstock}

This feedstock consists of a nominal 160-1000F boiling range product from the British COALITE carbonization process. The COALITE process was developed in the early 1900's (1) based on the use of a vertical retort. A COALITE plant built in 1936 at the Bolsover Works of Coalite and Chemical Products Ltd is still in operation and the 1000-gal sample was procured and delivered to LCI in November 1988 by United Coal Company Research Corporation (presently Coal Technology Corporation) of Bristol, VA. The COALITE was produced from a medium coking British coal and is expected to have properties similar to those of U.S. Eastern bituminous coals.

Upon receipt of the 20-drums, 1-quart aliquot samples were taken from each drum and a composite sample of all 20 drums was made. Additionally, grab samples from several of the drums were taken to check the consistency of the liquids from drum to drum. One of the difficulties in analyzing the COALITE is related to its water content and relatively wide boiling range, ca., 160 to about $1000 \mathrm{~F}$ (71-538C). We found it expedient to first dewater the sample using a rotavap apparatus and then performing the various whole oil and distillate fraction analyses on the dewatered COALITE.

Analytical distillation was accomplished in two steps: atmospheric distillation via the ASTM D-86 procedure followed by vacuum distillation of the atmospheric bottoms using the $D-1160$ procedure. The consolidated distillation curve for the composite sample is shown on Figure 3.1-1. Figure 3.1-2 shows the quality comparison of the MCG-based COALITE 1 iquids with that of conventional COED pyrolys is (2) oils.

In order to assess the amenability of COALITE distillates to hydroconversion to HEDF materials, it was determined that analytical characterization data on narrow boiling distillate fractions would be of value in formulating a hydroconversion test matrix. One objective of this analytical study was the determination of whether or not there was a sharp break point in cyclic HEDF precursor content with distillate boiling point. The COALITE composite was fractionated in laboratory true boiling point distillation apparatus to recover 16 successive distillate fractions spanning the range of $300-650 \mathrm{~F}$ (148-343C). The analyses of the individual fractions are shown in Table 3.1-1. Figure 3.1-3 shows the yield curve vs. the volumetric average boiling point (VABP) of the respective distillate fractions. The VABP parameter has also been used as the independent correlating variable in analyzing distillate properties as a function of boiling range.

A heart cut, i.e., 200-550F (93-288C), was also subjected to G.C./M.S. analysis using an SP-1000 column. The sample speciation, as provided by Professor Robert Baldwin of the Colorado School of Mines, is shown on Table 3.1-2. 

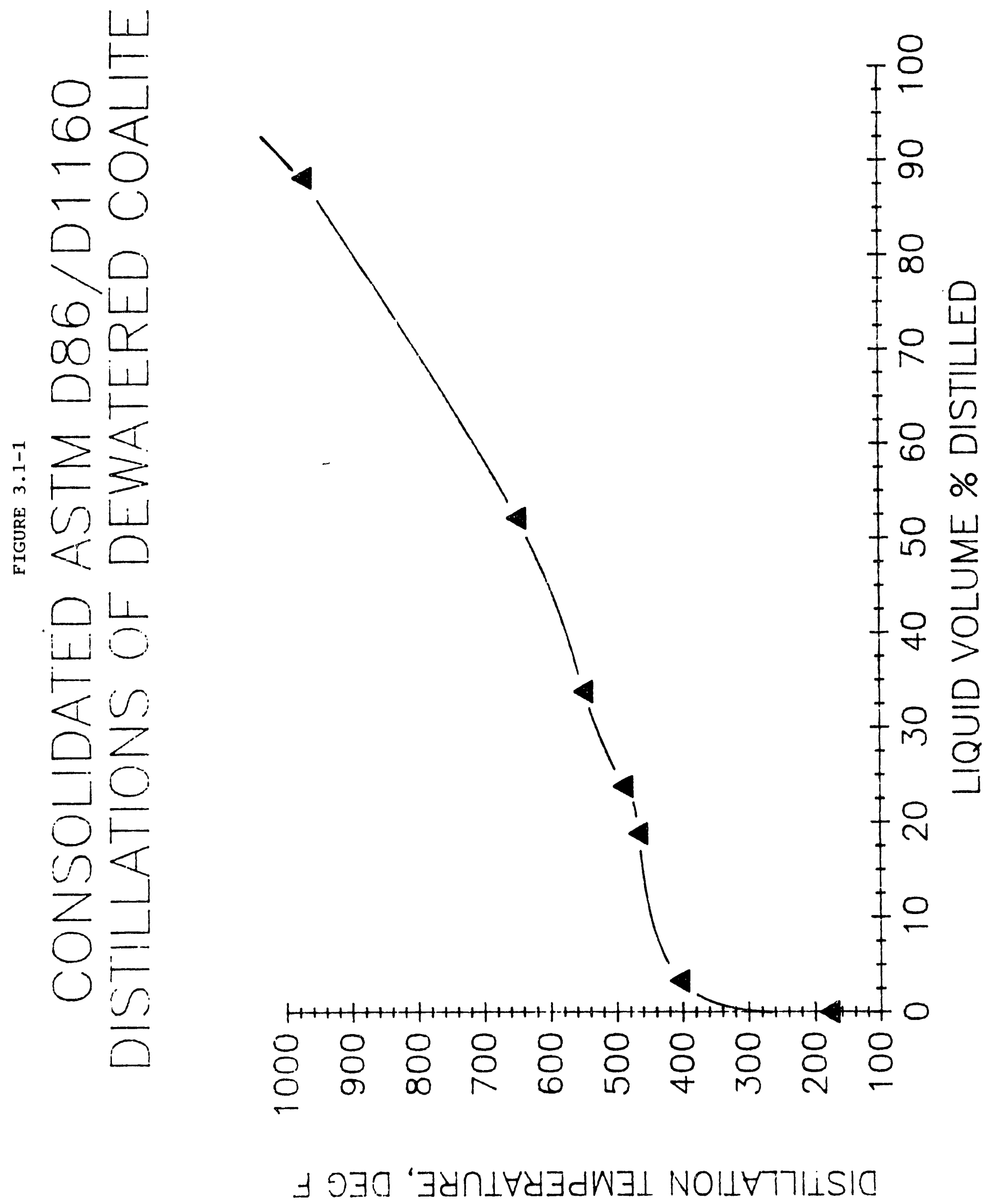

44. 


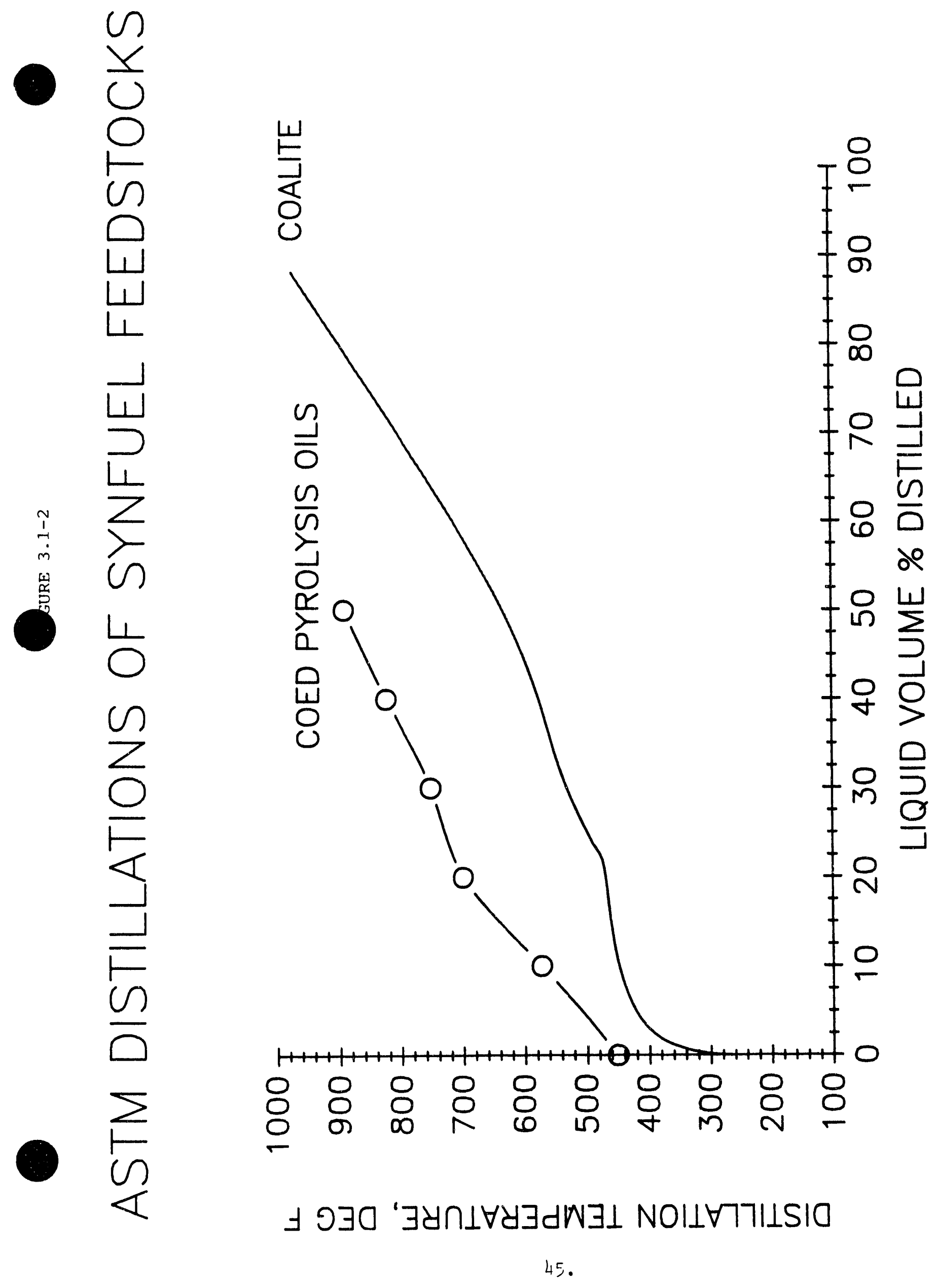




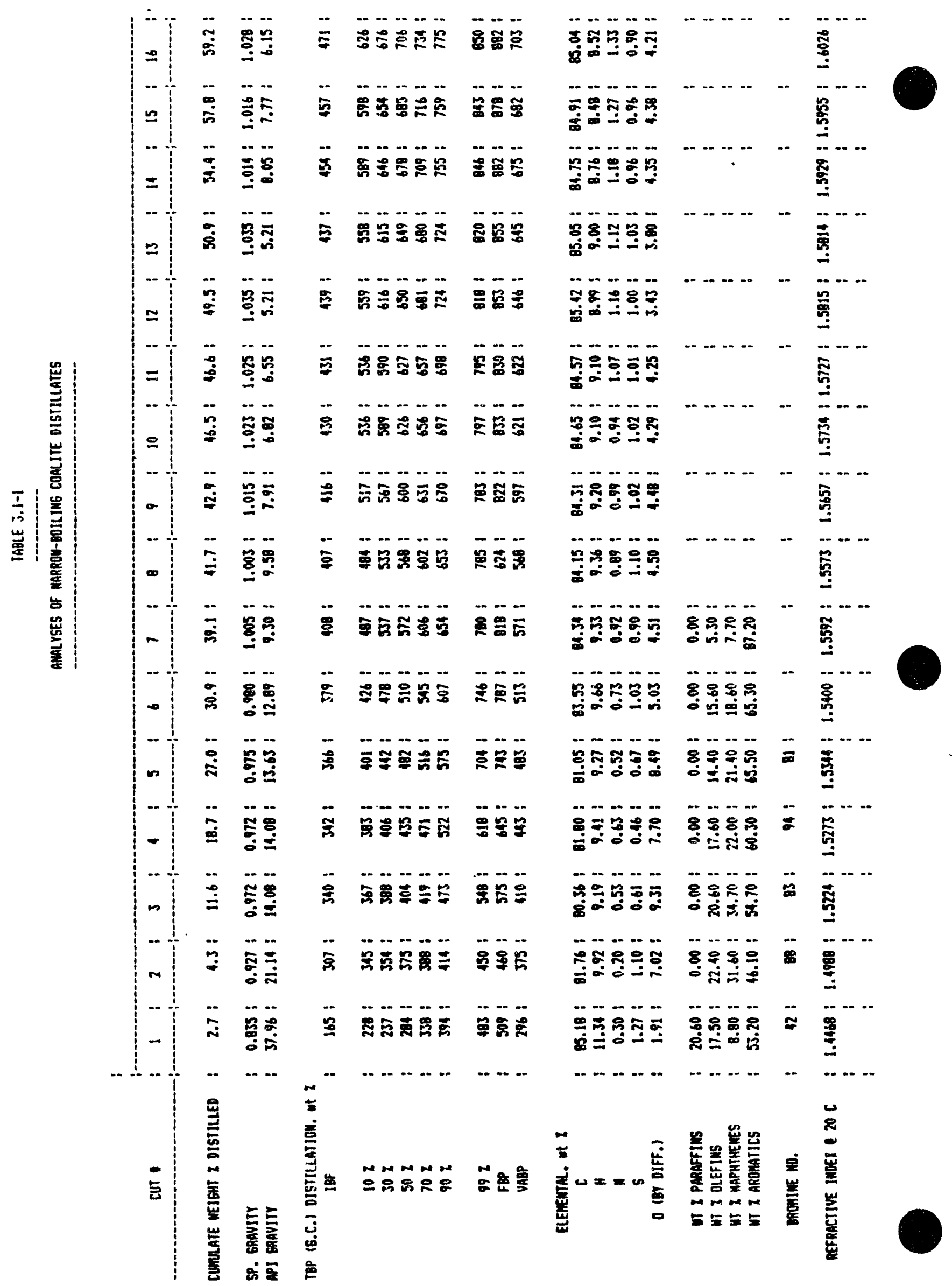




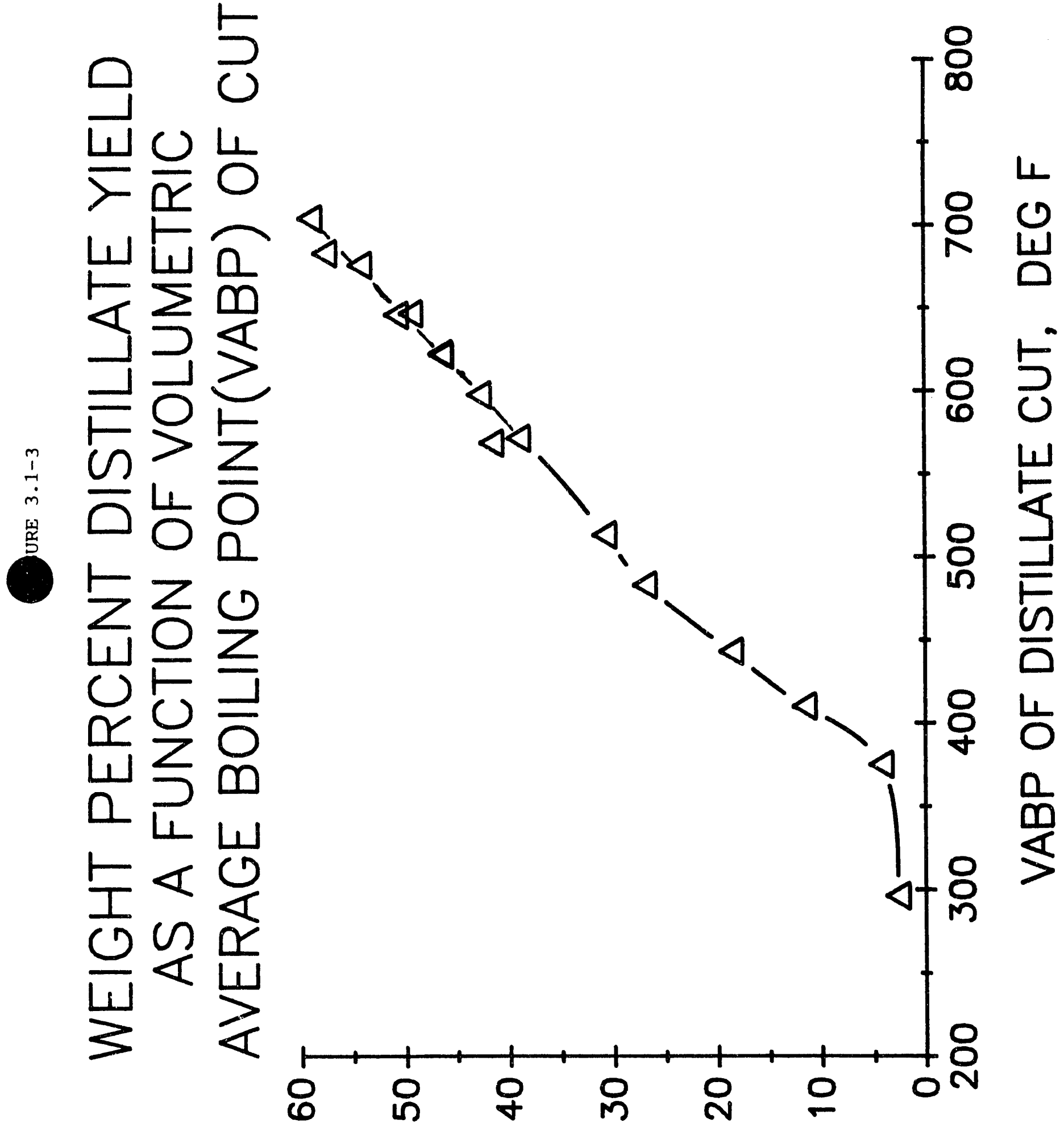

0 $3771 \perp S I O \perp N \exists J 4 \exists d \perp H O I \exists M$ 
COALJTE RID NISTJLLATE $(200-550 \mathrm{~F})$

USING SF-1OOO COLUKN

\begin{tabular}{|c|c|c|}
\hline RET TIME & AREAY & COAPOUND NAME \\
\hline 2.077 & 0.11 & paraffin or isooaraffin \\
\hline 2.215 & 0.14 & heptane \\
\hline 2.287 & 0.06 & Daraffin or isoparaffin \\
\hline 2.387 & 0.14 & Daraffin or isoparaffin \\
\hline 2.491 & 0.13 & octane \\
\hline 2.579 & 0.22 & 5-aethyl-2-hexanone \\
\hline 2.672 & 0.06 & paraffin or isoparaffin \\
\hline $\begin{array}{l}2.742 \\
2.788\end{array}$ & $\begin{array}{l}0.07 \\
0.10\end{array}$ & $\begin{array}{l}\text { paraffin or isoparaffin } \\
\text { paraffin or isoparaffin }\end{array}$ \\
\hline 2.981 & 0.36 & nonane \\
\hline 3.135 & 0.05 & paraffin or isoparaffin \\
\hline 3.237 & 0.21 & paraffin or isoparaftin \\
\hline 3.356 & 0.16 & Daraffin or isoparaffin \\
\hline 3.633 & 0.09 & Daraffin or isoparaffin \\
\hline 3.772 & 0.33 & decane \\
\hline 3.862 & 0.11 & paraffin or isoparaffin \\
\hline 3.939 & 0.14 & butrl ester of acetic acid \\
\hline 4.120 & 0.05 & paraffin or isoparaffin \\
\hline 4.228 & 0.15 & Daraffin or isoparaffin \\
\hline 4.296 & 0.80 & $1,3,5$-cycl oheptatriene \\
\hline 4.489 & 0.08 & paraffin or isoparaffin \\
\hline 4.716 & 0.10 & Daraffin or isoparaffin \\
\hline 4.881 & 0.55 & undecane \\
\hline 5.094 & 0.07 & paraffin or isoparaffin \\
\hline 5.246 & 0.03 & Daraffin or isoparatefin \\
\hline 5.357 & 0.02 & big 91 \\
\hline 5.459 & 0.38 & big 91 \\
\hline 5.559 & 0.60 & disethyl benzene \\
\hline 5.755 & 0.03 & Daraffin or isoparaffin \\
\hline 5.819 & 0.10 & paraffin or isoparaffin \\
\hline 5.985 & 0.03 & paraffin or 250paraffin \\
\hline 0.062 & 0.11 & Daraffin or isoparaffin \\
\hline 6.214 & 1.20 & dodecane \\
\hline 6.485 & 0.07 & big 91 \\
\hline 6.539 & 0.17 & paraffin or isoparaffin \\
\hline 6.724 & 0.45 & ethyl eethyl benzene \\
\hline $6.85 !$ & 0.27 & 1-dodecene \\
\hline 6.903 & 0.24 & 7-aethyl-tridecane \\
\hline 7.0108 & 0.52 & trinethyl benzene \\
\hline 7.167 & 0.09 & paraffin or isoparaffin \\
\hline 7.256 & 0.20 & ethyl eethyl benzene \\
\hline 7.372 & 0.08 & paraftin or isoparaffin \\
\hline 7.568 & 0.63 & ethyl aethyl benzene \\
\hline 7.644 & 0.86 & tridecane \\
\hline 7.723 & 0.15 & paraffin or isoparatfin \\
\hline 7.856 & 0.23 & aethyl propyl benzene \\
\hline 7.987 & 0.11 & Daraffin or isoparaffin \\
\hline 8.0901 & 0.10 & paraffin or isoparaftin \\
\hline 8.178 & 0.21 & ethyl diaethyl benzene \\
\hline 8.251 & 0.18 & Daraffin or isoparaffin \\
\hline $8 . \therefore 15$ & 0.50 & C13 isoparaffin \\
\hline 0.393 & 0.28 & trieethyl benzene \\
\hline
\end{tabular}




\begin{tabular}{|c|c|c|}
\hline $8.44 E$ & 0.51 & Cl3 isoparaffin \\
\hline 8.609 & 0.25 & nethyl phenyl pentadecane \\
\hline 8.710 & 0.43 & trioethyl propyl benzene \\
\hline 8.818 & 0.20 & wethyl ethyl benzene \\
\hline 8.918 & 0.31 & dihydro Indene \\
\hline 8.991 & 0.21 & triathyl pyrridine \\
\hline 9.101 & 1.14 & tetradecane \\
\hline 9.212 & 0.08 & paraffin or isoparaftin \\
\hline 9.275 & 0.28 & dihydro-aethyl-1H-Indene \\
\hline 9.413 & 0.42 & benzal dehyde \\
\hline 9.634 & 0.83 & 5-aethyl-5-ethyl decane \\
\hline $\begin{array}{l}9.761 \\
9.833\end{array}$ & $\begin{array}{l}0.43 \\
0.23\end{array}$ & $\begin{array}{l}\text { paraffin or isoparaffin } \\
\text { dicethyl benzene }\end{array}$ \\
\hline 9.890 & 0.16 & paraftin or isoparaftin \\
\hline 9.961 & 0.24 & paraffin or isoparaffin \\
\hline 10.213 & 0.18 & Daraffin or isoparaftin \\
\hline 10.308 & 0.07 & paraffin or isoparaffin \\
\hline 10.422 & 0.15 & Daraffin or isoparaftin \\
\hline 10.308 & 0.15 & paraffin or isoparaffin \\
\hline 10.422 & 0.39 & benzene coupound \\
\hline 10.521 & 1.16 & 2-uethyl-heptadec ane \\
\hline 10.605 & 0.28 & tetrauethyl benzene \\
\hline 10.712 & 0.34 & dihydro-disethyl-IH-Indene \\
\hline 10.788 & 1.01 & dihydro-aethyl-IH-Indene \\
\hline 10.986 & 0.28 & Daraffin or isoparaffin \\
\hline 11.088 & 0.30 & dihydro-di wethyl-IH-Indene \\
\hline 11.164 & 0.51 & Daraffin or isoparaffin \\
\hline 11.284 & 0.21 & Daraffin or isoparaffin \\
\hline 11.342 & 0.10 & Daraffin or isoparaffin \\
\hline 11.469 & 0.31 & Daraftin or iscparaffin \\
\hline 11.558 & 0.09 & Daraffin or iscoaraffin \\
\hline 11.632 & 0.11 & Daraffin or isoparaffin \\
\hline 11.679 & 0.21 & paraffin or isoparaffin \\
\hline 11.754 & 0.17 & Daraffin or isoparaffin \\
\hline 11.825 & 0.14 & Indene or benzene conpound \\
\hline 11.881 & 1.49 & hexadecane \\
\hline 12.146 & 0.60 & pyrridine cospound \\
\hline 12.239 & 0.70 & dihydro-diuethyl-IH-Indene \\
\hline 12.372 & 0.11 & paraffin or isoparaffin \\
\hline 12.426 & 0.22 & Indene or naphthalene conpound \\
\hline 12.518 & 0.40 & paraftin or isoparaffin \\
\hline 12.621 & 0.28 & Daraffin or isoparaftin \\
\hline 12.698 & 0.13 & paraffin or isoparaffin \\
\hline 12.765 & 1.01 & 5-propyl-tridecane \\
\hline 12.964 & 0.57 & dihydro diaethyl-IH-Indene \\
\hline 13.113 & 0.22 & Daraffin or isoparaffin \\
\hline 13.194 & 0.94 & 9-octyl-heptadecane \\
\hline 13.359 & 0.70 & Daraffin or isoparaffin \\
\hline 13.534 & 0.50 & pyrridine cospound \\
\hline 13.607 & 0.42 & dihydro-aethyl-naphthalene \\
\hline 13.734 & 0.35 & benzene or naphthalene coapound \\
\hline 13.815 & 0.42 & Daraffin or isoparaffin \\
\hline 14.002 & 1.56 & naphthal ene \\
\hline 14.146 & 0.57 & Daraffin or isoparaffin \\
\hline 14.357 & 0.26 & paraffin or isoparaffin \\
\hline 14.437 & 0.79 & heracosane \\
\hline
\end{tabular}




\begin{tabular}{|c|c|c|}
\hline 14.583 & 0.47 & trioethyl-dihydro-Indene \\
\hline 14.673 & 0.28 & Daraffin or isoparaftin \\
\hline 14.800 & 0.33 & nitrogen-containing cospound \\
\hline 14.942 & 0.38 & ethyl-propyl-benzicidazole \\
\hline 15.069 & 0.44 & ethyl naphthalene \\
\hline 15.176 & 0.21 & paraffin or isoparaffin \\
\hline 15.212 & 0.22 & paraffin or isoparaffin \\
\hline 15.380 & 2.26 & 1-ethylidene-IH-Indene \\
\hline 15.702 & 1.66 & diaethyl phenol \\
\hline 15.819 & 1.52 & aethyl naphthalene \\
\hline 16.102 & 0.52 & Indenone compound \\
\hline $\begin{array}{l}16.213 \\
16.313\end{array}$ & $\begin{array}{l}0.48 \\
0.54\end{array}$ & $\begin{array}{l}\text { wethyl ethyl phenol } \\
\text { paraffin or isoparaffin }\end{array}$ \\
\hline 16.457 & 0.56 & ethyl naphthalene \\
\hline 16.700 & 9.61 & wethyl ohenol \\
\hline 16.846 & 0.80 & Daraffin or isoparaffin \\
\hline 17.013 & 0.69 & disethyl naphthalene \\
\hline 17.112 & 1.52 & djoethyl naphthalene \\
\hline 17.237 & 0.63 & paraffin or isoparaffin \\
\hline 17.418 & 1.20 & ethyl phenol \\
\hline 17.571 & 8.49 & dioethyl phenol \\
\hline 17.675 & 5.22 & aethy! phenol \\
\hline 17.872 & 0.85 & paraffin or isoparaffin \\
\hline 18.042 & 0.52 & paraffin or isoparaffin \\
\hline 18.112 & 0.37 & paraffin or iscoaraffin \\
\hline 18.203 & 1.21 & 2-ethyl-4-eethyl phenol \\
\hline 18.365 & 2.10 & diwethyl phenol \\
\hline 18.548 & 1.70 & 2-ethyl-5-eethyl phenol \\
\hline 18.696 & 1.09 & ethyl phenol \\
\hline 18.780 & 2.20 & ethyl phenol \\
\hline 18.982 & 0.64 & phenol conpound \\
\hline 19.147 & 1.15 & phenol coupound \\
\hline 19.323 & 2.87 & disethyl phenol \\
\hline 19.480 & 0.37 & Daraftin or isoparaffin \\
\hline 19.604 & 0.48 & benzene conpound \\
\hline 19.701 & 0.29 & paraffin or isoparaftin \\
\hline 19.830 & 2.73 & ethyl wethyl phenol \\
\hline 20.16 .3 & 0.23 & Daraffin or isoparaffin \\
\hline 20.289 & 0.61 & paraffin or isoparaffin \\
\hline 20.434 & 0.48 & ethyl wethyl phenol \\
\hline 20.491 & 0.16 & pyrridine or sulfur-containing coapound \\
\hline 20.524 & 0.45 & sulfur-containing conpound \\
\hline 20.678 & 0.19 & poraffin or isoparaffin \\
\hline 201.818 & 0.20 & paraffin or isoparaffin \\
\hline 20.985 & 0.52 & Daraffin or isoparaffin \\
\hline 21.111 & 0.23 & nitrogen- or sulfur-containing conpound \\
\hline 21.597 & 0.77 & ar,ar,.alpha.-trioethyl benzeneaethanol \\
\hline 21.837 & 0.19 & benzene cospound \\
\hline
\end{tabular}


Figure 3.1-4 shows the $H / C$ atomic ratio of the COALITE distillates as a function of VABP. As expected, the $\mathrm{H} / \mathrm{C}$ ratio decreases as VABP increases. Also shown on the figure is the $H / C$ ratios required for the HEDF product. The $H / C$ atomic ratio of the raw COALITE distillates has to be improved by approximately $40 \%$.

Figure 3.1-5 shows the API Gravity of the COALITE distillates as a function of VABP. The API of the finished HEDF product should be about 20-40 degrees API higher than that of the raw COALITE 300-650F (148-343C) distillate.

Figures 3.1-6, 7, and 8 show the nitrogen, oxygen and sulfur contents of the COALITE distillates as a function of VABP. Nitrogen content increases linearly with VABP. Oxygen content, as determined by difference, appears to decrease almost linearly with VABP. Sulfur content shows an unusual minima at about $450 \mathrm{~F}$ (232C) average boiling point and then. lines out at a value of about $0.9-1.0$ wt percent at higher VABP.

PONA analysis based on the F.I.A./Refractive Index method was used as a measure of hydrocarbon types. The resultant data are presented on Figure 3.1-9. It is to be cautioned that the method may not be accurate for non-petroleum, synfuel-derived distillates such as COALITE. The general trend indicates a continual increase in aromaticity as VABP increases.

Proton NMR spectroscopy was used as an additional analytical tool to assess the hydrogen and carbon distributions in COALITE distillates. Table 3.1-3 shows the NMR parameters for a 390-650F (198-343C) boiling distillate. Figures 3.1-10, 11 , and 12 show the NMR hydrogen distributions, carbon distributions and $H / C$ atomic ratios respectively as a function of VABP.

Bromine No., which is a measure of carbon-carbon double bond content, for four lighter COALITE distillates is plotted vS VABP in Figure 3.1-13. There is little effect of VABP on Bromine No. over the range evaluated.

Refractive Index $(\Theta 20 C)$ is a rapid analytical tool and a good measure of distillate quality. Figure 3.1-14 shows the effect of VABP on distillate Refractive Index. Refractive Index can also be used as an independent correlating variable similar to that of the VABP parameter. Figures $3.1-15,16,17$, and 18 show the dependency of several distillate properties as a function of the Refractive Index. Also shown on the latter four graphs are data published by METC (3) for a variety of full-range coal liquids and shale oils. While the LCI and METC correlations are not compeletely congruent, the Refractive Index parameter does show to be a widely usable correlating tool.

\subsection{Colorado Shale 0il Feedstock}

The programs being performed under this contract are co-funded by the Coal Projects Management Division/Gasification Branch and by the 


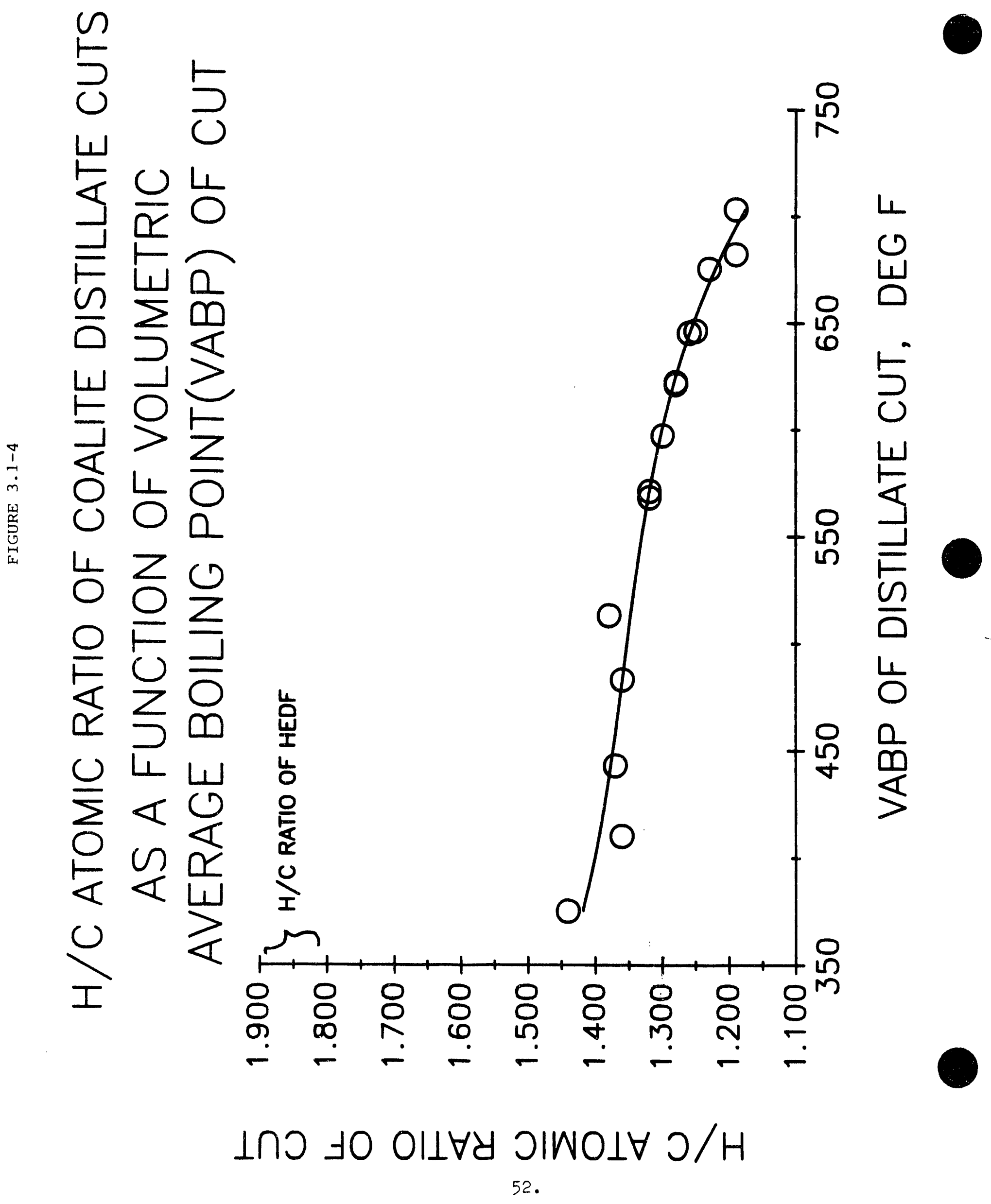




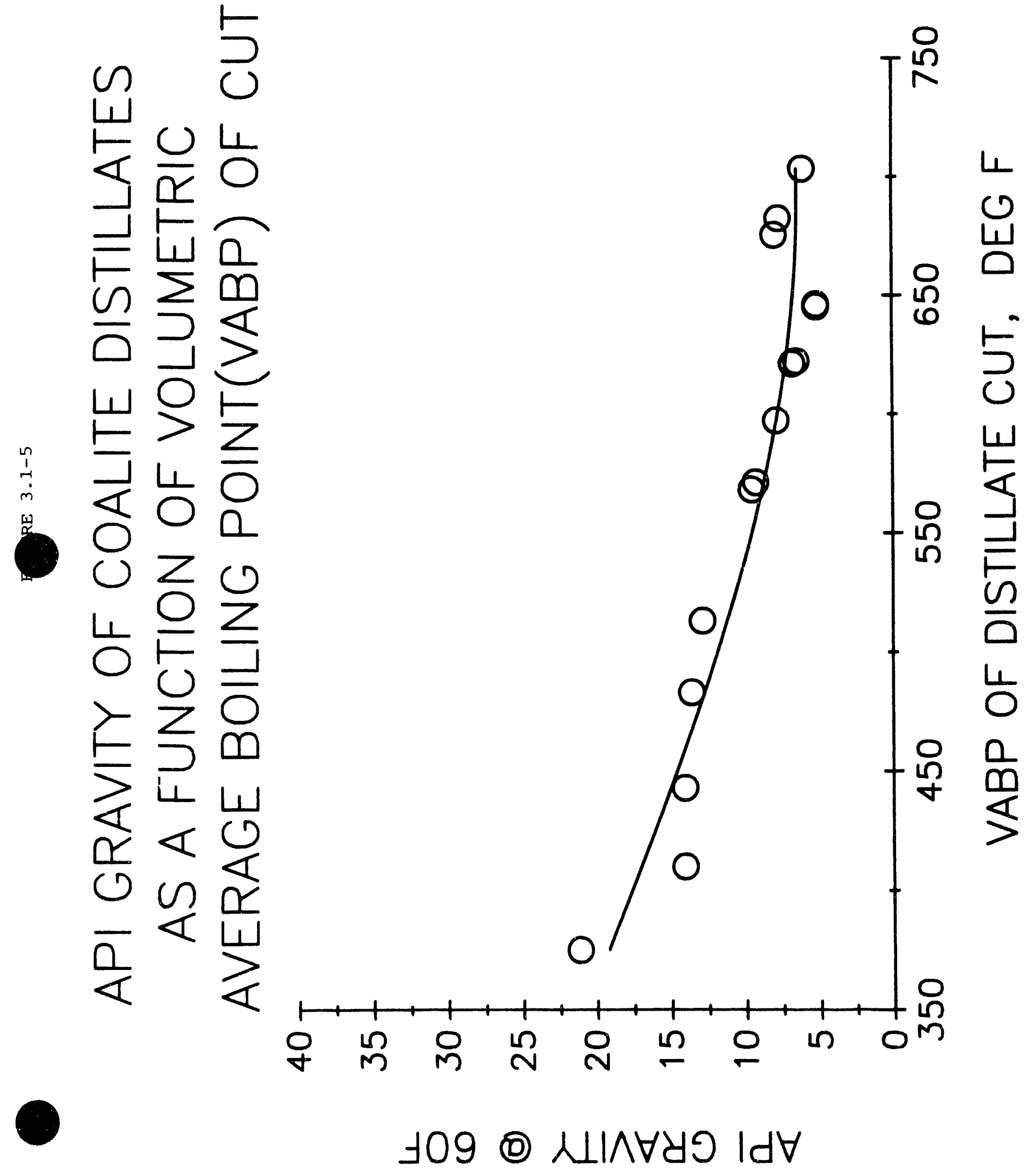




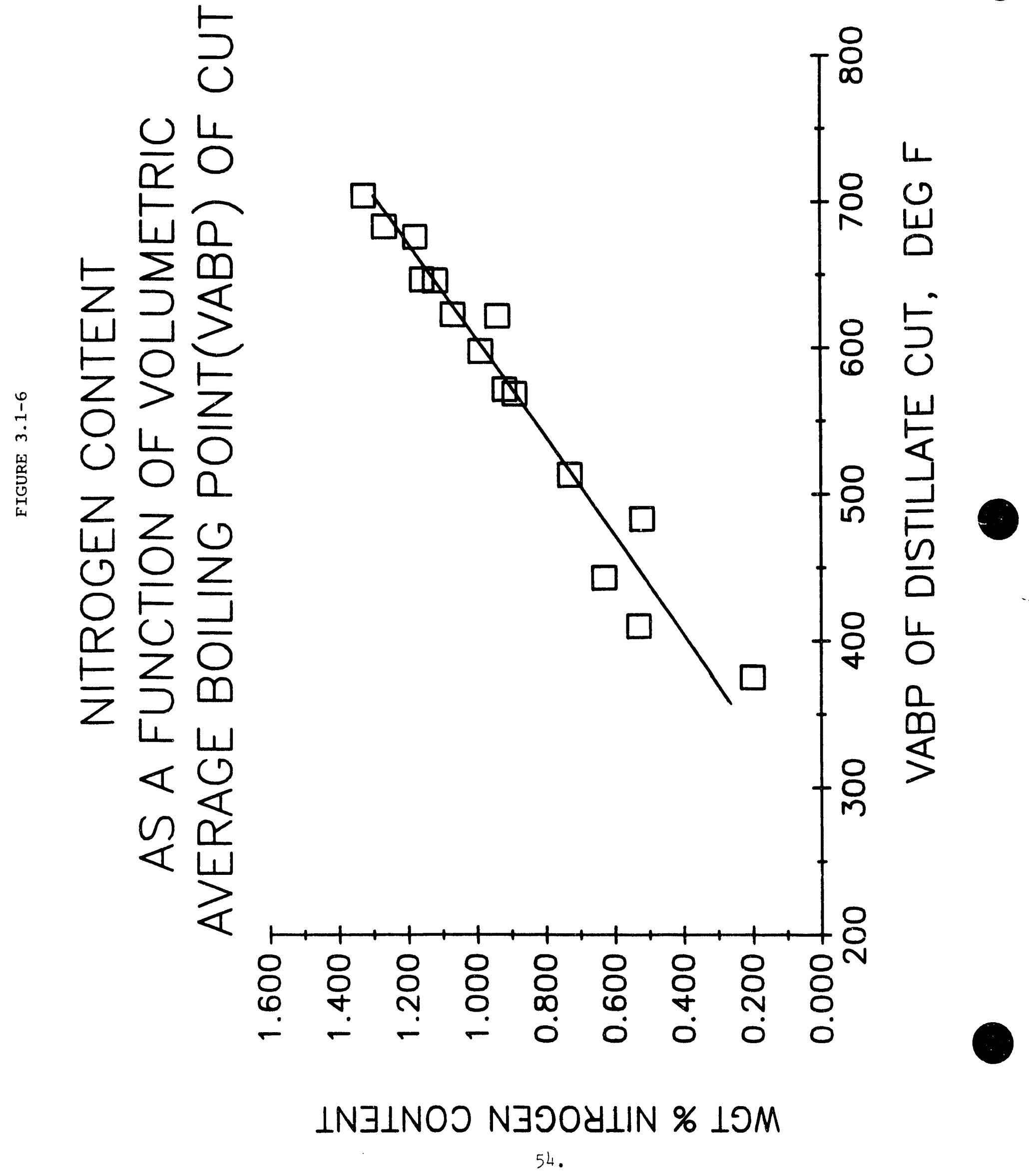




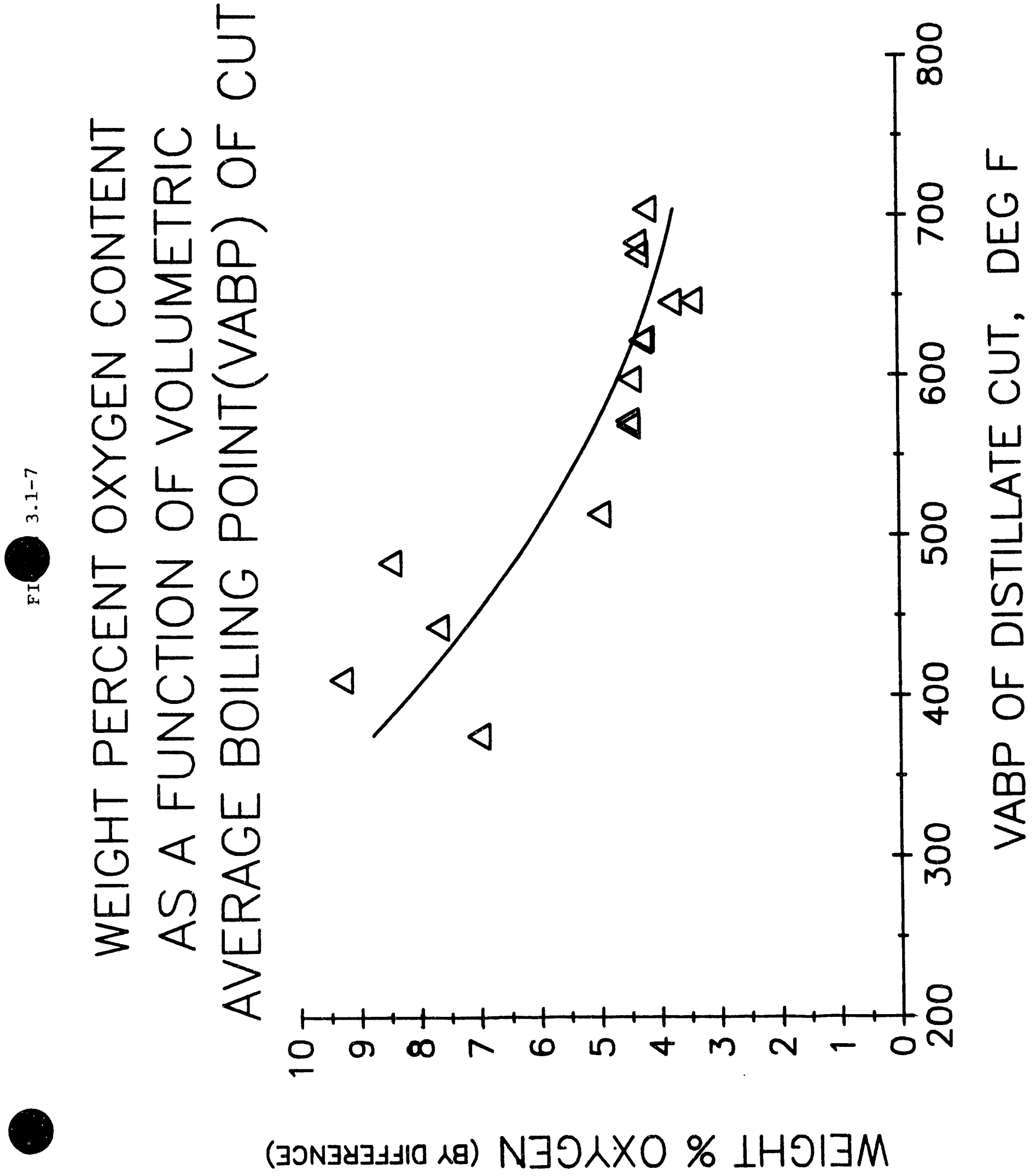




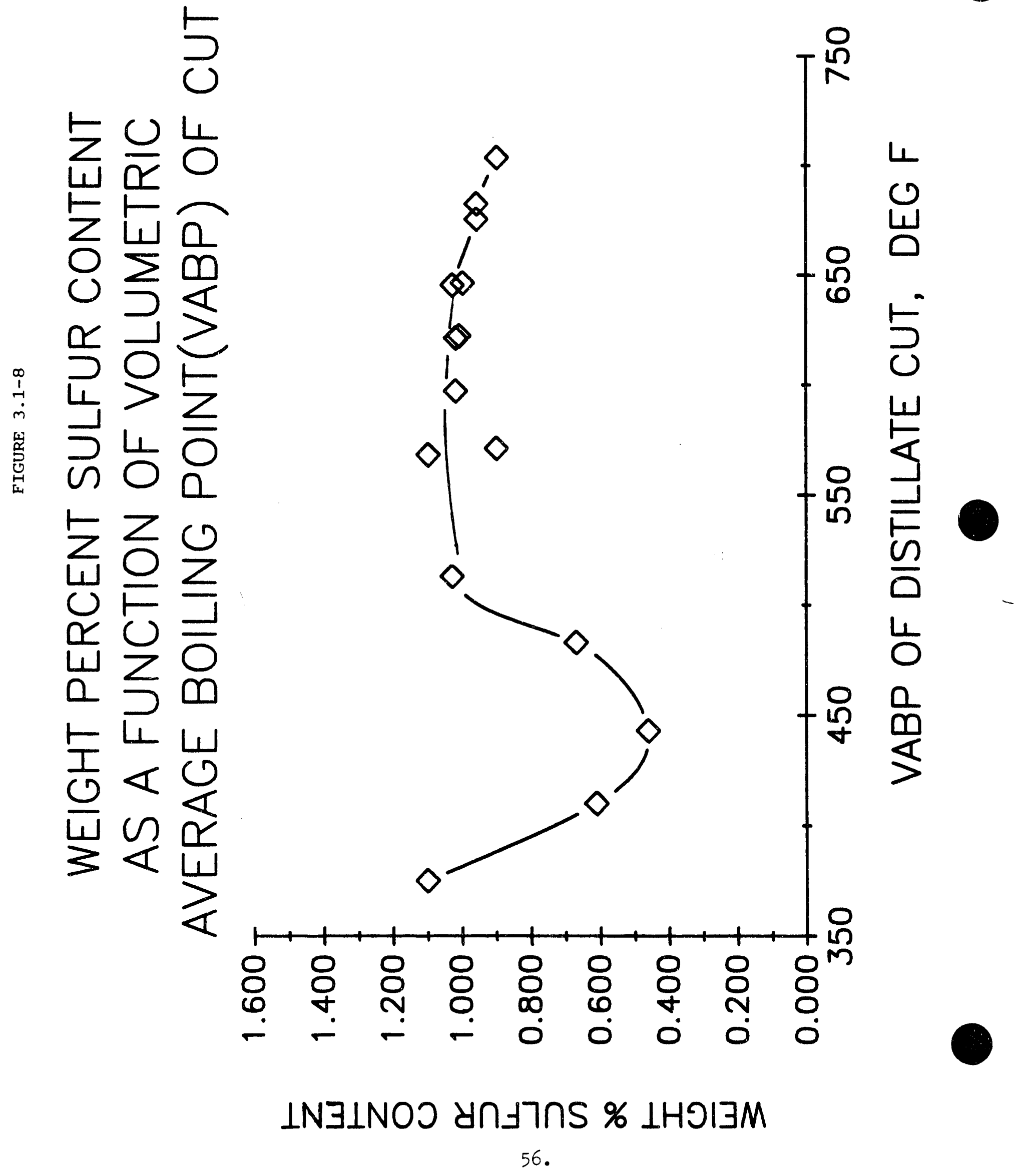




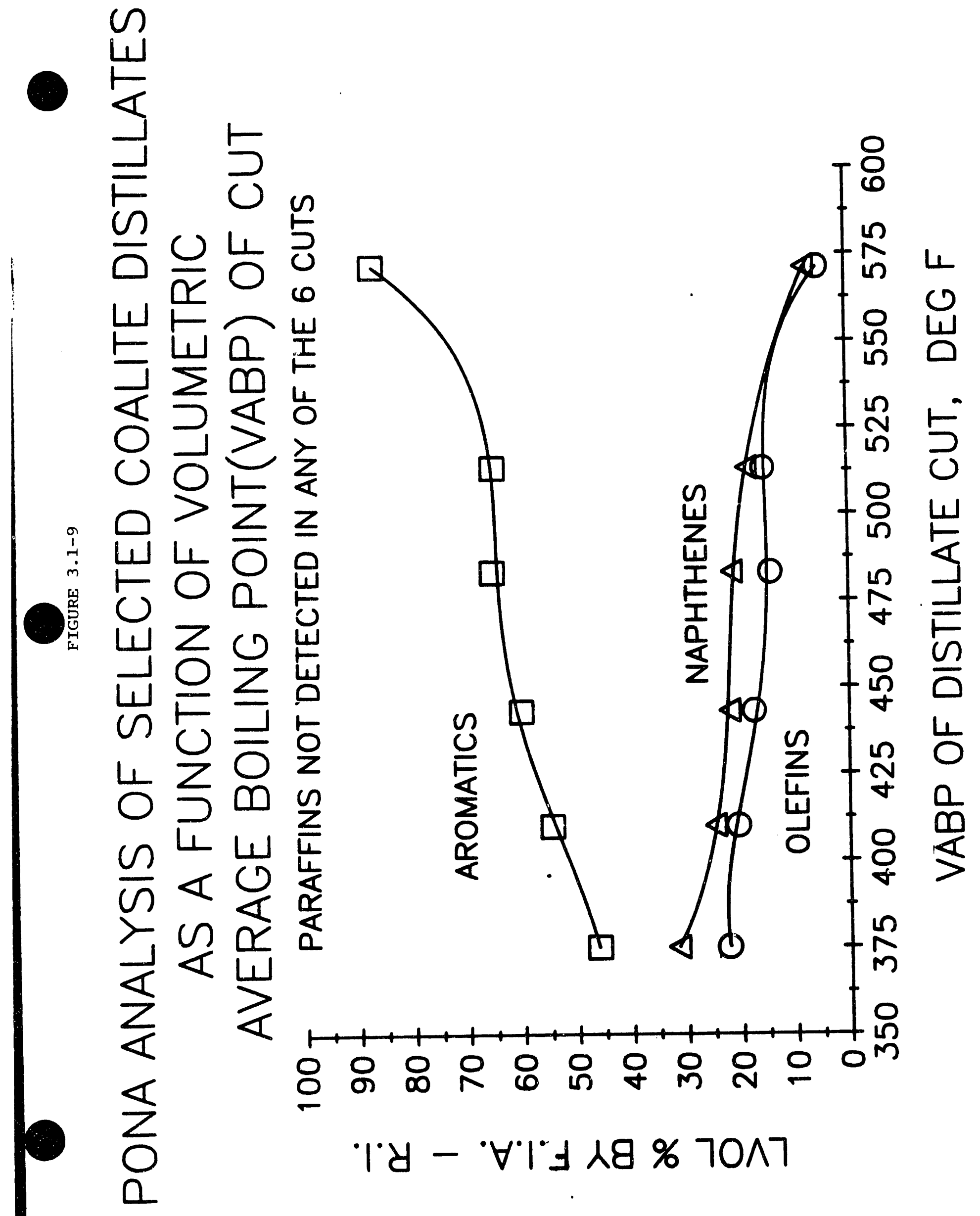


TABLE 3.1-3

NMR SPECTROSCOPY OF $390-650^{\circ} \mathrm{F}$ COALITE

HYDROGEN DISTRIBUTION

ELEMENTAL ANALYSIS \% $\mathrm{C}$

(H/C) ELEMENTAL ANALYSIS

(H/C) NMR

H AROM/C AROM

H SAT/C SAT.

H A POLY,\%

H A MONO

H F

$\mathrm{HAl}$

$\mathrm{HA} 2$

$\mathrm{HBl}$

$H B 2$

$H G$

TOTAL H

H AROM \%

H SAT\%
9.26

84.02

1.31

1.34

0.58

2.26

12.8

11.3

0

7.3

23.7

9.4

23.5

12.0

100.0

24.1

75.9

\section{CARBON DISTRIBUTION}

C A POLY

C A MONO

C F

C Al

C A2

$C$ B1

$C B 2$

C G

32.8

22.4

0

4.9

10.5

8.4

15.7

5.3

TOTAL C\% $\quad 100.0$

C AROM \% $\quad 55.2$

C SAT \% 44.8

C A SUB $\%$

27.9

C A UNS \%

58.4

C A INT \%

13.7

C A PER \% 86.3

C A INT \%

13.7

C NAPHT $\%$

18.8

$f$ AROM

$\%$ AS

CPER/CINT

B. I.

C/H SAT $W$

n CHAIN
0.552

32.4

6.29

0.37

5.27

2.5 


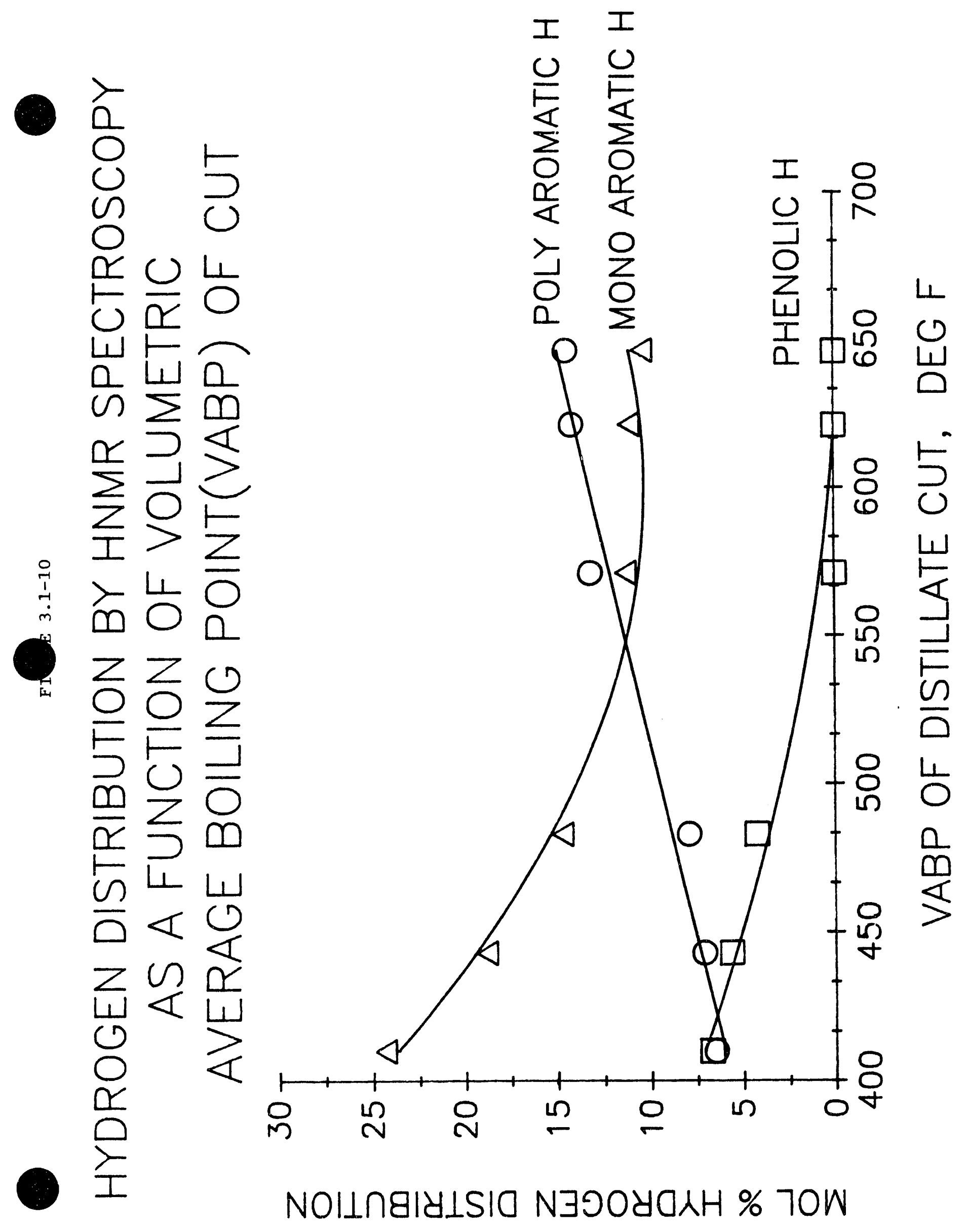




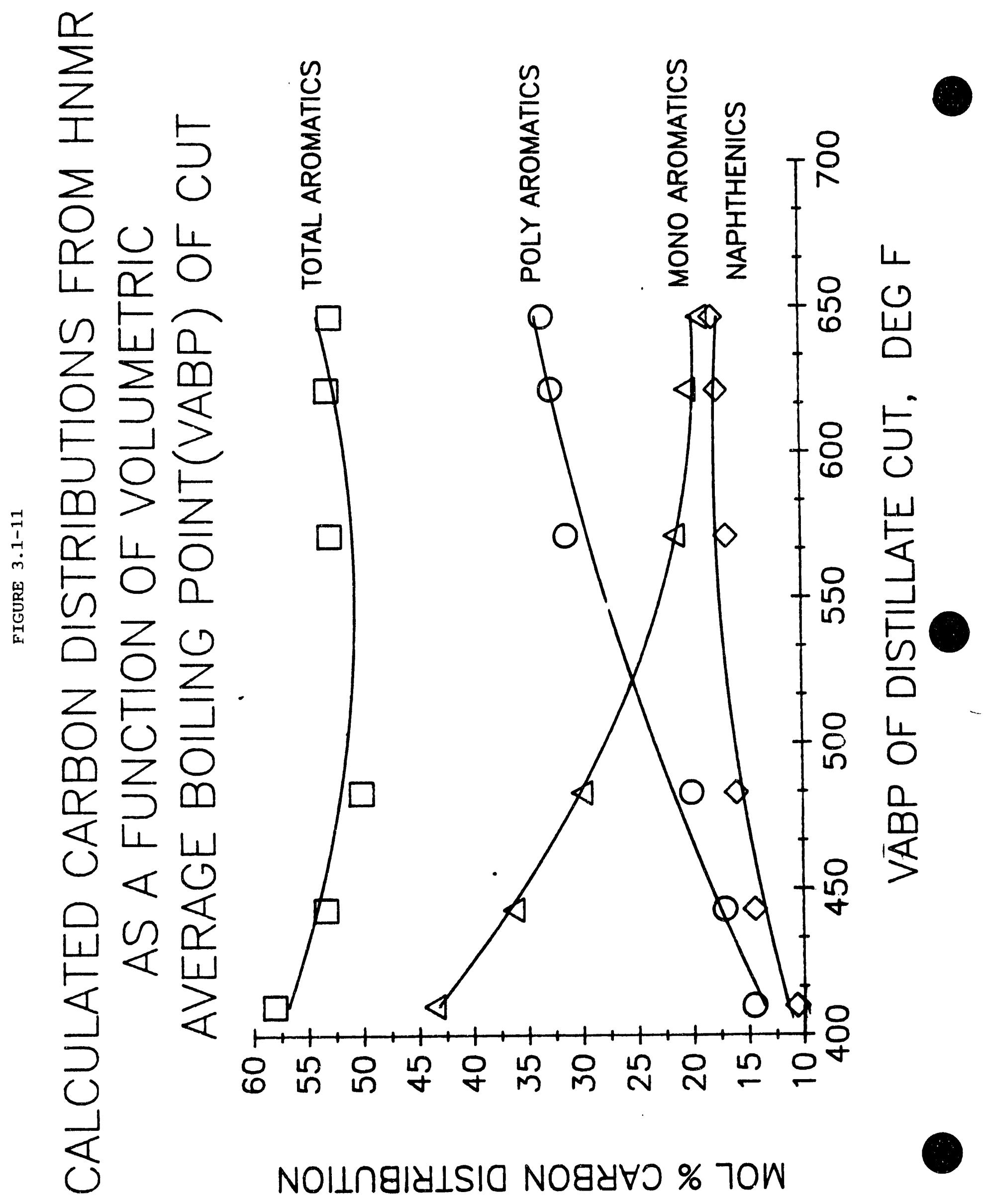




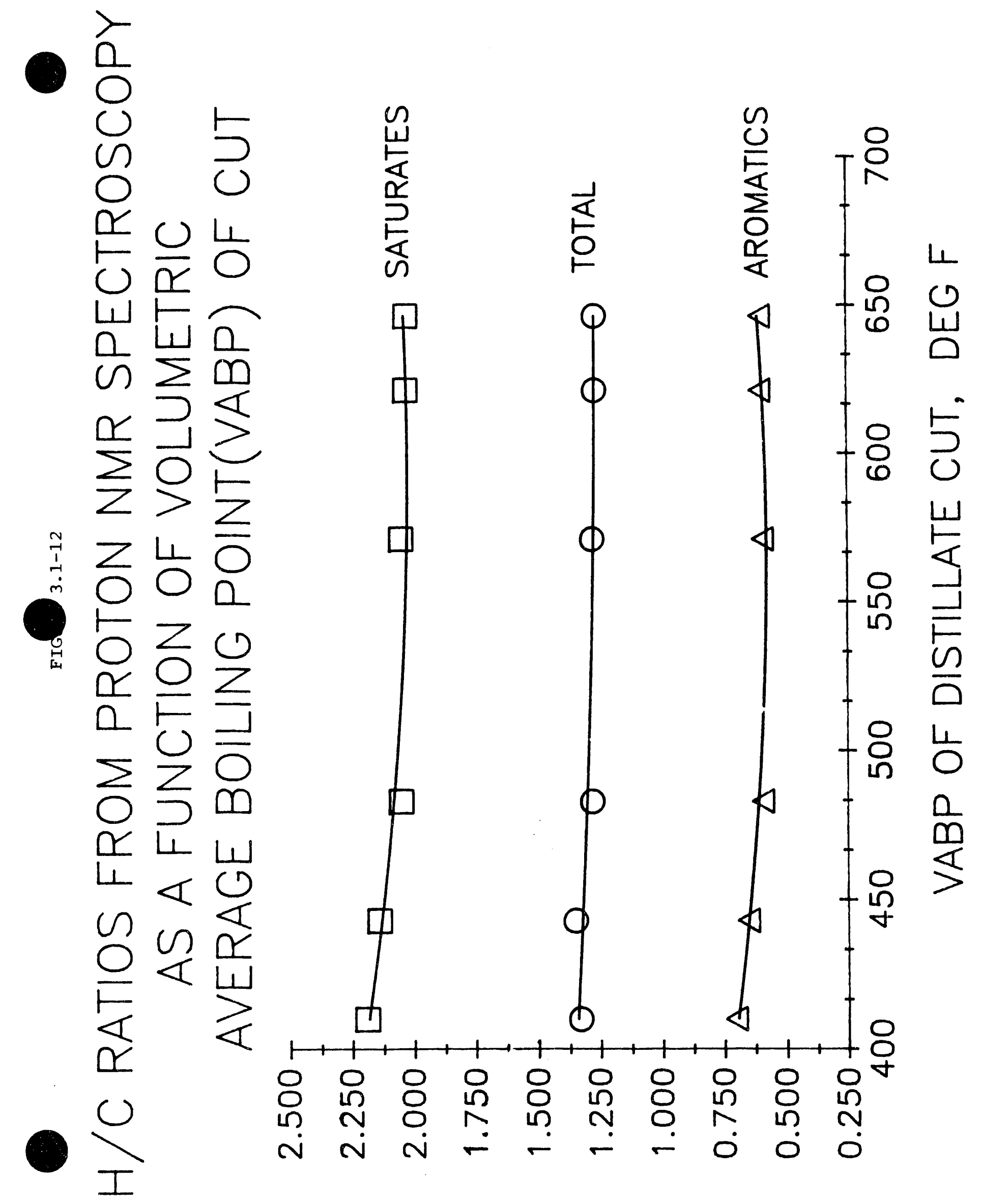

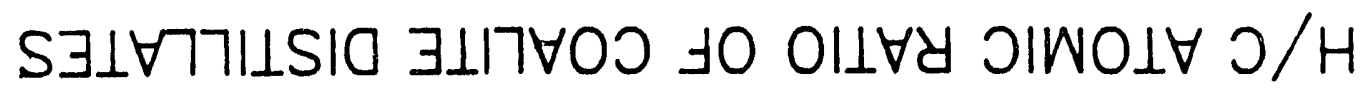




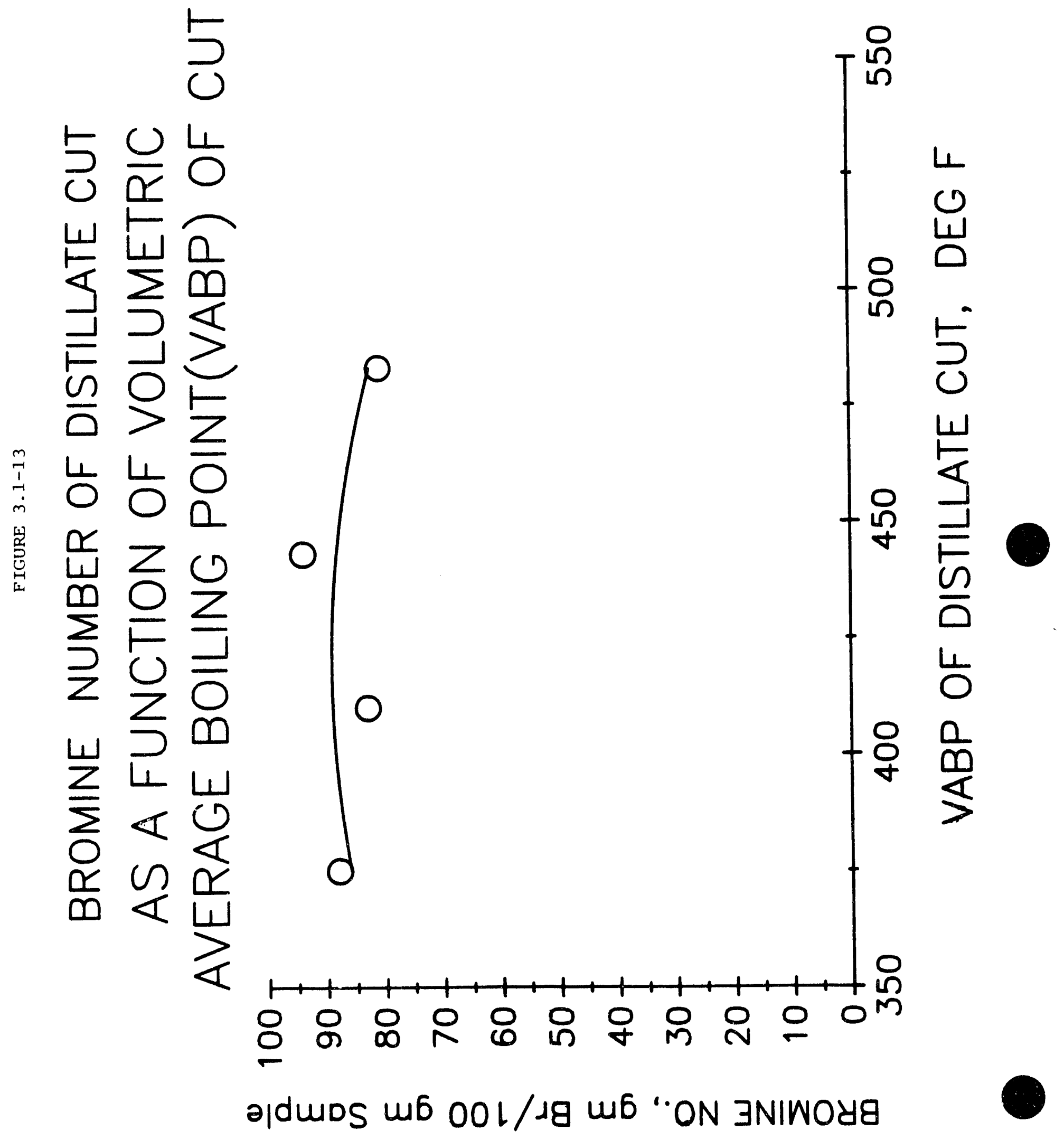




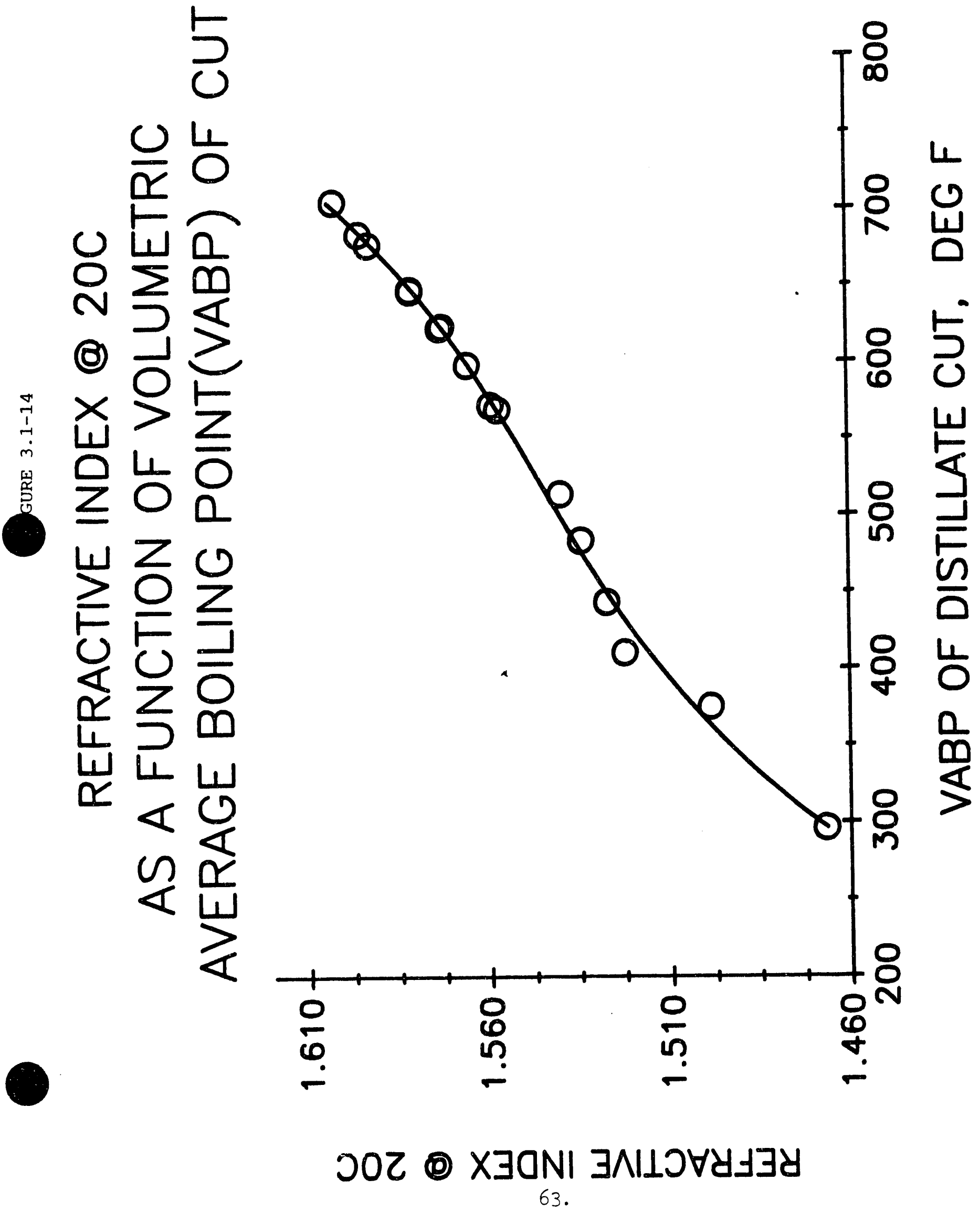




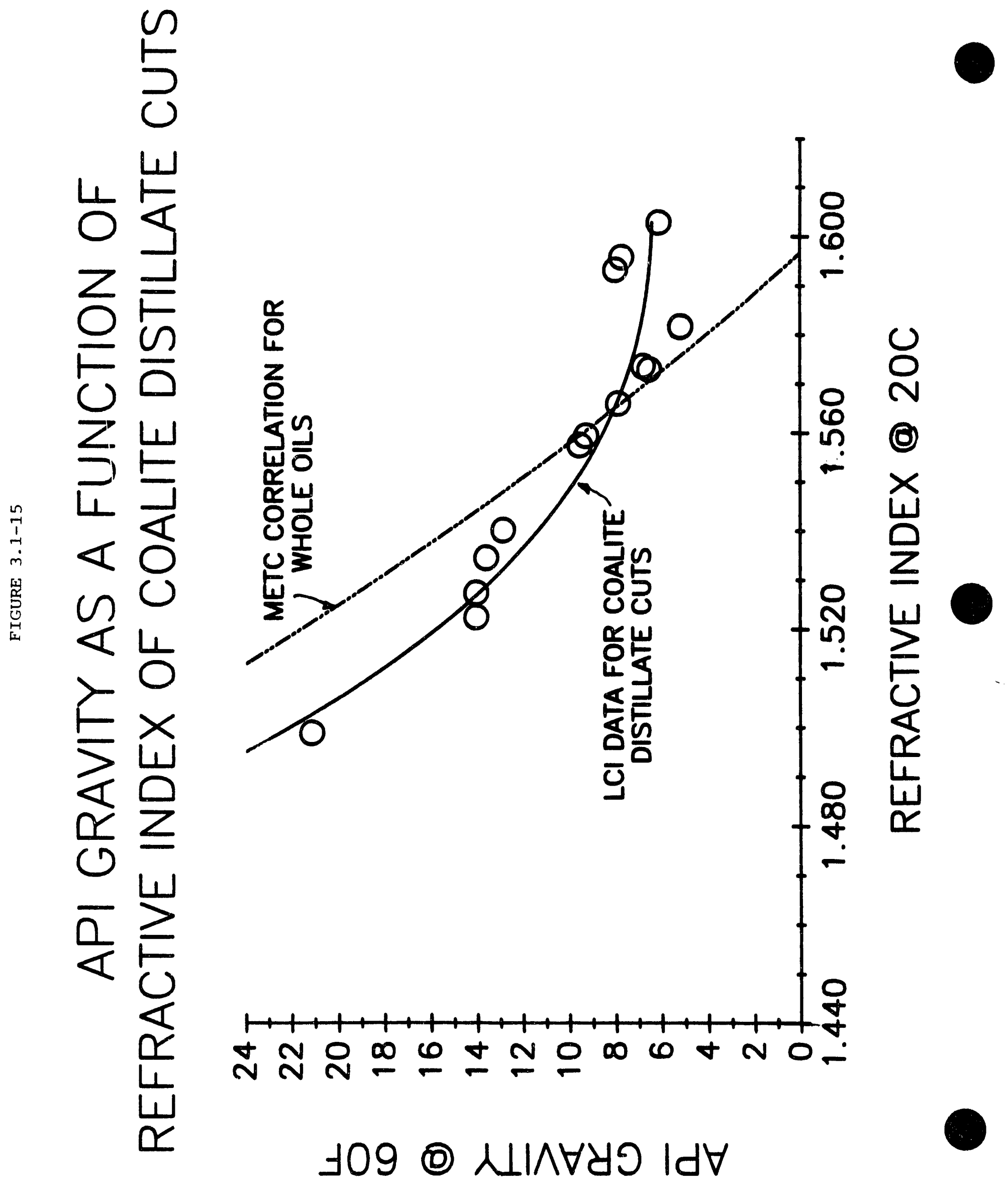




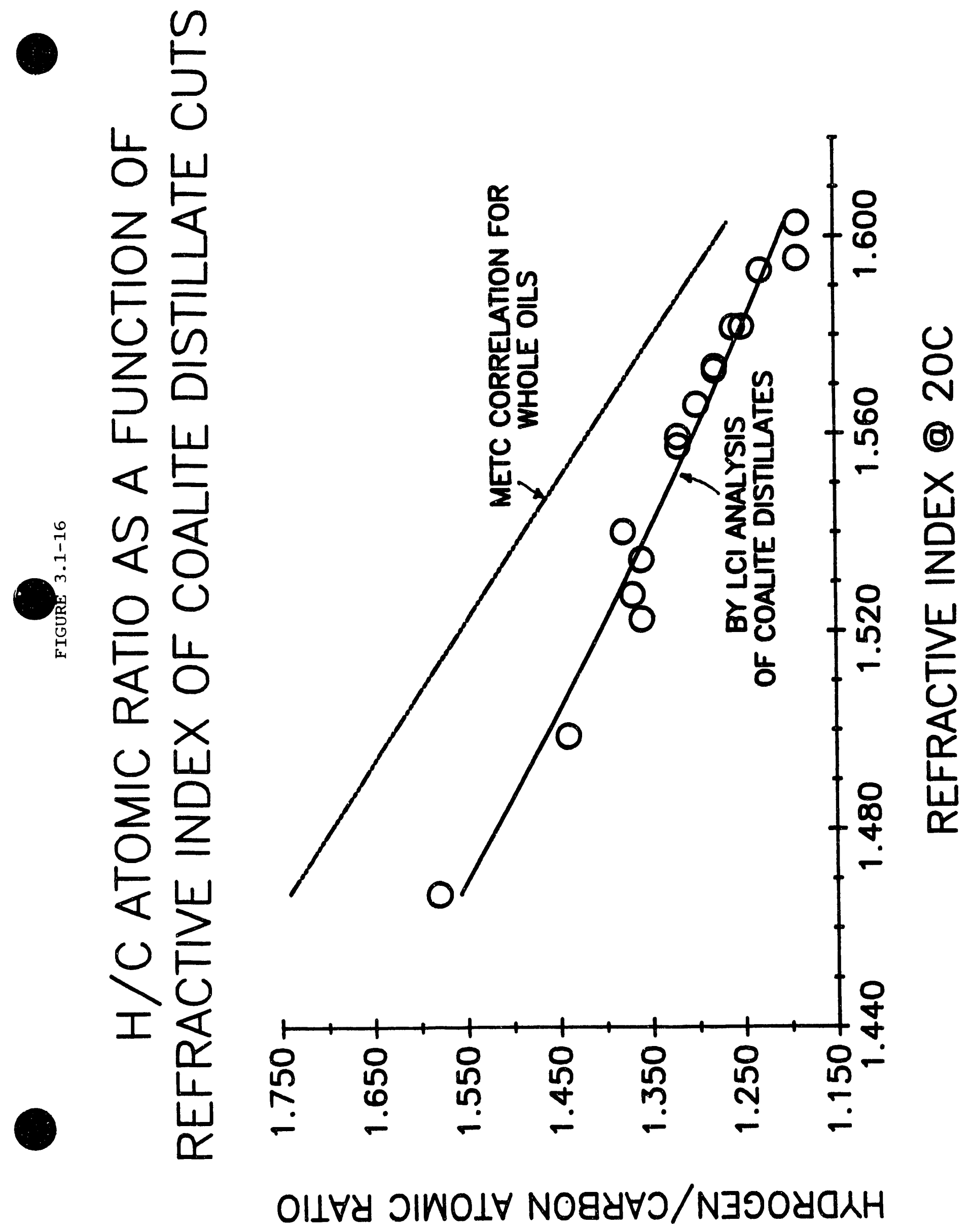

65. 


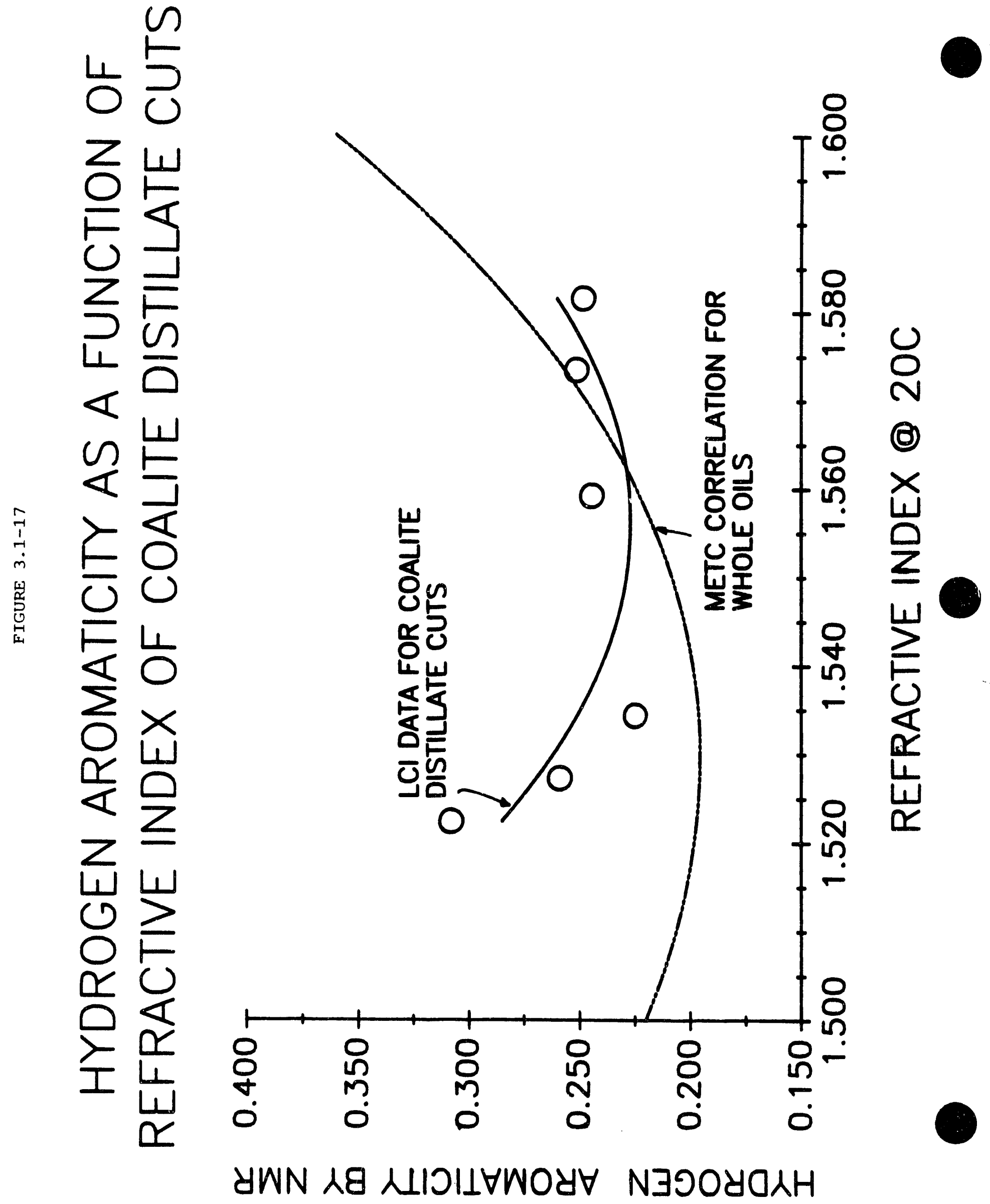




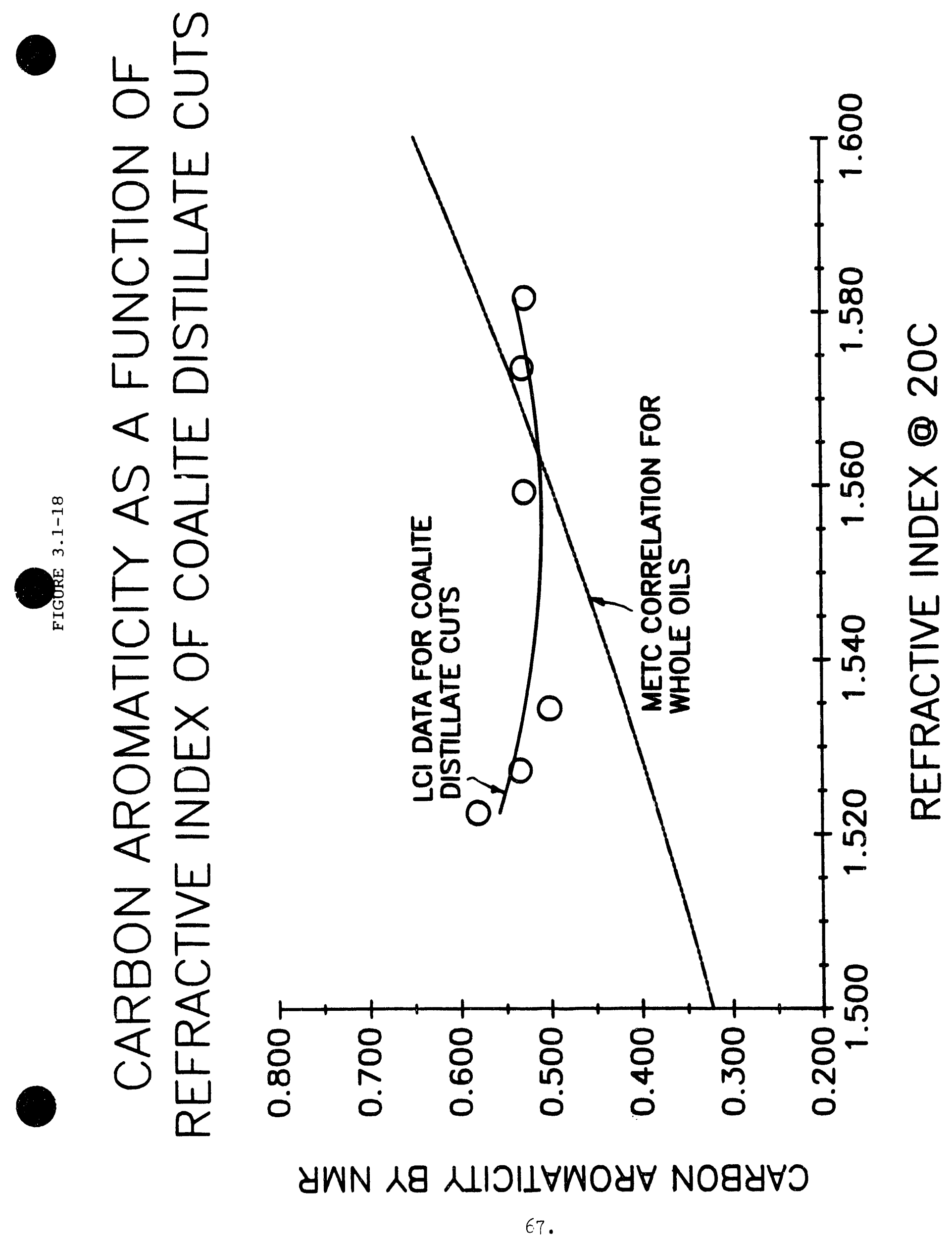


Extraction Projects Management Division. Thus, there is interest in producing HEDF from both MCG liquids as well as shale oils, tar sands and other liquid synfuels. The Colorado shale oil feedstock is derived from the Unocal retorting facility at Parachute Creek. The 1000-gal sample was provided to LCI by the Western Research Institute in Laramie, WY.

Upon receipt of the 19-drums, 1-quart aliquot samples were taken from each drum and a composite sample of all 19 drums was made. Additionally, grab samples from several of the drums were taken to check the consistency of the liquids from drum to drum.

Analytical distillation was accomplished in two steps: atmospheric distillation via the ASTM D-86 procedure followed by vacuum distillation of the atmospheric bottoms using the $D-1160$ procedure. The consolidated distillation curve for the composite sample is shown on Figure 3.2-1. As can be seen from the figure, there is a considerable vac resid component in this material approaching about about $35 \%$ at $975 \mathrm{~F}(524 \mathrm{C})$ as well as a major quantity of atmospheric resid amounting to $63 \%$ at $650 \mathrm{~F}+(343 \mathrm{C})$. The shale 0 il is somewhat heavier than the COALITE feed but lighter than a COED bituminous coal-derived pyrolysis oil as can be seen in Figure 3.2-2. Thus, considerable cracking, thermal or catalytic hydrocracking, is required to obtain significant yields of HEDF turbine fuels from this Colorado shale oil feedstock.

In order to assess the amenability of the turbine-range boiling distillates to hydroconversion to HEDF materials, it was determined that analytical characterization data on narrow boiling distillate fractions would be of value in formulating a hydroconversion test matrix. One objective of this analytical study was the determination of whether or not there was a sharp break point in cyclic HEDF precursor content with distillate boiling point. Therefore, the Colorado shale oil composite was fractionated in laboratory true boiling point distillation apparatus in a manner similar to that of the COALITE composite to recover 19 successive distillate fractions spanning the range of 300-700F (148-371C). The analyses of the individual fractions are shown in Table 3.2-1.

Figures 3.2-3 through -10 are presented to show the trends of volumetric average boiling point and refractive index with selected distillate properties. For comparative purposes, the analagous data for the COALITE distillates are also included on the figures.

Figure 3.2-3 shows the $\mathrm{H} / \mathrm{C}$ atomic ratio of the Colorado shale 0 il distillate and the COALITE distillate as a function of VABP. As expected, the $H / C$ ratios decrease as $V A B P$ increases. Also shown on the figure is the $H / C$ ratios required for the HEDF product. The $H / C$ atomic ratio of the raw Colorado shale oil distillates are essentially equal to that of the HEDF product.

Figure 3.2-4 shows the API Gravity of the two synfuel distillates as a function of VABP. The Colorado shale oil has a considerably higher API gravity across the VABP range evaluated but its rate of decline with VABP is about $33 \%$ higher than that of the COALITE. 


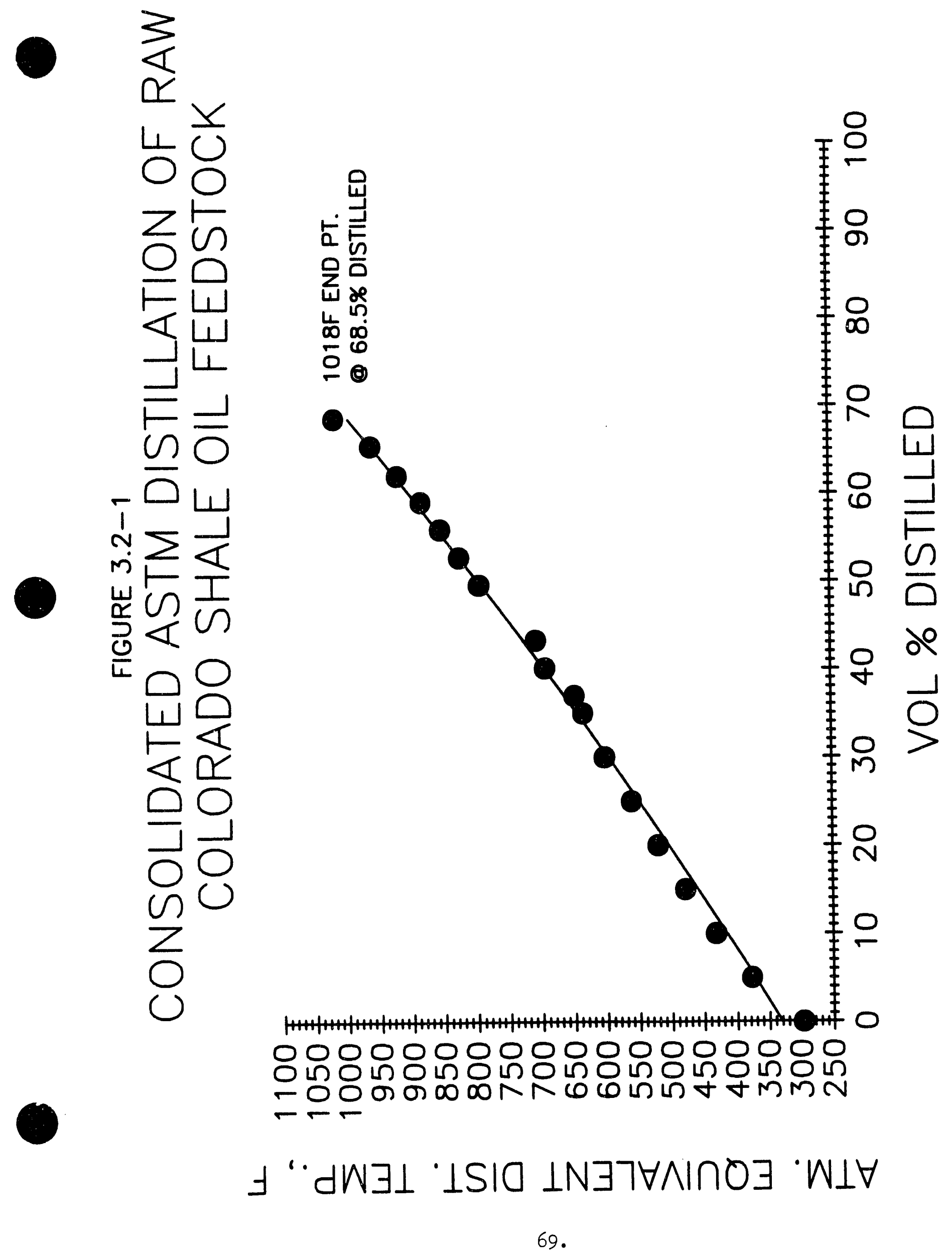



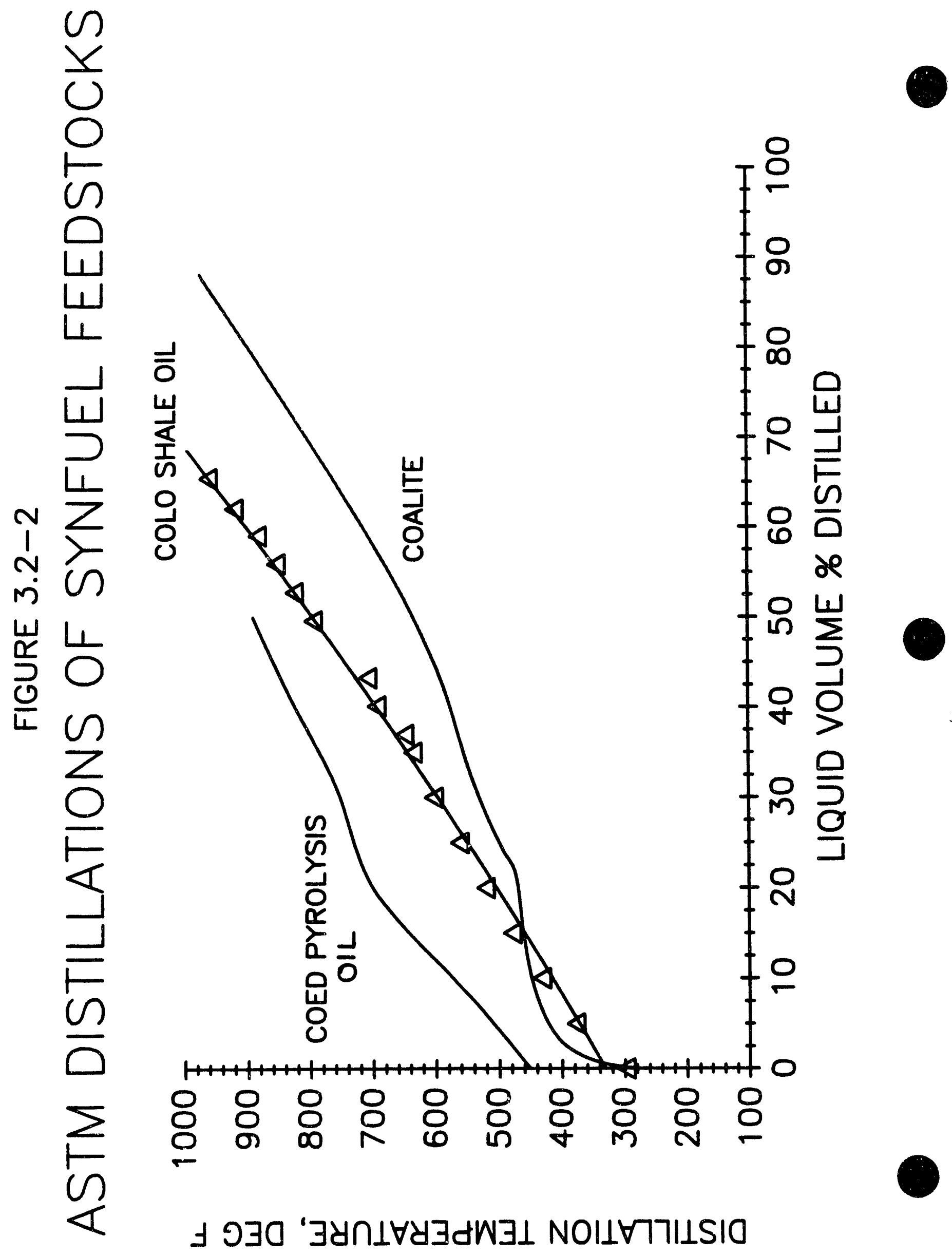
ANALYSES OF NARROY-BOILING COLORADC SHALE OIL DISTILLATES

\begin{tabular}{|c|c|c|c|c|c|c|c|c|c|}
\hline CUT 1 & $: 1,2.3 .4 .5:$ & 7 & 9 & 11 & 12 & 13 & 15 & 17 & 19 \\
\hline Y : YIELD OK YHOLE OI: & $5.5 !$ & $1.9 !$ & $3.5 !$ & $3.5 !$ & $3.6 !$ & $3.6:$ & $3.7:$ & $1.9 !$ & $1.2:$ \\
\hline SE.GRAK.. ORAT:E & $0.7905:$ & $0.8448:$ & $0.8463:$ & $0.8729:$ & $0.8805:$ & $0.8772:$ & $0.9052:$ & $0.9162 !$ & $0.9203:$ \\
\hline A.P.A. GRAYIIY & 47.5: & $36.0:$ & $35.7:$ & $30.6:$ & $29.2:$ & $29.8:$ & $24.8:$ & $22.9 !$ & $22.3:$ \\
\hline TBF MISTiLLAIIOK, Ut i & : & : & : & $!$ & $!$ & : & : & $\vdots$ & \\
\hline$l^{2} \mathrm{i}$ & $109:$ & $33 !:$ & $397:$ & $440:$ & $449:$ & $474:$ & $513:$ & $514:$ & $498:$ \\
\hline $\mathrm{CO}^{2}$ & $180:$ & $365 !$ & $426:$ & 493: & $318:$ & $550 !$ & $610 !$ & $641:$ & $661:$ \\
\hline $36:$ & $235:$ & 383: & 447： & $510:$ & $540^{\prime}$ & $572 ：$ & $633:$ & $663:$ & $685:$ \\
\hline $\mathrm{SO}_{0}$ & $265^{\circ}$ & $389 ：$ & $456:$ & $518:$ & $550:$ & $581:$ & $644:$ & $675:$ & 698: \\
\hline $70 \%$ & $30:$ & $395:$ & 464： & $526:$ & $564:$ & $588:$ & $656:$ & $685:$ & $707:$ \\
\hline $90:$ & $344:$ & 406: & 482： & $544 ：$ & 5BO： & $603:$ & $668:$ & $694 ：$ & $716:$ \\
\hline EBfi & 4jE : & $628:$ & $60 \hat{\imath}:$ & $773:$ & $793:$ & $616:$ & $815:$ & $842:$ & $829:$ \\
\hline V4: & $265:$ & $388:$ & 155: & $518:$ & $550:$ & $579:$ & $642:$ & $672 !$ & $693:$ \\
\hline \multicolumn{10}{|l|}{ ELERENTÁ, $! \therefore$} \\
\hline$i$ & $85.5 i:$ & $84.48:$ & 84.64 & $84.75:$ & 84.34： & $84.70:$ & 84.32: & $84.50:$ & 84.35: \\
\hline - & $.2 .8 \%$ & $19.9 ?$ & $13.0 \hat{e}$ & $12.5:$ & $12.28:$ & $12.65:$ & $11.87 !$ & $11.75:$ & $11.68^{\prime}$ \\
\hline$!$ & $0.48:$ & $0.98:$ & $0.84:$ & $0.96:$ & $1.21:$ & $1.31:$ & $1.50:$ & $1.60:$ & $1.70:$ \\
\hline$\vdots$ & i.14' & $1.00:$ & $0.8 \hat{E}:$ & $1.08:$ & $1.12:$ & $0.88:$ & $1.00 !$ & $1.00 !$ & $0.92:$ \\
\hline$E \because n: \vdots$ & $0.40^{\circ}$ & $6.60:$ & 0.58 & 0.70 & $1.05:$ & $0.46:$ & $1.31:$ & $1.15:$ & $1.35 !$ \\
\hline$\therefore \therefore P_{A}=4=F I N:$ & $31.4 !^{\prime}$ & $16.10:$ & $8.70:$ & $0.00:$ & 0.00 & $0.00 !$ & $\vdots$ & $\vdots$ & \\
\hline I: DSFINE & 32.80: & 33.30: & $39.10:$ & $37.30 !$ & 40.90: & $37.50:$ & $\vdots$ & : & \\
\hline$H^{\circ} \because$ NAERTHEKS: & $0.00^{\circ}$ & $27.50:$ & $34.88:$ & $4 i .40:$ & $37.70:$ & 39.10： & : & $!$ & \\
\hline 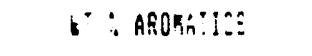 & $35.85:$ & $23.20:$ & 17.40: & 21.30: & $21.40:$ & $23.40 !$ & : & ; & \\
\hline
\end{tabular}




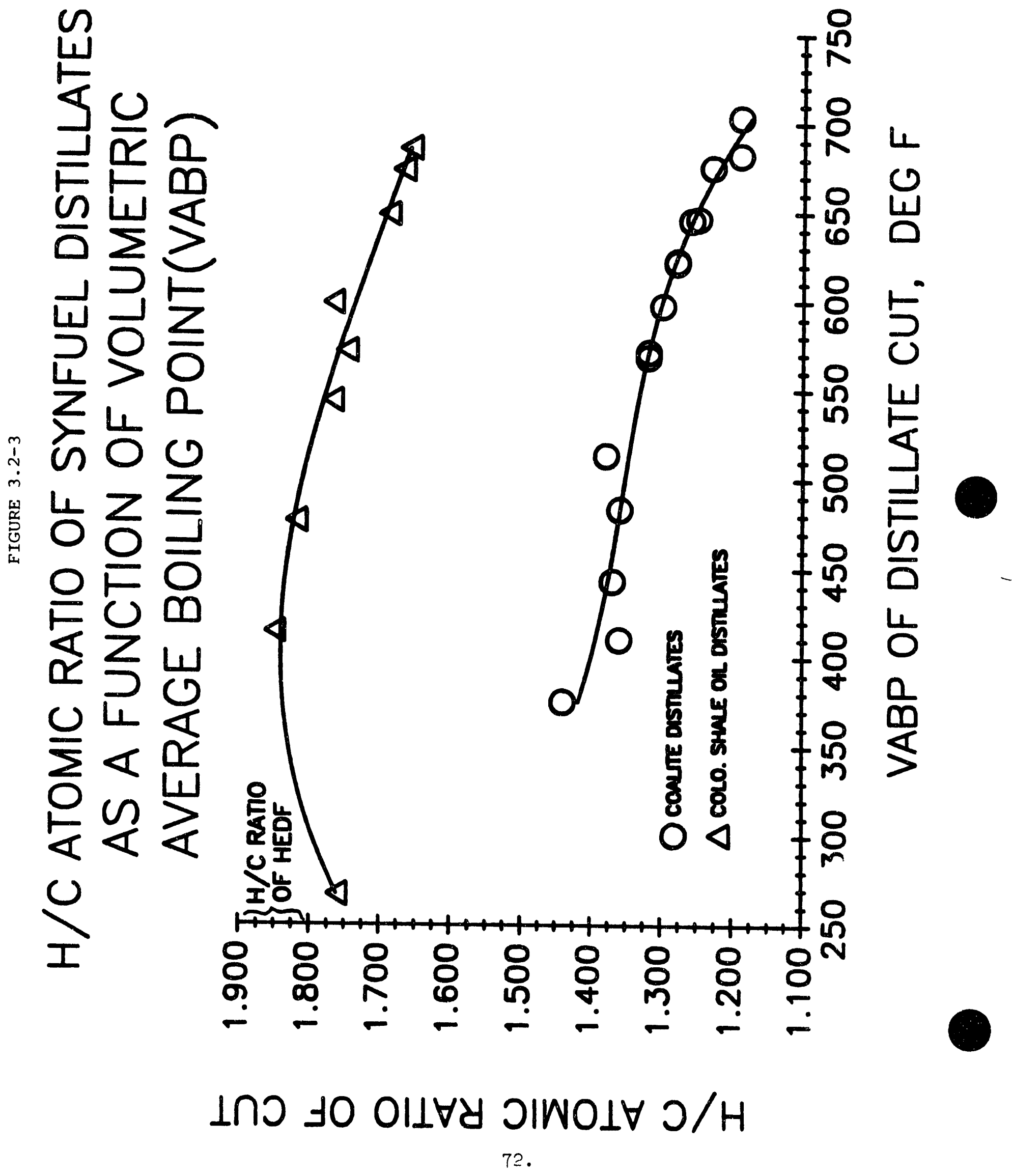




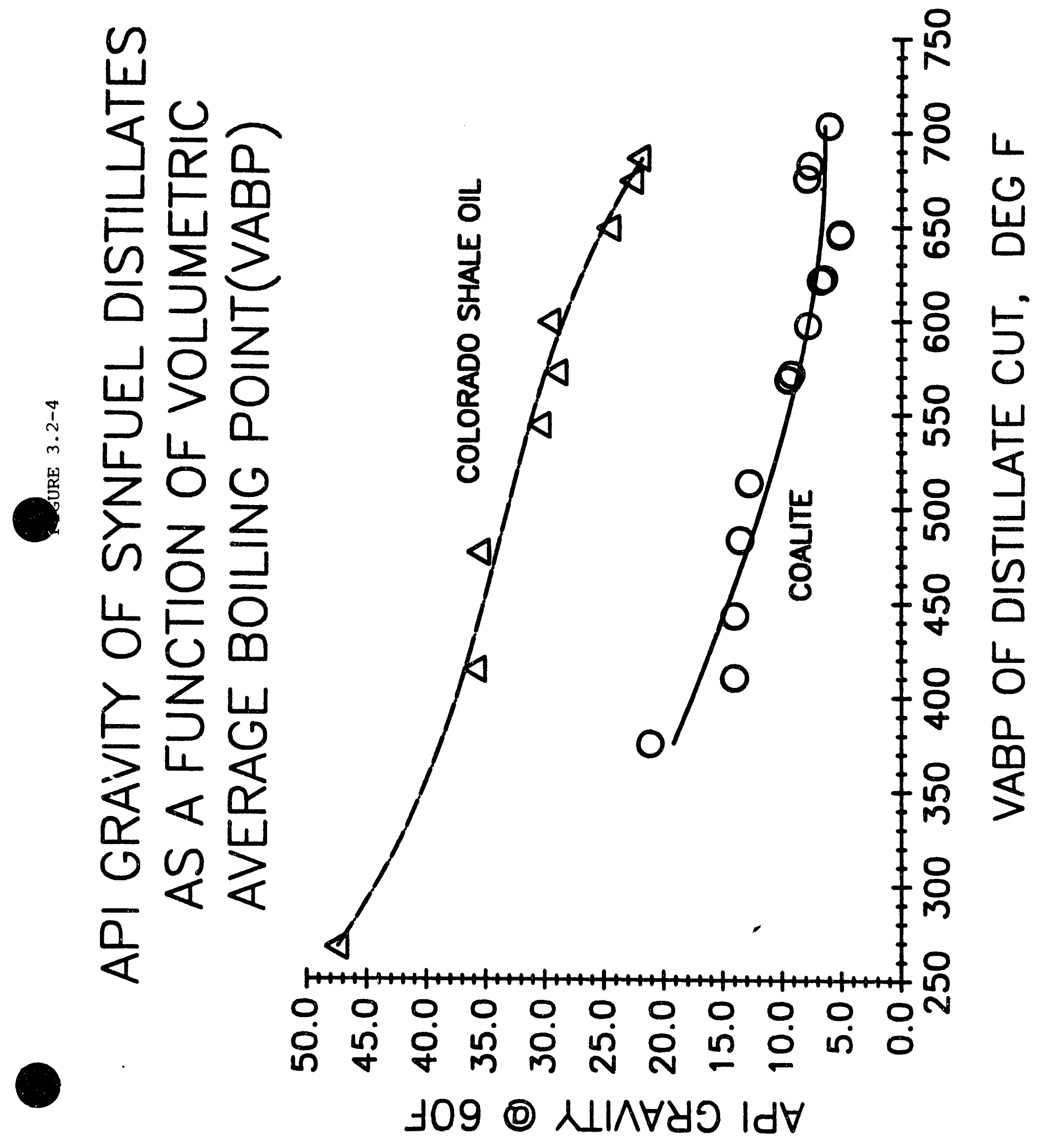




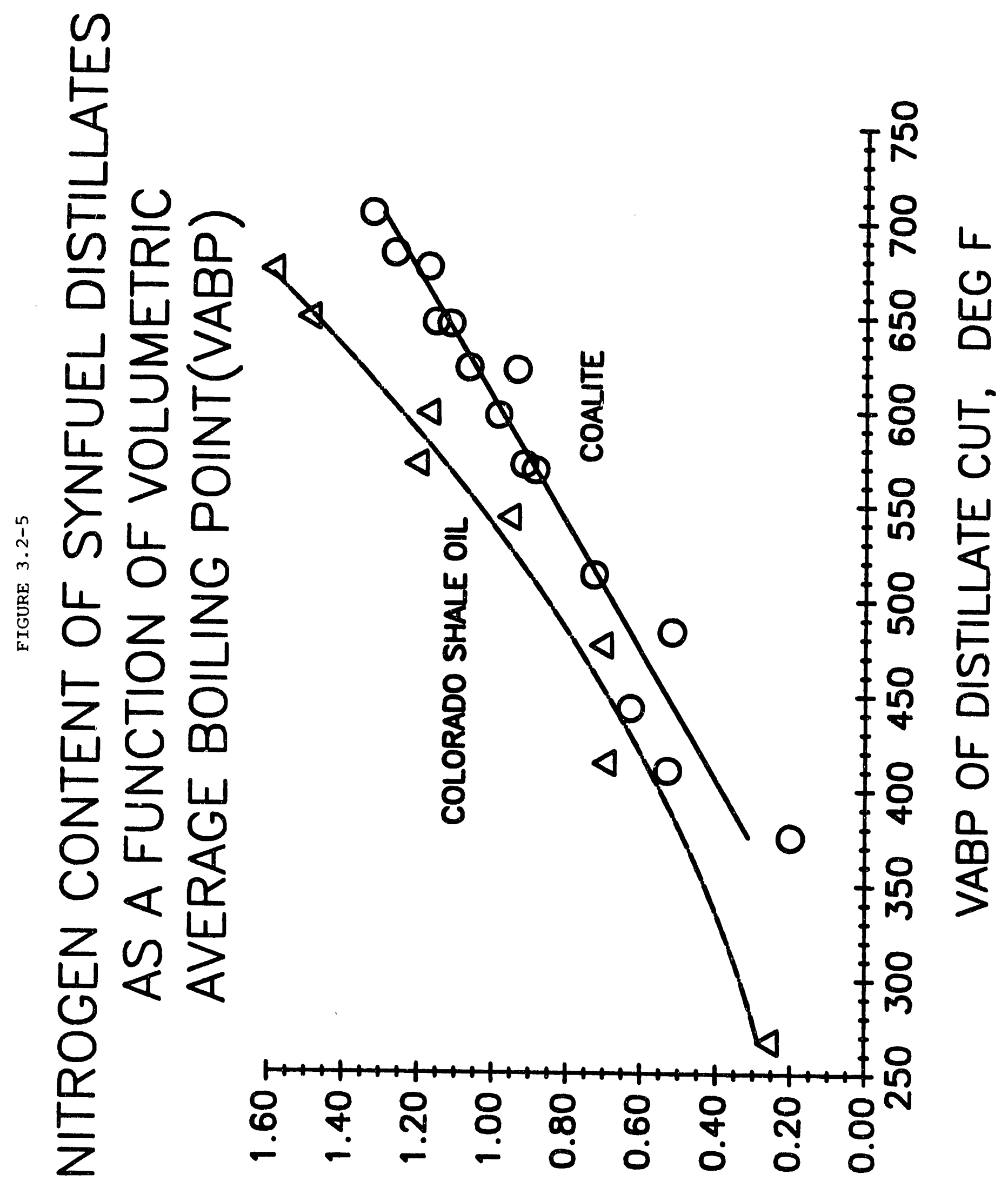

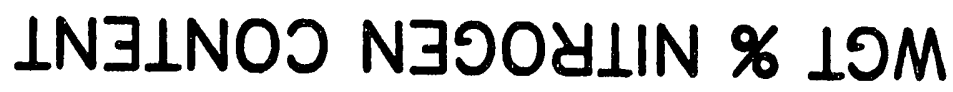




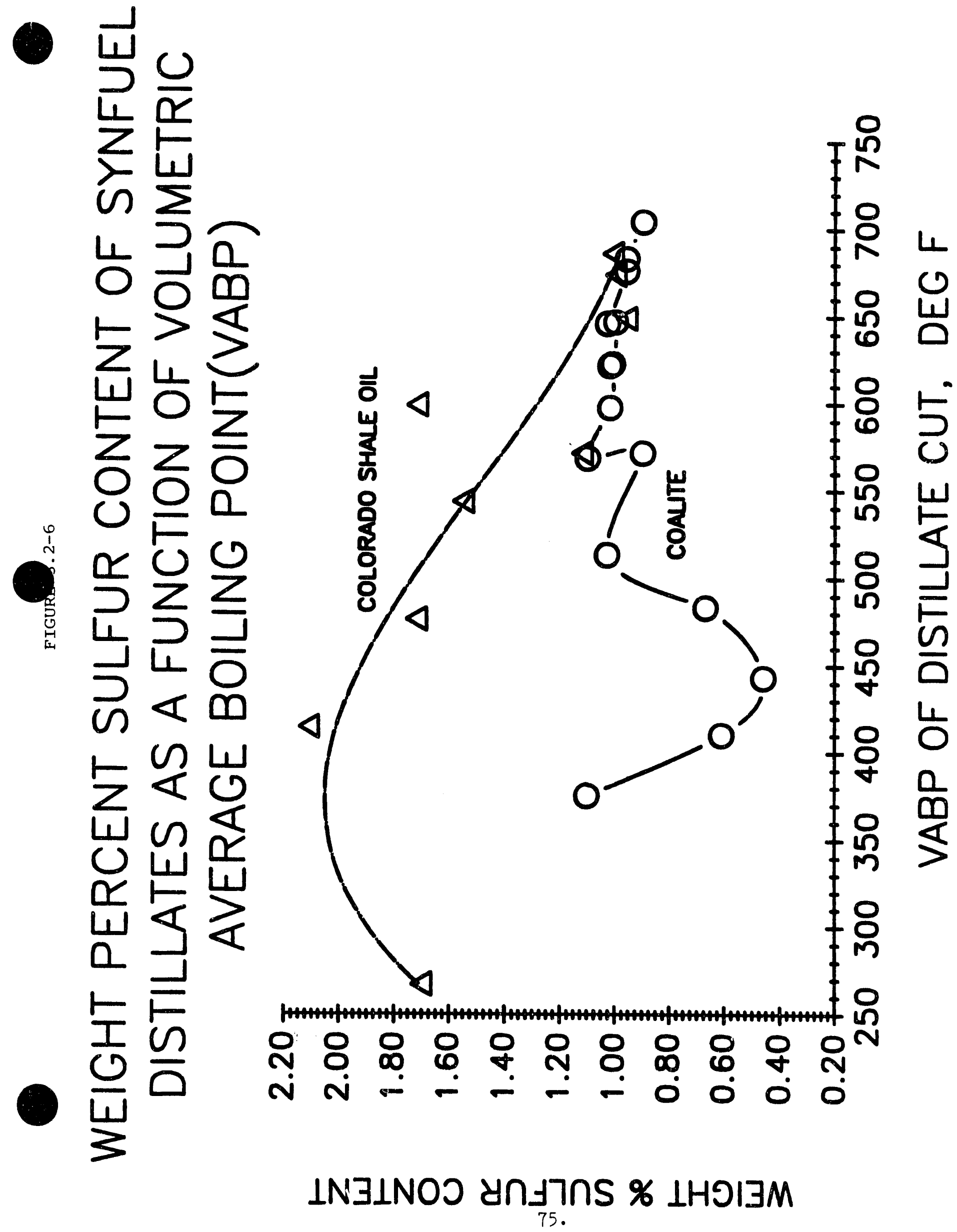




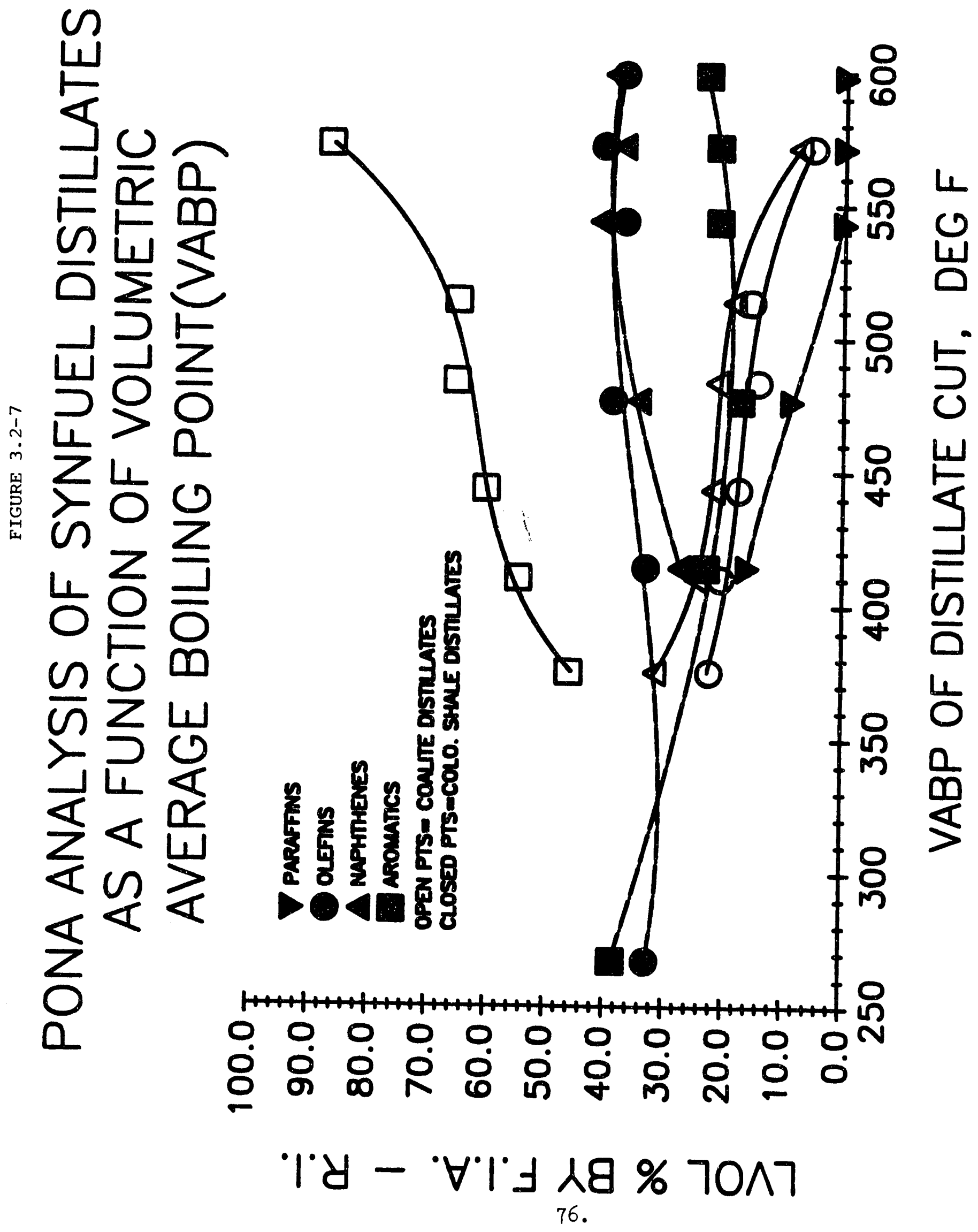




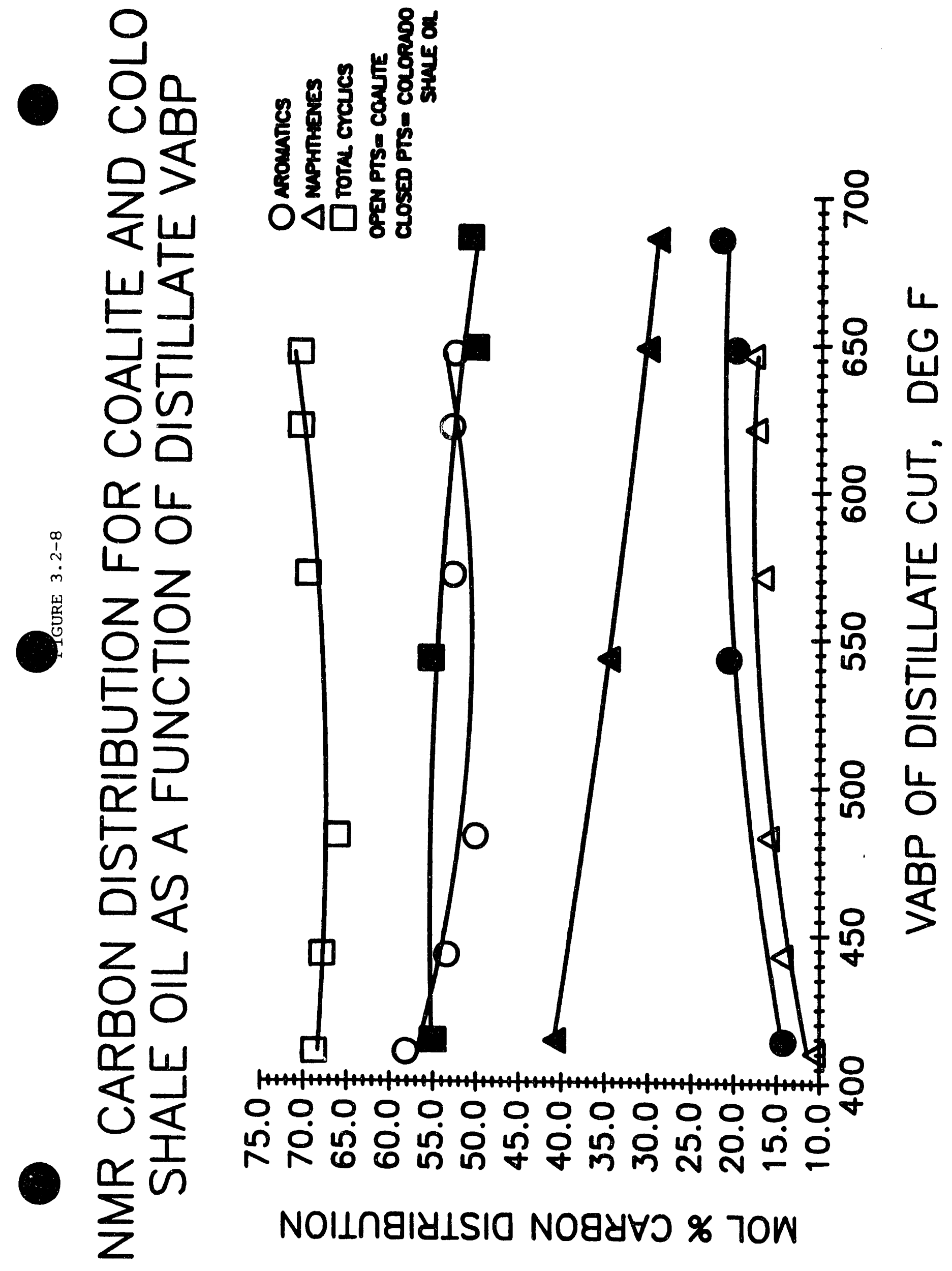



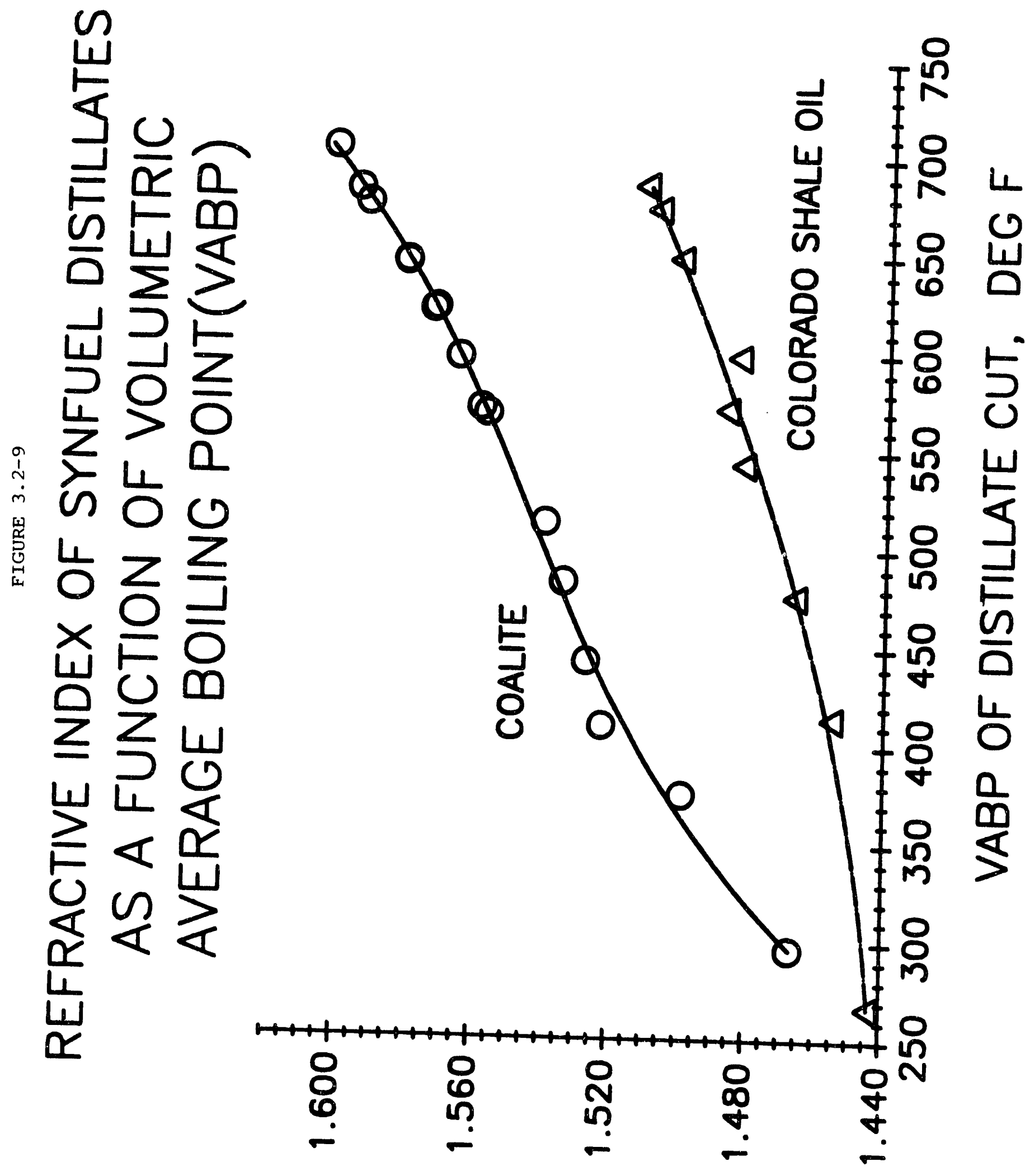

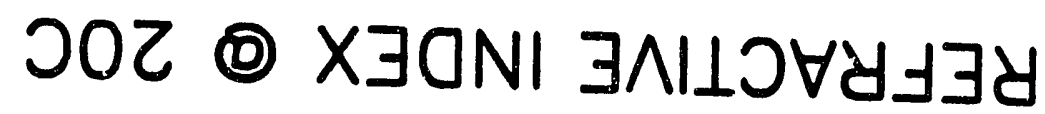




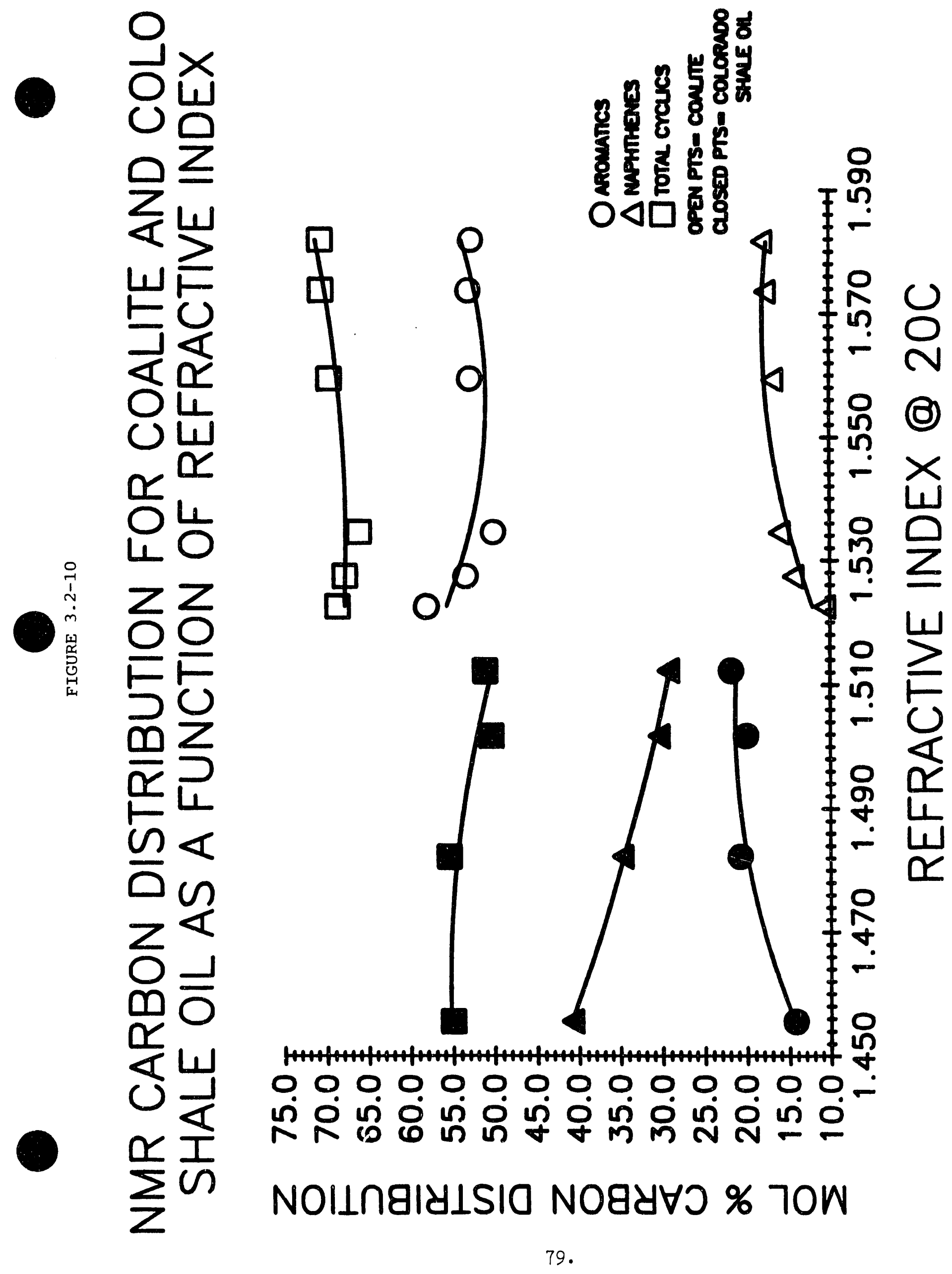


Figures 3.2-5 and 6 show the nitrogen and sulfur contents of the two synfuel distillates as a function of VABP. Nitrogen content increases almost linearly with VABP for both distillates with the shale oil having about a 2000 ppmw higher $N$ content than the COALITE.

While the sulfur content of the COALITE distillates shows an unusual minima at about $450 \mathrm{~F}(232 \mathrm{C})$ average boiling point, the Colorado shale oil-derived sulfur exhibits a broad maxima at about 325-425F $(163-218 \mathrm{C})$. The heavier shale oil and COALITE distillates, ca., 600-700F (315-371C), have essentially the same sulfur content, namely, 0.8-1.0 wt percent.

PONA analysis based on the F.I.A./Refractive Index method was used as a measure of hydrocarbon types. The resultant data are presented on Figure 3.2-7. It is to be cautioned that the method may not be accurate for non-petroleum, synfuel-derived distillates such as shale oil or COALITE. While the COALITE aromatics exhibit an increasing trend with VABP, the shale oil aromatics first decrease and then line out at the higher VABP. As expected, the shale oil aromatics contents are significantly lower than those of the COALITE, especially for the higher boiling distillates.

Proton NMR spectroscopy was used as an additional analytical tool to assess the carbon distributions in the shale oil and COALITE distillates. Figure 3.2-8 shows the NMR carbon distributions as a function of VABP. The shale oil distillates have about a 10-15 mol percent lower cyclic content (naphthenes plus aromatics) than that of the COALITE. However, the desirable naphthenic content, with the latter being key components of HEDF fuels, of the shale oil distillates is some 15-30 mol percent higher than that of the COALITE.

Refractive Index $(\odot 20 C)$ is a rapid analytical tool and a good measure of distillate quality. Figure $3.2-9$ shows the effect of VABP on distillate Refractive Index for the two synfuel distillates. Refractive Index can also be used as an independent correlating variable similar to that of the VABP parameter. Figure 3.2-10 shows the dependency of NMR carbon distribution as a function of the Refractive Index. This type of plot illustrates the major difference in compositional variations between the two feedstocks reflecting a discontinuity at a refractive index level of about 1.520 . 


\subsection{SUMMARY OF SCREENING PROGRAM OPERATIONS}

\subsection{Overview}

The major goals of the screening program were to: a) pinpoint those processing routes that would result in the production of high energy density turbine fuels (HEDF) meeting or exceeding the minimum energy density specification of $130,000 \mathrm{Btu} / \mathrm{gal}$; and b) collect sufficient processing data on the alternative processing routes for use in the subsequent Task 4 economic modelling study. A third goal was the collection of liter size samples of HEDF products for transmittal to DOE-METC.

The methodology chosen was to perform process variable scans in selected existing test units for each of the candidate processing schemes identified in the project management plan. As with any exploratory R\&D program, deviations from the original plan are to be expected as emerging test data are acquired. The direction taken during the course of the screening program was always towards the scanning of conditions that would result in achieving the maximum HEDF product energy density. The key processing routes evaluated are as follows:

- Raw distillate hydrotreating (single and two-stage)

- Raw atmospheric resid hydrocracking (LC-Fining ${ }^{\mathrm{Sm}}$ )

- Vacuum gas oil hydrocracking

- Raw atmospheric resid delayed coking

o Cracked distillate hydrotreating

- Hydrotreated distillate extraction (shale oil only)

These tests were carried out in five different bench-scale facilities. Additionally, test data were collected for the ancillary HEDF manufacturing processes of fractionation and clay treating. In order to maximize the operating efficiency of our pilot plant/analytical staffs and thereby maximize the return on the research investment, the scheduling of the various tests did not follow any predetermined order. Thus, operating campaigns with the COALITE feedstocks were intermingled with the Colorado shale oil feedstock campaigns. By necessity, the cracked distillate hydrotreating campaigns had to follow the hydrocracking and the delayed coking campaigns since these latter operations produced the cracked distillate feedstocks.

\subsection{COALITE Operations}

\subsubsection{Feedstock Preparation}

The raw COALITE feedstock was fractionated in the 4-in Batch Distillation unit in four different campaigns. The initial fractionation, referred to as $\mathrm{CC}-1$, resulted in the collection of 
sixteen successive distillate cuts and a vacuum resid fraction. The bulk of these materials was used for the analytical characterization tests (described in Section 3), the delayed coking evaluation of the $650 F+$ resid, and the LC-Fining evaluation of the $650 \mathrm{~F}+(343 \mathrm{C}+)$ resid.

Batch fractionation $\mathrm{CC}-2$ resulted in the collection of 24 distillate fractions and a $670 \mathrm{~F}+(354 \mathrm{C})$ resid fraction. Two composite blends for distillate hydrotreating were made: a nominal 350-650F (177-343C) blend of distillate fractions 5 through 22 to simulate a Category III boiling-range fuel; and a nominal 350-550F (177-288C) blend of distillate fractions 5 through 14 to simulate a Category I boiling-range fuel. Two additional blends were made with heavier end points (i.e., 750F and 820F) to determine whether the addition of the heavier gas oil components could increase energy densities above and beyond the $130,000 \mathrm{Btu} / \mathrm{gal}$ specification.

It should be kept in mind that the final Initial Boiling Point and End Point of the finished HEDF product is set in a post-hydrogenation topping and tailing operation. The nominal ranges of the feeds could not be fine-tuned in advance of and during the screening test work until sufficient information was acquired on the interaction of the process variables on all of the specified HEDF properties. Thus, the approach taken was to use the post-hydrogenation distillation operations to fine tune the critical distillation temperatures controlling the volatility (i.e., flash point spec) and the back-end viscosity/freeze point spec. Of course, in a commercial operation, the design of the fractionation systems would be optimized to reduce the cost of any unnecessary towers.

Batch fractionations $C C-3$ and $C C-4$ were used to prepare $300 \mathrm{~F}+(149 \mathrm{C}+)$ dewatered product for use in the selective hydrocracking campaigns and for use in preparing hydrotreated resid for a delayed coking test.

Table 4.2.1-1 presents the properties of the raw mid-distillate cuts used as feedstocks in the distillate hydrotreating campaigns.

\subsubsection{Virgin Distillate Hydrotreating Campaigns}

Six virgin distillate hydrotreating campaigns were made with the COALITE distillates to study the effects of catalyst type, distillate boiling range, single-stage vs two-stage, recycle of first-pass hydrotreated product and severity as controlled by space velocity, hydrogen partial pressure and reactor temperature. A Severity function has been defined as follows:

Severity $=10^{4} \star H 2$ Press, psig $* \operatorname{LHSV}{ }^{-1} \star \exp \left\{-35000 /\left[1.987 * T_{\text {avg }}, R\right]\right\}$

A total of 59 material balance tests were made of durations extending from 2-hours to 36-hours. The following table summarizes the salient features of each campaign and the summary table reference number. 

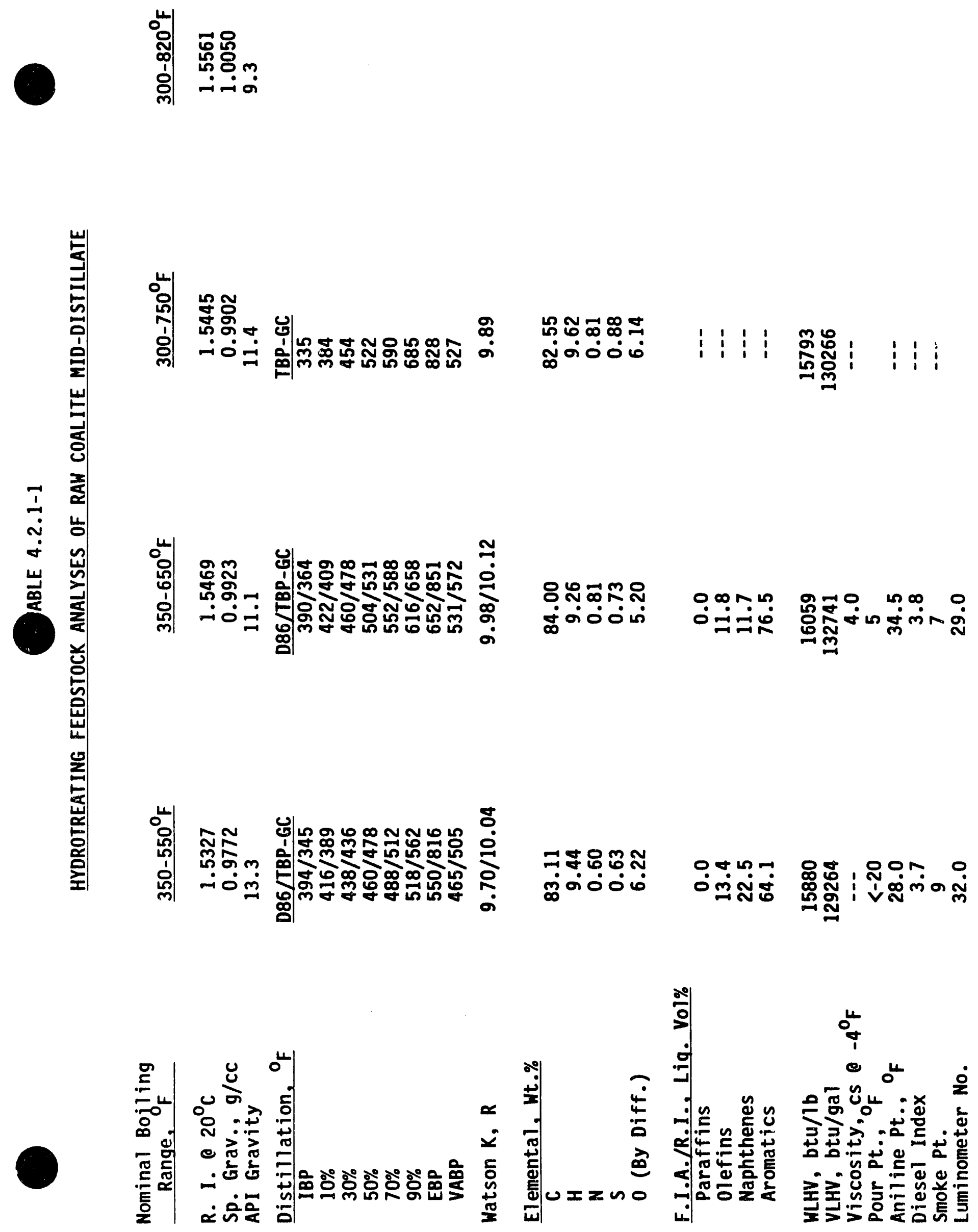


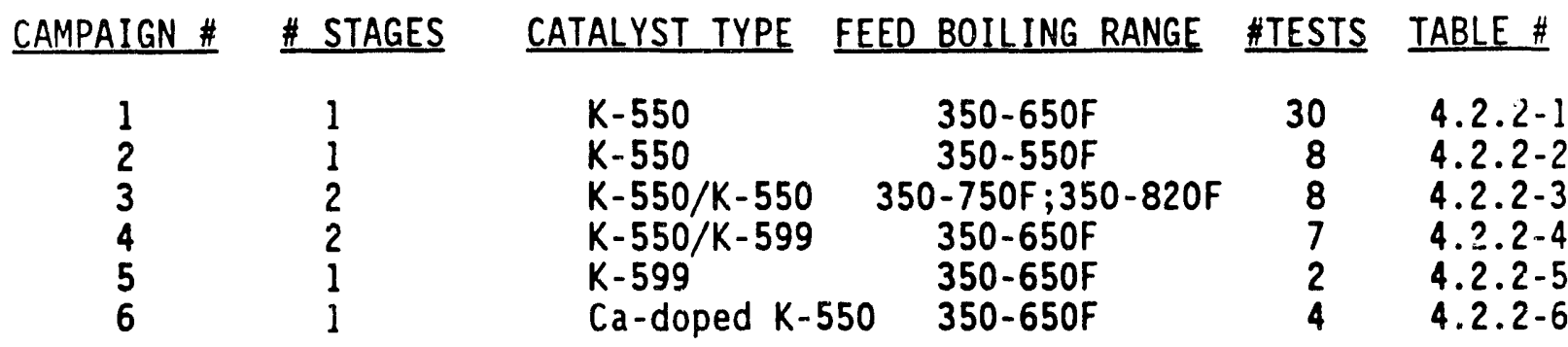

Campaign 5 was also used for the production of liter-size samples of finished HEDF samples required as a Task 3 deliverable. The specific objectives of each of these six campaigns are summarized below:

Campaign 1: Initial scans to evaluate the effects of space velocity, reaction temperature, hydrogen partial pressure and single-pass product recycle with a candidate NiWS hydrotreating catalyst in a single-stage reactor using the 350-650F COALITE distillate.

Campaign 2: Initial scans to evaluate the effects of space velocity, reaction temperature and single-pass product recycle with a candidate NiWS hydrotreating catalyst in a single-stage reactor using the $350-550 \mathrm{~F}$ COALITE distillate.

Campaign 3: Initial scans to evaluate the effects of temperature and space velocity with higher end point COALITE distillates using a two-stage NiWS catalyst reaction system.

Campaign 4: Initial scans to evaluate the effects of temperature and space velocity with the 350-650F COALITE distillate in a two-stage reactor system comprising a NiWS catalyst in the first-stage and a high moly nickel catalyst in the second-stage reactor.

Campaign 5: Production run to produce liter size samples of HEDF materials in a single-stage reactor with the high moly nickel catalyst using the 350-650F COALITE distillate.

Campaign 6: Scans of the effects of temperature and space velocity with a calcium-duped NiWS catalyst using the 350-650F COALITE distillate.

\subsubsection{Virgin Atmospheric Resid Cracking Campaigns}

There is a considerable yield of atmospheric resid in the raw COALITE. HEDF products are end-point limited because of viscosity and freeze point specifications. Therefore, it is necessary to crack the heavier components to the mid-distillate range comprising the desired HEDF turbine fuel products. Three cracking methods were considered: 1) Resid hydrocracking using the LC-Fining process; 2) Delayed Coking; and 3) VGO fixed-bed hydrocracking. The former two are discussed in the next two sections while the latter is discussed in Section 4.2.5. 
TABLE $4.2 .2-1$

SUHMARY OF OPERATING CONOIIIONS FOR FIXEO-BEO COALIIE HYOROTREATIHG TESTS

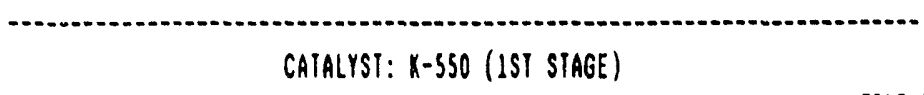

\begin{tabular}{|c|c|c|c|c|c|c|c|c|}
\hline IEST \& (FB-) & $17 A-1$ & $17 A-2$ & $18 A-1$ & $18 A-2$ & $18 A-3$ & $19 A-1$ & $19 A-2$ & $19 A-3$ \\
\hline DATE (1989) & $01-13$ & $01-13$ & $01-16$ & $01-16$ & $01-16$ & $01-11$ & $01-17$ & $01-17$ \\
\hline SIARI IIHE & $11: 30$ & $16: 30$ & 12:30 & $14: 15$ & $19: 00$ & $12: 30$ & 15:00 & $18: 20$ \\
\hline ENO IIKE & $16: 30$ & $11: 30$ & $13: 30$ & $15: 15$ & 21:00 & $13: 30$ & $17: 00$ & $20: 20$ \\
\hline FEEDSTOCK & A & $A$ & $A$ & $A$ & $A$ & $A$ & $A$ & $A$ \\
\hline FEEO RATE, cC/hr & 1542 & 590 & 372 & 373 & 167 & 154 & 155 & 135 \\
\hline OPERATING PRESSURE, DSIQ & 2000 & 2000 & 2000 & 2000 & 2000 & 2000 & 2000 & 2000 \\
\hline H2 PARTIAL PRESSURE, psig & 2000 & 2000 & 2000 & 2000 & 2000 & 2000 & 2000 & 2000 \\
\hline HZ TREAT RATE， sCF/OBDI & 3000 & 3000 & 5000 & 5000 & 5000 & 5000 & 5000 & 5000 \\
\hline \multicolumn{9}{|l|}{ REACIOR \ CONDIIIOH: } \\
\hline LHSV, cc/hr/cc cat. & 9.6 & 3.7 & 2.3 & 2.3 & 1.0 & 1.0 & 1.0 & 0.8 \\
\hline IMLET BED IENP.. F & $37 !$ & 393 & 499 & 602 & 606 & 609 & 644 & 605 \\
\hline \multicolumn{9}{|l|}{ UPPER HIO BED TEHP., F } \\
\hline LOHER BED TEHP., F & 396 & 104 & 507 & 672 & 654 & 628 & 704 & 667 \\
\hline AVERAGE BEO IEAPD., F & 384 & 399 & 503 & 637 & 630 & 619 & 674 & 636 \\
\hline SAND BATH IEMP., $\mathrm{F}$ & 399 & 404 & 579 & 606 & 571 & 606 & 534 & 481 \\
\hline \multicolumn{9}{|l|}{ REACIOP? : COHDIIION: } \\
\hline \multirow{2}{*}{\multicolumn{9}{|c|}{ LHSY, cc/hr/cc cat. }} \\
\hline & & & & & & & & \\
\hline \multicolumn{9}{|l|}{ INLET EEO TEMD.. F } \\
\hline \multicolumn{9}{|l|}{ UFEES HID BEC TENP. . F } \\
\hline \multicolumn{9}{|l|}{ LOHER BEO IENG., F } \\
\hline \multicolumn{9}{|l|}{ AVERAGS BED TEKF., F } \\
\hline \multicolumn{9}{|l|}{ SAHC BAIH IEKP.. F } \\
\hline SEYEFITY SIAGE I & 0.0018 & 0.0067 & 0.0992 & 0.9259 & 1.9210 & 1.6169 & 3.5959 & 2.6233 \\
\hline \multicolumn{9}{|l|}{ SEVERITY SIAGE ? } \\
\hline OYERALL SEVERITY & 0.0018 & 0.0067 & 0.0992 & 0.9259 & 1.9210 & 1.6169 & 3.5959 & 2.6233 \\
\hline
\end{tabular}

FEEDSTOCK IYPE:

A: 350-650 F VIRGIK COALIIE DISTILLATE. 
TABLE $4.2 \cdot 2-1$ (continued)

-............

SUHMARY OF OPERAIING COHDITIONS FOR FIXED-BED COALIIE RYOROTREAIING IESTS

CATALYST: 1 -55O (ISI SIAGE)

CATALYST: K-550 (1ST STAGE)

FILE ID: REPTBOI.UKI

\begin{tabular}{|c|c|c|c|c|c|c|c|c|}
\hline IEST $/(F B-)$ & $20 A-1$ & $\because 1-2$ & 21 & 22 & 23 & 24 & 25 & 26 \\
\hline DATE (1989) & $01-18$ & $01-18$ & $01-19$ & $01-20$ & $01-20$ & $01-23$ & $01-23$ & $01-24$ \\
\hline SIARI IIME & $16: 20$ & 19:00 & 19:00 & $16: 15$ & $19: 30$ & $11: 15$ & $20: 15$ & $15: 20$ \\
\hline END TIHE & $18: 20$ & 21:00 & $21: 00$ & $17: 45$ & $20: 30$ & $18: 45$ & $21: 45$ & $16: 30$ \\
\hline FEEDSTOCK & $A$ & $A$ & A & A & A & A & A & A \\
\hline FEED RAIE, $\mathrm{cc} / \mathrm{hr}$ & 152 & 144 & 107 & 109 & 106 & 150 & 151 & 166 \\
\hline OPERATING PRESSURE, DSIG & 2000 & 2000 & 2000 & 2000 & 2000 & 2400 & 2400 & 1600 \\
\hline K2 PARTIAL PRESSURE, dsig & 2000 & 2000 & 2000 & 2060 & 2000 & 2400 & 2400 & 1600 \\
\hline H2 TREAI RATE, ScF/bb] & 5000 & 5000 & 5000 & 5000 & 5000 & 5000 & 5000 & 5000 \\
\hline \multicolumn{9}{|l|}{ REACTOR I COHDIIIOKS } \\
\hline LHSY, cc/hr/cc cat. & 1.0 & 0.9 & 0.1 & 0.1 & 0.1 & 0.9 & 0.9 & 1.0 \\
\hline $\begin{array}{l}\text { INLEI BED IEHP.. F } \\
\text { UPPER HIO BEO IEAP., F }\end{array}$ & 389 & 603 & 612 & 621 & 650 & 601 & 560 & 651 \\
\hline LOUER BED IEAP., F & 696 & 617 & 660 & 691 & 659 & 602 & 684 & 678 \\
\hline AYERAGE BED TEKF. . F & 643 & 610 & 636 & 656 & 655 & 602 & 622 & 665 \\
\hline SAHO BATH TEKP, . F & 541 & 599 & 559 & 579 & 643 & 601 & 544 & 654 \\
\hline
\end{tabular}

REACTOR I COHCIIIONE

LHSY, CC/hr/CC Cat.

INIET BEO IEND..'

UPPEP. MIO BEO TEHP.. F

LONEÂ BEO IEHF.. F

AYERAGE BEC IEHF., F

SAMS BA?'H IEMP., F

SEVERITY STAGE 1

SEVERITY STAGE ?

OYERALL SEYERITY

$\begin{array}{llllllll}2.3072 & 1.5659 & 2.9981 & 3.9987 & 3.9146 & 1.6598 & 2.2729 & 2.5230 \\ 2.3072 & 1.5659 & 2.9981 & 3.9981 & 3.9146 & 1.6598 & 2.2729 & 2.5230\end{array}$

FEEDSIOCX IYPE:

A: 350-650 F YIRGIN COALIIE OISIILLATE. 
IHES: 3 -

SUHKARY OF OPERATING CONDIIIONS FOR FIXEO-BEO COALIIE HYDROTREATING IESTS

CATALYST: K-55O (ISI STAGE)

IEST 1 (FB-)

DATE (1989)

STARI TIME

ENO HIME

FEEDSTOCK

FEEO RATE, cC/hr OPERAIING PRESSURE, DSIG RZ PARTIAL PRESSURE. DSIG H2 TREAT RATE, scf/bbl

\begin{tabular}{|c|c|c|c|c|c|c|c|}
\hline 27 & 28 & 29 & 37 & 38 & 39 & 10 & 41 \\
\hline $01-24$ & $01-24$ & $01-25$ & $02-02$ & $02-02$ & $02-03$ & $02-03$ & $02-03$ \\
\hline $17: 45$ & $20: 15$ & $16: 40$ & $11: 30$ & $20: 15$ & $10: 35$ & $13: 35$ & $17: 30$ \\
\hline
\end{tabular}

18:45 21:15 17:40 19:00 21:45 12:05 15:05 18:45

REACTOR I COHOITIOHS

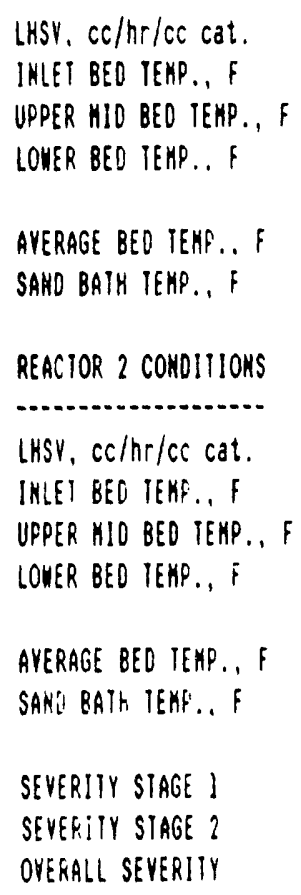

$\begin{array}{llllllll}4.52 & 2.11 & 4.99 & 1.78 & 10.69 & 1.49 & 1.74 & 4.53 \\ 4.52 & 2.11 & 4.99 & 1.18 & 10.69 & 13.27 & 1.74 & 4.53\end{array}$

FEEDSTOCK IYPE:

A: 350-650 F VIRGIN CORLIIE DISTILLAIE. B: LIOUIO PROOUCT FROH FB-37. 
lABLL 4.2.2-1 (concluded)

SUHYARY OF OPERATING CONOIIIONS FOR FIXEO-BEO COALIIE HYOROTREATING IESIS

CATALYST: K-SSO (1ST STAGE)

FILE ID: REPYBO2.UKI

IEST 1 (FB-)

DAIE (1989)

START IIKE

ENO IIHE

\begin{tabular}{|c|c|c|c|c|c|}
\hline 42 & 43 & 16 & 17 & 48 & 19 \\
\hline (n) & (n) & (n)............ & (n)............ & (n) & n. \\
\hline $02-06$ & $02-06$ & $02-21 / 22$ & $02-22$ & $02-23$ & $02-24$ \\
\hline 12:05 & $18: 45$ & $03: 15$ & $05: 45$ & $02: 00$ & $00: 00$ \\
\hline $17: 35$ & $20: 40$ & $04: 00$ & $24: 00$ & $22: 00$ & $20: 00$ \\
\hline
\end{tabular}

FEEDSTOCK

FEEO RAIE, CC/hr

OPERATIMG PRESSURE, PSIQ

H2 PARTIAL PRESSURE, DSIO

Ho IREAT RAIE, SCI/bOLI

$20: 40$

04:00

24:00

$22: 00-20: 00$

REACIOR \ CONDITIOHS

LHSY. cc/hr/sc cat.

IHLET BED IENP., F

UPPER HIO BEO IENP., $F$

LOHER BED TENP., F

AVERAGE BED IEHP.. $F$

SAND BATH TENA., F

$\begin{array}{rrrrrr}A & C & A & 0 & A & A \\ 104 & 104 & 113 & 114 & 113 & 160 \\ 2000 & 2000 & 2000 & 2000 & 2000 & 2000 \\ 2000 & 2000 & 2000 & 2000 & 2000 & 2000 \\ 5000 & 5000 & 5000 & 5000 & 5000 & 5000\end{array}$

REACTOP ? CONDIIIOKS

LHSI. cc/hricc cat.

IKIEI BEO IEMP., F

UPPER MIO BEO TENP.., $;$

LONER BEO IEAP., $F$

AHERAGS BES IEHF., F

SANO BATK TEKP., F

SEVERITY STAGE !

SEVEA!IY STAGE?

$\begin{array}{llllll}11.85 & 12.38 & 8.18 & 1.52 & 11.92 & 1.85 \\ 11.85 & 24.23 & 8.18 & 15.70 & 11.92 & 1.85\end{array}$

$\begin{array}{llllll}0.7 & 0.65 & 0.7 & 0.7 & 0.7 & 0.88\end{array}$

$\begin{array}{llllll}138 & 131 & 102 & 697 & 737 & 623\end{array}$

$\begin{array}{llllll}139 & 735 & 716 & 108 & 711 & 615\end{array}$

$\begin{array}{llllll}739 & 136 & 109 & 103 & 739 & 619\end{array}$

$\begin{array}{llllll}139 & 129 & 695 & 606 & 124 & 602\end{array}$

OVERALL SEVERIIY

FEEOSIOCK IYPE:

A: 350-650 F VIRGIN COALITE OISTILLAIE.

C: LIOUIO PROOUCI FROH F8-42.

D: LIQUIO PROOUCT FROH FB-16. 
TABLE $4.2 \cdot 2-2$

SUKHARY OF OPERATING CONOITIONS FOR FIXEO-BEO COALITE HYOROTREATING IESTS

CATALYST: K-SSO (1ST STAGE)

FILE ID: REPTBO3.UKI

\begin{tabular}{|c|c|c|c|c|c|c|c|c|}
\hline TEST $/(F B-)$ & 30 & 31 & 32 & 33 & 34 & 35 & $36-1$ & $36-2$ \\
\hline - & nan & nas & (non & - & -............ & 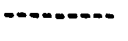 & $\cdots$ & - \\
\hline DATE (1989) & $01-25$ & $01-25$ & $01-26$ & $01-26$ & $01-21$ & $01-21$ & $01-30$ & $01-30$ \\
\hline START IIHE & 19:00 & $20: 55$ & $12: 55$ & $16: 15$ & $13: 25$ & $16: 45$ & $13: 40$ & $14: 10$ \\
\hline END IIHE & $20: 00$ & $21: \$ 5$ & $13: 55$ & $22: 00$ & $14: 10$ & $18: 45$ & $14: 10$ & $14: 10$ \\
\hline FEEDSTOCK & $A$ & A & A & A & $B$ & B & C & C \\
\hline FEED RATE, cc/hr & 160 & 159 & 157 & 156 & 136 & 104 & 108 & 102 \\
\hline OPERATING PRESSURE, DSIg & 2000 & 2000 & 2000 & 2000 & 2000 & 2000 & 2000 & 2000 \\
\hline H2 PARIIAL PRESSURE, DSIg & 2000 & 2000 & 2000 & 2000 & 2000 & 2000 & 2000 & 2000 \\
\hline H2 TREAT RATE, scF/Db] & 5000 & 5000 & 3000 & 5000 & 5000 & 5000 & 5000 & 3000 \\
\hline \multicolumn{9}{|l|}{ REACIOR \& CONOIIIOHS } \\
\hline \multicolumn{9}{|l|}{ (n) } \\
\hline LHSH, CC/hr/CC cat. & 1.0 & 1.0 & 1.0 & 1.0 & 0.85 & 0.65 & 0.67 & 0.64 \\
\hline INLET BED IEHP.. F & 709 & 659 & 606 & 100 & 701 & 699 & 698 & 698 \\
\hline \multicolumn{9}{|l|}{ UPPER HIO BEO IEME.. F } \\
\hline LOHER BED IEMP. . F & 696 & 668 & 636 & 694 & 693 & 698 & 102 & 700 \\
\hline AYERAGS BEO IEHE., F & 703 & 664 & 621 & 697 & 697 & 699 & 700 & 699 \\
\hline SANG BAIK IENE., F & $68 \mathrm{C}$ & 649 & 605 & 681 & 679 & 694 & 100 & 696 \\
\hline \multicolumn{9}{|l|}{ REACIOR I COHDIIIONS } \\
\hline \multicolumn{9}{|l|}{. } \\
\hline \multicolumn{9}{|l|}{ L Hôt, cc/hr/cc cat. } \\
\hline \multicolumn{9}{|l|}{ INLEI BED IEKP., F } \\
\hline \multicolumn{9}{|l|}{ UPPER KIO BEU IENP., F } \\
\hline \multicolumn{9}{|l|}{ LOHER BED IEKP., F } \\
\hline \multicolumn{9}{|l|}{ AYERAGE BEO IENP.. F } \\
\hline \multicolumn{9}{|l|}{ SAND BATK IEA?., F } \\
\hline SEVERITY STAGE i & 52623 & 3.1100 & 1.6792 & 4.8966 & 5.7607 & 1.6832 & 1.6018 & 7.8546 \\
\hline \multicolumn{9}{|l|}{ SEYERIIY SIAGE ? } \\
\hline OVERALL SEVERITY & 5.2623 & 3.1100 & 1.6792 & 4.8966 & 10.6573 & 12.5798 & 20.1700 & 20.4300 \\
\hline
\end{tabular}

FEEOSIOCK IYPE:

A: 350-550 F YIRGIN COALIIE DISTILLATE.

B: LIQUID PROOUCT FROH FB-33.

C: LIQUID PROOUCT FROH FB-34/F8-35. 
SUKHARY OF OPERATING COMOITIOHS FOR FIXEO-BED COALITE HYOROIREATING TESTS

CATALYST: K-SSO (IST STAGE)/K-55O (2NO STAGE) FILE IO: REPTBOA. YKL

TEST 1 (FB-)

DATE (1989)

START TIME

ENO TIME

\section{FEEOSTOCK}

FEEO RATE, CC/hr

OPERRTING PRESSURE, DSIg

H2 PARTIAL PRESSURE, DSIg

H? [REAT RATE, sCf/Lb]

\begin{tabular}{rrrrrrrr}
169 & 172 & 170 & 173 & 174 & 175 & 176 & 171 \\
\hline $06-21$ & $06-29$ & $06-28$ & $06-29$ & $06-30$ & $06-30$ & $06-30$ & $06-30$ \\
$04: 30$ & $09: 00$ & $00: 00$ & $15: 30$ & $22: 00$ & $02: 00$ & $06: 00$ & $10: 00$ \\
$20: 00$ & $10: 00$ & $12: 00$ & $20: 00$ & $24: 00$ & $04: 00$ & $08: 00$ & $20: 00$ \\
& & & & & & & \\
1 & $A$ & $B$ & $B$ & $B$ & $B$ & 8 & $B$ \\
124 & 119 & 118 & 120 & 124 & 118 & 116 & 117 \\
2000 & 2000 & 2000 & 2000 & 2000 & 2000 & 2000 & 2000 \\
2000 & 2000 & 2000 & 2000 & 2000 & 2000 & 2000 & 2000 \\
8000 & 8000 & 8000 & 8000 & 8000 & 8000 & 8000 & 8000
\end{tabular}

REACIOR I CONOIIIOHS

LHSY, Cc/hr/cc cat.

IMLET BEO TENP., $F$

UPPER HIO BEG TEHF.. F

LOHER BEO TEMP., F

AYERAGE BED TEHP., \&

SANO BATH TEHP., $F$

REACIOR 2 CONOIIIOHS

thor. celhrice cat.

INLET BEO TEMD.. F

UPPER HID BED IEHP., $F$

LONEP BED IEHP.. F

AVERAGE BEO TERP.. F

SAND BATH IEKP., $F$

SEVERIIY STAGE $]$

SEVERIIY SIAGE ?

OYERALL SEYERITY

$\begin{array}{llllllll}0.75 & 0.72 & 0.72 & 0.73 & 0.75 & 0.72 & 0.70 & 0.71 \\ 720 & 683 & 720 & 662 & 648 & 625 & 600 & 632 \\ 676 & 662 & 674 & 659 & 646 & 624 & 598 & 639 \\ 660 & 649 & 662 & 643 & 634 & 615 & 593 & 629 \\ & & & & & & & \\ 685 & 665 & 685 & 655 & 643 & 621 & 597 & 633 \\ 651 & 638 & 655 & 630 & 620 & 607 & 586 & 613\end{array}$

$\begin{array}{rrrrrrrr}0.75 & 0.72 & 0.72 & 0.73 & 0.75 & 0.72 & 0.70 & 0.71 \\ 713 & 695 & 117 & 658 & 644 & 616 & 593 & 627 \\ 123 & 702 & 721 & 675 & 650 & 624 & 600 & 636 \\ 713 & 120 & 705 & 643 & 655 & 625 & 600 & 621\end{array}$

$\begin{array}{rrrrrrrr}118 & 699 & 119 & 667 & 647 & 620 & 597 & 632 \\ 715 & 693 & 115 & 659 & 643 & 617 & 595 & 629 \\ & & & & & & & \\ 5.58 & 4.38 & 5.86 & 3.18 & 3.08 & 2.36 & 1.65 & 2.85 \\ 8.55 & 6.92 & 9.10 & 4.46 & 3.28 & 2.31 & 1.64 & 2.17 \\ 14.13 & 11.31 & 14.96 & 8.24 & 6.35 & 4.67 & 3.29 & 5.62\end{array}$

FEEDSTOCK TYPE:

A: 350-750F RAW COALITE DISTILIATE

B: 350-820F RAW COALITE DISTILLATE 


$$
\text { IABLE } 4.2 \cdot 2-4
$$

SUHWARY OF OPERATING CONOIIIOHS FOR FIXED-BED COALIIE HYOROTREATING IESTS

CATALYST: K-5SO (1ST STAGE)/K-S99 (2NO STAGE)

FILE IO: REPTBOS. HKI

\begin{tabular}{|c|c|c|c|c|c|c|c|}
\hline IEST $\mid(F B-)$ & $94-1$ & $94-2$ & $94-3$ & 101 & 102 & 103 & 104 \\
\hline (n).................... & (n)............. & -.......... & n............. & (n........... & (n).............. & (n)........... & 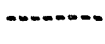 \\
\hline DAIE (1989) & $04-05$ & $04-06$ & $04-06$ & $04-10$ & $04-10$ & $04-10$ & $04-10$ \\
\hline START IIHE & 21:00 & $01: 00$ & 05:00 & $05: 00$ & $09: 30$ & $14: 00$ & $18: 00$ \\
\hline END TIME & $01: 00$ & 05:00 & 09:00 & $06: 30$ & 11:00 & $15: 30$ & $20: 00$ \\
\hline FEEDSIOCK & $A$ & $A$ & $A$ & $A$ & A & A & $A$ \\
\hline FEEO RAIE, cc/hr & 116 & 116 & 115 & 124 & 110 & 118 & 119 \\
\hline OPERATING PRESSURE, DSIG & 2000 & 2000 & 2000 & 2000 & 2000 & 2000 & 2000 \\
\hline H2 PARTIAL PRESSURE, DSIQ & 2000 & 2000 & 2000 & 2000 & 2000 & 2000 & 2000 \\
\hline H2 IREAT RATE, scf/bbI & 7000 & 7000 & 7000 & 7000 & 7000 & 7000 & 7000 \\
\hline \multicolumn{8}{|l|}{ REACIOR I COHOIIIONS } \\
\hline 年, & & & & & & & \\
\hline LHSY, cc/hr/ec cat. & 0.1 & 0.7 & 0.7 & 0.15 & 0.7 & 0.1 & 0.7 \\
\hline INLET BEO TEKP.. $F$ & 616 & 621 & 624 & 402 & 400 & 399 & 399 \\
\hline UPPER KID BEO IEMP. . F & 671 & 692 & 696 & 402 & 100 & 400 & 399 \\
\hline LOMEF BED IEHP. . F & 617 & 614 & 616 & 403 & 400 & 100 & 400 \\
\hline AYERAGE BED TEHF... F & 635 & 642 & 645 & 102 & 400 & 100 & 399 \\
\hline SANU BATH IEKP., F & 595 & 596 & 598 & $40 ?$ & 400 & 400 & 398 \\
\hline \multirow{2}{*}{\multicolumn{8}{|c|}{ REACIOR ? CONOIIIOHS }} \\
\hline & & & & & & & \\
\hline LHSY, cc/hr/cc cat. & 0.7 & 0.7 & 0.1 & 0.75 & 0.7 & 0.1 & 0.7 \\
\hline INLEI BEO IENP.. F & 628 & 628 & 627 & 632 & 660 & 739 & 112 \\
\hline UPPEE HID BED IEHP.. F & 623 & 625 & 624 & 653 & 705 & 704 & 701 \\
\hline LONER BED IEMP., F & 615 & 620 & 620 & 618 & 633 & 663 & 671 \\
\hline AYERAGE BED IEKE., F & 622 & 621 & 624 & 634 & 666 & $10 ?$ & 715 \\
\hline SANL BATH IEMP. . F & 608 & 618 & 618 & 611 & 626 & 660 & 670 \\
\hline SEYERITY STAGE I & 2.9399 & 3.2880 & 3.1338 & 0.0360 & 0.0364 & 0.0362 & 0.0359 \\
\hline SEVERIIY SIAGE ? & 2.4352 & 2.5220 & 2.4970 & 2.7305 & 1.6003 & 7.4687 & 8.7948 \\
\hline OYERALL SEYER!IY & 5.3752 & 5.8101 & 5.9307 & 2.7665 & 4.6367 & 1.5048 & 8.8307 \\
\hline
\end{tabular}

FEEDSIOCK TYPE:

A: 350-65O F VIRGIN COALITE OISTILLATE. 
IABLE $4 \cdot 2 \cdot 2-5$

SUHAARY OF OPERATING COHOITIOHS FOR FIXEO-BED COALIIE HYOROTREATIMG IESTS

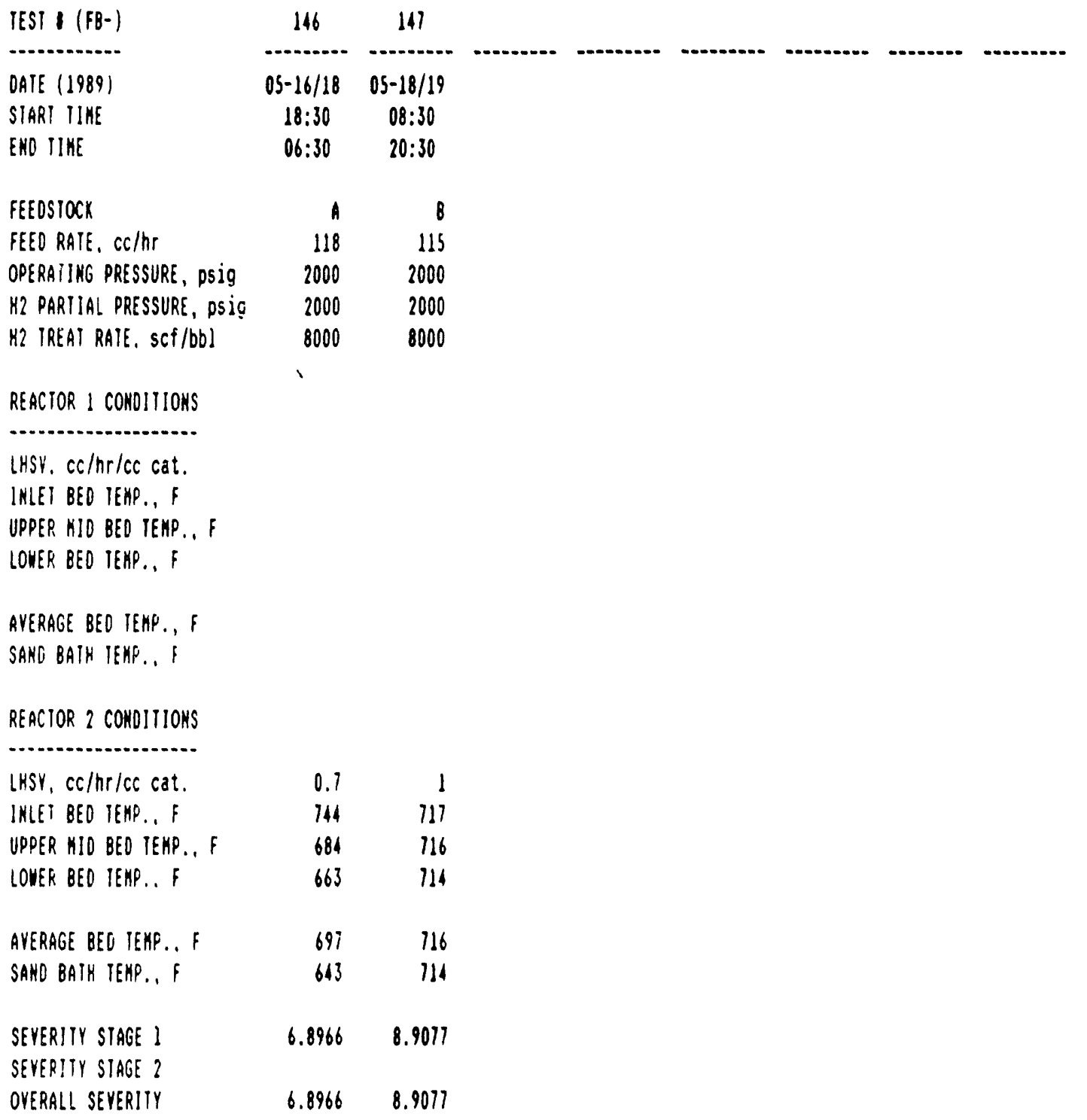

FEEDSTOCK TYPE:

A: 350-650 \& YIRGIN COALIIE OISTILLATE.

B: LIOUID PRODUCT FROH FB-146. 
IABLE $4 \cdot 2 \cdot 2-6$

SUMHARY OF OPERAIING COHOITIOHS FOR FIXED-BED COALITE HYOROTREATIHG IESTS

CATALYST: CACIUH PROHOIEO K-55O

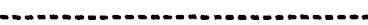

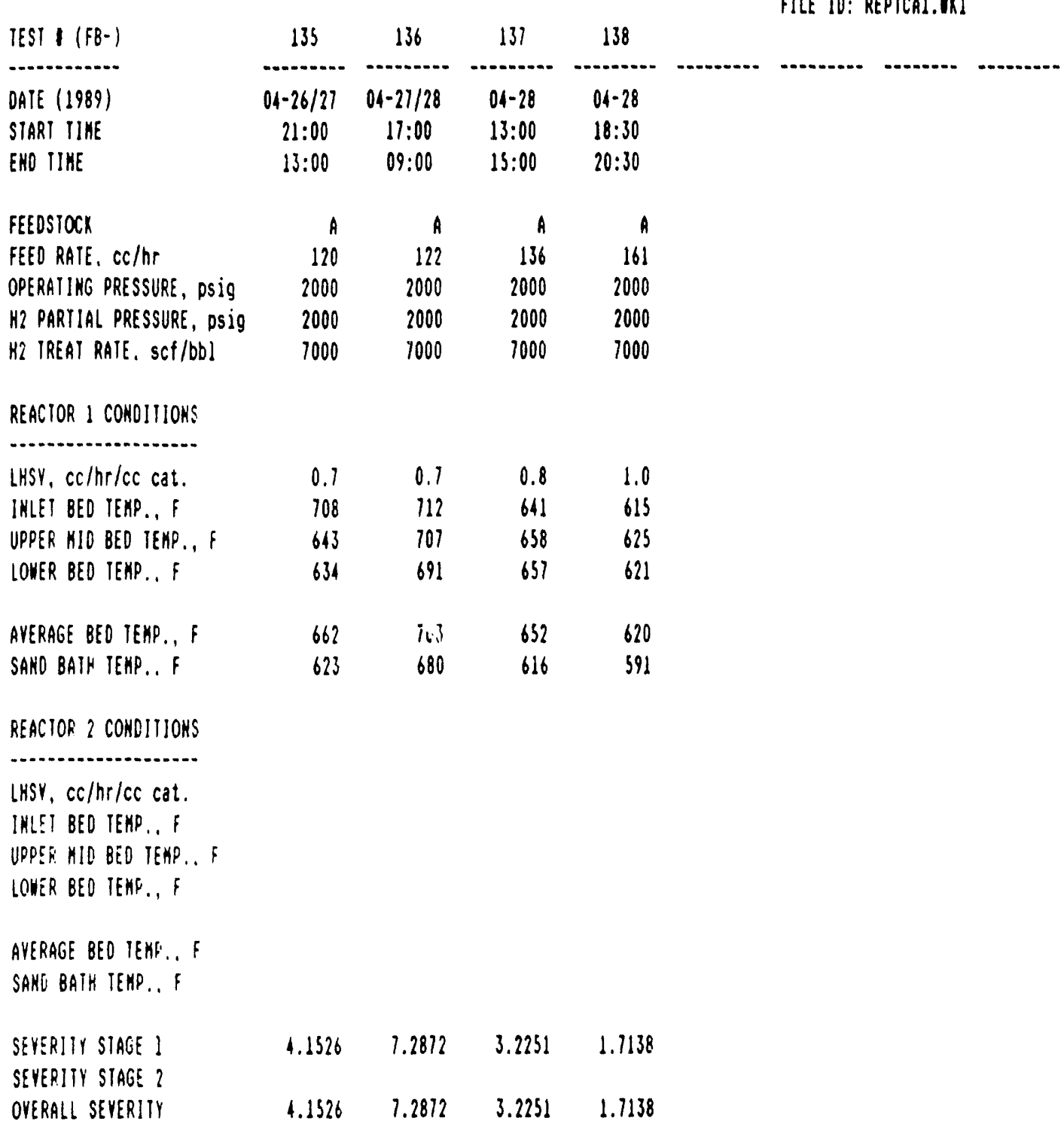

FEEDSTOCK IYPE:

A: 350-650 F VIRGIN COALITE OISTILLATE. 


\subsubsection{LC-Fining ${ }^{\text {tm }}$ (Residue Hydrocracking)}

LC-Fining ${ }^{\text {tm }}$, a service mark of Lummus and its co-licensors for engineering, marketing and technical services relating to hydrocracking and hydrodesulfurization processes for reduced crude and residual oils, is a commercial technology for upgrading heavy oils. In the context of the COALITE HEDF application, LC-Fining has been used to hydrotreat long residues (ca., 300F+) and to hydrocrack the 650F+ $(343 \mathrm{C}+)$ components into the HEDF boiling ranges. In the screening program, a stirred autoclave simulator of the LC-Fining process was used to collect the required data. Three feedstocks were considered: 1) a virgin or raw $650 \mathrm{~F}+(343 \mathrm{C}+)$ atmospheric resid fraction of the raw COALITE; 2) a virgin $300 \mathrm{~F}+(148 \mathrm{C}+)$ long resid fraction; and 3$)$ a hydrotreated $575 \mathrm{~F}+(301 \mathrm{C}+)$ atmospheric resid fraction. The analyses of these three feedstocks are presented in Table 4.2.3.1-1. The objectives of these three campaigns were as follows:

0 Evaluate the first-pass reactivity of the virgin $650 \mathrm{Ft}$ atmospheric resid fraction towards hydrocracking and the production of hydrocracked HEDF-boiling range materials;

- Evaluate the hydrocracking reactivity of the first-pass unconverted $(575 \mathrm{~F}+)$ atmospheric resid recovered from the virgin 650F+ LC-Fining tests of the above campaigns; and

- Prepare hydrotreated gas oil (650-975F) for downstream selective fixed-bed hydrocracking campaigns by subjecting the $300 F+$ long resid to mild LC-Fining ${ }^{2}$.

The summary of the operating conditions for these campaigns is presented in Table 4.2.3.1-2 and -3 .

\subsubsection{Delayed Coking}

Delayed Coking is another alternative technology for upgrading heavy oils to lighter products, such as HEDF materials. However, Delayed coking is not as selective as hydrocracking and results in the production of a variety of byproducts, the predominant one being coke. On the other hand, Delayed Coking is much less capital intensive than hydrocracking and the differential HEDF yield losses are modulated by lower capital and operating costs. The choice of Delayed Coking vs LC-Fining (residue hydrocracking) is an economic one and the preferred technology will be based on the results of the subsequent Task 4 economic optimization studies using a refinery linear programming computer model.

Three Delayed Coking tests were made in the Continuous Bench Coker (CBC) unit, two with virgin $650 \mathrm{~F}+$ atmospheric residua and one with a hydrotreated resid. Table 4.2.3.2-1 presents a summary of the feedstock properties. Two delayed coking severities were investigated: a) 100 psig coke Irum pressure; and b) 25 psig coke drum pressure, all other conditions kept constant. The detailed operating conditions for the three tests are presented in Table 4.2.3.2-2. 
TABLE $4.2 .3 .1-1$

\section{FEEDSTOCK ASSAYS FOR LC-FINING OF COALITE RESIDUA}

$\frac{\text { Coalite Type }}{\text { IBP, }{ }_{F}}$

Sp. Grav., g/cc

A.P.I Gravity ${ }_{O_{F}}$

IBP

$10 \%$

$30 \%$

$50 \%$

$70 \%$

$90 \%$

EBP

Elemental, Wt.\%

$\mathrm{C}$
$\mathrm{H}$
$\mathrm{N}$
$\mathrm{S}$

Ash

0 (By Diff.)

\begin{tabular}{|c|c|c|}
\hline $\begin{array}{c}\text { Virgin } \\
300 \\
\end{array}$ & $\begin{array}{c}\text { Virgin } \\
650\end{array}$ & $\begin{array}{c}\text { Hydrotreatec } \\
575 \\
\end{array}$ \\
\hline $\begin{array}{l}1.0513 \\
3.1\end{array}$ & $\begin{array}{l}1.1678 \\
-10.3\end{array}$ & $\begin{array}{l}1.0143 \\
8.0\end{array}$ \\
\hline $\begin{array}{l}407 \\
447 \\
512 \\
657 \\
776\end{array}$ & $\begin{array}{l}294 \\
703 \\
753 \\
812 \\
946\end{array}$ & $\cdots$ \\
\hline $50(84.8 \%)$ & $950 \quad(7$ & \\
\hline
\end{tabular}

85.10

8.53

1.06

0.81

0.01

4.50
85.47

7.75

1.18

0.75

0.01

4.84
88.25

9.18

0.87

0.09

0.01

1.60 
IABLE 4.2.3.1\%

SUHAARY OF OPERATING COHDITIONS FOR LC-FIMING IESTS

CATALYST: SHELL 324 IAGED

\begin{tabular}{|c|c|c|c|c|c|c|c|c|c|}
\hline IEST $/$ (BLCF- & $86-1$ & $86-2$ & $8 ?$ & $88-1 / 2$ & $88-3$ & $88-4$ & $88-5$ & 100 & $10 !$ \\
\hline DATE (1989: & $01-31$ & $02-01$ & $02-0 \varepsilon$ & $02-2112 \varepsilon$ & $02-28103-01$ & $03-1 / 2$ & $03-2 / 3$ & $05-17 / 19$ & $00-13 / 1 !$ \\
\hline SIART IIME & 19:00 & 01:00 & 02:00 & $15: 30$ & $16: 30$ & $09: 00$ & $07: 30$ & $20: 00$ & 08:00 \\
\hline ENG TIME & $23: 00$ & $15: 00$ & $16: 0 i$ & $10: 30$ & 09:00 & $07: 30$ & $18: 00$ & $19: 30$ & $02: 36$ \\
\hline FEEOSICOY & A & A & A & A & $A$ & A & A & 8 & $E$ \\
\hline FEEO RAii, ec/hr & 137 & 13 & 65 & 264 & 273 & 269 & 265 & 697 & 132 \\
\hline OPERAIING PRESSURE. DSIO & 2200 & 2200 & 2200 & 2200 & 2200 & 2200 & 2206 & 2000 & 2006 \\
\hline hi PARTTIAL PRESSURE, DSIC & 2200 & 2200 & 2200 & 2200 & 2200 & 2200 & 2200 & 2000 & 2006 \\
\hline HQ TREA? RATE. sCf/bOI & 10000 & 10000 & 10000 & 10000 & 10000 & 10000 & 10000 & 7000 & 7000 \\
\hline 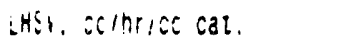 & $0.4 \mathrm{~s}$ & 0.45 & 0.43 & 0.53 & 0.55 & 0.54 & 0.53 & 1.4 & 1.5 \\
\hline 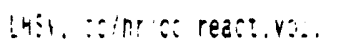 & 0.54 & 0.3 & 0.20 & 0.20 & 0.27 & $0 . \hat{2 i}$ & 0.27 & 0.70 & 0.73 \\
\hline iNLE" j!LkPY TEni.. & 656 & 010 & 630 & 130 & 748 & 746 & 743. & 100 & 764 \\
\hline UPREF SLURRY TERA., ' & 804 & 800 & 816 & 744 & 179 & 196 & 196 & & \\
\hline 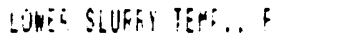 & 193 & 199 & 8019 & 506 & 604 & 6.6 & 617 & 556 & $53^{\circ}$ \\
\hline AVEKGG: SLLURFY TENE.. : & $i 4$ ? & 136 & 752 & 681 & 110 & $71^{\circ}$ & 120 & $62 j$ & tji \\
\hline
\end{tabular}

FEEDSIOCK TYPE:

4: GSE Fo VIRG̈IN ATROSPRRIC RESIL.

B: 300 iF VIRGIM ATMOSPHRIC RESID. 
TABLE 4.2.3.1-3

SUHAARY OF OPERAIIMG CONDIIIONS FOR LC-FINIMG IESTS

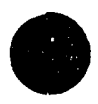

CATALYST: SHELL 324 (AGEO)

IEST I (BLCF-)

DAIE (1989)

START IIME

ENO TIME

FEEDSTOCK

FEEO RATE, $\mathrm{CC} / \mathrm{hr}$

OPERAIINO PRESSURE, DSIG

h2 PARTIRL PRESSURE, DSIO

H2 TREAT RATE, scf/bbl

SIIRRER SPEED, IPI

\begin{tabular}{|c|c|c|c|c|}
\hline 90 & 92 & 93 & 94 & 95 \\
\hline $04-04$ & $04-10$ & $04-11$ & $04-11$ & $04-12$ \\
\hline $01: 00$ & $12: 00$ & $24: 00$ & $14: 00$ & $02: 00$ \\
\hline 09:00 & 20:00 & $08: 00$ & 22:00 & 10:00 \\
\hline$A$ & A & $A$ & $A$ & A \\
\hline 2200 & 2250 & 2250 & 2250 & 2250 \\
\hline 2200 & 2250 & 2250 & 2250 & 2250 \\
\hline 7500 & 10000 & 10000 & 10000 & 10000 \\
\hline
\end{tabular}

LHSW, CC/hr/Ce cat.

LHSW, cc/hr/CC react.vOl.

IKLET SLURRY TEKP., F

UPPER SLURRY TERP.. F

LONER SLURRY TENP., F

$\begin{array}{lllll}698 & 675 & 681 & 389 & 709 \\ 719 & 760 & 780 & 800 & 798 \\ 699 & 736 & 753 & 710 & 772\end{array}$

AVERAGE SLURRY TEMP.. F

$\begin{array}{lll}738 & 153 \quad 760\end{array}$

FEEDSTOCK IYFE:

A: HYOROTREATEO 575 Ft PROOUCT FROH 8LCF-88. 
TABLE $4.2 \cdot 3 \cdot 2-1$

\section{ASSAYS OF DELAYED COKING COALITE-DERIVED FEEDSTOCKS}

$\begin{array}{lcc}\text { Feedstock Type } & \text { Virgin } & \text { Mildly Hydrotreated } \\ \text { Nominal IBP, }{ }^{\circ} \mathrm{F} & 650 & 650 \\ \text { Specific Gravity } 060^{\circ} \mathrm{F} & 1.1678 & 1.1399 \\ \text { API Gravity } & -10.3 & -7.4 \\ \text { ASTM Distillation, }{ }^{\circ} \mathrm{F} & & \\ 5 \% \text { distilled } & 650 & 675 \\ 10 \% & 703 & 732 \\ 30 \% & 753 & 760 \\ 50 \% & 812 & 825 \\ 70 \% & 946 & 928 \\ 90 \% & -\cdots & 980 \\ \text { Watson K, R } & & 9.50 \\ & -.- & \\ \text { Elementals, Wt\% } & & 87.15 \\ \text { C } & 85.47 & 7.99 \\ \text { H } & 7.75 & 0.95 \\ \text { N } & 1.18 & 0.56 \\ \text { S } & 0.75 & 3.35 \\ \text { O }+ \text { Ash (By diff) } & 4.85 & \end{array}$


TABLE 4.2.3.2-2

SUMMARY OF OPERATING CONDITIONS

FOR DELAYED COKING OF COALITE

Test No. (CBC-)

Feed Source

Coke Drum Temp, ${ }^{\circ} \mathrm{F}$

Coke Drum Pressure, psig

Coke Drum Preheater

Temp, ${ }^{\circ} \mathrm{F}$

Feed Rate, $\mathrm{lb} / \mathrm{hr}$

Run Length, $\mathrm{hr}$.

Recycle/Fresh Feed Ratio $\underline{6}$

.... Virgin 650F+ Resid

64

67

Mildly

Hydrotreated

$650 F+$ Resid

870

100

880

100

700

0.85

24

0.50
700

0.85

24

0.50
880

25

700

0.85

24

0.66
880

25

700

0.85

24

0.81 


\subsubsection{Cracked Distillate Hydrotreating Campaigns}

The above two cracking operations, namely, LC-Fining ${ }^{\text {tm }}$ and Delayed oking, are primarily conversion processes to produce HEDF precursor aterials that boil within tine HEDF boiling range. They therefore do not result in the production of finished HEDF products and a post-cracking hydrogenation operation is required for upgrading the cracked precursor materials. In a true commercial process, a fractionator would be installed between the cracking unit(s) with the cracked distillate fed continuously to the distillate hydrotreater and the heavier unconverted residuum being recycled back to the cracking unit. In this Task 3 screening program with the COALITE feedstock, the bench-scale cracking and hydrotreating units were not integrated and thus only first-pass crackates, either, delayed coker distillates or hydrocrackates (LC-Finates), were evaluated. Three distillate hydrotreating runs were made with delayed coker distillates and eleven distillate hydrotreating runs were made with LC-Finate (hydrocracked) distillates.

\subsubsection{Hydrotreating of LC-Finate Distillates}

Table 4.2.4.1-1 presents the feedstock assays for the three LC-Finate distillates used in the hydrocracked distillate hydrotreating campaigns. Table 4.2.4.1-2 and -3 present the summary of the operating conditions for the eleven hydrotreating tests. The objective of these campaigns was to evaluate the effects of hydrocracked distillate end point, catalyst type, space velocity, reactor temperature, and single-stage vs two-stage distillate hydrotreating.

\subsubsection{Hydrotreating of Coker Distillates}

Table 4.2.4.2-1 presents the feedstock assays for the coker distillates used in the thermally cracked distillate hydrotreating campaigns. Table $4.2 .4 .<-2$ presents the summary of the operating conditions for the three hydrotreating tests. The objective of these campaigns was to evaluate the effects of coker severity, coker distillate end point, reactor temperature, and single-stage vs two-stage distillate hydrotreating.

\subsubsection{Two-Step Selective Hydrocracking Campaigns}

During the early phases of the screening program, it was determined that the raw atmospheric resid fraction of COALITE was very reactive towards undesirable cracking and condensation reactions. Thus, it was postulated that a pretreatment based on hydrogenation would provide some degree of stabilization of reactive species and thereby allow better performance during subsequent cracking operations. Since the atmospheric COALITE resid contains some coal char particles, it was felt that hydrotreating in a fixed-bed unit would pose significant operability problems. The expanded-bed hydrocracking process of LC-Fining offers the capability to perform the hydrogen addition process in the presence of solids and other contaminants under commercially feasible conditions. 
TABLE 4.2.4.1-1

ASSAYS OF COALITE MID-DISTILLATE

LC-FINATE (HYDROCRACKATE) FEEDS TO HYDROTREATING

\begin{tabular}{|c|c|c|c|}
\hline $\begin{array}{l}\text { Nominal TBP } \\
\text { End Pt., }\end{array}$ & $\underline{650}$ & $\underline{600}$ & $\underline{575}$ \\
\hline $\begin{array}{l}\text { R.I. O } 20^{\circ} \mathrm{C} \\
\text { Specific Gravity, g/cc } \\
\text { A.P.I. Gravity } 000^{\mathrm{F}} \\
\text { Simulated Distillation, }{ }^{\circ} \mathrm{F}\end{array}$ & $\begin{array}{l}1.5493 \\
0.9619 \\
15.6\end{array}$ & $\begin{array}{l}1.5201 \\
0.9396 \\
19.1\end{array}$ & $\begin{array}{l}1.5200 \\
0.9297 \\
20.7\end{array}$ \\
\hline $\begin{array}{l}\text { IBP } \\
10 \% \\
30 \% \\
50 \% \\
70 \% \\
90 \% \\
\text { EBP } \\
\text { VAPB }\end{array}$ & $\begin{array}{l}342 \\
396 \\
445 \\
502 \\
546 \\
604 \\
680 \\
502\end{array}$ & $\begin{array}{l}354 \\
398 \\
448 \\
491 \\
535 \\
580 \\
761 \\
510\end{array}$ & $\begin{array}{l}247 \\
363 \\
411 \\
453 \\
493 \\
546 \\
729 \\
463\end{array}$ \\
\hline Watson $\mathrm{K}, \mathrm{R}$ & 10.19 & 10.35 & 10.31 \\
\hline $\begin{array}{l}\text { Elemental, Wt.\% } \\
\text { C } \\
\mathrm{H} \\
\mathrm{N} \\
\mathrm{S} \\
\mathrm{O} \text { (By Diff.) }\end{array}$ & $\begin{array}{r}89.38 \\
9.60 \\
0.45 \\
0.05 \\
0.52\end{array}$ & $\begin{array}{r}86.26 \\
10.52 \\
0.57 \\
0.05 \\
2.60\end{array}$ & $\begin{array}{r}87.97 \\
10.40 \\
0.69 \\
0.03 \\
0.91\end{array}$ \\
\hline $\begin{array}{l}\text { F.I.A/R.I., } 1 \text { Vol\% } \\
\text { Paraffins } \\
\text { 0lefins } \\
\text { Naphthenes } \\
\text { Aromatics }\end{array}$ & $\begin{array}{l}\text { N.D. } \\
0.6 \\
18.6 \\
80.8\end{array}$ & $\begin{array}{l}\text { N.D. } \\
2.5 \\
28.3 \\
69.2\end{array}$ & $\begin{array}{l}\text { N.D. } \\
5.3 \\
21.2 \\
73.5\end{array}$ \\
\hline $\begin{array}{ll}\text { WLHV, } & \text { Btu/1b } \\
\text { VLHV, } & \text { Btu/gal }\end{array}$ & $\begin{array}{r}16031 \\
128451\end{array}$ & $\cdots$ & $\begin{array}{r}17142 \\
132785\end{array}$ \\
\hline $\begin{array}{l}\text { Aniline Pt., }{ }^{0} \mathrm{~F} \\
\text { Diesel Index } \\
\text { Smoke Pt., mm } \\
\text { Lum. No. }\end{array}$ & $\begin{array}{l}-6.9 \\
-1.07 \\
7 \\
30.1\end{array}$ & $\begin{array}{ll}\cdots \\
\cdots \\
\cdots\end{array}$ & $\begin{array}{l}\cdots \\
\cdots \\
\cdots \\
-\cdots\end{array}$ \\
\hline
\end{tabular}


IABi: 4.2.4.1-?

SUAMAR, UF OPERATING CONDIIIONS FOR FIXEGI-BEQ KYOROTREATING IESTS OF

HYOROCRACXED COALITE OISTILLATE

CATALYSI: X-55O (IST SIAGE), K-599 (2NO STAGE)

\begin{tabular}{|c|c|c|c|c|c|c|c|c|}
\hline IEST $\mid F B-1$ & 44 & is & 96 & 97 & 98 & 99 & 100 & $10 s$ \\
\hline (n................... & $\ldots$ & (.............. & (n........... & n........... & $\ldots$ & (n............. & (n......... & (n)............. \\
\hline DAIE I1988; & $0 ?-a c$ & $04-00$ & $04-06$ & $04-0 i$ & $04-01$ & $04-07$ & $04-07$ & $04-11$ \\
\hline STAK: IIH: & $11: 23$ & $12: 26$ & $18: 00$ & $2 \hat{2}: 36$ & $12: 06$ & di:00 & $26: 00$ & $11: u_{i}$ \\
\hline ENO IIHE & $12: 35$ & $14: 50$ & $19: 30$ & $24: 00$ & $13: 30$ & 18:00 & $21: 30$ & $12: 00$ \\
\hline FEEOjiais & f & $B$ & 8 & B & 8 & $B$ & 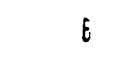 & $t$ \\
\hline 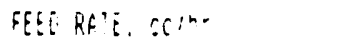 & $1 ! ?$ & 108 & $1 ! ?$ & 113 & 110 & 126 & 11: & $\lfloor! !$ \\
\hline 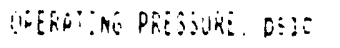 & ivúl & $20^{i}: 0^{0}$ & $200 i$ & 2uigl: & 2000 & $20 \%$ & 2000 & $266 !$ \\
\hline 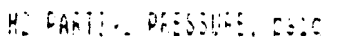 & 2006 & 2006 & $200 i$ & 2005 & 20 & 2006 & $20 \div$ & $261:$ \\
\hline 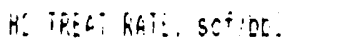 & soni & 1000 & icio & $100 !$ & 1005 & libiv & 1006 & $700 i$ \\
\hline \multirow{2}{*}{\multicolumn{9}{|c|}{ 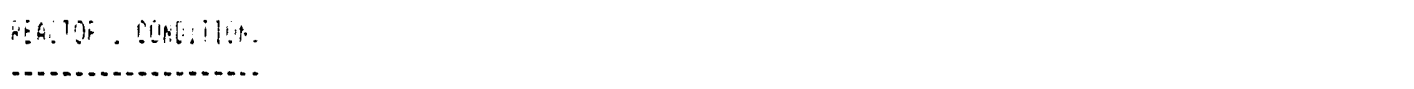 }} \\
\hline & & & & & & & & \\
\hline 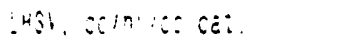 & $0 . b \hat{s}$ & $0.0 \vdots$ & 0.65 & 0.69 & $6.6 i$ & 0.13 & 0.70 & $6.6 ?$ \\
\hline 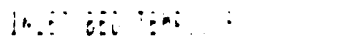 & $6:$ & $\because \vdots$ & 030 & $74\}$ & 406 & jos & 416 & $0 \because$ \\
\hline 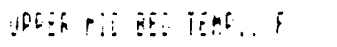 & & 65: & $70 ?$ & $73:$ & $40 ?$ & $40 ?$ & $10:$ & 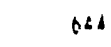 \\
\hline bn: 65: is . . ; & $i_{1} \vdots$ & $6 \hat{i}$ & 650 & $69:$ & 403 & $40:$ & 406 & ti. \\
\hline ulnon: & $\because 4$ & tis & o6! & 93 & $4: 5$ & 40.1 & $4 \because$ & $\therefore$ \\
\hline 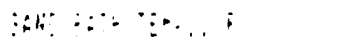 & $\because$ & $6 ! 6$ & $\therefore \because$ & $t i:$ & $4 ! ?$ & $4:$ & $\Delta 6$ & $b !:$ \\
\hline \multicolumn{9}{|l|}{ 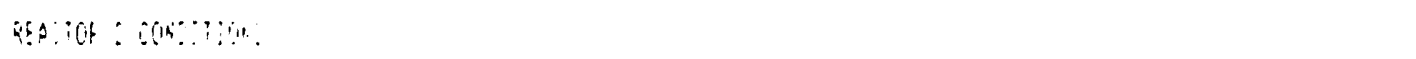 } \\
\hline (n, & & & & & & & & \\
\hline 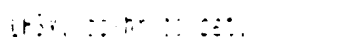 & & & & & $\therefore:$ & $\because:$ & i. & $\therefore$ \\
\hline 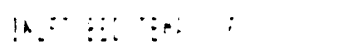 & & & & & $64:$ & $1 ! \vdots$ & 74: & tis \\
\hline 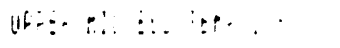 & & & & & 346 & $06^{\circ}$ & 10: & $\because 0 ;$ \\
\hline 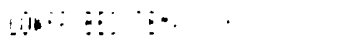 & & & & & 045 & $0 i:$ & 64 & 6 \\
\hline 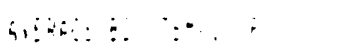 & & & & & $\Delta \&$ : & 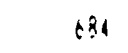 & $i_{4}$ & $\because \because$ \\
\hline$i 2 n: 86 i=1 ! \cdot i \ldots ;$ & & & & & 011 & of: & $6 ?$ & $6 \times 4$ \\
\hline SEYERII SAA:E. & $? .891 ?$ & 3.1500 & 1.3950 & $10.168 j$ & 0.0396 & $0.039 i$ & 0.0304 & $\therefore 6: 18$ \\
\hline 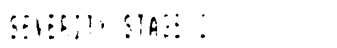 & & & & & $3.33: !$ & $3.884:$ & 8.790 & $6.934:$ \\
\hline GUEFL: SEVR: & $\therefore .86::$ & $3.150:$ & 4.3950 & 10.1685 & $3.375 \%$ & 3.9142 & $9.136 ?$ & 7.\$55 \\
\hline
\end{tabular}

FEEOSTOCI Trü:

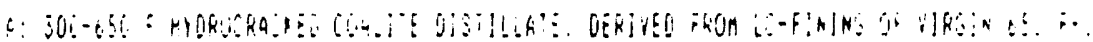

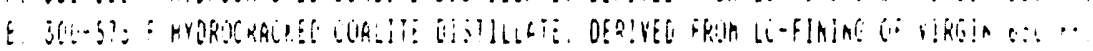


IAE: $4.2 .4 .1 \cdot ?$

………........

SUMARRY OF OPERATING CONOIIIONS FOR FIXEQI-BED HYOROTREAIINE IESTS O:

MYOROCRACKEQ COALIIE DISIILLATE

CATALYST: $K-599$ (ISI SIAGE)

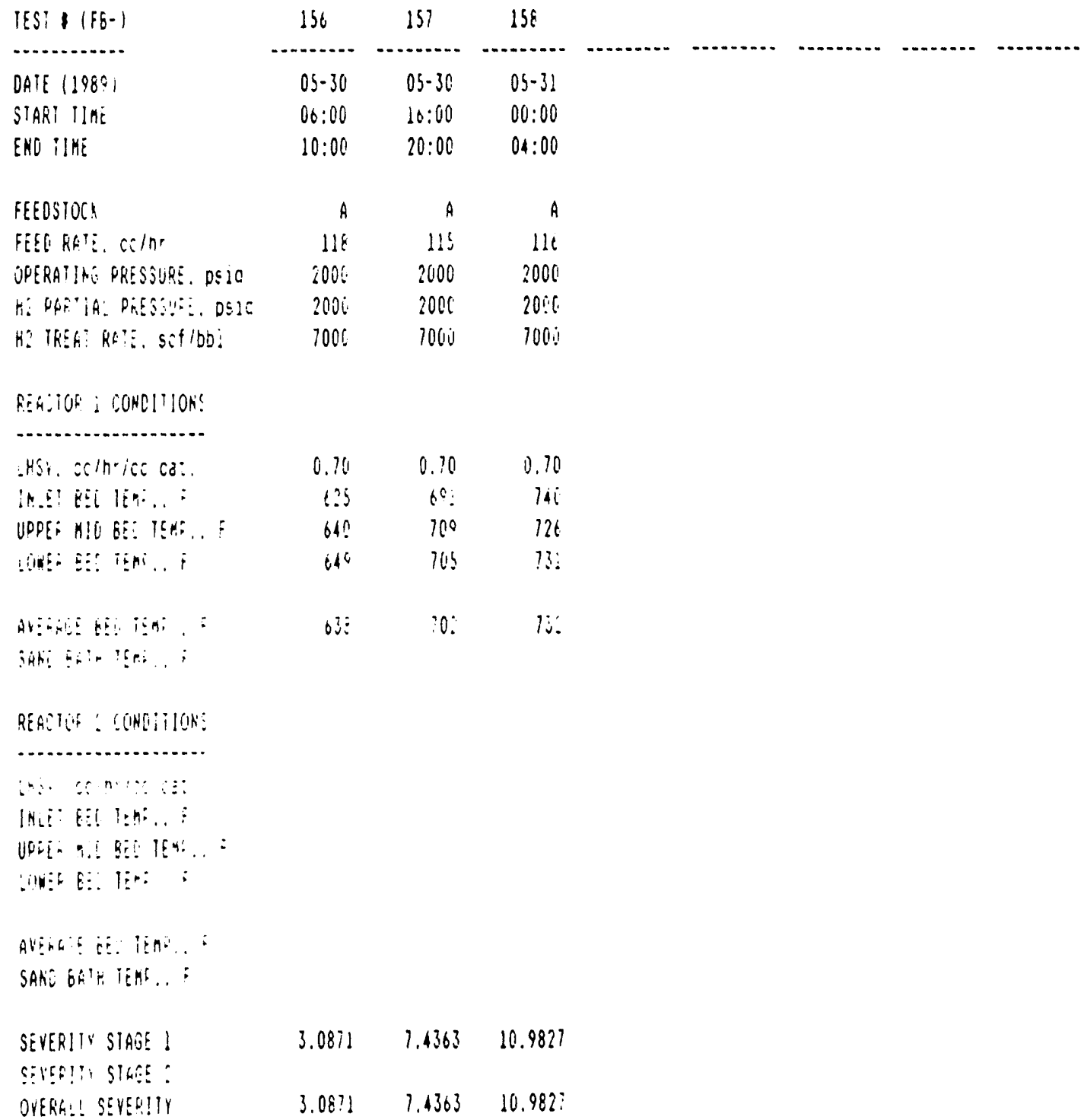

FEEDSIOA IHF:

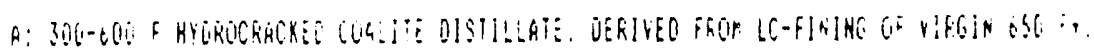


TABLE 4.2.4.2-1

\section{ASSAYS OF COALITE COKER MID-DISTILLATE}

FEEDS TO HYDROTREATING

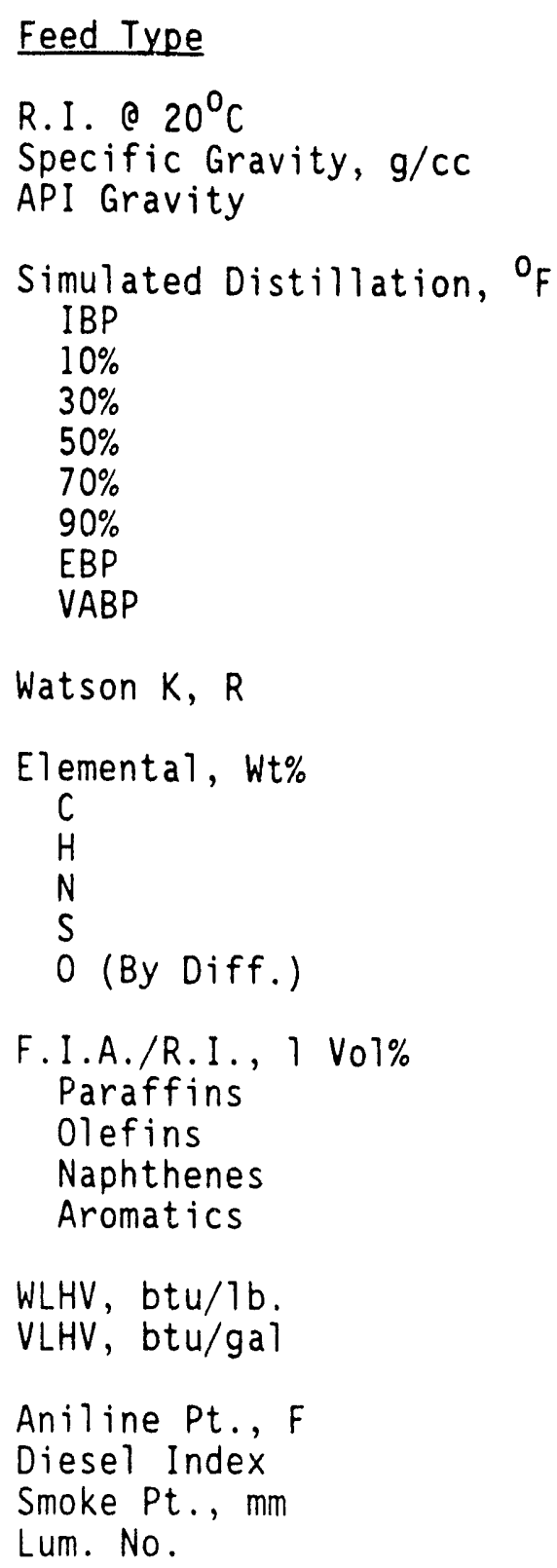

\section{0 psig \\ Coke Drum Pressure}

1.5406

0.9679

14.7

347

384

436

489

547

609

754

509

10.15

84.33

9.50

0.93

0.45

4.79

N.D.

14.6

24.3

61.1

15972

128775

37.4

5.50

5

29.5

.4
.50
.5

62 psig Average Coke Drum Pressure
1.4785
0.8676

31.6

300

370

409

454

497

559

725

473

11.17

83.88

10.10

0.65

0.46

4.91

N.D.

25.2

22.3

52.5

16374

118337 
IA6L! 4.6.4... - :

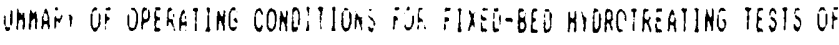

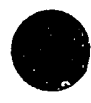

IHERRALLY PROCESSEO COALIIE OLSTILLATE

SATALYSI: K-SSG (IST SIAGES) K-S99 IZND STAGE)

IES: 1 1 if

OAIS: 1980

SIART IIME

EMC IIMG

FEEDJTOC

FEEC RHTE, CEIF.

OPERAIING PRE JSURE, DSIC

HE PARTIA. PRESJUR:, DSIC

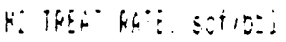

\section{5}

$126 \quad 12$

$02-1:$

$10: 50$

$11: 50$

$04-19 \quad 04-16$

$07: 30 \quad 13: 30$

00:0! 14:15

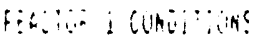

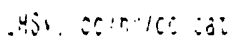

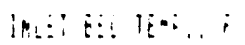

uosei mis art isen. :

. Un: bi.. IEr. . ;

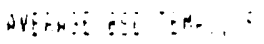

$21, \quad$ in:

$\because: \quad \cdots+\cdots$

$\therefore, \quad \therefore+\cdots:-3$

in $:$ ?

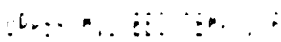

lon: is: ifr.

Ar:

SAAL EH + IEA: . :

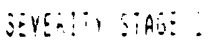

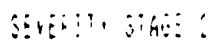

OYERE:L SEVERTI

$\begin{array}{rrr}A & 6 & 6 \\ 106 & 1 ! & 105 \\ 2000 & 2000 & 2000 \\ 2006 & 200 \% & 2006 \\ 1060 & 1000 & ? 005\end{array}$

\begin{tabular}{|c|c|}
\hline $0 . ?$ & 6.? \\
\hline & ui: \\
\hline lit. & osi \\
\hline$i d \vdots$ & $6 \vdots$ \\
\hline 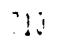 & $\Delta j_{i}$ \\
\hline
\end{tabular}

i.

i. $\quad 4^{\circ}$

as $\quad 8 \%$

i. 60.6

$0 \quad 64$.

$\begin{array}{lll}8.331 . & 2.8406 & 6.035 \\ & 5.2076 & 6.75 j 6 \\ 8.2311 & 8.0484 & 0.79 \% 5\end{array}$

FEcosion ippe

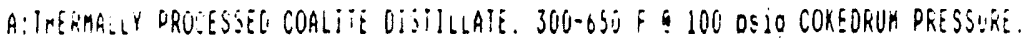

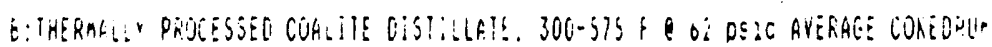
Fi: : 0 : - 
The two-step selective hydrocracking (TSSH) of COALITE consists of a hydrotreating pretreatment step using an LC-Fining reaction system followed by fractionation to recover a hydrotreated vacuum gas oil (HVGO) fraction and a hydrotreated middle distillate fraction, the latter of which can be directed to the HEDF pool. The HVGO fraction is then catalytically hydrocracked over a fixed-bed hydrocracking catalyst to convert the heavier gas oil-boiling species to HEDF precursors. The thus hydrocracked LC-Finate HVGO, is then subjected to distillate hydrotreating to produce the final HEDF product.

In a true commercial process, a fractionator between the fixed-bed hydrocracker and the hydrocracked distillate hydrotreater would allow for near extinction recycle of the heavy gas oil components. In the screening program, the fixed-bed hydrocracker and the hydrocracked distillate hydrotreater were not integrated and therefore hydrotreating of only the first-pass hydrocracked HVGO fiaction was evaluated. Finally, in order to minimize fractionation equipment costs in a commercial plant, it was decided to perform the initial LC-Fining pretreatment step with a $300 \mathrm{~F}+$ atmospheric resid fraction rather than with a $650 \mathrm{~F}+$ atmospheric resid fraction. The residual vacuum resid $(975 \mathrm{~F}+)$ fraction after the initial LC-Fining pretreatment step can be used for power generation by combustion in a steam boiler or be recycled to extinction in the MCG pyrolysis reactor. Figure 4.2.5-1 is a schematic of the processing flow scheme for the TSSH approach.

Table 4.2.5-1 presents the feedstock assays for the two gas oil feeds to the fixed-bed hydrocracking step. Two hydrocracking campaigns were made: 1) hydrocracking of virgin COALITE VGO; and 2) hydrocracking of hydrotreated LC-Finate VGO. Table 4.2.5-2 summarizes the operating conditions for the nine tests made with the virgin VGO and Table 4.2.5-3 summarizes the conditions for the ten tests made with the hydrotreated LC-Finate VGO. The objective of these tests was to evaluate the effects of space velocity, reactor temperature and VGO feedstock type. All nineteen tests were made with a proprietary fixed-bed hydrocracking catalyst supplied by Amoco Oil Company.

The hydrocracked LC-Finate VGO was fractionated to recover a mid-distillate fraction for distillate hydrotreating. The assay of this selectively hydrocracked mid-distillate feedstock is presented in Table 4.2.5-4.

A contract modification was approved by $D O E$ to perform further screening studies of the two-stage selective hydrocracking route with the goal of exceeding the $130,000 \mathrm{Btu} / \mathrm{gal}$ energy density target of the finished HEDF test fuels. It was further expanded to also consider the impact of the energy density-JFTOT fuel stability relationships. A new Subtask 3.2 test matrix was formulated and the details of this phase of Task 3 are presented in Section 5.5.3. 

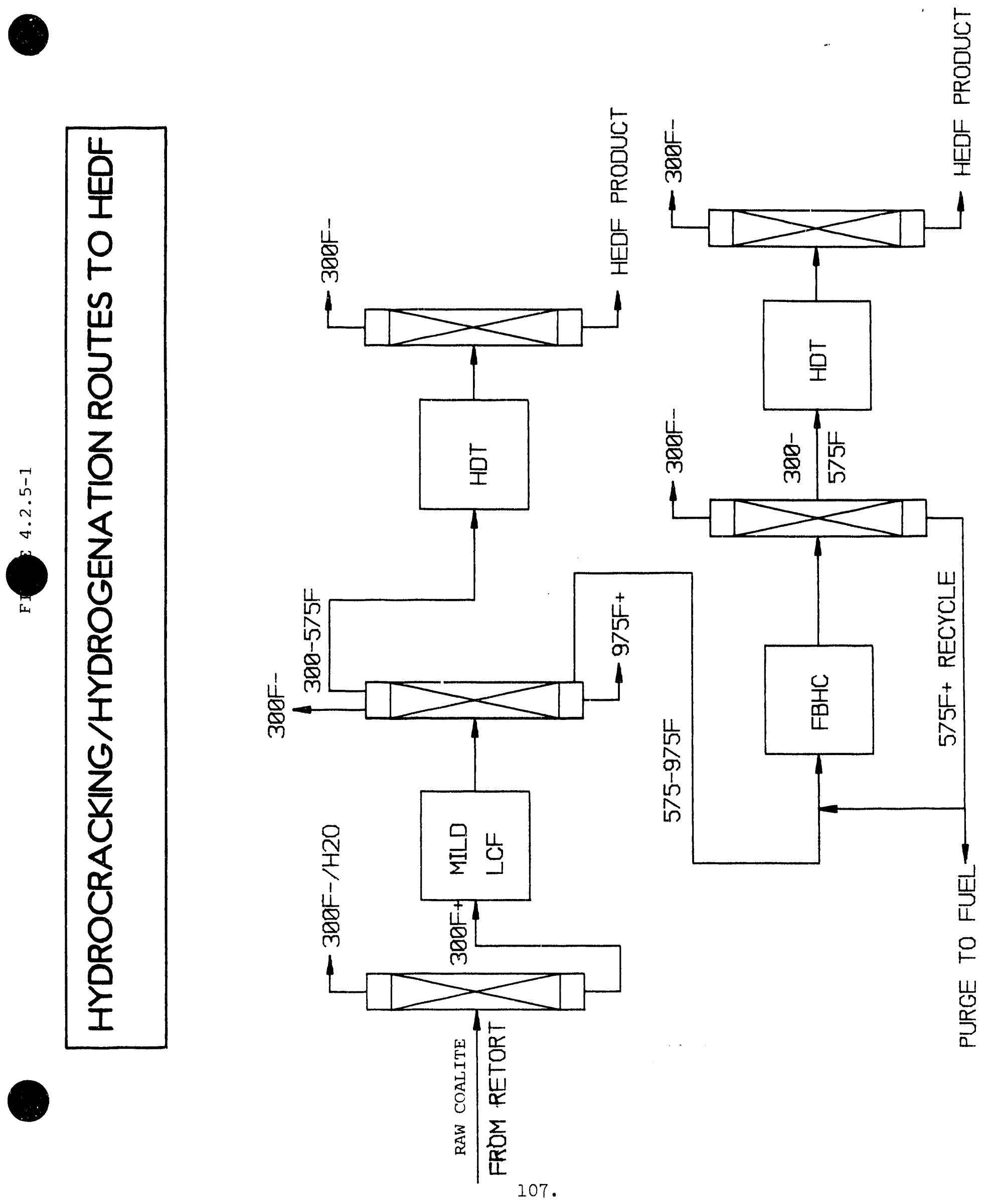
TABLE 4.2.5-1

ASSAYS OF COALITE VGO FEEDSTOCKS

TO FIXED-BED HYDROCRACKING

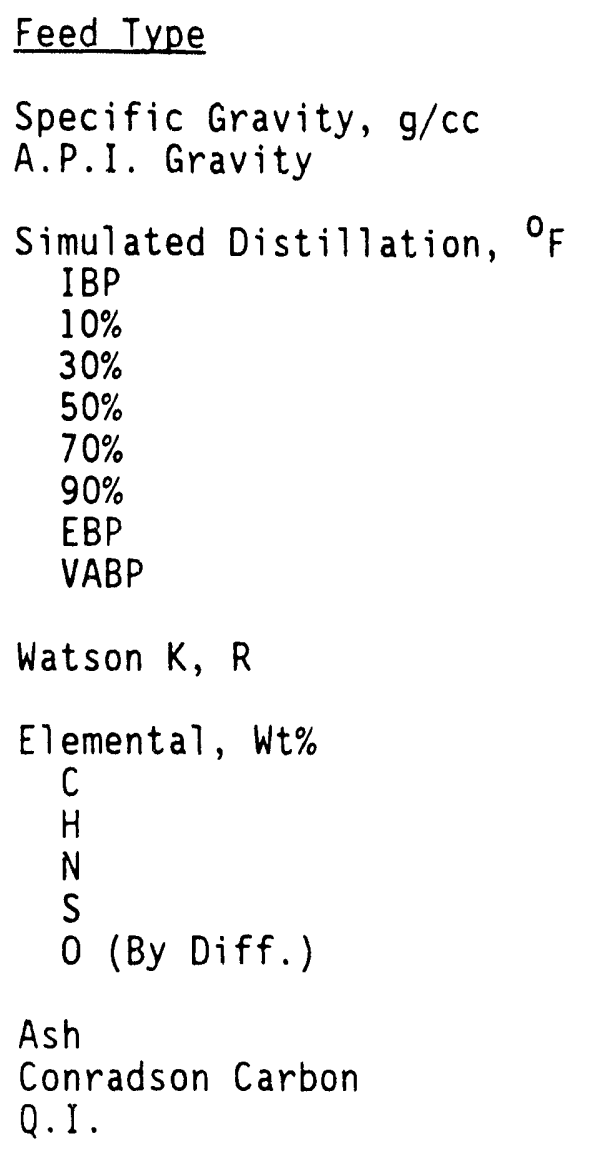

$\begin{array}{cc}\text { Virgin } & \text { Hydrotreated } \\ & 1.0180 \\ -4.7 & 7.5 \\ & \\ 561 & 530 \\ 695 & 618 \\ 750 & 663 \\ 792 & 710 \\ 835 & 765 \\ 901 & 849 \\ 1001 & 965 \\ 791 & 729 \\ 9.66 & 10.38\end{array}$

85.34

7.79

88.02

1.28

0.85

9.29

0.67

0.30

$\begin{array}{ll}4.74 & 1.72\end{array}$

$<0.01$

2.90

0.55

0.018

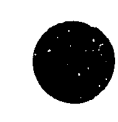

108. 
IABLE $4.2 .5 \cdot 2$

SUMHAPY OF OPERATING COKOIIIOHS FOR FIXEO-BEO COALIIE HYOROCRACYING IESTS

CAIALYST: AMOCE PRORRIEIGRY

\begin{tabular}{|c|c|c|c|c|c|c|c|c|c|}
\hline IEST IFBHC-1 & 1 & 2 & 3 & 1 & 13 & 14 & 15 & 16 & $! ?$ \\
\hline 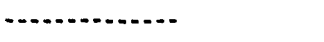 & 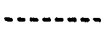 & -........... & $\ldots . . . .$. & -......... & (......... & $\cdots+\ldots$ & - & -......... & $\cdots \cdots$ \\
\hline DATE 11989 ! & $04-27$ & $04-28$ & $04-28$ & $04-28$ & $0 j-0 ?$ & $05-04$ & $05-04$ & 05.04 & $05-6:$ \\
\hline SIARI IIN: & $21: 30$ & $03: 30$ & $13: 00$ & $18: 30$ & $15: 30$ & $21: 30$ & $03: 30$ & $11: 00$ & $19: 00$ \\
\hline ENGL TIFE & $27: 36$ & $05: 36$ & $15: 00$ & $20: 36$ & $17: 30$ & $23: 30$ & $08: 36$ & $14: 06$ & $08: 06$ \\
\hline FEEGjTOCA & $A$ & $A$ & $A$ & $A$ & $A$ & A & A & $A$ & $A$ \\
\hline Bist fitib, ccinr & $17 \%$ & 170 & $10:$ & 125 & 243 & 179 & 103 & $6 i$ & $10^{\circ}$ \\
\hline OPEFATING PRESSURE, DSIC & 2000 & $200 !$ & 2000 & 2000 & 2000 & 2000 & 2000 & 2000 & 2060 \\
\hline 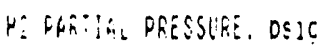 & 200: & 2000 & 200: & 2006 & $200 C$ & 2000 & 2000 & 2006 & $206:$ \\
\hline 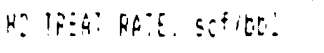 & 1006 & 1064 & lon? & $100 i$ & 10010 & $100:$ & 1000 & $106 i$ & $76 n$ \\
\hline 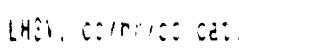 & 1.: & 1.! & $0 . i$ & i. $\varepsilon$ & $i .4$ & $i .1$ & 0.6 & 0.4 & 1. \\
\hline 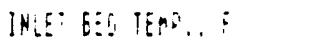 & 656 & $b \hat{\varepsilon} \hat{\imath}$ & 693 & 675 & 714 & $7 \hat{\imath} 4$ & $73 ?$ & 739 & $72:$ \\
\hline 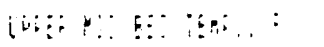 & 70: & 73 & 796 & $i 2$. & $\because$ & $80:$ & $86:$ & $8 !::$ & $\because:$ \\
\hline 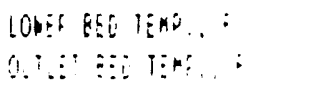 & $? 3$ & 756 & 730 & 710 & 78: & 795 & 773 & $100^{\circ}$ & $86:$ \\
\hline 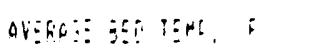 & $\therefore 06$ & $i i:$ & 736 & $70:$ & $76:$ & 774 & 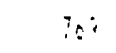 & in: & \\
\hline
\end{tabular}

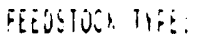

6: sti-s: : vinish bij. 
TAELE $4.2 .3 \cdot 3$

-.................

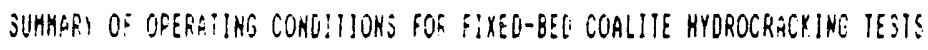

CATALYSI: AMOCO PROPRIEIARY

\begin{tabular}{|c|c|c|c|c|c|c|c|c|c|c|}
\hline IES! 1 (FET: $:-1$ & 18 & 19 & 20 & 21 & $2 ?$ & 23 & 24 & 25 & 26 & .7 \\
\hline n. & - & $\cdots \ldots$ & -......... & - & ............ & -........ & (n......... & -......... & $\ldots$ & .......... \\
\hline DATE 11989 ! & $0 j-24$ & $05-25$ & $05-25$ & $05-25$ & $05-26$ & $05-26$ & $05-26$ & $05-26$ & $05-30$ & $0 t-0 s / 0 s$ \\
\hline SIAF" IIAE & $2: 36$ & $04: 3:$ & $10: 36$ & $17: 00$ & $23: 06$ & OS:0i & 13:00 & $20: 06$ & $07: 00$ & $9: 06$ \\
\hline ENE iln: & $24: 36$ & $00: 30$ & $16: 36$ & $14: 00$ & $0 \mathrm{~s}: 00$ & $04: 00$ & $17: 06$ & $21: 00$ & Os:ós & $\theta: i:$ \\
\hline "EER:? & 8 & $\dot{8}$ & 6 & 6 & 6 & b & $B$ & $E$ & $\varepsilon$ & $E$ \\
\hline FEEt R: : : i::- & $1 i s$ & $1 \hat{2}$ & .18 & 150 & $14 ?$ & 19 & $10 ?$ & $10 ?$ & $1: i$ & 139 \\
\hline 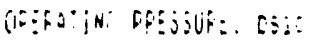 & 2006 & 263 & 20106 & 2006 & 2000 & 2006 & 2000 & 2000 & 2000 & $200:$ \\
\hline 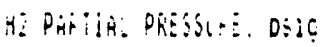 & 20060 & 2006 & 2004 & 2060 & 2006 & 2000 & 2000 & 2060 & 2006 & $2060 i$ \\
\hline HE TREFi fGIE, scf/Ds: & $1000^{\circ}$ & 7000 & 7000 & 7000 & 1000 & 7000 & 1000 & 7000 & 1000 & 70is: \\
\hline lysr. oc/ntics ce: & 0.9 & 0.4 & 0.8 & 1.1 & 1.1 & 0.4 & $0 . ?$ & 0.8 & C! & $i . i$ \\
\hline 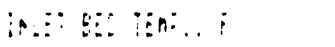 & 06 & $6: 6$ & $76 ;$ & $76^{\circ}$ & 696 & $i j i$ & 99 & $i .4$ & $\therefore: \vdots$ & $\because$ \\
\hline WGFE HII EEQ IENF. . ; & 714 & 735 & $71 \%$ & $i 74$ & $76:$ & 170 & $74 j$ & 199 & $7 i \vdots$ & $10:$ \\
\hline 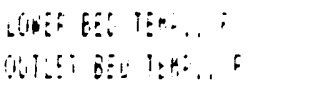 & $?:$ & $? 36$ & $\because$ & $\because ;$ & 96 & 765 & $76 ?$ & $x$ & 73 & $\because$ \\
\hline 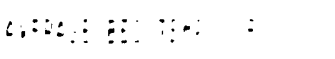 & $\because:$ & $\because$ & $\because:$ & $\because \vdots$ & $7: 4$ & is! & $7 i:$ & $\because !$ & $\because$ & $\therefore$ \\
\hline
\end{tabular}




\section{ASSAY OF SELECTIVELY HYDROCRACKED}

\section{COALITE MID-DISTILLATE FEED TO HYDROTREATING}

\begin{tabular}{|c|c|}
\hline $\begin{array}{l}\text { TBP Boiling Range }{ }^{{ }} \mathrm{F} \\
\text { R.I. O } 20 \mathrm{C} \\
\text { Specific Gravity, g/CC } \\
\text { API Gravity }\end{array}$ & $\begin{array}{l}300-750 \\
1.5406 \\
0.9619 \\
15.6\end{array}$ \\
\hline $\begin{array}{l}\text { Distillation, }{ }^{0} \mathrm{~F} \\
\text { IBP } \\
10 \% \\
30 \% \\
50 \% \\
70 \% \\
90 \% \\
\text { EBP } \\
\text { VABP }\end{array}$ & $\begin{array}{l}362 \\
552 \\
631 \\
666 \\
697 \\
739 \\
781 \\
633\end{array}$ \\
\hline Watson $K, R$ & 10.62 \\
\hline $\begin{array}{l}\text { Elemental, Wt\% } \\
\text { C } \\
\mathrm{H} \\
\mathrm{N} \\
\mathrm{S} \\
\mathrm{O} \text { (By Diff.) }\end{array}$ & $\begin{array}{r}88.26 \\
10.97 \\
0.35 \\
0.05 \\
0.37\end{array}$ \\
\hline $\begin{array}{l}\text { F.I.A./R.I., I Vol\% } \\
\text { Saturates } \\
\text { Aromatics }\end{array}$ & $\begin{array}{r}6.3 \\
93.7\end{array}$ \\
\hline $\begin{array}{l}\text { WLHV, btu/Ib } \\
\text { VLHV, btu/ga1 }\end{array}$ & $\begin{array}{r}17339 \\
138931\end{array}$ \\
\hline
\end{tabular}




\subsection{Colorado Shale 0il Operations}

\subsubsection{Feedstock Preparation}

Western Research Institute (WRI) provided nineteen drums of Colorado shale oil produced at the Unocal plant in Parachute Creek. The drums were blanketed with nitrogen prior to and during shipment as well as during the storage time at Lummus. The drums were shipped from WRI's Laramie facility on November 7, 1988.

One drum of the raw Colorado shale oil feedstock was fractionated in the 4-in Batch Distillation unit in distillation campaign referred to as S01. Twenty-three successive distillate cuts were recovered as well as a nominal $650 \mathrm{~F}+(343 \mathrm{C}+)$ vac resid cut. The distillate cuts were consolidated into three composites: IBP-355F raw naphtha; 355-618F mid-distillate; and 618-650F heavy gas 0il. The mid-distillate cut was used as the feedstock for the virgin distillate hydrotreating campaigns the 650F+ bottoms was evaluated as a feedstock to LC-Fining and delayed coking. It was also fractionated in the Equilibrium Flash Vaporization (EFV) pilot plant to produce a vacuum gas oil (650-975F) feedstock for fixed-bed hydrocracking. The selective hydrocracking evaluations utilized the raw full-range shale oil in the initial LC-Fining hydrotreating campaign. The thus hydrotreated LC-Finate was then fractionated to recover the 575-975F VGO fractions for subsequent fixed-bed distillate hydrotreating evaluations. Table 4.3.1-1 summarizes the properties of the 355-618F mid-distillate feed to the hydrotreating test campaigns.

Based on the processing information and analyses developed during the COALITE campaigns, the test matrix for evaluation of the Colorado shale oil feedstock was readily downsized (relative to that of the COALITE feed) while still allowing the collection of sufficient data for engineering and economic analysis.

\subsubsection{Virgin Distillate Hydrotreating Campaigns}

Three virgin distillate hydrotreating campaigns were made with the 355-618F mid-distillate fraction to study the effects of catalyst type, single-stage vs two-stage, space velocity, reactor temperature and hydrogen partial pressure. A total of 37 material balance tests were made of durations extending from 2-hours to 15-hours. The specific objective of each campaign is summarized below:

Campaign \# Test \# (FB-)

I

(Table 4.3.2-1)

II $148-155$

(Table 4.3.2-2)

III 159-164

(Table 4.3.2-3)
Objective

Initial scans of the effects of space velocity, temperature and number of stages using NiW (K-550) and NiMo (K-599) hydrotreating catalysts

Initial scans of the dehydroisomerization of raw shale oil distillate using molybdena (Mo-1230) reforming catalyst

Initial scans of the two-stage dehydroisomerization/distillate hydrotreating using the Mo-1230/K-599 catalyst system 
TABLE 4.3.1-1

\section{ASSAY OF RAW COLORADO SHALE OIL MID-DISTILLATE FEEDSTOCK TO HYDROTREATING}

\begin{tabular}{|c|c|}
\hline TBP Boiling Range, ${ }^{\circ} \mathrm{F}$ & $355-618$ \\
\hline $\begin{array}{l}\text { R.I. O } 20^{\circ} \mathrm{C} \\
\text { Specific Gravity, g/cc } \\
\text { A.P.I. Gravity }\end{array}$ & $\begin{array}{l}1.4785 \\
0.8676 \\
31.6\end{array}$ \\
\hline $\begin{array}{l}\text { Distillation, }{ }^{0} \mathrm{~F} \\
\text { IBP } \\
10 \% \\
30 \% \\
50 \% \\
70 \% \\
90 \% \\
\text { EBP } \\
\text { VABP }\end{array}$ & $\begin{array}{l}348 \\
411 \\
467 \\
521 \\
577 \\
630 \\
787 \\
521\end{array}$ \\
\hline $\begin{array}{l}\text { Watson } \mathrm{K}, \mathrm{R} \\
\text { Elemental, } \mathrm{Wt} \%\end{array}$ & \\
\hline $\begin{array}{l}\mathrm{C} \\
H \\
N \\
S \\
O(\text { By Diff.) }\end{array}$ & $\begin{array}{r}84.32 \\
12.68 \\
1.13 \\
0.92 \\
0.95\end{array}$ \\
\hline $\begin{array}{l}\text { F.I.A./R.I., I Vol\% } \\
\text { Paraffins } \\
\text { Olefins } \\
\text { Naphthenes } \\
\text { Aromatics }\end{array}$ & $\begin{array}{l}\text { N.D. } \\
39.9 \\
32.9 \\
27.2\end{array}$ \\
\hline $\begin{array}{l}\text { WLHV, btu/lb. } \\
\text { VLHV, btu/gai. }\end{array}$ & $\begin{array}{r}17527 \\
126670\end{array}$ \\
\hline
\end{tabular}


CATALYST: X-5SO (IST STAGE)/K-S99 (2HO STAGE)

FILE 10: REPTSOL.VKI

\begin{tabular}{|c|c|c|c|c|c|c|c|c|}
\hline IEST $\mid(F B-)$ & 106 & 107 & 108 & 109 & 110 & 111 & 112 & 113 \\
\hline DATE (1989) & $04-11$ & $04-11 / 12$ & $04-12$ & $04-1 \hat{\imath}$ & $04-12$ & $04-13$ & $04-13$ & $04-13$ \\
\hline SIAPT IIKE & $17: 30$ & $23: 30$ & $05: 30$ & $11: 30$ & $18: 30$ & $00: 30$ & $06: 30$ & $13: 00$ \\
\hline END TIHE & $19: 30$ & $01: 30$ & 01:30 & $13: 30$ & $20: 30$ & $02: 30$ & $08: 30$ & 15:00 \\
\hline FEECSTOCA & $A$ & $A$ & $A$ & $A$ & $A$ & A & $A$ & $A$ \\
\hline FEED RAIE, cC/hr & 115 & 119 & 120 & 115 & 119 & 120 & 119 & 170 \\
\hline OPERAiING PRESSLRE, psic & 2000 & 2000 & 2000 & 2000 & 2000 & 2000 & 2000 & 2000 \\
\hline H. PARTISL PRESSOURE, DSIOQ & 2000 & 2000 & 2000 & 2000 & 2000 & 2000 & 2000 & 2000 \\
\hline$K_{L}$ IREST RAIE, scf/bb] & 1006 & 1000 & 7000 & 1000 & 1000 & 1000 & 7000 & 1000 \\
\hline \multicolumn{9}{|l|}{ REACIOR I COHDITIONS } \\
\hline LHSV, ce/hrice cat. & 0.70 & 0.72 & 0.73 & 0.70 & 0.12 & 0.73 & 0.12 & 1.03 \\
\hline INIE: BEE TEHF. . & 395 & 396 & 396 & 400 & 398 & 397 & 399 & 401 \\
\hline UPFEK HIO BEO IEHF., F & 395 & 396 & 395 & 400 & 398 & 397 & 399 & 101 \\
\hline LOHER BEC TERO.. F & 395 & 396 & 396 & 400 & 398 & 397 & 399 & 401 \\
\hline AVERGSE BEL TEMH.. F & 39 s & 390 & $390^{\circ}$ & 400 & 398 & $39 ?$ & 399 & 401 \\
\hline SARj Bhin IENF.. F & $39:$ & $39 j$ & 393 & 398 & 390 & 394 & 395 & 399 \\
\hline \multicolumn{9}{|l|}{ REGCTOR a CONDITIUHS } \\
\hline 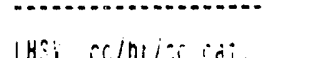 & & & & 0.70 & 0.72 & 0.73 & 0.72 & $1.0 ?$ \\
\hline & $\begin{array}{l}6.14 \\
596\end{array}$ & $\begin{array}{r}0.16 \\
61 ?\end{array}$ & $\begin{array}{r}0.10 \\
699\end{array}$ & $14 ?$ & $\begin{array}{l}.16 \\
64 ?\end{array}$ & 741 & 744 & $\begin{array}{r}1.0 \mathrm{i} \\
74 \mathrm{i}\end{array}$ \\
\hline UPGES HIO BED iEH: .. F & 389 & 633 & 679 & 104 & 732 & 102 & 697 & 120 \\
\hline LONEE RED IENE..' & $58 ?$ & 633 & 676 & 699 & $63 !$ & 700 & 692 & 707 \\
\hline AVERAGE EEC TERE.. F & $59 i$ & 638 & 685 & 115 & 670 & 714 & 111 & 123 \\
\hline SAMŨ BAIH IEHF... F & 584 & 624 & $67 i$ & 696 & 624 & 696 & 690 & 698 \\
\hline SEYERIIY STAGE ! & 0.0325 & 0.0321 & 0.0316 & 0.0366 & - & - & - & - \\
\hline SEVEPITY STAAGE & $1.505 ?$ & 3.0109 & 5.7143 & 8.8707 & $4.719 ?$ & 8.4290 & 8.1446 & 6.6131 \\
\hline OVERA:L SEYEK:iY & 1.5377 & 3.0431 & 5.7459 & 8.9073 & 4.7196 & 8.4290 & 8.1446 & 6.6131 \\
\hline
\end{tabular}

FEEDSIOCK TYPE:

A: 3j5-618 F VIRGIN COLORRDO SHALE OIL OISTILLATE. 
TABLE $4 \cdot 3 \cdot 2-1$ (contd)

..............

SUHAGRY OF OPERAIIHG CONOIIIONS FOR FIXEO-BED COLORADO SHALE OIL

HYOROTREATING IESTS

CATALYST: $K-550$ (1ST STAGE)/K-399 (2ND STAGE)

FILE 1D: REPTSOL.UKI

\begin{tabular}{|c|c|c|c|c|c|c|c|c|}
\hline \multirow[b]{2}{*}{ IEST $\mid$ (FB-) } & \multicolumn{5}{|c|}{ a } & \multicolumn{3}{|c|}{ FILE IU: REPISUI. OKI } \\
\hline & 114 & 115 & 116 & 117 & 118 & 119 & 120 & 121 \\
\hline (n).................. & n......... & (n) & $\ldots+\ldots$ & (n........... & (n) & (n) & (n) & $\ldots+\ldots$ \\
\hline DATE (1989) & $04-13$ & $04-14$ & $04-14$ & $04-14$ & $04-11$ & $04-17$ & $04-18$ & $04-18$ \\
\hline SIART IIME & $22: 00$ & $04: 00$ & $10: 00$ & $16: 00$ & $06: 30$ & $12: 30$ & $19: 30$ & $01: 30$ \\
\hline ENO TIME & $21: 00$ & $06: 00$ & $12: 00$ & $18: 00$ & $08: 30$ & $14: 30$ & $21: 30$ & $03: 30$ \\
\hline FEEDôTOCH. & $A$ & $A$ & $A$ & A & $A$ & A & A & A \\
\hline FEEO RAIE, CC/hr & 119 & 115 & 115 & 115 & 118 & 115 & 230 & 116 \\
\hline OPERATING PRESSURE, DSIG & 2000 & 2000 & 2000 & 2000 & 2000 & 2000 & 2000 & 2000 \\
\hline H: PARTIAL PRESSSURE, DSIO & 2000 & 2000 & 2000 & 2000 & 2000 & 2000 & 2000 & 2000 \\
\hline H? IREAT RATE, $\left.s c^{f} / b t\right]$ & 7000 & 7000 & 7000 & 1000 & 1000 & 1000 & 7000 & 1000 \\
\hline
\end{tabular}

REACIOR I CONDIIIOHS

\begin{tabular}{|c|c|c|c|c|c|c|c|c|}
\hline LHSY. CC/hr/CC cat. & 0.72 & 0.70 & 0.70 & 0.70 & 0.72 & 0.70 & 1.39 & 0.70 \\
\hline INLI! GEC IEKF .. F & 599 & 631 & 100 & 138 & 650 & 739 & 124 & 740 \\
\hline UPFEK HIO BED IERF., F & 580 & 640 & 688 & 100 & 640 & 105 & 741 & 108 \\
\hline LOHEP BEG TEMP.. ? & 578 & $6: 0$ & $6 ? i$ & $69 \mathrm{i}$ & 627 & 695 & 70? & $60:$ \\
\hline AVERASEE BEO IEMP., F & 588 & $63:$ & $68 t$ & 110 & 639 & 713 & 724 & 714 \\
\hline SAN: BG!S IENS., F & 574 & 618 & 659 & 688 & 617 & 689 & 670 & $69 i^{2}$ \\
\hline
\end{tabular}

REACIOR: C CONDITIONS

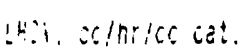

INLE: BEL TEMT... F

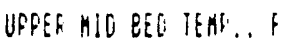

LOHEP PED TEHS., F

AVERAGS GEO IEHF., F

SANG BAIK IEMF.. F

SEYERITY STAGE I

SEVERITY STAGE ?

OVERA:L SEYERITY 
IABLE $4 \cdot 3 \cdot 2-1$ (concld)

SUHAARY OF OPERATING CONDIIIONS FOR FIXEO-BED COLORADO SHALE OIL

HYOROIREATING IESTS

CAIALYST: K-5SO (1SI SIAGE)/K-599 (2NO SIAGE)

FILE 1D: REPTSOL.VKL

IESI $\mid(F B-)$

DAIE (1989)

START IIHE

END IIHE

$\begin{array}{cccccccc}122 & 123 & 124 & 123 & 128 & 129 & 130 & \\ 04-18 & 04-18 & 04-18 & 04-19 & 04-19 / 20 & 04-20 / 21 & 04-21 & \\ 07: 30 & 13: 30 & 19: 30 & 01: 30 & 18: 30 & 12: 30 & 07: 30 & \\ 09: 30 & 15: 30 & 21: 30 & 03: 30 & 09: 30 & 03: 30 & 21: 00 & \end{array}$

FEEOSTOCA

PEEO RAIE, CC/hi

OPERATINE PKESSURE. DSIO

MI PART]AL PRESSURE, DSIQ

$\because \because$ IREAT RAIE, SCFIODDI

$09: 30$

$15: 30$

$03: 30$

$09: 30$

$03: 30$

21:00

$\begin{array}{rrrrrrr}A & A & A & A & A & A & A \\ 118 & 116 & 117 & 11 ? & 116 & 117 & 115 \\ 2000 & 2000 & 2000 & 2000 & 2000 & 2000 & 2000 \\ 2000 & 2000 & 2000 & 2000 & 2000 & 2000 & 2000 \\ 7000 & 1000 & 1000 & 7000 & 1000 & 7000 & 1000\end{array}$

FEACIOE ! CONOLIIONE

\begin{tabular}{|c|c|c|c|c|c|c|c|}
\hline LHồ, Co/hr/CC Cat. & $0.7 \hat{\imath}$ & 0.70 & $0.7 !$ & 0.71 & 0.70 & 0.11 & 0.70 \\
\hline INLE: BED TENE. , & 599 & 699 & 647 & 606 & 650 & 139 & 100 \\
\hline UPPEK MIO BEO IENF., F & 589 & 689 & 637 & 590 & 646 & 709 & 691 \\
\hline LOHE: EED IENE. . F & 584 & $6 ! 9$ & 625 & $58 \div$ & 633 & 693 & 673 \\
\hline AYERAGE BEC lEHE., ' & S०! & $68 t$ & 635 & 590 & 643 & 714 & 688 \\
\hline SAN: GHIt IENE... 5 & S?S & $666^{\circ}$ & 617 & 588 & 633 & 689 & 664 \\
\hline \multicolumn{8}{|l|}{ REAC'OF ? CONOIIIOHS } \\
\hline . & & & & & & & \\
\hline 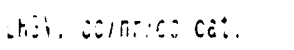 & $0.7 \%$ & 0.76 & 0.71 & $0.7 !$ & 0.71 & 0.11 & \\
\hline IN:Ei BEP IEAF. . $:$ & 760 & 691 & 643 & 590 & $64 ?$ & $73 t$ & \\
\hline UPF & 728 & 695 & 645 & 600 & 656 & 131 & \\
\hline LONEF BEO IEATE.. F & $19 ?$ & 698 & 647 & $60 j$ & 653 & 139 & \\
\hline GYERAGE BES TEAE. I & 73? & 695 & 045 & 600 & 650 & 137 & \\
\hline SANE EifT. TERS., F & 123 & 695 & 645 & 600 & 650 & $74 ?$ & \\
\hline SEVERITY STAGE I & 1.4669 & 6.0181 & 2.9741 & 1.4638 & 3.3056 & 8.5718 & 6.2352 \\
\hline SEVERITY STAGE? & 10.6615 & 6.7540 & 3.3735 & 1.7238 & 3.6559 & 11.5317 & - \\
\hline OYERR:! SEYEŔRIT & 12.1283 & 12.1761 & 6.3476 & 3.1876 & 6.9615 & 20.1036 & $6.235 ?$ \\
\hline
\end{tabular}

FEEDSTOCK IYPE:

A: 355-6I8 F VIRGIN COLORACI SHR!E OIL OISTILLAIS. 
SUMMARY OF OPERAIING CONDIIIOHS FOR FIXEO-BED COLORADO SHALE OIL

HYOROTREAIING IESIS

CATALYSI: K-S99 (ISI STAGE)/MO-1230 (2NO STAGE)

FILE 10: REPTSOZ.HK!

\begin{tabular}{|c|c|c|c|c|c|c|c|c|}
\hline IESI / FB- & 148 & 149 & 150 & 151 & 152 & 153 & 154 & 155 \\
\hline . & -.......... & 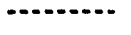 & . & . & nas........ & . & -....... & $\cdots \cdots$ \\
\hline DAIE (1989) & $05-24$ & $05-25$ & $05-25$ & $05-25$ & $05-26$ & $05-26$ & $05-26$ & $05-26$ \\
\hline START TIKE & $16: 00$ & $00: 00$ & 08:00 & $16: 00$ & $00: 00$ & $08: 00$ & $16: 30$ & $20: 00$ \\
\hline ENO TIKE & $20: 00$ & $04: 00$ & $12: 00$ & $20: 00$ & $04 ; 00$ & $12: 00$ & $11: 30$ & $21: 00$ \\
\hline EDSTOCK & $A$ & $A$ & $A$ & A & $A$ & A & $A$ & $A$ \\
\hline FEED RATE, CC/hr & $8 ?$ & 85 & 83 & 83 & 332 & 333 & 195 & 83 \\
\hline OPERA:INÓ PRESSURE, DSIO & 500 & 500 & 500 & 500 & 500 & 500 & 500 & 500 \\
\hline H? PRRTIA! PRESSURE, DSIC & SOO & 500 & 500 & 500 & 500 & 500 & 500 & 500 \\
\hline H2 IREAT RATE, sCF/DDI & 9000 & 9000 & 9000 & 9000 & 9000 & 9000 & 9000 & 9000 \\
\hline \multirow{2}{*}{\multicolumn{9}{|c|}{ REACTOS ! COKOIIIOHS }} \\
\hline (n) & & & & & & & & \\
\hline HSY, cc/hr/cc cat. & 0.50 & 0.52 & 0.50 & 0.50 & 2.01 & 2.02 & 3.00 & 0.50 \\
\hline INLET GEO TENP., ? & 304 & 306 & 295 & 303 & 293 & 296 & 295 & 298 \\
\hline UPPEF KIO BED IEHO., F & 304 & 306 & 294 & 302 & 294 & 299 & 292 & 290 \\
\hline LOWEF BED IEMF.. F & 305 & 308 & 295 & 304 & 296 & 301 & 300 & 296 \\
\hline AHERAEI BEG IENG. F & 304 & 307 & 295 & 303 & 294 & 299 & 296 & 293 \\
\hline SANG BAIK IEME., ' & $30 ?$ & 307 & 295 & 303 & 298 & 305 & 315 & 284 \\
\hline \multirow{2}{*}{\multicolumn{9}{|c|}{ 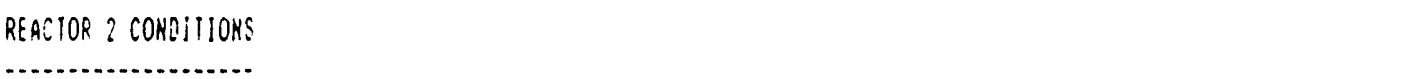 }} \\
\hline , & & & & & & & & \\
\hline LHSL, Zin:ににC2t. & 0.56 & $0.3 ?$ & 0.50 & 0.50 & 2.02 & $2.0 ?$ & 3.00 & 0.50 \\
\hline INLË: BEE TENS., F & $79 i$ & 840 & 891 & 924 & 854 & 194 & 817 & 19: \\
\hline UPPES MIO BED TEMF., F & 778 & 833 & 886 & 922 & 911 & 831 & 880 & $79 !$ \\
\hline LOWEF BES TEKP. . : & 174 & $8 i 7$ & $88 ?$ & 915 & 924 & $84 !$ & 911 & 190 \\
\hline AVERASG: BEC IEMH.. ; & $78 !$ & 833 & 886 & 920 & 899 & 822 & $86^{\circ}$ & 79: \\
\hline SARL BATH IENF.. F & 176 & 832 & 883 & 917 & 916 & 835 & 914 & $18 i$ \\
\hline SEYERITY SIAGE I & 0.0010 & 0.0011 & 0.0007 & 0.0010 & 0.0002 & 0.0002 & 0.0001 & 0.0006 \\
\hline SEYERI'Y SIAGE ' & 6.8760 & 11.8248 & 20.6993 & 28.5693 & 5.8459 & 2.6760 & $2.936 !$ & 7.6097 \\
\hline OVER̈ALL SEYERITi & 6.8770 & 11.8259 & 20.7001 & 28.5703 & 5.8461 & 2.6762 & 2.9363 & 7.6104 \\
\hline
\end{tabular}

FEEOSTOCA TYPE:

A: 3Sj-6IS F VIRGIN COLORADO SHAIE OIL OISTILLATE. 
TABLE $4 \cdot 3 \cdot 2-3$

SUHMARY OF OPERAIING CONDITIONS FOR FIXEO-BED COLORADO SHALE OIL

HYOROTREAIING IESTS

CATALYSI: K-S99 (IST STAGE)/MO-1230 (2NO STAGE)

FILE ID: REPISO2. VKI

\begin{tabular}{|c|c|c|c|c|c|c|}
\hline IEST $\mid$ (FB-) & 159 & 160 & 161 & 162 & 163 & 164 \\
\hline (n)................. & -.......... & (............ & (............. & (........... & (n......... & (n)............. \\
\hline DATE (1989) & $06-05 / 06$ & $06-06 / 07$ & $06-08$ & $06-08$ & $06-08$ & $06-09$ \\
\hline SIART IINE & $16: 00$ & $18: 00$ & $00: 00$ & 08:00 & $16: 00$ & $00: 00$ \\
\hline END IIME & $16: 00$ & 18:00 & $06: 00$ & $14: 15$ & $22: 00$ & $06: 00$ \\
\hline FEEDSTOCY & $A$ & $A$ & $B$ & 8 & $c$ & C \\
\hline FEED RAIE, CC/hr & 87 & 84 & 80 & 78 & 82 & 82 \\
\hline OPERATING PRESSURE, DSIQ & 500 & 500 & 2000 & 2000 & 2000 & 2000 \\
\hline H? PARIIAL PRESSURE, DSIQ & 500 & 500 & 2000 & 2000 & 2000 & 2000 \\
\hline HL TREAI RAIE, sct/bb] & 9000 & 9000 & 1000 & 1000 & 7000 & 7000 \\
\hline \multicolumn{7}{|l|}{ REACTOP ! COHCITIOHS } \\
\hline \multicolumn{7}{|l|}{ (n) } \\
\hline Lhsir, cc/hr/cc cat. & 0.53 & 0.51 & 0.48 & $0.4 ?$ & 0.50 & 0.50 \\
\hline INLE: BEE TEHF., F & 300 & 306 & $\$ 99$ & 694 & 699 & 600 \\
\hline UPSEE HIO BEO TEKP.. F & 300 & 300 & 599 & 697 & 698 & 600 \\
\hline DOHEF BEO TEMF.. : & 300 & 300 & 600 & 700 & $10 \%$ & $60 ?$ \\
\hline AVERAUE BE! IERI.. : & 300 & 306 & 509 & 697 & 100 & $60 j$ \\
\hline SANE BGTH IENE. . F & $30 ?$ & $30 i$ & $60 \%$ & 698 & 699 & 604 \\
\hline \multicolumn{7}{|l|}{ REACIOR I CONOIIIONS } \\
\hline . & & & & & & \\
\hline iHs, . $2: 1 n *: \Omega$ cat. & 0.53 & $0.5 i$ & & & & \\
\hline IKLS: BEG IEHE. . ; & 840 & 796 & & & & \\
\hline UPPEF HIO BEO TEMD.. F & $83 ?$ & $78 \hat{8}$ & & & & \\
\hline LOHEK BEO IENR. . ! & 836 & $18:$ & & & & \\
\hline AVERAGE BEO TEHF.. F & 836 & $18 ?$ & & & & \\
\hline SAKO BKIT IENF., F & $83 ?$ & 783 & & & & \\
\hline SEVERITY SIAGE 1 & 0.0008 & 0.0008 & 2.1818 & 10.3582 & 10.2039 & 2.4724 \\
\hline SEHERIIY SIAGE? & 11.8398 & 1.1870 & & & & \\
\hline OVERALL SEYER!iY & 11.8406 & 7.1878 & 2.4818 & 10.3582 & 10.2039 & 2.4724 \\
\hline
\end{tabular}

FEEDSTOCK TYPE:

A: 355-618 F VIRGIN COLORAOO SHALE OI! OISTILLAIE.

B: LIQUIO PRODUCT FROA FB-159.

C: LIOUIO PRODUC? FROH FE-160. 


\subsubsection{Virgin Atmospheric Resid Cracking Campaigns}

Like the COALITE, there is also a considerable yield of atmospheric resid in the raw Colorado shale oil. Therefore, it is also necessary to crack the heavier components to the mid-distillate range comprising the desired HEDF turbine fuel products. In a manner similar to that when processing the COALITE, three cracking methods were considered: 1) Resid hydrocracking using the LC-Fining process; 2) Delayed coking; and 3) VGO fixed-bed hydrocracking. The former two are discussed in the next two sections while the latter is discussed in Section 4.3.5.

\subsubsection{LC-Fining (Residue Hydrocracking)}

Two LC-Fining ${ }^{t m}$ campaigns were made with atmospheric residues from the Colorado shale oil feedstock in the stirred autoclave simulator of the LC-Fining process. Campaign I included five material balance tests made with a virgin $650 \mathrm{~F}+$ atmospheric resid fraction which evaluated the effect of reactor temperature. A NiMo catalyst (Shell 324M) that had previously been aged on coal-oil service was used in the tests. Table 4.3.3.1-1 summarizes the operating conditions evaluated.

Campaign II also included five material balance tests made with a first-pass hydrotreated $575 \mathrm{~F}+$ fractiop recovered by distillation from the liquids processed in LC-Fining Campaign I. This allowed a comparison of the hydrocracking processabilities of virgin and first-pass hydrotreated residua. Table 4.3.3.1-2 summarizes the operating conditions evaluated.

\subsubsection{Delayed Coking}

Two Delayed Coking tests were made in the Continuous Bench Coking unit with the virgin $650 \mathrm{Ft}$ atmospheric resid to study the effects of coke drum pressure at constant coke drum temperature. Table 4.3.3.2-1 presents the summary of the feedstock properties. The detailed operating conditions for the two tests are presented in Table 4.3.3.2-2.

\subsubsection{Cracked Distillate Hydrotreating Campaigns}

The above two cracking operations, namely, LC-Fining tm and Delayed Coking, are primarily conversion processes to produce HEDF precursor materials that boil within the HEDF boiling range. They therefore do not result in the production of finished HEDF products and a post-cracking hydrogenation operation is required for upgrading the cracked precursor materials. In a true commercial process, a fractionator would be installed between the cracking unit(s) with the cracked distillate fed continuously to the distillate hydrotreater and the heavier unconverted residuum being recycled back to the cracking unit.

In this Task 3 screening program with the Colorado shale oil feedstock, the bench-scale cracking and hydrotreating units were not integrated and thus only first-pass crackates, either, delayed coker 
i $\vdots \vdots \vdots 1, \vdots \vdots . \cdot$.

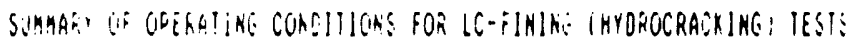

COLGRAQI: SHGLI OIL UISIILLATI

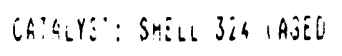

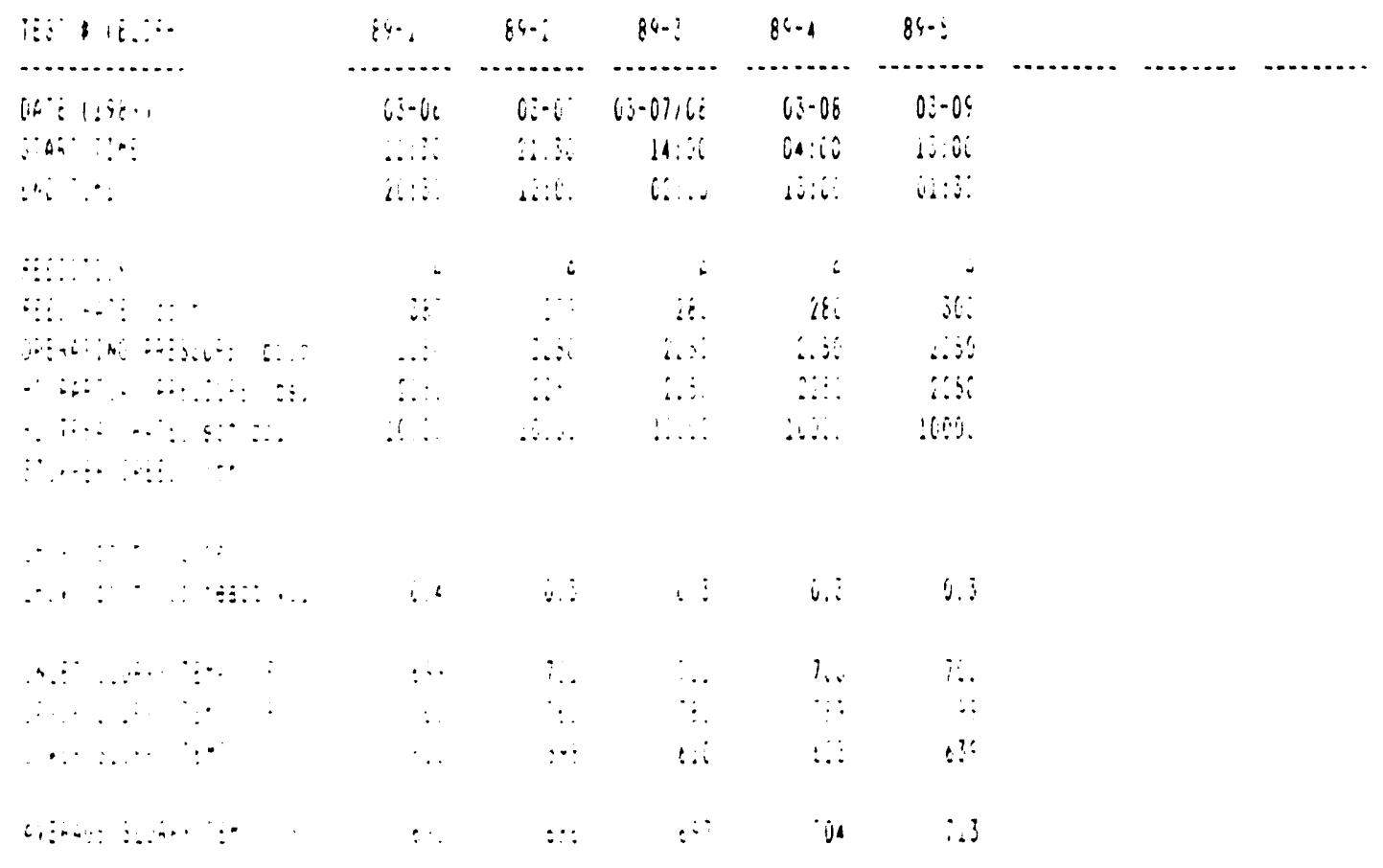


$45 . \therefore \cdot 3.2 \cdot:$

(...................

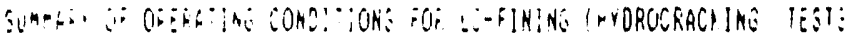

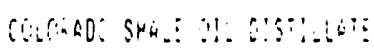

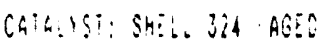

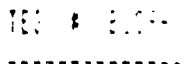

$\therefore$ It $\quad$ is li $\quad$ is $\quad$ :

$\cdots \quad \cdots$

inis: ir:

$\vdots \because$

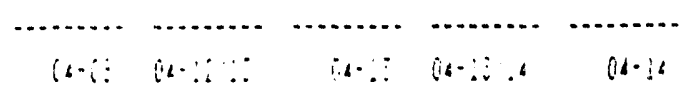

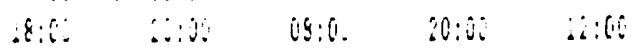

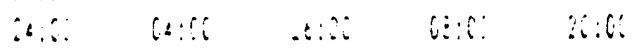

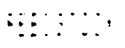

$\therefore \therefore:$

$\therefore \therefore, \therefore \therefore \quad \therefore$

$\because \ldots \quad \cdots, \cdots$

$\begin{array}{cc}\vdots & \vdots \\ \cdots & \vdots\end{array}$

$\vdots$
$\vdots$
$\vdots \vdots$
$\cdots \vdots$
$\cdots$
$\cdots$

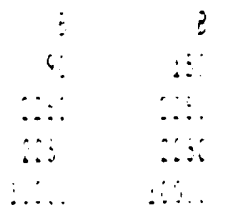

$\therefore$

$\begin{array}{ccccc}\therefore & \ddots & \ddots & \ddots & \therefore \\ \therefore & \vdots & \vdots & \ddots & \because \therefore \\ \therefore & \ddots & \ddots & \therefore & \vdots \\ \because & \ddots & \ddots & \ddots & \ddots\end{array}$

$\because \therefore i \cdots \cdot \cdots$

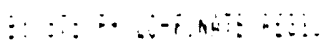

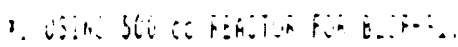

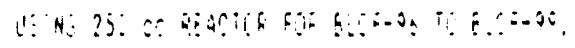


TABLE 4.3.3.2-1

ASSAY OF DELAYED COKING COLORADO SHALE OIL - DERIVED FEEDSTOCK

\begin{tabular}{lc} 
Feedstock Type & Virgin \\
\hline Nominal IBP, ${ }^{\circ} \mathrm{F}$ & 650 \\
Specific Gravity $06{ }^{\circ} \mathrm{F}$ & 0.9680 \\
API Gravity & 14.7 \\
& \\
ASTM Distillation, ${ }^{\circ} \mathrm{F}$ & 655 \\
$5 \%$ Distilled & 763 \\
$10 \%$ Distilled & 824 \\
$30 \%$ Distilled & 889 \\
$50 \%$ Distilled & 975 \\
$70 \%$ Distilled & \\
& \\
Elementals, Wt\% & 84.41 \\
C & 11.05 \\
$H$ & 2.69 \\
$N$ & 0.75 \\
S & 1.10 \\
O Ash (By Diff.) &
\end{tabular}


TABLE 4.3.3.2-2

\section{SUMMARY OF OPERATING CONDITIONS}

FOR DELAYED COKING OF COLORADO SHALE OIL

Test No. (CBC-)

Feed Source

Coke Drum Temp., ${ }^{0} \mathrm{~F}$

Coke Drum Pressure, psig

Coke Drum Preheater Temp., ${ }^{0} \mathrm{~F}$

Feed Rate, 1b/hr

Run Length, hr.

Recycle/Fresh Feed Ratio

$\begin{array}{cc}65 & 66 \\ \cdots \text { Virgin } & 650 \mathrm{~F}+\text { Resid } \ldots \\ 880 & \\ 100 & 880 \\ 700 & 25 \\ 0.85 & 600 \\ 24 & 0.65 \\ 0 . \hat{c} 0 & 24 \\ & 0.75\end{array}$


distillates or hydrocrackates (LC-Finates), were evaluated. Four distillate hydrotreating runs were made with delayed coker distillates and five distillate hydrotreating runs were made with LC-Finate (hydrocracked) distillates.

\subsubsection{Hydrotreating of LC-Finate Distillates}

One fixed-bed hydrotreating campaign was made to evaluate the effects of catalyst type, two-stage vs single-stage, feedstock boiling range, space velocity and reaction temperature. Table 4.3.4.1-1 presents the analyses of the LC-Finate feedstocks to distillate hydrotreating. The campaign included three fixed-bed tests (Table 4.3.4.1-2) made to evaluate the effect of reactor temperature using a $300-575 \mathrm{~F}$ HEDF precursor-boiling stream.

\subsubsection{Hydrotreating of Coker Distillates}

Table 4.3.4.2-1 presents the feedstock assay for the coker distillate used in the four fixed-bed hydrotreating tests. The summary of the operating conditions for these tests is presented in Table 4.3.4.2-2. The objective of the hydrotreating tests was to evaluate the effects of space velocity, reactor temperature, and two-stage severity.

\subsubsection{Two-Step Selective Hydrocracking Campaigns}

The two-step selective hydrocracking (TSSH) approach used for the COALITE was also carried out for the Colorado shale oil feedstock. Three feedstocks were considered for the VGO fixed-bed hydrocracking step: 1) a virgin 650-975F VGO; 2) LC-Finate hydrocracked VGO; and 3) LC-Finate hydrocracked and hydrodenitrogenated VGO. The flowscheme with test number denotation for the latter two campaigns is presented in Figure 4.3.5-1. The feedstock assays for all three test campaigns are presented in Table 4.3.5-1. Eight fixed-bed hydrocracking tests were made with the virgin VGO (Table 4.3.5-2) to study the effects of space velocity and reactor temperature using the proprietary Amoco hydrocracking catalyst. Four tests were made with the LC-Finate hydrocrackates to study the effect of space velocity at constant temperature and hydrogen partial pressure. Four tests were made with hydrodenitrogenated LC-Finate VGO to study the effects of space velocity and reactor temperature. Table 4.3.5-3 presents the summary of the operating conditions for both of the latter fixed-bed hydrocracking campaigns. The summary of the operating conditions for the LC-Finate VGO hydrodenitrogenation campaigns is presented in Table 4.3.5-4.

The thus hydrocracked denitrogenated LC-Finate VGO product containing the 300-575F HEDF precursors was subjected to a final hydrogenation step to saturate aromatics to the low levels required for achieving high energy densities. A post-hydrogenation fractionation step was used to recover the final HEDF product meeting the front-end flash point and back-end freeze point specifications. Two distillate hydrotreating campaigns, made at two different space velocities and 
TABLE 4.3.4.1-1

\section{ASSAY OF COLORADO SHALE OIL}

\section{LC-FINATE MID-DISTILLATE TO HYDROTREATING}

$\begin{array}{lc}\text { T.B.P. Bojling Range, }{ }^{0} \mathrm{~F} & 300-575 \\ \text { R.I. } 20{ }^{\circ} \mathrm{C} & 1.4715 \\ \text { Specific Gravity, g/CC } & 0.8504 \\ \text { API Gravity } & 34.9 \\ & \\ \text { Distillation, }{ }^{0} \mathrm{~F} & \\ \text { IBP } & 272 \\ 10 \% & 364 \\ 30 \% & 425 \\ 50 \% & 467 \\ 70 \% & 507 \\ 90 \% & 570 \\ \text { EBP } & 767 \\ \text { VABP } & 467 \\ & \\ \text { Watson K, R } & 11.44 \\ \text { Elemental, Wt\% } & \\ \text { C } & 84.30 \\ \text { H } & 13.11 \\ \text { N } & 1.14 \\ \text { S (By Diff.) } & 0.70 \\ \text { O (By } & 0.75 \\ \text { F.I.A./R.I., I Vol\% } & \\ \text { Paraffins } & N . D \\ \text { Olefins } & 17.8 \\ \text { Naphthenes } & 53.9 \\ \text { Aromatics } & 28.3 \\ & \end{array}$


IABLE $4.3 \cdot 4 \cdot 1-2$

SUHAARY OF OPERATING CONDIIIOHS FOR FIXED-BEO HYOROTREATING IESTS OF

HYOROPROCESSEO COLORADO SHALE OIL DISTILLATE

CATALYST: 1 -599 (2NO STAGE)

FILE 10: REPISLCL. NKI

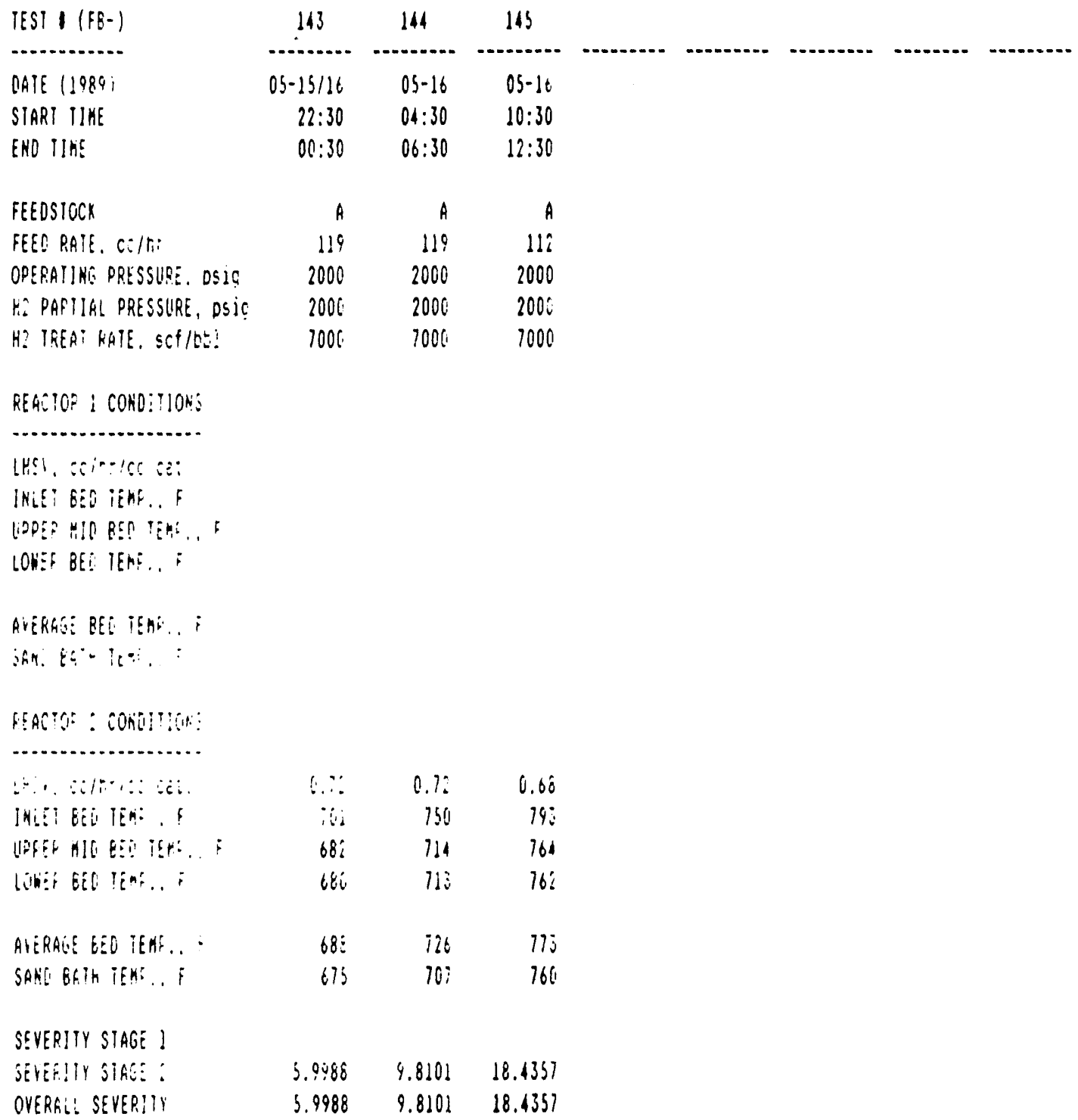

iegionet IMt:

Ä: 3GII-SIS F HYOROPROCESSEO COLORAOC SHRIE OIL DISTILLATE. 
TABLE $4.3 \cdot 4 \cdot 2-1$

ASSAY OF COLORADO SHALE OIL (CSO) DELAYED

COKER MID-DISILLATE FEED TO HYDROTREATING

Feed Source

R.I. $20^{\circ} \mathrm{C}$

Specific Gravity, $\mathrm{g} / \mathrm{cc}$

A.P.I. Gravity

Simulated Distillation, ${ }^{\circ} \mathrm{F}$ IBP

$10 \%$

$30 \%$

$50 \%$

$70 \%$

$90 \%$

EBP

VABP

Watson $K, R$

Elemental, Wt\%

C

H

N

$S$

0 (By Diff.)
Delayed Coking of $650^{\circ} \mathrm{F}+\mathrm{CSO}$ resid at 62.5 psig average coke drum pressure
1.4780
0.8591

33.2

245

324

383

427

478

540

733

447

11.26

84.76

12.21

1.54

0.75

0.74

F.I.A./R.I., Vol\% Paraffins

olefins

Naphthenes

Aromatics
N.D.

40.4

26.0

33.6 
TABLE $4 \cdot 3 \cdot 4 \cdot 2-2$

SUHHARY OF OPERAIING CONOIIIONS FOR FIXEO-BED HYDROTREATING IESIS OF

THERHALLY PROCESSED COLORADO SHALE OIL DISTILLATE

CATALYST: K-55O (IST STAGE) K-S99 (2HO STAGE)

FILE ID: REPTSC1.VKI

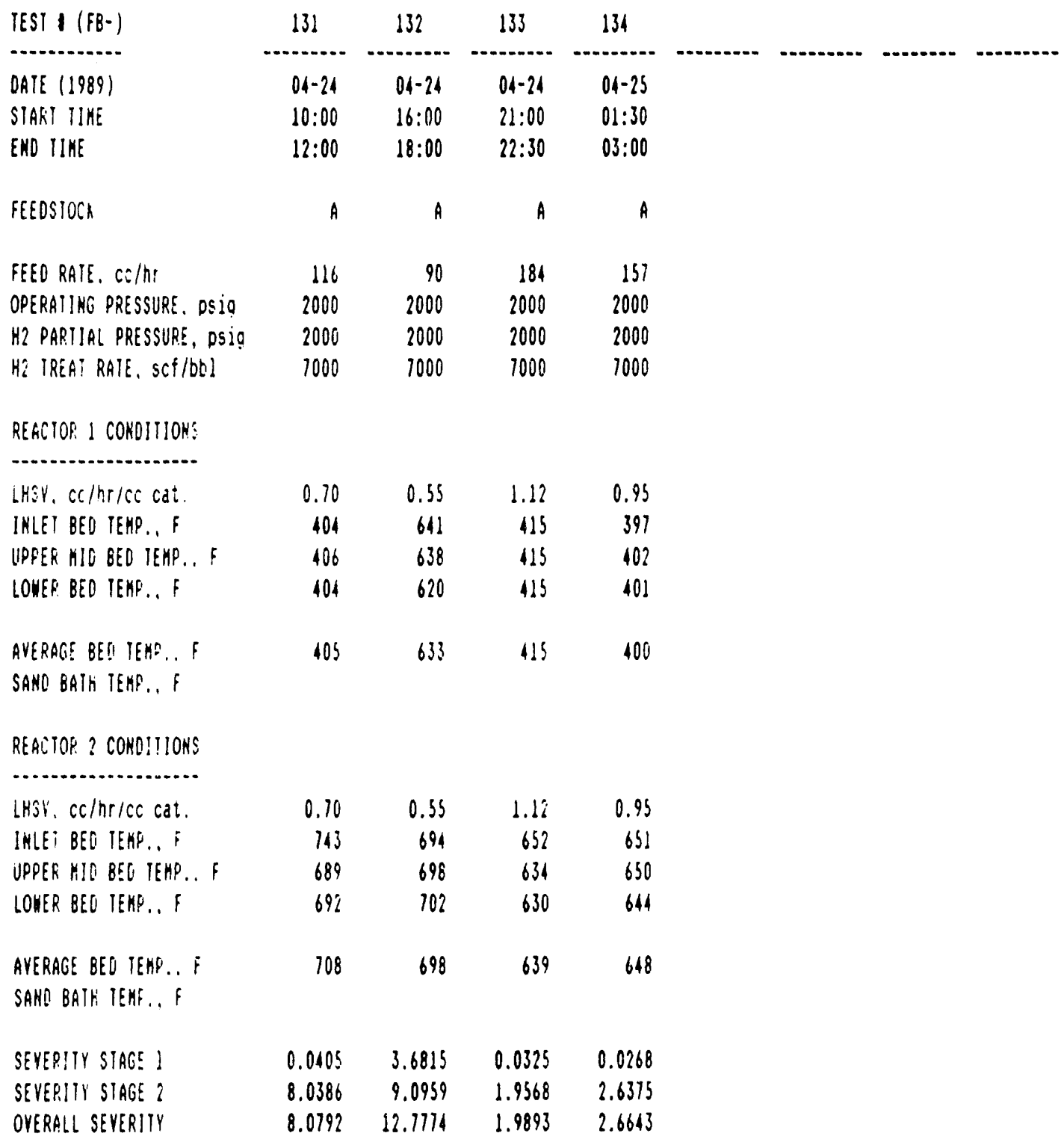

FEEDSTOCK IYPE:

A:THERHALLY PROCESSEO COLORADO SHALE OIL OISTILLATE, 300-575 F. 
FIGURE $4 \cdot 3 \cdot 5-1$

\section{PROCESSING APPROCHES \\ TO COLORADO SHALE OIL HEDF}

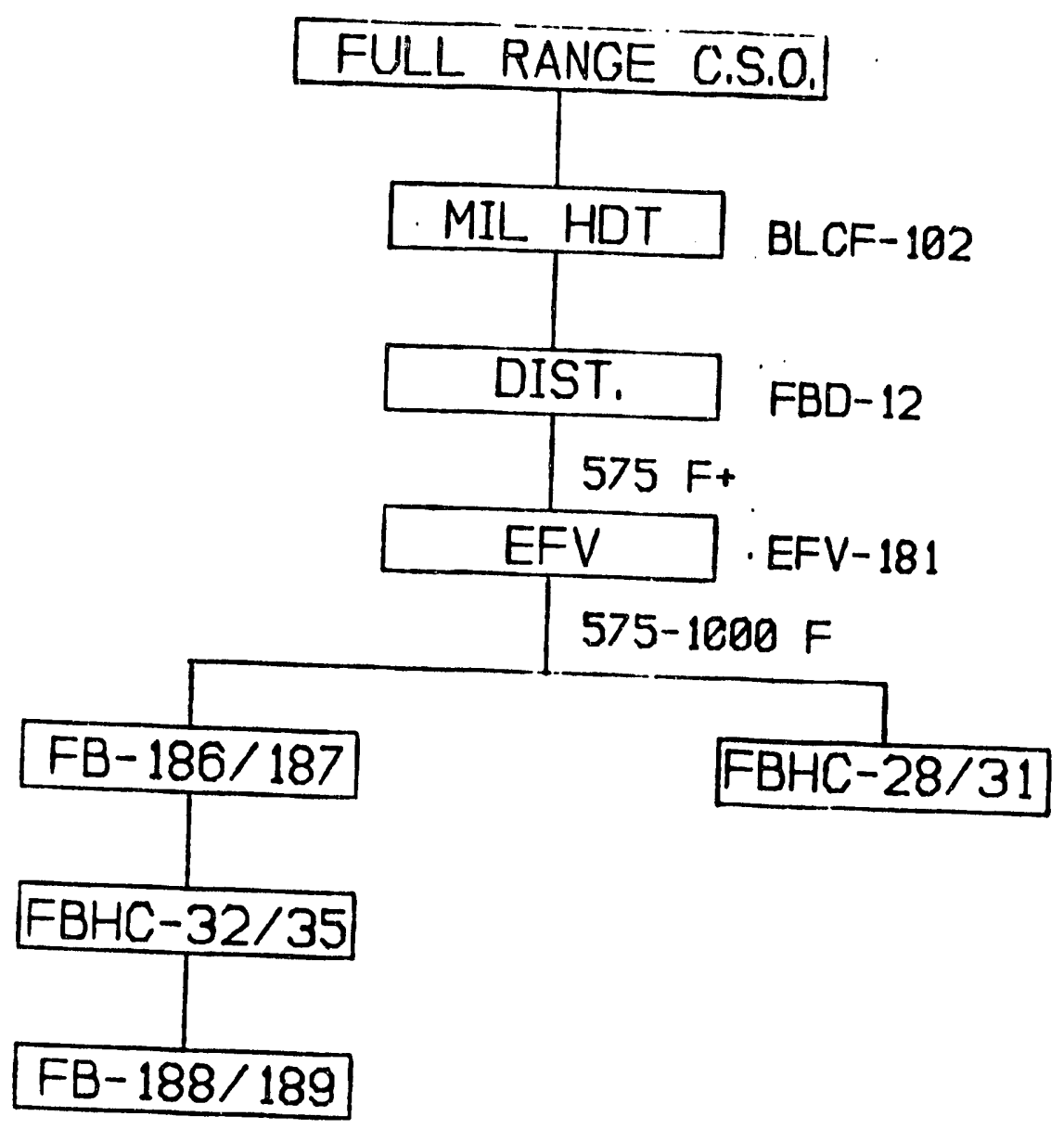


TABLE 4.3.5-1

\section{ASSAYS OF COLORADO SHALE OIL VGO FEEDS}

TO FIXED-BED HYDROCRACKING

\begin{tabular}{|c|c|c|}
\hline Feed Type & Virgin & $\begin{array}{c}\text { Mildly Hydrocracked } \\
\text { (LC-Finates) }\end{array}$ \\
\hline $\begin{array}{l}\text { Specific Gravity, g/cc } \\
\text { A.P.I. Gravity }\end{array}$ & $\begin{array}{l}0.9482 \\
17.7\end{array}$ & $\begin{array}{l}0.9030 \\
25.2\end{array}$ \\
\hline $\begin{array}{l}\text { Distillation, }{ }^{0} \mathrm{~F} \\
\text { IBP } \\
10 \% \\
30 \% \\
50 \% \\
70 \% \\
90 \% \\
\text { EBP } \\
\text { VABP }\end{array}$ & $\begin{array}{r}604 \\
738 \\
790 \\
833 \\
879 \\
950 \\
1044 \\
834\end{array}$ & $\begin{array}{r}600 \\
639 \\
688 \\
750 \\
812 \\
881 \\
1000 \\
754\end{array}$ \\
\hline Watson $\mathrm{K}, \mathrm{R}$ & 11.49 & 11.71 \\
\hline $\begin{array}{l}\text { Elemental, Wt\% } \\
\mathrm{C} \\
\mathrm{H} \\
\mathrm{N} \\
\mathrm{S} \\
\mathrm{O} \text { (By Diff.) }\end{array}$ & $\begin{array}{l}84.51 \\
11.64 \\
1.95 \\
0.90 \\
1.00\end{array}$ & $\begin{array}{r}85.68 \\
12.79 \\
1.29 \\
0.07 \\
0.17\end{array}$ \\
\hline $\begin{array}{l}\text { Ash } \\
\text { Conradson Carbon } \\
\text { Q.I. }\end{array}$ & $\begin{array}{l}<0.01 \\
0.78 \\
0.007\end{array}$ & $\begin{array}{l}\cdots \\
\cdots \\
\cdots\end{array}$ \\
\hline
\end{tabular}


TABLL $4 \cdot 3 \cdot 5-2$

SUMAARY OF OPERAIING COHOIIIONS FOR FIXED-BED

COLORADO SHALE OIL HYOROCRACKING IESTS

CATALYST: AMOCO PROPRIETARY

\begin{tabular}{|c|c|c|c|c|c|c|c|c|}
\hline \multirow[b]{2}{*}{ TEST I (FBHC-) } & \multirow[b]{2}{*}{5} & \multirow[b]{2}{*}{6} & \multirow[b]{2}{*}{7} & \multirow[b]{2}{*}{8} & \multicolumn{4}{|c|}{ PILE IU: REPISHCI.UNI } \\
\hline & & & & & 9 & 10 & 11 & 12 \\
\hline DATE (1989) & $05=01$ & 05-01 & $05-01$ & $05-01$ & $05-02$ & $05-02$ & $05-02$ & $05=03$ \\
\hline SIART IIME & $07: 30$ & $13: 30$ & $19: 30$ & $01: 30$ & $07: 30$ & $13: 30$ & $19: 30$ & $04: 30$ \\
\hline END IIME & $09: 30$ & $15: 30$ & $21: 30$ & $03: 30$ & $09: 30$ & $15: 30$ & $24: 30$ & $09: 30$ \\
\hline FEEDSTOCK & $A$ & A & A & A & A & A & A & A \\
\hline FEED RAIE, cc/hr & 98 & 105 & 211 & 211 & 211 & 190 & 110 & 76 \\
\hline OPERATING PRESSURE, DSIQ & 2000 & 2000 & 2000 & 2000 & 2000 & 2000 & 2000 & 2000 \\
\hline H? PARIIAL PRESSURE, DSIg & 2000 & 2000 & 2000 & 2000 & 2000 & 2000 & 2000 & 2000 \\
\hline Hi IREAT RATE, scf/bbl & 7000 & 1000 & 7000 & 1000 & 1000 & 7000 & 1000 & 1000 \\
\hline LHSY, CC/hr/cs cat. & 0.59 & 0.64 & 1.28 & 1.28 & 1.28 & 1.15 & 0.67 & 0.46 \\
\hline IMLET BEO TEHF.. F & 680 & 716 & 710 & 675 & 125 & 747 & 138 & 162 \\
\hline UPPER HIO BEO TEMP.. F & 721 & 763 & 758 & 714 & 179 & 803 & 185 & 804 \\
\hline $\begin{array}{l}\text { LONER BEO TEHP., F } \\
\text { OUTLET BED TEWP., F }\end{array}$ & 717 & 746 & 760 & 721 & 784 & 806 & 711 & 785 \\
\hline AYERAJS EEO TEMP., $F$ & 706 & $74 i$ & 743 & 703 & 763 & 785 & 765 & 784 \\
\hline
\end{tabular}

FEEOSTOCK TYPE:

A: $650-975$ F COLORADO SHALE OIL YOO. 
iABLE 4.3.5 - 3

SUAMARY OF OPERATING CONOITIOKS FOR FIXEOI-BE:

COLORADU SHALE OIL HYOROCRACKING IESIS

CATALYSI: AMOCO PROPRIETARY

\begin{tabular}{|c|c|c|c|c|c|c|c|c|}
\hline IESI I $(F B H C-1$ & 28 & 19 & 30 & 31 & 32 & 33 & 34 & 35 \\
\hline (n) & - & $\ldots \ldots$ & ........... & -........ & -........ & ............ & -........ & \\
\hline DATE (1989: & $08-10$ & $08-17$ & $08-17 / 18$ & $08-18 / 21$ & $08-28 / 29$ & $08-29 / 30$ & $08-30 / 31$ & $08-31 / 09-01$ \\
\hline Sifñi ill: & $00: \hat{v}_{i}$ & $00: 00$ & $12: 06$ & $13: 00$ & $21: 00$ & $20: 60$ & $20: 0 \hat{\imath}$ & $12: 00$ \\
\hline ENO TIME & 08:00 & $08: 00$ & 08:00 & $20: 00$ & $18: 00$ & $18: 00$ & $12: 00$ & 21:00 \\
\hline iosiun & $A$ & A & A & k & $\delta$ & $B$ & 8 & 6 \\
\hline E[ RAIE, SC/TI & 17 & 144 & 105 & $8 \varepsilon$ & 111 & 19 & 119 & 139 \\
\hline 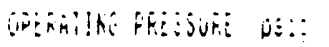 & 206. & 206. & 2000 & 6000 & $24 \hat{0}$ & $2400^{\circ}$ & $240 c$ & 2406 \\
\hline 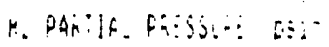 & 2600 & ione & $200 ?$ & 2000 & 2406 & 2400 & 2400 & 2400 \\
\hline 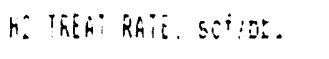 & $10 \div:$ & 1000 & 1000 & 100: & 6008 & 6000 & 6000 & $600:$ \\
\hline 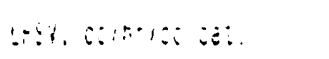 & $! 6^{\circ}$ & t. $\hat{\varepsilon} ?$ & $6.0 \vdots$ & C.ji & $0.6 ?$ & 0.16 & $0 . i i$ & 0.84 \\
\hline 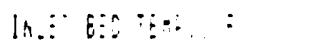 & $68:$ & 606 & $68 \%$ & 685 & $68:$ & $68 \vdots$ & $10 i$ & $72 i$ \\
\hline 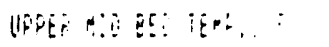 & $?: ?$ & $7 i i$ & 706 & 758 & 724 & $13 i$ & 751 & 166 \\
\hline $4:: \vdots: \because \vdots: \ldots$ & $\because n$ & $8:=$ & $80 i$ & $8 C_{6}$ & is: & $13 \%$ & $7 i 6$ & $i 9 i$ \\
\hline$i: \vdots 86$ if & oi. & 79 & $7 i ?$ & 796 & $74 t$ & 740 & $76 \varepsilon$ & ios. \\
\hline 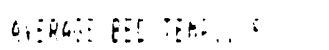 & 16: & 756. & 750 & 114 & $71^{\circ}$ & $72 i$ & $74 ?$ & 106 \\
\hline
\end{tabular}

Pa:Bion tros:

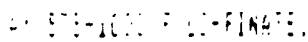

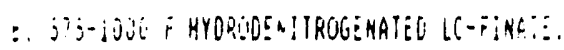


IABLE $4.3 .5-1$

SUKKARY OF OPERATIHE CONCIIIOAS FOR FIXEC-BEO KYORCIREAIING IESTS OF

HYOROPROCESSEO COLORADO SHALE OIL DISTILLATE

CATALYST: K-55O (IST STAGE) / K-599 (2NO STAGE)

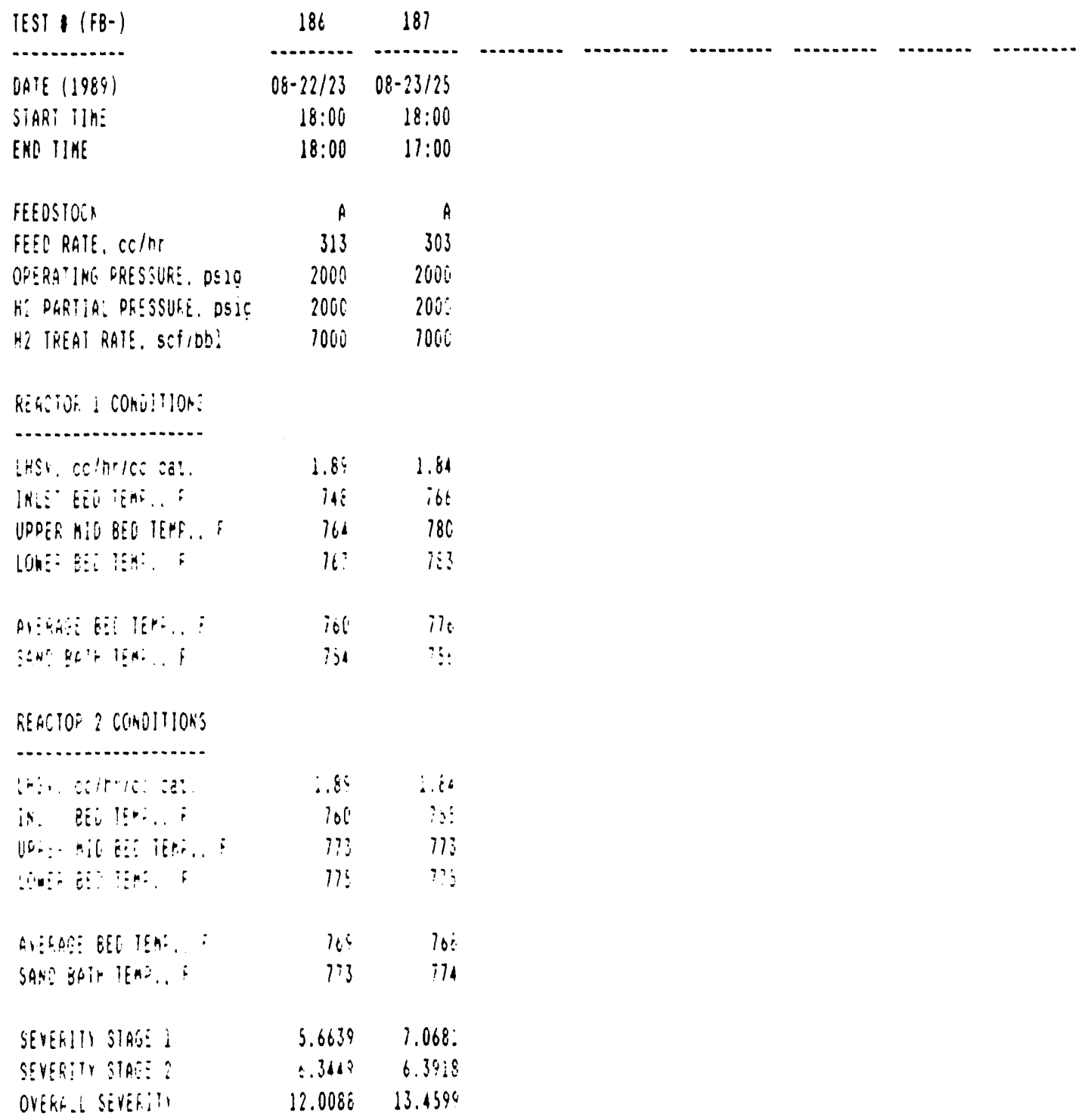

FEEDSTOA TYPE:

6: 575-100?: LC-FINAIS VGT: 
constant temperature/hydrogen partial pressure, were made to produce sufficient sample for detailed analytical evaluation. The summary of the operating conditions for these tests is presented in Table 4.3.5-5.

\subsubsection{Extraction Studies}

The initial results of the hydroprocessing campaigns summarized above indicated that HEDF volumetric energy densities were practically limited to several thousand Btu/gal below the minimum specification. It was accordingly theorized that this resulted from the relatively high aliphatics content of the shale oils relative to their cyclics content. Thus, it was hypothesized that a hydrocarbon type separation step, such as for example, solvent extraction, could be implemented to generate an extract and a raffinate stream, one being enriched in cyclics and having a significantly higher volumetric energy density than that of either the initial feed or the other reject stream. The disposition of the high energy density cyclics, i.e., in the extract or in the raffinate, would depend upon the choice of solvent and the extraction conditions. The aliphatics-rich stream, albeit in the extract or the raffinate, would represent a high cetane-quality diesel byproduct or alternatively could be further processed catalytically to "reform" the aliphatics to cyclic structures thereby increasing the yield of the desired HEDF.

In applying the solvent extraction approach, there are many parameters that can be considered. Firstly, the HEDF precursor stream (s) for extraction need to be identified. There are several combinations to consider here:

- Prior to or subsequent to hydroprocessing operations. Prior to hydrogenation, the cyclics in the Colorado shale oil exist as a mixture of aromatics and naphthenics, with the ratios depending upon boiling range of the precursor. Also present prior to hydroprocessing are a considerable quantity of heteroatomic compounds (e.g., organic N, S \& 0 ) which could interfere with the solvents.

0

Use of HEDF boiling range precursors vs use of heavier ends. Separation of cyclics from aliphatics might be accomplished with the VGO fraction of the shale oil prior to hydrocracking. Conversely, solvent extraction might be applied after hydrocracking and prior to or after hydrocrackate hydrogenation. In either case, a different solvent would probably be considered from the points of view of solvent effectiveness and method of separation of the solvent from the extract.

In an optimized flowscheme for conversion of the full-range Colorado shale oils to HEDF products, one or more solvent extraction applications may be feasible.

The choice of solvent (s) is also a critical parameter affecting the technical and economic feasibility of the solvent extraction route. If 
TABLE $4.3 .5 \cdot 5$

SUMHARY OF OPERATIHG COHOITIONS FOR. FIXEO-BEO HYOROTREATING TESTA OF

HYOROCRACKEO COLORADC SHALE OIL OISTILLATE

CATALYST: K-S5O (IST STAGE) / KS99 (2KD STAGE)

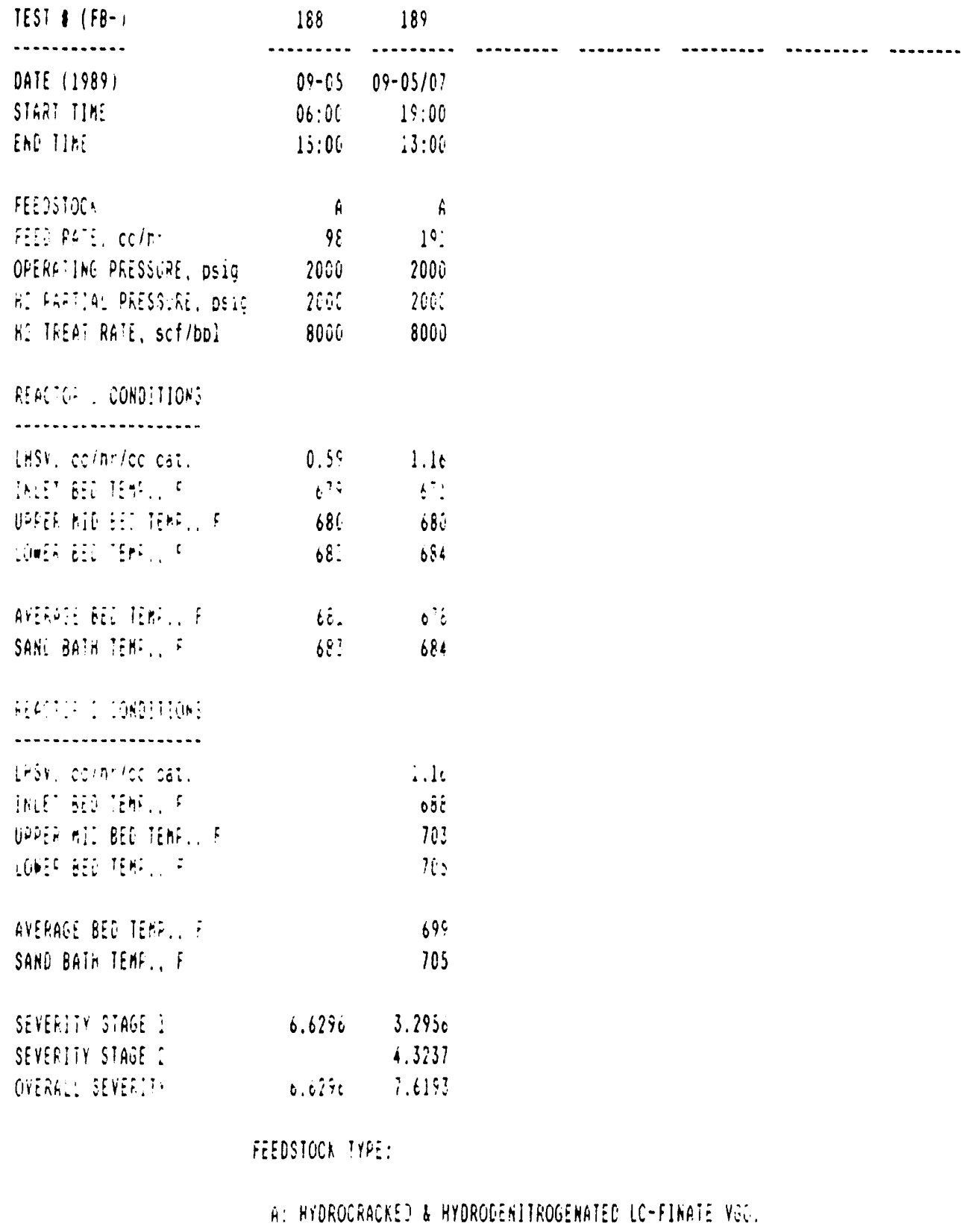


the solvent is most effective above ambient temperature, separation would be achieved by decanting and solvent recovery would most likely be achieved by either distillation or water extraction followed by distillation, the latter occuring only if the solvent is totally miscible in water. If the solvent is most effective at sub-ambient conditions, separation would be accomplished by fractional crystallization and the solvent recovery method would be either of the two methods identified above.

One of the most widely used commercial solvent extraction technologies is the dewaxing of petroleum lube oils. In this case, the lube oil feedstocks are heavy boiling fractions, relative to the $300-575 F$ HEDF range. Solvents in use include for example, $\mathrm{N}$-methylpyrrolidone (NMP), $\mathrm{N}, \mathrm{N}$-dimethylformamide (DMF), furfural, phenol, etc. These all boil below that of the lube oil feedstocks and are readily separated from the extracts by distillation with the solvent boiling overhead. Other lube oil dewaxing solvents in use include methyl ethyl ketone (MEK), methyl isobutyl ketone (MIBK), acetone, etc., the latter resulting in the initial paraffin separation via fractional crystallization.

When applying solvent extraction to the Colorado shale oil HEDF precursor streams, the solvent should boil either below about $300 \mathrm{~F}$ or above about $575 \mathrm{~F}$ if it is to be readily separated by distillation from the extracts. In the initial evaluation studies completed as part of Task 3, two solvent candidates were identified: DMF, a low boiling solvent (B.P. = 307F); and TEG (tetraethylene glycol), a higher boiling solvent (B.P. $=597 F)$.

Four HEDF precursor streams were examined in the initial solvent extraction evaluation campaigns:
1. LC-Finate VGO
2. Hydrodenitrogenated LC-Finate VGO
3. HEDF from selective hydrocracking of VGO
4. HEDF from hydrotreating of virgin mid-distillate

Table 4.3.6-1 summarizes the batch equilibrium extraction test cycles performed with the two candidate solvents at constant temperature, pressure, solvent/feed ratio, extraction time and stirrer speed. 


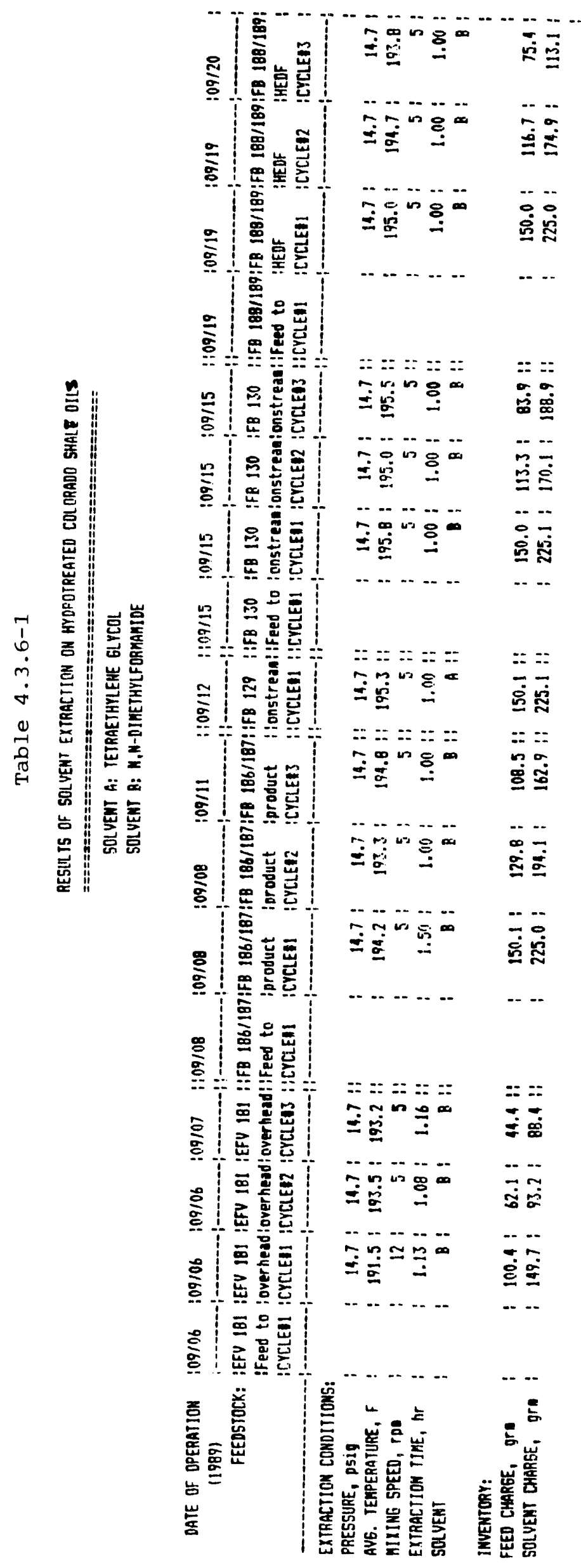




\subsection{SUMMARY OF RESULTS OF COALITE SCREENING OPERATIONS}

\subsection{Overview}

The Task 3 screening program consisted of an experimental investigation of thermal and catalytic processing responses of COALITE feedstocks with regard to their conversion to HEDF fuels, namely, Category I high density aviation turbine (jet) fuel; Category II endothermic aviation turbine (jet) fuel; and Category III high density diesel fuel. The overall objectives and technical directions taken in the screening program are as follows:

- Generate experimental processing data, analyze data and formulate processing strategies aimed at meeting the goal of producing COALITE-derived HEDF fuels meeting a minimum volumetric energy density specification of $130,000 \mathrm{Btu} / \mathrm{gal}$ as well as satisfying tire other required turbine fuel properties. A secondary goal was the identification of processing strategies that would result in HEDF fuels achieving the energy density target of 135,000 Btu/gal; and

- Collect sufficient data for use in the refinery LP computer model of Task 5 which is aimed at determining economically optimized process flowschemes for producing HEDF products in a conceptualized refinery processing facility.

The basic technical approach taken consisted of cracking the heavier ends of the COALITE boiling above the HEDF precursor range using thermal (delayed coking) cracking technology and catalytic (LC-Fining and fixed-bed VGO hydrocracking) hydrocracking technology followed by fixed-bed distillate hydrotreating of both the virgin COALITE distillates as well as the cracked COALITE distillates. Since the experimental data are collected in small bench-scale or pilot-scale units, the scaleup interpretation of the resultant

data to the HEDF processing requirements must not be underestimated. Although the screening tests could not be comprehensive enough to quantify every commercial processing parameter, including for example, catalyst deactivation, catalyst makeup requirements, extinction recycle requirements, etc., these parameters had to be considered in the execution and resultant analysis of the screening test matrix.

Commercial jet (and diesel) fuel products require a considerable number of detailed specifications that must be met. In this screening program, the major emphasis was on the analytical determination and evaluation of certain key fuel properties in addition to the volumetric energy density specification. These include:

1. Freeze Point

2. Flash Point

3. Viscosity

4. Smoke Point

5. Cetane Number

6. Hydrogen Content

7. Trace sulfur and nitrogen

8. Specific gravity

9. Aromatics 
Those properties not investigated for most of the 73 distillate hydrotreating tests made with the COALITE feedstocks included existent gum, JI OT (thermal stability), copper strip corrosion, naphthalenes content, Saybolt color, acid number, mercaptans, particulate matter, water separation index, inhibitor content, carbon residue and ash content. It was assumed that the high degree of hydrogenation required to meet the stringent hydrogen and aromatics content specifications for the finished HEDF products would result in the achievement of the specifications for the above chemical and physical tests.

The following sections sequentially summarize the analyses of the results of the four major processing approaches investigated during the Task 3 screening efforts with the COALITE feedstocks.

\subsection{Virgin Distillate Hydrotreating}

One of the key advantages of Mild Coal Gasification over those of conventional pyrolysis technologies is the production of coal liquids enriched in distillates having relatively high hydrogen/carbon ratios and leaner in the tarry residue materials. The COALITE sample used in this program contained more than about 50 weight percent boiling in the mid-distillate range. Accordingly, these materials were the first precursors considered for conversion of COALITE to HEDF fuels.

The category I (jet) and III (diesel) fuel specifications differ primarily on the basis of distillation end point, with the diesel allowing a higher end point. It was arbitrarily decided to select two raw mid-distillate fractions for distillate hydrotreating evaluation. The raw jet fraction to hydrotreating was specified as a nominal 350-550F (TBP) cut and the raw diesel fraction was specified as a nominal 350-650F (TBP) cut. In practice, the bulk of the testing was made with the 350-650F fraction, which included the jet precursors as well as the diesel precursors. This allowed for cut point (front-end as well as back-end) control by distillation after hydrotreatir.g. This insured that any heavy materials, i.e., 550f+, boiling above the finished jet fuel range would, upon hydrogenation, be allowed to pass into the jet fuel range. Using model compounds as an example, the hydrogenation of the heteroatomic compound 2-ethylaminonaphthalene $(B . P .=591 F)$ might result in the formation of 2 -ethylnaphthalene which boils at 496F and 2-ethyldecahydronaphthalene, a 2-ring naphthene, which also boils within the HEDF range.

The resultant ammonia product of hydrogenation would be a byproduct of the process. There are analagous situations for the hydrotreating of the heavier boiling oxygenates and sulfur-containing compounds present in the 550F+ mid-distillate fractions. These would result in the byproduct formation of $\mathrm{H}_{2} \mathrm{O}$ and $\mathrm{H}_{2} \mathrm{~S}$. In addition to the heteroatom conversion aspect of hydrotreating, there also exists some degree of hydrocarbon hydrocracking which would convert the heavier 550F+ hydrocarbons to the finished jet fuel range materials.

There is also an analogy to the front-end of the mid-distillate fraction. Front-end cut point is limited in part by the flash point specification. Heteroatom conversion such as hydrogenation of 
multi-phenols to alkylated aromatics coupled with ring saturation of the resultant alkylated aromatics would result in a fraction boiling below the $300 \mathrm{~F}$ nominal HEDF initial boiling point. These materials, which include alkylcyclohexanes for example, represent excellent stocks for the Category II endothermic fuels.

Depending upon the particular aircraft requirements, there are several specifications for jet or aviation turbine fuels as defined by the rsepective JP- designations (Table 5.2.1-1). With the exception of $J P-10$, a missile fuel, the other JP fuels have volumetric energy density specifications of about 115 to $121 \mathrm{KBtu} / \mathrm{gal}$. These latter values are ultimately limited by the hydrocarbon structures characteristic of the petroleum stocks used to produce these jet fuels, these being a predominance of aliphatics as opposed to naphthenics. The latter class of hydrocarbons is known to have a unique combination of desirable high specific gravity and high mass heat of combustion which translates to high (net) volumetric energy densities, ca., 130+ KBtu/gal. This is depicted in Figure 5.2.1-1 which shows the volumetric (gross) energy densities as a function of hydrogen content for the cyclics class of hydrocarbons and the conventional petroleum-derived JP- fuels. The difference between gross and net heat of combustion is the latent heat of vaporization of the water product generated during the combustion of the fuel.

Thus, the objective of the hydroprocessing operations with the coal-derived COALITE mid-distillate feedstock is to saturate the existing alkylated single and multi-ring aromatics to alkylated single and multi-ring naphthenics and to hydrotreat the contained heteroatomics sufficiently to achieve a thermally stable fuel product in such a way that the vo?umetric energy density is maximized. This is accomplished by using active and selective Group $6 \mathrm{~b}$ and 8 transition metal-based hydrogenation catalysts. In this screening effort, two such commercially available catalysts were utilized: 1) K-550, a nickel-tungsten on alumina catalyst manufactured by Katalco Corporation; and 2) K-599, a nickel-molybdenum on alumina catalyst al so manufactured by Katalco. Other competing catalyst vendors also make commercial products similar to the ones utilized in this study. In one series of tests, the K-550 catalyst was specially treated in our laboratories with a calcium promoter in an attempt to improve the catalyst selectivity towards suppression of ring-opening activity. Table 5.2.1-2 summarizes the properties of the fresh catalyst oxides as reported by the manufacturer. Catalyst activation via presulfiding with an $\mathrm{H}_{2} \mathrm{~S} / \mathrm{H}_{2}$ mixture was practiced prior to hydrotreating operations.

The results are summarized in a series of spreadsheet tables with the "A" tables presenting the run performance data and the "B" tables presenting the properties of the full-range hydrotreated distillates. The organization of the tabulated results is as follows: 


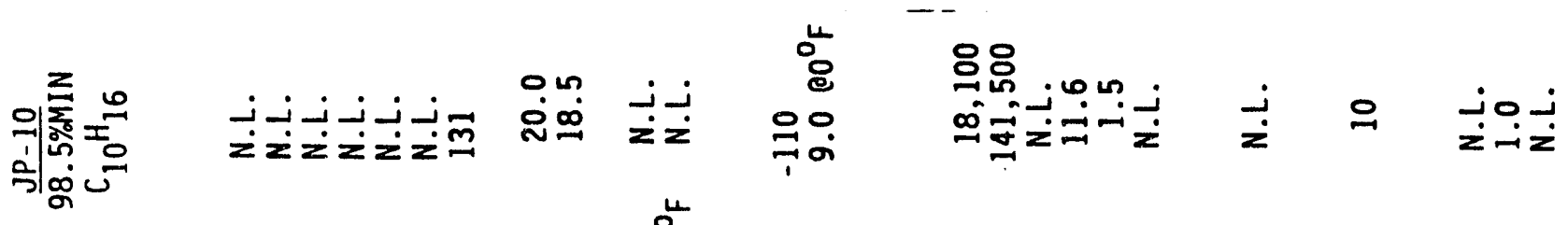

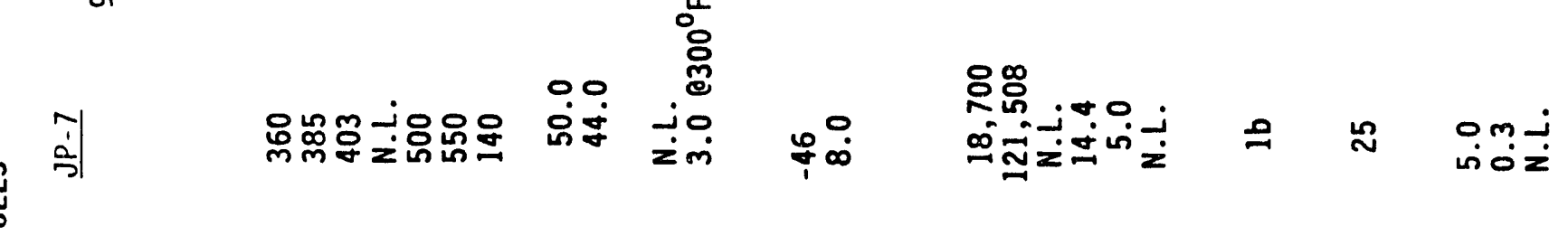

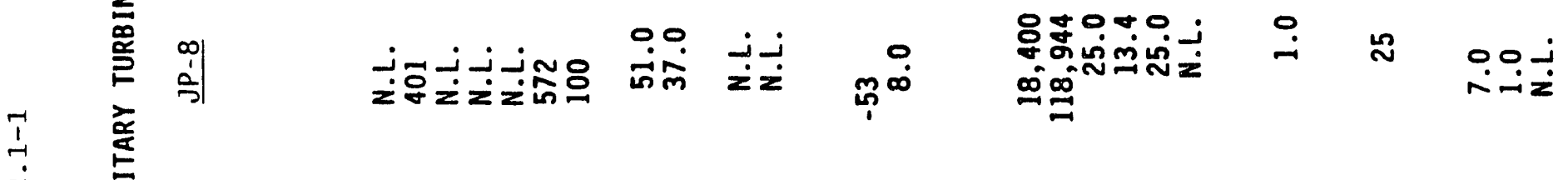

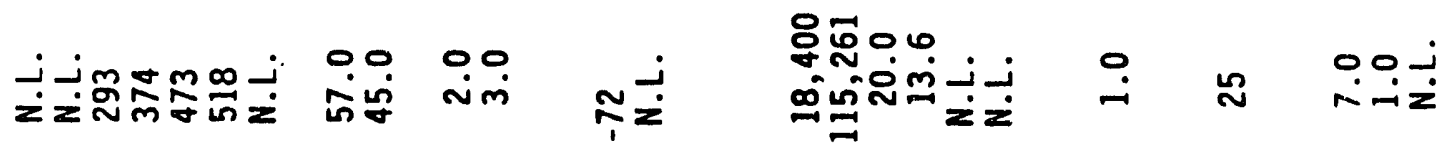
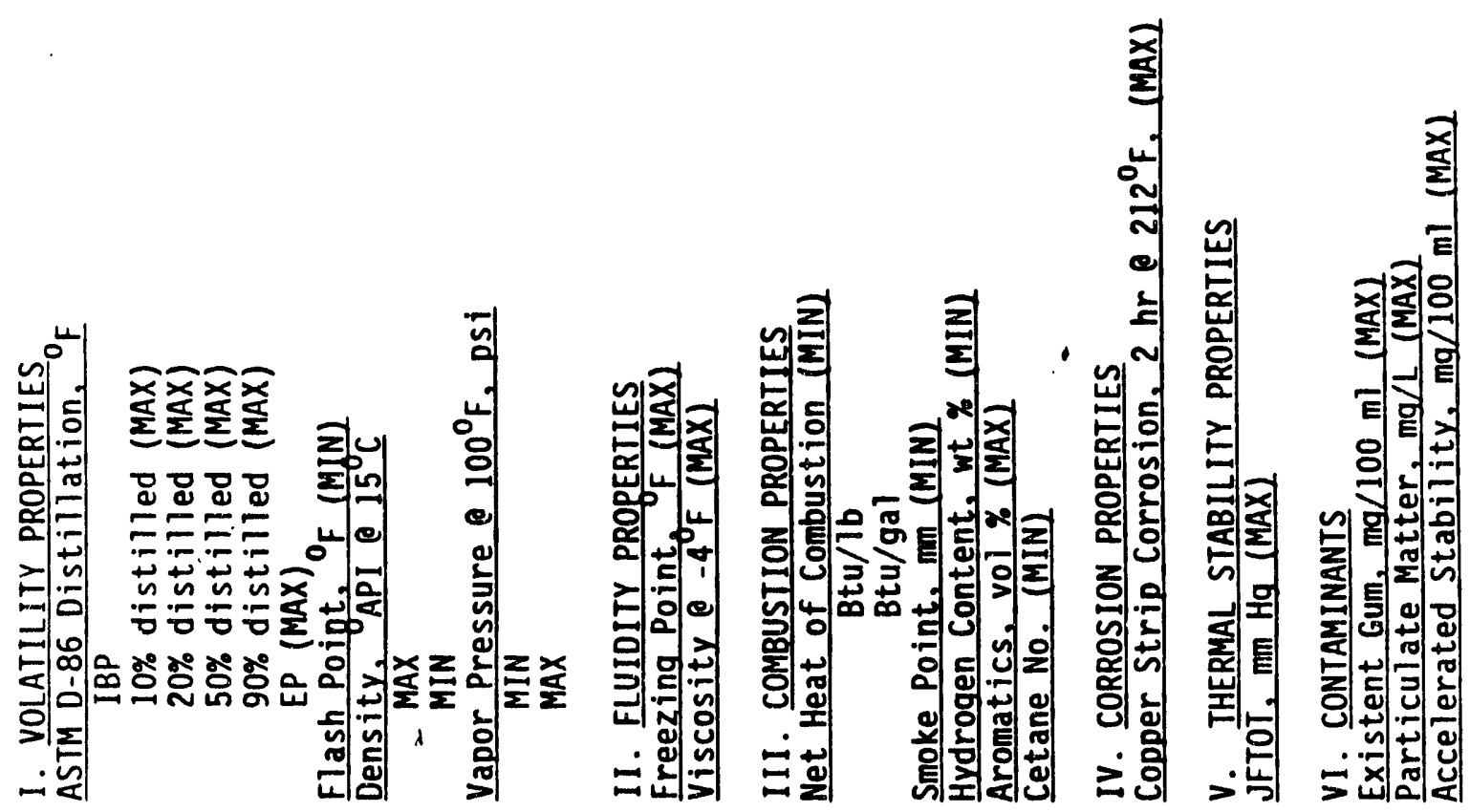

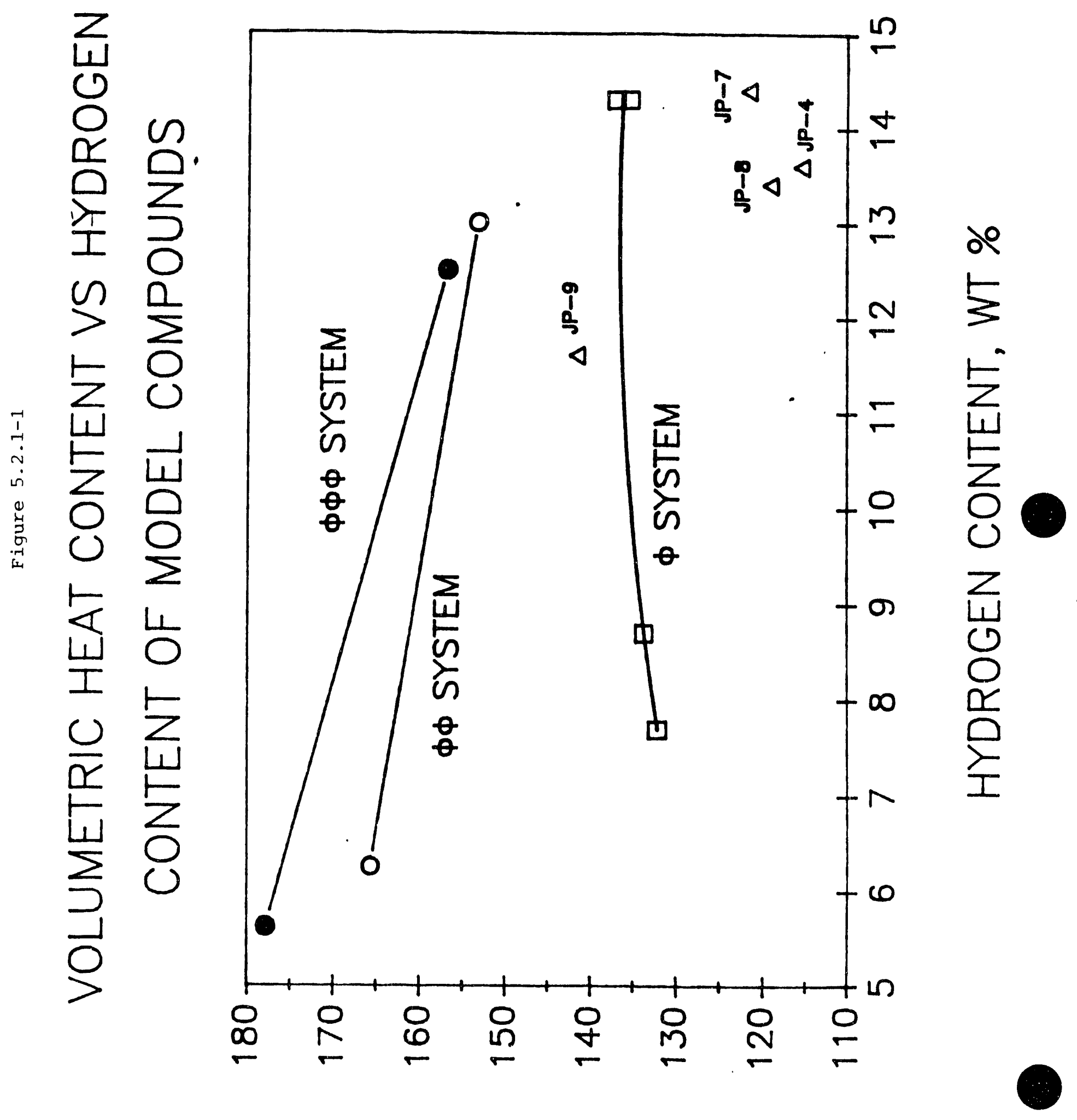

$7 \forall 5 / \cap 19 w^{\prime} \wedge H H$ 
IABLE 5.2.1-2

ASSAYS OF DISTILLATE HYDROTREATING CATALYSTS

Catalyst Designation

(Oxided/calcined form)

$\underline{K-550}$

$\underline{K-599}$

B.E.T. Surface Area, $\mathrm{m}^{2} / \mathrm{gm}$

230

220

Crush Strength, Ib

15

20

Compacted Bulk Density, $1 \mathrm{~b} / \mathrm{ft}^{3}$

49.92

57.41

Bulk Chemical Analysis, wt\% dry basis

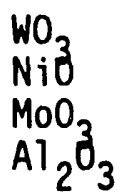

20.0

5.0

0

Bal ance

0

6.7

27.0

Balance

Trace Metals, ppmw on ashed catalyst ${ }^{*}$

Vanadium

Arsenic

$<2$

Calcium

1600

Copper

Sodium

B.D.L.

Lead

633

286

* Via Atomic Absorption Spectrophotometry 
Table No Catalyst Type Feed Boiling Range (F) \# Reaction Stages

$\begin{array}{llll}5.2 .1-3 A, B & K-550 & 350-650 & 1 \\ 5.2 .1-4 A, B & K-550 & 350-550 & 1 \\ 5.2 .1-5 A, B & K-550 / K-550 & 350-750(820) & 2 \\ 5.2 .1-6 A, B & K-550 / K-599 & 350-650 & 2 \\ 5.2 .1-7 A, B & K-599 & 350-650 & 1 \\ 5.2 .1-8 A, B & K-550 / C a 1 c i u m & 350-650 & 1\end{array}$

Several interesting correlations were developed for the hydrotreating of the raw 350-550F and 350-650F COALITE distillates. Correlations were developed of the HEDF properties vs the kinetic hydrotreating severity parameter (KSF described in Section 4). These are shown graphically in Figures 5.2.1-2 through -9. Cross-correlations of key HEDF properties vs aromatics contents are depicted in Figures 5.2.1-10 through -12. Cross-correlations of key HEDF properties vs Refractive Index are shown in Figures 5.2.1-13 through -17 .

At a quarterly project review meeting held in Morgantown in November 1989, WRI presented some data on their efforts to evaluate the hydrotreating of COALITE. Two hydrotreating tests were made with the COALITE mid-distillate fraction at conditions not very dissimilar to tests made at Lummus during the early Task 3 screening operations. While an exact comparison of the operating procedures and analytical methodologies was not able to be made, some interesting relationships and correlations were observed based on a comparison of the major known parameters. These are summarized below:

- Shell 424, a nickel-molybdenum on alumina catalyst, and Katalco 550, a nickel-tungsten on alumina catalyst, both demonstrated excellent activity for saturating COALITE aromatics in the presence of heteroatomic contaminants.

- Both catalysts appear to result in comparable specific gravity reductions in the hydrotreated products as a function of the degree of aromatics conversion. Specific gravity reduction is important because it has a direct impact on the desired improvement of the HEDF volumetric energy densities. Approximately $85 \%$ of the ultimate specific gravity reduction occurs at aromatics conversions up to about 60-70 percent (Figure 5.2.4-1).

- Average catalyst bed temperature appears to correlate the extent of aromatics conversion at constant space velocity and hydrogen partial pressure for both catalysts with no discernible differences for the two catalyst types (Figure $5.2 .4-2)$.

- The experimentally observed hydrogen uptake-average catalyst bed temperature correlation for the two catalysts are nearly parallel suggesting similar activation energies for the two catalyst types. The WRI data obtained with the Shell 424 


$$
\text { IABLE } 5.2 .1-3 A \quad 1 \text { of } 4
$$

SUHHARY OF OPERATING RESULIS FOR FIXEO-BED COALIIE HYOROTREAIIKO IESTS

$$
\text { CATALYSI: X-SSO (IST STAGE) }
$$

\begin{tabular}{|c|c|c|c|c|c|c|c|c|}
\hline TEST । (FB-) & $17 A-1$ & $17 A-?$ & $18 A-1$ & $18 A-2$ & $18 A-3$ & $19 A-1$ & $19 A-2$ & $19 A-3$ \\
\hline DATE (1989) & $01-13$ & $01-13$ & $01-16$ & $01-16$ & $01-16$ & $01-17$ & $01-11$ & $01-17$ \\
\hline START IIME & $14: 30$ & $16: 30$ & $12: 30$ & 14:15 & $19: 00$ & $12: 30$ & 15:00 & $18: 20$ \\
\hline END IIHE & $16: 30$ & $11: 30$ & $13: 30$ & $15: 45$ & $21: 00$ & $13: 30$ & 11:00 & $20: 20$ \\
\hline FEEDSTOCK & A & A & A & A & A & $A$ & A & A \\
\hline H HDS & 9.36 & & 22.97 & 87.25 & 94.08 & 91.93 & 95.68 & 91.04 \\
\hline 8 HON & 25.28 & & 9.03 & 16.60 & 50.67 & 24.82 & 83.12 & 60.05 \\
\hline HOO & 25.51 & & -9.08 & 10.08 & 75.91 & 21.99 & 87.86 & 91.10 \\
\hline HL UPIAKE, scfibb] & 3000 & 3000 & 5000 & 5000 & 5000 & 5000 & 5000 & 5000 \\
\hline I F.I.A. OLEFINS SATURATIOH & & & 66.31 & & 91.76 & & 92.87 & 95.43 \\
\hline F.L.A. aROMATICS SATURAIION & 24.268 & & 13.18 & 31.578 & 50.17 & 38.881 & 53.25 & 48.96 \\
\hline API IMPROVENENT & 0.9 & 0.2 & 1.0 & 9.4 & 19.4 & 10.8 & 23.3 & 20.6 \\
\hline R.I. DEPRESSION & 0.0015 & & 0.0040 & 0.0339 & 0.0601 & 0.0385 & 0.0147 & 0.0657 \\
\hline EST. HEAT OF REACIIOH, BtU/1D & & & 83 & & 335 & & 385 & 363 \\
\hline
\end{tabular}

FILE ID: REPTBEL.UKI

FEEQSTOCK IYPE:

A: 350-650 F VIRGIN COALIIE OISTILLATE.

- Estianteo froh regression amalysis. 


$$
\text { IABLE } 5.2 .1-3 A \quad 2 \text { of } 4
$$

SUMHARY OF OPERATING RESULIS FOR FIKEO-BED CORLITE HYOROTREATIMG IESTS

\section{CATALYST: K-SSO (IST STAGE)}

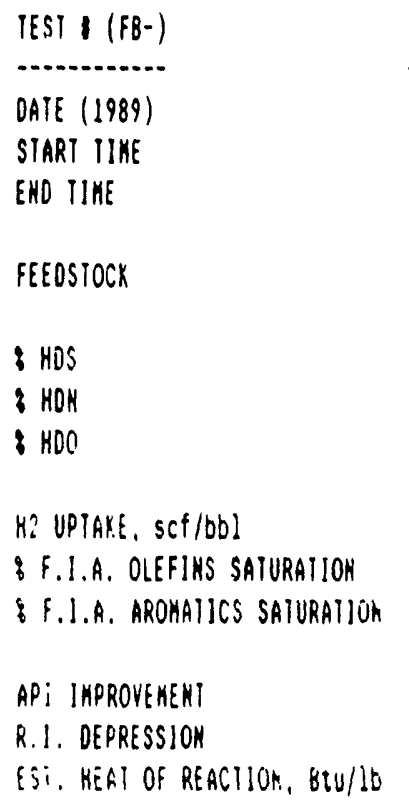

\begin{tabular}{cccccccc}
$20 A-1$ & $20 A-2$ & 21 & 22 & 23 & 24 & 25 & 26 \\
\hdashline $01-18$ & $01-18$ & $01-19$ & $01-20$ & $01-20$ & $01-23$ & $01-23$ & $01-24$ \\
$16: 20$ & $19: 00$ & $19: 00$ & $16: 45$ & $19: 30$ & $17: 45$ & $20: 45$ & $15: 20$ \\
$18: 20$ & $21: 00$ & $21: 00$ & $17: 45$ & $20: 30$ & $18: 45$ & $21: 45$ & $16: 30$ \\
& & & & & & & \\
A & A & $A$ & $A$ & $A$ & $A$ & $A$ & $A$
\end{tabular}

$\begin{array}{lll}94.48 & 90.33 & 91.19 \\ 68.89 & 12.82 & 48.21 \\ 80.03 & 20.65 & 55.05\end{array}$

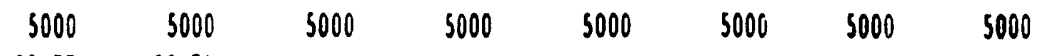

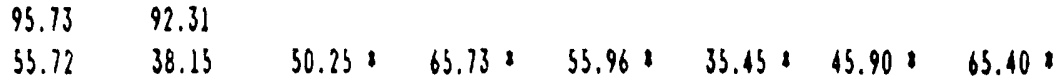

$\begin{array}{llllllll}21.0 & 9.6 & 15.0 & 21.4 & 19.8 & 10.3 & 15.7 & 21.0\end{array}$

$\begin{array}{llllllll}0.0707 & 0.0344 & 0.0530 & 0.0723 & 0.0625 & 0.0361 & 0.0511 & 0.0685\end{array}$

FEEDSTOCY TYPE:

A: 350-650 F VIRGIN COALITE DISTILLATE.

I ESTIHATEO FROH REGRESSION AMALYSIS. 
TABLE $5.2 .1-3 A \quad 3$ of 4

SUGMARY OF OPERATING RESULTS FOR FIXEO-BEO COALIIE HYOROTREATING IESTS

CATALYST: K-S5O (1ST STAGE)

FILE IO: REPIBE2.VMI

\begin{tabular}{|c|c|c|c|c|c|c|c|c|}
\hline IEST $\cap(F B-)$ & 11 & 28 & 29 & 37 & 38 & 39 & 10 & 41 \\
\hline OAIE (1989) & $01-24$ & $01-24$ & $01-25$ & $02-02$ & $02-02$ & $02-03$ & $02-03$ & $02-03$ \\
\hline START TIME & $17: 15$ & $20: 15$ & $16: 40$ & $11: 30$ & $20: 15$ & $10: 35$ & $13: 35$ & $17: 30$ \\
\hline ENO IIHE & $18: 45$ & $21: 15$ & $17: 40$ & 19:00 & $21: 45$ & 12:05 & $15: 05$ & 18:45 \\
\hline FEEDSTOCK & A & $A$ & A & A & $A$ & $B$ & B & A \\
\hline \multicolumn{9}{|l|}{ I HDS } \\
\hline \multicolumn{9}{|l|}{ \& HOH } \\
\hline \multicolumn{9}{|l|}{ \& 100} \\
\hline HL UPTAKE, scf/bbl & 3000 & 5000 & 3000 & 5000 & 5000 & 5000 & 5000 & 5000 \\
\hline I F.I.A. OLEFIHS SATURATIOH & & & & 57.91 & 97.66 & 100.00 & 100.00 & 93.36 \\
\hline I F.I.A. AROHATICS SATURATIOH & 61.96 & $58.57 \%$ & 58.75 & 76.40 & 80.42 & 94.22 & 98.59 & 12.59 \\
\hline API IMPROVEHENT & 22.90 & 19.90 & 19.90 & 27.21 & 27.39 & 28.01 & 28.61 & 26.20 \\
\hline R.I. DEPRESSION & 0.0699 & 0.0625 & 0.0585 & 0.0867 & 0.0903 & 0.0933 & 0.0965 & 0.0853 \\
\hline
\end{tabular}

FEEOSIOC IYPE:

A: 350-650 F VIRGIN COALITE DISTILLATE.

B: LIQUIO PROOUCT FROH F8-37.

- ESTIHATEO FROK REgRESSION ANALYSIS. 


$$
\text { IABLE 5.2.1-3A } 4 \text { of } 4
$$

SUHKARY OF OPERATING RESULTS FOR FIXED-BED COALITE HYOROTREAIIKG TESTS

CAIALYST: K-S5O (ISI STAGE)

FILE ID: REPTBE2.VKL

\begin{tabular}{|c|c|c|c|c|c|c|}
\hline IEST 1 (FB-) & 42 & 13 & 46 & 11 & 48 & 49 \\
\hline DATE (1989) & $02-06$ & $02-06$ & $02-21 / 22$ & $02-22$ & $02-23$ & $02-24$ \\
\hline START IIKE & 12:05 & $18: 15$ & $03: 15$ & $05: 45$ & $02: 00$ & 00:00 \\
\hline END TIKE & $17: 35$ & $20: 40$ & 04:00 & 24:00 & $22: 00$ & $20: 00$ \\
\hline FEEDSIOCK & A & c & A & 0 & A & \\
\hline I HOS & & & 94.48 & & 98.64 & \\
\hline HON & & & 68.9 & & 87.18 & \\
\hline $8 \mathrm{KOO}$ & & & 100.58 & & 92.01 & \\
\hline H2 UPIAKE, sct/bb] & 5000 & 5000 & 5000 & 5000 & 3000 & 300 \\
\hline \& F.I.A. OLEFIMS SATURATIOH & & & 96.58 & & 96.65 & \\
\hline I F.I.A. AROHATICS SATURAIIOH & & & 70.63 & & 78.92 & \\
\hline API IMPROYEHENT & 8.5 & 28.5 & 24.6 & 28.2 & 21.2 & 9.1 \\
\hline R.I. OEPRESSIOH & 0.0357 & 0.0947 & 0.0810 & 0.0943 & 0.0879 & 0.03 \\
\hline EST. HEAT OF REACTIOK, BtU/Lb & & & 478 & & 516 & \\
\hline
\end{tabular}

FEEOSTOCK IYPE:

A: 350-650 F VIRGIN COALITE OISTILLATE.

C: LIOUIO PROOUCT FROH FB-42.

D: LIOUIO PRODUCT FROH FB-16.

I ESTIMATEO FROH REGRESSIOK AMALYSIS. 
TABLE $5.2 \cdot 1-3 B \quad 1$ of 4

SUMHARY OF PROPERTIES OF FULL-RANGE HYDROTREATEO COALIIE PRODUCTS

FROA FIXED-BED HYDROTREATING

CATALYST: K-SSO (IST STAGE)

FILE ID: REPTBPI.UKI

\begin{tabular}{|c|c|c|c|c|c|c|c|c|}
\hline TEST $:(F B-1$ & $17 A-1$ & $17 A-2$ & $18 A-1$ & $18 A-2$ & $18 A-3$ & $19 A-1$ & $19 A-2$ & $19 A-3$ \\
\hline (n).................. & (n.............. & $\ldots \ldots$ & ............. & (n............... & (n............ & (n.............. & $\ldots$ & (n......... \\
\hline DAIE 119891 & $01-13$ & $01 \cdot 13$ & $01-16$ & $01-16$ & $01-16$ & $01-17$ & $01-17$ & $01-17$ \\
\hline START TIME & $14: 30$ & $16: 30$ & $12: 30$ & $14: 45$ & $19: 00$ & $12: 30$ & $15: 00$ & $18: 20$ \\
\hline ENE TIME & $16: 30$ & $17: 30$ & $13: 30$ & $15: 45$ & $21: 00$ & $13: 30$ & $17: 00$ & $20: 20$ \\
\hline FEEDSTOCK & A & $A$ & A & A & A & A & A & A \\
\hline SPECIFIC GRAVITY, OO/CG & 0.9861 & 0.9909 & 0.9854 & 0.9309 & 0.8735 & 0.9224 & 0.8529 & 0.8670 \\
\hline API GRAVITY I $60 \mathrm{~F}$ & 12.0 & 11.3 & 12.1 & 20.5 & 30.5 & 21.9 & 34.4 & 31.7 \\
\hline REFRACIIVE INDEX E $20 \mathrm{C}$ & 1.5454 & & 1.5429 & 1.5130 & 1.4868 & 1.5084 & 1.4722 & 1.4812 \\
\hline \multicolumn{9}{|l|}{ ELERERTALS, WI: } \\
\hline 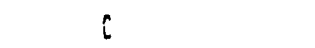 & 84.30 & & 83.42 & 84.04 & 86.17 & 84.28 & 86.51 & 86.89 \\
\hline$H$ & 9.33 & & 9.39 & 10.65 & 12.26 & 10.91 & 12.73 & 12.39 \\
\hline
\end{tabular}

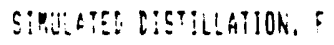

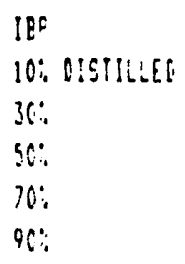

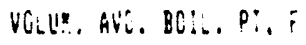
DATSGK

F.I.A. ANALYSIS. IVOI:

OLE'INS

SATURATES

AROMATICS

NLH: Rtu/Th

VLHV, Btu/Oal

PLASH Pi., F

SHOKE Pi., a

FREIE PT., $F$

AKI:INE PT.. P

CEIANE (NIE)

VISCCSITY, CSt -4 F

$\begin{array}{rrrr}365 & 178 & 183 & 133 \\ 409 & 237 & 314 & 218 \\ 177 & 369 & 429 & 327 \\ 531 & 452 & 487 & 422 \\ 589 & 517 & 549 & 493 \\ 663 & 606 & 632 & 583 \\ & & & \\ 534 & 436 & 482 & 409 \\ 10.06 & 10.95 & 10.55 & 11.10\end{array}$

$\begin{array}{rrrrrrrrr} & 4.1 & & 0.9 & & 0.8 & 0.5 \\ 71.8 & 27.4 & & 63.8 & & 65.2 & 63.3 \\ 16046 & 68.5 & 50.6 & 35.3 & 47.6 & 34.0 & 36.2 \\ 131807 & 16087 & 16820 & 17869 & 17021 & 18132 & 17934 \\ & 132048 & 130429 & 130019 & 130781 & 128822 & 129520 \\ 3 & & & & & & & & \\ 36 & 3 & 1 & 61.3 & 81.8 & 64.9 & 93.2 & 86.21 \\ 4 & 5 & 13 & 25 & 14 & 32 & 27\end{array}$

FEEDSTOCK TYPE:

A: J50-65O F UIRGIN COALITE DISTILLATE.

I ESTIMATEO FROR REGRESSIOH AKA:YSIS. 
IABLE $5.2 .1-3 B \quad 2$ of 4

SUMMARY OF PROPERTIES OF FULL-RAMGE MYOROTREATED COALIIE PROOUCTS

FRON FIXEO-BEO KYOROTREAIING

CATALYST: R-S5O (IST STAGE)

IEST I (FB-)

DATE (1989)

START TIME

END IIRE

FEEOSTOCK

SPECIFIC GRAYIIY, gI/CC API GRAVIIT $860 \mathrm{~F}$

REFRACIIVE IHOEX $\perp 20 \mathrm{C}$

\begin{tabular}{ccrrrrrr}
$20 A-1$ & $20 A-2$ & 21 & 21 & 23 & 24 & 25 & 26 \\
\hdashline $01-18$ & $01-18$ & $01-19$ & $01-20$ & $01-20$ & $01-23$ & $01-23$ & $01-24$ \\
$16: 20$ & $19: 00$ & $19: 00$ & $16: 45$ & $19: 30$ & $17: 45$ & $20: 45$ & $15: 20$ \\
$18: 20$ & $21: 00$ & $21: 00$ & $17: 45$ & $20: 30$ & $18: 45$ & $21: 45$ & $16: 30$
\end{tabular}

ELEMENTALS, wt?

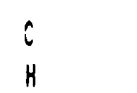

86.18
12.50

84.36

85.59

85.46

10.18

11.59

12.61

$12.15,10.90,11.63$

12.438

SIHULATEO DISIILLATION, F

$\begin{array}{ll}18 P & 176 \\ 108 \text { OISIILLE } & 222 \\ 308 & 357 \\ 508 & 446 \\ 708 & 511 \\ 9.98 & 602\end{array}$

$\begin{array}{rr}178 & 183 \\ 224 & 212 \\ 351 & 419 \\ 442 & 484 \\ 307 & 547 \\ 598 & 640 \\ & \\ 124 & 472 \\ 11.11 & 10.85\end{array}$

VOLUH. AVG. BOLL. PI, \& 428

MAISOK I.

11.07

11.11

10.85

\section{F.I.A. AMALYSIS, IVOIS

OLETINS
SAIURATES
AROHATICS

VLHT, BLU/LE

VLHV, Btu/gal

FLASH PT., F

SHOKE PI., II

FREZE PI., F

aNlilhe Pi, $F$

CETANE IMOEX

viscosity, cst - -4

$$
\begin{array}{rrrrrrrr}
0.5 & 0.9 & & & & & & \\
65.9 & 52.2 & & & & & & \\
33.6 & 16.9 & 38.1 & 25.5 & 31.9 & 19.2 & 39.3 & 28.0 \\
& & & & & & & \\
18051 & 16868 & 17440 & 18069 & 17786: & 17015: 17465: & 17958: \\
129554 & 130633 & 130430: 129085 & 129088: 131159: 130047: & 129384:
\end{array}
$$

$\begin{array}{rccccccc}11 & 3 & 4 & 9 & 5 & 9 & 9 & 6 \\ 94.3 & 61.78 & 76.3 & 91.3 * & 83.71 & 66.6 & 16.3 & 87.8 \\ 31 & 13 & 20 & 31 & 26 & 14 & 20 & 28 \\ 7.5 & & & & 3.5 & & 12.0 & 4.4\end{array}$

FEEDSTOCK IYPE:

A:350-650 F VIRGIM COALITE OISTILLAIE.

I ESTIMATEd FROM regRESSION ahalysis. 
IABLE $5.2 \cdot 1-3 B \quad 3$ of 4

SUHAARY OF PROPERIIES OF FULL-RAMGE HYOROTREATEO COALITEO PRODUCTS

FROH FIXED-BED HYOROIREAIING

CATALYST: K-SSO (ISI STAGE)

FILE ID: REPIBP?

IEST I (FB-)

DATE (1989)

START TIME

END IIHE

\begin{tabular}{cccccccc}
27 & 28 & 29 & 37 & 38 & 39 & 10 & 11 \\
\hdashline $01-24$ & $01-24$ & $81-25$ & $02-02$ & $02-02$ & $02-03$ & $01-03$ & $02-03$ \\
$17: 45$ & $20: 15$ & $16: 40$ & $11: 30$ & $20: 15$ & $10: 35$ & $13: 35$ & $17: 30$ \\
$18: 45$ & $21: 15$ & $17: 40$ & $19: 00$ & $21: 45$ & $12: 05$ & $15: 05$ & $18: 45$
\end{tabular}

FEEDSTOCK

SPECIFIC GRAVITY, go/CC

API GRAVIIY I $60 \mathrm{~F}$

REFRACIIVE IHDEX $\& 20 \mathrm{C}$

$\begin{array}{rrrrrrrr}A & A & A & A & A & B & B & A \\ 0.8550 & 0.8708 & 0.8708 & 0.8333 & 0.8324 & 0.8294 & 0.8265 & 0.8383 \\ 34.0 & 31.0 & 31.0 & 38.3 & 38.5 & 39.1 & 39.7 & 37.3 \\ 1.4770 & 1.4844 & 1.4844 & 1.4602 & 1.4566 & 1.4536 & 1.4504 & 1.4616\end{array}$

ELEMENTALS. WtK

$12.50 \div 12.15: 12.22 \div 13.29 \div 13.16: 13.60: 13.15: 13.22:$

SIHULATEO OISTILLATIOK. F

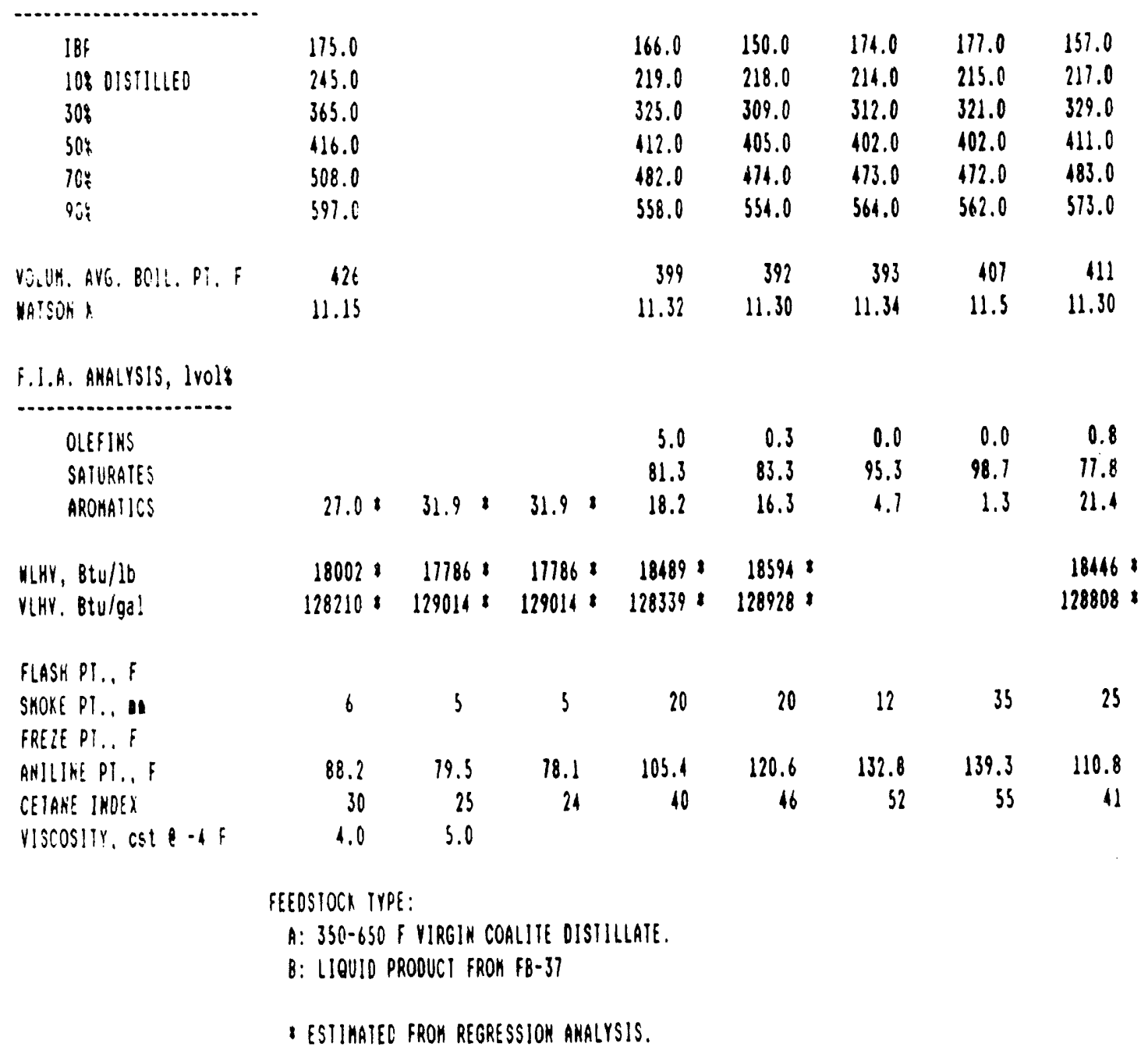


TABLE $5.2 .1-3 B \quad 4$ of 4

SUHAARY OF PROPERIIES OF FULL-RAMGE HYOROTREATEO COALITEO PROOUCTS

FROH FIXEO-BED HYOROTREATING

CATALYST: K-55O (1ST STAGE)

FILE ID: REPTBP?

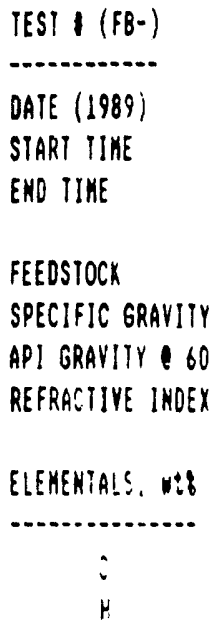

\begin{tabular}{rrrrrr}
12 & \multicolumn{1}{c}{13} & \multicolumn{1}{c}{46} & \multicolumn{1}{c}{47} & \multicolumn{1}{c}{48} & \multicolumn{1}{c}{49} \\
\hdashline $02-06$ & $02 \cdot 06$ & $02-21 / 22$ & $02-22$ & $02-23$ & $02-24$ \\
$12: 05$ & $18: 45$ & $03: 45$ & $05: 45$ & $02: 00$ & $00: 00$ \\
$17: 35$ & $20: 40$ & $04: 00$ & $24: 00$ & $22: 00$ & $20: 00$ \\
& & & & & \\
$A$ & $C$ & $A$ & 0 & $A$ & $A$ \\
0.9365 & 0.8270 & 0.8462 & 0.8285 & 0.8333 & 0.9328 \\
19.6 & 39.6 & 35.7 & 39.3 & 38.3 & 20.2 \\
1.5112 & 1.4522 & 1.4659 & 1.4526 & 1.4590 & 1.5144
\end{tabular}

SIMULATEO DISIILLATIOK, F

186
108 OISTLLLE
305
$50 \%$
709
909

VIUU., AVG. BOIL, DI, F

$\begin{array}{rrrrr}10.88,13.67: & 86.6 & 85.8 & 86.0 & 83.8 \\ 13.10 & 14.0 & 13.50 & 10.8\end{array}$

WhISOH 1

$\begin{array}{rrrrr}171.0 & 148.0 & 159.0 & 104.0 & 186.0 \\ 215.0 & 219.0 & 219.0 & 218.0 & 354.0 \\ 322.0 & 334.0 & 315.0 & 315.0 & 431.0 \\ 402.0 & 419.0 & 403.0 & 405.0 & 490.0 \\ 468.0 & 490.0 & 412.0 & 175.0 & 553.0 \\ 560.0 & 517.0 & 561.0 & 569.0 & 635.0 \\ & & & & \\ 393 & 408 & 394 & 396 & 193 \\ 11.4 & 11.2 & 11.4 & 11.3 & 10.5\end{array}$

F.I.A. ANALYSIS, IVOIS

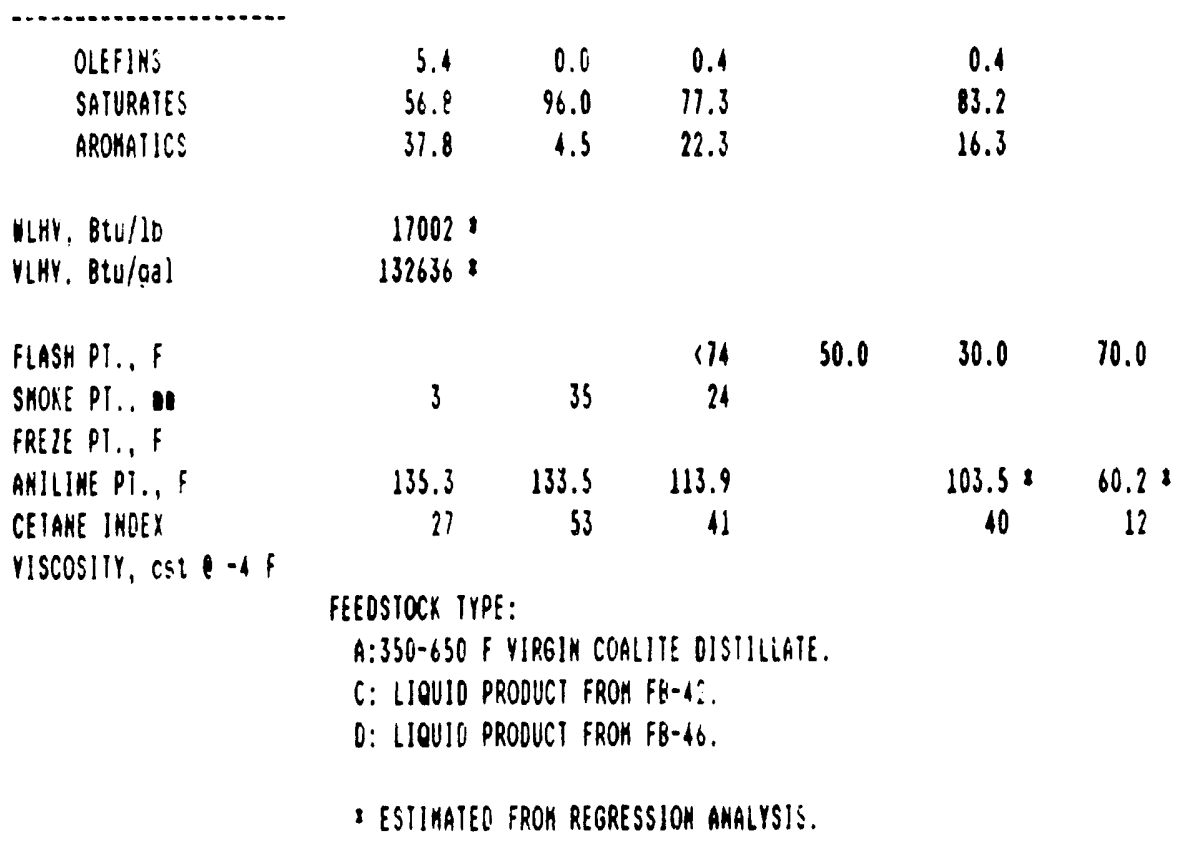


TABLE $5 \cdot 2 \cdot 1-4$ A

SUHHARY OF OPERATING RESULTS FOR FIXEO-BED COALITE HYOROTREATIMG IESTS

CATRLYST: K-S5O (IST STAGE)

FILE ID: REPTBE3.UK!

\begin{tabular}{|c|c|c|c|c|c|c|c|c|}
\hline IEST $\mid(F B-)$ & 30 & 31 & 32 & 33 & 34 & 35 & $36-1$ & $36-2$ \\
\hline OAIE (1989) & $01-25$ & $01-25$ & $01-26$ & $01-26$ & $01-27$ & $01-27$ & $01-30$ & $01-30$ \\
\hline START IIME & 19:00 & $20: 55$ & $12: 55$ & $16: 15$ & $13: 25$ & $16: 45$ & $13: 40$ & $14: 10$ \\
\hline END IIKE & 20:00 & 21:55 & $13: 55$ & 22:00 & $14: 10$ & 18:45 & 14:10 & 14:40 \\
\hline FEEDSTOCK & A & A & A & A & 8 & 8 & c & c \\
\hline 8 HOS & 98.39 & & 91.90 & 95.18 & 98.55 & 97.94 & & 98.62 \\
\hline$\&$ HON & 86.49 & & -3.12 & 100.00 & 18.68 & 89.18 & & 100.00 \\
\hline$\&$ HDO & 93.48 & & 22.92 & 99.02 & 92.95 & 89.36 & & 97.20 \\
\hline H2 UPTAKE, scf/DDI & 5000 & 5000 & 5000 & 5000 & 5000 & 5000 & 5000 & 5000 \\
\hline I F.I.A. OLEFINS SATURATIOK & 93.94 & 96.28 & 93.90 & & & 95.13 & & 100.00 \\
\hline I F.I.A. AROKATICS SAIURAIIOH & 37.48 & 46.47 & 33.87 & $65.90 \%$ & $19.07:$ & 85.13 & 87.758 & 97.83 \\
\hline API IHPROVEKENT & 20.3 & 20.4 & 10.7 & 24.0 & 26.5 & 28.9 & 29.2 & 29.4 \\
\hline R.1. OEPRESSIOK & 0.0552 & 0.0551 & 0.0328 & 0.0676 & 0.0778 & 0.0860 & 0.0864 & 0.0887 \\
\hline EST. HEAT OF REACTIOH, BtU/1D & 23.60 & 26.80 & 16.00 & & & 51.90 & & 57.60 \\
\hline
\end{tabular}

FEEOSTOCK IYPE:

A: 35T-S5O F VIRGIN COALIIE DISTILLATE.

B: LIOUID PROOUCT FROH FB-33.

C: LLQUID PROOUCT FROH FB-34/FB-35.

I ESTIKATEQ FROH REgRESSIOH aMaLYSIS. 
TABLE $5 \cdot 2 \cdot 1-4 \mathrm{~B}$

SUMMARY OF PROPERTIES OF FULL-RAMGE HYDROTREATEO COALIIE PRODUCTS

FROH FIXED-BED HYDROTREATING

CATALYST: K-950 (15T SIAGE)

TEST (FB-)

-............

DAIE (1989)

STARI IIAE

ENO VIHE

FEEDSTOCK

SPECIFIC GRAVITY, QO/LG

API GRAVITY $60 \mathrm{~F}$

REFRACTIVE INDEX $\& 200$

ELEMENIALS, WT:

h

87.30

12.21

12.26

83.57

87.13

12.78

86.02

85.49

13.94

13.91

85.55

13.35

FILE ID: REPTBPJ

$\begin{array}{cc}36-1 & 36-2 \\ 01-30 & 01-30 \\ 13: 40 & 14: 10 \\ 14: 10 & 14: 10\end{array}$

SIMULATEE DISTILLATIOK, F

IB!

10\% DISTILLED

30:

50:

$70 \%$

$90 \%$

VO:LR. AVE. BCHE, PI, F

VATSON $K$

F.I.A. ANALYSIS. IVOI\%

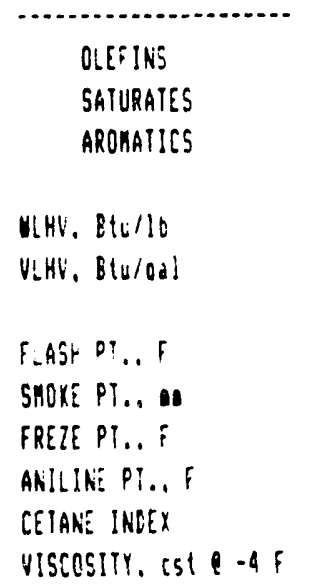

FEEDSTOCK IYfE:
173

220

296

392

461

527

379

11.16
174

219

274

$36 !$

419

498

354

11.40

$\begin{array}{rrrrrrrr}0.8 & 0.5 & 0.8 & & & 0.4 & & 0.0 \\ 39.7 & 65.0 & 57.5 & & & 92.2 & & 98.4 \\ 39.6 & 34.5 & 11.6 & 21.6 & 14.71 & 7.4 & 8.91 & 1.6 \\ & & & & & & & \\ 17995 & 17605 & 16645 & 18072 & 18251 & 18600 & 18582 & 18512 \\ 128478 & 125609 & 126174 & 126197 & 125575 & 126211 & 125874 & 125261\end{array}$

$\begin{array}{rrrrrrr}12 & 61 & 9 & 30 & 30 & 30 \\ 74.5 & 80.2 & 60.8 & 101.31 & 125.4 & 135.7 \\ 25 & 27 & 15 & 38 & 53 & 58\end{array}$

A: 350-550 ए VIRGIN COALIIE OISTILLATE.

B: LIOUID PRODUET FROK FB-3J.

C: LIOUID PRODUCT FROA FB-34/FE-35.

I ESTIKATEC FROK REGRESSION ANALYSIE. 
TABLE $5.2 \cdot 1-5 \mathrm{~A}$

SUMHARY OF OPERAIING RESULTS FOR FIXEO-BEO COALIIE HYOROIREATING IESTS

CAIALYST: K-53O (1ST STAGE)/K-S5O (2HO STAGE)

IEST I (FB-)

DATE (1989)

START IIME

ENO TIME

FEEOSTOCK

I HOS

I HOH

HOO

H2 UPTAKE, scf/bbi
\$F.I.A. OLEFIHS SATURATIOH

8.I.A. aROHATICS SaTURATIOH

API IMPROVEREKT

R.1. DEPRESSIOK

EST. HEAT OF REACTION. BtU/Lb

$\begin{array}{llllllll}8000 & 8000 & 8000 & 8000 & 8000 & 8000 & 8000 & 8000\end{array}$

$\begin{array}{lll}34.6 & 33.6 & 33.9\end{array}$

30.6

28.1

22.7

$18.5 \quad 25.4$

FILE ID: REPTBEA, UKL

\begin{tabular}{cccccccc}
169 & 172 & 170 & 173 & 174 & 175 & 176 & 177 \\
\hdashline $06-21$ & $06-29$ & $06-28$ & $06-29$ & $06-30$ & $06-30$ & $06-30$ & $06-30$ \\
$04: 30$ & $09: 00$ & $00: 00$ & $15: 30$ & $22: 00$ & $02: 00$ & $06: 00$ & $10: 00$ \\
$20: 00$ & $10: 00$ & $12: 00$ & $20: 00$ & $24: 00$ & $04: 00$ & $08: 00$ & $20: 00$ \\
& & & & & & & \\
1 & $A$ & $B$ & $B$ & $B$ & $B$ & $B$ & $B$
\end{tabular}

$90 \quad 75.4$

$\begin{array}{lll}1.4699 & 1.4716 \quad 1.4103\end{array}$

FEEOSTOCK IYPE:

A: $350-750$ F VIRGIN COALITE OISIILLATE.

8: 350-820 \& VIRGIN COALIIE DISTLLLATE. 
IABLE $5 \cdot 2 \cdot 1-5 B$

SUHAARY OF PROPERTIES OF FULL-RAMGE hYOROTREATEO CORLITE PROOUCTS

FROH FIXED-BED HYOROIREAIING

CATALYST: K-5SO (1ST STAGE)/K-5SO (2NO STAGE)

FILE IO: REPTBPA.UKI

\begin{tabular}{|c|c|c|c|c|c|c|c|c|}
\hline IEST $:$ (FB-) & 169 & 172 & 170 & 173 & 174 & 175 & 176 & 177 \\
\hline (n.................. & (n............. & (n........... & (nen. & 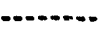 & (n).......... & 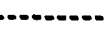 & -........ & $\ldots$ \\
\hline DATE (1989) & $06-27$ & $06-29$ & $06-28$ & $06-29$ & $06-30$ & $06-30$ & $06-30$ & $06-30$ \\
\hline START IIME & $04: 30$ & 09:00 & $00: 00$ & $15: 30$ & 22:00 & $02: 00$ & $06: 00$ & $10: 00$ \\
\hline ENO TIME & $20: 00$ & 10:00 & 12:00 & 20:00 & $24: 00$ & $04: 00$ & 08:00 & $20: 00$ \\
\hline FEEDSTOCK & $A$ & A & $B$ & $B$ & $B$ & $B$ & 8 & 8 \\
\hline SPECIFIC GRAVIIY, GD/CC & 0.8519 & 0.8571 & 0.8555 & 0.8729 & 0.8866 & 0.9176 & 0.9433 & 0.9018 \\
\hline AP] GRAYIIY $160 \mathrm{~F}$ & 34.6 & 33.6 & 33.9 & 30.6 & 28.1 & 22.7 & 18.5 & 25.1 \\
\hline REFRACTIVE INOEX Q $20 \mathrm{C}$ & 1.4699 & 1.4716 & 1.4703 & 0.8729 & 0.8866 & 0.9176 & 0.9433 & 0.9018 \\
\hline \multicolumn{9}{|l|}{ ELEMENTALS, UIZ } \\
\hline \multicolumn{9}{|l|}{ (n) } \\
\hline$c$ & 86.49 & 86.60 & 86.64 & & & & & 86.27 \\
\hline $\mathrm{H}$ & 13.19 & 13.37 & 13.30 & & & & & 11.86 \\
\hline
\end{tabular}

SIHULATEO OISIILLATIOH. $F$

IBP

108 OISIILLEO

308

508

508

108

908

VOLUH. AVi, BOIL, PI. F

WOISOH $X$

F.I.A. ANALYSIS. IVOIS

OLEFINS

SATURATES

AROKATICS

YLHY, BtU/Ib

VLHY. BtU/gal

FLASH PI., F

SHOKE PI., 1

FRELE PT., F

ANILINE PI, F

CETANE INOEY

visrositi. cst e -4 F

$\begin{array}{rrrr}2.0 & 0.0 & 1.3 & 0.8 \\ 86.8 & 83.1 & 82.6 & 50.8 \\ 11.3 & 16.3 & 16.1 & 18.4 \\ & & & \\ 18195 & 17876 & 18116 & 17563 \\ 29118 & 127564 & 129100 & 131933\end{array}$

17.6

26.6

10.4

71.15

13

FEEDSTOCK IYPE:

A: 350-750 F VIRGIN COALIIE DISTILLATE.

B: 350-820 \& VIRGIN CORLIIE OISTILLAIE. 
IABLE $5 \cdot 2 \cdot 1-6$ A

SUMHARY OF OPERATING RESULIS FOR FIXED-BED COALIIE HYOROTREATIMG TESTS

CATALYST: K-S5O (IST STAGE)/K-S99 (2HO STAGE)

TEST 1 (FB-)

DAIE (1989)

START IIHE

END IIME

FEEDSTOCK

\begin{tabular}{|c|c|c|c|c|c|c|}
\hline $94-1$ & $94-2$ & $94-3$ & 101 & 102 & 103 & 104 \\
\hline $04-05$ & $04-06$ & $04-06$ & $04-10$ & $04-10$ & $04-10$ & $04-10$ \\
\hline 21:00 & 01:00 & 05:00 & $05: 00$ & $09: 30$ & 14:00 & $18: 00$ \\
\hline 01:00 & 05:00 & 09:00 & $06: 30$ & 11:00 & $15: 30$ & 20:00 \\
\hline A & A & A & A & A & A & A \\
\hline
\end{tabular}

HOS

\&OK

HOO

H2 UPTAKE. SCf/bOI
F.1.A. OLEFIMS SATURATIOH

$\begin{array}{rrrrrrr}7000 & 7000 & 1000 & 1000 & 1000 & 7000 & 1000 \\ 94.1 & 90.1 & 100 & 91.4 & 95.7 & 95.2 & 95.2 \\ 94.4 & 93.9 & 93.8 & 59.5 & 64.2 & 79.8 & 80.5\end{array}$

API IMPROVERENT

R.I. OEPRESSION

$\begin{array}{lllllll}34.4 & 34 & 20.7 & 32.4 & 34.6 & 37.3 & 37.5\end{array}$

ESI. HEAT OF REACTIOH,BtU/16

$\begin{array}{lllllll}1.4672 & 1.4686 & 1.468 & 1.4763 & 1.4696 & 1.4585 & 1.4583\end{array}$

FEEOSIOCK TYPE:

A: 350-650 F VIRGIN COALITE DISTILLATE. 
TABLE $5.2 .1-6 \mathrm{~B}$

SUHHARY OF PROPERTIES OF FULL-RAMGE HYOROTREATEO COALIIE PROOUCTS

FROM FIXEO-BED KYOROTREATING

CATALYST: K-5SO (IST STAGE)/K-S99 (2ND STAGE)

IEST \& (F8-)

DAIE (1989)

START IIHE

EHD IIHE

FEEOSIOCK

SPECIFIC GRAYIIY, gD/CC

A.P.I. GRAYIIY O $60 \mathrm{~F}$

REFRACIIVE INDEX $20 \mathrm{C}$

ELEHENIAL, Mi.t

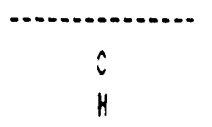

DISIILLAIIOH, F

$18 P$
108 IDSTILLEO
308
508
708
908

YOLUK, AYG, BOIL, PI, F NATSON $K$

F.I.A./R.I., IVOI.8
OLEFINS
SAIURAIES
AROHRTICS

VLHY, btU/LO.

VLhY, btu/gal.

FLASH PI., $F$

SHOKE PI.,

FREZE TP.. F

ANILINE PT. ,F

CEIAHE INOEX

YISCOSIIY, cst - - :

$\begin{array}{rrrrrrr}1.0 & 1.2 & 0.0 & 1.0 & 0.5 & 0.6 & 0.6 \\ 92.9 & 94.0 & 64.0 & 68.5 & 12.4 & 82.9 & 83.7 \\ 6.1 & 4.8 & 36.0 & 30.5 & 21.1 & 16.5 & 15.7\end{array}$

FILE IO :REPTBPS.VK

$\begin{array}{rrrrrrr}94-1 & 94-2 & 94-3 & 101 & 102 & 103 & 104 \\ 04-05 & 04-06 & 04-06 & 04-10 & 1-10 & 04-10 & 04-10 \\ 21: 00 & 01: 00 & 05: 00 & 05: 00 & 09: 30 & 14: 00 & 18: 00 \\ 01: 00 & 05: 00 & 09: 00 & 06: 30 & 11: 00 & 15: 30 & 20: 00 \\ & & & & & & \\ 0.8529 & 0.8550 & 0.8529 & 0.8633 & 0.8519 & 0.8383 & 0.8373 \\ 34.4 & 34.0 & 34.4 & 32.4 & 34.6 & 37.3 & 37.5 \\ 1.4672 & 1.4686 & 1.4680 & 1.4763 & 1.4696 & 1.4585 & 1.4583\end{array}$


TABLE $5.2 \cdot 1-7 \mathrm{~A}$

SUHMARY OF OPERATING RESULTS FOR FIXED-BEO COALIIE HYOROTREAIING IESTS

CATALYST: K-S99 (IST STAGE)

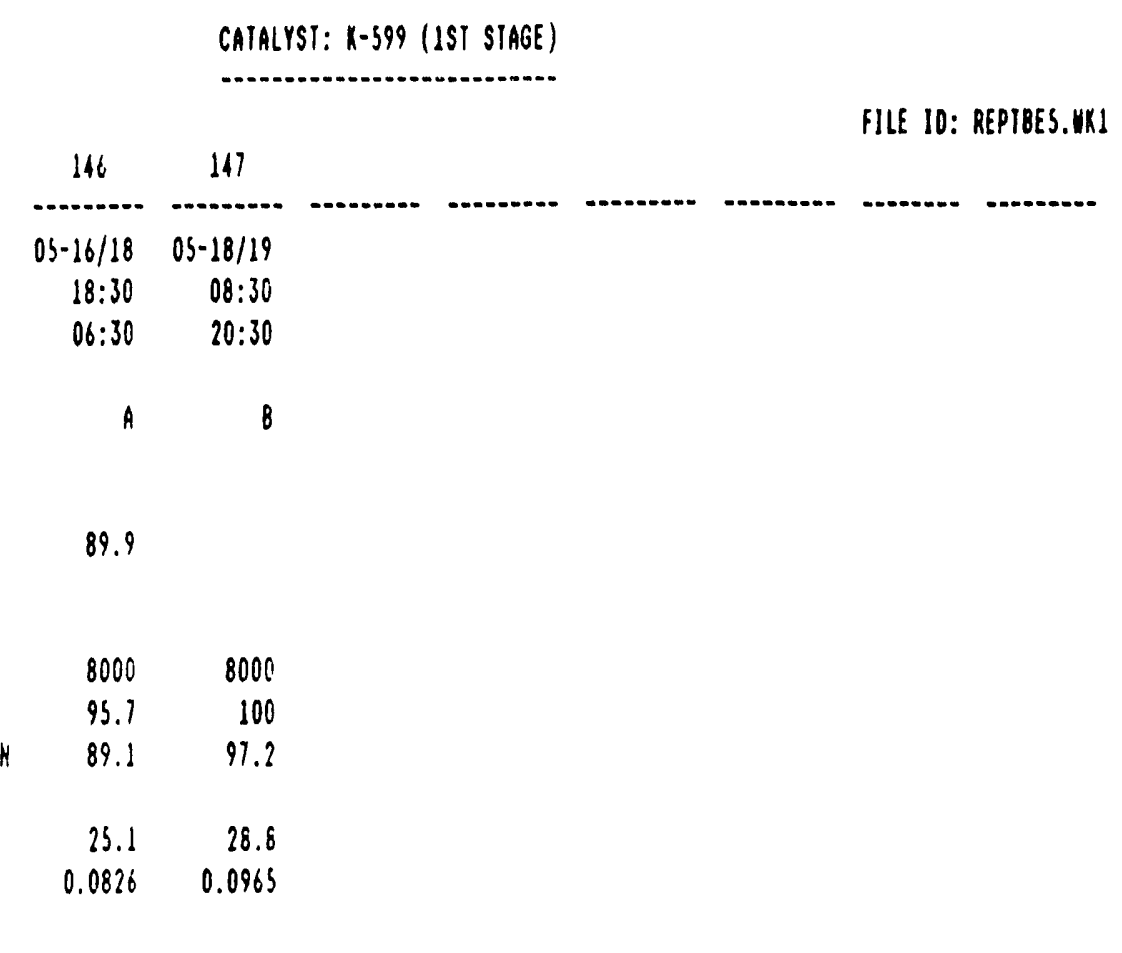

FEEDSTOCK IYPE:

A: 350-650 \& VIRGIN COALIIE DISTILLATE.

B: LLOUIO PROOUCT FROH FB-146. 
IABLE $5.2 .1-7 \mathrm{~B}$

SUMKARY OF PROPERTIES OF FULL-RANGE HYOROTREATED COALIIE PRODUCTS

FROH FIXED-BED HYOROTREATING

\section{CATALYST: X-S99 (1ST STAGE)}

FILE IO :REPIBPS.VK

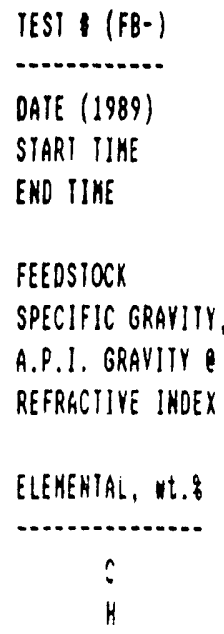

\begin{tabular}{rc}
146 & 147 \\
\hdashline $05-16 / 18$ & $05-18 / 19$ \\
$18: 30$ & $08: 30$ \\
$06: 30$ & $20: 30$ \\
& \\
$A$ & $B$ \\
0.8438 & 0.8256 \\
36.2 & 39.9 \\
1.4643 & 1.4504
\end{tabular}

$86.49 \quad 85.08$

$13.33 \quad 14.12$

DISTILLATIOK, F

$\begin{array}{lll}\text { IBD } & 157 & 155 \\ 108 \text { 10STILLED } & 217 & 216 \\ 308 & 336 & 314 \\ 508 & 126 & 403 \\ 708 & 492 & 472 \\ 908 & 579 & 563\end{array}$

VOLUK. AYS. BOIL. PI. F $\quad 110 \quad 394$ MAISON $K$

$11.23 \quad 11.40$

P.I.A./R.1.. IVOI.\&
OLEFINS
SATURATES
AROHATICS

VLHY, btu/lb. VLHY, btu/gal.

$\begin{array}{rr}0.5 & 0.3 \\ 91.4 & 96.2 \\ 8.1 & 3.5\end{array}$

FLASH PI., F SHOKE PT,, FREZE TP., F ANILINE PI., F CETARE INDE) viscosith, cst $-4 ;$

\section{FEEOSTOCK TYPE:}

A: 350-650 F VIRGIN CORLITE DISTILLATE.

B: LIQUIO PROOUCT FROH FB-14t. 


$$
\text { IABLE } 5.2 \cdot 1-8 \mathrm{~A}
$$

SUHAARY OF OPERATING RESULIS FOR FIXEO-BED CORLIIE HYDROIREAIING IESTS

\section{CATALYST: CACIUH PROHOTED K-SSO}

IEST I (FB-)

DATE (1989)

START IIME

ENO IIHE

FEEDSTOCK

1 KOS

1 HOH

$\& \mathrm{HOC}$

H? UPTAKE, SCf/Db]

I F.l.A. olefins Saturatiok

I F.I.A. arOHATICS SATURATIOH

AFI IMPROYENENT

R.I. OEPRESSIOH

EST. HEAT OF REACTIOK, BLU/lD
FILE ID: REPTCA3.UKL

\begin{tabular}{cccc}
135 & 136 & 137 & 138 \\
\hdashline$\ldots 4-26 / 27$ & $04-27 / 28$ & $04-28$ & $04-28$ \\
$21: 00$ & $17: 00$ & $13: 00$ & $18: 30$ \\
$13: 00$ & $09: 00$ & $15: 00$ & $20: 30$ \\
& & & \\
A & $A$ & $A$ & $A$
\end{tabular}

$\begin{array}{rrrr}1000 & 1000 & 1000 & 1000 \\ & 96.5 & 86.3 & 85.7 \\ & 93.5 & 11.1 & 39.1 \\ & & & \\ 20.4 & 27.1 & 27.8 & 12.1 \\ 0.0654 & 0.0926 & 0.0574 & 0.0009\end{array}$

FEEDSTOCK TYPE:

A: 350-65O F VIRGIH COALITE OISTILLATE. 
TABLE $5.2 .1-8 B$

SUMKARY OF PROPERTIES OF FU!L-RAMGE hYOROTREATEO COALITE PROOUCYS

CATALYST: CACIUH PROHOIEO $\times-550$

IEST $\mid(F B-)$

DATE (1989)

START IIME

ENO IIIKE

FEEOSTOCK

SPECIFIC GRAYITY, GO/CC

API GRAYITY O $60 \mathrm{~F}$

REFRACIIVE INOEX $20 \mathrm{C}$

\begin{tabular}{cccc}
135 & 136 & 137 & 138 \\
\hdashline $04-26 / 27$ & $04-21 / 28$ & $04-28$ & $04-28$ \\
$21: 00$ & $17: 00$ & $13: 00$ & $18: 30$ \\
$13: 00$ & $09: 00$ & $15: 00$ & $20: 30$
\end{tabular}

FILE 10: REPICA?

ELEMENTRLS, VIt

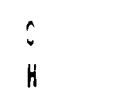

86.54
12.40

86.36

86.32

84.36

12.40

15.53

11.95

11.14

SIMULATEO DISIILLAIJOH, F

$18 F$

108 DISTILLEO

308

508

708

$90:$

VOLLH, AVG. BOIL, PI, F WATSON 1

\section{P.1.4. ANALYSIS. IVOII

OLEFINS
SAFURATES
AROHAIICS

NLHY, BtU/lO

VLHY, Btu/gal

FLASH PI., $F$ SHOKE PI., II FREELE PI., $P$ ANILINE PI., $F$ CEIANE INOEX Viscosity. cst - -4

$\begin{array}{rrrr}0.6 & 0.5 & 1.6 & 1.6 \\ 62.1 & 93.5 & 53.8 & 54.6 \\ 31.3 & 6.0 & 44.6 & 43.8\end{array}$

$18315 \quad 17553 \quad 17124$

$127208 \quad 128992 \quad 130475$

FEEDSIOÁR TYPE:

R: 350-65O F VIRGIN COALIIE DISTILLAIE. 


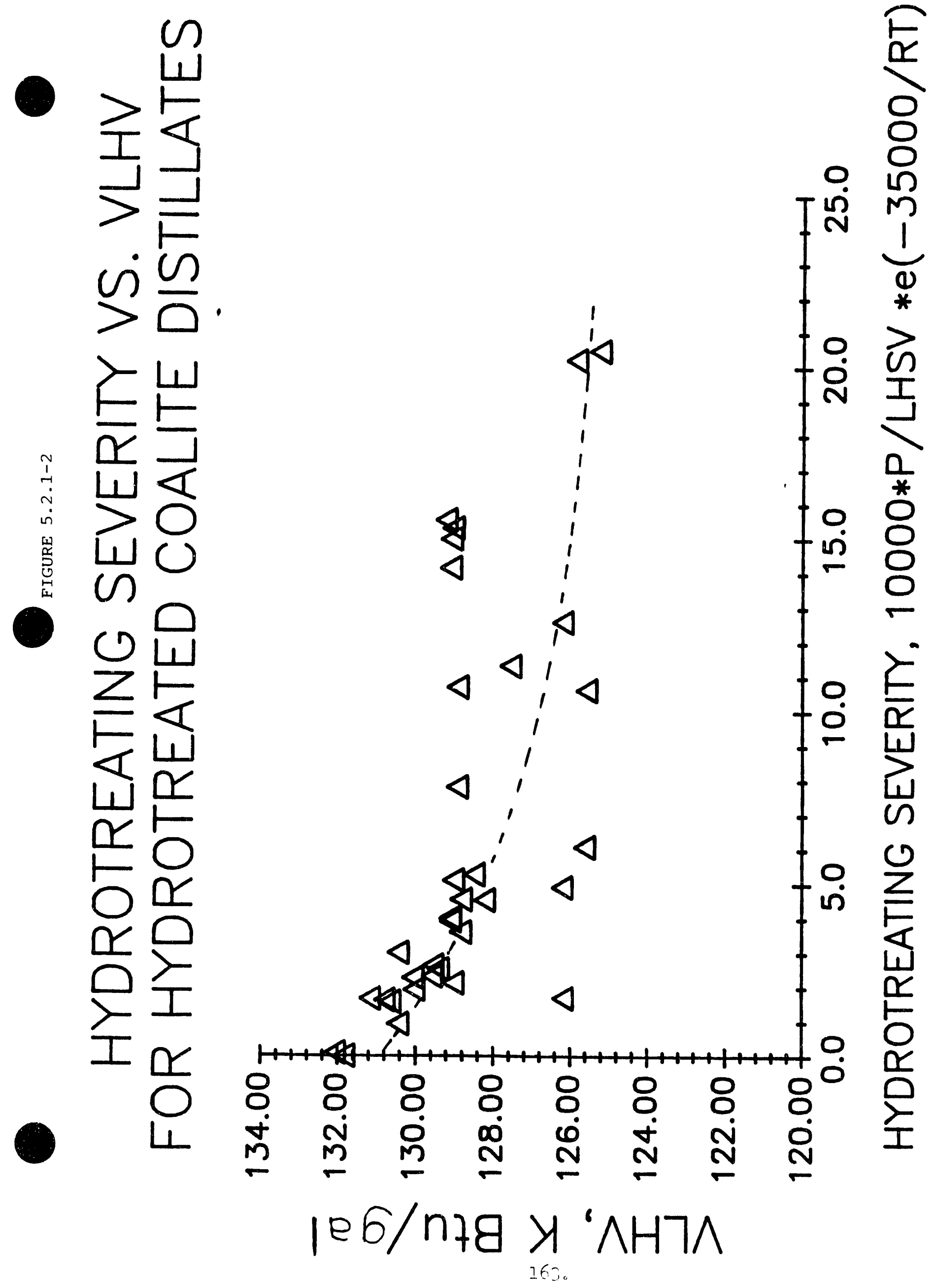



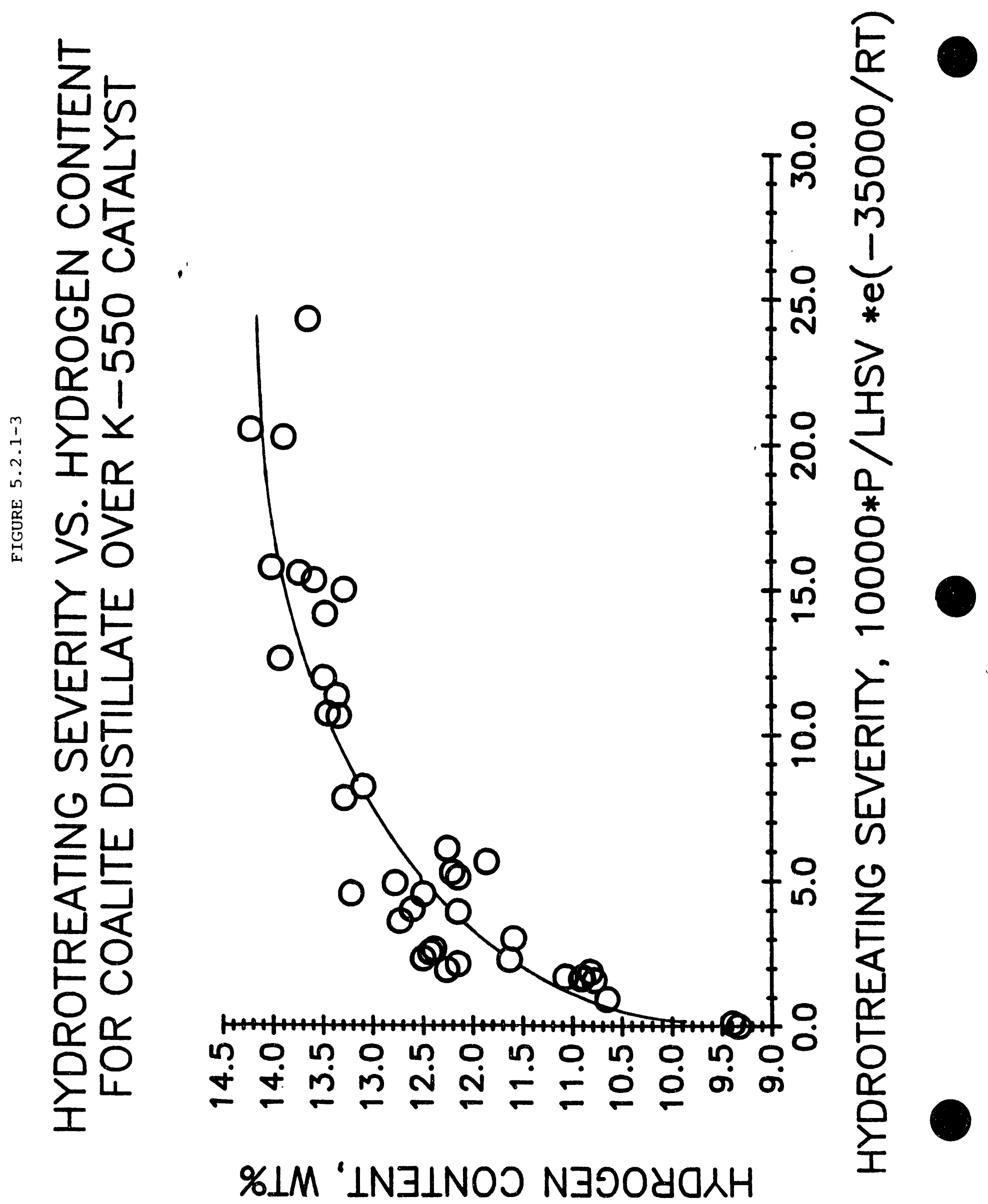


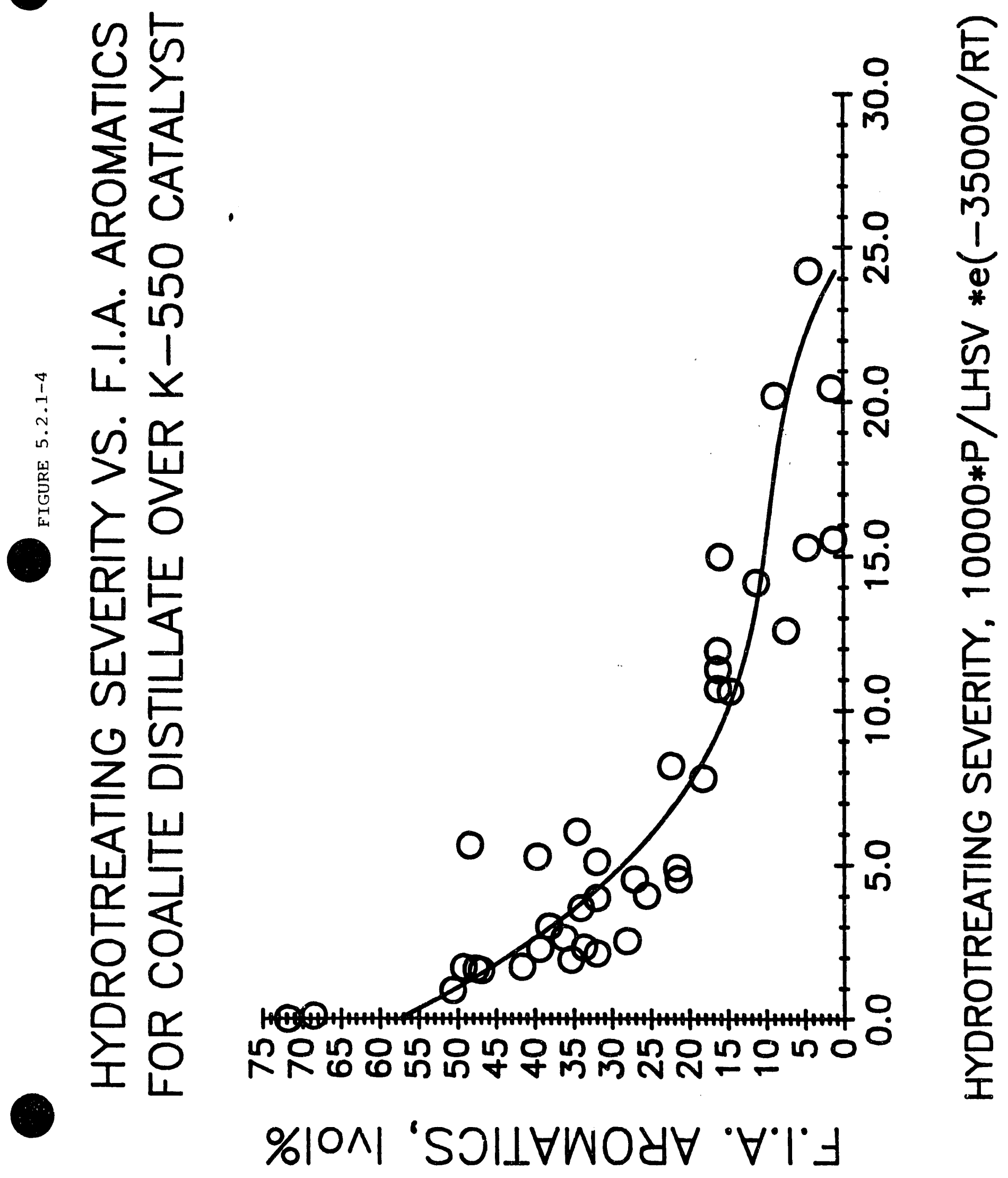




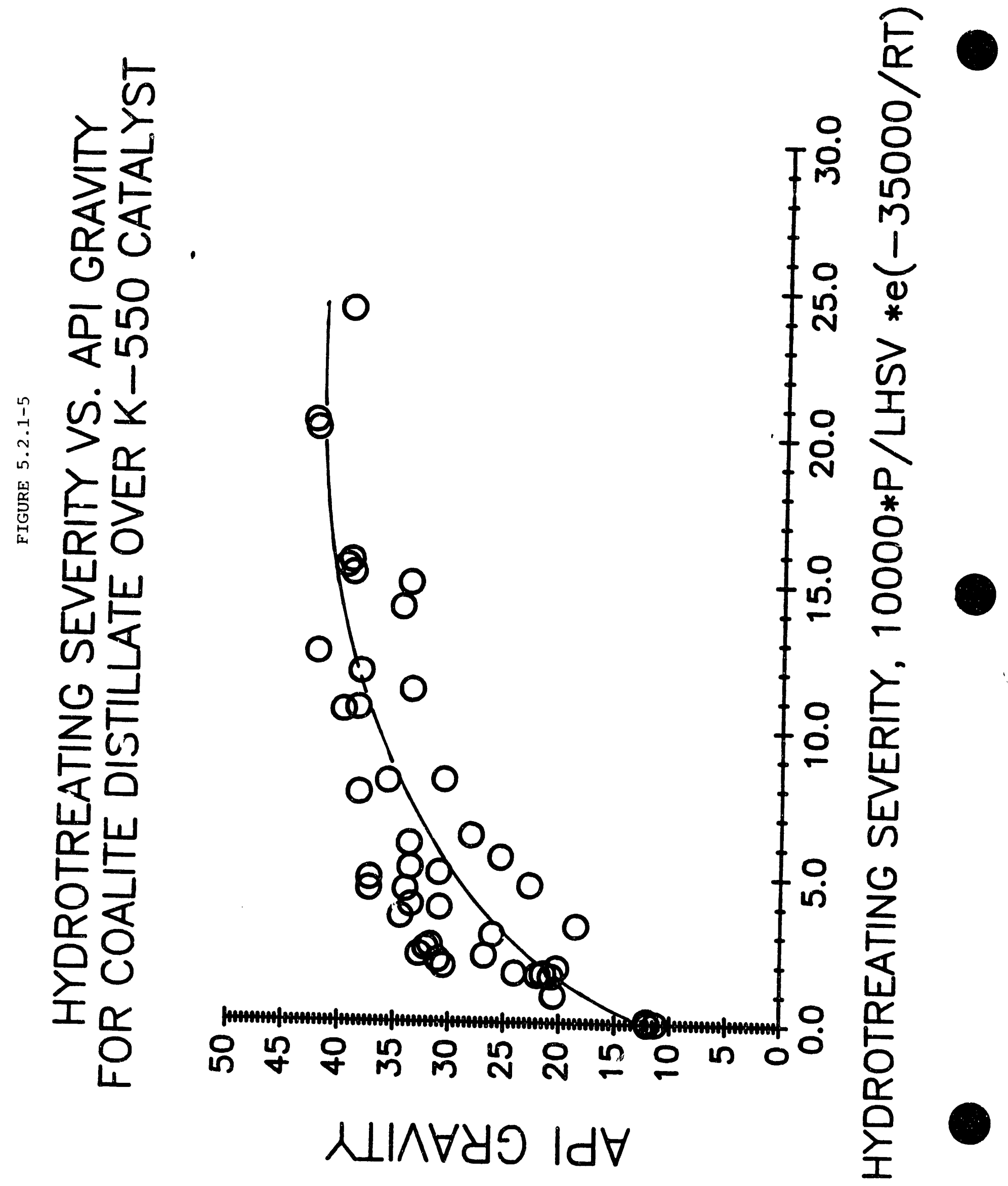




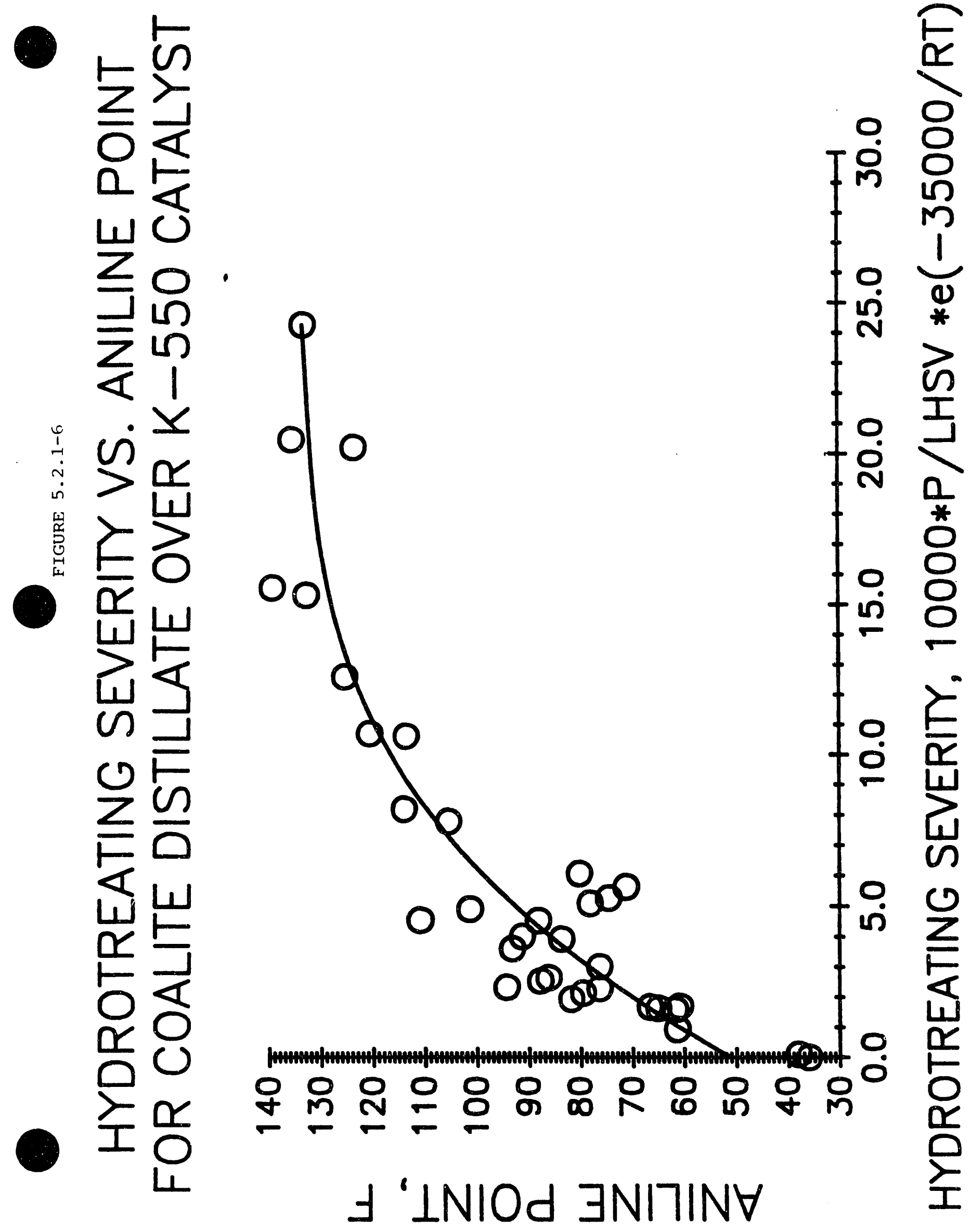



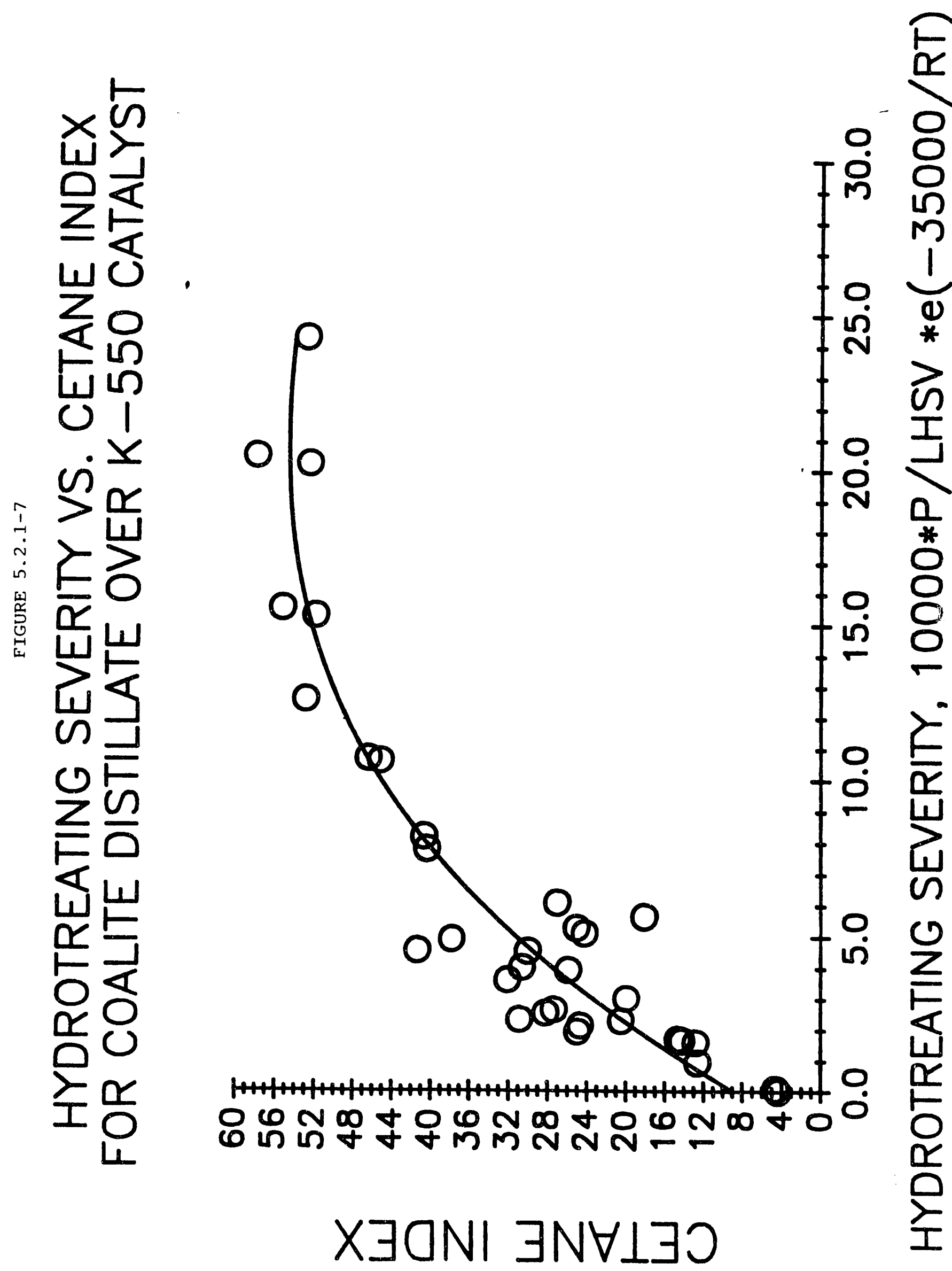

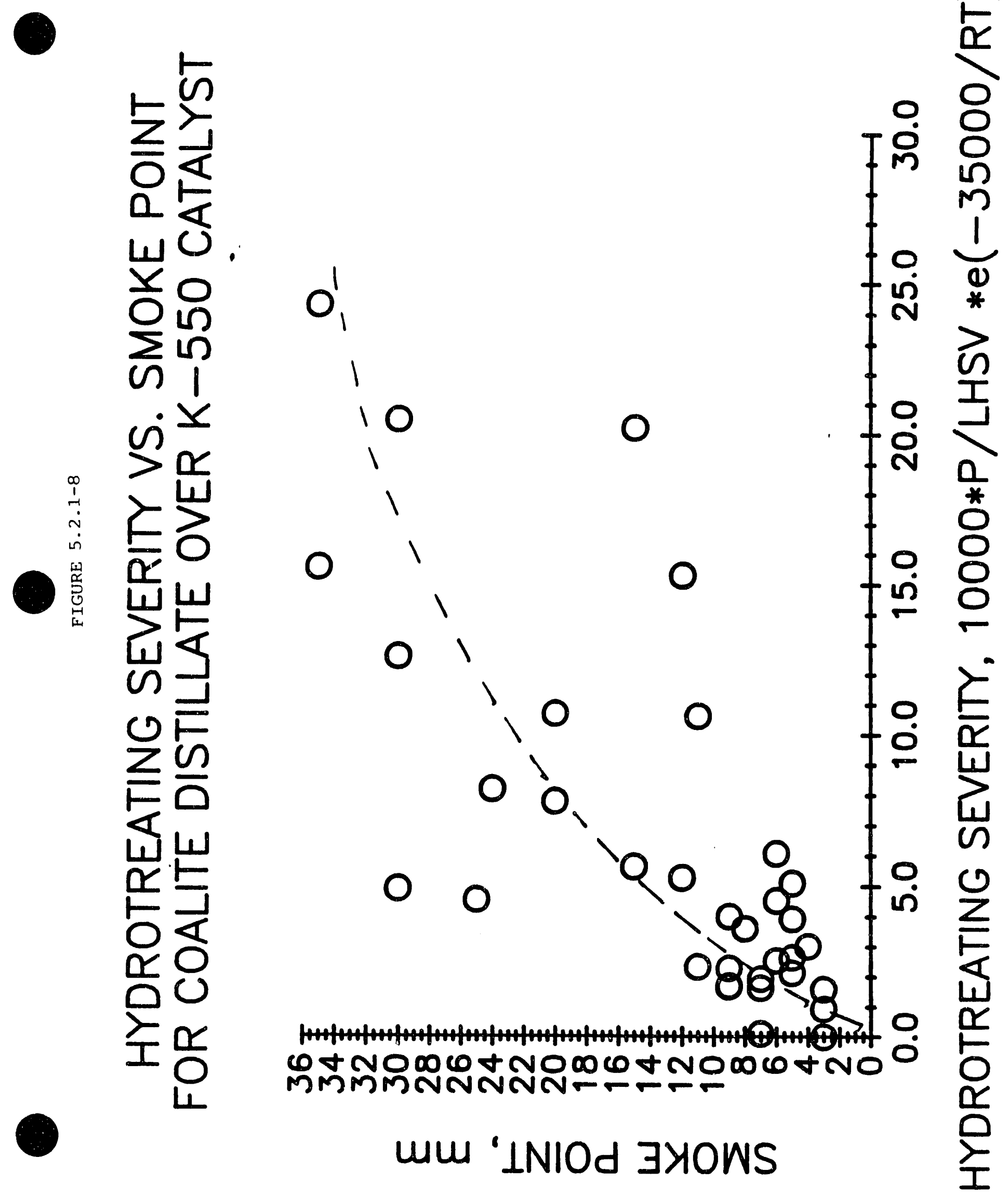

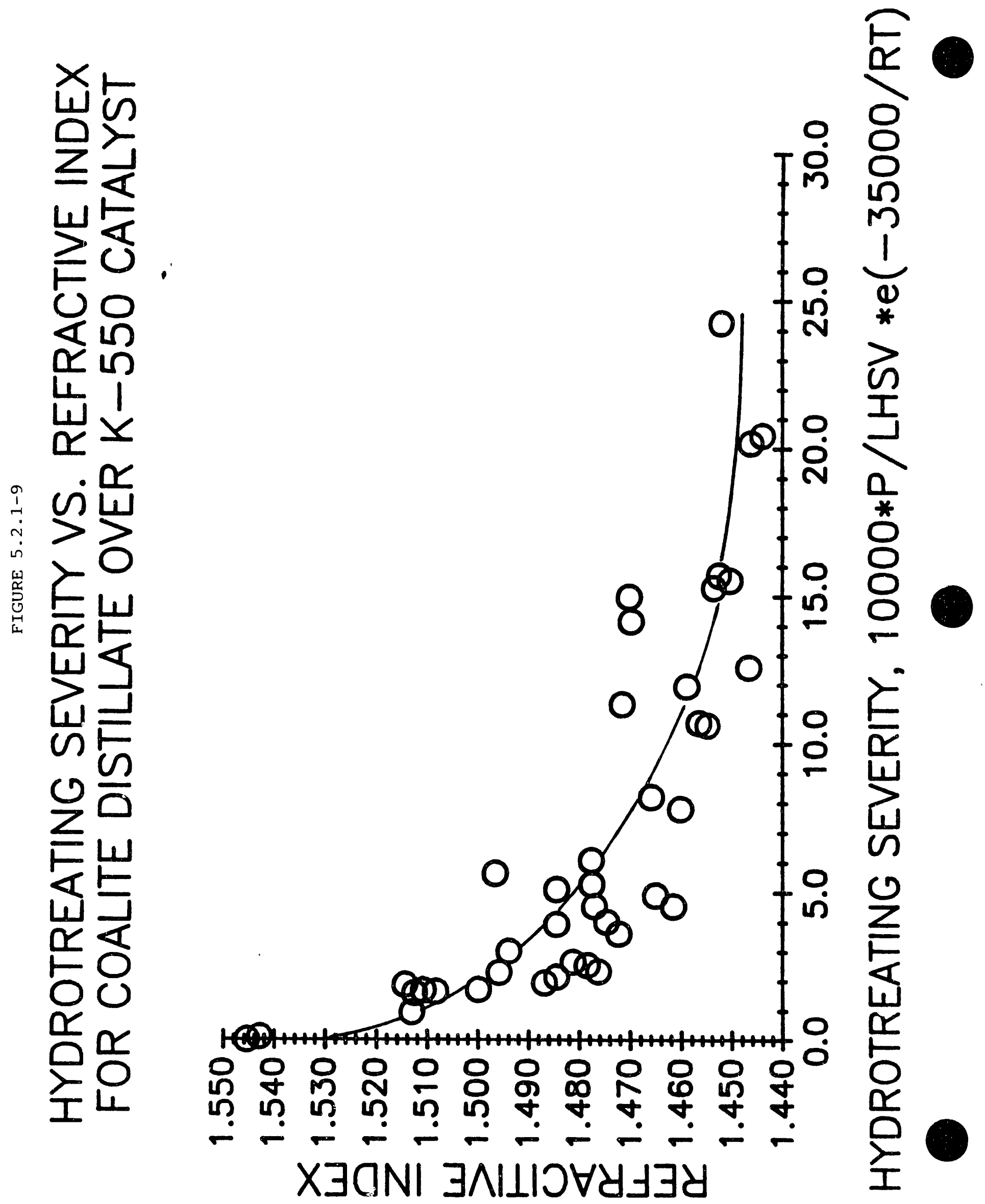


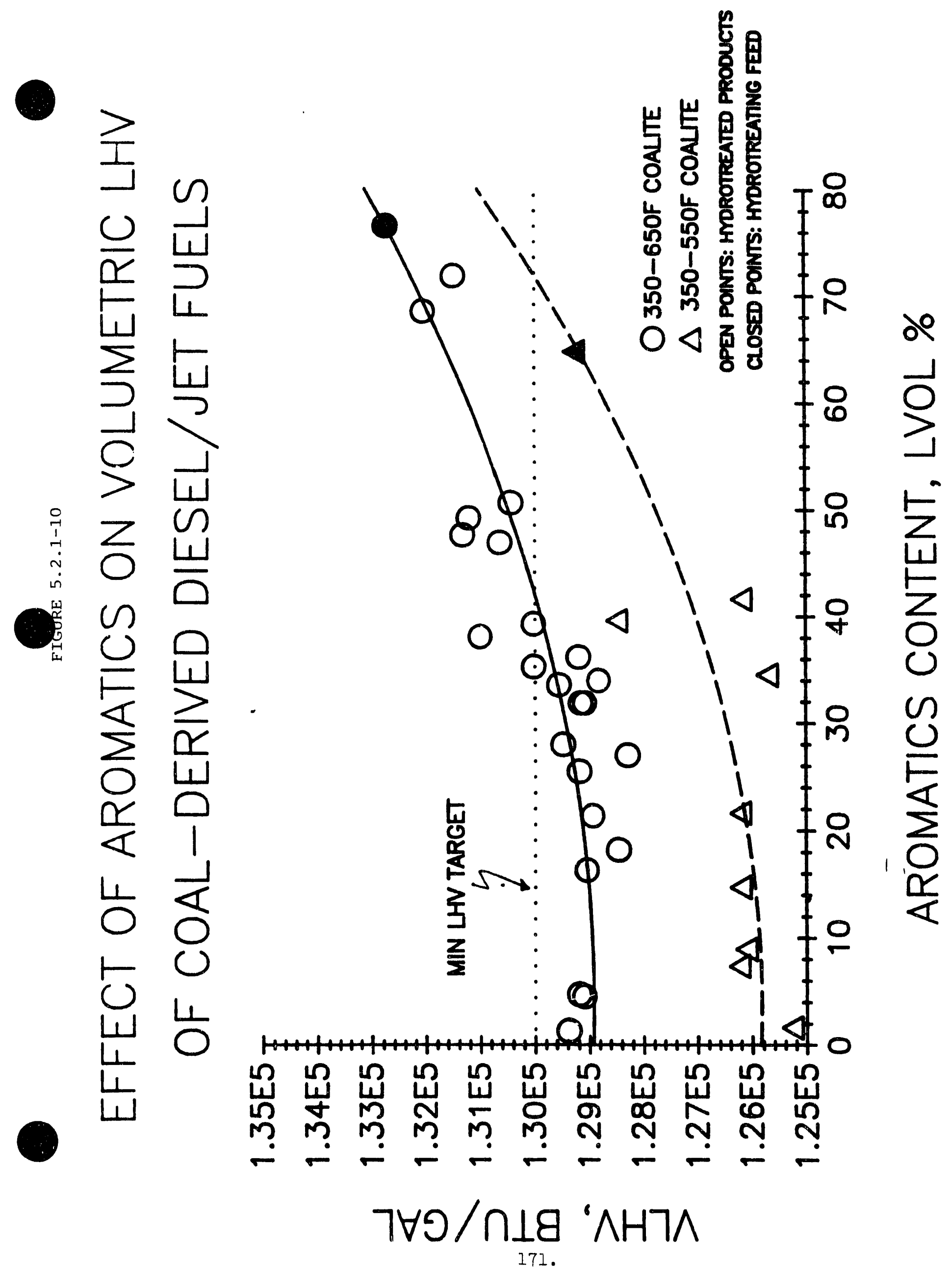




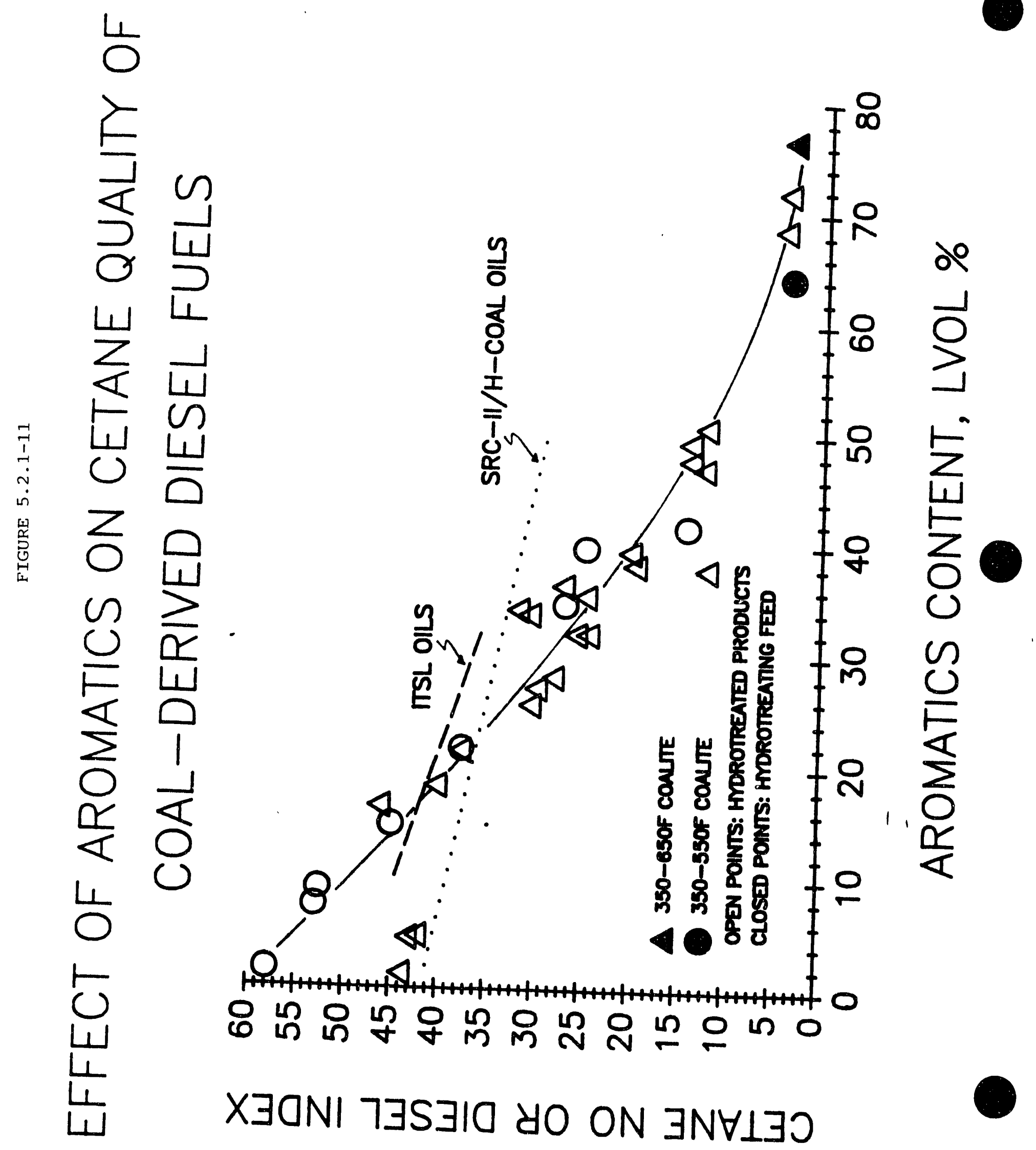




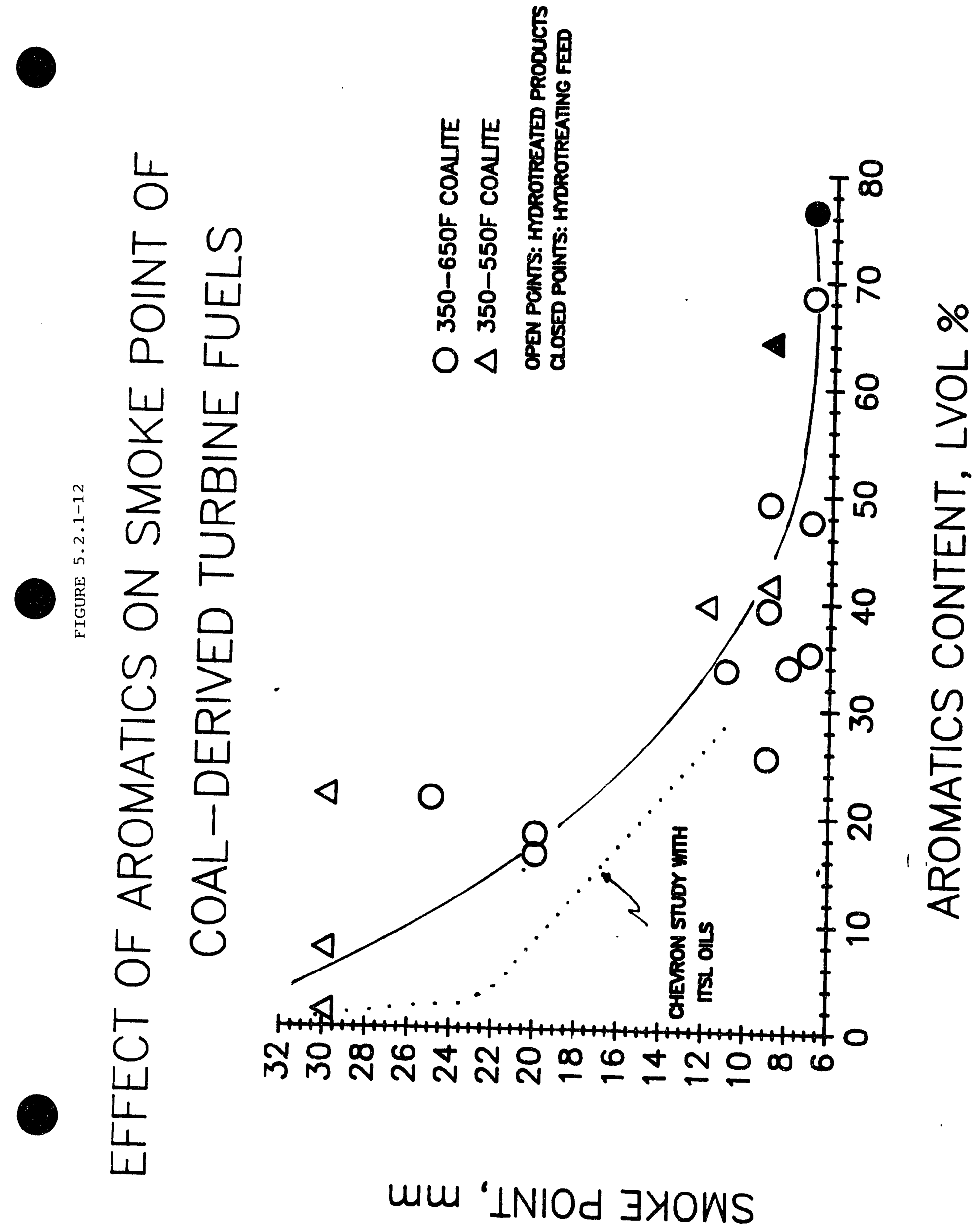




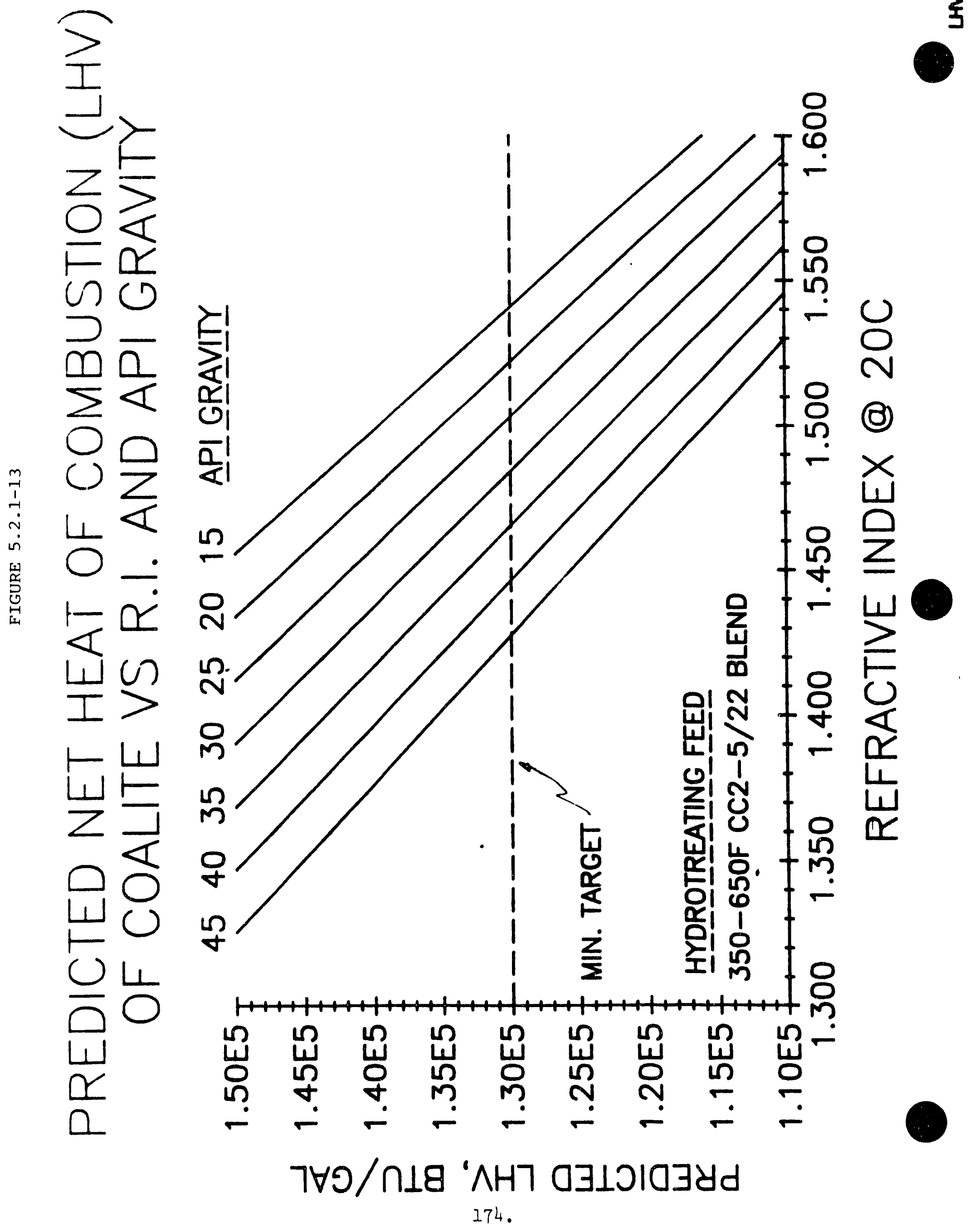




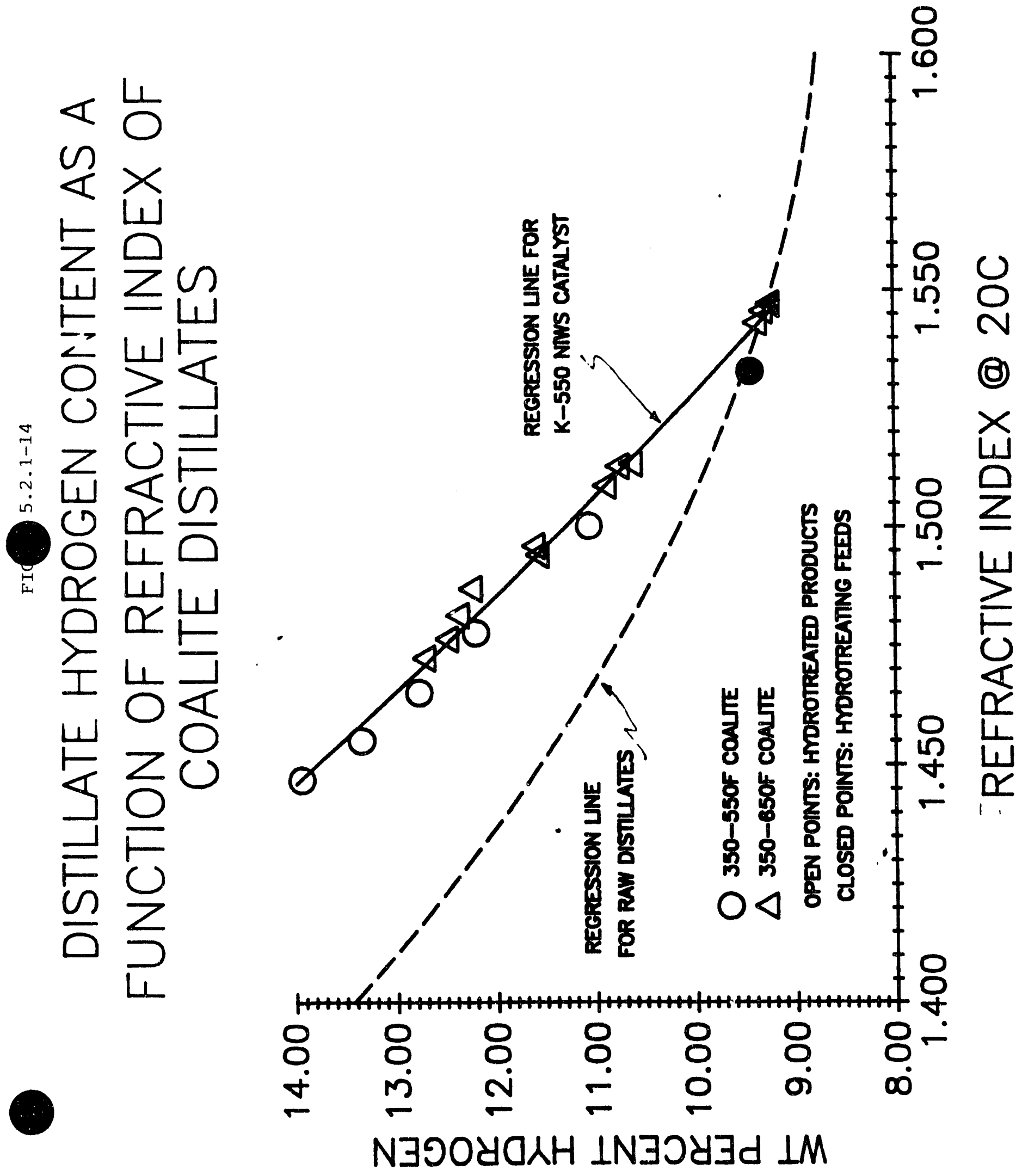



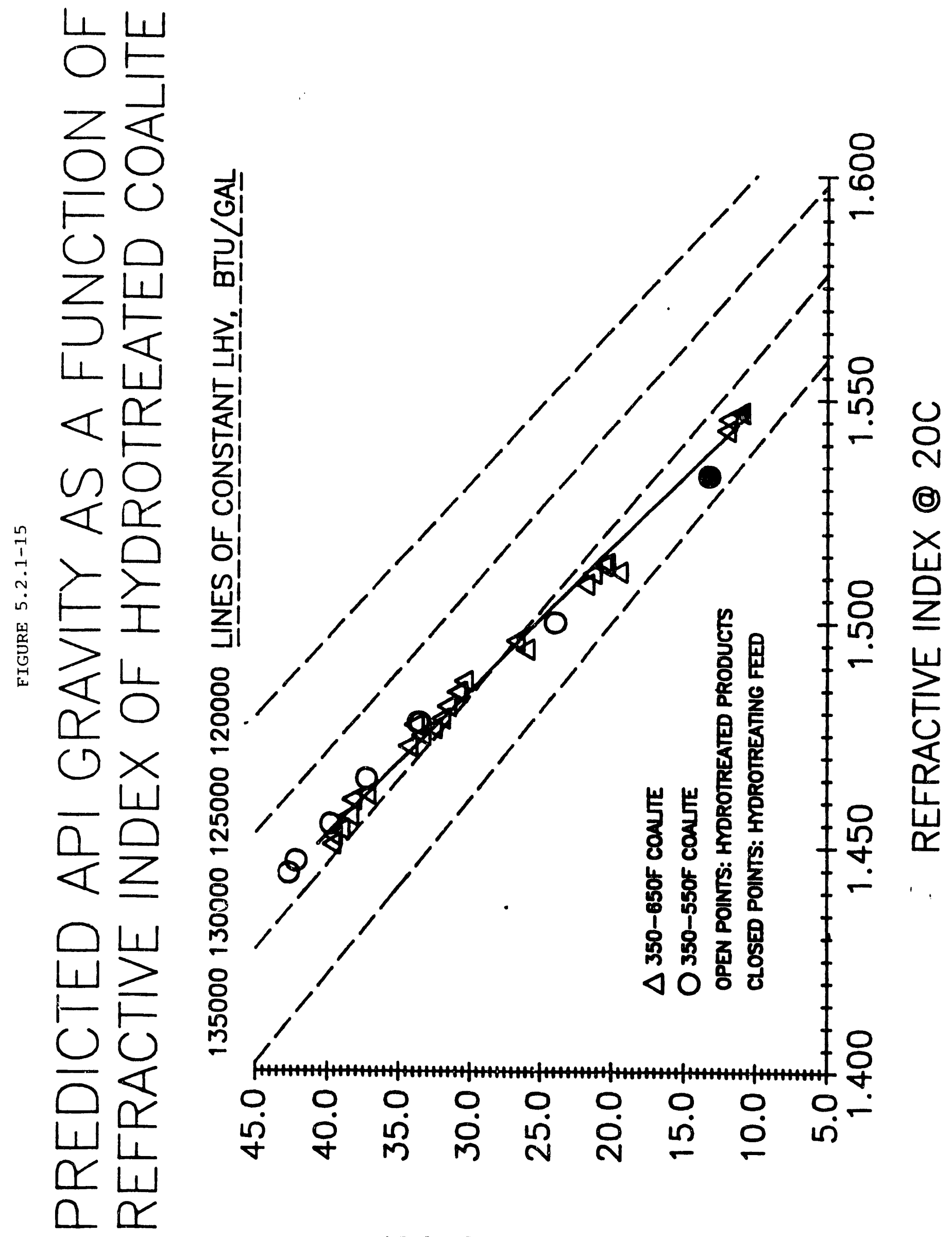

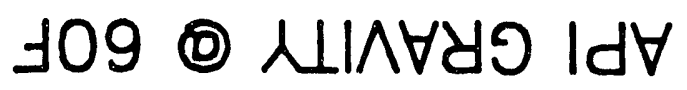



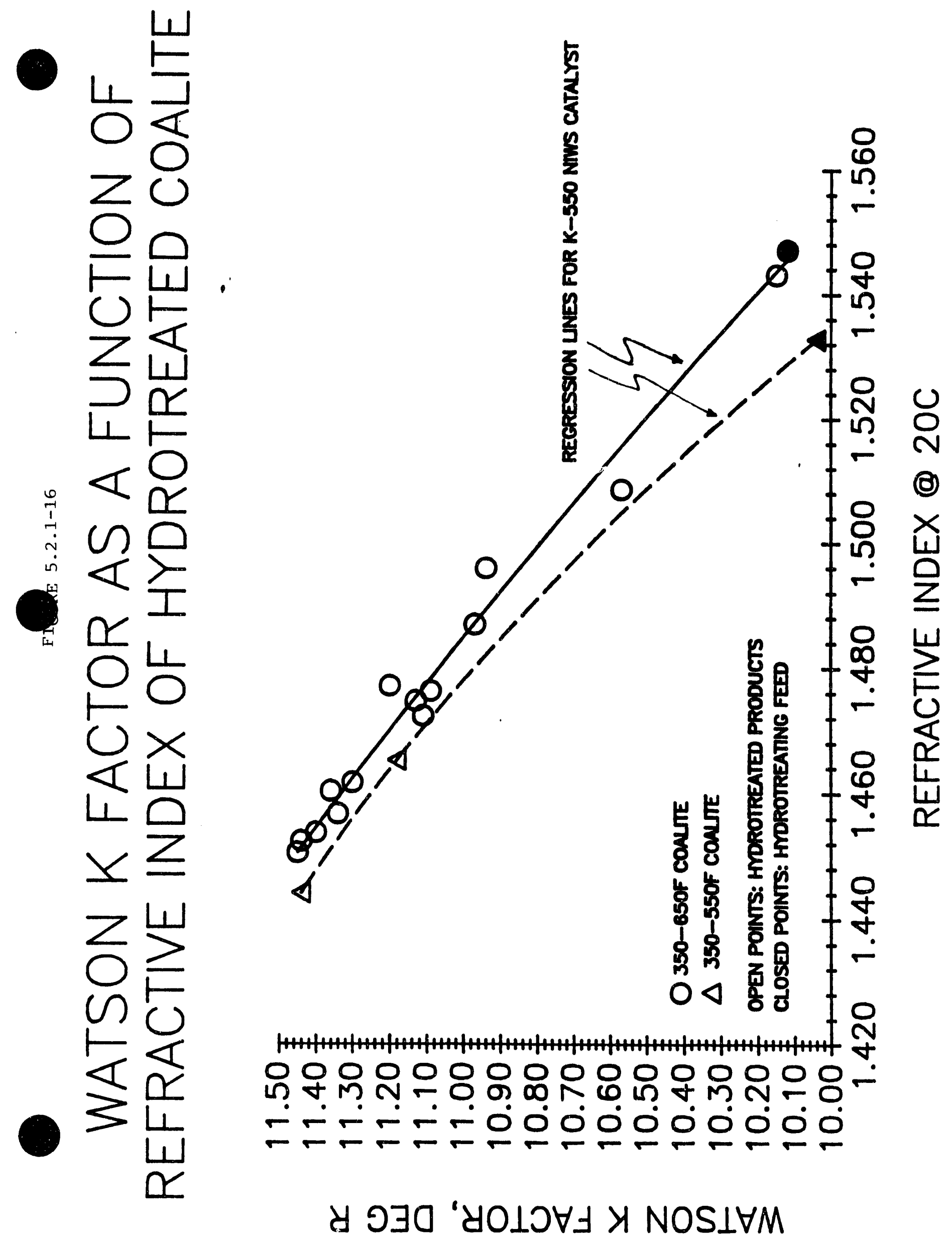

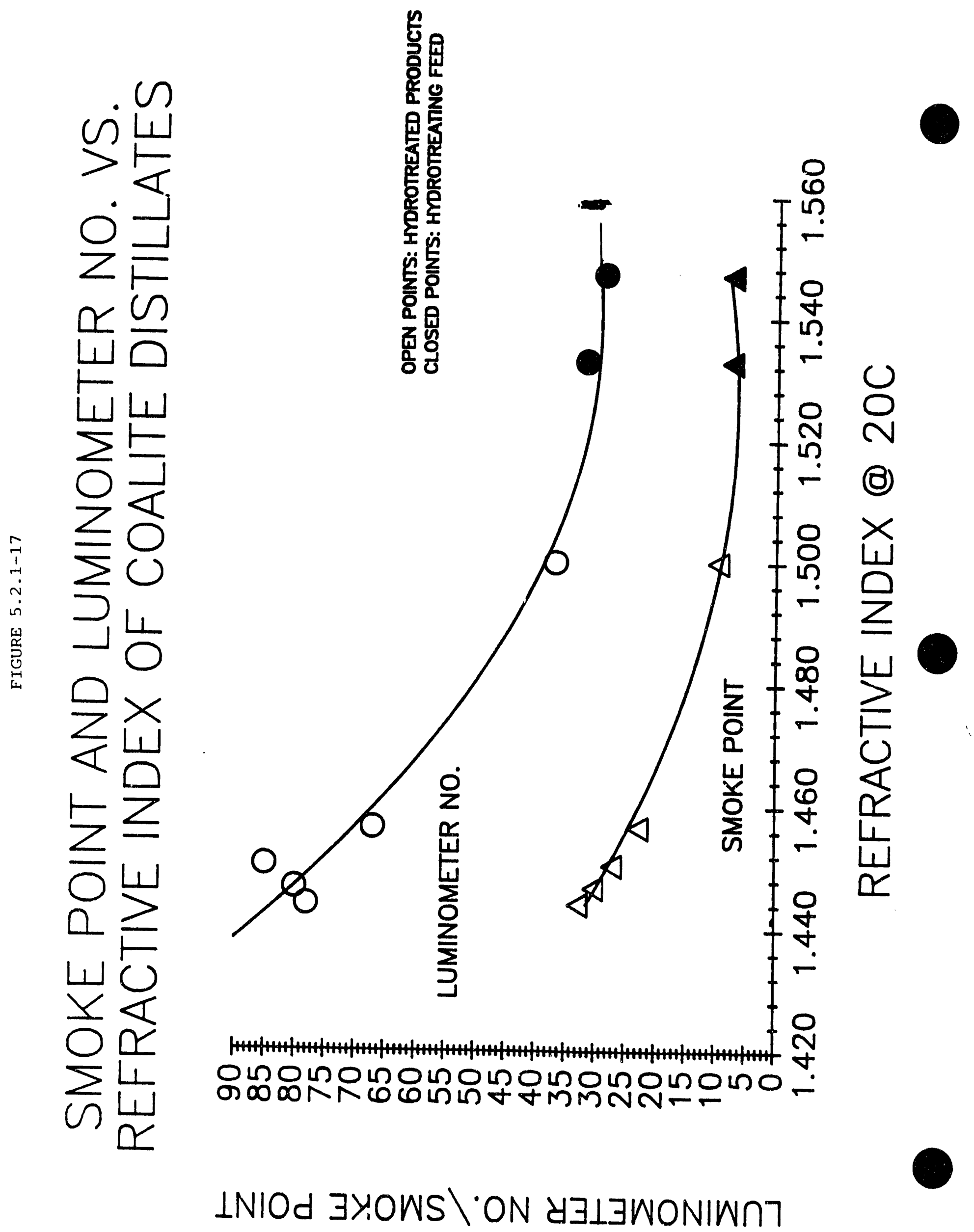


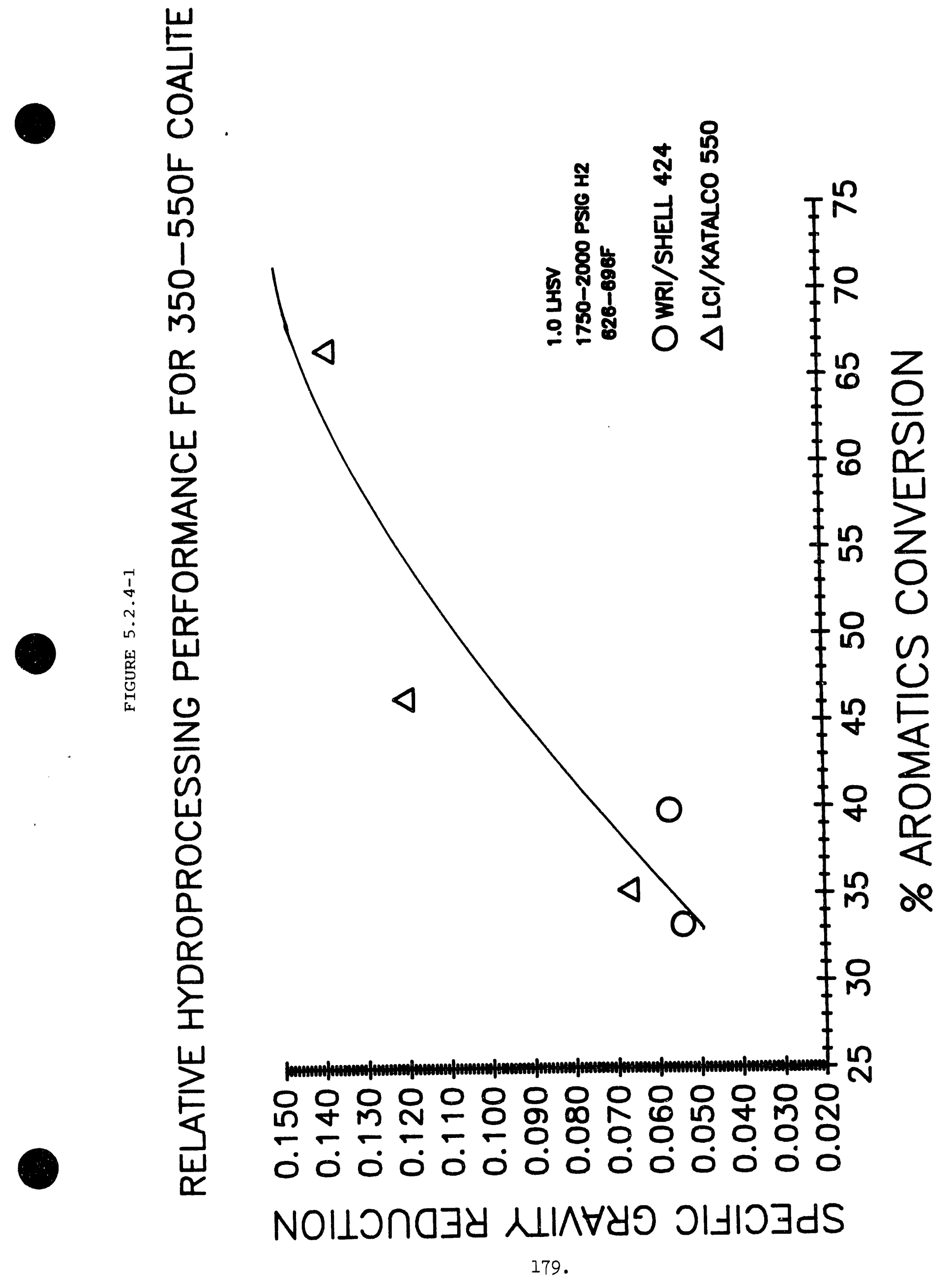



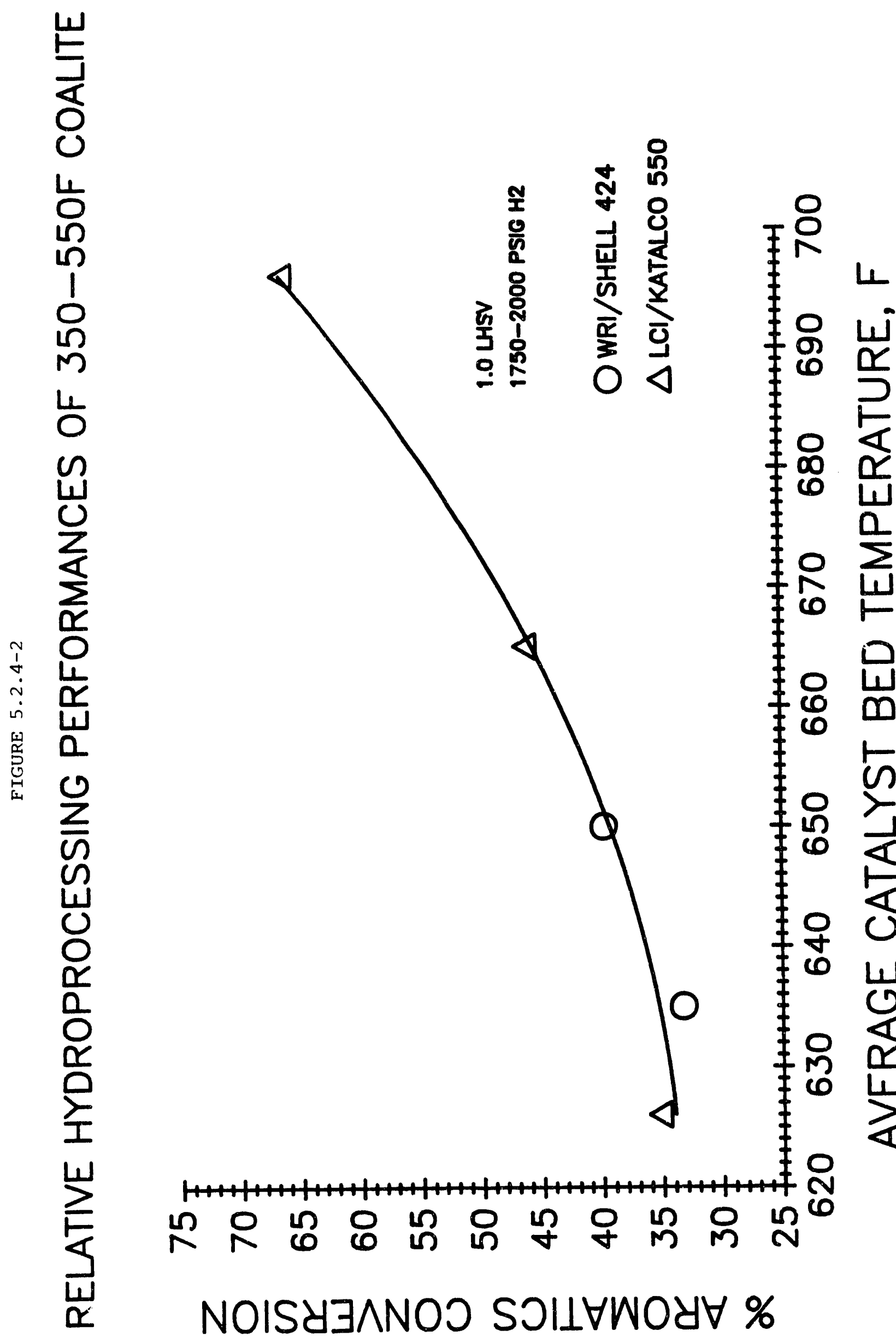
catalyst appear to result in significantly higher absolute hydrogen uptake levels. However, this may have resulted from calculational and/or experimental precision differences between the two laboratories in their efforts to quantify the hydrogen uptake values rather than from catalyst type (Figure 5.2.4-3).

\subsection{Virgin Atmospheric Resid Cracking}

\subsubsection{LC-Fining}

The LC-Fining process utilizes an expanded-bed of hydrotreating catalyst to provide for backmixing and near isothermal operation during the hydrogenation of heavy oils and residua that contain significant catalyst poisons, e.g., trash metals, organometallics, coke precursors, etc. The process has been widely commercialized, especially for vacuum residua, and the continuous addition and withdrawal of catalysts allows for continuous operation without having to shutdown to replace poison or coked catalysts. While the raw COALITE does not contain much vac resid content, it does contain considerable atmospheric resid $(650 \mathrm{~F}+)$. LC-Fining is a potential technology for upgrading the atmospheric resid fraction of MCG liquids, especially as a means of inputting the high overall hydrogen uptakes required to convert the hydrogen-deficient liquids to hydrogen-rich HEDF.

Four LC-Fining test campaigns were made: two with virgin residua $(300 \mathrm{Ft}$ and $650 \mathrm{Ft})$ and two with hydrotreated resid recovered from the first-pass LC-Fining operation with the $650 \mathrm{Ft}$ virgin resid. The performance results for these campaigns are presented in Tables 5.3.1-1 and -2 . The summary of the properties of the full-range LC-Finate products from these campaigns is presented in Tables 5.3.1-3 and -4 . The main objective of these tests was to produce feedstock for the cracked distillate hydrotreating campaigns in which the jet boiling range aromatics hydrocracked from the VGO material are saturated to high energy density cycloparaffins.

\subsubsection{Delayed Coking}

With very thermally reactive feedstocks such as pyrolysis oils from the COALITE process, processing in catalytic systems can result in relatively high levels of carbon on the catalysts. This can be ameliorated by operating at low thermal severities which in turn requires high catalyst inventories, i.e., operation at low space velocities, to achieve commercially feasible conversion levels. Another processing approach is based on the use of thermal processing technologies which produce lighter and hydrogen-enriched liquids by rejection of feed carbon as coke. Delayed coking is a mature commercial process for production of distillate fuels from heavy residua. The resultant coke byproduct generated can be upgraded to fuel gas via partial oxidation technology or in the case of MCG can be blended with the MCG char and upgraded to any of the premium solid products being targeted via Mild Coal Gasification. 


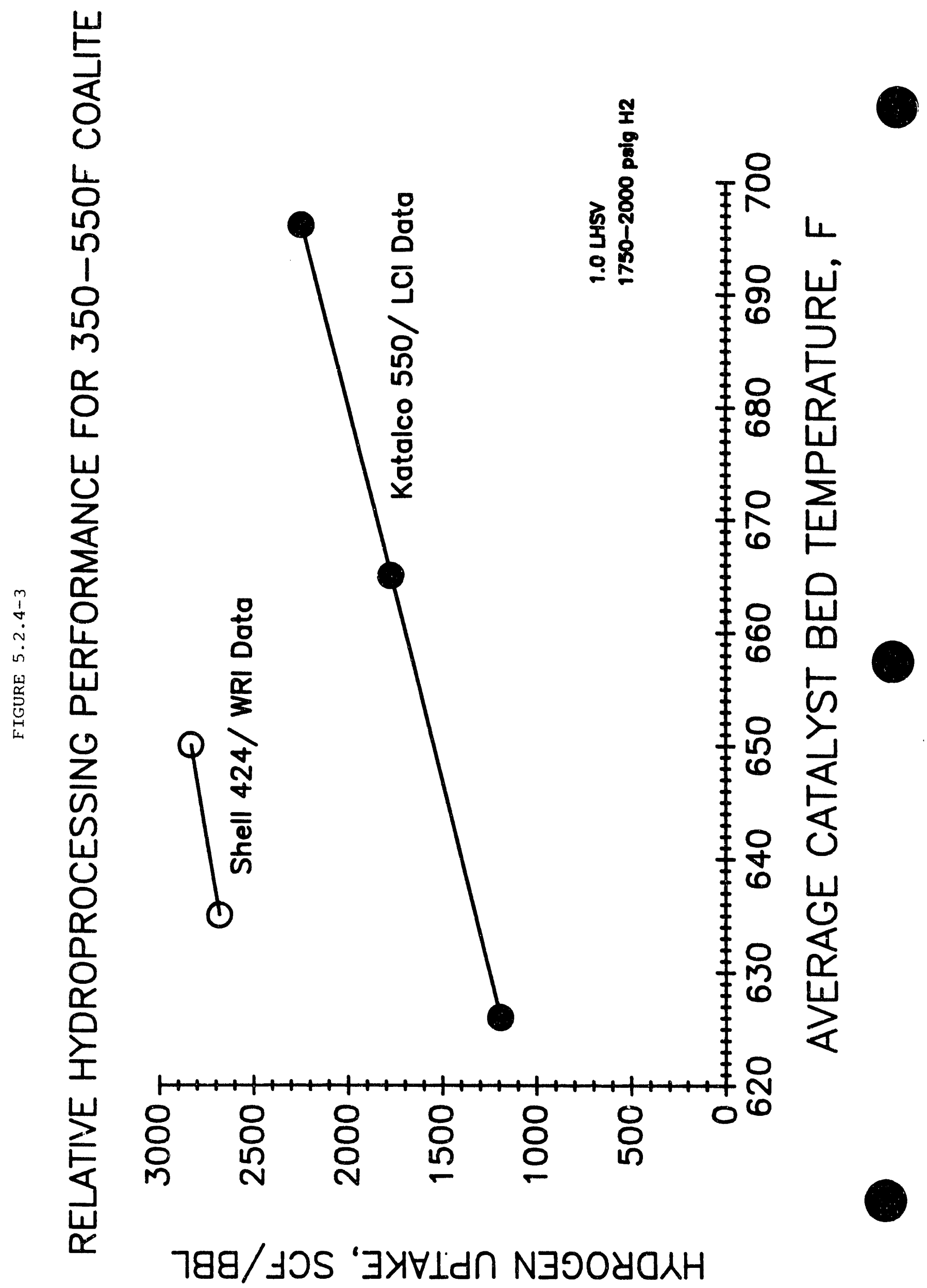


IABLE $5 \cdot 3 \cdot 1-1$

SUHHARY OF OPERAIIHG RESULIS FOR LC-FIHING (HYOROCRACKING) IESTS

CATALYSI: SHELL 324 ( $66 E O)$

FILE ID: REPTBLC2. IK!

\begin{tabular}{|c|c|c|c|c|c|c|c|c|}
\hline IEST $\mid(B L \hat{F}-)$ & $86-1$ & $86-2$ & 87 & $88-1 / 2$ & $88-3$ & $88-4$ & $88-5$ & 90 \\
\hline DAIE (1989) & $01-31$ & $02-01$ & $02-08$ & $02-27 / 28$ & $02-28 / 03-01$ & $103-1 / 2$ & $03-2 / 3$ & $04-04$ \\
\hline START IIME & $19: 00$ & 07:00 & 02:00 & $15: 30$ & $16: 30$ & $09: 00$ & $07: 30$ & $01: 00$ \\
\hline ENO IIME & $23: 00$ & $15: 00$ & $16: 00$ & $16: 30$ & 09:00 & $07: 30$ & 18:00 & 09:00 \\
\hline FEEDSTOCK & A & A & A & A & A & A & A & B \\
\hline \multicolumn{9}{|l|}{ HDS } \\
\hline \multicolumn{9}{|l|}{ \& HOK } \\
\hline \multicolumn{9}{|l|}{ \& $\mathrm{HDO}$} \\
\hline H2 UPTAKE, scf/bbl & & & & 10000 & 10000 & 10000 & 10000 & 10000 \\
\hline API IAPROVEHEN] & & & & 21.4 & 19.6 & 19.0 & 18.3 & 4.0 \\
\hline \multicolumn{9}{|l|}{ R.1. REGRESSIOH } \\
\hline EST. HEAT OF REACT & & & & & & & & \\
\hline
\end{tabular}

FEEOSTOCK IYPE:

A: COALIIE AIK RESID, 65Ot $F$.

B: HYROPROCESSED COALITE DISTILL RESID, 575+ F. 


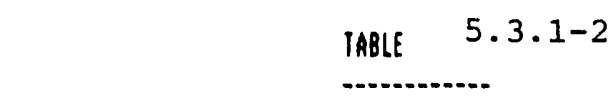

SUHMARY OF OPERATIHG RESULIS FOR LC-FIMING (hYOROCRACKIMG) TESTS

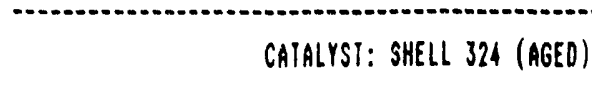

FILE I0: REPTBLC2.VKL

IEST 1 (BLCF-)

\begin{tabular}{cccccc}
92 & 93 & 94 & 95 & 100 & 101 \\
\hdashline $04-10$ & $04-11$ & $04-11$ & $04-12$ & $05-17 / 19$ & $06-13 / 15$ \\
$12: 00$ & $24: 00$ & $14: 00$ & $02: 00$ & $20: 00$ & $08: 00$ \\
$20: 00$ & $08: 00$ & $22: 00$ & $10: 00$ & $19: 30$ & $02: 30$ \\
& & & & & \\
8 & $B$ & 8 & 8 & $C$ & $C$
\end{tabular}

FEEDSTOCK

: HOS

$\because$ KDN

$\&$ HDO

H2 UPTAKE, sct/bbl

$\begin{array}{llllll}10000 & 10000 & 10000 & 10000 & 1000 & 1000\end{array}$

API IMPROYEMENT

$\begin{array}{llll}8.4 & 6.7 & 11.9 & 1.3\end{array}$

R.I. KEGRESSIOK

EST. HEAT OF REACIION, BLU/lb

FEEOSTOCK IYPE:

B: HYDROPROCESSED CORLITE OISTILL RESIO, S75 F.

C: COALITE DISTILLATE, $300+F$. 
IABLE $5 \cdot 3 \cdot 1-3$

SUMHARY OF PROPERTIES OF FULL-RANGE LC-FINATE IESTS

CATALYST: SHELL 324 (AGEO)

FILE ID: REPTBLC3.UKI

IEST $(B L C F-)$

-...............

DAIE (1989)

START TINE

END TIME

FEEDSIOCK

SPECIFIC GRAYIIY, gO/CC

API GRAVITY $~ \&$ 6OF

REFRACTIVE INDEX $20 C$

ELEKENTRLS, itt

c

H

SIHULATEG O!STILLATIOK, \&

IBP

108 Distilled

300

502

108

908

rOLUR. AVE. BOIL. PI., F

MAISON $A$

\begin{tabular}{|c|c|c|c|c|c|c|c|}
\hline $86-1$ & $86-2$ & 87 & $88-1 / 2$ & $88-3$ & $88-4$ & $88-5$ & 90 \\
\hline $01-31$ & $02-01$ & $02-08$ & $02-27 / 28$ & $02-28 / 03-$ & $03-1 / 2$ & $03-2 / 3$ & $04-04$ \\
\hline 19:00 & 01:00 & 02:00 & $15: 30$ & $16: 30$ & 09:00 & 07:30 & 01:00 \\
\hline 23:00 & 15:00 & $16: 00$ & $16: 30$ & 09:00 & $07: 30$ & $18: 00$ & 09:00 \\
\hline A & A & A & A & A & A & A & 8 \\
\hline & & & 0.9923 & 1.0050 & 1.0093 & 1.0143 & 1.0306 \\
\hline & & & 11.1 & 9.3 & 8.7 & 8.0 & 5.8 \\
\hline
\end{tabular}

$\begin{array}{rrrr}87.33 & 88.24 & 88.81 & 87.05 \\ 9.35 & 9.18 & 9.16 & 9.15\end{array}$

N:HI, BLU!lt

YLHY, BtU/ge!

$\begin{array}{rrrr}184 & 209 & 196 & 194 \\ 368 & 399 & 100 & 405 \\ 189 & 539 & 543 & 565 \\ 583 & 628 & 636 & 657 \\ 666 & 697 & 704 & 712 \\ 760 & 783 & 791 & 800 \\ & & & \\ 573 & 609 & 615 & 628 \\ 340.4 & 348.0 & 348.4 & 350.9\end{array}$

FEEDSTOCX TYPE:

A: COALIIE AIM RESID, GSO+ $F$.

B: HYOROPROCESSEO COALIIE OISTILL RESID, S75+ F. 


$$
\text { IABLE } 5.3 .1-4
$$

SUHAARY OF PROPERIIES OF FULL-RAMGE LC-FIMAIE TESIS

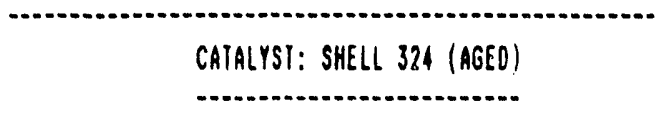

FILE 10: REPTBLC3.VKL

TEST I (BLCF-)
OATE (1989)
START TIKE
ENO HIME
FEEOSTOCK

\begin{tabular}{|c|c|c|c|c|c|}
\hline 92 & 93 & 94 & 95 & 100 & 101 \\
\hline $04-10$ & $04-11$ & $04-11$ & $04-12$ & $05-17 / 19$ & $06-13 / 15$ \\
\hline 12:00 & $21: 00$ & 14:00 & $02: 00$ & $20: 00$ & 08:00 \\
\hline 20:00 & 08:00 & $22: 00$ & 10:00 & $19: 30$ & $02: 30$ \\
\hline \multirow[t]{3}{*}{$B$} & 8 & 8 & $B$ & c & c \\
\hline & & 0.9986 & 1.0107 & 0.9659 & 1.0409 \\
\hline & & 10.2 & 8.5 & 15.0 & 4.4 \\
\hline
\end{tabular}

SPECIFIC GRAVITY, go/CC

API GRAVITY I GOF

REFRACIIVE INOEX $20 \mathrm{C}$

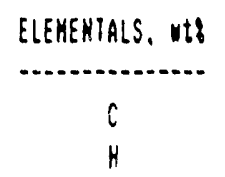

SIMULATEO DISTILLRTION. F

180

109 Distilled

308

508

$10 \%$

908

VOLUR. AVG. BOLL. PI., F VAISOR $A$

VLHV, BtU/lb

VLHY. BtU/ga!
$216 \quad 393$

$385 \quad 453$

$479 \quad 335$

$566 \quad 667$

$600 \quad 791$

$181 \quad 191$

$563 \quad 647$

$11.1 \quad 10.3$

FEEDSIOCK IYPE:

8: HYDROPROCESSEO COALIIE DISIILL RESID, S75t F.

C: COALITE DISTILLATE, 300 F. 
All four tests made with the two feedstocks (virgin 650F+ and mildly hydrotreated $650 \mathrm{~F}+$ residua) gave similar yield structures: $41-49 \%$ coke yields, $31-43 \%$ liquids yields, and $14-20 \%$ gas yields. The mildly hydrotreated resid feed did result in the lowest coke make but the coke suppression did not lead to a concomitant increase in liquids yield. The test made with the virgin resid at $100 \mathrm{psig}$ coke drum pressure had a mid-distillate product with more than $60 \%$ aromatics content and an energy density (before hydrogenation) of 128,775 Btu/gal. The mid-distillate product from the coker test made at 62 psig coke drum pressure had a higher olefins content and a lower aromatics content than that for the $100 \mathrm{psig}$ drum pressure. In both cases, coke yields represented a significant loss of potential HEDF yield. However as pointed out previously the capital cost of the coker-derived liquids is relatively lower than that of the higher liquids producing, hydrocracking process-derived route.

\subsection{Cracked Distillate Hydrotreating}

Products from both the LC-Fining and Delayed Coking tests were fractionated to recover $650 \mathrm{~F}$ - distillate fractions which served as the feedstocks for the final hydrogenation step necessary to convert aromatics to cycloparaffins, the latter being the high energy density components of the HEDF test fuels. Distillate hydrotreating was carried out in several campaigns to reflect the different sources of the distillate feeds to hydrotreating.

\subsubsection{Hydrotreating of LC-Finate Distillates}

The results of these campaigns are summarized in a series of spreadsheet tables with the "A" tables presenting the run performance data and the "B" tables presenting the properties of the full-range hydrotreated distillates. The organization of the tabulated results is as follows:

Table No Catalyst Type Feed Boiling Range (F) \# Reaction Stages

$\begin{array}{llll}5.4 .1-1 A, B & K-550 / K-599 & 300-575(650) & 2 \\ 5.4 .1-2 A, B & \text { K-599 } & 300-600 & 1 \\ 5.4 .1-3 A, B & \text { Amoco Propr. } & 650-975 V \text { irgin } & 1 \\ 5.4 .1-4 A, B & \text { Amoco Propr. } & 650-975 \mathrm{HDT} & 1 \\ 5.4 .1-5 A, B & \text { K-599/K-599 } & 350-750 & 2\end{array}$

\subsubsection{Hydrotreating of Coker Distillates}

The results of the three hydrotreating tests with coker distillates are presented in Table 5.4.2-1A (run performance data) and 5.4.2-1B (properties data). 
IAGLE $5.4 .1-1 \mathrm{~A}$

SUMAARY OF OPERATING RESULTS OF FIXEO-BEO HYDROTKEATED PROOUCIS FRCA

HYOROCRACKEO CORLITE OISTILLATE

CATALYSI: K-55C (IST SIAGE), K-599 (2ND STAGE)

IESI | $\mid F E-1$

-..............

DAF l:989:

SIAF" IIH:

ENC IIME

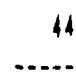

44

96

97

98

$02-09$

$1:: 45$

$04-06$

$04-00$

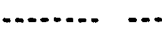

$12: 35$

$13: 28$

$18: 00$

2a: $3:$

$04-07$

$14: 50$

$19: 30$

$24: 06$

$: 2: 0 i$

$13: 30$

99

tegsidis

a

6

$\varepsilon$

6

8

$17: 00$

$04-01$

$04-11$

17:00 20:6i $\quad 01: 00$

$i r$

$\therefore r i$

$\therefore$

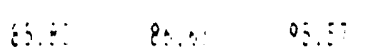

$x .38$

84.70

84.08

6:.11

76.23

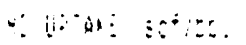

$3006 \quad 2000 \quad 1000$

70.90

7005

1000

1006 $\quad 1056$

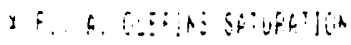

6.?

i.:

$1 . i$

4.0

i.!

1.

l. .

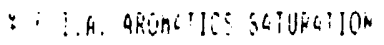

11.1

i.?

16.2

4.4

9.i

Ai. indiongath

36. $\quad 3 . \quad 34 . \hat{0}$

$3+. \hat{2}$

32.4

$34.4 \quad 3.5 \quad 3:$.

$\therefore$ inthisis

: 15:

1.4 .44

i. $4 .$.

1.4.

1.464 ?

.4596

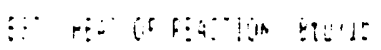

\section{$\because 3 \ldots+r_{1}$}

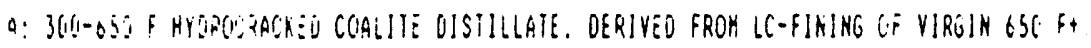

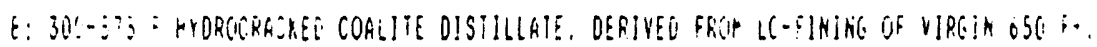


IABLE $5.4 .1-1 B$

SUAHARY OF PROPERTIES OF FIXEO-BED HYDROTREATEO PRODUCTS FROH

HYOROCRACKEO COALIIE DISTILLATE

CATALYSI: X-5SO (1ST STAGE). X-599 (2NO STAGE)

\begin{tabular}{|c|c|c|c|c|c|c|c|c|}
\hline TES! $(F E-1$ & 14 & 95 & 96 & 97 & 98 & 99 & 100 & 105 \\
\hline ................ & ........... & ............ & . & . & . & . & . & . \\
\hline DATE 11089: & $02-00$ & $04-08$ & $04-06$ & $04-07$ & $04-07$ & $04-07$ & $04-07$ & $(14-1)$ \\
\hline SIAG: IIHE & $11: 35$ & $16: 20$ & $10: 00$ & $20: 30$ & $12: 00$ & $17: 00$ & $20: 00$ & $01: 00$ \\
\hline ENL TIME & $1 ?: 33$ & $14: 50$ & 15:00 & $24: 00$ & $13: 30$ & $18: 00$ & $21: 30$ & $12: 00$ \\
\hline PEEUSTOS? & $A$ & B & 8 & $B$ & $B$ & 6 & B & $\dot{i}$ \\
\hline 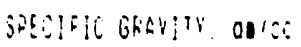 & $0.8: 7 \div$ & 0.8054 & 0.8540 & 0.8468 & 0.8033 & 0.8529 & $0.817 \%$ & 0.8453 \\
\hline AC! GRoGi: o ui: & 36.6 & $3: .6$ & $34 . \hat{\imath}$ & 35.0 & 36.4 & 34.4 & 35.5 & 35.9 \\
\hline 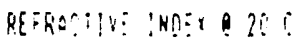 & 1.1319 & 1.174 & 1.1641 & $1.15 ? ?$ & 1.1727 & 1.4643 & 1.4608 & 1.456 \\
\hline \multicolumn{9}{|l|}{ ELEAENTKL: MIT } \\
\hline 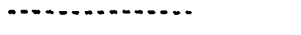 & & & & & & & & \\
\hline : & $85.6 ?$ & $87.6 \%$ & 86.35 & $85.64:$ & 86.80 & 80.34 & $85.9 !$ & $80 . \therefore t$ \\
\hline$n$ & $1 \vdots .8:$ & 10.80 & $13.4 i$ & 13.81 & 17.84 & 13.45 & $13.0 ?$ & 13.84 \\
\hline
\end{tabular}

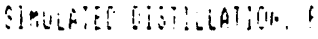

\begin{tabular}{|c|c|}
\hline 198 & $17 \dot{x}$ \\
\hline$\vdots: \because \cdots \cdots$ & $\because:$ \\
\hline $3 \hat{\jmath}$ & $i j i$ \\
\hline 3 & $t \therefore$ \\
\hline י. & $\therefore:$ \\
\hline$\because$ & $\vdots$ \\
\hline$c_{i} \ldots \ldots f \ldots$ & $\because \because$ \\
\hline it. & : \\
\hline
\end{tabular}

i.t.h. Alriglsli. Irci:

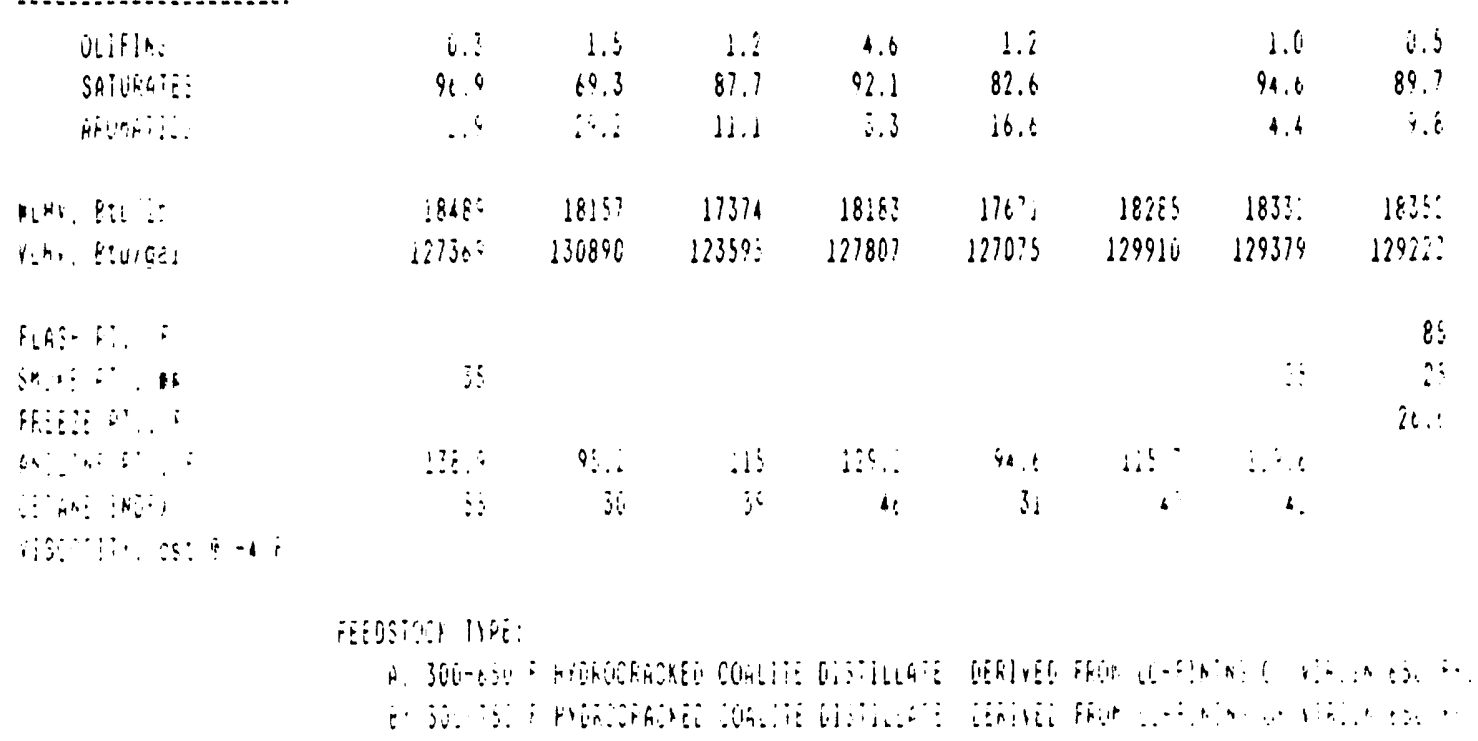


IAE!: $5.4 .1-2 A$

SUAMART OF OPERAIIHG RESUIIS OF FIXEO-BEO RYOROIREAIEO OROOUCI: FROP HYOROCRACKEO COALIIE OISIILLATE

CATALYST: $X-599$ (LOT SIAGE)

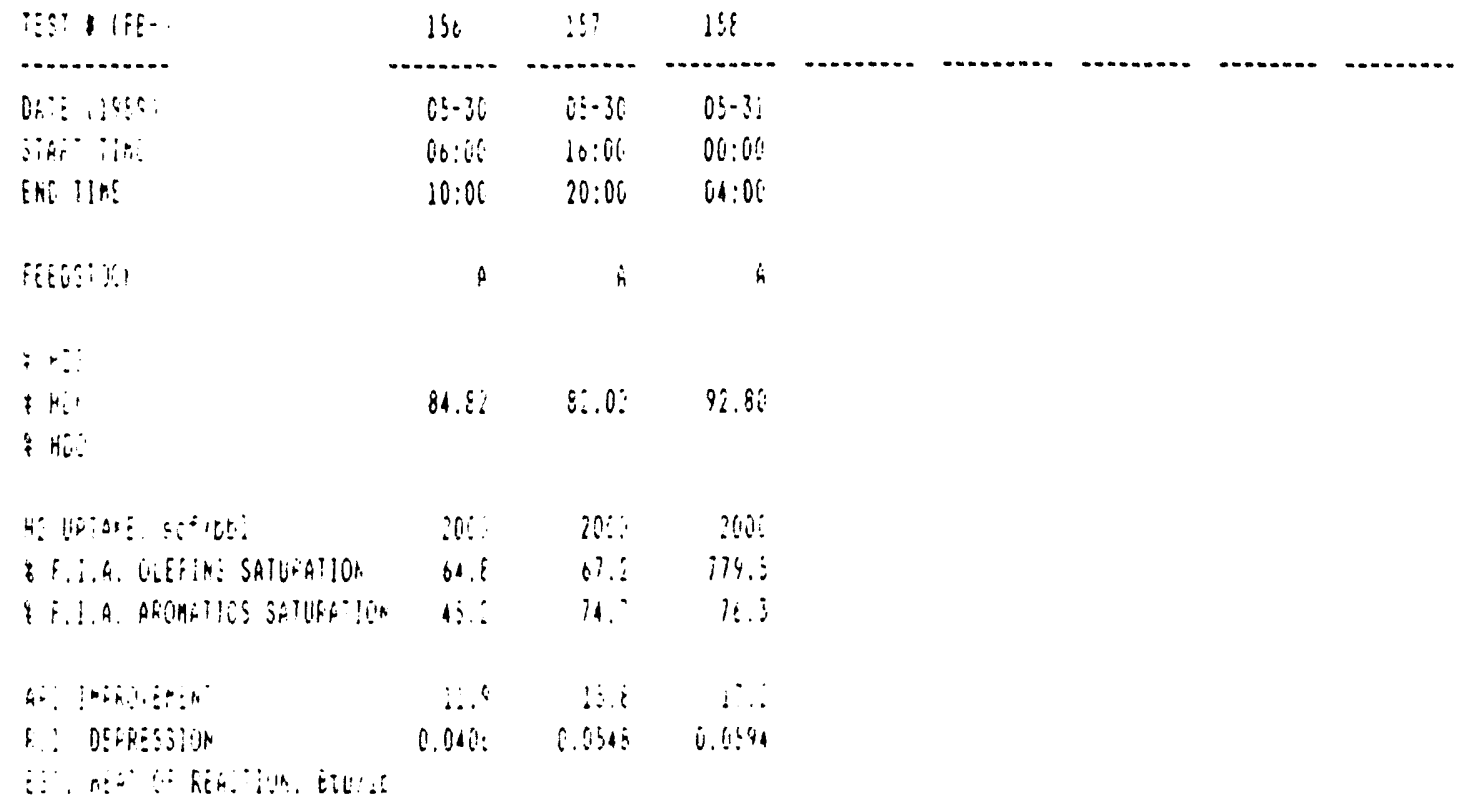

pigf:?ug: ive:

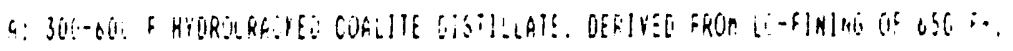


TABL: $5.4 .1-2 B$

-..................

SUMAARY OF PROPEFTIES OF FIXER-BEO HYDROTREATEO PROOUCTS FROR.

HYOROCRACKED COALITE DISTILLATE

CATALYST: K-S99 IIST STAGE!

IEST $\mid$ (FP-)

OR!: 11989

SIART IIME

EKS TINE

FEEOSIOS:

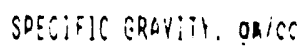

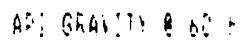

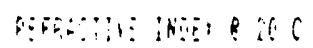

EIEHEMTGLS MI?

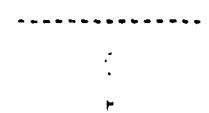

$8 i .1$

$85 \div$

\&: at

$1 ?, 1$

23.45

i3. 34

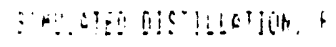

..........................

!n:

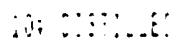

$156 \quad 157 \quad 158$

$05-30 \quad 0 ;-30 \quad 05-3 !$

06:00 16:00 00:00

10:00 20:00 01:00

A A A

$0.8708 \quad 0.85014 \quad 0.843 j$

$31.6 \quad 34.9 \quad 30.3$

1.409 1465? 1.46?

$30:$

is

$i$

$\therefore i$.

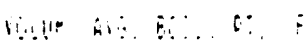

iti" jut ,

i.t. FHALISIE Iro:

QLifik:

SATURATES

ARUMH: :

Nith, E:L .:

Vitir. Btilad:

F.ASB Z: . :

jnip: $i$ i. in

CQE:?: $0 ;$

Q. . . It:

I: inh: ina:

is
$18:$

200

38:

$4: \vdots$

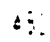

jus

$4: 2$

11.26

$\begin{array}{lll}0.9 & 0.8 & 0.5\end{array}$

$\begin{array}{lll}60.3 & 86.1 & 83.5\end{array}$

$38.8 \quad 17.2 \quad 56.6$

foglin lin:

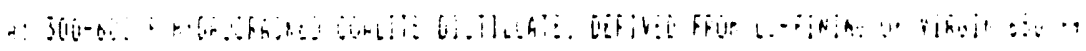


IABLE $5.4 \cdot 1-3 A$

SUHWAPY OF OPERATING RESULTS FOR FIXEO-BEO CORLITE HYOROCRACKING ISSIS

CAIALYST: AHOCO PROPRIETARI

IEST I IFBKC-

(.....................

DAIE $1198^{\circ}$

START TINE

EN: IIM:

FEEOSTOCA

$\begin{array}{ccccccccc}1 & i & 3 & 4 & 13 & 14 & 15 & 16 & 1 ? \\ \ldots 4-2 ! & 01-28 & 01-28 & 04-28 & 05-03 & 05-04 & 05-04 & 05-04 & 05-0: \\ 21: 30 & 03: 30 & 13: 06 & 18: 30 & 15: 30 & 21: 30 & 03: 30 & 11: 00 & 19: 00 \\ 23: 36 & 05: 30 & 15: 00 & 20: 30 & 17: 30 & 23: 30 & 08: 36 & 14: 00 & 08: 06\end{array}$

$23: 36$

$0: 30 \quad 15: 00$

A

h

A

A

$\div \mathrm{H}:$

\& H[O.

init

Hi UDTA: sotilot:

7005 70sis 7006

7065.9006

1000

1006

17.5

92.7

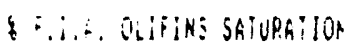

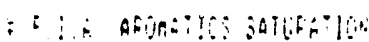

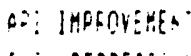

$\dot{*}$

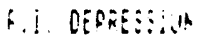

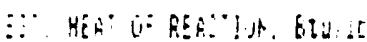

patsstos tri:

A: 656-9is \& VIREIR VOS. 
TABLE $5 \cdot 4 \cdot 1-3 B$

SUMAARY OF PROPERIIES OF HYOROCRACKATES FROH FIXEO-BED COALITE HYOROCRACXINE.

CATALYSI: AHOCO PROPRIEIARI

\begin{tabular}{|c|c|c|c|c|c|c|c|c|c|}
\hline IEST $\mid$ IFBHE-! & 1 & 2 & 3 & 4 & 13 & 14 & 15 & 16 & 17 \\
\hline 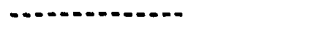 & -....... & $\cdots$ & - n. & $\cdots$ & $\cdots$ & (n)..... & $\cdots$ & (n.......- & -non \\
\hline DATE (1989) & $04-27$ & $04-28$ & $04-28$ & $04-28$ & $05-03$ & $05-04$ & $05-04$ & $05-04$ & $05-05$ \\
\hline SIART IIHE & $21: 30$ & $03: 30$ & $13: 00$ & $18: 30$ & $15: 30$ & $21: 30$ & $03: 30$ & 11:00 & $19: 00$ \\
\hline ENC IIME & $23: 30$ & $05: 30$ & $15: 00$ & $20: 30$ & $17: 30$ & $23: 36$ & $08: 30$ & $14: 00$ & $08: 00$ \\
\hline EEEGSTOCY & $A$ & A & $A$ & A & A & $A$ & $A$ & A & A \\
\hline SDECITIC GRAYIIT, QD/CE & 1.0404 & 1.0217 & 1.0021 & 1.0071 & 0.9806 & 0.9806 & 0.9574 & 0.9597 & 0.9797 \\
\hline 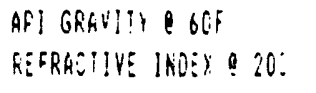 & 1.5 & 7.0 & $9 . ?$ & 9.0 & 12.8 & $1: .8$ & 16.3 & 15.9 & 159 \\
\hline LAENIG!: I: & & & & & & & & & \\
\hline (1) & & & & & & & & & \\
\hline $\begin{array}{l}i \\
H\end{array}$ & & & & & & & $\begin{array}{r}88.2 \\
11.03\end{array}$ & & \\
\hline 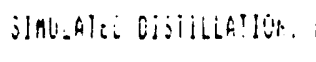 & & & & & & & & & \\
\hline$i$ & .61 & 254 & $2: 5$ & 274 & $2 \hat{\imath} \hat{v}$ & ids & $2: 3$ & ¿i? & $2 \hat{4}$ \\
\hline at lo: & St: & $\because 0^{\circ}$ & 495 & $5 ?:$ & ats & 446 & $4 ! 9$ & $11 i$ & 4!: \\
\hline $3 i^{i}$ & 095 & 6i1 & 638 & 654 & 611 & 599 & 571 & $5 j 4$ & 54? \\
\hline$\because \vdots$ & $i 38$ & 764 & $i)^{6}$ & $12 \%$ & $64 !$ & $686^{\circ}$ & $00 !$ & $0 ?$ & $6 \vdots$ \\
\hline $7 i:$ & 811 & 805 & 100 & $79 \%$ & 768 & 763 & 140 & $? 1 i$ & 757 \\
\hline $0::$ & 883 & 980 & 805 & 2:? & $85 ?$ & 858 & E4j & $8: \div$ & 826 \\
\hline 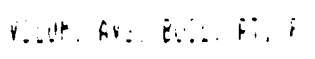 & $74 !$ & 128 & 101 & $? 14$ & 074 & $67 i$ & 617 & $63:$ & $66^{\circ}$ \\
\hline ASISSin' & 11.69 & $16 . ?$ & 20.4 & 16.5t & $1 j .18$ & 20.15 & $9.8 j$ & $9 . i^{\prime}$ & 10.14 \\
\hline
\end{tabular}

FEEDSTOCK TYPE:

A: 650-975 F VIRGIN VGC. 
IABLE $5.4 .1-4 \mathrm{~A}$

SUHHARY OF OPERATING RESULTS FOR FIXEO-BED CORLIIE HYOROCRACKING IESTS

CATALYST: AMOCO PROPRIEIARY

\begin{tabular}{|c|c|c|c|c|c|c|c|c|c|c|}
\hline IEST $\mid$ IFBHC- & 18 & 19 & 20 & 21 & 22 & 23 & $? 4$ & 25 & 26 & 27 \\
\hline DhIE $1108 \mathrm{O}$ & $05-21$ & $0 j-25$ & $05-25$ & $05-25$ & $05-26$ & $05-20$ & $05-26$ & $05-26$ & $05-30$ & $0 n-05 i n g$ \\
\hline START UIKE & $2 z: 36$ & $04: 30$ & $10: 30$ & 17:00 & 23:0c & OS:00 & $13: 00$ & $20: 00$ & $07: 00$ & $07: 06$ \\
\hline ENO 11\%: & $24: 30$ & $00: 3 i$ & $12: 30$ & 19:00 & $01: 00$ & $09: 00$ & 17:00 & 21:00 & $09: 0 i$ & Di:Or \\
\hline Fosion & $b$ & $k$ & 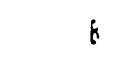 & $\varepsilon$ & $B$ & $B$ & $B$ & $\xi$ & 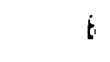 & 6 \\
\hline 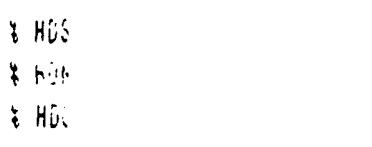 & & & & & & & & & & 03.2 \\
\hline 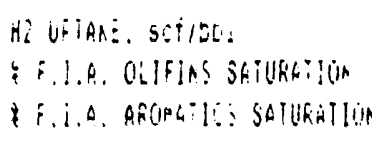 & 760 & $700 i$ & 10601 & 1000 & 1000 & 7000 & 7006 & 1000 & 7006 & 1000 \\
\hline 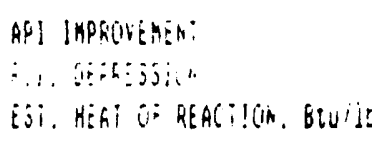 & 5.5 & & & & & & & & & \\
\hline
\end{tabular}

fegisic ing:

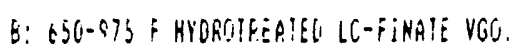


TABLE $5.4 .1-4 B$

SUHAARY OF PROPERTIES OF HYOROCRACXATES FROH FIXEO-BEO COALLIE HYOROCRACKING

CATALYST: AHOCO PROPRIETARY

\begin{tabular}{|c|c|c|c|c|c|c|c|c|c|c|}
\hline TEST $\mid$ (FBHi-) & 18 & 19 & 20 & 21 & 22 & 23 & 24 & 25 & 26 & 27 \\
\hline DPIE (1987 & $05-24$ & $05-25$ & $05-25$ & $05-25$ & $05-26$ & $05-26$ & $05-26$ & $05-26$ & $05-30$ & $00-01508$ \\
\hline SIART IINE & $22: 30$ & $04: 30$ & $10: 30$ & 17:00 & $23: 00$ & 05:00 & $13: 00$ & $20: 00$ & $07: 00$ & $07: 06$ \\
\hline ENO IIHE & $24: 30$ & $06: 30$ & $12: 30$ & 19:00 & $01: 00$ & 09:00 & $17: 00$ & 21:00 & 09:00 & $07: 00$ \\
\hline FEEDSTOS & 8 & 6 & 8 & 8 & $B$ & $B$ & E & 8 & 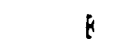 & $\mathrm{i}$ \\
\hline 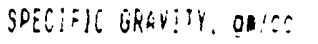 & $0.979 ?$ & 0.9705 & $0.957 \mathrm{~A}$ & 0.9613 & 0.9672 & 0.9285 & 0.9765 & 0.9433 & 0.9876 & 0.9905 \\
\hline 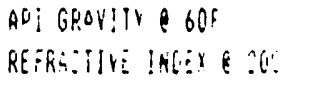 & 13.0 & 14.3 & 16.3 & 15.7 & 14.8 & 20.9 & 13.1 & $18 . \vdots$ & 11.8 & 14.3 \\
\hline \multicolumn{11}{|l|}{ ELEREH:GLi n: } \\
\hline : & & & & & & & & & & $8 \varepsilon, \dot{q}$ \\
\hline$r$ & & & & & & & & & & $16, \therefore$ \\
\hline \multicolumn{11}{|l|}{ 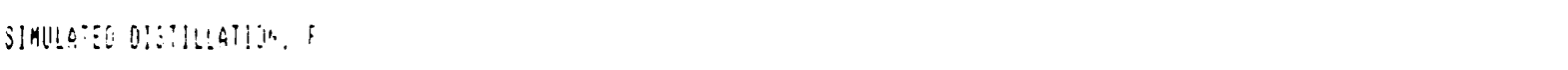 } \\
\hline$\pi:$ & 316 & 24. & 213 & 2:? & 218 & 215 & $25:$ & 217 & 35 & 234 \\
\hline 10: lisii...Ei & 5 & 549 & 498 & 505 & 520 & 44! & $j j_{t}$ & $45 t$ & 590 & $5 \hat{i}$ \\
\hline $3 !$ & $6 \because:$ & $6 ?:$ & $01:$ & $6: t$ & 0.4 & 570 & $63 !$ & 595 & $6 ! !$ & $\therefore .$. \\
\hline $30 \%$ & 090 & 680 & $66 !$ & 668 & 67: & $63 !$ & $68^{\prime}$ & 656 & $89 t$ & $6 \%$ \\
\hline $0:$ & $75:$ & 740 & 107 & $22 \varepsilon$ & $73 ?$ & 690 & 748 & $11 !$ & $73 ?$ & $?:$ \\
\hline 84 & 84. & $\varepsilon ? 6$ & $8:$ & $\varepsilon_{i t}$ & $\{3:$ & $79 i$ & $84 !$ & $8: 1$ & $8::$ & $\therefore$. \\
\hline 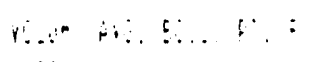 & $i i$ & $\leqslant \&$ & 606 & 667 & t:? & 128 & $10 ;$ & Bdi & 16 & $\because:$ \\
\hline 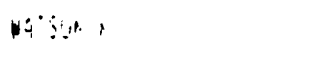 & 16.33 & 10.20 & 9.90 & 9.95 & 16.04 & 9.48 & 16.18 & 0.65 & 10.35 & 10.8 \\
\hline
\end{tabular}

FEOSight iYGE:

8: 650-975 F HYOROTREATEO LC-FINATE VGI. 
IABLE $5.4 .1-5 \mathrm{~A}$

SUMHARY OF OPERATING RESULTS FOR FIXED-BED HYDROTREATING TESTS OF

MYOROCRACKEO COALIIE OISTILLATE

CATALYSI: K-599 (IST STAGE)/K-599 (2NO STAGE)

TEST \& (FB-1

$\begin{array}{rrrr}165 & 166 & 167 & 168 \\ \cdots 06-12 & 06-13 / 14 & 06-15 & 06-15 \\ 21: 00 & 03: 00 & 10: 00 & 19: 00 \\ 23: 00 & 06: 00 & 15: 00 & 06: 00 \\ & & & \\ A & A & A & A\end{array}$

DATE (1989)

START IIME

ENO IIHE

FEEOSTOCK

HO:

: HOW

$\therefore$ HO:

H! VOTARE, SCT/LE!

$7000 \quad 1000 \quad 7000 \quad 1000$

I F.I.G. OLEFINE SATURATIOR

\& F.1.A. AROKATICS SATURATION

AF: :HPRIVEAER:?

P... DEPRESSIOK

$\begin{array}{rrrr}18.0 & 25.5 & 21.4 & 17.6 \\ 1.5230 & 1.1909 & 1.5088 & 1.5360\end{array}$

E... HEAT OF REPCHIOK. BtU/Lt

FEEDSIOCI IYPE:

R: 350-75O F CRACXEO COALITE DISTILLAIE. FROK INO-SIEPS. $300 \mathrm{FH}$ COALIIE LC-FIKIKG FOLLOMEO BY FIXEQ-BEO HYDROCRACKING OF 575-975 F LC-FINATE VGO. 
TABLE $5.4 .1-5 B$

-...........

SUMHARY OF PROPERTIES OF FIXED-BEO HYOROTREATEO PRODUCTS

FROH HYOROCRACKEO CORLITE DISTILLATE

CATALYST: K-S99 (1ST STAGE)/K-S99 (2ND STAGE)

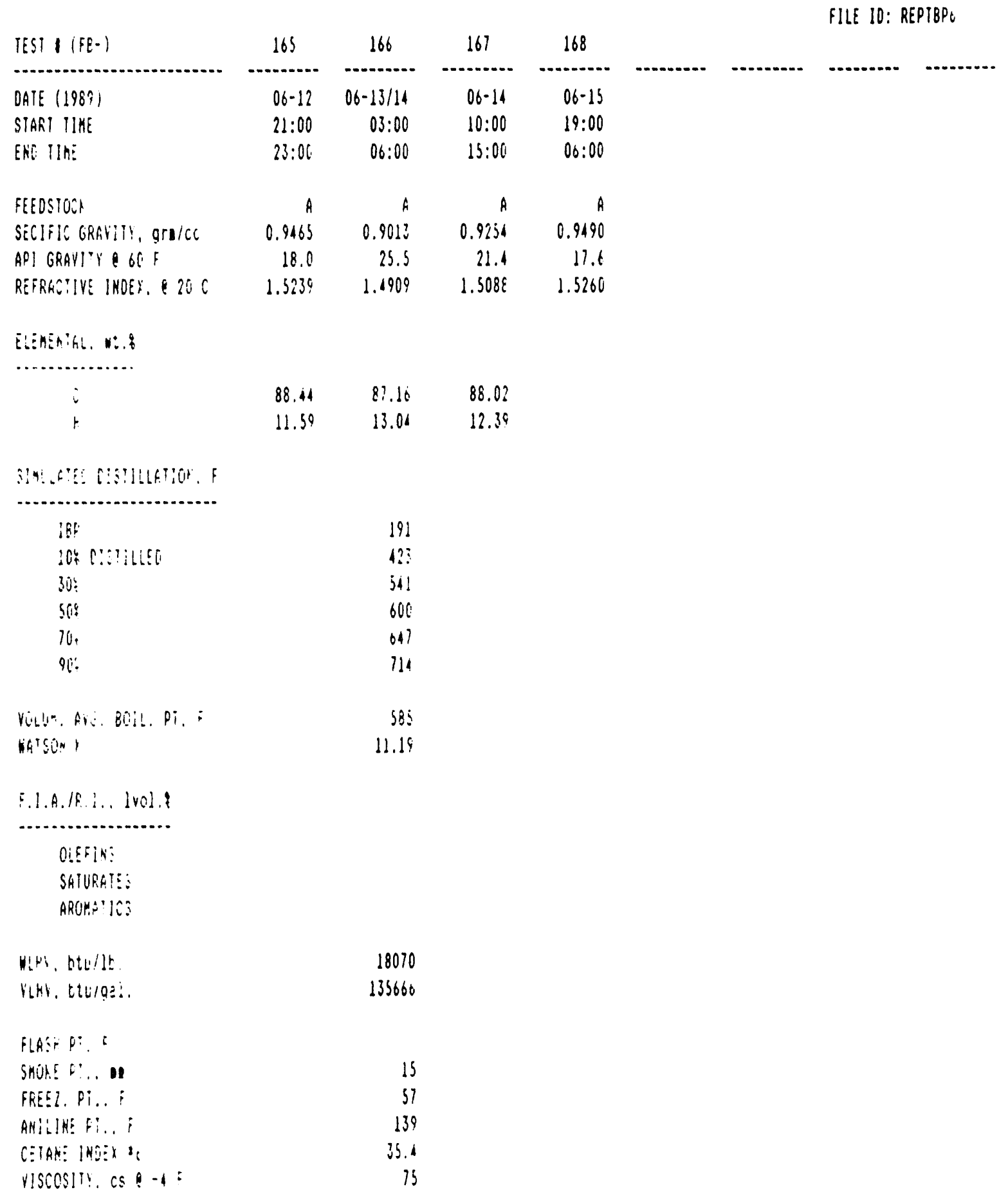

FEEOSTOCR IYFi:

A: 35L1-75E \& CRACKEO COR:!IE O1STiLLATE. FROA TWO-SIEFS, 300 F+ COK!IIS LC-FINIHG

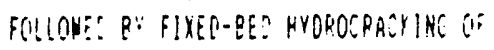
Sij-4ij F LG-Flikt? 66i. 
IABLE $\quad 5.4 .2-1 \mathrm{~A}$

..............

SUKHARY OF OPERATING RESULIS HYOROTREAIEO PROOUCTS FROH FIXES-BEO HYOROTREAIING OF

THERMALIY PROCESSEO COALIIE DISTIILLALE

CAIALYSI: $X$-55O (1SI STAGE) $X-399$ (2ND STAGE)

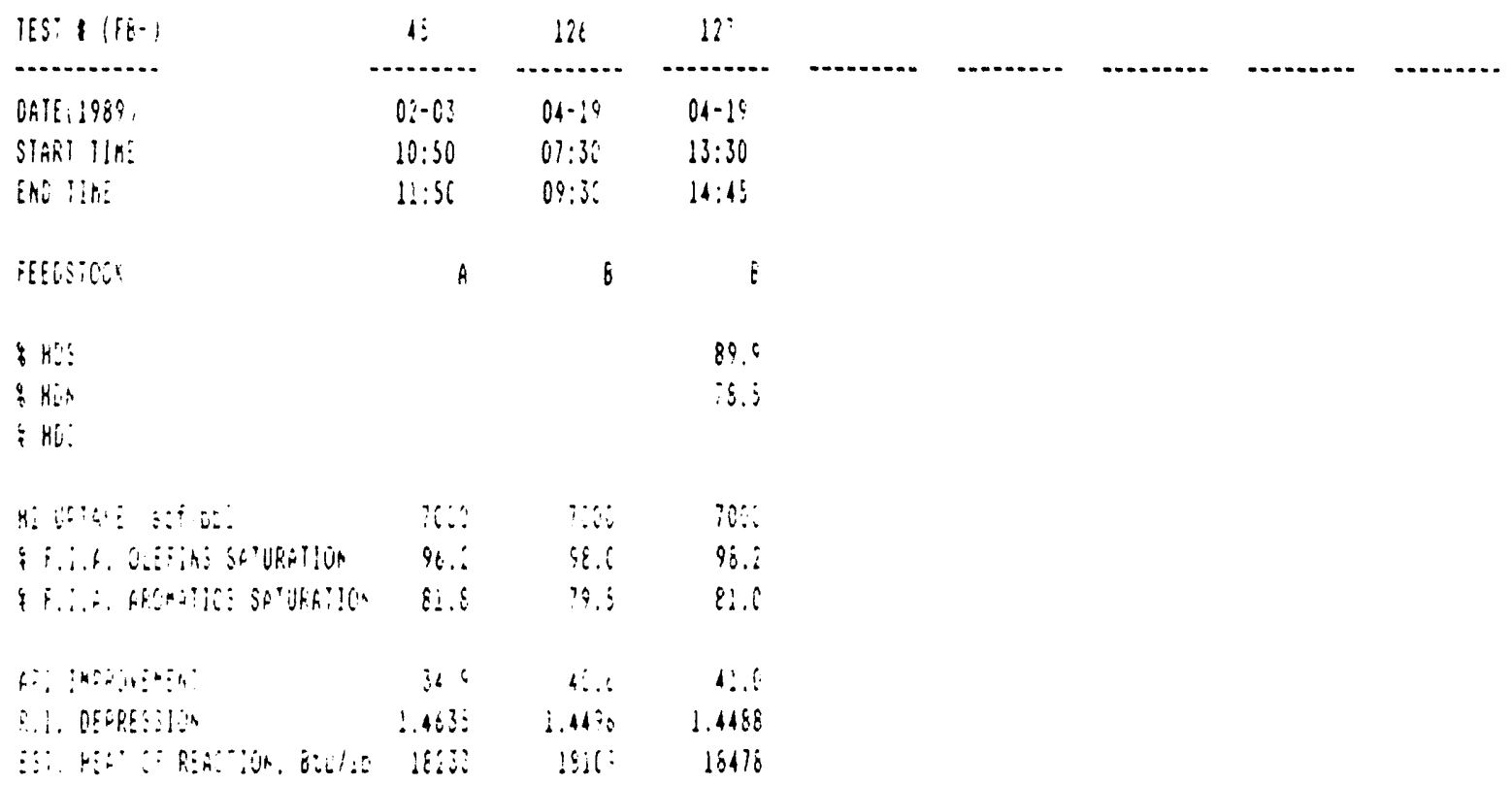

FEEGSTOD TYPE:

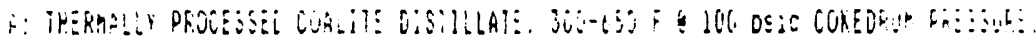

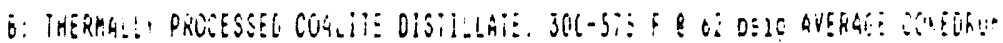
PKESJuF:. 
TAEL: $5 \cdot 4 \cdot 2-1 \mathrm{~B}$

..............

SUHAARY OF PRODERTIES OF HYOROTREATED PROOUC'S FROH FIXEO-BEO HYOROTREATINI CI:

THERARLLY PROQESSEO CURIIIE OISIILLAIE

CATALYSI: N-55O ULST STAGEI K-599 I2NO STRUE.

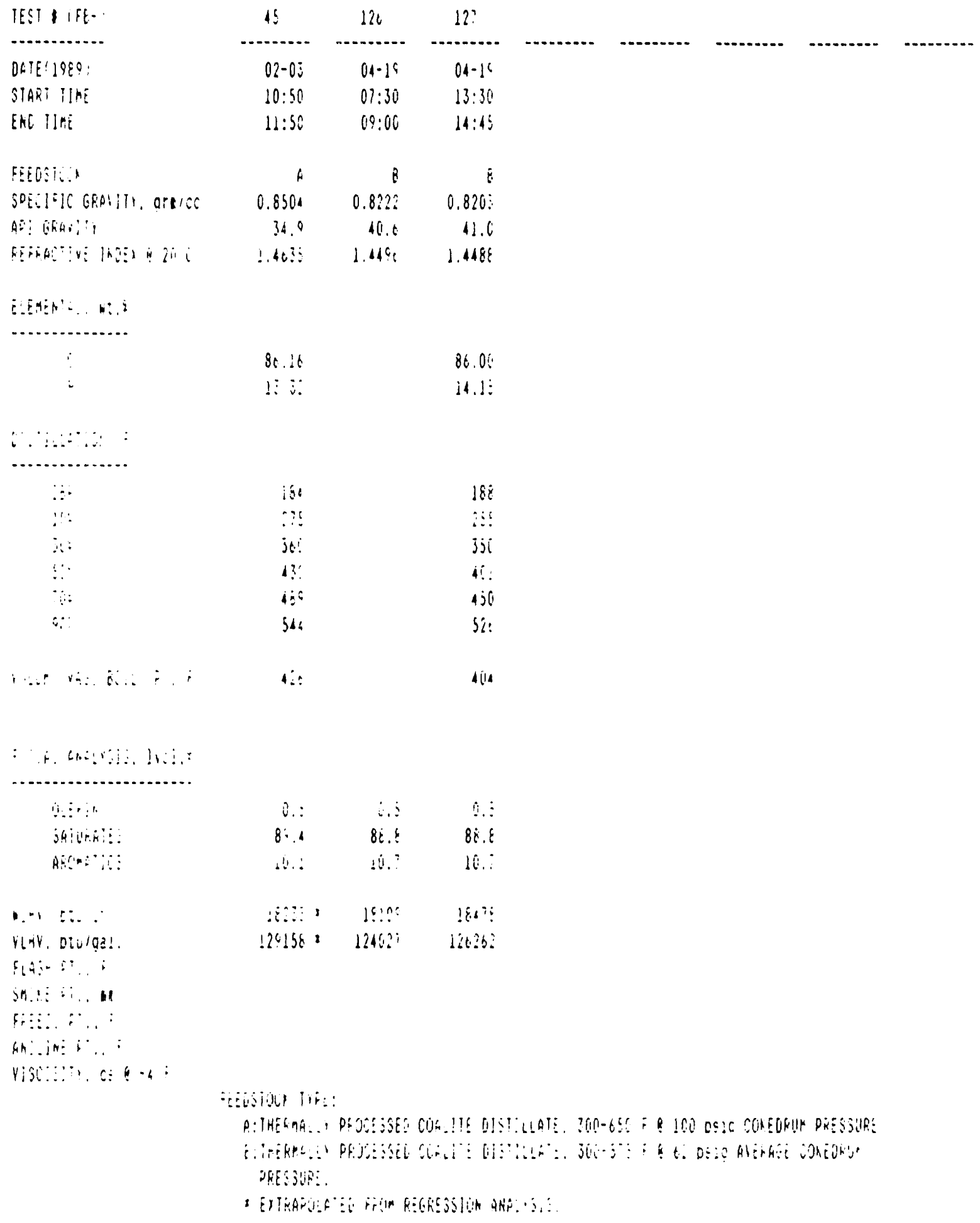

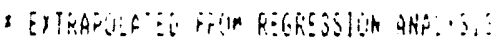




\subsection{Two-Step Selective Hydrocracking of Vacuum Gas 0 il (VGO)}

\subsubsection{Overview of Early Results}

Early Task 3 screening tests were aimed at investigating the hydrocracking via expanded-bed LC-Fining (using a base metal hydrocracking catalyst) of the 650F+ COALITE feedstock. This was followed by an alternative hydrocracking route consisting of fixed-bed hydrocracking of a VGO fraction (650-975F) of the 650F+ COALITE over a more selective, proprietary, zeolite-based hydrocracking catalyst. The latter operation was somewhat hampered by temperature control/hot spot problems associated with the high hydrogen uptake rates. This problem would be magnified in a true adiabatic commercial unit necessitating multi-bed quenching operations.

As an alternative to the afore-mentioned approach, an initial hydrotreating step prior to the fixed-bed hydrocracking step would input some degree of hydrogen uptake and thus ameliorate the heat removal requirements in the subsequent downstream hydrocracker. In view of the various distillate fractions that will be required io process the raw COALITE, it was decided to hydrotreat a dewatered and essentially full-range $(300 \mathrm{~F}+)$ COALITE stream. This was carried out in the stirred autoclave simulator of the LC-Fining process at nominal conditions of $750 \mathrm{~F}, 1950 \mathrm{psig}$ hydrogen partial pressure and 0.8 liquid hourly space velocity. (The "standard" hydrocracking severity used in the earlier 650F+ COALITE LC-Fining studies included 800-820F temperature, 0.4 space velocity and 2000 psig).

The resultant hydrotreated $300 \mathrm{~F}+$ COALITE was then fractionated in the 4-in Batch Still and the Equilibrium Flash Vaporization units to produce a hydrotreated 300-600F distillate; a hydrotreated 600-975F HVGO; and a hydrotreated $975 \mathrm{~F}+$ vac resid.

The hydrotreated $600-975 \mathrm{~F}$ vacuum gas $0 i 1$ (HVGO) was subjected to fixed-bed hydrocracking over the proprietary Amoco hydrocracking catalyst in a series of test scans to evaluate temperature, hydrogen partial pressure and space velocity. The thus hydrotreated hydrocrackates were distilled in a laboratory column to produce a nominal 300-750F distillate for subsequent fixed-bed hydrotreating and upgrading to HEDF product. The higher $750 \mathrm{~F}$ cut point was selected to allow the continued evaluation of the effect of higher cut points on volumetric energy densities.

The two 300-750F distillates, namely, the raw COALITE and that recovered from the selective fixed-bed hydrocracking of a $650-975 \mathrm{~F}$ LC-Finate derived from mild LC-Fining of the $300 F+$ COALITE, had similarities in physical properties as per the following:

Feed Source

Refractive Index

API Gravity

Specific Gravity

Hydrogen Content, wt\%

VLHV, Btu/gal
RaW COALITE

1.5445

11.4

0.9902

9.62

133,000
Selectively Hydrocracked LC-Finate-derived HVGO
1.5406
15.6
0.9619
10.97
138,931 
of note is the fact that the selectively hydrocracked HVGO has a higher hydrogen content but a lower specific gravity than that of the comparable raw COALITE distillate.

Upon fixed-bed hydrogenation (test FB-166), the selectively hydrocracked LC-Finate HVGO appeared to generate a higher specific gravity product at comparable hydrotreating severity to that achieved with the raw COALITE distillate feedstock (test FB-172). Moreover, the volumetric energy density was significantly higher as can be seen from the following table:

$\begin{array}{lcc}\text { Product Source } & \frac{\text { HDT COALITE }}{\text { (FB-172) }} & \frac{\text { Hydrotreated Selectively }}{\text { Hydrocracked LC-Finate }} \\ \text { Specific Gravity } & 0.8571 & \text { Derived HVGO (FB-166) } \\ \text { API Gravity } & 33.6 & 0.9013 \\ \text { Refractive Index } & 1.4716 & 25.5 \\ \text { Hydrogen Content, wt\% } & 13.37 & 1.4909 \\ \text { FIA Aromatics, wt\% } & 16.3 & 13.04 \\ \text { VLHV, Btu/gal } & 130,050 & -\end{array}$

It would appear that the hydrogenation of the HEDF precursors contained in the selectively hydrocracked LC-Finate derived HVGO retain their desirably higher specific gravity-energy content properties to a greater extent than that of the raw COALITE distillate counterparts.

It should be pointed out that in both cases, the product energy densities are based on the measurement of the total liquid product, unfractionated, recovered from the hydrotreating operations. In order to meet all of the required turbine fuel specifications, a fractionation post-treatment would be required to adjust volatility and viscosity/freeze point properties. In the case of the above two examples, the end points were extended to 750F as per DOE's suggestion in order to maximize product energy densities. Although this was achieved, as noted by the ca. $130,000+B t u / g a l$ values, the higher end points corresponded to unacceptably high freeze points.

The final distillation operations for adjustment of front-end volatiles (i.e., flash point) and back-end waxes (i.e., freeze point, viscosity) were completed for the HEDF product derived from the selective VGO hydrocracking route. Table 5.5-1 summarizes the properties of the final product. All specifications were met and all identified target properties were exceeded with the exception of smoke point. It appears that the F.I.A. aromatics content of $10 \%$ was a little high resulting in the adverse $15 \mathrm{~mm}$ smoke point. Thus, FB-166 should have been operated at a slightly higher hydrogenation severity to reduce the aromatics to below $10 \%$, preferably between 5 and $7.5 \%$. From the earlier data on the hydroprocessing of the raw 300-600F COALITE, it would appear that an increase in smoke point of $5 \mathrm{~mm}$ would require an aromatics reduction of about $5 \%$ suggesting that both the smoke point and the aromatics content specs can be met. 


\section{COMPARISON OF COALITE-DERIVED HEDF FUELS}

\section{PRODUCED VIA TWO HYDROPROCESSING SCHEMES}

\begin{tabular}{|c|c|c|c|}
\hline Property & ecification & Selective HYC & Raw Dist. HD \\
\hline VLHV, Btu/gal & $130,000(\mathrm{~min})$ & 132,915 & $1: 9,095$ \\
\hline FREEZE PT, $F$ & -50 & -60 & -54 \\
\hline FLASH PT, F & $100(\min )$ & 115 & 115 \\
\hline \% HYDROGEN & $12.5(\mathrm{~min})$ & 13.2 & 13.9 \\
\hline \% AROMATICS & $5 \min ; 25 \max$ & 10.0 & 5.0 \\
\hline SULFUR, ppmw & $500 \max$ & $<2$ & $<5$ \\
\hline$\%$ OLEFINS & $5 \max$ & $<0.5$ & $<0.5$ \\
\hline VISC, cst/-4F & $8 \min ; 12 \max$ & 11.0 & 8.0 \\
\hline
\end{tabular}


This small but finite incremental hydrogenation unfortunately will result in some further reduction in the volumetric energy density. On the positive side, the prior hydroprocessing data with the raw COALITE distillate indicated that at HEDF aromatics levels below about $20 \%$, there was not a great effect of aromatics content on volumetric energy densities.

\subsubsection{Subtask $3.1 / 3.2$ Scope}

In view of these promising results and $D O E^{\prime} s$ desire to increase the target HEDF energy density from $130,000 \mathrm{Btu} / \mathrm{gal}$ to $135,000 \mathrm{Btu} / \mathrm{gal}$, a contract modification was executed. A new Subtask 3.1/3.2 was formulated to concentrate on the selective hydrocracking route by investigating alternative catalysts that will simultaneously produce HEDF test fuels having the targetted high (ca., 135,000 Btu/gal) energy densities and acceptable thermal stability characteristics. The Colorado shale oil studies were to be deemphasized because of their apparent limited cyclics content that prevents the achievement of the $130,000+B t u / g a l$ energy densities.

It has been hypothesized that there is a set of operating conditions that exists in which a high density jet fuel fraction, derived from hydroprocessing of COALITE heavy dictillates, will have an energy density of $135,000 \mathrm{Btu} / \mathrm{gal}$ or higher ind meet some acceptable thermal stability criterion. Of the many parameters that might affect the achievement of these goals, those that are anticipated to have the greatest influence on energy density and stability include:

- COALITE feedstock definition

- Hydroprocessing steps including fractionation between steps to pinpoint preferred distillate compositions

- Catalyst type

- Thermal severity as measured by reaction temperature and space velocity

\section{COALITE Feedstock Definition}

From the prior Task 3 screening efforts, it was determined that hydrocracked heavy distillates had higher energy densities, by some $3000-4000 \mathrm{Btu} / \mathrm{gal}$, than those of distillates boiling in the jet fuel range by virtue of being thermally cracked during the COALITE MCG process. By tailoring the selective hydrocracking operations to near optimal conditions, it might be possible to increase the energy density advantage over the as-produced jet fuel-range distillates by as much as 5000-6000 Btu/gal.

Assuming the end-point of the finished HEDF product will be $575 \mathrm{~F}$, the raw COALITE was fractionated to generate a $575 \mathrm{~F}+$ resid, more than $90 \%$ of which boils below 975F. The latter vacuum gas oil (VGO) cut, namely, 575-975F, is the candidate feedstock for the selective hydrocracking campaigns of Subtask 3.2 . 


\section{Hydroprocessing Sequence}

The hydroprocessing of the heavy COALITE fractions is carried out in several steps of hydrogen uptake, heteroatom removal, hydrocracking and aromatics saturation. The multi-step operation represents the best approach from the points of view of reactor design, heat removal, and catalyst selectivity/activity. The stepwise process consists of:

1. LC-Fining of $575 F+$ resid

2. Flash vaporization to recover the $975 \mathrm{~F}-\mathrm{LC}-\mathrm{Finates}$

3. Fixed-bed hydrodenitrogenation of the $975 \mathrm{~F}-\mathrm{LC}-\mathrm{F}$ inates

4. Fixed-bed hydrocracking of the hydrodenitrogenated $975 \mathrm{~F}$ - LC.Finates

5. Fixed-bed hydrogenation (aromatics saturation) of the selectively hydrocracked LC-Finates

6. Fractionation to recover the Category I HEDF product (and Category II and III distillate byproducts)

\section{LC-Fining}

The LC-Fining step might commercially be substituted with a fixed-bed resid hydrotreating process. Its primary function is to perform some degree of hydrogen uptake in a manner that can cost effectively remove the corresponding exothermic heats of reaction. Along with HDN, olefins are saturated, some aromatics are saturated and much of the organic oxygen is removed. Additionally, there is some degree if hydrocracking, defined as conversion to $575 \mathrm{~F}-$. The LC-Finer aiso allows the hydroprocessing of the resid portion of the COALITE which contains some coal char fines and coal mineral matter that are normally poisons and deactivators in fixed-bed hydroprocessing units.

The LC-Finer is being used as a unit to prepare feedstock for downstream hydroprocessing technology evaluations and is operated at constant conditions of 2000 psig pressure, $760 \mathrm{~F}$ reactor temperature, 0.8 LHSV (based on catalyst volume) and $6000 \mathrm{scf} / \mathrm{bbl}$ treat gas rate using Criterion 324M catalyst, a nickel-moly catalyst used extensively in coal hydroliquefaction operations.

\section{Flash Vaporization}

The LC-Finate product, containing hydrocracked 575F- distillates, hydrotreated $575-975 \mathrm{~F}$ distillates, and hydrotreated $975 \mathrm{~F}+$ resid, is flashed in a continuous equilibrium flash vaporization (EFV) unit operated at $575 \mathrm{~F}$ and $25 \mathrm{~mm} \mathrm{Hg}$ absolute. These flashing conditions approximate a $975 \mathrm{~F}$ atmospheric equivalent end point of the recovered HVGO (hydrotreated VGO). The hydrocracked jet fuel-range distillates co-produced with the HVGO during the LC-Fining operations were not separated from the HVGO and are co-hydroprocessed in the downstream units. Thus, the final HEDF product will have the LC-Finate hydrocrackate and fixed-bed hydrocrackate products co-mingled.

\section{Fixed-Bed Hydrodenitrogenation (HDN)}

The primary function of the fixed-bed HDN step is to reduce the nitrogen content of the HVGO sufficiently to protect the downstream 
selective hydrocracking catalyst, which is sensitive to $\mathrm{N}$ poisons. The catalyst selected for this step is Akzo KF-843, a commercial high moly nickel on alumina, first-stage (HDN) hydrocracking catalyst. The thermal operating severity as measured by reaction temperature and residence time (i.e., space velocity) at constant pressure will be scanned to determine the best conditions for production of hydrodenitrogenated HVGO for the downstream fixed-bed hydrocracking scans.

\section{Fixed-Bed Hydrocracking}

The fixed-bed hydrocracking step represents the key in being able to selectively hydrocrack HVGO components to the desirable two-ring and three-ring aromatic precursors to HEDF. The key to the selectivity potential resides in the catalyst type. In this program, three catalysts are under consideration: 1) Akzo KF-1015, a commercial nickel-moly Mild Hydrocracking catalyst; 2) a proprietary Amoco nickel-tungsten catalyst previously tested in Task 3 ; and 3 ) a new sulfur-resistant, proprietary zeolitic hydrocracking catalyst being offered by Zeolyst Enterprises.

Each catalyst was evaluated in a series of scans to identify that combination of thermal severity and hydrogen partial pressure that results in maximum HEDF precursor yield and maximum precursor quality, the latter being used as a measure of HEDF energy density. From an analytical viewpoint, HEDF precursor quality may be assessed from FIA analysis, HNMR analysis and density-hydrogen content relationships.

\section{Fixed-Bed Hydrogenation (Aromatics Saturation)}

A final aromatics saturation step may be required for final hydro-finishing depending upon the selectivity of the hydrocracking catalyst. The proprietary zeolitic catalyst from Zeolyst Enterprises had dual functionality, namely, hydrocracking and ring saturation. In this situation, a final fixed-bed hydrogenation step was not required. For the other hydrocracking catalysts, fixed-bed hydrogenation is required. The key here is to determine the optimal extent of aromatics saturation that will maximize HEDF energy density. This is a function of the hydrogenation severity. Although many nickel-moly or nicke? - tungsten hydrogenation catalysts are commercially available, Katalco K-599, a nickel-moly catalyst used extensively in the earlier Task 3 screening program and for which a database exists, was utilized for this hydroprocessing step. A post-hydrogenation finishing step, namely, clay treating, was used to reduce trace polar compounds that might otherwise detrimentally affect the fuel properties of thermal stability and corrosion resistance.

\subsubsection{Subtask $3.1 / 3.2$ Results}

The purpose of subtask 3.2 was to explore ways to produce a stable high energy density $(130,000+\mathrm{Btu} / \mathrm{gal})$ HEDF test fuel from raw COALITE feed through a selective hydrocracking/hydrotreating approach. The campaign initiated to achieve this goal is summarized below: 
Step 1. The COALITE feed was charged to the 8 " batch distillation unit. Run EBD-41 was an atmospheric distillation to produce a $300^{\circ} \mathrm{Ft}$ material followed by $E B D-42$ which was a vacuum distillation to produce the $575^{\circ} \mathrm{Ft}$ material for the LC-Fining reactors.

Step 2. The $575^{\circ} \mathrm{F}+$ COALITE was then fed to the LC-Fining ${ }^{\text {tm }}$ unit consisted of 2 expanded-bed reactors in series each loaded with $3000 \mathrm{cc}$ of Shell 324M catalyst. The operating conditions were 2000 psig pressure, $765 \mathrm{~F}$ average reactor temperature and 1.6 LHSV per bed. The product from the LC-Fining stage achieved an HDN rate of $84 \%$, HDS of $98 \%$, $575 \mathrm{~F}+$ conversion of $30 \mathrm{vol \%}$, and a $975^{\circ} \mathrm{F}+$ conversion of 65 vol\%. Enough LC-Finate was generated to conduct the subsequent HDN, hydrocracking and hydrogenation scans.

Step 3. The LC-Finate from Step 2 was then processed in an Equilibrium Flash Yaporization Unit (EFV) operated at yacuum to remove the $900 \mathrm{~F}+$ material. The resulting IBP-900 $\mathrm{F}$ material was then used as feed for the HDN fixed bed scans.

Step 4. The IBP- $900^{\circ} \mathrm{F}$ distillate then sent to an HDN fixed bed unit where the nitrogen was reduced from $1700 \mathrm{ppm}$ to $43 \mathrm{ppm}$. The HDN unit was a downflow fixed bed unit with 2 reactors in series. The catalyst charged to each reactor was $165 \mathrm{cc}$ Katalco KF-843 extrudates. A total of 18 scanning runs (Runs FB-194-211) were performed at different pressures, liquid hourly space velocities, and reactor temperatures. Production runs were then made to generate HDN material for subsequent fixed bed hydrocracking and hydrotreating operations. The conditions were 2000 psig unit pressure, 1.0 liquid hourly space velocity, and $780^{\circ} \mathrm{F}$ average reactor temperatures.

Step 5. Material from the hydrodenitrogenation step was then hydrocracked in a single stage downflow fixed bed reactor. The scanning tests employed AKZO KF-1015 Ni/Mo catalyst for Runs FBHC 37 and 38 and a proprietary zeolitic catalyst for Runs FBHC $39-43$.

Run FBHC-37 was a scanning campaign with seven different conditions of space velocity and reactor temperatures at a set pressure of 2000 psig. As a result of the scanning tests, a production run (Run FBHC-38) was made at 2000 psig, $760 \mathrm{~F}$ reactor temperature, and a liquid hourly space velocity of $0.5 \mathrm{hr}^{-1}$ to generate material for the hydrotreating step.

Run FBHC-39 was a scanning test using the proprietary zeolitic catalyst with six different conditions of space velocity and temperature at a set pressure of 2000 psig. The catalyst activity was so high at the conditions that all of the material cracked out of the jet fuel range into the $275 \mathrm{~F}$ - naphtha range. Based on the above obsarvations a 
second scanning run (FBHC-40) was initiated at lower operating pressures of $1000 \mathrm{psig}$ and reactor temperatures of $550-650 \mathrm{~F}$. Based on the results of the scanning tests, three different production runs (FBHC-41, 42, and 43) were performed with the proprietary zeolitic catalyst. The activity of this catalyst towards hydrocracking and ring saturation was so high that the final hydrotreating step to produce the desirable cycloparaffins was not required. The products from $F B H C-41,42$ and 43 were then fractionated and treated with bentonite clay.

Step 6. A series of hydrotreating runs was performed with a 2 stage fixed bed reactor system using a) hydrodenitrogenated but not hydrocracked LC-Finate distillate from Run FB-213; and b) hydrocracked LC-Finate distillate from Run FBHC-38.

The fixed bed hydrogenation Run FE-214 employed two reactors in series each containing $165 \mathrm{cc}$ of Criterion 424 NiMo catalyst. Three scanning tests were performed with the hydrodenitrogenated LC-Finate distillate prior to a production run (Run FB-214D) at 2000 psig unit pressure, 0.5 liquid hourly space velocity, and $715^{\circ} \mathrm{F}$ average reactor temperature. This run was followed by a production run (FB-214E) at the same conditions except using the hydrocracked (FBHC-38) hydrodenitrogenated LC-Finate distillate as the feed. After the two production runs, one more test was made with the hydrodenitrogenated LC-Finate distillate at 2000 psig unit pressure, 0.25 liquid hourly space velocity and $750 \mathrm{~F}$ reactor temperature. This test was made to assess the impact of a loF increase in thermal severity on HEDF fuel properties.

\subsubsection{LC-Fining Studies}

The first step in the overall sequence to produce finished HEDF test fuel from the raw COALITE feed is to hydroprocess the atmospheric resid cut via expanded-bed LC-Fining. The throughput to the LC-Fining unit was specified to insure that there would be a minimum quantity of HEDF precursors in the LC-Finate products necessary for the susbequent screening studies. Run 6LCF-11 was carried out using fresh She $11324 M$ NiMo catalyst. The 6LCF-11 feed was derived from the 575F+ atmospheric resid fraction recovered during the batch fractionation (in an 8-in batch fractionation unit) of the raw COALITE material.

The pilot plant LC-Fining unit was used because of its large size and short operating time needed for production of the Task 3 quantities of materials required. All of the downstream screening tests for the HDN, selective hydrocracking and aromatics saturation were made in bench-scale unit. After the LC-Finer was successfully pressure tested at 2500 psig hydrogen pressure, it was commissioned with a $350-575 \mathrm{~F}$ raw COALITE distillate until the catalyst bed temperature was 500F. At this point, the distillate feed was removed and the $575 \mathrm{~F}+$ resid was introduced which increasing the heat inputs until the desired catalyst bed temperature was achieved. 
The run proceeded for four days without any major operating problems. The reactor operating conditions were 2000 psig operating pressure, $764 \mathrm{~F}$ average catalyst bed temperature, $6000 \mathrm{scfb}$ treat gas rate and 1.64 LHSV per each of the two catalyst beds.

As indicated in Table 5.5.3.1-1, the products from this LC-Fining step resulted in an HDN rate of $84 \%$, and HDS rate of $98 \%$, a $575 \mathrm{~F}+$ conversion of $30 \mathrm{vol} \%$ and a $975 \mathrm{~F}+$ conversion of $65 \mathrm{vo} \% \%$. At the end of run 6 LCF-11, the composited heavy oil fraction containing unconverted $975 \mathrm{~F}+\mathrm{COALITR}$ was processed in the Equilibrium Flash Vaporization unit to remove the vac resid material. The entire IBP-900F LC-Finate distillate, which contains HEDF precursor components as well as the vacuum gas oil (VGO) fractions, was composited and drummed for subsequent processing in the bench-scale, fixed-bed hydrotreating unit for deep denitrogenation.

\subsubsection{Fixed-Bed Hydrodenitrogenation Studies}

A total of $165 \mathrm{CC}$ of KF-843 catalyst was charged to each of the two fixed-bed reactors. The catalysts were calcined in situ at $750 \mathrm{~F}$ for two hours followed by presulfiding with a $2 \% \mathrm{H}_{2} \mathrm{~S} / \mathrm{H}_{2}$ gas mixture. After the presulfiding operations following the vendor' ${ }^{2}$ procedure, the unit was successfully pressure tested at 2500 psig.

The IBP-900F LC-Finate distillate was then subjected to hydrodenitrogenation in a series of 18 brief scanning runs (Table 5.5.3.2-1) to assess the effects of reactor pressure, LHSV and bed temperature at constant hydrogen treat gas rate. From these scans, the conditions of 2000 psig reactor pressure, 1.0 LHSV and 780F average bed temperature were selected as the preferred conditions for an HDN production run. The material thus produced was used for the downstream fixed-bed hydrocracking and aromatics saturation screening tests.

\subsubsection{Fixed-Bed Selective Hydrocracking Studies}

The full-rane hydrodenitrogenated LC-Finate distillate was then subjected to selective hydrocracking in a single-stage fixed-bed reactor. Two candidate hydrocracking catalysts were evaluated: a NiMo catalyst (Akzo KF-1015) in runs FBHC-37 and -38 and a proprietary zeolitic catalyst (Zeolyst 2704A) in runs FBHC 39-41.

Run FBHC-37 consisted of seven process variable scans of space velocity and bed temperature at 2000 psig reactor pressure and 6000 scfb treat gas rate (see Table 5.5.3.3-1). Based on these scans, a production run (FBHC-38 as delineated in Table 5.5.3.3-2) was made at 2000 psig, $6000 \mathrm{scfb}$ treat gas rate, 0.5 LHSV and average bed temperature of $758 \mathrm{~F}$ to generate enough HEDF precursors for final aromatics saturation prior to HEDF finishing.

Run FBHC-39 consisted of six process variable scans of space velocity and bed temperature at 2000 psig reactor pressure and 6000 scfb treat gas rate. The hydrocracking activity of this zeolitic catalyst was so high at bed temperatures above about 700F that essentially all of the jet fuel range material was cracked into the naphtha range as shown on Table 5.5.3.3-3. 


\begin{tabular}{|c|c|}
\hline PERIOD NUMBER & 3 \\
\hline 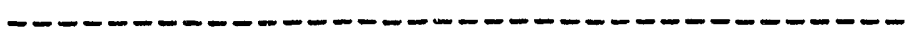 & $--\infty-$ \\
\hline $\begin{array}{l}\text { DATE } \\
\text { AVG. CATALYST TEMP. (15t STAGE) } \\
\text { AVG. CATALYST TEMP. (2nd STAGE) } \\
\text { TOTAL PRESSURE, PSIG } \\
\text { LHSV, HOURS-1 } \\
\text { CATALYST AGE, BBL/LB } \\
\text { WDSV, BBL/LB/DAY } \\
\text { CATALYTIC H2, SCF/BBL } \\
\text { CARBON BALANCE, WT. } \% \text { RECOVERY } \\
\text { OVERALL MAT. BAL. WT. * RECOVERY }\end{array}$ & $\begin{array}{r}3 / 31 \\
759 \\
769 \\
2000 \\
0.82 \\
0.17 \\
0.071 \\
5900 \\
101 \\
96\end{array}$ \\
\hline $\begin{array}{l}\text { FEED COALITE }(575 F+) \text { PROPERTIES } \\
\text { API GRAVITY } \\
\text { CARBON, WT.* } \\
\text { HYOROGEN, WT.* } \\
\text { SULFUR, PPM } \\
\text { NITROGEN, PPM } \\
\text { OXYGEN, WT.* } \\
\text { ASH, WT.\% } \\
975 F+\text { RESID, VOL. } *\end{array}$ & $\begin{array}{r}-3.7 \\
85.37 \\
8.01 \\
10200 \\
14100 \\
4.03 \\
0.16 \\
18\end{array}$ \\
\hline $\begin{array}{l}\text { LIGHT OIL PRODUCT PROPERTIES } \\
\text { API GRAVITY } \\
\text { CARBON, WT. } \% \\
\text { HYDROGEN, WT.\% } \\
\text { SULFUR, PPM } \\
\text { NITROGEN, PPM } \\
\text { OXYGEN, WT. } \% \text { (DIFF. ) } \\
575 F+\text { RESID, VOL.\% }\end{array}$ & $\begin{array}{r}28.2 \\
87.82 \\
12.05 \\
195 \\
1118 \\
0 \\
23\end{array}$ \\
\hline
\end{tabular}

\section{HEAVY OIL PRODUCT PROPERTIES}

API GRAVITY

CARBON, WT .\%

HYDROGEN, WT.\%

11.6

SULFUR, PPM

89.32

10.24

NITROGEN, PPM

186

OXYGEN, WT.\% (DIFF.)

3121

ASH, WT.\%

0.11

$575 F+$ RESID, VOL .\%

0.02

$975 F+$ RESID, VOL.\%

88.8

9.0

DAILY PRODUCT YIELDS, WT.* FEED

$\begin{array}{lr}\text { OFFGAS H2S } & 1.07 \\ \text { OFFGAS NH3 + H2O } & 5.89 \\ \text { OFFGAS C1 } & 0.69 \\ \text { OFFGAS C2 } & 0.66 \\ \text { OFFGAS C3 } & 0.70 \\ \text { OFFGAS C4 } & 1.66 \\ \text { OFFGAS C5+ } & 0.81 \\ \text { LIGHT OIL } & 29.68 \\ \text { HEAVY OIL } & 62.30 \\ \text { TOTAL } & 103.46\end{array}$

H2 CONSUMPTION, SCF/BBL

2700

DENITRIFICATION, WT.\%

DESULFURIZATION, WT.*

84

VOL.\% 575 DEG. F + CONVERSION

98

VOL.\% 975 DEG. F + CONVERSION

30

65 


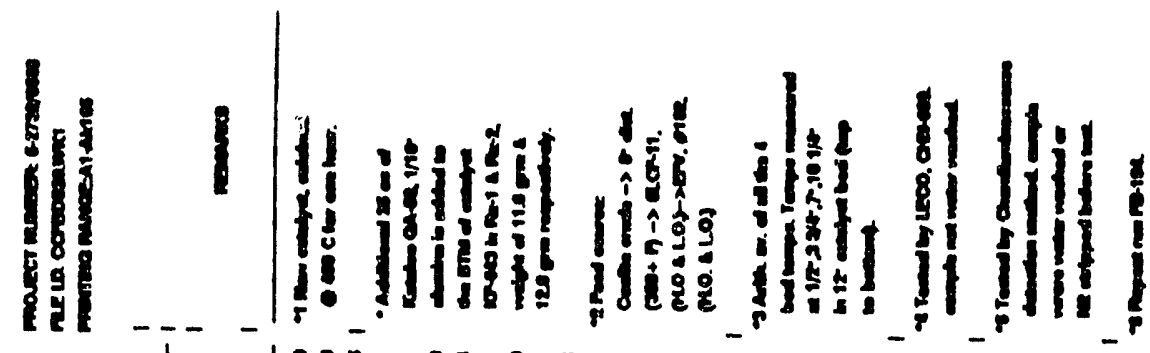

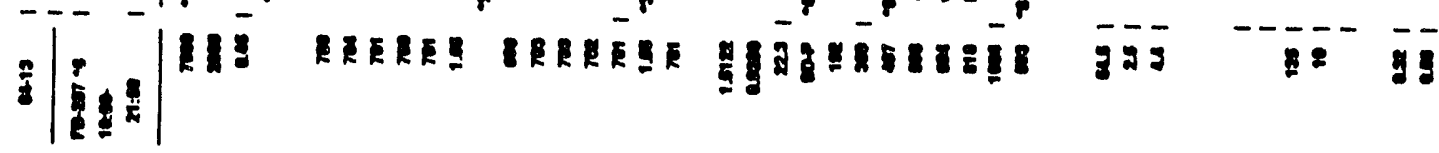

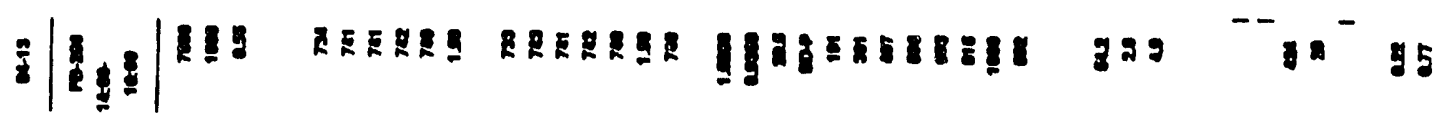

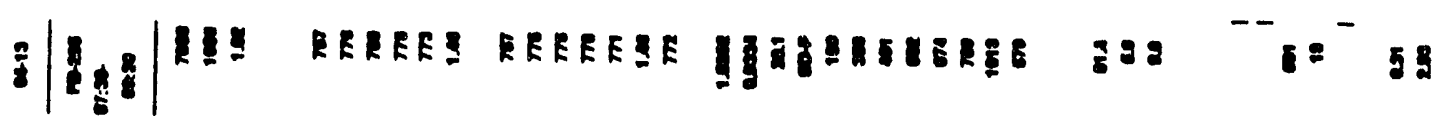

|

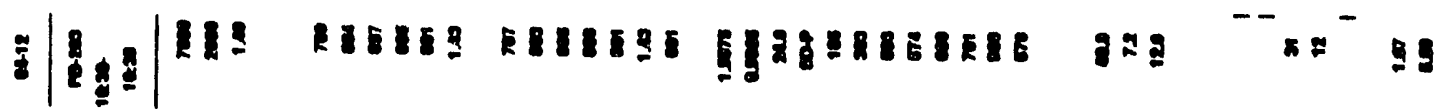

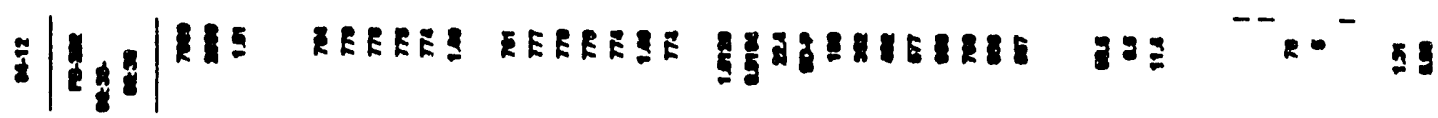

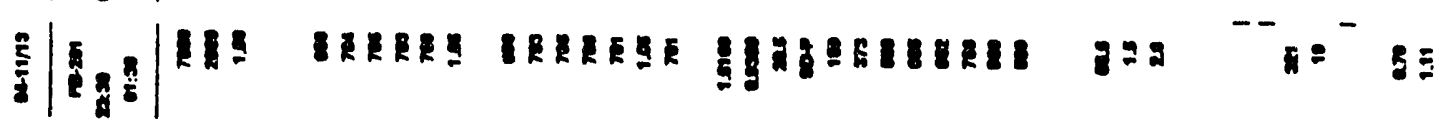

3|

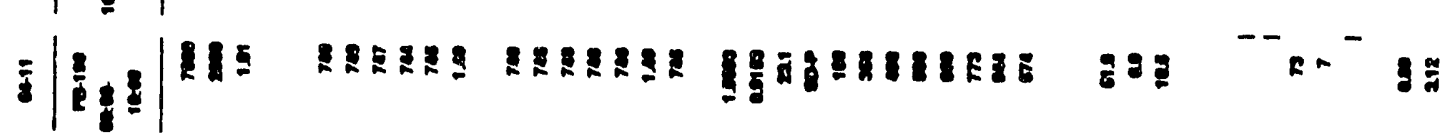

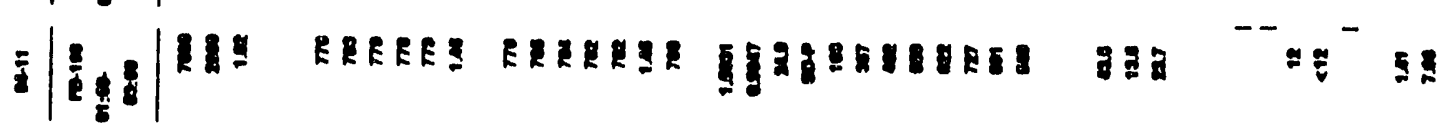

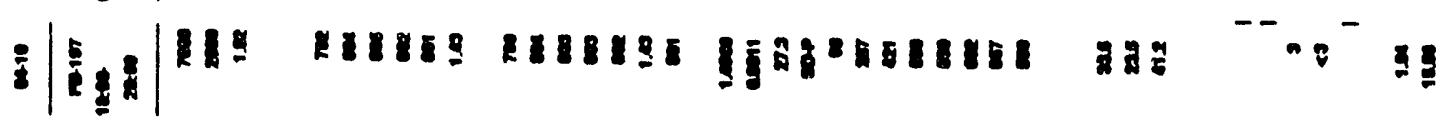

8Eห3: E

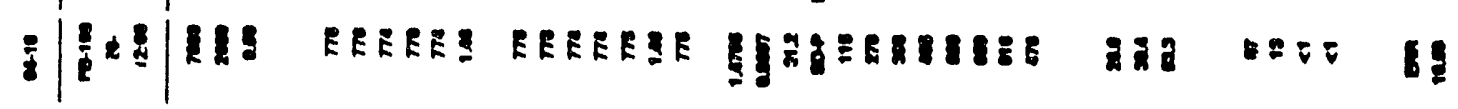

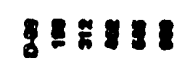

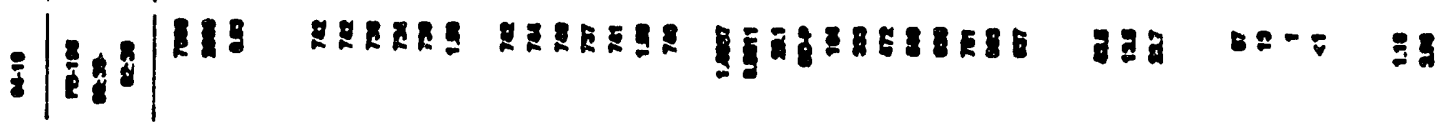

| 1 8ดละ

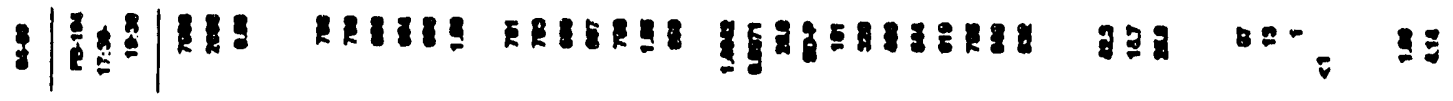

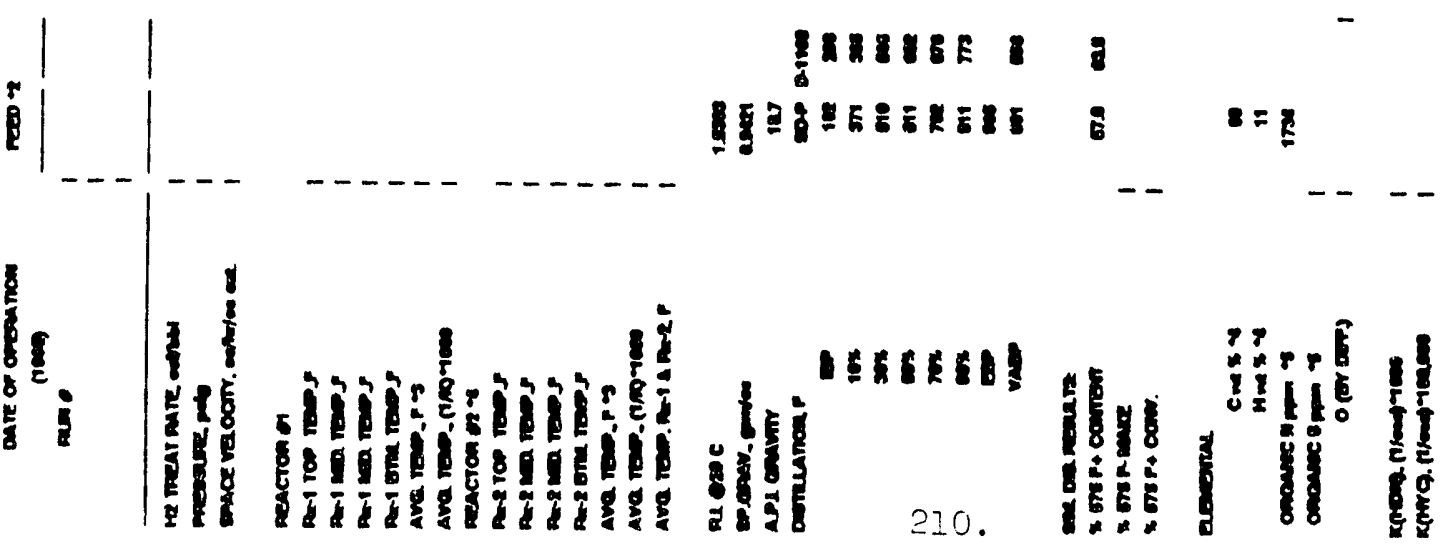




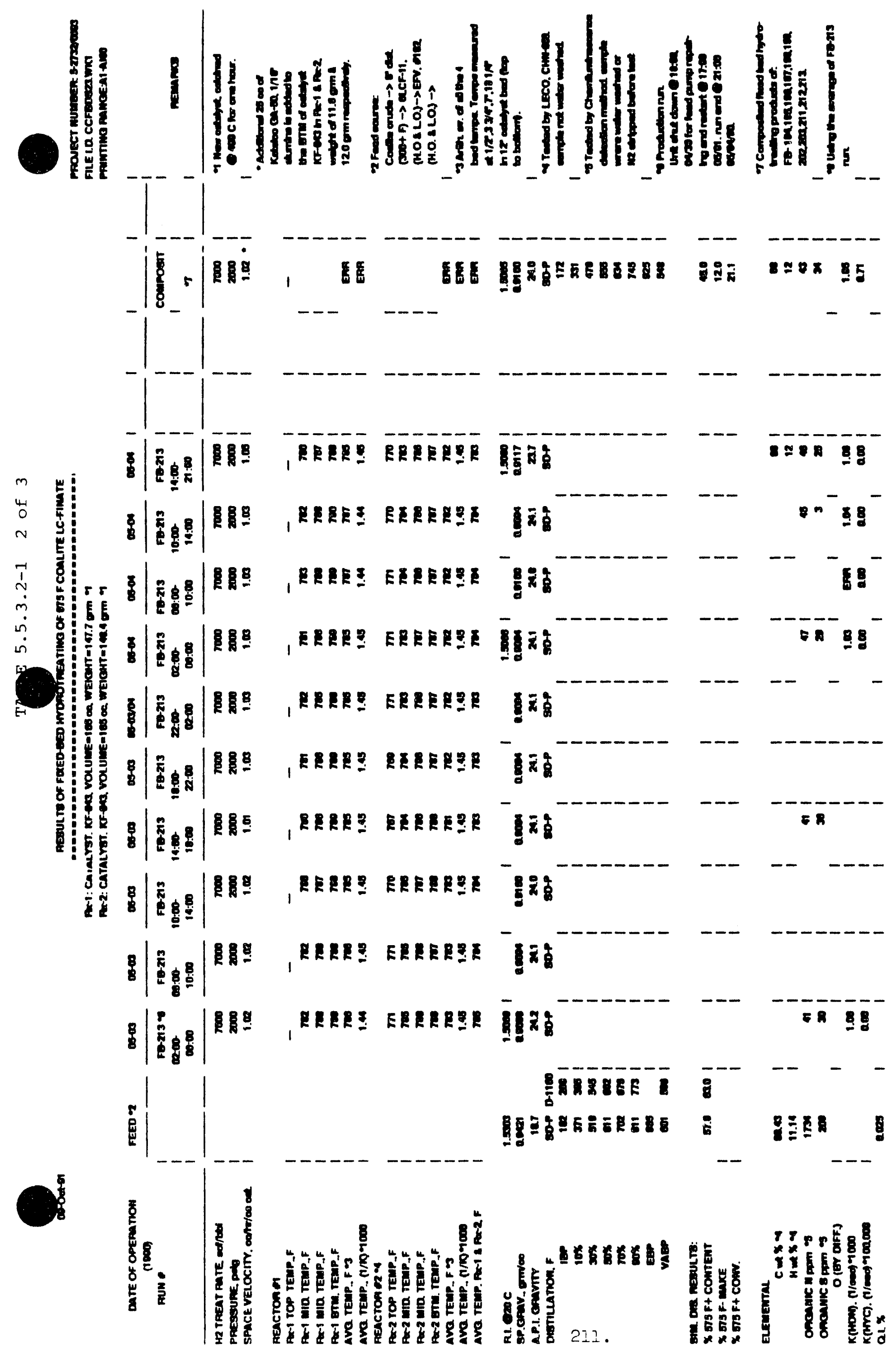


i|

最|

\&

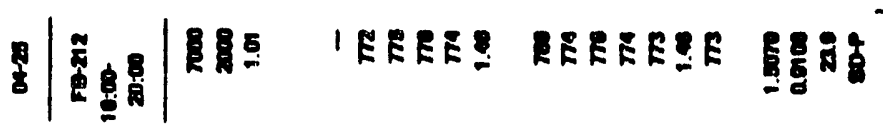

是|

8|

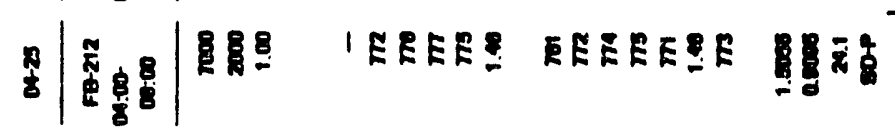

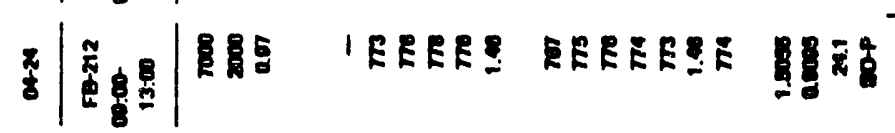

8|

8

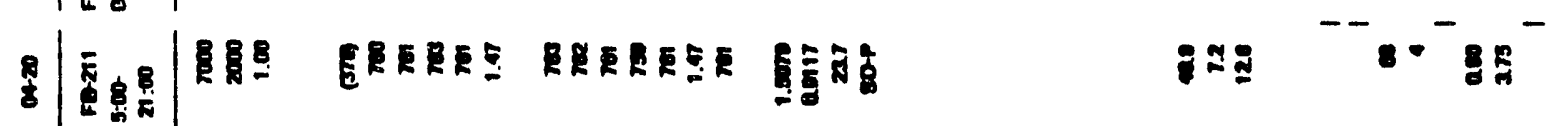

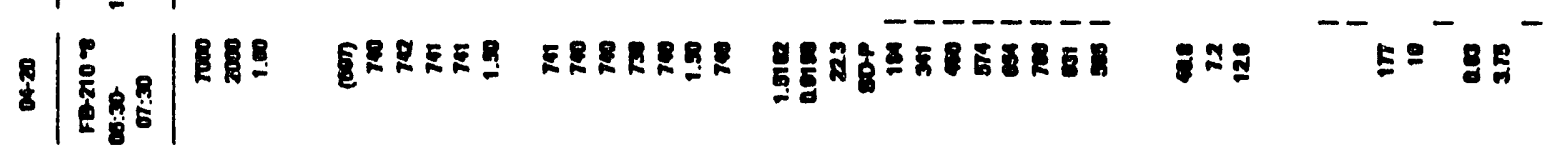

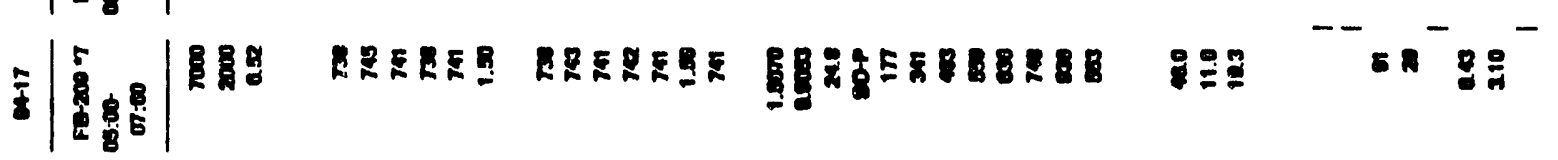

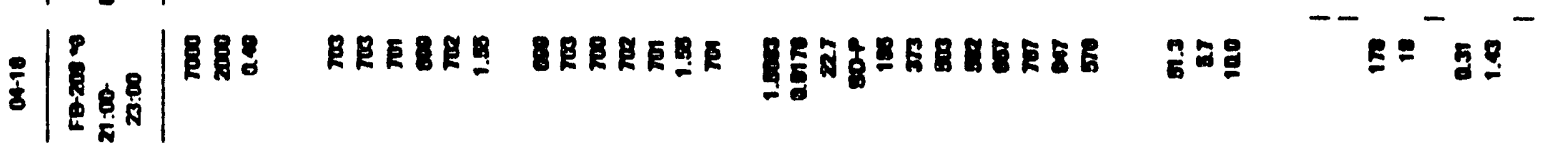

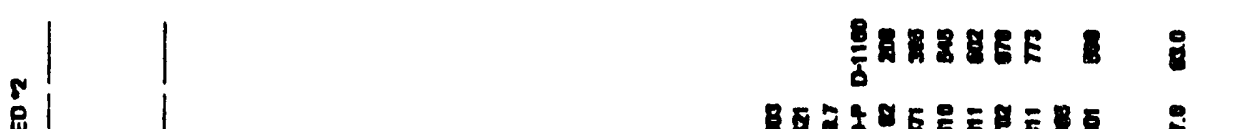

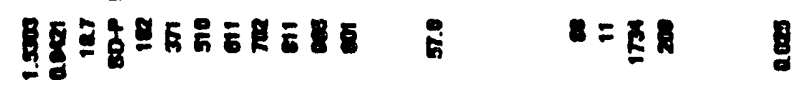

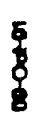

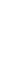

要:

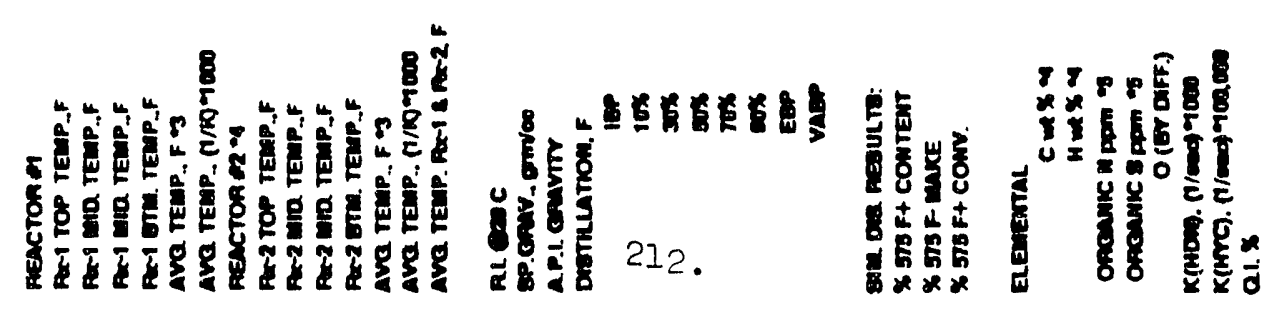


TABLE $5 \cdot 5 \cdot 3 \cdot 3-1$

FIXED BED

HYDROCRACKING

RUN FBHC-37

CATALYST: 165 CC AKZO KF-1015 Ni/MO

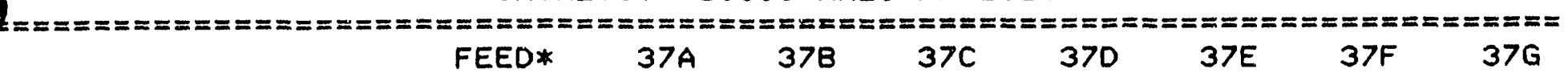

- - - - -

OPERATING CONOITIONS:

CATALYTIC H2, SCF/BBL

RUN DURATION, HRS.

AVG. RX. TEMP., DEG. F

PRESSURE, PSIG

AVG. FEED RATE, cc/hr

LHSV, cC/hr/CC cat.

FEED IN, gms.

TLP OUT, gMS.

RECOVERY, *

$\begin{array}{rrrrrrrr}- & 6000 & 6000 & 6000 & 6000 & 6000 & 6000 & 6000 \\ - & 2 & 2 & 4 & 2 & 4 & 2 & 1 \\ - & 655 & 656 & 703 & 708 & 754 & 751 & 734 \\ - & 2000 & 2000 & 2000 & 2000 & 2000 & 2000 & 2000 \\ - & 85 & 188 & 68 & 163 & 61 & 178 & 310 \\ - & 0.52 & 1.14 & 0.41 & 0.98 & 0.37 & 1.08 & 1.88 \\ - & 154 & 341 & 245 & 295 & 220 & 322 & 282 \\ - & 176 & 318 & 235 & 322 & 222 & 297 & 307 \\ - & 114 & 93 & 96 & 109 & 101 & 92 & 109\end{array}$

ANALYTICAL RESULTS:

TLP GRAVITY, gMS/CC

TLP GRAVITY, API

OISTILLATION:

IBP-275 F, WT .*

275-575 F, WT.*

$575 \mathrm{Ft}$, WT.z
0.90820 .8956

24.326 .5

0.9013

25.5

0.8789

29.5

0.8916

27.2

0.8639

32.3

0.8762

30.0

0.8888

5.3

5.5

5.1

49.3

50.4

51.8

7.0

58.1

6.7

53.9

8.7

66.6

10.5

59.0

30.5

24.7

JET FUEL CUT, 275-575 F:

GRAV., GMS/CC
GRAV., API
R.I., 20 DEG.
H/C RATIO
ELEMENTALS, WT.\%
CARBON
HYDROGEN
F. I.A., VOL.\%
AROMATICS
OLEFINS
SATURATES

46

33

21

3

0.88

28.2

0.8827

0.8713

0.8783

0.8618

32.7
0.8729
30.6

0.8783 29.6

1.4709

$1.4794 \quad 1.4840$

$\begin{array}{lllll}1.4888 & 1.4817 & 1.4838 & 1.4755\end{array}$

1.481

$\begin{array}{rrrr}1.65 & 1.74 & 1.71 & 1.78 \\ 87.88 & 87.20 & 87.38 & 87.07 \\ 12.12 & 12.67 & 12.45 & 12.90\end{array}$

1.71

1.80

1.70

1.66

87.48

12.50

86.84

87.23

87.04

40.7

0.9

58.4

* the feed for the run is coalite oil that was topped to 300 deg f + in the 8" BATCH AND PROCESSED IN THE LC-FINING UNIT (RUN 6LCF-11 UPGRADED \& REMOVED NITROGEN TO 1000 PPM). THE LC-FINATE WAS THEN RUN THROUGH THE EFV UNIT TO OBTAIN THE 300-975 FRACTION. FINALLY THE FEED WAS HYDROTREATED AND NITROGEN REMOVED ( 40 PPM) IN FIXED BED RUNS FB-194-199, 202-203, \& 211-213.

THE SAMPLE \# IS 3610 . 
RUN FBHC-38

HYDROCRACKING COALITE DISTILLATE MATERIAL BALANCE

\begin{tabular}{|c|c|c|}
\hline PERIOD NUMBER & FEED* & $\mathrm{FBHC}-38$ \\
\hline $\begin{array}{l}\text { DATE } \\
\text { TOTAL PRESSURE, PSIG } \\
\text { LHSV, HOURS-1 } \\
\text { AVERAGE TEMPERATURE, DEG. F } \\
\text { CATALYST AGE, BBL/LB } \\
\text { WDSV, BBL/LB/DAY } \\
\text { CATALYTIC H2, SCF/BBL } \\
\text { CARBON BALANCE, WT.* RECOVER } \\
\text { OVERALL MAT. BAL. WT. } \\
\text { HYDROGEN CONSUMPTION, SCF/BBI } \\
575 \text { DEG F+ CONVERSION, WT.\% }\end{array}$ & VERY & $\begin{array}{r}8 / 30 \\
2000 \\
0.49 \\
758 \\
0.947 \\
0.037 \\
5900 \\
97 \\
98 \\
700 \\
61\end{array}$ \\
\hline $\begin{array}{l}\text { TLP OIL PRODUCT PROPERTIES } \\
\text { API GRAVITY } \\
\text { CARBON, WT.* } \\
\text { HYDROGEN, WT.* } \\
\text { SULFUR, PPM } \\
\text { NITROGEN, PPM }\end{array}$ & $\begin{array}{r}24.3 \\
87.99 \\
12.00 \\
34 \\
43\end{array}$ & $\begin{array}{r}35.3 \\
87.16 \\
12.84 \\
9 \\
0.9\end{array}$ \\
\hline $\begin{array}{l}\text { DAILY PRODUCT YIELDS, WT * FI } \\
\text { OFFGAS H2S } \\
\text { OFFGAS NH3 + H2O } \\
\text { OFFGAS C1 } \\
\text { OFFGAS C2 } \\
\text { OFFGAS C3 } \\
\text { OFFGAS C4 } \\
\text { OFFGAS C5+ } \\
\text { IBP-275 DEG. F } \\
275-575 \text { DEG. F } \\
575 \text { DEG. F + } \\
\text { TOTAL }\end{array}$ & $\begin{array}{r}5.3 \\
49.3 \\
45.4 \\
100.00\end{array}$ & $\begin{array}{r}0.00 \\
0.01 \\
0.27 \\
0.17 \\
0.57 \\
0.37 \\
0.62 \\
19.42 \\
61.83 \\
17.84 \\
101.10\end{array}$ \\
\hline $\begin{array}{l}\text { JET FUEL CUT }(275-575 \text { DEG F) } \\
\text { GRAVITY, API } \\
\text { GRAVITY, SP. } 60 / 60 \\
\text { ELEMENTALS, WT.* } \\
\text { CARBON } \\
\text { HYDROGEN }\end{array}$ & $\begin{array}{r}\text { PROPER } \\
28.2 \\
0.8860\end{array}$ & $\begin{array}{r}\text { ES } \\
32.8 \\
0.8612\end{array}$ \\
\hline $\begin{array}{l}\text { R.I., 2ODEG C } \\
\text { F.I.A., VOL.* } \\
\text { AROMATICS } \\
\text { OLEFINS } \\
\text { SATURATES }\end{array}$ & $\begin{array}{r}42.0 \\
0.5 \\
57.5\end{array}$ & $\begin{array}{r}30.5 \\
1.0 \\
68.5\end{array}$ \\
\hline
\end{tabular}

* the feed for fBHC-38 is the same as run FBHC-37. REFER TO RUN FBHC-37. 
SUMMARY OF FIXED_BED HYDROCRACKING RUN

RUN $F B H C-39$

CATALYST: $165 \mathrm{CC}$ ZEOLITE Z-704A

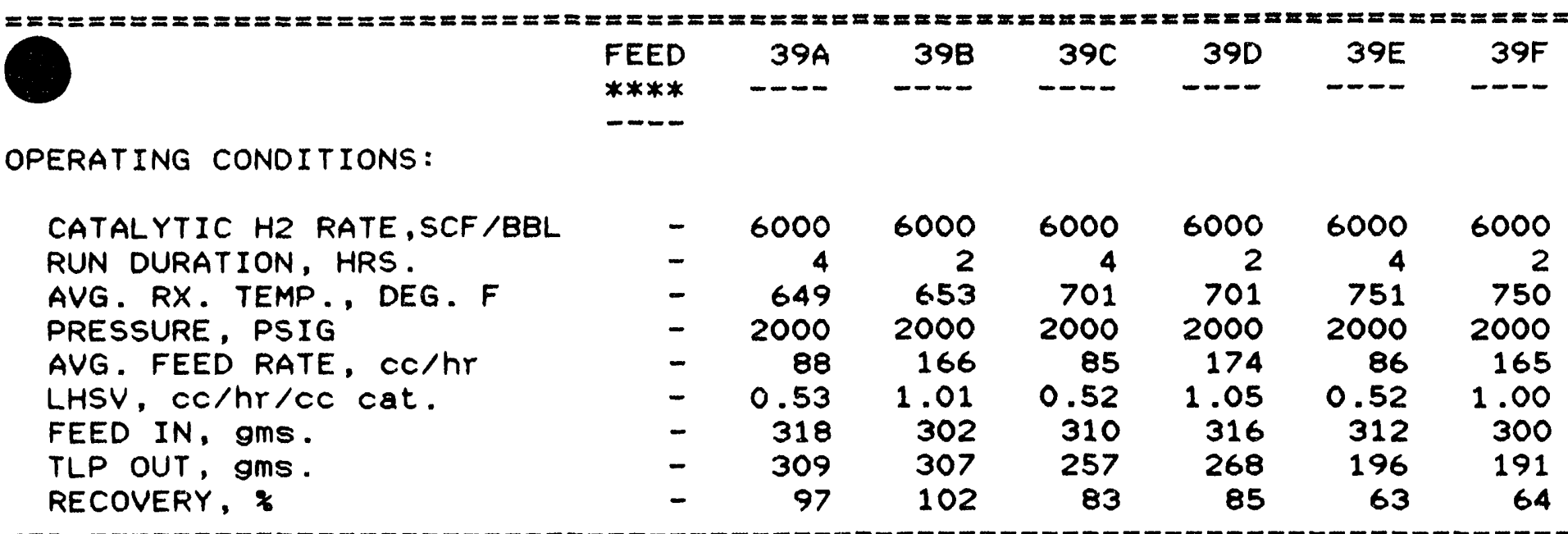

ANALYTICAL RESULTS:

TLP GRAVITY, IMS/CC

TLP GRAVITY, DEG. API

H/C RATIO

TLP ELEMENTALS: * CARBON HYDROGEN $\begin{array}{lllll}0.9082 & 0.7796 & 0.8473 & 0.7\end{array}$ $24.3 \quad 50.0 \quad 35.5$

0.7286 62.7

0.7475

57.8

0.68030 .6879

$\begin{array}{ll}76.5 & 74.2\end{array}$

$\begin{array}{lll}1.64 & 2.05 \quad 1.91\end{array}$

2.17

2.13

2.30

2.24

$88.00 \quad 84.90$

86.48

83.64

83.95

81.98

83.18

$12.00 \quad 14.50$

13.73

15.10

14.92

15.52

ISTILLATION:

IBP, DEG. F

ENDPOINT, DEG. F

- $105 \quad 190$

108

115

595

81

310

80

DISTILLATION RECOVERY, ***

$\begin{array}{lll}93.8 & 95.9 & 77.0\end{array}$

67.3

$89.1 \quad 86.2$

IBP-275 F, WT .\%

275-575 F, WT.\%

5.3

49.9

14.9

77.3

70.4

$98.8 \quad 96.4$

$575 \mathrm{Ft}$, WT .\%

49.3

42.2

61.3

22.7

27.4

1.2

3.6

$\begin{array}{lll}45.4 & 7.9 & 23.8\end{array}$

0.0

2.2

0.0

0.0

CONV. 575+, WT.\%

83

48

100

95

$100 \quad 100$

JET FUEL CUT, 275-575 F:

GRAV., gms/CC

GRAV., DEG. API

$\begin{array}{llllll}0.8860 & 0.8222 & 0.8458 & 0.7844 & 0.8090\end{array}$

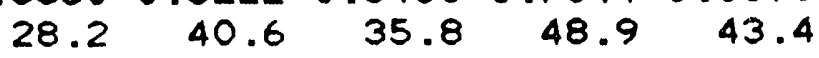

****

****

R.I., 20 DEG. C

$\begin{array}{llllllll}1.4888 & 1.4470 & 1.4585 & 1.4303 & 1.4420 & 1.4168 & 1.4248\end{array}$

H/C RATIO

1.652 .00

1.94

2.08

2.03

2.12

2.09

JET FUEL ELEMENTALS, WT .\%
CARBON
HYDROGEN
$87.88 \quad 85.33$
$85.53 \quad 84.77$
84.62
84.58
85.06
$\begin{array}{lllllll}12.12 & 14.20 & 13.80 & 14.71 & 14.34 & 14.94 & 14.79\end{array}$

* the tlp samples for runs C thru f were very volatile resulting in eRRatic

ELEMENTAL RESULTS.

THE SAMPLES FORM FBHC-39 C-F WERE VERY VOLATILE. THE D-86 DISTILLATION COULD NOT CAPTURE THE VERY LIGHT ENDS WHICH RESULTED IN POOR RECOVERIES. *** INSUFF ICIENT SAMPLE FOR GRAVITY ANALYSIS.

**** THE FEED FOR FBHC-39 IS THE SAME AS FBHC-37. SEE NOTE ON RUN FBHC-37. 
A second scanning test $(F B H C-40)$ was made at a lower hydrogen partial pressure by reducing reactor pressure from $2000 \mathrm{psig}$ to $1000 \mathrm{psig}$ and by reducing bed temperatures to the 550-600F range. This resulted in a reduction in the per pass $575 \mathrm{~F}+$ conversion but with a significant increase in the selectivity to the HEDF jet precursor range as shown in Table 5.5.3.3-4. Based on these results, a production run (FBHC-41) was made at $1000 \mathrm{psig,} 6000 \mathrm{scfb}$ treat gas rate, 0.5 LHSV and 650F average bed temperature as shown on Table 5.5.3.3-5. During the run as the hyperactivity of the freshly activated catalyst declined, the bed temperature was increased a few degrees in order to maintain the gravity and hydrogen content of the jet range product approximately constant. Upon subsequent analysis of the results, it was determined that this catalyst had dual functionality, namely, simultaneous hydrocracking and ring saturation. Accordingly, the hydrocrackate product did not have to be further hydrotreated as was the case for the hydrocracked products generated from the NiMo based catalysts.

\subsubsection{Hydrotreating Studies}

Two series of two-stage, fixed-bed hydrotreating runs using Criterion 424 NiMo catalyst were performed with a) the hydrodenitrogenated LC-Finate distillate from FB-213; and b) the selectively hydrocracked hydrodenitrogenated LC-Finate distillate from run FBHC-38. The data are sumnarized on Table 5.5.3.4-1. Three scans were performed with the hydrodenitrogenated LC-Finate distillate and an HEDF production run (FB-214D) was then selected at the following conditions: 2000 psig reactor pressure, $4500 \mathrm{scfb}$ treat gas rate, 0.5 LHSV and $715 \mathrm{~F}$ average bed temperature. Subsequent to this production run, the feed was replaced with the selectively hydrocracked hydrodenitrogenated LC-Finate distillate (FBHC-38 product) and an HEDF production run was made at the same conditions as that of run FB-214D. After the completion of this run, a final hydrogenation scan was made (FB-214F) with the hydrodenitrogenated LC-Finate feedstock $a$ : a hydrogenation severity equivalent to higher temperature/lower space velocity in an effort to increase the degree of hydrogenation (as measured by both specific gravity and aromatics reduction) over and above that of the prior tests.

\subsubsection{HEDF Finishing}

All four candidate HEDF products generated during the production campaigns were fractionated in a laboratory TBP distillation column. The front-end distillate cuts were blended to meet the HEDF jet fuel flash point specification and the back-end distillate cuts were blended to meet the freeze point/viscosity specifications. The resultant composites were then clay treated in a laboratory-scale, glass adsorption column packed with bentonite to remove trace polar compounds. The resultant treated HEDF test fuels were subjected to full analytical testing and the results are presented in Table 5.5.3.5-1.

Energy densities of the finished HEDF test fuels varied from a low of $130,860 \mathrm{Btu} / \mathrm{gal}$ for $\mathrm{FBHC}-41$ produced during selective hydrocracking with the proprietary zeolitic catalyst to a high of $133,992 \mathrm{Btu} / \mathrm{gal}$ 
SUMMARY OF FIXED-BED HYDROCRACKING RUN

RUN FBHC-4O

CATALYST: $165 \mathrm{CC}$ ZEOLITE Z-704A

\begin{tabular}{|c|c|c|c|c|c|c|c|c|}
\hline \multirow[b]{2}{*}{ PERATING CONDITIONS: } & FEED* & $40 A$ & $40 B$ & $40 \mathrm{C}$ & 400 & 4OE & $40 F$ & $40 G * *$ \\
\hline & & & & & & & & \\
\hline $\begin{array}{l}\text { CATALYTIC H2, SCF/BBL } \\
\text { RUN DURATION, HRS. } \\
\text { AVG. RX. TEMP., DEG. F } \\
\text { PRESSURE, PSIG } \\
\text { AVG. FEED RATE, cC/hr } \\
\text { LHSV, CC/hr/CC cat. } \\
\text { FEED IN, gms. } \\
\text { TLP OUT, gmS. } \\
\text { RECOVERY, * }\end{array}$ & $\begin{array}{l}- \\
- \\
- \\
- \\
- \\
-\end{array}$ & $\begin{array}{r}6000 \\
2 \\
550 \\
1000 \\
167 \\
1.01 \\
302 \\
310 \\
103\end{array}$ & $\begin{array}{r}6000 \\
2 \\
551 \\
1000 \\
252 \\
1.53 \\
458 \\
457 \\
100\end{array}$ & $\begin{array}{r}6000 \\
2 \\
600 \\
1000 \\
168 \\
1.02 \\
304 \\
308 \\
101\end{array}$ & $\begin{array}{r}6000 \\
2 \\
600 \\
1000 \\
250 \\
1.52 \\
454 \\
456 \\
100\end{array}$ & $\begin{array}{r}6000 \\
2 \\
652 \\
1000 \\
161 \\
0.98 \\
292 \\
297 \\
102\end{array}$ & $\begin{array}{r}6000 \\
4 \\
650 \\
1000 \\
83 \\
0.50 \\
302 \\
296 \\
98\end{array}$ & $\begin{array}{r}6000 \\
4 \\
650 \\
2000 \\
90 \\
0.55 \\
328 \\
333 \\
102\end{array}$ \\
\hline
\end{tabular}

ANALYTICAL RESULTS:

TLP GRAVITY, gms/CC

TLP GRAVITY, API

H/C RATIO

TLP ELEMENTALS:

CARBON

HYDROGEN
0.90820 .8794 $24.3 \quad 29.4$

0.8879

$0.8718 \quad 0.8756$

0.8483

0.8309

0.8468

27.9

1.641 .80

1.78

30.8

30.1

35.3

38.8

35.6

88.00

86.75

12.98

86.70

1.83

1.80

1.88

1.94

1.90

12.00

12.87
85.81

13.44
$85.84 \quad 86.04$

$13.89 \quad 13.63$

DISTILLATION:

IBP, DEG. F

ENDPOINT, DEG. F

205
$-\quad 736$

$218 \quad 190$

188

160

130

143

DISTILLATION RECOVERY,

IBP- $275 \mathrm{~F}, \mathrm{WT} . \%$

275-575 F, WT.*

575 F+, WT.\%

\section{3}

100.0

$100.0 \quad 100.0$

99.9

748

678

706

CONV. 575+, WT.*

49.3

7.8

14.5

45.3

6.6

57.9

7.3

90.4

98.1

98.5

$45.4 \quad 39.6$

40.2

35.5

57.2

15.7

19.6

14.0

35.5

55.3

60.8

60.8

29.0

19.6

25.2

JET FUEL CUT, 275-575 F:

GRAV., gms/CC

GRAV., API

13

11

22

22

36

57

44

R.I., 20 DEG. C

$0.8860 \quad 0.8665$

0.8783

0.8545

0.8618

7

.8413

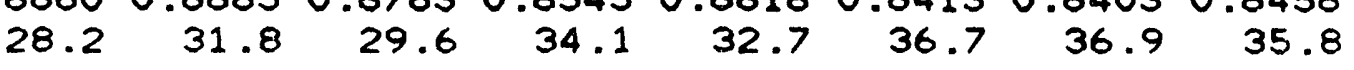

0.84030 .8458

H/C RATIO

1.4888

81.47071 .47

.47821 .46

31.46851

$.45851 .4558 \quad 1.4575$

JET FUEL ELEMENTALS, WT.\%
1.65
1.78

1.78

1.87

1.83

1.90

1.92

1.92

CARBON

$87.88 \quad 86.81$

87.10

86.28

86.65

85.70

86.08

86.13 HYDROGEN

$12.12 \quad 12.89$

12.90

13.46

13.23

13.56

13.74

13.76

* the fEed fOR fBHC-39 is the same as FBHC-37. SEe nOte ON RUN FBHC-37.

RUN FBHC-4OG IS A REPEAT OF RUN FBHC-39A TO CHECK IF THERE IS THE SAME ACTIVITY. 
RUN FBHC-41

COMPARISON OF

RUN FBHC-4OF WITH RUN FBHC-41

CATALYST: $165 \mathrm{CC}$ ZEOLITE Z-704A

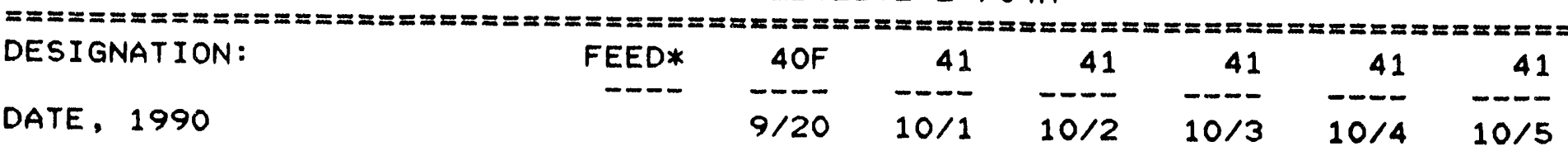

OPERATING CONDITIONS:

CATALYTIC H2 RATE, SCF/BBL

RUN DURATION, HRS.

AVG. RX. TEMP., DEG. F

PRESSURE, PSIG

AVG. FEED RATE, $\mathrm{cc} / \mathrm{hr}$

LHSV, $\mathrm{CC} / \mathrm{hr} / \mathrm{CC}$ cat.

FEED IN, gms.

TLP OUT, gms.

RECOVERY, $\%$

$\begin{array}{lrrrrrr}- & 6000 & 6000 & 6000 & 6000 & 6000 & 6000 \\ - & 4 & 2 & 2 & 4 & 4 & 6 \\ - & 650 & 651 & 658 & 657 & 655 & 659 \\ - & 1000 & 1000 & 1000 & 1000 & 1200 & 1200 \\ - & 83 & 89 & 88 & 86 & 89 & 89 \\ - & 0.50 & 0.54 & 0.53 & 0.52 & 0.54 & 0.54 \\ - & 302 & 161 & 160 & 312 & 324 & 487 \\ - & 296 & 167 & 147 & 307 & 329 & 492 \\ - & 98 & 104 & 92 & 98 & 101 & 101\end{array}$

ANALYTICAL RESULTS:

TLP GRAVITY, gms/CC

TLP GRAVITY, DEG. API

0.90820 .83090 .8423

$\begin{array}{lll}24.3 & 38.8 & 36.5\end{array}$

37.2

$\begin{array}{llll}0.8368 & 0.8468 & 0.8438\end{array}$

H/C RATIO

TLP ELEMENTALS:

$1.64 \quad 1.94$

CARBON

HYDROGEN

$88.00 \quad 85.84$

$12.00 \quad 13.89$

DISTILLATION:

IBP, DEG. F

ENDPOINT, DEG. $F$

$-130$

130

120

128

125

DISTILLATION RECOVERY, *

- 678

720

$726 \quad 702$

680

700

$\begin{array}{llllll}98.1 & 98.8 & 99.1 & 100.0 & 98.8 & 99.3\end{array}$

IBP-275 F, WT.\%

275-575 F, WT.\%

$575 \mathrm{Ft}$, WT.\%

$\begin{array}{lllll}5.3 & 19.6 & 16.0 & 16.4 & 18.3\end{array}$

15.1

16.0

49.3

60.8

59.9

60.7

58.2

58.2

57.1

$45.4 \quad 19.6$

24.1

$22.9 \quad 23.5$

26.7

26.9

CONV. 575+, WT.*

57

47

50

48

41

41

JET FUEL CUT, 275-575 F:

GRAV., GMS/CC

GRAV., DEG. API

0.8860

.88600 .8403

0.8438

0.8388

8393

0.84330 .9433

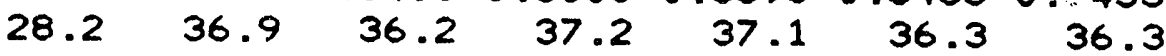

R.I., 20 DEG. C

$\begin{array}{llllllll}1.4888 & 1.4558 & 1.4574 & 1.4566 & 1.4575 & 1.4592 & 1.4580\end{array}$

H/C RATIO

JET FUEL ELEMENTALS, WT.\%

CARBON

HYDROGEN

$1.65 \quad 1.92$

1.92

1.93

$-\quad 1.91$

NA

$\begin{array}{lllll}87.88 & 86.08 & 85.87 & 86.18\end{array}$

$\begin{array}{llll}12.12 & 13.74 & 13.74 & 13.85\end{array}$

$-\quad 86.08$

$-\quad 13.73$

NA

NA

* the feed for fBhC-39 is the same as fBHC-37. See note on RUN fBhC-37. 
CATALYST: USED CRITERION 424

2 REACTORS IN SERIES \& $165 \mathrm{cC}$ CATALYST PER REACTOR

OPERATING CONOITIONS:

CATALYTIC H2, SCF/BBL

RUN DURATION, HRS.

DC-101 AVG. TEMP.. F

DC-201 AVG. TEMP., F

PRESSURE, PSIG

AVG. FEED RATE, cc/hr

LHSV, CC/hr/CC cat.

FEED IN, gms.

TLP OUT, gMS.

RECOVERY,\%

\begin{tabular}{rrrr}
- & 4500 & 4500 & 4500 \\
- & 1 & 3 & 3 \\
- & 655 & 655 & 707 \\
- & 651 & 651 & 707 \\
- & 2000 & 2000 & 2000 \\
- & 165 & 162 & 162 \\
- & 0.50 & 0.49 & 0.49 \\
- & 150 & 440 & 440 \\
- & 149 & 461 & 466 \\
\hline
\end{tabular}

4500

3

725

724

2000

173

0.53

472

439

93
4500

48

718

713

2000

170

0.52

7425

7275

98
4500

16

715

713

2000

167

0.51

2274

2184
4500

2

755

752

2000

83

0.25

150

149

99

ANALYTICAL RESULTS:

TLP GRAVITY, gms/CC
TLP GRAVITY, API

DISTILLATION:

IBP-275 F, WT.

275-575 F, WT.\%

$575 \mathrm{Ft}, \mathrm{WT} . \%$

CONV. 575t, WT.*
0.90820 .8789

$24.3 \quad 29.5$

5.3

$49.3 \quad 53.8$

45.4
0.8778 29.7

0.8718 30.8

0.8660 31.9

0.8724 30.7

0.83

8383

0.8576

96 33.5 $\begin{array}{ll}5.5 & 5.8\end{array}$

$56.2 \quad 58.2$

$38.3 \quad 36.0$
6.8

60.8

32.4
6.9

57.5

35.6

29

22

15.0

$$
916
$$

21

$-0.8586$
0.8618
32.6

0.8602

32.9

0.8607
32.8

$\begin{array}{rr}0.8428 & 0.8545 \\ 36.3 & 34.0\end{array}$

GRAV., API

28.2

$-\quad 33.2$

32.

66.6

7.5
70.0

18.422 .5

R.I., 20 DEG.C

$1.4888 \quad 1.467$

H/C RATIO

ELEMENTALS, WT.*

CARBON HYDROGEN

61.4674

41.46

$$
1.65
$$

\section{$-1.86$}

87.88
12.12
42.0
0.5
57.5

$-86.42$

$-\quad 13.43$

1.89

1.87

86.44

13.60

86.13

13.40

- 6.5

6.5
$-\quad 0.5$

- 93.0

5.0

8.5

1.0

0.5

94.0

91.0

1.4686

$1.4593 \quad 1.4670$

SATURATES

* THE FEED FOR THE RUN IS BATCH, AND PROCESSED IN NITROGEN TO 1000 PPM ). THE OBTAIN THE 300-975 FRACTION. FINALLY THE FEED WAS HYDROTREATED AND NITROGEN REMOVED ( 40 PPM) IN FIXED BED RUNS FB-194-199, 202-203, \& 211-213. THE SAMPLE \# IS 3610 .

THE FEED FOR RUN FB-214E IS THE TLP FROM THE FIXED BED HYDROCRACKING RUN 37 (RUN FBHC-37) WHICH HAS 30.5 VOL.* AROMATICS \& 18 WT.\% 575 F+ MATERIAL. 
TABLE $5 \cdot 5 \cdot 3 \cdot 5-1$

COALITE DERIVED

HEDF FUEL PROPERTIES

TASK 3.2 SCREENING PROGRAM RESULTS

\begin{tabular}{|c|c|c|c|c|}
\hline $\begin{array}{l}\text { DESIGNATION } \\
\text { BOILING RANGE } \text { DEG. F }\end{array}$ & $\begin{array}{l}\text { FBHC }-41 \\
300-600\end{array}$ & $\begin{array}{l}F B-2140 \\
300-610\end{array}$ & $\begin{array}{l}F B-214 E \\
300-620\end{array}$ & $\begin{array}{l}F B-214 F \\
300-600\end{array}$ \\
\hline $\begin{array}{l}\text { GRAVITY, SP. } 600 \\
\text { GRAVITY, DEG. API }\end{array}$ & $\begin{array}{r}0.8560 \\
33.8\end{array}$ & $\begin{array}{r}0.8745 \\
30.3\end{array}$ & $\begin{array}{r}0.8571 \\
33.6\end{array}$ & $\begin{array}{r}0.8702 \\
31.1\end{array}$ \\
\hline \multicolumn{5}{|l|}{ ELEMENTALS: } \\
\hline & 86.36 & 86.84 & $\begin{array}{l}86.55 \\
13.45\end{array}$ & 86.78 \\
\hline $\begin{array}{l}\text { HYDROGEN, WT. } \\
\text { NI TROGEN, PPM }\end{array}$ & $\begin{array}{r}13.64 \\
<1\end{array}$ & $\begin{array}{r}13.16 \\
<1\end{array}$ & $\begin{array}{l}13.45 \\
<1\end{array}$ & 13.22 \\
\hline SULFUR, PPM & 5 & 4 & 1 & $<1$ \\
\hline VISCOSITY $-4 \mathrm{~F}$, cst. & 9.1 & 14.1 & 9.3 & 11.0 \\
\hline FLASH POINT, DEG. $F$ & $>120$ & $>145$ & $>140$ & $>150$ \\
\hline FREEZE POINT, DEG. $F$ & $<-50$ & $<-50$ & $<-50$ & $<-q$ \\
\hline SMOKE POINT, mm & 22 & 18 & 20 & 20 \\
\hline ANILINE POINT, DEG. C & 61.9 & 58.0 & 62.0 & 54.9 \\
\hline $\begin{array}{l}\text { F.I.A.: } \\
\text { AROMATICS, VOL.* } \\
\text { OLEFINS, VOL.* } \\
\text { SATURATES, VOL.* }\end{array}$ & $\begin{array}{r}4.6 \\
0.5 \\
94.9\end{array}$ & $\begin{array}{r}3.7 \\
0.5 \\
95.8\end{array}$ & $\begin{array}{r}6.6 \\
0.5 \\
92.9\end{array}$ & $\begin{array}{r}15.2 \\
0.5 \\
84.3\end{array}$ \\
\hline COPPER CORROSION, $212 \mathrm{~F}$ & 3A & $1 \mathrm{~A}$ & $1 \mathrm{~A}$ & $1 \mathrm{~A}$ \\
\hline POTENTIAL GUM, mg/100ml & 7.0 & - & 7.4 & 16.4 \\
\hline $\begin{array}{l}\text { THERMAL STABILITY ( JFTOT): } \\
\text { TUBE DEPOSIT RATING } \\
\text { TUBE DEPOSIT RATING, MAX. } \\
\text { DIFF. PRESS. MAX., mm Hg }\end{array}$ & $\begin{array}{r}0 \\
0.5 \\
3.0\end{array}$ & $\begin{array}{r}0 \\
1.0 \\
3.0\end{array}$ & $\begin{array}{r}0 \\
1.5 \\
3.0\end{array}$ & $\begin{array}{r}2 \\
8.0 \\
3.0\end{array}$ \\
\hline ENERGY DENSITY, BTU/GAL & 130,860 & 133,992 & 131,622 & 132,901 \\
\hline
\end{tabular}


for FB-214D produced for the scheme comprised of hydrodenitrogenation of LC-Finate followed by aromatics saturation with Criterion C-424 catalyst.

Although the highest volumetric energy density is desired, there are two other criteria to consider. The first is a function of economics and the resultant tradeoffs between the additional cost of the incremental energy density improvement vs the value of the higher density fuel to the end user. The other criteria concerns the storage stability and thermal stability of the fuel for use in high speed aircraft. One analytical device for assessing stability performance is the Standard Test Method for Thermal Oxidation Stability of Aviation Turbine Fuels (JFTOT Procedure, ASTM D3241-85). JFTOT subjects the test fuel to conditions that are relatable to those occurring in gas turbine engine fuel systems. The fuel is pumped at a fixed volumetric flow rate through a heater after which it enters a precision stainless steel filter where fuel degradation products become trapped. The essential data derived are the amount of deposits on an aluminum heater tube and the rate of plugging of a 17 micron nominal porosity filter located just downstream of the heater tube. This test has long been used by petroleum refiners to meet process specifications for shipment of aviation fuel products to the end users, namely, the commercial airline industry and the U.S. Air Force. With the advent of new aircraft engines and new fuel compositions, the JFTOT test is not always an accurate gauge for assessing on-board fuel stability performance. The Air Force is continually improving technology for on-ground determination of thermal stability of aviation turbine fuels. With regard to the new fuel type, High Energy Density (Category I) fuel, it is not known how applicable the JFTOT test will be for assessing thermal stability. 


\subsection{SUMMARY OF RESULTS OF COLORADO SHALE OIL SCREENING OPERATIONS}

\subsection{Overview}

The Work Statement for this contract, which was co-funded by METC's Coal Gasification group and by the Extraction Projects division which is responsible for non-coal resources such as oil shale, tar sands and gases, called for assessment of HEDF test fuel production from several fossil fuel sources. In addition to the MCG liquids generated in the COALITE process, a sample of Colorado shale oil derived from the UNOCAL plant at Parachute Creek. This feedstock is of importance because of its commercial availability and its demonstrated conversion to conventional jet fuel and subsequent on-board testing under past DOE contracts.

\subsection{Virgin Distillate Hydrotreating}

The results of the several campaigns are summarized in a series of spreadsheet tables with the "A" tables presenting the run performance data and the "B" tables presenting the properties of the full-range hydrotreated distillates. The organization of the tabulated results is as follows:

Table No Catalyst Type Feed Boiling Range (F) \# Reaction Stages

$\begin{array}{llll}6.2-1 A, B & \text { K-599/MO-1230 } & 350-600 & 2 \\ 6.2-2 A, B & \text { K-550/K-599 } & 350-600 & 2 \\ 6.2-3 A, B & \text { K-550/K-599 } & 575-1000 \mathrm{HDT} & 2 \\ 6.2-4 A, B & \text { K-599 } & 300-575 \mathrm{HDT} & 1 \\ 6.2-5 A, B & \text { Amoco Propr. } & 575-100 \mathrm{HDT} & 1 \\ 6.2-6 A, B & \text { Amoco Propr. } & 650-975 \mathrm{Virgin} & 1\end{array}$

Several interesting correlations were developed for the hydrotreating of the raw 350-550F and 350-650F COALITE distillates. Correlations were developed of the HEDF properties vs the kinetic hydrotreating severity parameter (KSF described in Section 4). These are shown graphically in Figures 6.2-1 through -6 . The data for the COALITE correlations are shown on the figures for reference purposes. Cross-correlations of key HEDF properties vs aromatics contents are depicted in Figures $6.2-7$ and -8 . Cross-correlations of key HEDF properties vs Refractive Index are shown in Figures 6.2-9 through -11.

Unlike the MCG liquids, the Colorado shale oil distillates are less concentrated in the cyclics and more concentrated in the aliphatic materials as seen in the table below:

\section{Colo. Shale 0il}

39.9

$\%$ Olefins

$\%$ Saturates (cyclictaliphatic)

\%Aromatics

The COALITE olefins are cyclooctene, cyclodecene,
32.9

27.2

\section{COALITE}

11.8

$<13.7$

$>74.5$

primarily cyclic in structure, e.g., whereas the shale-derived olefins are 
IABLI $6.2-1 A \quad 1$ of 2

SUMAARY OF OPERATINE RESULIS FOR FIXEO-BED COLORADO SHALE OIL

HYOROTREAIING IESTS

CATALYST: $K-599$ (1ST SIAGE) / HO-1230 (2NO SIAGE:

FILE ID: REPTSE2. WKL

\begin{tabular}{|c|c|c|c|c|c|c|c|c|}
\hline IEST $\mid(F B-)$ & 148 & 119 & 150 & 151 & 152 & 153 & 154 & 155 \\
\hline 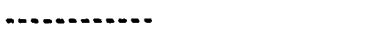 & -.......... & -.......... & -........ & -......... & . & 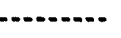 & -....... & 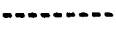 \\
\hline DRTE $11989 ;$ & $05-24$ & $05-25$ & $05-25$ & $05-25$ & $05-26$ & $05-26$ & $05-26$ & $05-2 i$ \\
\hline STARI TIME & $16: 00$ & $00: 00$ & 08:00 & $16: 00$ & $00: 00$ & 08:00 & $16: 30$ & $20: 00$ \\
\hline END IIHE & $20: 00$ & $04: 00$ & $12: 00$ & $20: 00$ & $04: 00$ & $12: 00$ & $17: 30$ & $21: 00$ \\
\hline FEEOSTOLI & A & A & $A$ & A & $A$ & $A$ & $A$ & A \\
\hline \multicolumn{9}{|l|}{ \& KOS } \\
\hline \multicolumn{9}{|l|}{ i KUT } \\
\hline \multicolumn{9}{|l|}{ \&in: } \\
\hline H: thitili. $\operatorname{set} / b t:$ & $900 !:$ & 9000 & 9096 & 9000 & 8008 & 9000 & 9006 & 9010 \\
\hline \multicolumn{9}{|l|}{ CI.I.A OU!E:IHES SAIURGIIOH } \\
\hline \multicolumn{9}{|l|}{ \& R.A.A AROHGIICS SAIURGTION } \\
\hline 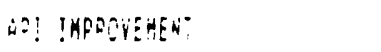 & $? . ?$ & 8.3 & $1 ! .1$ & 11.5 & 1.0 & 3.3 & 5.6 & 5.8 \\
\hline R.I. OEFRESSIOAN & 0.0167 & $0.016 \mathrm{i}$ & $0.017 \mathrm{t}$ & 0.0194 & 0.0115 & 0.0109 & $0.009 i$ & $0.0113:$ \\
\hline
\end{tabular}

FEEDSTOCK TYPE:

4: 3:S-OAS F VIKGIN COLORPDE SHALE OI! OLSIILIGTE 
TABLE $6.2-1 A \quad 2$ of 2

SUAKAPY OF OPERATING RESULIS FOR FIXEO-BEO COLORADO SHALE OIL

HYOROTREATING IESTS

CAIALYST: K-599 (1ST STAGE) / HO-1230 (2NO STAGE)

FILE ID: REPTSE2. WKI

$i \xi \hat{j}) \mid(\hat{\beta} \beta-)$

OATE (1989)

START IIME

EKD TIME

$\begin{array}{rrrrrrr}159 & 160 & 161 & 162 & 163 & 164 & \\ 06-05 / 06 & 06-06 / 07 & 06-08 & 06-08 & 06-08 & 06-09 & \\ 16: 00 & 18: 00 & 00: 00 & 08: 00 & 16: 00 & 00: 00 & \\ 16: 00 & 18: 00 & 06: 00 & 14: 15 & 22: 00 & 06: 00 & \\ & & & & & & \\ A & A & B & B & C & C & \end{array}$

FEERSTOCY

$\{H D$ :

Hin

$\vdots \mathrm{Hil}$

$\therefore$ Ur

9000

10010

1000

1000

7000

T.I.F. OLEFINE SATURATICH

\& i.D.A ARUMATICS SATURPTION

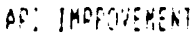

f.. DEPFESS!in

$1.7 \quad 6$

6.5

9.5

12.6

$12.5 \quad 9.0$

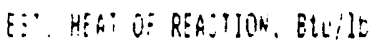

$\begin{array}{llllll}0.0145 & 0.0143 & 0.0249 & 0.0355 & 0.0340 & 0.0241\end{array}$

PEEDSTOCH IYPE:

A: 355-t:S \& VIRGIK COLORADG SHÁ:S UL! OISTiLLGTS.

E: LlQuIt PROOUC: Fron fE- 15 .

C: LLQUIO PRODUCT FROR FE-16?. 
IABLE $6.2-1 B \quad 1$ of 2

SUMMARY OF PROPERTIES OF FULL-RANGE HYOROTREATEO COLORADO SHALE OIL PROOUCTS

FROH FIXED-BEO KYOROTREATING

CATALYST: K-5SO (1SI STAGE) / KO-1230 (2ND STAGE)

FILE ID: REPTSP2.NKL

\begin{tabular}{|c|c|c|c|c|c|c|c|c|}
\hline IEST $\mid$ (FB-) & 118 & 149 & 150 & 151 & 152 & 153 & 154 & 155 \\
\hline (n)................... & (n............ & (n........ & 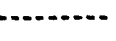 & nan & n...n. & 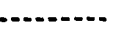 & -......... & \\
\hline DATE $11989 ;$ & $05-24$ & $05-25$ & $05-25$ & $05-25$ & $05-26$ & $05-26$ & $05-26$ & $05-26$ \\
\hline SIART TIME & $16: 00$ & $00: 00$ & 08:00 & $16: 00$ & 00:00 & $08: 00$ & $16: 30$ & $20: 00$ \\
\hline END IIHE & $20: 00$ & $04: 00$ & 12:00 & $20: 00$ & $04: 00$ & 12:00 & $17: 30$ & $21: 00$ \\
\hline SEEDS:OS! & A & A & h & A & $A$ & $A$ & $A$ & A \\
\hline SPECIFIC GRAYIHI, Qa/CC & 0.8304 & $0.825 t$ & 0.8170 & 0.8104 & 0.8319 & 0.8603 & 0.8388 & 0.8378 \\
\hline AP! SRAVIIY e 65: $F^{\circ}$ & 38.9 & 39.9 & 41.7 & 43.1 & 38.6 & 36.9 & 37.2 & 37.4 \\
\hline REFRGSTIVE INGEX Q ?C C & 1.4018 & 1.4624 & 1.4609 & $1.459 !$ & 1.4670 & 1.4070 & 1.4688 & 1.4654 \\
\hline \multicolumn{9}{|l|}{ :LEAENTP!: } \\
\hline 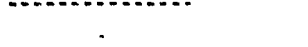 & & st 10 & 8614 & 613 & se of & 8568 & 8511 & 8617 \\
\hline i & $\begin{array}{l}00.04 \\
13.75\end{array}$ & 13.60 & $\begin{array}{l}00.91 \\
13.52\end{array}$ & 13.26 & 13.29 & 13.38 & 13.28 & 13.63 \\
\hline
\end{tabular}

SIRUIATE OISIILLAION, F

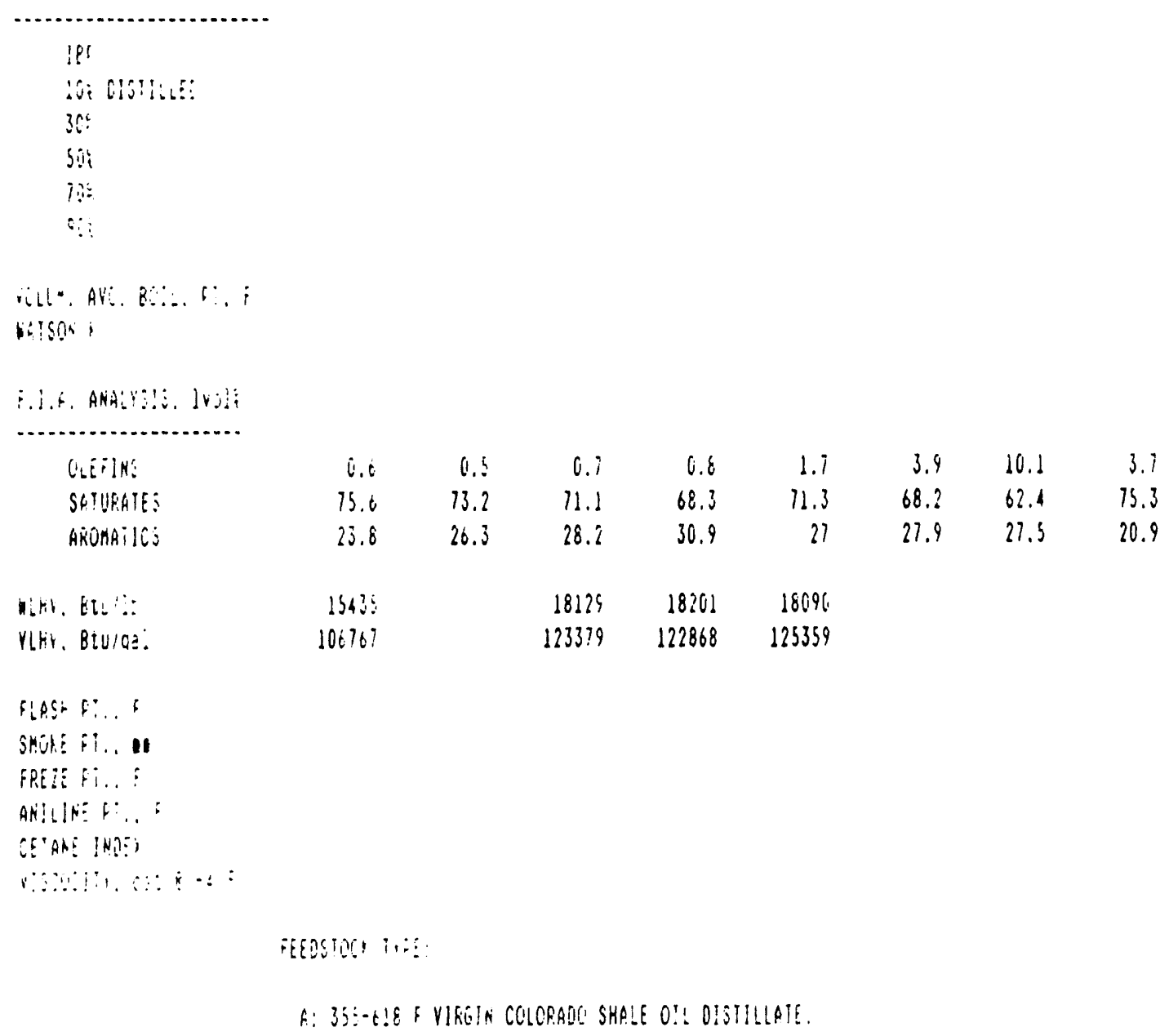

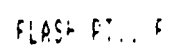

SHult it..

Freitifi..

ARILIN: $F: .$.

CEAAS !n?:;

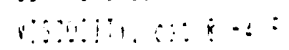

FeEstors in:

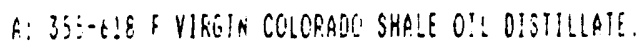




$$
\text { IABLE } 6.2-1 B \quad 2 \text { of } 2
$$

SUHHARY OF PROPERTIES OF FULL-RANGE HYDROTREATEO COLORADO SHALE OIL PROOUCTS

FROH FIXED-BEO HYOROTREAIING

CATALYST:CATALYST: K-S5O (IST STAGE) / NO-1230 (2ND STAGE)

IEST $/$ (F8-)

DAIE 11989

START IIM!

ENO IIHE

FeEDSio:i

SPECIFIC GRAIIIY, ge/CS

AS: GRAY!IY Q 6C: F

REFRECIILE INDEX Q 2OS

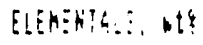

$i$

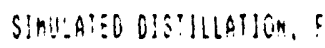

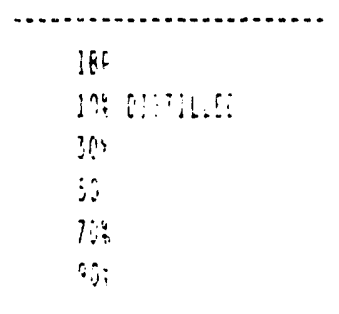

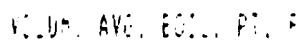

Whison 1

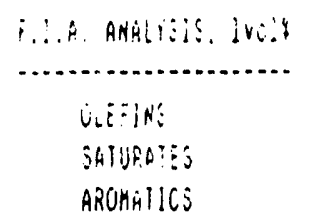

$n, m i, b i L^{\prime}: i$

NLHi. Biulga!

E.t.j+fi, f

jkors bl. in

iki?

GIINE Fi.. F

CETANE INOEY

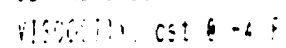

FILE ID: REPTSP2.WK!

\begin{tabular}{|c|c|c|c|c|c|c|}
\hline 159 & 160 & 161 & 162 & 163 & 164 & 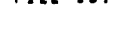 \\
\hline . & 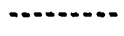 & 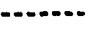 & 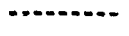 & 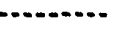 & 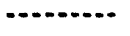 & $\ldots . .$. \\
\hline $00-05 / 06$ & $06.06 / 07$ & $06-08$ & $06-08$ & $06-08$ & $06-09$ & \\
\hline $16: 00$ & $18: 00$ & $00: 00$ & $08: 00$ & $16: 00$ & $00: 00$ & \\
\hline $16: 00$ & $18: 00$ & $06: 00$ & $14: 15$ & $22: 00$ & $06: 00$ & \\
\hline
\end{tabular}

$\begin{array}{llllll}86.36 & 86.05 & 86.3 \hat{\imath} & 65.72 & 86.00 & 85.87 \\ 13.64 & 13.10 & 14.37 & 14.57 & 14.80 & 14.87\end{array}$

$\begin{array}{rrrrrr}A & A & B & B & C & C \\ 0.8304 & 0.8343 & 0.8198 & 0.8054 & 0.8058 & 0.822 ? \\ 38.9 & 38.1 & 41.1 & 44.2 & 44.1 & 10.6 \\ 1.4046 & 1.464 i & 1.4536 & 1.4436 & 1.4436 & 1.4544\end{array}$


IABLE 6.2-2A 1 of 3

......

SUMAARY OF OPERATING RESULTS FOR FIXEO-BED COLORADO SHALE OIL

HYOROTREATING IESTS

CATA!YSI: K-550 (1ST STAGE) / k-599 (2nd STAGE)

FILE IO: REPTSEI. MK!

\begin{tabular}{|c|c|c|c|c|c|c|c|c|}
\hline IEST 1 (FE-) & 106 & 107 & 108 & 109 & 110 & 111 & 112 & 113 \\
\hline 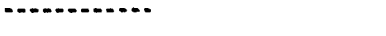 & 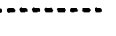 & 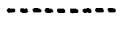 & . & . & , nan. & 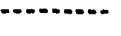 & . & 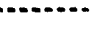 \\
\hline OAIE (1989) & $04-11$ & $04-11 / 12$ & $04-12$ & $04-12$ & $04-12$ & $04-13$ & $04-13$ & $01-13$ \\
\hline SIART IIHE & $17: 30$ & $23: 30$ & $05: 30$ & $11: 30$ & $18: 30$ & $00: 30$ & $06: 30$ & 13:0! \\
\hline ENE: TIKE & $19: 30$ & $01: 30$ & $07: 30$ & $13: 30$ & $20: 30$ & $02: 30$ & $08: 30$ & $15: 00$ \\
\hline FEEDồIOCK & A & A & $A$ & A & A & A & A & A \\
\hline \multicolumn{9}{|l|}{ : HDS } \\
\hline \multicolumn{9}{|l|}{ \& $\mathrm{HOH}$} \\
\hline \multicolumn{9}{|l|}{ \& hDi } \\
\hline H. UDTAYi, sif/ot? & 7000 & 7000 & 7000 & 7000 & 7000 & 7000 & 1000 & 7000 \\
\hline \multirow{2}{*}{\multicolumn{9}{|c|}{$\begin{array}{l}\text { \& S.L.F, O!EFINS SAIURATIOA } \\
\text { \& F.I.A. AROHGIICS SATUKATIOK }\end{array}$}} \\
\hline & & & & & & & & \\
\hline AOI IMPROY:Y:A & 0 & 8.8 & 10.6 & 11.7 & $9 . \hat{\imath}$ & 11.8 & 11.2 & 11.5 \\
\hline K..!. DEPhEŜSIOR & $0.016 ?$ & $0.024 i$ & 0.0303 & 0.0333 & 0.0256 & 0.0340 & 0.0321 & $0.032:$ \\
\hline
\end{tabular}

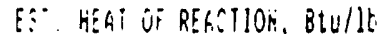

\section{FEEOSTOCK TYPE:}

A: 355-6:S F VIRTIL COLORADU SHALE OI! DISTILLHIE. 
IASLL $6.2-2 A \quad 2$ of 3

SUHARY OF OPERAIING RESULIS FOR FIXEO-BEO COLORADO SHALE OIL

HYOROTREATING IESTS

CAIALYST: $K$-55O (ISI STAGE) / $k-599$ (2nd STAGE)

FILE 10: REPISE1. HK.

IEST 1 (fq-1

-..............

OATE (1989)

START IIME

ENE IIHE

$\begin{array}{cccccccc}114 & 115 & 110 & 117 & 118 & 119 & 120 & 121 \\ 04-13 & 04-14 & 04-14 & 04-14 & 04-11 & 04-17 & 04-18 & 04-18 \\ 22: 00 & 04: 00 & 10: 00 & 16: 00 & 06: 30 & 12: 30 & 19: 30 & 01: 30 \\ 24: 00 & 06: 00 & 12: 00 & 18: 00 & 08: 30 & 14: 30 & 21: 30 & 03: 36 \\ & & & & & & & \\ \text { A } & \text { A } & \text { A } & \text { A } & A & A & A & A\end{array}$

I HOS

$\{\mathrm{HON}$

\& HC:

H. Weicls. scitit:

$7 \mathrm{CO}$

$100 i$

7006. 7006

$700: \quad 7000 \quad 7000$

706 i:

: ¿... O.EFIN! JAIURGIIO

? 1.6. AROKA?IC: SAIURATION

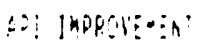

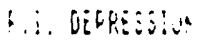

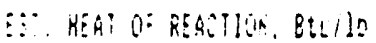

\begin{tabular}{|c|c|c|c|c|c|c|}
\hline 3.6 & 7.8 & 9.8 & 10.1 & 8.1 & 10.5 & 13.0 \\
\hline 0.0163 & $0.0: 3$ & $0.0: 65$ & 0.0258 & 0.0228 & 0.0298 & 0.0359 \\
\hline
\end{tabular}

FEEOSTOC TYP::

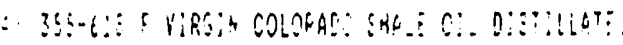




$$
\text { IABL: } 6.2-2 A \quad 3 \text { of } 3
$$

SUAMARY OS OPEFAIING RESULTS FOR. FIXEO-BED COLORADC SHALE OIL

HYOROTREATING IESTS

CAIALYS): K-55O (1ST STAGE) / $k-599$ (2nd STAGE)

FILE IO: REPTSEL. UK!

\begin{tabular}{|c|c|c|c|c|c|c|c|}
\hline TESI 1 (FE-1 & 122 & 123 & 124 & 125 & 128 & 129 & 130 \\
\hline - & . & 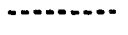 & . & 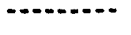 & , & 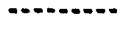 & (n) \\
\hline DATE 119851 & $04-18$ & $04-18$ & $04-18$ & $04-19$ & $04-19 / 20$ & $04-20 / 21$ & $01-21$ \\
\hline Siafí tikE & $07: 30$ & $13: 30$ & $19: 30$ & $01: 30$ & $18: 30$ & $12: 30$ & $07: 30$ \\
\hline ENC IIME & $04: 36$ & $13: 36$ & $21: 30$ & $03: 36$ & $09: 30$ & $03: 30$ & 21:00 \\
\hline EEEOSTIOSK & f & A & $A$ & $A$ & $A$ & A & A \\
\hline 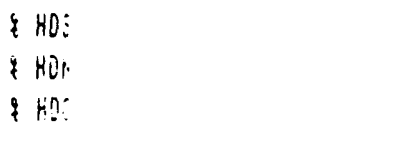 & & & & & & & \\
\hline 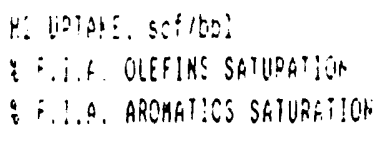 & $100 !$ & $70 i_{4}$ & 7006 & 1006 & $700 !$ & 1000 & 7000 \\
\hline GP! IKFPCCLEME:" & $\vdots \vdots . \vdots$ & $Q . \Sigma$ & $10 . \vdots$ & 8.3 & $10 . ?$ & 13.6 & 6.7 \\
\hline 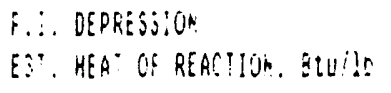 & $0.03: 6$ & 0.0345 & 0.0285 & 0.0225 & 0.0288 & 0.0381 & $0.026^{\circ}$ \\
\hline
\end{tabular}

EETioit 10.

A: 35S-6:\& G VIREIN COLORADO SHALE OIL OISTILLATE. 
IABLE $6.2-2 B \quad 1$ of 3

SUMAARY OF PROPERIIES OF FULL-RANGE hYOROTREATEO COLORADO SHALE OIL PROOUCTS

FROH FIXED-BEO HYOROTREAIIHG

CAIALYST: $X-550$ (IST STAGE) / $K-599$ (2ND STAGE)

\begin{tabular}{|c|c|c|c|c|c|c|c|c|}
\hline & & & & & & & FILE ID: & REPISPL. WKL \\
\hline IEST $\mid(F B-)$ & 100 & 107 & 108 & 109 & 110 & 111 & 112 & 113 \\
\hline (................... & (............. & -............ & ............. & (........... & -............ & ........... & -......... & ............. \\
\hline DATE 11989$)$ & $04-11$ & $04 \cdot 11 / 12$ & $04-12$ & $04-12$ & $04-12$ & $04-13$ & $04-13$ & $04 \cdot 13$ \\
\hline SIART IIME & $17: 30$ & $23: 30$ & $05: 30$ & $11: 30$ & $18: 30$ & $00: 00$ & $06: 30$ & $13: 00$ \\
\hline END IIME & $19: 30$ & $01: 30$ & $07: 30$ & $13: 30$ & $20: 30$ & $02: 30$ & $08: 30$ & $15: 00$ \\
\hline FEEDSTOCK & $A$ & $A$ & A & $A$ & $A$ & A & A & h \\
\hline SPECIFIC GREVIIY, GN/CC & $0.836 \varepsilon$ & $0.823 ?$ & 0.8146 & 0.8095 & 0.8212 & 0.8090 & 0.8118 & 0.8104 \\
\hline AS! GRAVITY $60^{\circ}$ & 37.6 & $4 ! .4$ & 42.2 & 43.3 & 10.8 & 43.4 & 12.8 & 43.1 \\
\hline REFBAC?IYE INDE I $\cong$ : & $1.161 t$ & $1.454 ?$ & $1.418 \hat{\imath}$ & $1.145 ?$ & 1.4529 & 1.4445 & 1.4464 & 1.1463 \\
\hline ELEMENTALS. LES & & & & & & & & \\
\hline (n) & & & & & & & & \\
\hline$\therefore$ & 85.70 & 85.80 & 85.60 & $8 \vdots 13$ & 85.80 & $85.4 \%$ & 84.86 & 85.08 \\
\hline$r$ & $1: 8 ?$ & $14 . \hat{\vdots}$ & 14.47 & 14.62 & 14.20 & 14.66 & 14.56 & 14.50 \\
\hline Bitulalgi lisillahlloh. & & & & & & & & \\
\hline (n) & & & & & & & & \\
\hline$!: !$ & & & & & & & & \\
\hline at & & & & & & & & \\
\hline $30 i$ & & & & & & & & \\
\hline $3:$ & & & & & & & & \\
\hline $7 ! \vdots$ & & & & & & & & \\
\hline $9: \vdots$ & & & & & & & & \\
\hline 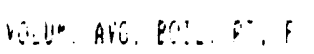 & & & & & & & & \\
\hline Whisigh & & & & & & & & \\
\hline ¿.I.F. AKA!Yjij. IVOLi & & & & & & & & \\
\hline . & & & & & & & & \\
\hline ilepiri: & 1.8 & 1.0 & 1.1 & 0.8 & 0.9 & 0.0 & 0.8 & 0.5 \\
\hline SATURG!S: & 76.8 & 84.7 & 96.8 & 93.0 & 83.7 & 94.6 & 89.9 & $9: .6$ \\
\hline AROARTILS & $2 i .4$ & 14.3 & 8.1 & 6.2 & 15.4 & 4.8 & 9.3 & 7.9 \\
\hline D.r. ELL.: & 18358 & $184 i i$ & 18169 & 18639 & & & & \\
\hline riki. Etulod! & 127965 & 126660 & 123288 & 125685 & & & & \\
\hline$F L A S=1: \ldots=$ & & & & & & & & \\
\hline jkile $0^{\circ}$. II & 25 & 25 & 35 & $3 j$ & 30 & 35 & 35 & 30 \\
\hline BF::: & & & & & & & & \\
\hline An :..IN: :'..: & & & & & & & & \\
\hline OIAR: !HO: & & & & & & & & \\
\hline 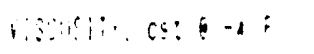 & & & & & & & & \\
\hline
\end{tabular}

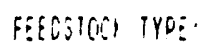

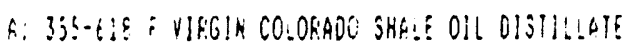


IABLE $6.2-2 B \quad 3$ of 3

SUMYARY OF PROPERTIES OF FULL-RANGE HYOROIREATEO COLORADO SHALE OIL PRODUCTS

FROH FIXED-BEO HYOROIREAIING

-.................................

CATALYST: $K-5 S O$ (1ST STAGE) / K-S99 (2ND STAGE)

\begin{tabular}{|c|c|c|c|c|c|c|c|}
\hline IEST $\mid$ (FB-) & 122 & 123 & 124 & 125 & 128 & 129 & $\begin{array}{l}\text { FILE 1D: } \\
130\end{array}$ \\
\hline (n.................. & …........ & $\ldots$ & (n............ & $\ldots \ldots$ & $\ldots \ldots$ & -........... & $\cdots \ldots$ \\
\hline DAIL (1989) & $04-18$ & $04-18$ & $04-18$ & $04-19$ & $04-19 / 20$ & $04-20 / 21$ & $04-2 i$ \\
\hline SIART IIME & $07: 30$ & $13: 30$ & $19: 30$ & $01: 30$ & $18: 30$ & $12: 30$ & $07: 30$ \\
\hline END IIKE & $09: 30$ & $15: 30$ & $21: 30$ & $03: 30$ & $09: 30$ & $03: 30$ & $21: 00$ \\
\hline FEECjiOL & A & A & A & A & $A$ & $A$ & A \\
\hline SPECIIIC GRAVII!, Q̣/CS & 0.8026 & 0.8207 & 0.8160 & 0.8256 & 0.8160 & 0.8008 & 0.8189 \\
\hline ADi GRALITY O OC F & 44.8 & 10.9 & 41.9 & 39.9 & 11.9 & 45.2 & $4 ! .3$ \\
\hline REFPARETILE INEEX O 2OC & 1.4115 & 1.4440 & 1.4500 & 1.4560 & 1.4491 & 1.1404 & 1.1516 \\
\hline \multicolumn{8}{|l|}{ 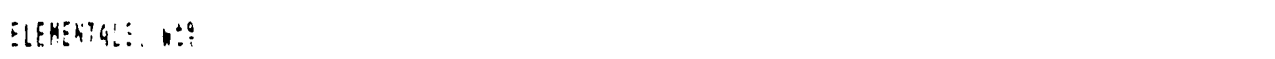 } \\
\hline \multicolumn{8}{|l|}{ (..................... } \\
\hline$\vdots$ & $85.0 i$ & & & & 85.89 & 85.55 & 85.25 \\
\hline$r$ & 14.11 & & & & 14.35 & 14.78 & 14.31 \\
\hline \multicolumn{8}{|l|}{ SIMULAIER DiSIILLIIOM. F } \\
\hline \multicolumn{8}{|l|}{ 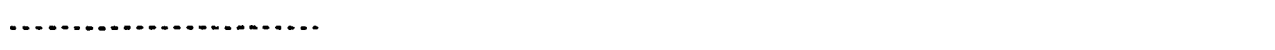 } \\
\hline lit & & & & & & & 197 \\
\hline $10401: \because \therefore: \therefore$ & & & & & & & 371 \\
\hline 3 & & & & & & & 431 \\
\hline $3 i:$ & & & & & & & 484 \\
\hline$i v:$ & & & & & & & sil \\
\hline $90 !$ & & & & & & & 606 \\
\hline VG:UH, AVE, 80:L, f!: : & & & & & & & $4 \hat{i}$ \\
\hline Motsin 1 & & & & & & & 11.91 \\
\hline \multicolumn{8}{|l|}{ 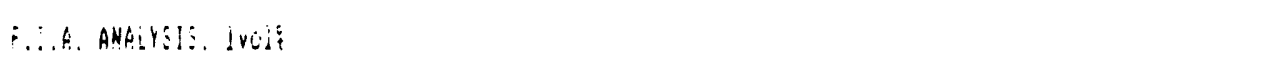 } \\
\hline \multicolumn{8}{|l|}{ 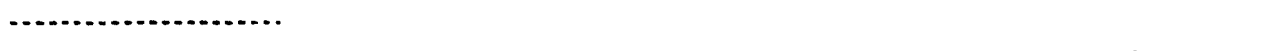 } \\
\hline OLEF!N: & $0 . j$ & 0.5 & 0.7 & 0.9 & 0.1 & 0.5 & 0.7 \\
\hline SATIPGTES & 96.1 & 95.1 & 88.4 & 78.6 & 86.0 & 95.7 & 83.5 \\
\hline AROMATIIS & 3.6 & 4.1 & 10.9 & 20.5 & 13.3 & 3.8 & 15.8 \\
\hline netr. Etu:lt & & & & & 18518 & $1843 !$ & 18200 \\
\hline VLFY. Btu/Oa!! & & & & & 125872 & 122940 & 124150 \\
\hline FlaSt F: . 5 & & & & & & & 90 \\
\hline \multicolumn{8}{|l|}{ SHEIE Pi.. $\|$} \\
\hline ERELE F"..F & & & & & & & 6.8 \\
\hline \multicolumn{8}{|l|}{ hni:Ih: P!., } \\
\hline CEIANE INDS: & & & & & & & \\
\hline Visuvalis is: $4-1:$ & & & & & & & \\
\hline
\end{tabular}

FEEDSIOCK TYPE:

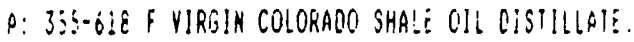




$$
\text { IABLE } 6.2-3 A
$$

SUWHARY OF OPERATING RESULTS OF FIXEO-BED HYOROTREAIEO PROOUCIS FROH

HYDROPROCESSEO COLORAOO SHALE OIL DISTILLATE

CATALYST: X-55O (IST STAGE), K-S99 (2NO STAGE)

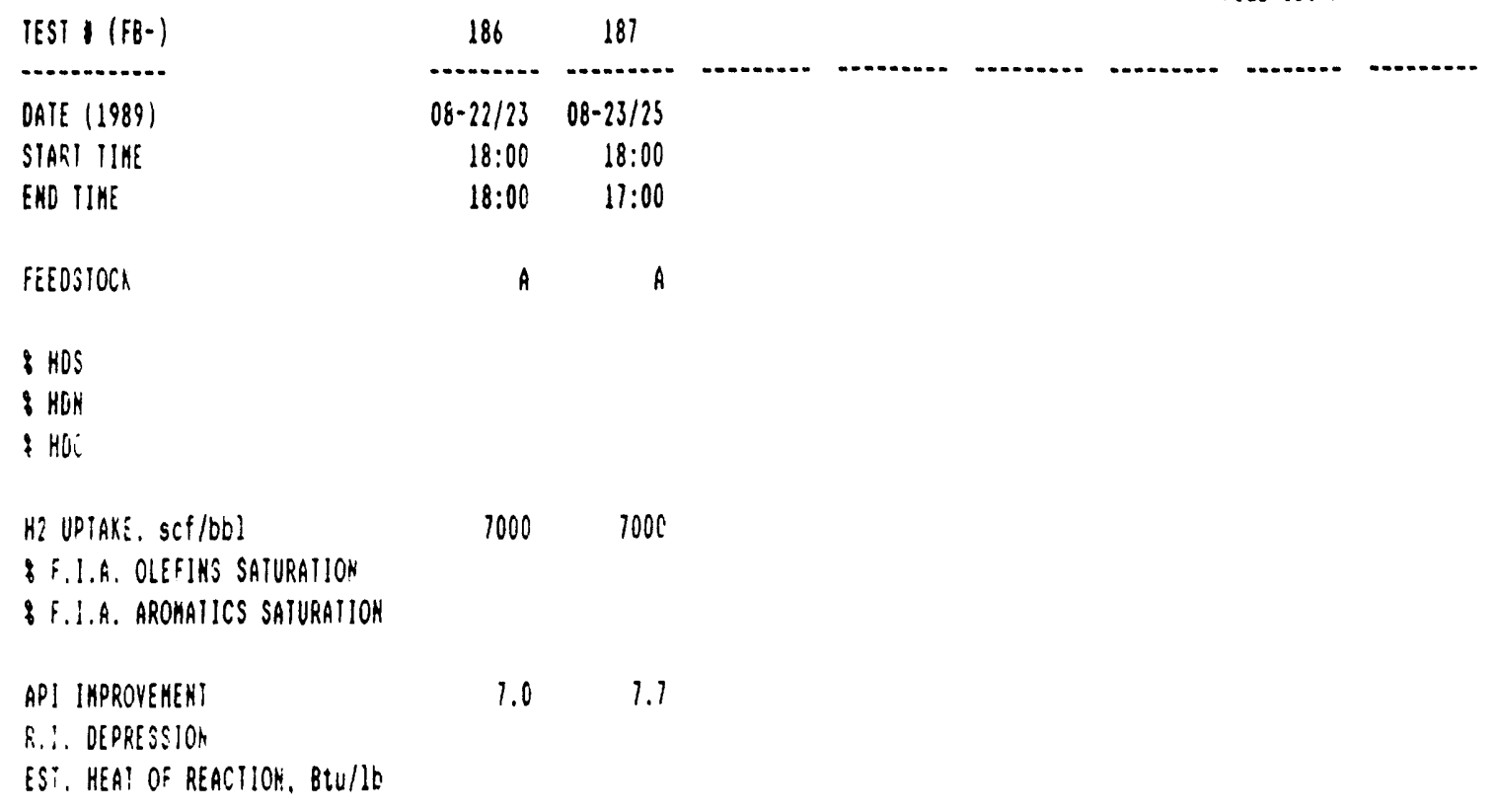

FEESTOC! TYFE:

A: 575-1000 F HYOROPROCESSEO COLORADO SHALE OIL DISTILLATE. 
TABLE $6.2-3 B$

SUKAARY OF PROPERTIES OF FIXEO-BED HYOROTREATEO PROOUCTS FROH

HYOROPROCESSEO COLORADO SHALE OIL OISTILLAIE

CATALYST: K-S5O (IST STAGE), K-599 (2NO STAGE)

FILE ID: REPTSLCS.UKI

IEST 1 (FB-)

DAIE (1989)

START TIME

ENO TIME

\begin{tabular}{rr}
186 & 187 \\
\hdashline $08-22 / 23$ & $08-23 / 25$ \\
$18: 00$ & $18: 00$ \\
$18: 00$ & $17: 00$
\end{tabular}

FEEDSTOCK

A $\quad A$

SPECIFIC GRAVIIY, gO/CC

API GRAVIIY 60 F

REFRACIIVE IMDEX $\mathrm{O} 20 \mathrm{C}$

ELEESNTALS, Wt?

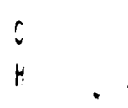

$86.47 \quad 86.41$

$14.04 \quad 13.65$

SIPI!ATEO DINMILLATIOH, \&

IEF

10: CISTILEC

3014

50:

$70:$

$3 P^{2}$

VELUH, AVE, BOIL. PI., F VATSON A

S.A.A. AHRLYSIS, JVOIS

OLIFINS
SATURATES
AROKATICS

WLHY, Btu/lt

YiHT. BiU/QR!

FLASH PI., F

SHOKE PI.. II

FREELE PI.. F

AMILINE PI., $F$

CEIANE IROEY

viscos!m, cst of -4

FEEDSTOCK IYPE:

A: S75-1000 F hYOROPROCESSEO COLORADC SHA!E OIL OISTILLG!! 
IABLE $6.2-4 \mathrm{~A}$

SUMHARY OF OPERATING RESULTS OF FIXEO-BED HYOROTREATEO PROOUCTS FROH

HYOROPROCESSED COLORAOO SHALE OIL OISTILLATE

CATALYST: K-599 (2NO STAGE)

IEST 1 (FB-)

DATE (1989)

START IIME

END TIME

FEEDSTOCK

8 HOS

HOK

$\because \mathrm{KOO}$

H? UPTAKE, SCF/bbL

I F.I.A. OLEFINS SATURATION

I F.I.A. arohatics Saturation

API IKPROVEMEST

R.1. DEPRESSIOH

EST. HEAT OF REACTION, BTU/db

\begin{tabular}{rrr}
143 & 144 & 145 \\
\hdashline $05-15 / 16$ & $05-16$ & $05-16$ \\
$22: 30$ & $04: 30$ & $10: 30$ \\
$00: 30$ & $06: 30$ & $12: 30$ \\
& & \\
$A$ & $A$ & $A$
\end{tabular}

FILE ID: REPISLC2. WKI

$1000 \quad 1000 \quad 1000$

$\begin{array}{rrr}8.0 & 9.0 & 8.1 \\ 0.0250 & 0.0267 & 0.0235\end{array}$

FEEDSTOCK IYPE:

A: 300-575 F HYOROPROCESSEO COLORADO SHALE OIL OISTILLATE. 
IABLE $6.2-4 B$

SUHAARY OF PROPERTIES OF FIXED-BED HYDROTREATEO PROOUCTS FROH

HYOROPROCESSED COLORADO SHALE OIL OISTILLATE

CATALYST: X-S99 (2NO STAGE)

TEST 1 (FB-)

DATE (1989)

STAR: TIHE

ENO IIME

FEEDSTOCK

SPECIFIC GRAVIIY, Ga/CC

API GRAVITY $O$ GO F

REFRACTIVE INOEY $\& 20 \mathrm{C}$

ELEKENTALS, NT\&

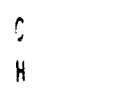

$85.61 \quad 85.59 \quad 86.06$

$14.44 \quad 14.19 \quad 14.13$

SIHULATEU DISTILLAIION. $F$

$16:$
108 OISIILLED
$30:$
$50 ?$
$70:$
$90 \%$

VGLUK. AYG, BOIL, PI, F WATSOH

F.I.A. ANALYSIS. IVOIS

\begin{tabular}{|c|c|c|c|}
\hline OLIFINS & 0.5 & 0.1 & 0.3 \\
\hline SRTURATES & 91.9 & 91.6 & 81.3 \\
\hline AROHATICS & 7.6 & 8.0 & 18.4 \\
\hline VLHY, 8tu/ID & 1840 : & 18552 & 18400 \\
\hline VIHY, Btu/Qą & 124372 & 124666 & 123859 \\
\hline 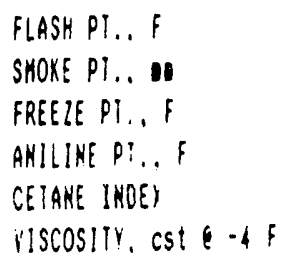 & & & \\
\hline
\end{tabular}

FEEOSIOCK IYPE:

A: 575-1000 F HYOROFROCESSEU COLORADO SHALE OIL OISTILLAIE. 


$$
\text { TABLE } 6.2-5 A
$$

SUHMARY OF OPERATING RESULTS FOR FIXEO-BEO

COLORADO SHALE OIL HYDROCRACKING IESTS

CATALYST: AMOCO PROPRIETARY

\begin{tabular}{|c|c|c|c|c|c|c|c|c|}
\hline \multirow[b]{2}{*}{ TEST । (FBHC-) } & \multirow[b]{2}{*}{28} & \multirow[b]{2}{*}{29} & \multirow[b]{2}{*}{30} & \multirow[b]{2}{*}{31} & \multicolumn{4}{|c|}{ FILE ID: REPTSHCS.UKI } \\
\hline & & & & & 32 & 33 & 34 & 35 \\
\hline DKIE (1989) & $08-10$ & $08-17$ & $08-17 / 18$ & $08-18 / 21$ & $08-28 / 29$ & $08-29 / 30$ & $08-30 / 31$ & $08-31 / 09-01$ \\
\hline START IIME & $0 t: 00$ & $00: 00$ & $12: 00$ & $13: 00$ & 21:00 & $20: 00$ & $20: 00$ & $12: 00$ \\
\hline END IIKE & $08: 00$ & $08: 00$ & $08: 00$ & $20: 00$ & $18: 00$ & $18: 00$ & $12: 00$ & 21:00 \\
\hline FEEDSTOCY & A & $A$ & A & A & $B$ & 8 & $B$ & B \\
\hline $\begin{array}{l}\text { : HOS } \\
: H i n \\
\text { HOS }\end{array}$ & 13 & & 84 & 90 & & & & \\
\hline 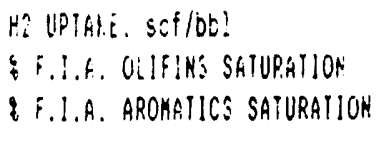 & 1000 & 7000 & 1000 & 1000 & 7000 & 6000 & 6000 & 6000 \\
\hline 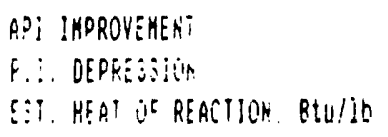 & $6 . ?$ & 5.6 & 6.6 & 9.8 & 3.9 & 3.1 & 1.9 & 4.4 \\
\hline
\end{tabular}

FEEQSTOCY TYPS:

A: S75-1000 F HYOROPROCESSEO COLORADO SHALE OIL OISTILLATE.

B: 575-1000 F. HYDROPROUESSEO COLORADO SKALE OIL OISTILLATE FOLLONEO RY FIXED-BEO KYDROTREATING. 


$$
\text { IABLE } 6.2-5 B
$$

SUAHARY OF PROPERTIES OF HYOROCRACKATES FROH FIXEO-BED

COLORADO SHALE OIL HYOROCRACKING

\title{
CATALYST: AKOCO PROPRIETARY
}

IEST (FBHC-)

OAIE (1989)

SIART IIME

ENO IIKE

FEEDSTOCX

SPECIFIC GRAYIIY, gI/CS API GRAYIIY $60 \mathrm{~F}$

PEFRAÔTIVE INCEY \& 260

ELEMENTALS, h:
86.23

13.42
86.07

13.87

14.21

85.38

85.41

85.43

85.37

FILE ID: REPTSHCG.HKI

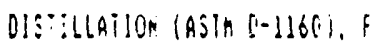

\begin{tabular}{|c|}
\hline $\operatorname{lBF}$ \\
\hline log 0!stilis: \\
\hline $30 \%$ \\
\hline 5 \\
\hline$i v i$ \\
\hline $90 !$ \\
\hline
\end{tabular}

$\begin{array}{lllllll}3 ! 5 & 316 & 31 ! & 275 & 311 & 315 & 304 \\ 57: & 53 ? & 15 t & 419 & 478 & 590 & 419 \\ 64 t & 630 & 573 & 62 \hat{2} & 615 & 624 & 602 \\ i 1 ! & 695 & 659 & 691 & 684 & 686 & 67 i \\ 783 & 762 & 737 & 718 & 766 & 763 & 163 \\ 88 ! & 858 & 838 & 893 & & 858 & \end{array}$

Voslh ove Büi:. pi i

NATSÜR

12.05

$694 \quad 653$
$12.04 \quad 12.12$

$68 ?$

12.35

\begin{abstract}
336
\end{abstract}
690

12.21

621

12.14

Nhii, Eilit:

VhH, Btulą:

FEEDSTOCK IYPE:

A: 575-1000 F, HYOROPROCESSEO COLORADO SHALE OIL OISIILLATE.

6: 575-1000 F, HYOROPROCESSED COLORADO SHALE OIL OISTILLATE FOLLOHEO BY FIXEO-BED HYOROTREAIING. 


$$
\text { TABLE } 6.2-6 A
$$

SUMHARY OF OPERATING RESULIS FOR FIXEO-BED

COLORADO SHALE OIL HYOROCRACKING IESTS

CAIALYST: AMOCO PROPRIETARY

IEST I (FBHC-)

DATE (1989)

START TIME

ENO TIKE

FEEDSTOCK.

\& HO:

8 HOW

\& HOS

H? UPTAKE, scf/bb!

I F.I.A. OLIFIKS SATURATIOK

I.I.A. arokatics satURation

AFI IFPRONEWENT

R.I. DEPRESSIOH

ESi. HEAT OF REACTIOK. BtU/LO
FILE ID: REPTSHC2.VKI

$\begin{array}{cccccccc}3 & 6 & 1 & 8 & 9 & 10 & 11 & 12 \\ \cdots 05-01 & 05-01 & 05-01 & 05-01 & 05-02 & 05-02 & 05-02 & 05-03 \\ 07: 30 & 13: 30 & 19: 30 & 01: 30 & 07: 30 & 13: 30 & 19: 30 & 04: 30 \\ 09: 30 & 15: 30 & 21: 30 & 03: 30 & 09: 30 & 15: 30 & 24: 30 & 09: 30 \\ & & & & & & & \\ \text { A } & \text { A } & \text { A } & \text { A } & \text { A } & \text { A } & \text { A } & \text { A }\end{array}$

$\begin{array}{llllllll}7000 & 7000 & 7000 & 7000 & 7000 & 1000 & 1000 & 7000\end{array}$

$\begin{array}{llllllll}5.6 & 9.4 & 7.1 & 4.6 & 8.5 & 11.2 & 11.4 & 14.5\end{array}$

FEEDSTOCK TYPE:

A: $650-975$ \& COLORADO SHALE OIL V6O. 
IABLE $6.2-6 B$

SUHFARY OF PROPERIIES OF HYOROCRACKATES FROH FIXEO-BEO

COLORADO SHALE OIL HYOROCRACKING

CAIALYST: AMOCO PROPRIETARY

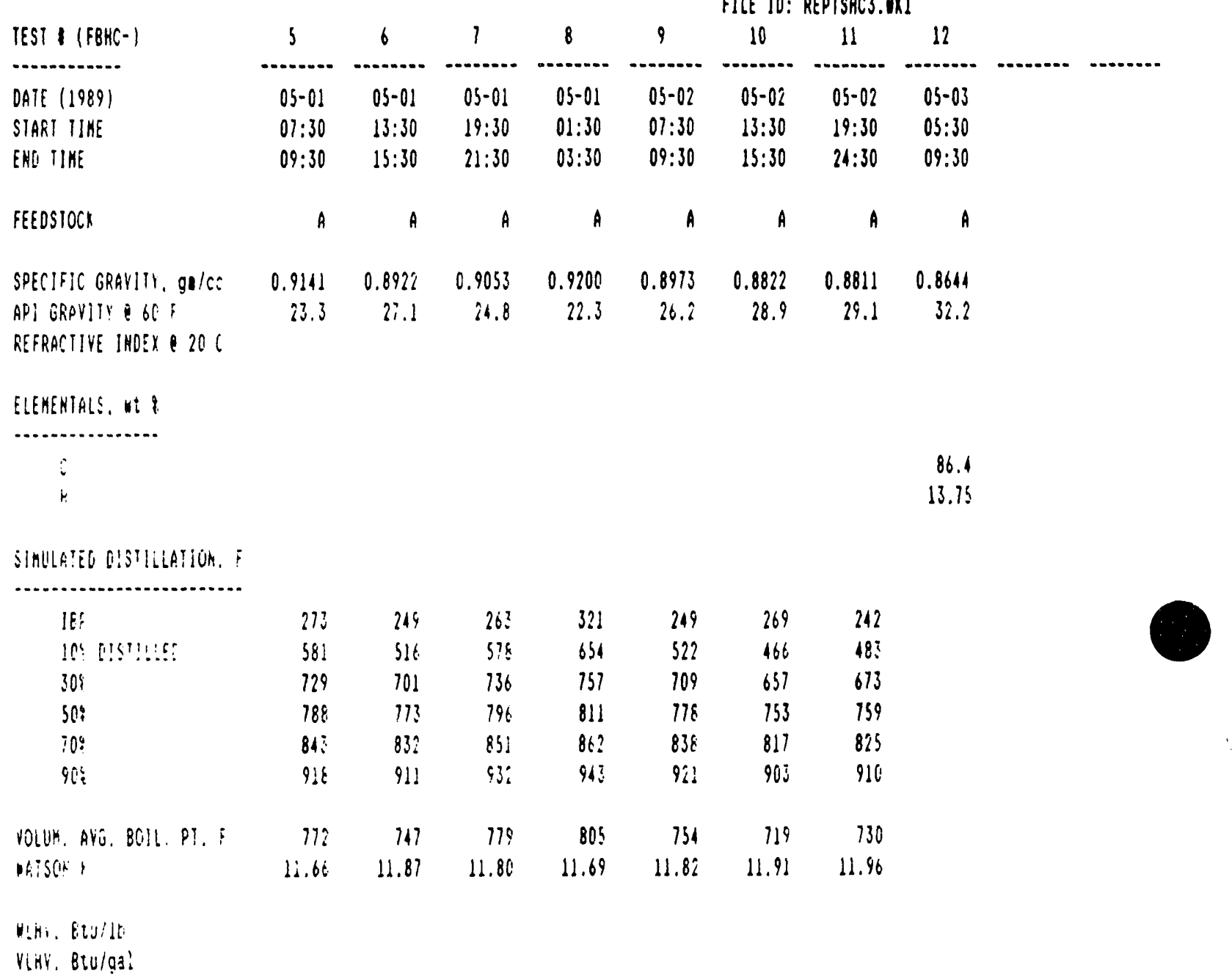

FEEDSTOCK TYPE:

A: 650-9?' \& COLORADO SHALE OIL VGO.

240. 


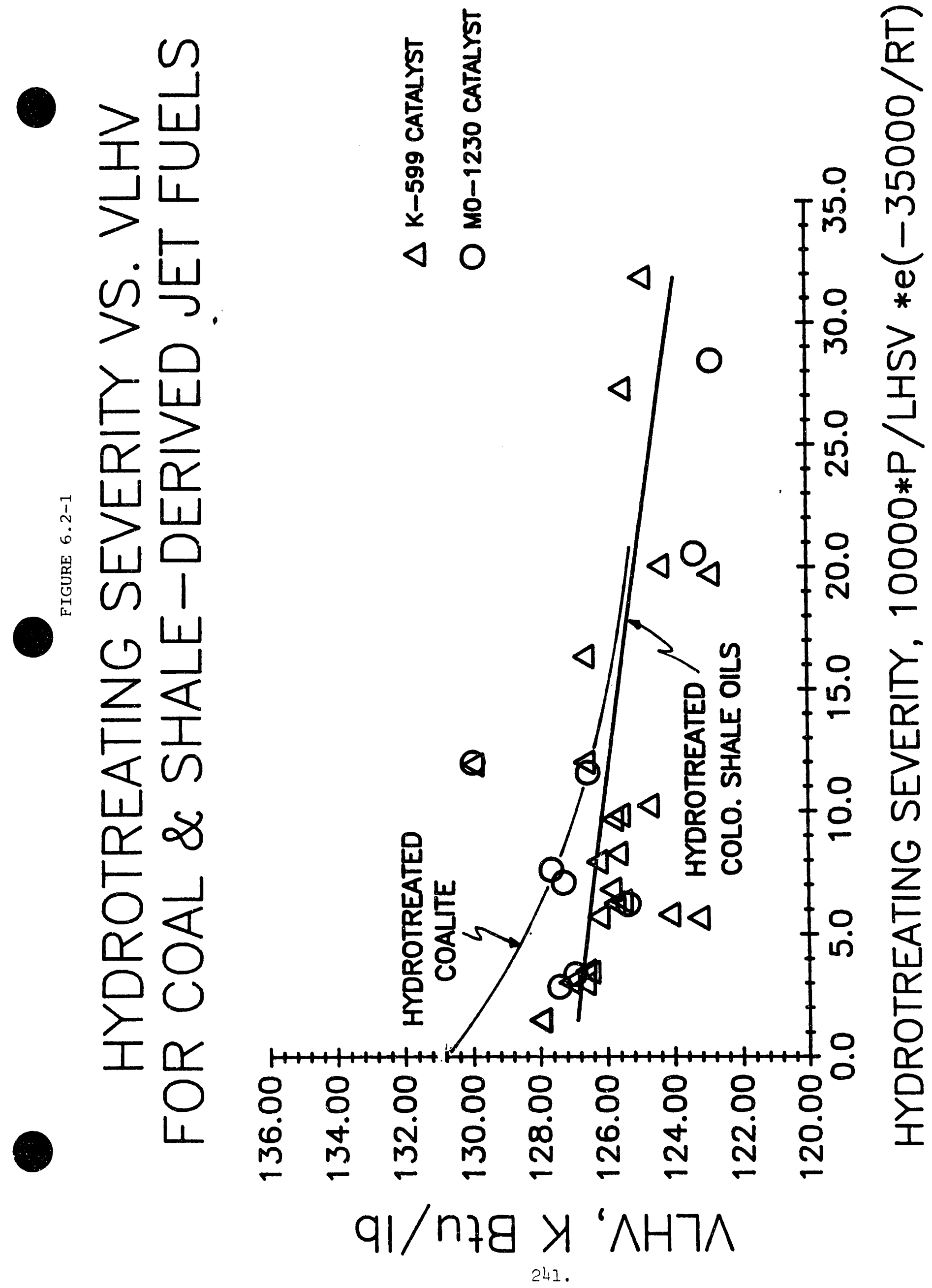




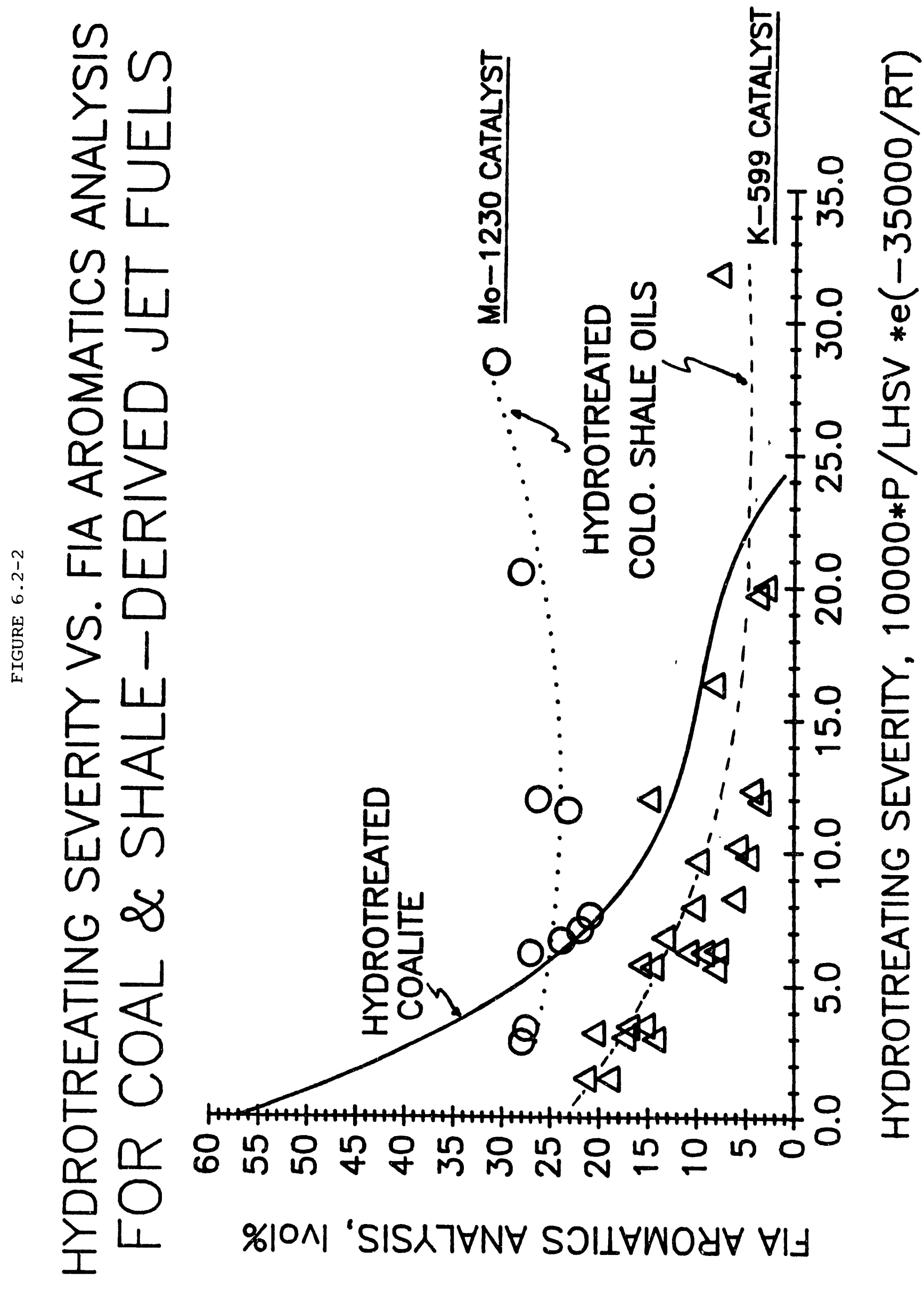




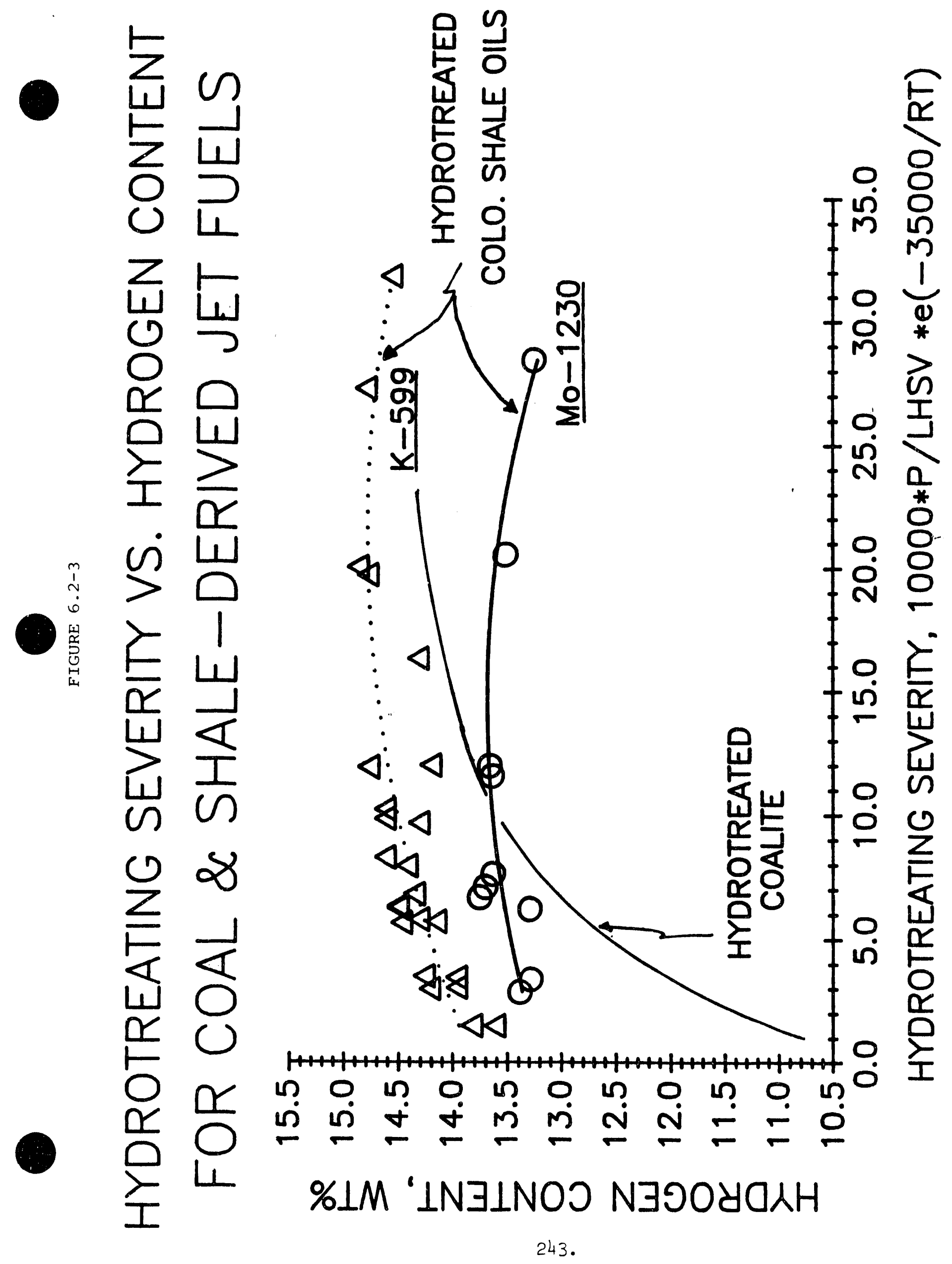




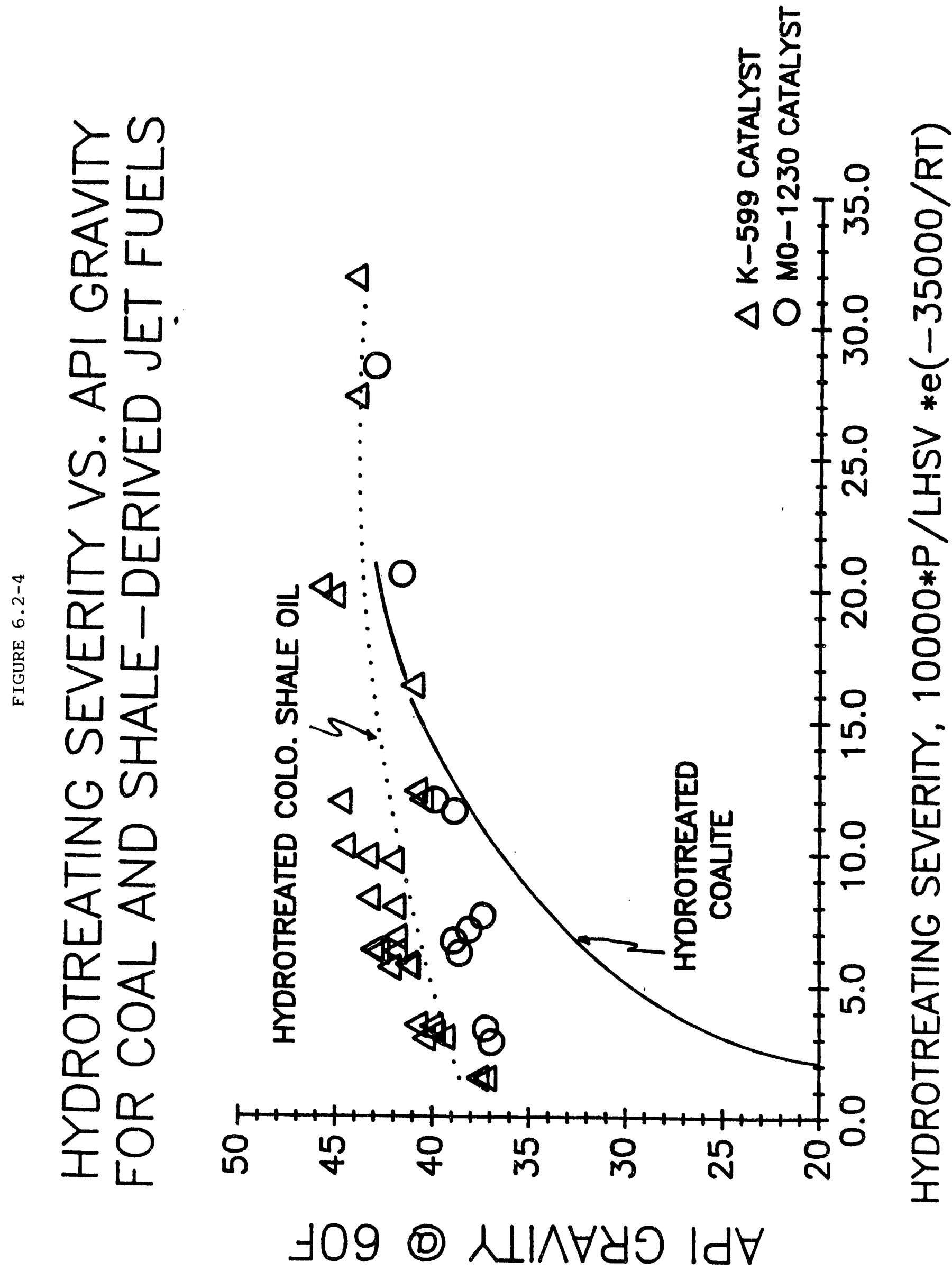




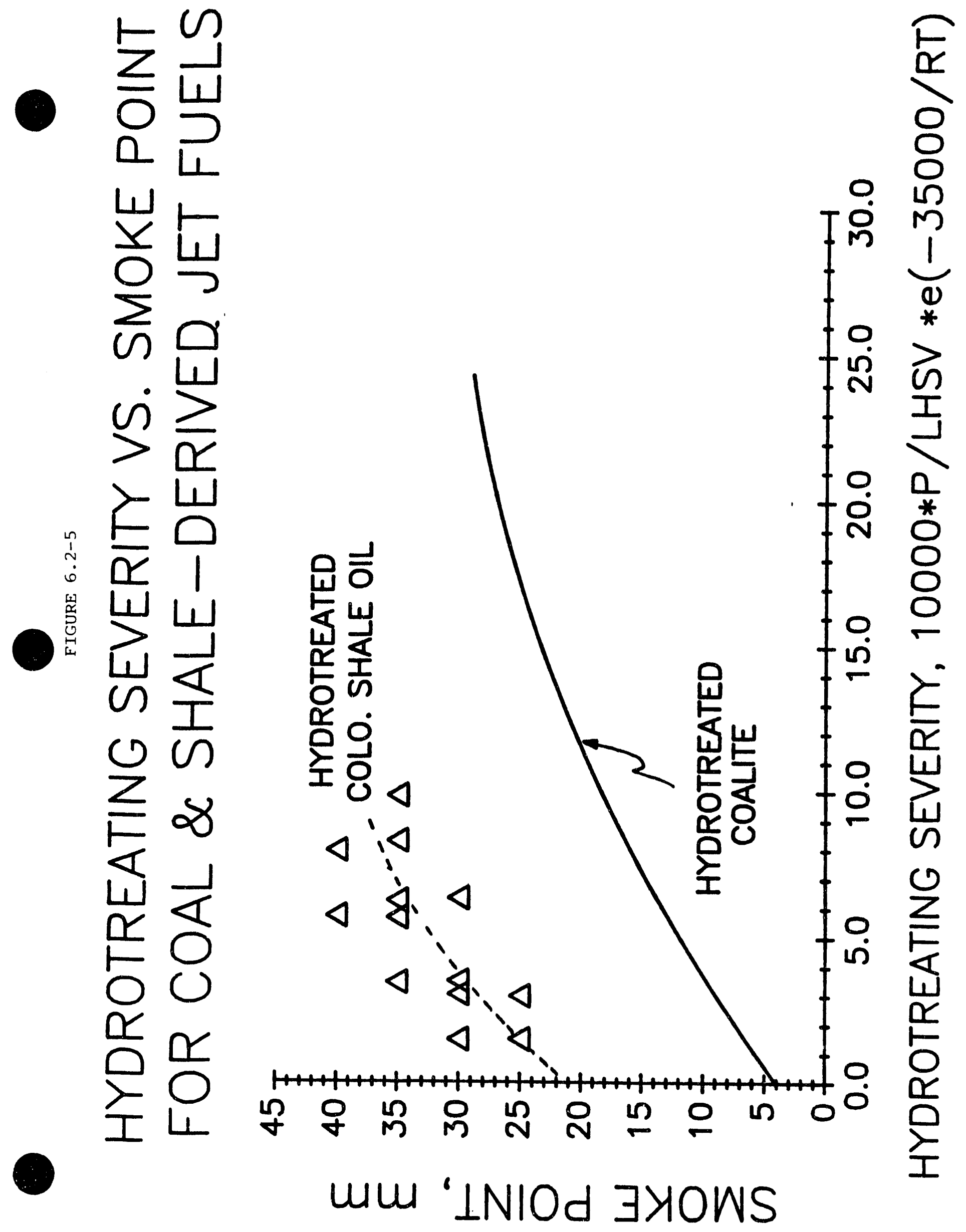




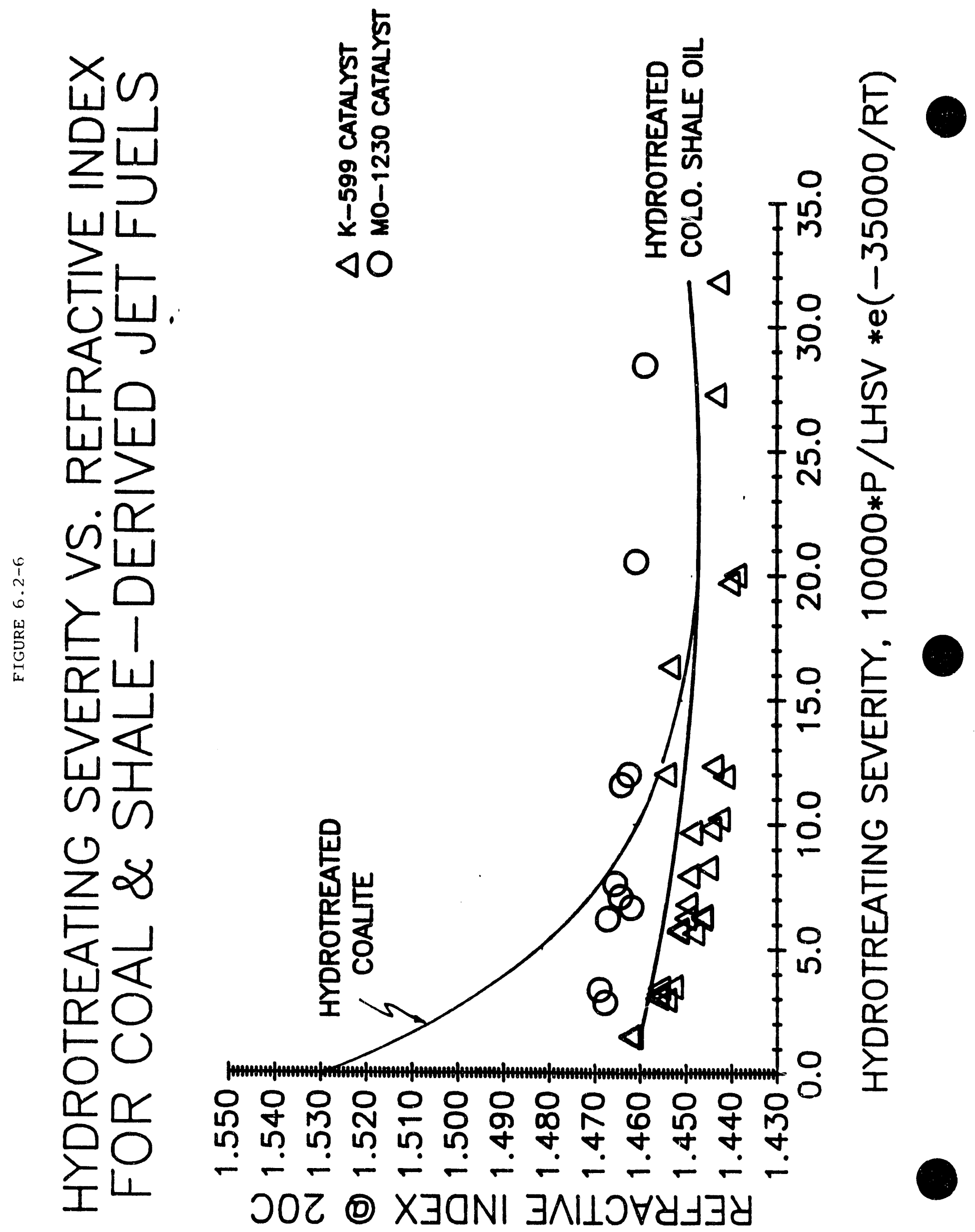




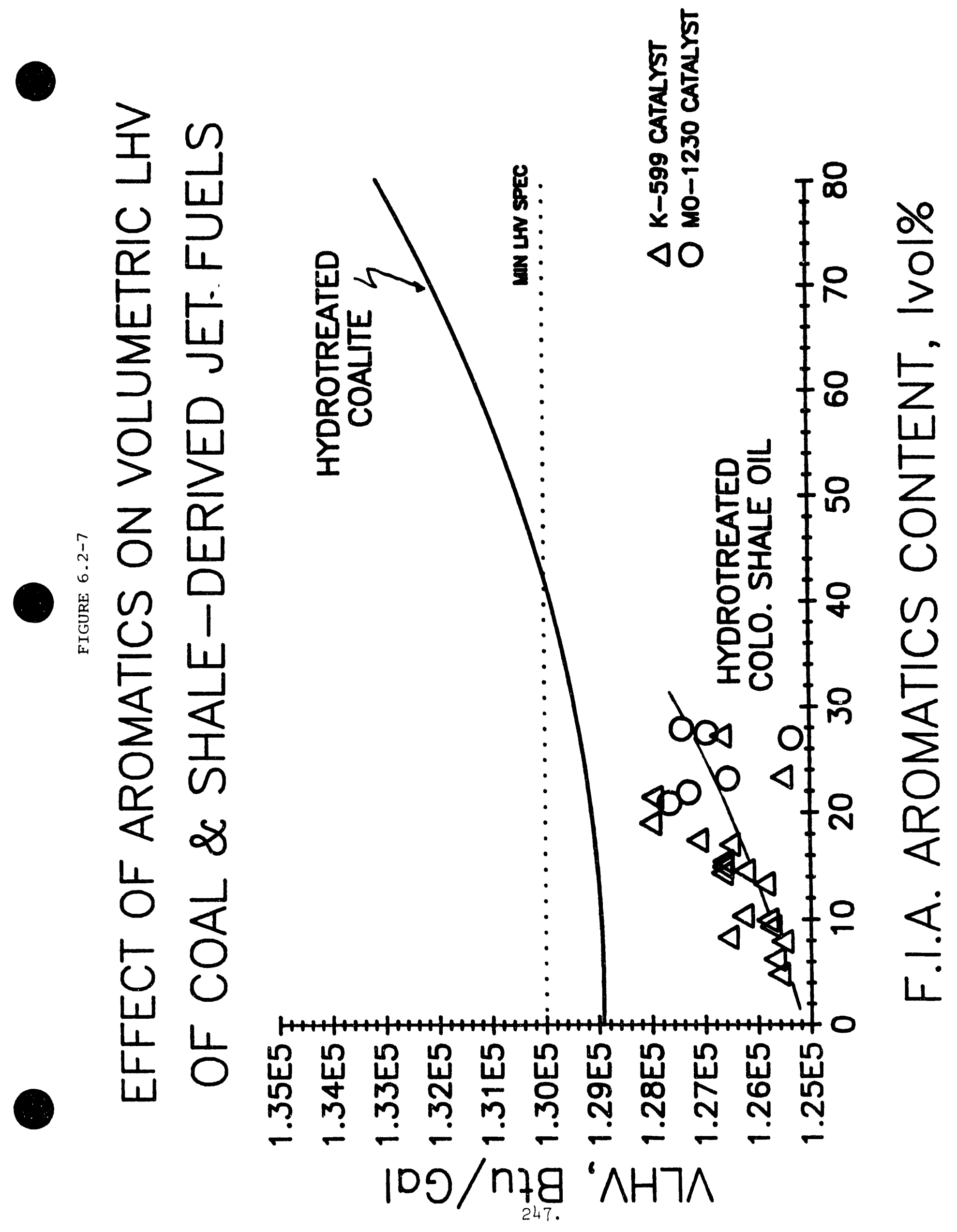



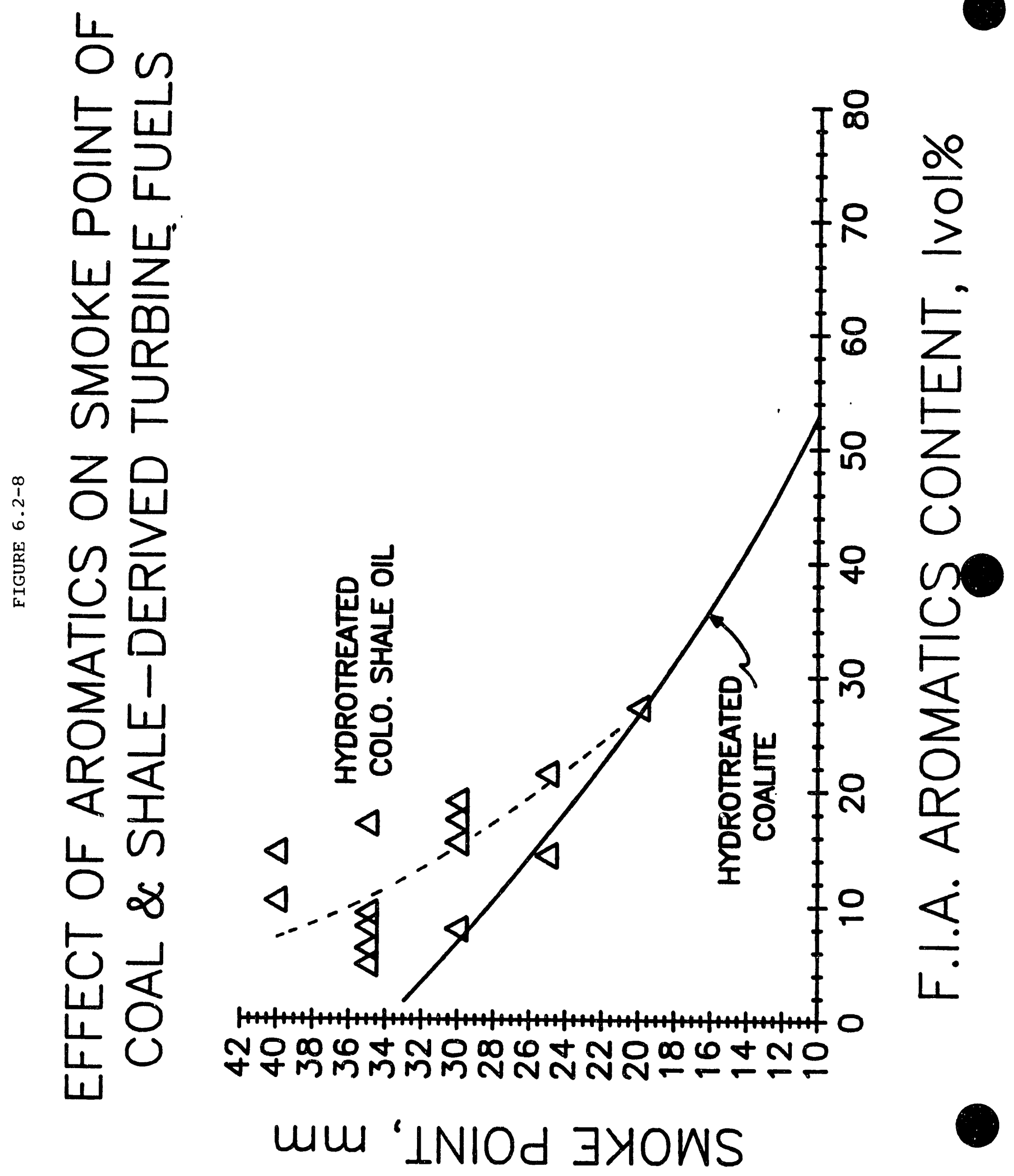


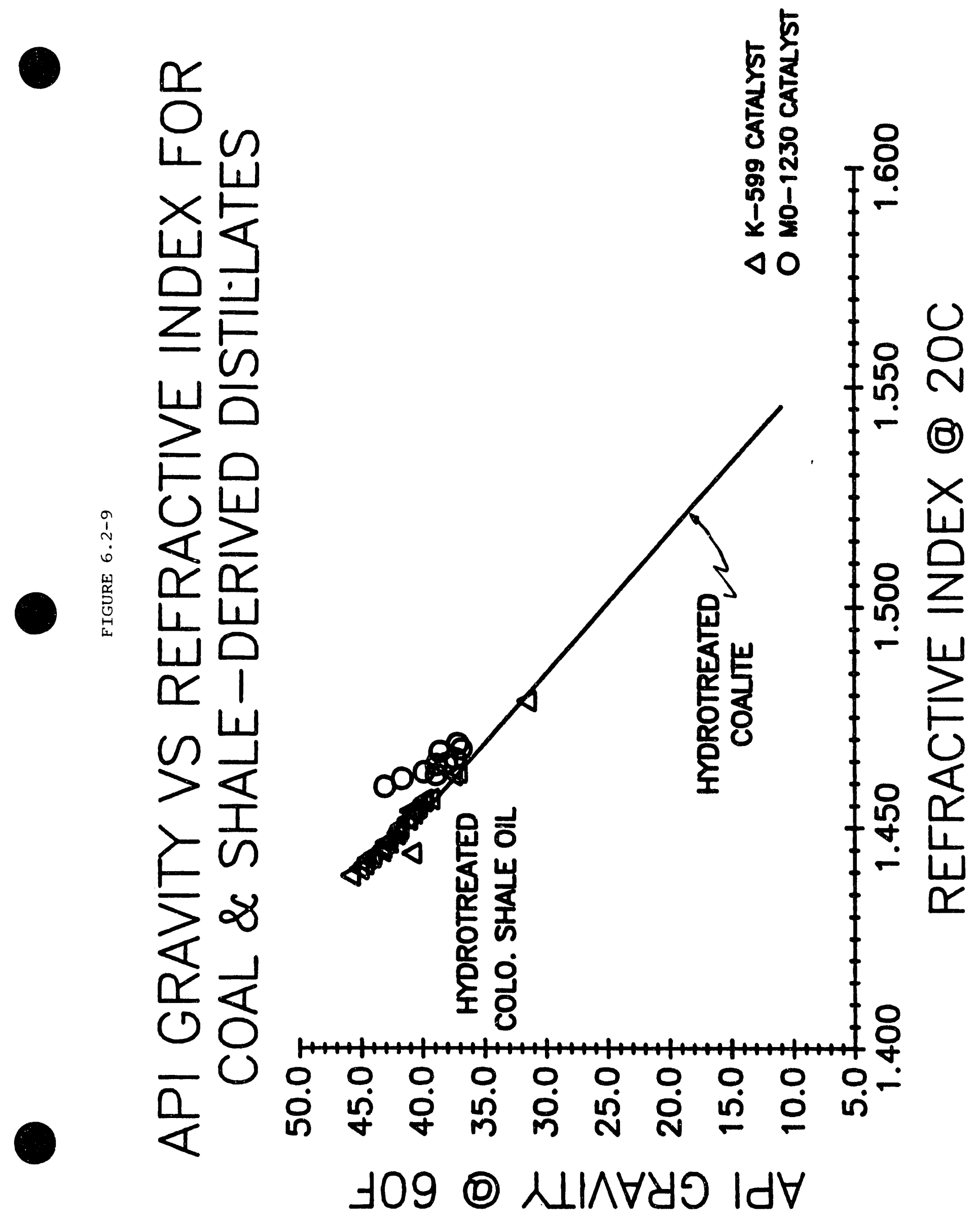



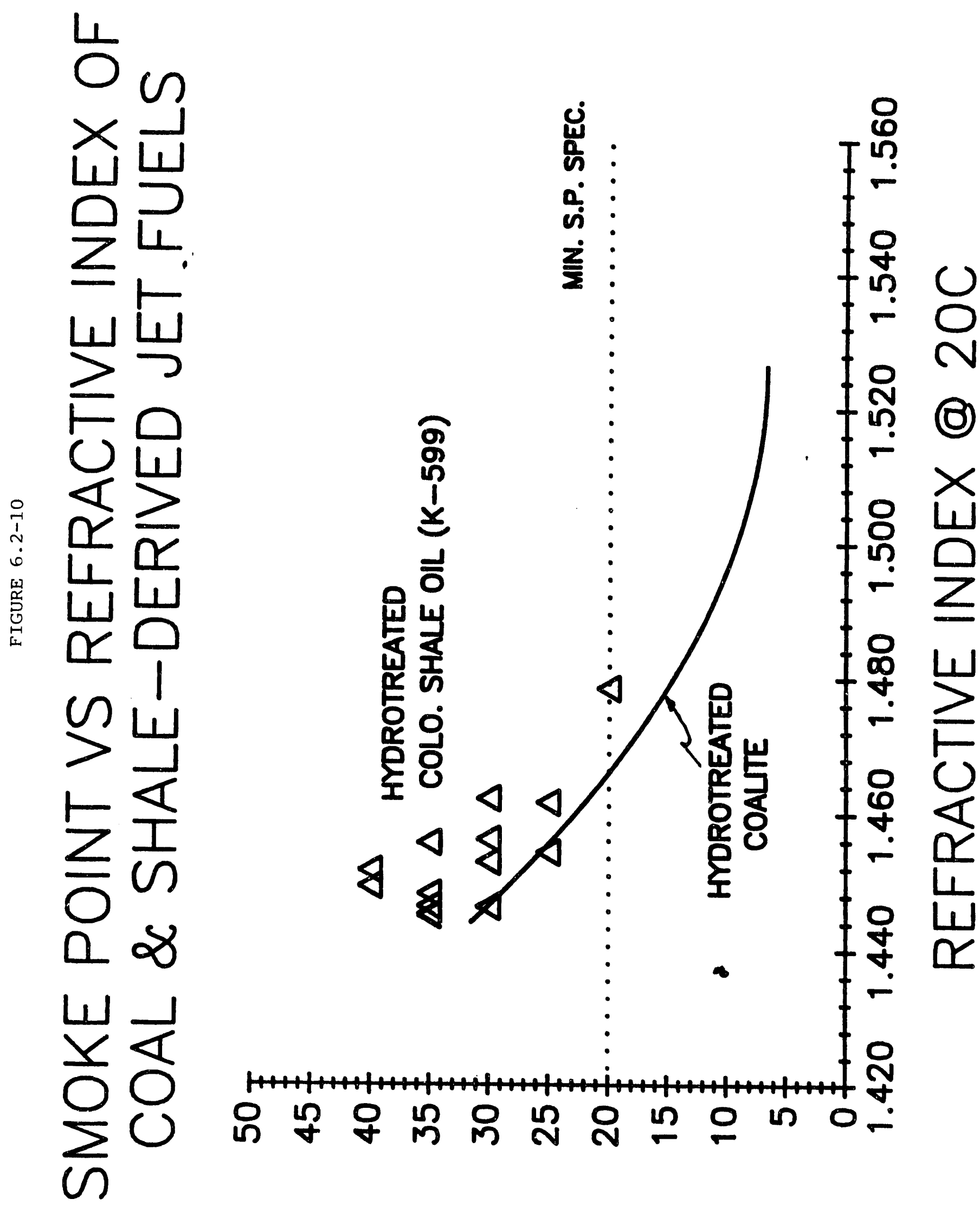

mu 'INIOd JYYOWS 


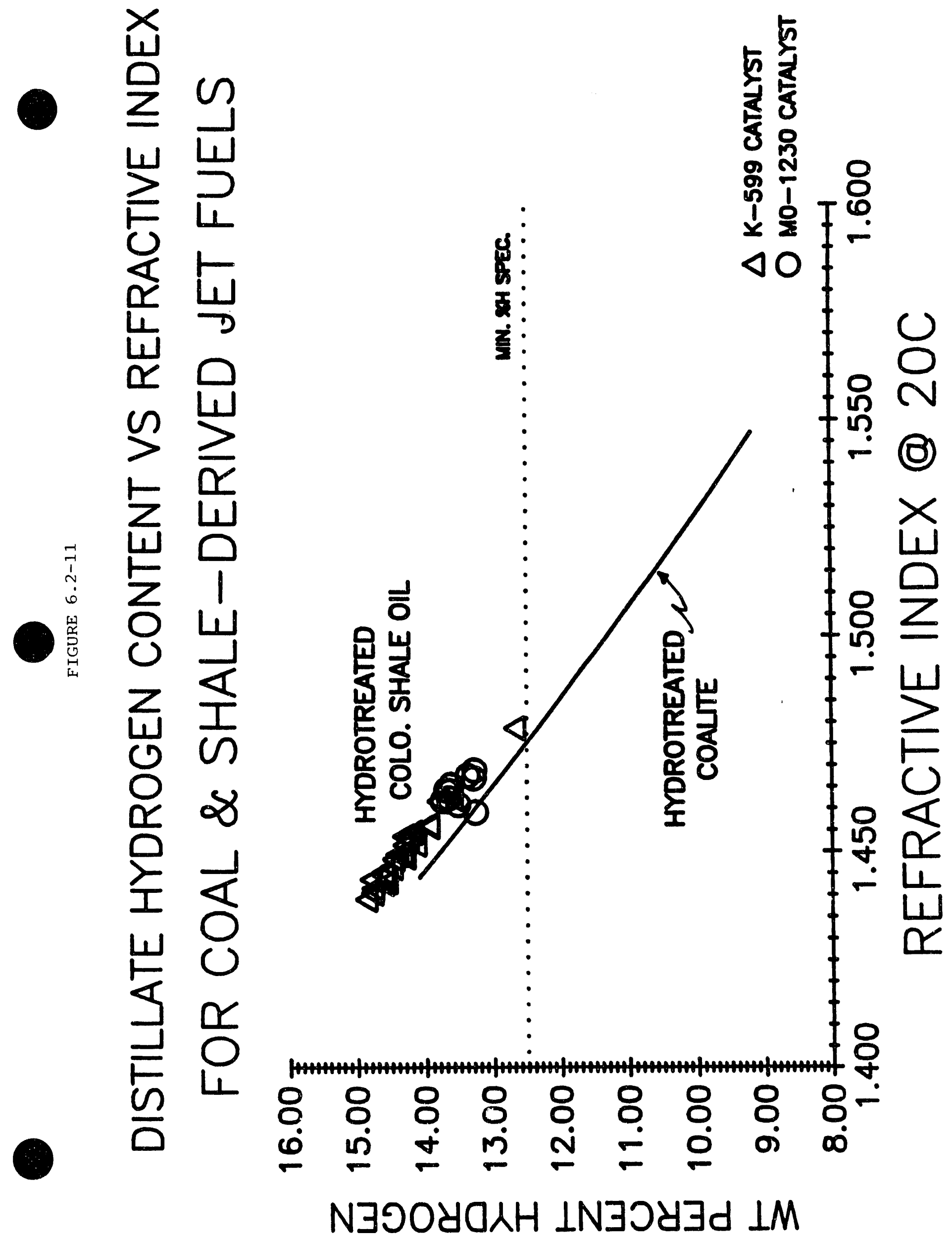


primarily aliphatic, e.g., n-octene/iso-octene, $n$-decene/iso-decene. The saturates types, naphthenes vs. paraffins, for these raw synfuels were not readily differentiated by the sulfonation/R.I. technique.

For the case of the Colorado shale 0il, the raw 300-600F distillate had a volumetric heat content of only about $127 \mathrm{KBtu} / \mathrm{gal}$, some 3000 Btu/gal below the target. Upon hydrotreatment as seen in Figure 6.2-7, the volumetric energy content decreases significantly away from the target. Thus, the K-550 NiWS and K-599 NiMo catalysts do not appear to have the right functionality to preserve and/or form the desirable cyclic structures. It may be possible to obviate this situation by extending the end point of the distillates beyond 600F and the initial point beyond $300 \mathrm{~F}$ in order to increase the concentration of the denser 2- and 3-ring cyclics.

One possible alternative to nickel-based aromatics saturation is the use of selective hydroisomerization (or aromatization or reforming) catalysts to reform aliphatics into the desirable aromatic precursor structures. The product of this operation would then be subjected to the nickel-based aromatics saturation catalysts thereby generating the naphthenic-rich HEDF fuels. Current state-of-the-art reforming catalysts are based on noble metals such as platinum, rhenium, palladium, etc. However, these catalysts are extremely sensitive to poisons, e.g., sulfur and nitrogen, and therefore cannot be used without a high severity pretreatment.

Prior to the advent of the noble metal catalysts, there was another family of reforming catalysts that was resistant to heteroatom contamination. These included chromia-alumina and molybdena-alumina catalysts. These catalysts are not as active as the noble metal catalysts and require higher operating severities to achieve comparable performance. A sample of a Harshaw Mo-1230 molybdena catalyst was obtained and used to evaluate the feasibility of this approach. A series of tests was made in the fixed-bed unit to screen the molybdena-based hydroisomerization of the 300-600F Colorado shale oil distillates. The hydroisomerizates were recovered and separately hydroprocessed over the K-599 nickel-moly catalyst to saturate aromatics, those originally present in the raw shale oil distillate as well as any produced during the molybdena reforming step. The data from the tests made did not however achieve the desired improvement. In fact, the highest volumetric energy density $(125,359 \mathrm{Btu} / \mathrm{gal})$ achieved was still lower than that achievable with the two-stage NiMo hydrotreating catalysts. Further improvements might be achieved by extending the distillate initial and end points to increase the content of the aromatics as well as the straight or branched chain aliphatics that might be more amenable to hydroisomerization.

\subsection{Virgin Atmospheric Resid Cracking}

Two campaigns of resid hydrocracking via LC-Fining technology were made and the results are summarized in Tables 6.3-1A,B for the virgin resid feedstock and Tables 6.3-2A,B for the hydroprocessed resid feedstock. One campaign of resid thermal cracking via delayed coking was completed and the results are summarized in Table 6.3-3A (operating results) and 6.3-3B (properties of coker distiliate products). 
TABLL $6.3-1 \mathrm{~A}$

SUHMARY OF OPERATING RESULTS FOR LC-FINIHG (HYOROCRACKING) IESTS

COLORADO SHALE OIL DISTILLATE

CATALYSI: SHELL 324 (AGED)

FILE ID: REPISBL2. UKI

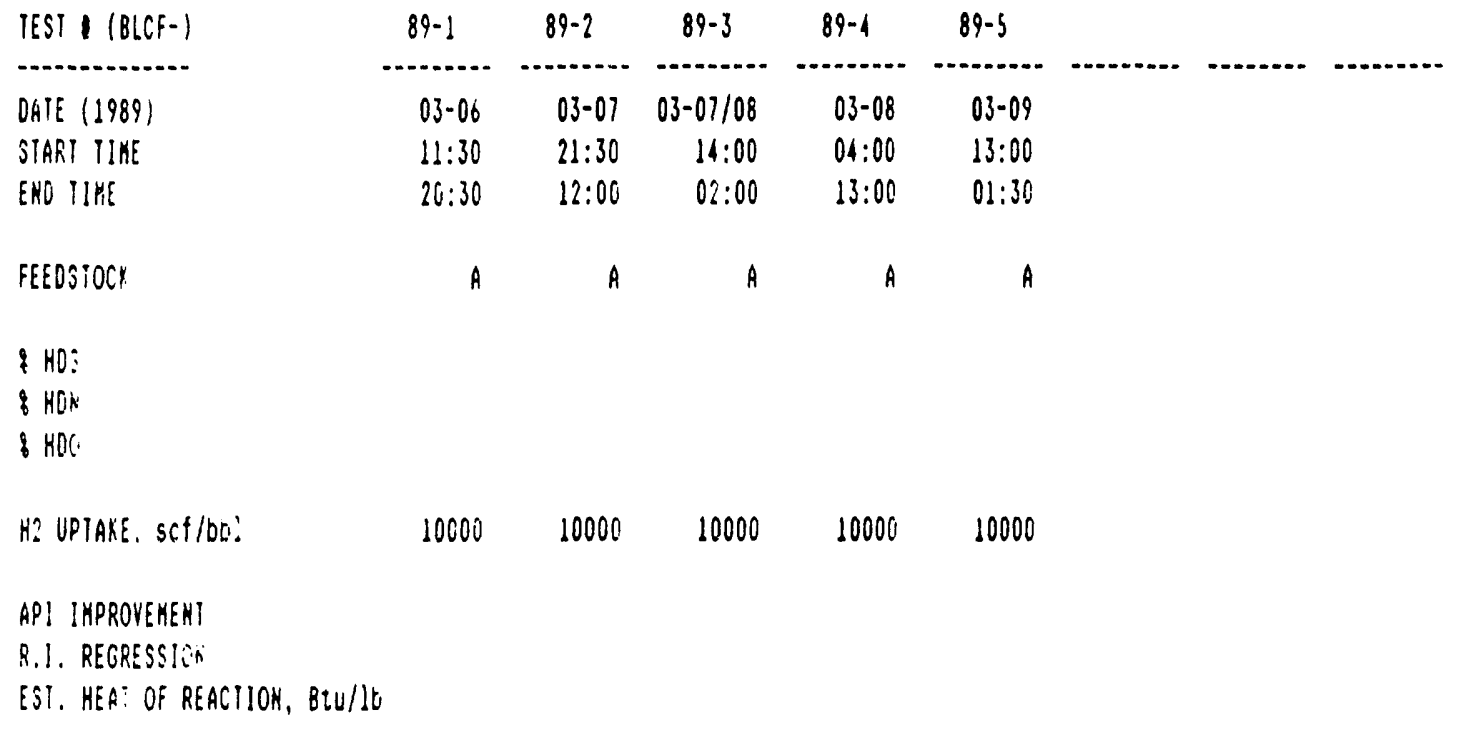

FEEDSTOCK IYPE:

A: COLORAOC SHALE OIL AIM RESIO $650+F$. 
TABLE $6.3-1 \mathrm{~B}$

SUMHARY OF PROPERIIES OF FULL-RANGE LC-FIMAIE IESTS

COLORADO SHALE OIL OISTILLAIE

CATALYST: SHELL 324 (AGED)

FILE ID: REPTSBL3.UKI

IEST 1 (BLCF-)

\begin{tabular}{|c|c|c|c|c|}
\hline $89-1$ & $89-2$ & $89-3$ & $89-1$ & $89-5$ \\
\hline 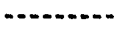 & ............ & - & - & - \\
\hline $03-06$ & $03-07$ & $03-07 / 08$ & $03-08$ & $03-09$ \\
\hline $11: 30$ & $21: 30$ & 14:00 & $04: 00$ & $13: 00$ \\
\hline $20: 30$ & $12: 30$ & $02: 00$ & $13: 00$ & $01: 30$ \\
\hline
\end{tabular}

feEesiock

SPECIFIC GRAYITY, go/C? API GRAVITY $60 \mathrm{~F}$

REFRACIIVE INDEX $\& 20$ C

$\begin{array}{rrrrr}A & A & A & A & A \\ 0.9934 & 0.9911 & 0.8959 & 0.9094 & 0.9123 \\ 10.9 & 11.3 & 26.4 & 24.1 & 23.6\end{array}$

ELEMENTALS, Nt?

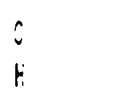

$\begin{array}{rrrrr}85.11 & 85.63 & 85.56 & 85.74 & 85.72 \\ 11.6 & 11.92 & 12.0 & 11.86 & 11.77\end{array}$

SIKULATEO OISTHLLATIOK. F

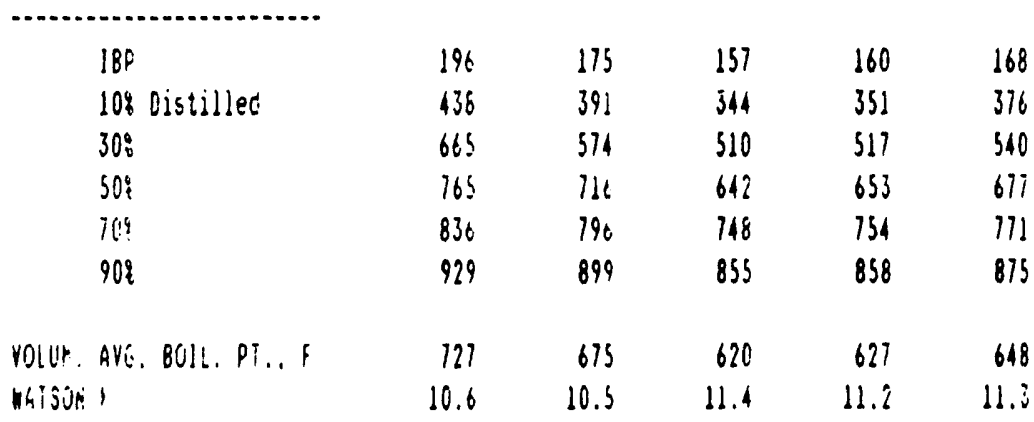

VLHY, BtU/lS

VLHT, BtU/ai:

FEEOSTOCY TYPE:

A: COLORADO SHALE OIL ATK RESID $650+F$. 
TABLE $6 \cdot 3-2 A$

…....

SUMHARY OF OPERATING RESULIS FOR LC-FIHIMG (HYOROCRACKING) IESTS

COLORADO SHALE OIL OISTILLATE

CATALYST: SHELL 324 (AGED)

FILE ID: REPTSBLL.UKL

IEST I (BLCF-)

-..............

DiIE (198:;

START TIKE

END TIME

FEEDsiock

$\begin{array}{rrrrrr}91 & 96 & 97 & 98 & 99 & \\ \ldots 0.1-05 & 04-12 / 13 & 04-13 & 04-13 / 14 & 04-14 & \\ 18: 00 & 20: 00 & 08: 00 & 20: 00 & 12: 00 & \\ 24: 00 & 04: 00 & 16: 00 & 08: 00 & 20: 00 & \\ B & B & B & B & B & \end{array}$

\& HDS

\& HOH

$\because \mathrm{HOC}$

H: UPTAKE, SCF/bDI

$7500 \quad 10000 \quad 10000 \quad 10000 \quad 10000$

API IMPROYENENT

:i. REGKESSID:

EST HEA: OF REACIION. BtU/LO

FEEOSTOCK TYPE:

B: HYDROPROCESSEO COLORADO SHALE OIL OISTILL RESIU. S75\% F. 
SUMHARY OF PROPERIIES OF FULL-RANGE LC-FIMAYE TESTS

COLORAOO SHALE OIL DISTILLATE

CATALYSI: SHELL 324 (AGED)

FILE IO: REPTSBLJ.IK!

TEST I (BLCF-)

DATE (1989)

START IIHE

ENO IIME

FEEOSIOCK

SPECIFIS GRAVIIY, gI/CG

API GRAYITY Q GOF

REFRACIIVE INOEX $20 \mathrm{C}$

\begin{tabular}{rrrrrr}
91 & \multicolumn{1}{c}{96} & \multicolumn{1}{c}{97} & 98 & 99 & \\
$04-05$ & $01-12 / 13$ & $04-13$ & $04-13 / 14$ & $04-14$ & \\
$18: 00$ & $20: 00$ & $08: 00$ & $20: 00$ & $12: 00$ & \\
$24: 00$ & $04: 00$ & $16: 00$ & $08: 00$ & $20: 00$ & \\
& & & & & \\
8 & 8 & 8 & 8 & 8 & \\
0.9123 & 0.9267 & 0.9188 & 0.9170 & 0.9371 \\
23.6 & 21.2 & 22.5 & 22.8 & 19.5
\end{tabular}

ELEMENTALS, ntq
\[ \]
H

SIMULATEG DISTILLATION, $F$

IEF

10 vistilies

$30 \%$

Sog

$? 0$ ?

908

VO:!n. AYa. BO!!, fi, :

Wijon:

Hithi. Btulile

Viris Btulo?:

FEEDSTOCR IYPE:

B: HYOROPROCESSED COLORADO SHALE OIL DISIILL RESID, 575+ $F$.

C: COALITE OISIILLATE, $300+F$. 
IABLE $6.3-3 A$

SUKHARY OF OPERAIIHG RESULTS ON HYOROTREATEO PROOUCTS FROH FIXEO-BEO HYOROTREATING OF

IHERMALLY PROCESSEO COLORADO SHALE OIL DISTILLATE

CATALYST: $K-55 O$ (IST STAGE) K-599 (2NO STAGE)

FILE 10: REPTSC3. HK!

IESI I (FB-)

DATE(1989)

SIART TIME

ENO IIME

FEEOSIOCY

8 HOS

\& HOW

$+\mathrm{HOC}$

H. UPIAXE. sif/bb!

Z F.I.A. OLEFINS SATURATIOH

F.I.A. AROHATICS SATURATION

API IMPROVEHENI

R.1. OEPRESSION

EST. HEAT OF REACTION, BEU/ID

$\begin{array}{cccc}131 & 132 & 133 & 134 \\ 04-24 & 04-24 & 04-24 & 04-25 \\ 10: 00 & 16: 00 & 21: 00 & 01: 30 \\ 12: 00 & 18: 00 & 22: 30 & 03: 00 \\ & & & \\ \text { A } & \text { A } & A & A\end{array}$

$1000 \quad 7000 \quad 1000 \quad 1000$

$\begin{array}{rrrr}11.9 & 12.4 & 8.9 & 9.60 \\ 0.0369 & 0.0374 & 0.0260 & 0.0 ?\end{array}$

FEEOSTOCK TYPE:

A: THERHALLY PROCESSEO COLORADO SHALE OIL DISTILLATE, 30O-57S F. 
IABLE $6.3-3 B$

SUMHARY OF PROPERTIES OF HYOROTREATEO PROOUCTS FROH FIXED-BEO HYOROTREATING OF

IHERHALLY PROCESSED COLORADO SHALE OIL OISTILLATE

CATALYST: $X-550$ (IST STAGE) K-599 (2NO STAGE)

FILE 10:REPISC2.IKI

IEST $\mid$ ( $F B$ - )

OATEI1989)

STARI IIME

ENO IINE

FEEDSIOCK

SPECIFIC GRAVITI, gro/CC

API GROVITY

REFPACIIYE INOEY I AT

$\begin{array}{cccc}131 & 132 & 133 & 134 \\ 04-24 & 04-24 & 04-24 & 04-25 \\ 10: 00 & 16: 00 & 21: 00 & 01: 30 \\ 12 \cdot 00 & 18: 00 & 22: 30 & 03: 00\end{array}$

12:00 18:00 22:30 03:00

ELEMENTGL, Ut.?

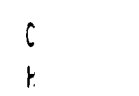

$\begin{array}{llll}85.47 & 85.34 & 86.04 & 85.61 \\ 14.50 & 14.53 & 13.89 & 13.65\end{array}$

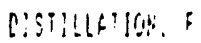

isi
10.
$30 i$
$50 t$
705
$90 i$

Mo:Uh VAL, BSiE, PI, F Petsith 1

… A.HALYS!S. IVO!.?

OLEFINE
SATURATES
AROHAIICS

HLHY, Otu/lo.

VLHY, b:U/Q̣a:.

FLASH PI., F

SHOHE PT., 1

FPEEL, Pi.. F

An!IJHE Fi.., $F$

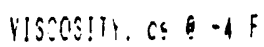

$\begin{array}{rrrr}0.5 & 0.3 & 0.3 & 0.30 \\ 91.1 & 91.7 & 16.4 & 15.50 \\ 8.1 & 8.0 & 23.1 & 24.20 \\ & & & \\ & 18283 & & 18200 \\ & 121686 & & 123074\end{array}$

FEEDSTOCY IYPE:

A:TH!RHO:!Y PROCESSE! COLORADO SHALE OIL OISTILLATE, 306-575 F. 


\subsection{Cracked Distillate Hydrotreating}

Only one test campaign was completed for the hydrotreating of cracked distillates. Tables 6.4-1A,B summarize the results for the tests made with a hydroprocessed distillate derived from fixed-bed hydrocracking of LC-Finate VGO.

\subsection{Two-Stage Selective Hydrocracking of Vacuum Gas 0il (VGO)}

Early Task studies demonstrated that volumetric energy densities for 300-600F raw Colorado shale oils after fixed-bed hydrotreating were limited to about $125,000 \mathrm{Btu} / \mathrm{gal}$. While this value is some 5000 Btu/gal below the spec, it still represents a 5000-10,000 Btu/gal energy density premium above that of conventional jet fuels. Nevertheless, a campaign was initiated with the heavy (550F+) Colorado shale oil fraction following parallel processing routes that successfully generated a $132,000+B t u / g a l$ energy density HEDF from the $550 F+$ COALITE feedstock.

The selective hydrocracking route, as successfully implemented with the COALITE feedstock, basically consists of mild expanded-bed hydrofining (LC-Fining) of the $300 \mathrm{~F}+$ dewatered feed; fractionation to recover the $550-975 \mathrm{~F}$ LC-Finate vacuum gas oil (VGO); selective hydrocracking of the VGO over the Amoco proprietary fixed-bed hydrocracking catalyst; and fixed-bed hydrogenation of the VGO hydrocrackate.

In the current campaign with the Colorado shale oil feedstock, the selective hydrocracking route followed the steps delineated below:

0 The whole (IBP to end point), undewatered Colorado shale oil was subjected to the mild LC-Fining (test BLCF-102) step. The water collected in the LC-Finate product receivers was phase separated by decanting. The LC-Finate full-range product was fractionated to generate a 575-975F VGO fraction for downstream hydrocracking/hydrogenation.

- Since the nitrogen content of the LC-Finate VGO was still very high, ca., $15000 \mathrm{ppm}$, a subsequent fixed-bed hydroireating (test FB-186/187) step using a NiW/NiMo two-stage catalyst system was used to reduce nitrogen content to $200 \mathrm{ppm}$.

- The thus hydrotreated LC-Finate VGO was then subjected to fixed-bed hydrocracking (test FBHC-32/35) over the Amoco proprietary hydrocracking catalyst. The resultant full-range hydrocrackate was then subjected to fixed-bed hydrotreating (FB-188/189) over a NiW/NiMo two-stage catalyst system without fractionating out the unconverted $575-975 \mathrm{~F}$ gas 011 fraction.

0 The hydrogenated hydrocrackate was fractionated to recover a 275-550F HEDF product that met flash point and freeze point specs. 


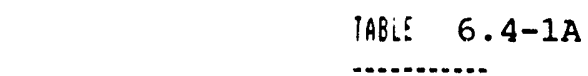

SUMHARY OF OPEPATING RESULIS FOR FIXED-BEO HYOROTREAIING IESIS OF

HYOROCRACKEC COLORADO SHALE OIL OISTILLATE

CATALYST: K-5SO (1ST SIAGE)/K-599 (2NO STAGE)

IEST \& |F: : !

Dits l:ogs

START IIME

EN: IIS:

FEEOSTOC?

$\sum H_{i}:$

Hin

i $H:$ :

H: HiTALE, sot/DE!

¿ II.F. OLEFIRE SATURETIOA

8000

$806 \hat{6}$

¿ $\therefore \therefore$ : ARIMAT!CS SATURARICR:

af: ingei:in:

3.6

K.i. LEPRESislon

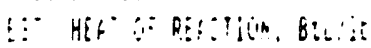

\begin{tabular}{rr}
188 & \multicolumn{1}{c}{189} \\
00.05 & $09-05 / 0 ?$ \\
$06: 00$ & $19: 00$ \\
$15: 00$ & $13: 0 ?$ \\
$A$ &
\end{tabular}

FILE ID: REPISE3.UKI

BEEOSING TIF:

A. CFACKEO VIRGIN COLORADO SHALE OI:.

FRCH THREE-STEPS, HYOROPROCESSEO VIRGIT

COLORADO SHALE OIL FOLLONEO BY FIXEO-BEO

HYOROTPEAIING ANG HYOROCRACKING. 
IABLE $\quad 6.4-1 B$

-...........

SUHMARY OF PFOPERTIES OF FIXEO-OBEO HYOROTREATED PRODUCIS

FROH HYOROCRACXEO COLORADO SHALE OIL DISTILLATE

CATALYST: K-SSO (IST STAGE)/K-S99 (2HO STAGE)

FILE 10: REPTSP3

$\begin{array}{rr}180 & 189 \\ 09-05 & 09.05 / 0 ? \\ 06: 00 & 10: 00 \\ 15: 00 & 13: 00 \\ & \\ 4 & 4 \\ & 0.83 \\ & 38.9\end{array}$

SiHMaIEG DISTILLAIIOR, F

.............................

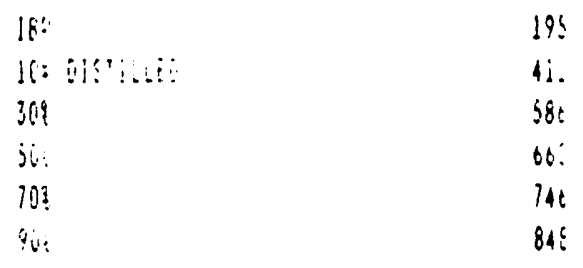

Vintu. Ar: Git. Di.;

Me:sin, 1 o.te

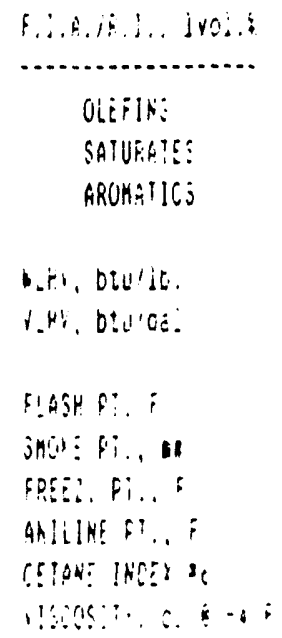

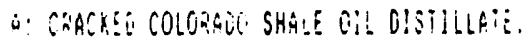

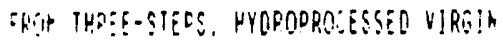

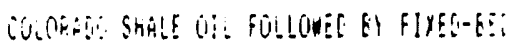

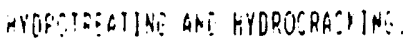


The measured energy density of this latter product was still only about 125,000 Btu/gal, comparable to that generated when hydrotraating the raw 300-600F Colorado shale oil distillate. Thus, the selective hydrocracking of the $575 \mathrm{~F}+$ fraction of the Colorado shale oil did not improve energy density quality as was observed with the COALITE feedstock. Furthermore, the per pass conversions during the LC-Fining (BLCF-102) and the fixed-bed hydrocracking (FBHC-32/35) were very low indicating the relative refractory nature of the gas oil fraction of the Colorado shale oils.

This campaijn did generate samples of Colorado shale oil-derived HEDF and HEDF precursor streams for testing in the extraction evaluation screening program.

\subsection{Extraction Studies}

The plan for the evaluation of the extracticil/hydrogenation route (schematic diagram shown in Figure 6.6-1) consists of: a) collection of basic equilibrium solvent selectivity data for the two candidate solvents, namely, diwlethylformamide (DMF) and tetraethylene glycol (TEG); b) analytical evaluation of the extracts and raffinates with respect to energy density improvements; and c) recommendations for preparation of bench-scale quantities of extracts for demonstration of the potential of fixej-bed hydrotreating (and hydrocracking) to upgrade extricted HEDF precursors to the 130,000 min. Btu/gal energy density spec.

The four feedstocks selected for the initial evaluation include:

- mildly LC-Fined vac gas oil (BLCF-102 product)

- severely hydrotreated LC-Finate vac gas oil (FB-186/187)

- selectively hydrocracked mid-distillate (FB-188/189)

- hydrotreated raw mid-distillate (FB-130)

The first two feedstocks represent the evaluation of heavier extracts boiling above the HEDF boiling range prior to hydrocracking. The latter two feedstocks to extraction represent HEDF products having nominal 125,000 Btu/gal energy densities.

The test equipment consists of a stirred, externally heated, glass extraction vessel. Testing consisted of three stages of contact using fresh solvent in each stage. Conditions held constant in these initial tests were as follows:

- Nominal temperature of $195 \mathrm{~F}$

- Atmospheric pressure

o Stirrer speed of $5 \mathrm{rpm}$

- 1 hour extraction contact time per stage

$0 \quad$ Fresh solvenc to feed ratio of $1.5 \mathrm{gm} / \mathrm{gm}$

Raffinate and solvent-rich extract phases were separated by decanting ii a separatory funnel. The extract was separated from the solvent by introduction of water which dissolved the solvent and freed the hydrocarbon-rich extract. The two solvents selected were premised on 


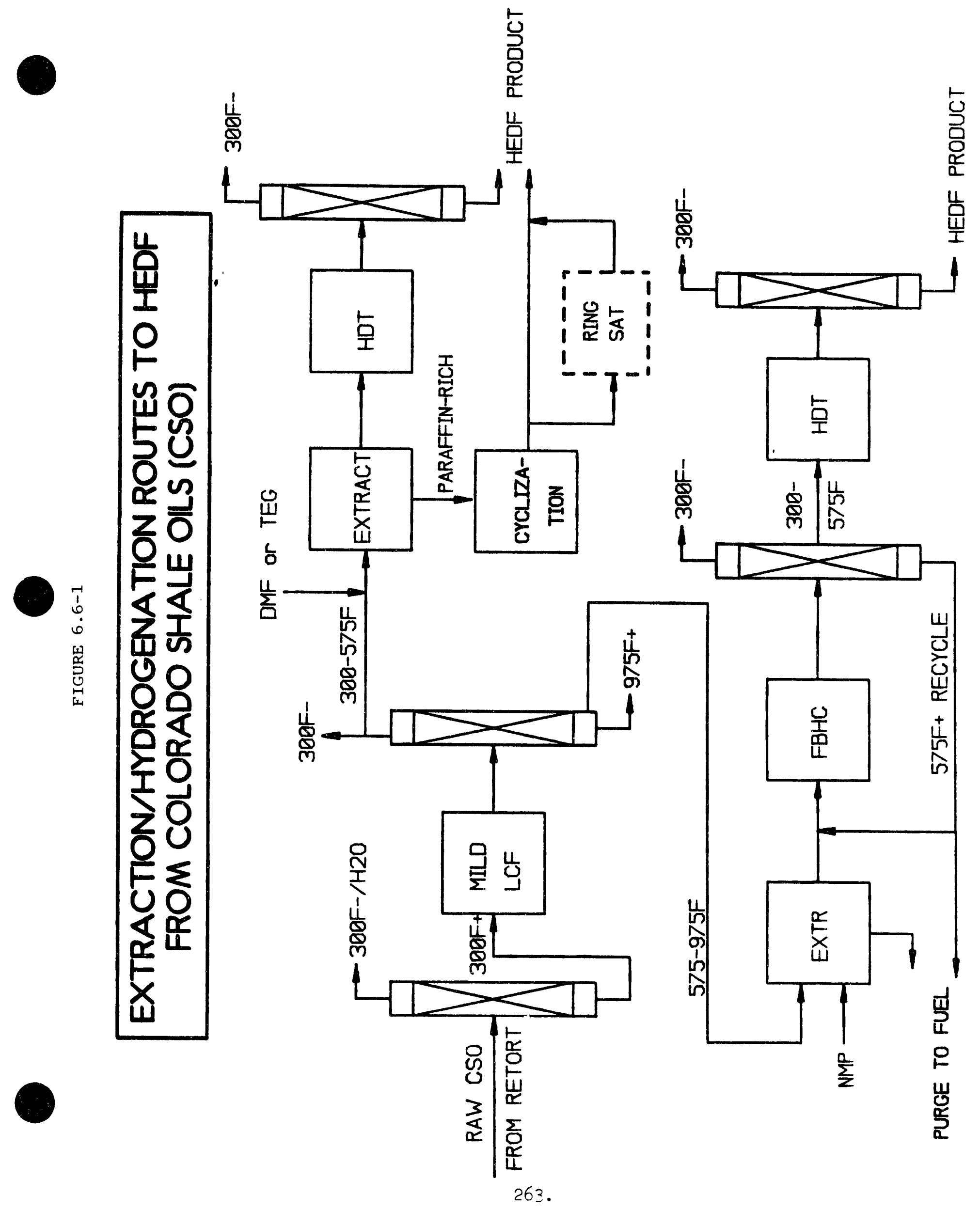


separation from the extract by distillation. The TEG, the heavier boiling solvent (B.P. = 622F), was to have been used for the lighter (275-575F) boiling mid-distillate stream. The DMF, the lighter boiling solvent (B.P. = 307F), was to have been used for the heavier (575-975F) boiling gas oil stream.

The summary of the operating conditions and raffinate properties is presented on the spreadsheet of Table 6.6-1. The initial testing indicated that the DMF solvent demonstrated a good degree of effectiveness in extracting some species from the heavier feedstock. The TEG solvent appeared to have no specificity for any of the components in the lighter distillate feedstock. Since the DMF solvent is soluble in water, it may be separated from the extract in a commercial-scale application by introduction of a third phase, namely, water or an aqueous-rich recycle stream, instead of distillation.

The results are summarized on Table 6.6-2 which shows that DMF extraction of a hydrotreated $300-650 \mathrm{~F}$ distillate can increase the energy density of the extract by some $2335 \mathrm{Btu} / \mathrm{gal}$ over that of the feed but at the expense of a reduction in the energy density of the raffinate. 


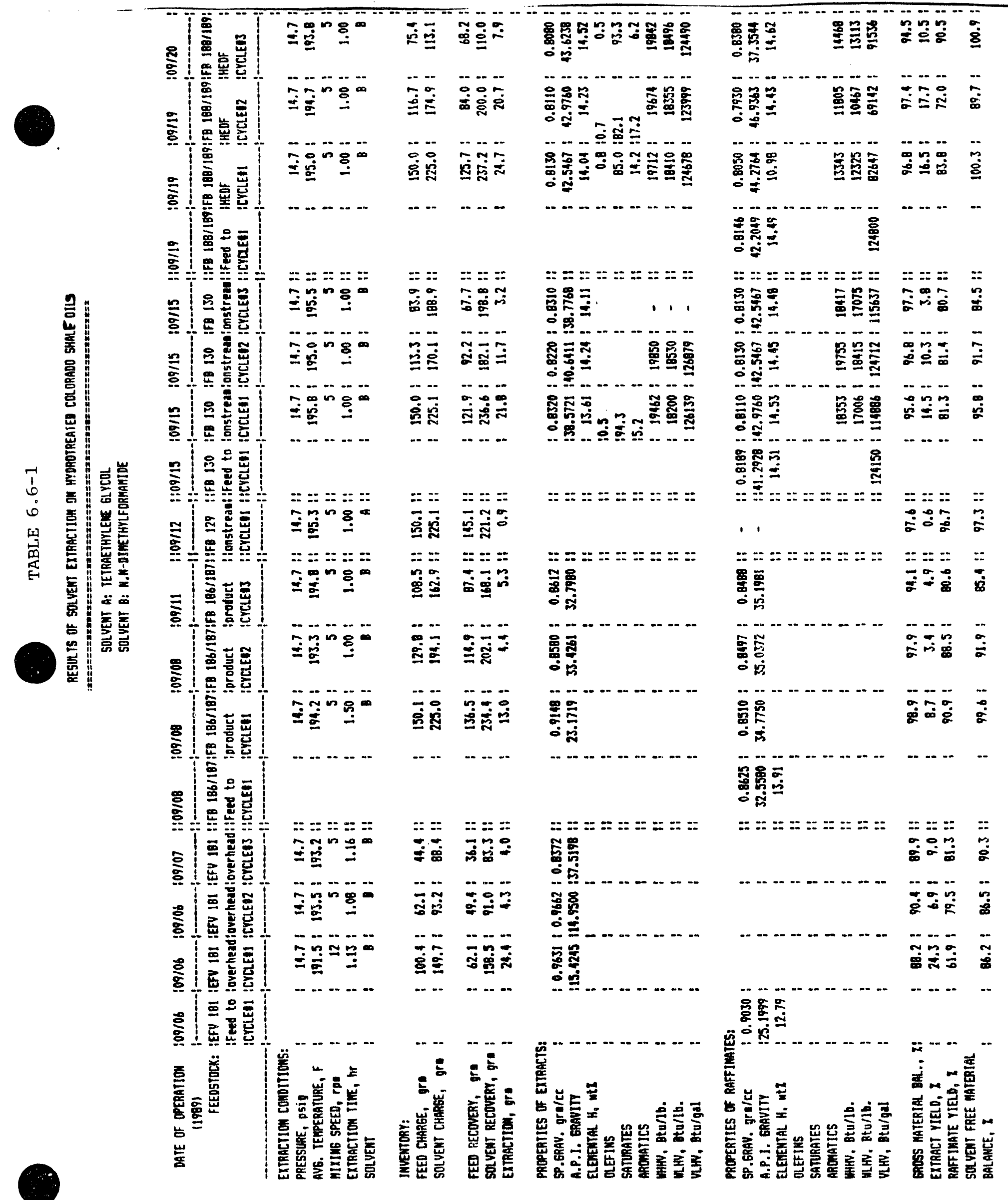


TABLE $6.6-2$

\section{LAB EXTRACTION STUDY RESULTS}

FEED: HYDROTREATED 300-650F COLO SHALE OIL DISTILLATE SOLVENT: DIMETHYLFORMAMIDE (DMF)

MATERIAL BALANCE

SPECIFIC GRAVITY

$\triangle$ API IMPROVEMENT

\% HYDROGEN CONTENT

$\triangle H$ REDUCTION, scf/bbl

VLHV, Btu/gal

$\triangle$ VLHV, Btu/gal

3-STAGE PERFORMANCE RESULTS

FEED

100

0.8189

$-$

14.31

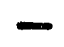

124,150
EXTRACT

26.22

0.8285

2.0

13.88

232

126,485

2335
RAFFINATE

73.78

0.8130

(1.25)

14.46

(80)

122,951

(1199) 


\subsection{SUMMARY OF RESULTS OF PILOT PLANT SAMPLE PREPARATION (Task 5)}

\subsection{Overview}

The specific objectives of Task 5 (in addition to the preparation of this topical report) were to:

- Perform laboratory characterization tests on the raw COALITE feed, the intermediate liquids to the required hydroprocessing units and final advanced fuels and byproducts; and

0 Produce a minimum of 25-gal of Category I test fuel for evaluation by DOE and its contractors.

While sample preparation for the purpose of end user assessment is a very important component of process development. The end user assessment can provide good feedback to the process developer on the properties of the test fuels under static and dynamic engine test evaluations. However, the structure of this project allowed for only a single interface between the process developer and the end user of the HEDF test fuel and this interface will occur after the termination of the project. Accordingly, the decision on what fuel samples of the many options available to the process developer is a critical one. In selecting processing conditions, it was necessary to consider the tradeoffs in ultimate HEDF yield with fuel cut points, the latter having great effects on the energy density and thermal stability properties of the candidate HEDF fuels. It was also necessary to consider the severities of the various hydroprocessing steps and their impacts on capital and operating costs. Finally, good judgment had to be applied in selection of screening conditions since the project, and especially the Task 5 pilot plant sample preparation program, had definitive cost and schedule limitations.

The original work statement called for production of test samples from both the COALITE MCG liquids as well as from UNOCAL Process-derived Colorado shale oils. Since the Colorado shale oils were shown during the Task 3 screening studies to be less responsive to hydroprocessing with regards to achieving $130,000+B t u / g a l$ energy densities, the work statement was modified to concentrate on the COALITE liquids and to produce two different quality HEDF test fuel samples based on COALITE processing. The particular processing methodology selected for the sample preparation efforts was based on a target of optimizing the volumetric energy density-thermal stability relationships for the HEDF fraction. The processing steps consisted of:

- Fractionating the raw full-range COALITE to generate a $575 \mathrm{~F}+$ atmospheric resid fraction;

- LC-Fining of the 575F+ COALITE to hydrocrack some of the vac resid components as well as to impart part of the hydrogen uptake requirements in a backmixed, near isothermal reaction systein; 
- Flash vaporizing the full-range LC-Finates to remover the unconverted $900 \mathrm{~F}+$ vac resid;

- Hydrodenitrogenating in a fixed-bed hydrotreater the thus prepared IBP-900F LC-Finate gas oils using a NiMo catalyst selective to deep denitrogenation removal;

- Selectively hydrocracking the hydrodenitrogenated LC-Finate gas oils using a proprietary zeolitic-based hydrocracking catalyst in a fixed-bed hydrotreater at two operating severities;

- Fractionating the hydrocrackate products to recover the nominal 280-580F HEDF precursors;

- Clay treating the $280-580 \mathrm{~F}$ materials over bentonite to remove trace polar impurities; and

o Treating the HEDF test fuels with anti-oxidant and corrosion inhibitor.

\subsection{LC-Fining ${ }^{\text {Sm }}$ Operations}

The first step in the overall sequence to produce finished HEDF test fuel from the raw COALITE feed is to hydroprocess the atmospheric resid cut via expanded-bed LC-Fining. The throughput to the LC-Fining unit was specified to insure that there would be a minimum quantity of HEDF precursors in the LC-Finate products necessary for the achievement of at least 25-gal of HEDF test fuels. Run 6LCF-14 was carried out using Shell 324M NiMo catalyst recovered from a prior campaign in the LC-Fining pilot unit made during Subtask 3.2 to recover LC-Finates for the screening studies. The 6LCF-14 feed was derived from the $575 \mathrm{~F}+$ atmospheric resid fraction recovered during the batch fractionation (in an 8-in batch fractionation unit) of the raw COALITE material.

The LC-Fining unit was successfully pressure tested at 2500 psig hydrogen pressure and commissioned with a 350-575F raw COALITE distillate until the catalyst bed temperature was 500F. At this point, the distillate feed was removed and the $575 \mathrm{~F}+$ resid was introduced which increasing the heat inputs until the desired catalyst bed temperature was achieved.

The run proceeded for four days without any major operating problems and a total of 105 gallons of LC-Finate were recovered. The reactor operating conditions were 2000 psig operating pressure, $773 \mathrm{~F}$ average catalyst bed temperature, $6000 \mathrm{scfb}$ treat gas rate and 1.5 LHSV per each of the two catalyst beds.

As indicated in Table 7.2-1, the conditions for run 6LCF-14 were more severe than those of the prior Subtask 3.2 screening test of run $6 L C F-11$. The bed temperatures were about $9 F$ higher and space velocity per bed was about $0.1 \mathrm{hr}^{-1}$ lower. The incremental increase in severity was an attempt to match the possible catalyst activity loss 
TABLE 7.2-1

RUN 6LCF-14 LC-FINING PRODUCIION RUN

\begin{tabular}{|c|c|c|}
\hline 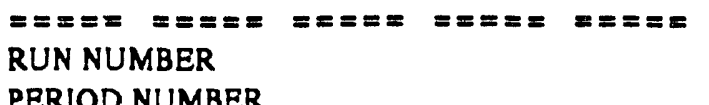 & $\begin{array}{l}= \pm== \pm \\
6 L C F-11\end{array}$ & $\begin{array}{l}==x== \\
6 L C F-14\end{array}$ \\
\hline PERIOD NUMBER & 3 & 2 \\
\hline DATE (1990) & $3 / 31$ & $12 / 12$ \\
\hline AVO. CATALYST TEMP. (1st BED) & 759 & 774 \\
\hline AVG. CATALYST TEMP. (2nd BED) & 769 & 772 \\
\hline TOTAL PRESSURE, PSIG & 2000 & 2000 \\
\hline LHSV PER BED, HOURS-1 & 1.63 & 1.49 \\
\hline SHELL 324M CATALYST AGE, BBL/LB & 0.17 & 0.272 \\
\hline TWO-STAGE WDSV, BBLRB/DAY & 0.071 & 0.064 \\
\hline TREAT OAS (HZ), SCP/BBL & $\operatorname{sen} 0$ & 6000 \\
\hline CARBON BALANCE WT.\% RECOVERY & 101 & $\$$ \\
\hline OVERALL MAT. BAL, WT. $\%$ RECOVERY & 100 & 100 \\
\hline \multicolumn{3}{|l|}{ PEED COALITE (S7SF +) PROPERTIES } \\
\hline API GRAVITY & -3.7 & -3.7 \\
\hline CARBON, WT.\% & 8537 & 24.72 \\
\hline HYDROGEN, WT.\% & 8.01 & 7.86 \\
\hline SULFUR, ppm & 10200 & 9340 \\
\hline NITROGEN, ppm & 14100 & 8500 \\
\hline OXYGEN, WT.\% & 4.03 & 5.48 \\
\hline ASH, WT.\% & 0.16 & 0.16 \\
\hline 97SF + RESID. VOL.\% & 18 & 123 \\
\hline \multicolumn{3}{|l|}{ LC-FINATE LIGHT OIL PRODUCT PROPERTIES } \\
\hline API ORAVITY & 28.2 & 24.8 \\
\hline CARBON, WT.\% & 87.82 & $\mathbf{4 . 3 3}$ \\
\hline HYDROGEN, WT.\% & 1205 & 11.52 \\
\hline SULFUR, ppm & 195 & 167 \\
\hline NITROGEN, ppm & 1118 & 1253 \\
\hline STSF + RESID, VOL.\% & 23 & 31 \\
\hline \multicolumn{3}{|l|}{ LC-FINATE HEAVY OIL PRODUCT PROPERTIES } \\
\hline API GRAVITY & 11.6 & 10.3 \\
\hline CARBON, WT.\% & 89.32 & 89.39 \\
\hline HYDROOEN, WT.\% & 1024 & 9.99 \\
\hline SULFUR. ppm & 126 & 22 \\
\hline NITROGEN, ppm & 312 & 3106 \\
\hline OXYGEN, WT.\% (DIFF.) & 0.11 & 0.29 \\
\hline ASH, WT.\% & 0.02 & 0.02 \\
\hline S75F + RESID, VOL.\% & 28.8 & 93.9 \\
\hline 975F + RESID, VOL.\% & 9.0 & 9.8 \\
\hline \multicolumn{3}{|l|}{ PRODUCT YIELDS, WT.\% PEED } \\
\hline OPPGAS HZS & 1.07 & 099 \\
\hline OPFGAS $\mathrm{NH} 3+\mathrm{H} 2 \mathrm{O}$ & 5.89 & 6.83 \\
\hline OFFGAS C1 & 0.69 & 0.86 \\
\hline OFFGAS C2 & 0.66 & 0.82 \\
\hline OFFGAS C3 & 0.70 & 0.86 \\
\hline OFFGAS C4 & 1.06 & 205 \\
\hline OFFGAS CS+ & 0.81 & 1.00 \\
\hline LIGHT OlL & 29.68 & 49.26 \\
\hline HEAVY OIL & 6230 & 41.02 \\
\hline TOTAL & 103.46 & 103.67 \\
\hline H2 CONSUMPTION, SCP/BBL & 2700 & 2800 \\
\hline DENITROGENATION, WT.\% & 84 & 78 \\
\hline DESULFURIZATION, WT.\% & 98 & 98 \\
\hline VOL.9 S75 DEG.F + CONVERSION & 30 & 38 \\
\hline VOL..\% 975 DEG. F + CONVERSION & 65 & 64 \\
\hline
\end{tabular}


attributable to the use of the spent catalyst. The LC-Finate product characteristics did indicate that the catalytic activity was less than that of run $6 L C F-11$ based on the HDS and HDN removal efficiencies. However, thermal conversion activity was greater as indicated by the $575 \mathrm{~F}+$ conversion. Chemical hydrogen consumptions were approximately equivalent for both tests (2700-2800 scfb).

At the end of run 6LCF-14, the composited heavy oil fraction containing unconverted $975 \mathrm{~F}+$ COALITB was processed in the Equilibrium Flash Vaporization unit to remove the vac resid material. The entire 110 gallons of IBP-900F distillate, which contains HEDF precursor components as well as the vacuum gas oil (VGO) fractions, was composited and drummed for subsequent processing in the pilot plant fixed-bed hydrotreating unit for deep denitrogenation.

\subsection{Fixed-Bed Hydrodenitrogenation Oparations}

The LC-Fining pilot plant unit was modified to be able to operate in the two-stage, downfiow fixed-bed mode of hydroprocessing. The SHELL $324 M$ catalysts from the LC-Fining campaign were removed and replaced with AKzo Chemicals KF-843 NiMo catalyst designed for deep denitrogenation removal. Deep denitrogenation is required to protect the downstream zeolite-based VGO hydrocracking catalysts from poisoning by basic nitrogen compounds.

A total of 4000 cc of KF-843 catalyst was charged to each of the two fixed-bed reactors. The catalysts were calcined in situ at $750 \mathrm{~F}$ for two hours followed by presulfiding with a $2 \% \mathrm{H}_{2} \mathrm{~S} / \mathrm{H}_{2}$ gas mixture. After the presulfiding operations following the vendor's procedure, the unit was successfully pressure tested at 2500 psig.

The conditions selected for the HON campaign were based on the screening test results of Subtask 3.2. These consisted of 2000 psig operating pressure, $785 \mathrm{~F}$ average bed temperature, 2.0 LHSV per each of the two reactors and 3400 scfb treat gas rate. The latter treat gas rate had to be reduced from the previously used $6000 \mathrm{scfb}$ because at the higher space velocity, the absolute flow rate limitations of the unit. Treat gas rate has been specified at a considerable excess over stoichiometry and it was not. deemed detrimental to operate at the 3400 scfb rate. In both cases, hydrogen partial pressures are high and close to that of the system operating pressure. Table 7.3-1 summarizes the operating conditions and results.

The nitrogen content of the full-range hydrodenitrogenated VGO product was $31 \mathrm{ppm}$ vs $2185 \mathrm{ppm}$ for the feed representing an HDN rate of about $98.6 \%$. Sulfur content was reduced from $295 \mathrm{ppm}$ to $1 \mathrm{ppm}$. At the $785 \mathrm{~F}$ bed temperatures, there was a modest conversion of $575 \mathrm{~F}+$ equivalent to 23 wt\% with a corresponding chemical hydrogen consumption rate of 600 scfb. This hydrocracking achieved over the HDN catalyst represents a reduction in the severity of hydrocracking required in the downstream selective hydrocracking step for conversion of additional VGO components to HEDF precursors. 
TABLE 7.3-1

RUN 6LCF-15 PRODUCTION RUN

FIXED BED HYDRODENITROGENATIO N OF 900F-COALITE-DERIVED LC-FINATE

\begin{tabular}{|c|c|}
\hline JER & $6 \mathrm{LCF}-15$ \\
\hline DATE & $1 / 17$ \\
\hline TOTAL PRESSURE, PSIG & 2000 \\
\hline LHSV PER BED, 1/HOURS & 2.03 \\
\hline 1st STAGE AVG. BED TEMP., DEG. F & 781 \\
\hline 2nd STAGE AVG. BED TEMP., DEG. F & 788 \\
\hline AKZO KF-843 CATALYST AGE, & 0.179 \\
\hline WO-STAGE WDSV, BBL/LB/DAY & 0.076 \\
\hline TREAT GAS (H2), SCF/BBL & 3400 \\
\hline ARBON BALANCE, WT.\% RECOVERY & 99 \\
\hline BAL., WT.\% & 98 \\
\hline
\end{tabular}

FEED PROPERTIES:

$\begin{array}{lr}\text { API GRAVITY } & 19.2 \\ \text { CARBON, WT.\% } & 88.55 \\ \text { HYDROGEN, WT.\% } & 11.06 \\ \text { SULFUR, ppm } & 295 \\ \text { NITROGEN, ppm } & 2185 \\ \text { OXYGEN, WT.\% (BY DIFFERENCE) } & 0.14\end{array}$

FULL-RANGE HDN PRODUCT PROPERTIES:

API GRAVITY

24.0

CARBON, WT.\%

88.37

HYDROGEN, WT.\%

11.63

SULFUR, ppm

NITROGEN, ppm

PRODUCT YIELDS, WT.\% FEED

OFFGAS H2S 0.03

OFFGAS NH3 + $\mathrm{H} 2 \mathrm{O} \quad 0.42$

OFFGAS C1 0.44

OFFGAS C2 0.44

OFFGAS C3 $\quad 0.37$

OFFGAS C4 FEED 0.47

OFFGAS C5 $+\quad \quad---\quad 1.27$

$\begin{array}{lll}\text { IBP-275 DEG. F } & 2.8 & 2.83\end{array}$

275-575 DEG. F $\quad 41.7 \quad 52.13$

575 DEG. F $+\quad 55.5 \quad 42.48$

$\begin{array}{lrr}\text { TOTAL } & 100.00 & 100.88\end{array}$

HYDROGEN CONSUMPTION, SCF/BBL $\quad 600$

575 DEG F + CONVERSION, WT.\% 23

HYDRODENITROGENATION, \% REMOV 99

HYDRODESULFURIZATION, \% REMOV 100 
The net recovery of hydrotreated product at the completion of the HDN step was 118 gallons (approximately half of which was in the HEDF precursor boiling range). This material serves as the feedstock supply to the subsequent selective hydrocracking operations.

\subsection{Fixed-Bed Selective Hydrocracking Operations}

The same reactor configuration as that used for the hydrodenitrogenation campaign was used for the selective hydrocracking operations. The objective of this campaign is to maximize the selective hydrocracking of $575 \mathrm{Ft}$ in the hydrodenitrogenated VGO material to high energy density, jet range components. During the Subtask 3.2 screening studies, three catalysts were evaluated and a proprietary zeolitic-based catalyst (manufactured by Zeolyst Enterprises, a joint venture of $P Q$ Corporation, Shell Polymers and Catalysts Enterprises), was selected as the preferred candidate on the basis of its simultaneous hydrocracking-hydrotreating performance. Thus, an additional hydrotreating step to saturate hydrocracked aromatics is avoided.

A total of $4000 \mathrm{CC}$ of $Z-704 \mathrm{~A}$ catalyst was charged to each reactor. The unit was then successfully pressure tested at 1500 psig. The catalyst was dried in situ at 550F for 2 hours followed by reduction with hydrogen at $500 \mathrm{psig}$ and $750 \mathrm{~F}$ for 8 hours. Two operating severities were employed to allow production of two samples of HEDF test fuels.

The low severity condition was carried out at 500 psig hydrogen pressure, 1.16 LHSV per catalyst bed, 525F average bed temperature and treat gas rate of $5700 \mathrm{scfb}$. The high severity condition was carried out at 1000 psig hydrogen pressure and 650F average bed temperature. When excessive light ends make was observed, the bed temperatures were reduced to an average of 550F. Table 7.4-1 summarizes the operating conditions and results for both selective hydrocracking campaigns.

Performance as measured by extent of HDN, 575F+ conversion and chemical hydrogen consumption rates was approximately equal. The major differences in the full-range hydrocracked products were the API Gravities and elemental hydrogen contents. While these differed only by a couple of API degrees and two-tenths of a percent hydrogen contents, respectively, these latter parameters can have significant effects on volumetric energy density and JFTOT stability.

\subsection{Post-Hydrotreatment Operations}

The products from each campaign of the selective hydrocracking operations were fractionated in the pilot plant 4-in Batch Fractionation Unit as runs FBD-16 and FBD-17, respectively. The batch fractionation was operated to collect multiple narrow boiling fractions in the vicinity of the key cut points, namely, 280F representing the front end volatility affecting the HEDF flash point specification, and 550F representing the back end volatility affecting the viscosity and freeze point specifications. 
TABLE 7.4-1

RUN 6LCF-16 PRODUCTION RUN

PIXED BED SELECTIVE HYDROCRACKING

OF HYDRODENITROGENATED LC-FINATE GAS

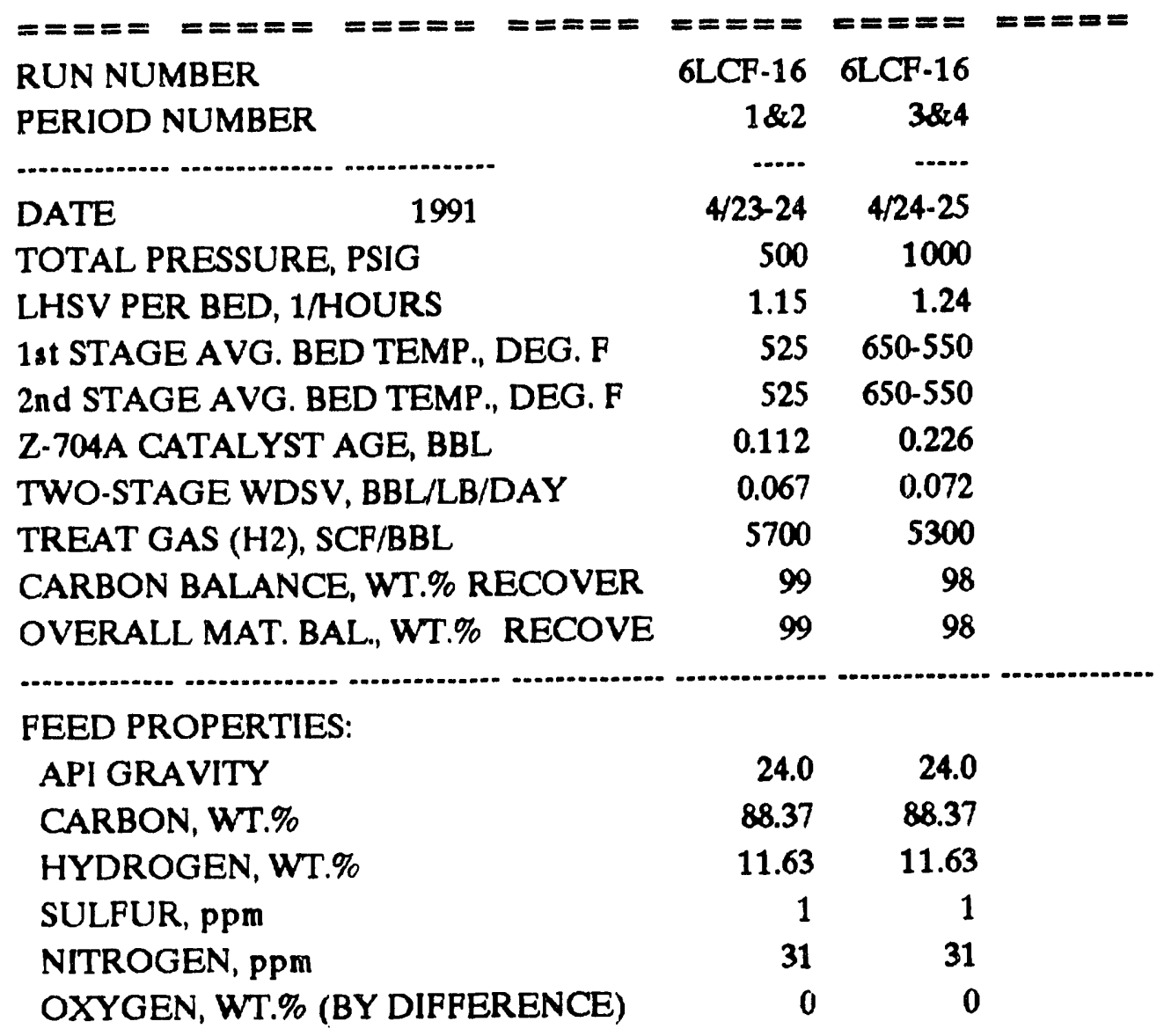

FULL-RANGE HYDROCRACKATE PRODUCT PROPERTIES:

\begin{tabular}{|c|c|c|c|}
\hline \multirow{2}{*}{\multicolumn{2}{|c|}{$\begin{array}{l}\text { API GRAVITY } \\
\text { CARBON, WT.\% }\end{array}$}} & 36.3 & 38.5 \\
\hline & & 86.45 & 86.28 \\
\hline \multicolumn{2}{|l|}{ HYDROGEN, WT.\% } & 13.55 & 13.72 \\
\hline \multicolumn{2}{|l|}{ SULFUR, ppm } & $<1$ & $<1$ \\
\hline \multicolumn{2}{|l|}{ NITROGEN, ppm } & $<1$ & $<1$ \\
\hline \multicolumn{4}{|c|}{ PRODUCT YIELDS, WT.\% FEED } \\
\hline OFFGAS H2S & & 0.00 & 0.00 \\
\hline OFFGAS NH3 + $\mathrm{H} 2 \mathrm{O}$ & & 0.00 & 0.00 \\
\hline OFFGAS C1 & & 0.68 & 0.63 \\
\hline OFFGAS C2 & & 0.68 & 0.62 \\
\hline OFFGAS C3 & & 0.58 & 0.53 \\
\hline OFFGAS C4 & FEED & 0.73 & 0.67 \\
\hline OFFGAS C5+ & -... & 1.96 & 1.80 \\
\hline IBP-275 DEG. F & 2.9 & 12.82 & 19.49 \\
\hline 275-575 DEG. F & 53.5 & 73.30 & 68.10 \\
\hline 575 DEG. F + & 43.6 & 11.74 & 10.83 \\
\hline TOTAL & 100.00 & 102.49 & 102.66 \\
\hline
\end{tabular}

HYDROGEN CONSUMPTION, SCF/BBL $\quad 1500 \quad 1600$ 575 DEG F+ CONVERSION, WT.\% $\quad 73 \quad 75$ HYDRODENITROGENATION, \% REM $\quad 100 \quad 100$ HYARODFSIILFIIRIZATION \% REMO $273.100 \quad 100$ 
The batch distillations were each carried out in two discrete operations: an atmospheric distillation from the initial boiling point up to $450 \mathrm{~F}$ distillate temperature followed by a $100 \mathrm{~mm} \mathrm{Hg}$ vacuum distillation up to $610 \mathrm{~F}$ atmospheric equivalent distillate temperature. Table 7.5-1 presents the summary of the distillate fractions and corresponding yields. As expected, the product from the low severity hydrocracking operation contained the highest yield of 610F+ (unconverted) material.

The distillate cuts from each batch fractionation run were blended in proportion to their overall batch fractionation yields to generate small samples for analytical testing of flash point, freeze point and energy density. As shown in Table 7.5-2, the heart cut HEDF blend (280-550F) met the flash point specification. Subsequent aliquot blends were made by adding the narrow boiling cuts above the 550F point and checking freeze point. Volumetric energy density increases with end point while freeze point also increases. The hydrogen content however decreases which is directionally adverse to good JFTOT stability. Because of the large sample quantity and cost of the JFTOT test, only selected blends were subjected to JFTOT testing.

Based on these results, it was decided that the preferred HEDF boiling range is 280-580F for both the low severity and high severity hydrocrackates. The full quantity distillate ble ids having the 280-580F boiling range were made from all the materials fractionated in the four-in batch fractionation unit.

Clay treating is a process aimed at removing trace polar compounds that could have an adverse effect on fuel stability. It is practiced commercially in refineries for petroleum-based aviation turbine fuels. Many types of clays can be used and we selected bentonite for this program. A total of $4500 \mathrm{cc}$ of bentonite clay was charged to the pilot plant clay treating column.

Both the low severity and high severity materials were treated by clay treating. The conditions selected for the pilot plant clay treating unit were based on some laboratory screening studies of clay treating using a small diameter glass column. These conditions consisted of operation at ambient temperature, 4 psig pressure with a liquid percolation rate of $1.3 \mathrm{gph}$ equivalent to a bentonite space velocity of $1.2 \mathrm{gal} / \mathrm{hr} / \mathrm{gal}$. The results of the batch-continuous clay treating operations are presented in Table 7.5-3. The loss of material of about $1 \%$ was primary a result of liquid holdup in the packed bed as well as physical adsorption of polar compounds in the HEDF test fuel. In a true continuous process, the holdup component, which represents the bulk of the apparent loss of material, would be a very small fraction of the total liquid processed.

\subsection{HEDF Assays}

The bentonite-treated HEDF products were stored in clean 30-galion drums with about 25-gal of each sample type (low severity hydrocracking and high severity hydrocracking) available for delivery to DOE-METC and/or its contractors. Representative samples were taken for assay. The results are summarized in Table 7.6-1. 


\section{TABLE $7.5-1$}

BATCH DISTILLATION OF

HYDROTREATED COALTTE PRODUCTS FROM

SELECTIVE HYDROCRACKING RUN GLCF-16

\begin{tabular}{|c|c|c|}
\hline BATCH DIST. RUN \# & FBD-16 & FBD-17 \\
\hline HYDROCRACKING RUN \# & 6LCF-16 & GLCF-16 \\
\hline HYDROCRACKING SEVERTYY & "LOW" & "HIGH" \\
\hline AVG. HYDROCRACKING BED TEMP, DEG. F & 550 & $650-550$ \\
\hline HYDROCRACKING PRESSURE, PSIG & 500 & 1000 \\
\hline TWO-STAGE HYDROCR SKING LHSV, HR-1 & 0.5 & 0.7 \\
\hline
\end{tabular}

DISTILLATION YIELDS, $W T$. \% ON FEED

IBP-260 DEG F (CUT \#1)

260-270 DEG F (CUT *2)

270-280 DEG F (CUT \#3)

280-290 DEG F (CUT \#4)

290-300 DEG F (CUT \#5)

300-310 DEG F (CUT \#6)

310- 150 DEG F (CUT \#7)

450-550 DEG F (CUT \#8)

550-560 DEG F (CUT \#9)

560-570 DEG F (CUT \#10)

570-580 DEG F (CUT \#11)

580-590 DEG F (CUT \#12)

600-610 DEG F (CUT \#14)

610 DEG F + BTMS. (CUT \#15)
590-600 DEG F (CUT \#13)

6.1

1.2

1.0

0.8

1.0

1.0

25.0

27.9

2.9

1.6

1.7

2.1

1.9

2.1

23.7

TOTAL

100.0
12.0

1.5

1.4

1.3

1.7

1.3

31.5

27.2

1.4

1.2

0.9

3.2

0.7

2.0

12.7

100.0

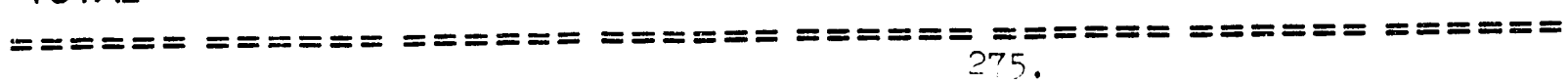


TABLE 7.5-2

OPTIMUM BLENDING STUDY OF

FINISHED COALTE JET FUEL CUTS

FROM FBD-16 \& FBD-17

\begin{tabular}{|c|c|c|c|c|c|c|}
\hline $\begin{array}{l}=========== \\
\text { HEDF BOILING RANGE }\end{array}$ & $\begin{array}{c}==== \\
\text { FLASH } \\
\text { POINT } \\
\text { DEG. F }\end{array}$ & $\begin{array}{c}===== \\
\text { FREEZE } \\
\text { POINT } \\
\text { DEG. F }\end{array}$ & $\begin{array}{c}===== \\
\text { GRAVITY } \\
\text { @60/60 } \\
\mathrm{gm} / \mathrm{cc}\end{array}$ & $\begin{array}{c}===== \\
\text { CARBON } \\
\text { WT. } \%\end{array}$ & $\begin{array}{c}====== \\
\text { HYDROGE } \\
\text { WT. } \%\end{array}$ & $\begin{array}{l}===== \\
\text { ENERGY } \\
\text { DENSTYY } \\
\text { BTU/Gal }\end{array}$ \\
\hline \multicolumn{7}{|c|}{ FBD-16:LOW SEVERITY HYDROCRACKATES } \\
\hline $280-550 \mathrm{~F}$ & 130 & $<-85$ & 0.8565 & 86.29 & 13.37 & 131,460 \\
\hline $280-560 \mathrm{~F}$ & - & $<-85$ & 0.8581 & 86.25 & 13.35 & 131,962 \\
\hline $280-570 \mathrm{~F}$ & - & $<-85$ & 0.8591 & 86.57 & 13.36 & 131,766 \\
\hline $280-580 \mathrm{~F}$ & - & -76 & 0.8602 & 86.20 & 13.30 & 132,140 \\
\hline $280-590 \mathrm{~F}$ & - & -72 & 0.8607 & 86.31 & 13.29 & 132,036 \\
\hline $280-600 \mathrm{~F}$ & - & -67 & 0.8623 & 86.36 & 13.23 & 132,525 \\
\hline $280-610 \mathrm{~F}$ & - & -63 & 0.8633 & 86.26 & 13.18 & 132,523 \\
\hline 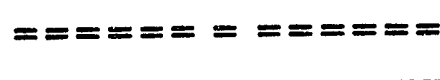 & $===\quad=$ & $=====$ & $=====$ & $=====$ & $====\mathbf{=}$ & $====0$ \\
\hline \multicolumn{7}{|c|}{ FBD-17: HIGH SEVERITY HYDROCRACKATES } \\
\hline $280-550 \mathrm{~F}$ & 125 & $<-85$ & 0.8473 & 86.24 & 13.55 & 127,677 \\
\hline $280-560 \mathrm{~F}$ & - & $<-85$ & 0.8473 & 85.83 & 13.49 & 130,350 \\
\hline $280-570 \mathrm{~F}$ & - & -85 & 0.8488 & 86.22 & 13.51 & 130,625 \\
\hline $280-580 \mathrm{~F}$ & - & -72 & 0.8493 & 86.25 & 13.51 & 130,858 \\
\hline $280-590 \mathrm{~F}$ & - & -63 & 0.8514 & 85.95 & 13.51 & 131,011 \\
\hline $280-600 \mathrm{~F}$ & - & -58 & 0.8514 & 85.87 & 13.53 & 130,927 \\
\hline $280-610 \mathrm{~F}$ & - & -49 & 0.8524 & 86.00 & 13.45 & 130,863 \\
\hline
\end{tabular}


TABLE 7.5-3

BENTONITE CLAY TREATING

OF HEDF FUEL BLENDS

TEST FUEL DESIGNATION

FBD-16

FBD-17

COLUMN I.D., In.

23

2.3

COLUMN SURFACE AREA, in2

4.15

4.15

COLUMN SURFACE AREA, It2

0.029

0.029

BENTONITE CLAY :

VOLUME, CC

4500

4000

VOLUME, gal

1.19

1.06

WEIGHT, IbS. START

8.28

7.31

WEIGHT, Ibs. END

10.47

10.77

PICKUP WEIGHT, IbS.

2.19

3.46

TREATMENT PRESSURE, psIg

PACKED BED FLOW DIRECTION

4

DOWN

DOWN

FEED RATE, GPH

1.33

1.30

FEED RATE, Ib/hr

9.53

9.45

LHSV, 1/HR

1.12

1.23

FEED IN, lbs.

207.50

208.00

PRODUCT OUT, Ibs.

205.21

205.50

APPARENT LOSS, Ibs*

2.29

250

APPARENT \% LOSS*

1.1

1.2

* Apparent Loss Consists of Liquid Holdup in Interstices of Clay Bed Plus Adsorbed Trace Polar Compounds 
FNAL CONUTE HEDF TEST FUEL PAOPERTES*

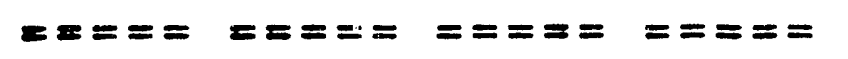

DESIGNATION FBD-16

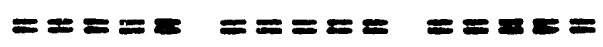

ELEMENTALS, WT.*

CARBON

MMOROCEN

F.I.A. VOL\%

AROMATICS

OLEFWS

SATURATES

FLASH PONT, DEG. F

FREE IE PONNT, DEQ. F

ANUNE PONT, DEG. C

SMOKE PONT, mm

uscosiry,cot@-4F

COPPER CORROSION, @212F

POTENTIL GUM, mg/100 ml

DZ274 ACCEL STORACE STABUTY

(@95e, 16 Hr, 02), mo/100 ml

THEPMAL STABIUTY (JFTOT-D3241)

TUBE DEPOSIT VSUAL RATWO(TDR) TUBE DEPOSIT RATING MUX SPUN RATI DFFERENTLL PRESSURE $M A X, m m$ Ho

ENERGY DENEITY, BTU/GNLLN
86.63

1.2

0.3

98.5

130

$<-76$

60.8

25

7.0

34

$<1$

$<1$
$<1$

$<1$

83.69

13.41

0.4

0.7

82.8

125

$<-76$

64.4

25

7.5

IA

- WITHOUT ANTIOXDANTS, ANTIDEICNG AGENTS, METAL DEACTMATORS 
The volumetric energy densities for the two samples were 130,506 $\mathrm{Btu} / \mathrm{gal}$ for the high severity hydrocracking route and 131,740 for the low severity route, both meeting the original Work Statement energy density target of $130,000 \mathrm{Btu} / \mathrm{Gal} \mathrm{min}$. Subsequent to the original Statement of Work, DOE set a new technical goal of achieving an energy density target of $135,000 \mathrm{Btu} / \mathrm{gal}$. As shown previously, energy densities for the low severity hydrocracking sample increased with distillate end point to a high value of $132,523 \mathrm{Btu} / \mathrm{gal} 0610 \mathrm{~F}$ end point vs the $580 \mathrm{~F}$ value for the test fuel sample. Even higher values can be achieved depending upon hydroprocessing reaction conditions. During the Subtask 3.2 screening program, four tests were made in bench-scale equipment and energy densities as high as 133,992 Btu/gal were achieved).

Although the highest volumetric energy density is desired, there are two other criteria to consider. The first is a function of economics and the resultant tradeoffs between the additional cost of the incrementa? energy density improvement vs the value of the higher density fuel to the end user. The other criteria concerns the storage stability and thermal stability of the fuel for use in high speed aircraft. One analytical device for assessing stability performance is the Standard Test Method for Thermal Oxidation Stability of Aviation Turbine Fuels (JFTOT Procedure, ASTM D3241-85). JFTOT subjects the test fuel to conditions that are relatable to those occurring in gas turbine engine fuel systems. The fuel is pumped at a fixed volumetric flow rate through a heater after which it enters a precision stainless steel filter where fuel degradation products become trapped. The essential data derived are the amount of deposits on an aluminum heater tube and the rate of plugging of a 17 micron nominal porosity filter located just downstream of the heater tube. This test has long been used by petroleum refiners to meet process specifications for shipment of aviation fuel products to the end users, namely, the commercial airline industry and the U.S. Air Force. With the advent of new aircraft engines and new fuel compositions, the JFTOT test is not always an accurate gauge for assessing on-board fuel stability performance. The Air Force is continually improving technology for on-ground determination of thermal stability of aviation turbine fuels. With regard to the new fuel type, High Energy Density (Category I) fuel, it is not known how applicable the JFTOT test will be for assessing thermal stability.

In any event, JFTOT testing (as well as Potential Gum and Acceierated Storage Stability) was used to assess fuel stability. Directionally, increasing fuel end point to increase specific gravity and volumetric energy density is inversely proportional to stability. The JFTOT stability criterion, Maximum Heater Tube Deposit/Visual Rating (TDR), was 0 for both the high severity and the low severity hydrocracking routes, both meeting the spec for conventional JP-3 turbine fuel. The specs for the JFTOT stability criterion of Change in Pressure Drop were not met. However, the specs for both Accelerated Storage Stability and Potential Gum were met.

In view of the JFTOT pressure drop results, aliquots of the test fuel samples were rerun through the laboratory clay treating column and the 
resultant samples were analyzed for JFTOT. These samples passed both the TDR criterion and the pressure drop criterion. It was concluded that there were some trace polar compounds in the HEDF test fuels that were not removed in the pilot plant clay treating unit as a result of a hydrodynamic bypassing of material in the column. Probably optimization of the liquid contacting efficiency in the pilot plant clay treating unit, such as by operating at higher Reyrolds Numbers or by recycling material through multiple passes, would result in the clay-treated material passing both JFTOT criteria. Unfortunately, the 50 gallons of test fuel could not be scheduled to be rerun.

The finished HEDf test fuels after the clay treating operations were dosed with the following additives while in storage awaiting shipment to DOE-METC:

- BHT (anti-oxidant)

$24 \mathrm{mg} / \mathrm{L}$

- DCI-4A (DuPont corrosion inhibitor)

$20 \mathrm{mg} / \mathrm{L}$ 


\subsection{SUMMARY OF REFINERY UPGRADING ECONOMIC ASSESSMENT (Task 4)}

\subsection{Basis of LP Model}

Several processes for treating raw COALITE liquid, or some substituent boiling fractions thereof, were experimentally tested in the initial Task 3 campaigns. These processes were selected because of their potential ability to change some of the properties of the feed stream towards those required of the finished HEDF products. The desired properties for HEDF are discussed in the Task 3 (4) and Task 4 (5) topical reports and are summarized in Table 8.1-1. The selected processes performed generally as expected in the Task 3 studies. However, no one process was able to provide all the properties needed for the production of HEDF. For instance, hydrotreating reduced aromatics and heteroatom levels, but also reduced energy density. To meet all the specifications for HEDF, it was expected that several processing steps would need to be combined. This may have involved combining processes in ways that could not have been either predicted at the start of this program or studied experimentally in the limited time available.

A linear program (LP) model was built which incorporated the most promising test periods from the experimental program in Task 3 . In addition, there were a number of other conventional hydrocarbon processes that might also move stream properties towards the specifications for HEDF. These were also included in the linear program model. Table 8.1-2 lists all the process alternatives incorporated in the model developed for this study. Sometimes, each process alternative included more than one process condition. For example, the hydrotreating alternatives included several reactor severities. When process data were not available from the Task 3 program, process performance and costs were estimated from correlations based on either literature studies with coal-based stocks or AOC's in-house experience with petroleum-based stocks. An example of a process option that was included in the L.P model but could not be studied in Task 3 is the recycle of hydrocracker bottoms product to the extinction of that stream. Investigators are continuing to find other ways to produce high quality liquid products from coal-derived liquids.

The linear program model was able to combine any or all of these process alternatives and to blend various streams from these alternatives to make finished products, preferably HEDF. When the streams could not be used to make HEDF, they were allowed to be blended into some conventional co-products. Sales of these co-products could help subsidize the cost of HEDF production and make sure the plant did not produce any waste streams that might be an environmental disposal problem. Table 8.1-3 lists the co-products that were included in the LP model for this study. The L.P model included technology to blend process streams to meet the product specifications for all the products listed in Table 8.1-3. Proprietary AOC technology was used to describe properties, such as viscosity and flash point, that do not blend linearly. Typical ASTM specifications were used for the 
TABLE 8.1-1

HEDF SPECIFICATIONS USED

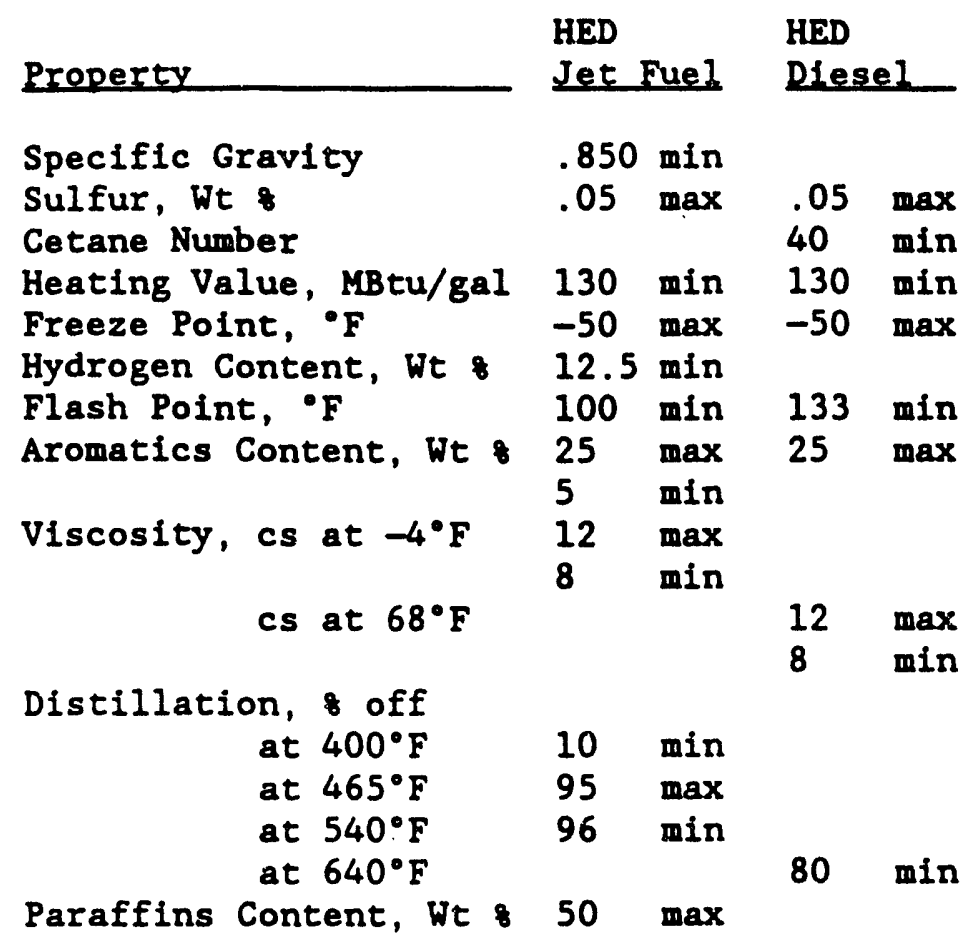


TABLE 8.1-2

PROCESS ALTERNATIVES INCLUDED

\author{
Alkylation \\ Aromatics Recovery \\ Catalytic Cracking \\ Coking \\ Diolefin Saturation \\ Distillate Extraction \\ Distillation \\ Dynaphen \\ Ebullated Bed Hydrotreating (LC-Fining) \\ Fixed Bed Naphtha Hydrotreating \\ Fixed Bed Distillate Hydrotreating \\ Fixed Bed Gas 011 Hydrotreating \\ Hydrocracking \\ Hydrogen Production (Steam Reforming) \\ Hydrogen Purification (PSA) \\ Isomerization \\ Naphtha Reforming for Aromatics \\ Naphtha Sweetening \\ Polygasoline Production \\ Sulfur Production \\ Utilities Generation
}


TABLE: $8.1-3$

FEEDSTOCK COST/CO-PRODUCT PRISE BASES

\begin{tabular}{|c|c|c|c|}
\hline Stock & Price & Volume & Unit \\
\hline $\begin{array}{l}\text { Natural gas } \\
\text { LPG/ Propane } \\
\text { Mixed/ n-Butanes } \\
\text { Isobutane } \\
\text { Coalite/ HS Crude } \\
\text { Toluene }\end{array}$ & $\begin{array}{r}12.61 \\
7.60 \\
11.76 \\
19.11 \\
18.00 \\
38.00\end{array}$ & $10 \mathrm{M}, 40 \mathrm{M}$ & $\begin{array}{l}\text { FOE Barrel } \\
\text { Barrel } \\
\text { Barrel } \\
\text { Barrel } \\
\text { Barrel } \\
\text { Barrel }\end{array}$ \\
\hline $\begin{array}{l}\text { Unleaded Regular } \\
\text { Unleaded Premium } \\
\text { Unleaded Mid-Grade } \\
\text { Hydtrt Sweet Naphtha } \\
\text { Reformer Feed } \\
\text { Naphtha Jet Fuel(JP-4) } \\
\text { Jet Fuel(JP-8)/Kerosene } \\
\text { HED Jet Fuel } \\
\text { HED Diesel } \\
\text { Diesel Fuel } \\
\text { Furnace Oil/ No. } 2 \\
\text { Coke } \\
\text { Sulfur }\end{array}$ & $\begin{array}{l}23.35 \\
26.29 \\
24.61 \\
25.40 \\
24.61 \\
24.20 \\
21.84 \\
21.84 \\
21.84 \\
21.60 \\
21.00 \\
16.00 \\
63.00\end{array}$ & $\begin{array}{l}4 \mathrm{M}, 16 \mathrm{M}, \max \\
4 \mathrm{M}, 16 \mathrm{M}, \max \end{array}$ & $\begin{array}{l}\text { Barrel } \\
\text { Barrel } \\
\text { Barrel } \\
\text { Barrel } \\
\text { Barrel } \\
\text { Barrel } \\
\text { Barrel } \\
\text { Barre1 } \\
\text { Barrel } \\
\text { Barrel } \\
\text { Barrel } \\
\text { Ton } \\
\text { Ton }\end{array}$ \\
\hline $\begin{array}{l}\text { Fuel } \\
\text { Cooling Water } \\
\text { Power } \\
\text { Steam- High Pressure } \\
\text { Steam- Medium Pressure } \\
\text { Steam- Low Pressure }\end{array}$ & $\begin{array}{l}2.00 \\
0.20 \\
0.05 \\
5.00 \\
4.40 \\
4.25\end{array}$ & & $\begin{array}{l}\text { MM Btu } \\
\text { M gal } \\
\text { KWH } \\
\text { M pound } \\
\mathbf{M} \text { pound } \\
\text { M pound }\end{array}$ \\
\hline
\end{tabular}

Note: $M$ - thousand 
conventional fungible coproducts and are not repeated here. Two different high energy density fuels were targeted - one in the jet fuel boiling range (Category I) and the other in the diesel fuel boiling range (Category III). Category II endothermic HEDF fuel was not considered in this study. The specifications used in the LP model for these high energy density fuels which were developed in consultation with DOE, are shown in Table 8.1-1. These are expected to result in compatibility with current jet fuel engine hardware components and mission requirements.

Because it was not always possible to measure each of the qualities needed for these specifications with each stock in the experimental program (usually because of limited sample size), the needed quality rarameters were sometimes estimated from correlations with those properties that were measured. For example, Figure 8.1-1 shows how the hydrogen content and the heating value of the total liquid product (TLP) from hydrotreating 350-650F COALITE vary with hydrotreating reactor severity, while Figure $8.1-2$ shows how stream flash point varies with simulated distillation (SD) initial boiling point. Other correlations were used that were developed from the extensive Task 3 experimental data set.

The linear program model contained almost 600 balance constraints (rows) and over 1200 process, blending, and economics options (columns). Each of the cases and sensitivities reported later considered each of these large numbers of process alternatives.

Since it is not possible to produce HEDF without consuming some feedstocks and utilities or without producing some co-products, the economics require a pricing scenario for the feed, products, and utilities. Table 8.1-3 shows the price and volume bases used. For this study, it was assumed that the mild gasification coal liquids exemplified by COALITE, was available for about the same price as current crude oil, namely $\$ 18$ per barrel. A crude $0 i 1$ price of $\$ 30 / B b 1$ was studied later in a sensitivity case. The relative prices of the other feeds and products come from an average of $\mathrm{AOC}^{\prime} \mathrm{s}$ in-house historical data.

Another component of the economics requires return on the capital that is employed to build the necessary processing units. The capital investment costs for these units were scaled to represent the size of the units required in each case using a power law factor. The investment costs were then escalated to be equivalent to mid-1988 construction completion. The calculated investment requirement for a process plant included a prorated portion for typical utilities and OSBL support facilities. It was assumed that $65 \%$ of the capital was financed at an annual cost of $12 \%$, while the remaining $35 \%$ was financed internally at a required $15 \%$ annual DC.F rate of return. Other economic parameters include a generic U.S. Gulf Coast location, three year plant construction period, no investment tax credit, a 20 year project life, a $90 \%$ on-stream operating factor, and no net plant salvage value at the end of the project life. Using the ten-year plant depreciation schedule from the Tax Recovery Act of 1986 and a $38 \%$ tax 


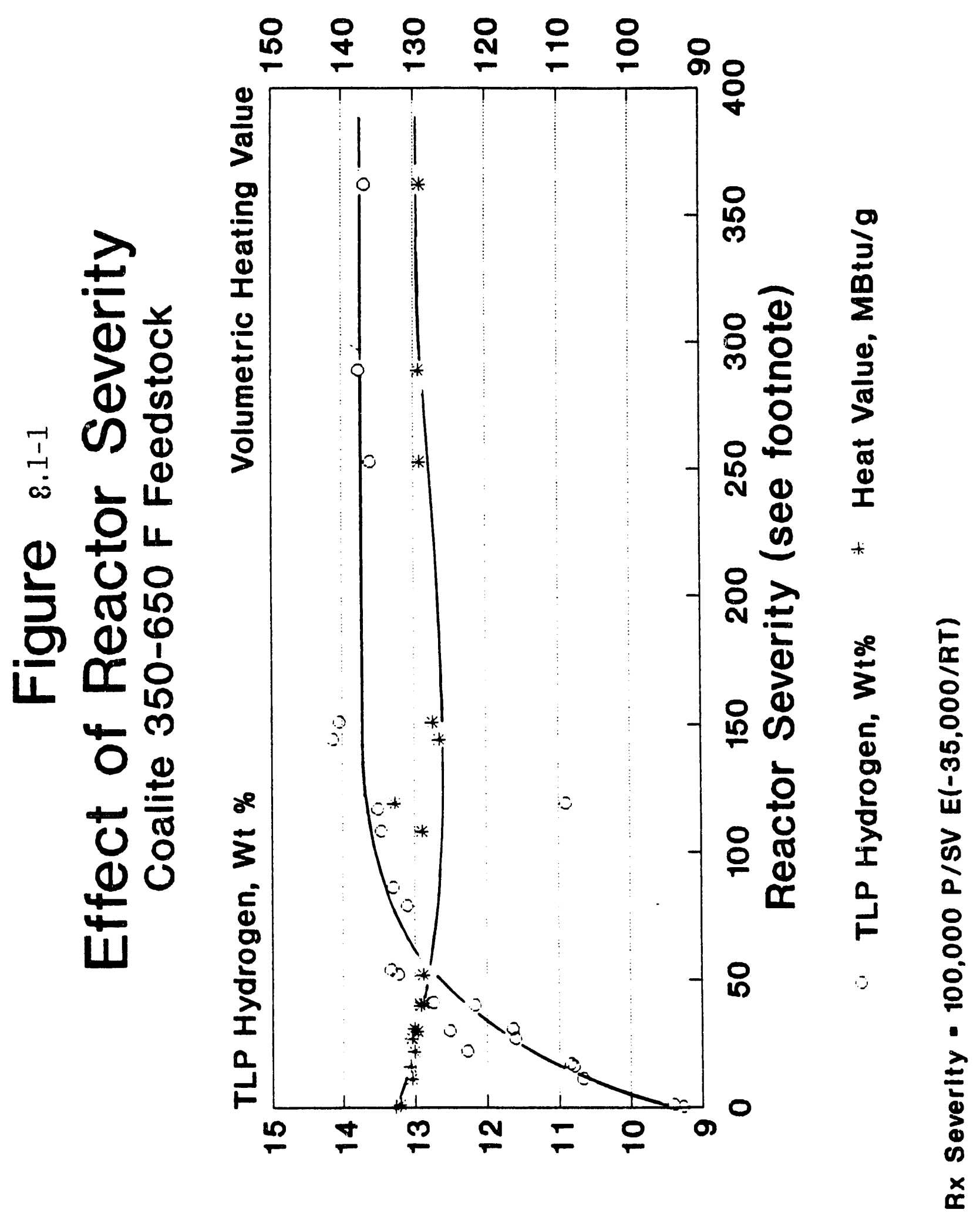




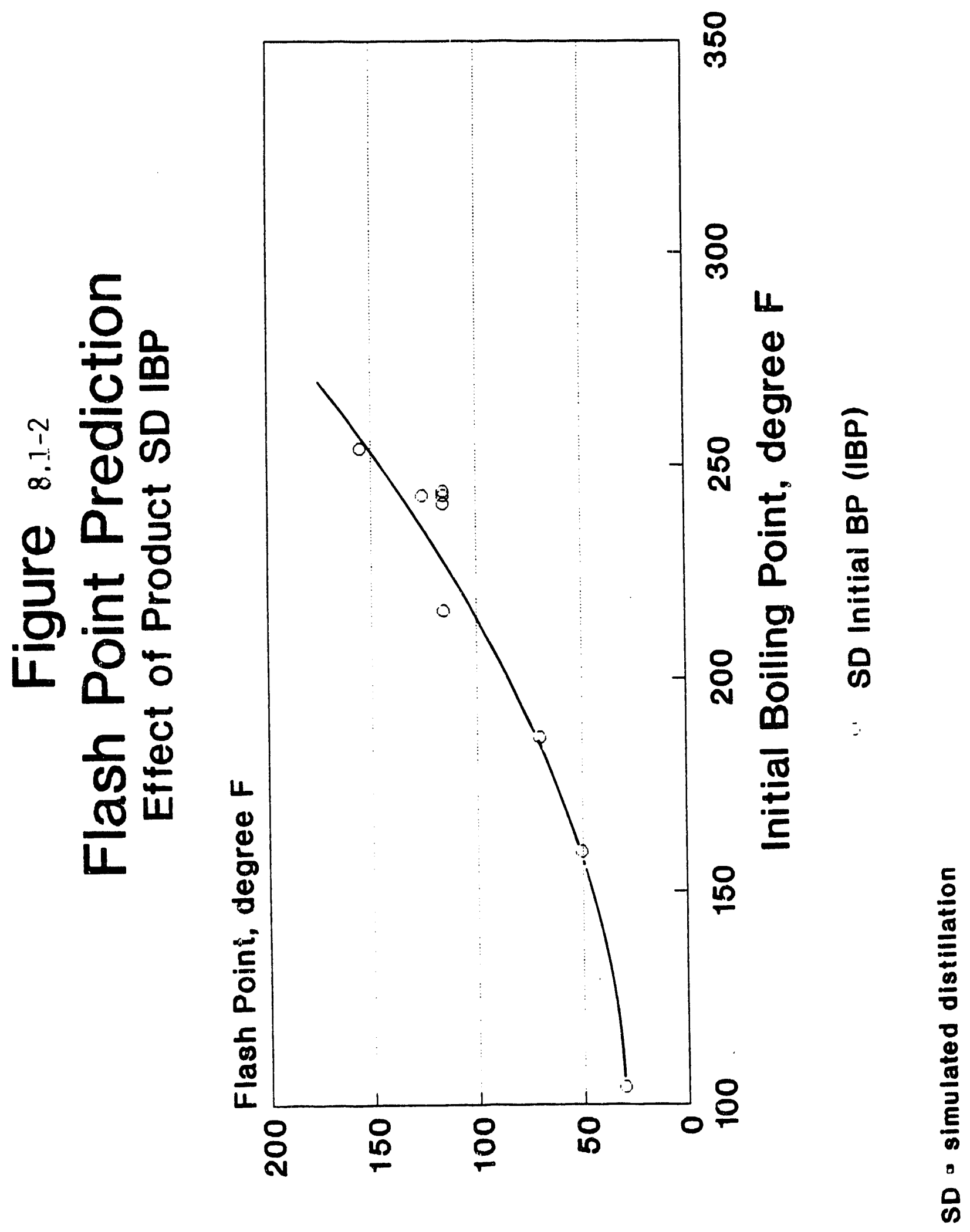


rate, a capital recovery factor of about $21 \%$ per year was found to represent these parameters. Another $4 \%$ per year was added to account for the cost of maintenance, local taxes, insurance, and overhead.

\subsection{Results of Linear Programming Model Study}

The LP model was not able to produce HEDF in the diesel boiling range from COALITE liquid when using the specifications listed in Table 8.1-1. There were indications that HEDF diesel could be produced if the viscosity specification was changed. However, the linear program computer modeling effort was halted due to budget limitations before additional studies could be done on this fuel target. However, HEDF jet fuel was produced in many case studies as discussed in the following section. A sensitivity case described below for waiving the HEDF jet fuel distillation specifications resulted in producing a heavier diesel-like HEDF fuel.

Several case studies were done on the LP model which produced various quantities of HEDF jet fuel from two alternative commercial feedrates, 40 MBCD (thousands of barrels per calendar day) and 10 MBCD. Interpolation and extrapolation of these cases can be used to project the economics at other feedrates. The case studies completed are disc ssed individually below. The first two cases are documented in detall to explaill the implementation of the bases used in the model. Only the important economic parameters are given for the other cases, since all the economic and process conclusions can be drawn from these values.

Figure 8.2-1 shows the liquid stream process units selected when the 1 inear program model produced the maximum amount of HEDF jet fuel from 40 MBCD of COALITE liquids. The processing system first fractionated the COALITE liquids at $300 \mathrm{~F}$ and at $650 \mathrm{~F}$ to produce three streams for optimum processing. The $0.8 \mathrm{MBCD}$ of raw 3CJF- naphtha was sweetened and had its diolefin content saturated to make it into an acceptable gasoline blending stock. This stock was sold as a co-product. The 20 MBCD of 300-65OF raw COALITE distillate was hydrotreated using fixed bed hydrotreating technology. Most of the product from this step wa: redistilled, al though $0.8 \mathrm{MBCD}$ was directly blended to HEDF. The $400 \mathrm{~F}$ minus naphtha from the redistillation was either blended to JP-4 jet fuel or sold as reformer charge stock. The $400-575 \mathrm{~F}$ distillate from the redistillation was blended to HEDF jet fuel. The $575 \mathrm{~F}+$ from redistillation was routed to hydrocracking.

The 19.2 MBCD of raw 650F+ COALITE was first hydrotreated using expanded-bed technology (LC-Fining). The naphtha from this step was blended to JP-4 jet fuel while the distillate was split between HEDF blending, redistillation, and further upgrading by hydrotreating in the fixed bed distillate hydrotreater, as shown in Figure 8.2-1. The $575 \mathrm{~F}+$ stream from the LC-Finer was hydrocracked along with the bottoms stream from the redistillation step. The naphtha produced in the hydrocracking step was blended to JP-4, while the distillate was split between direct blending to HEDF and redistillation. The recycle of the heavy stock to hydrocracking through redistillation resulted in extinction of this stream and in the sales of no products heavier than 


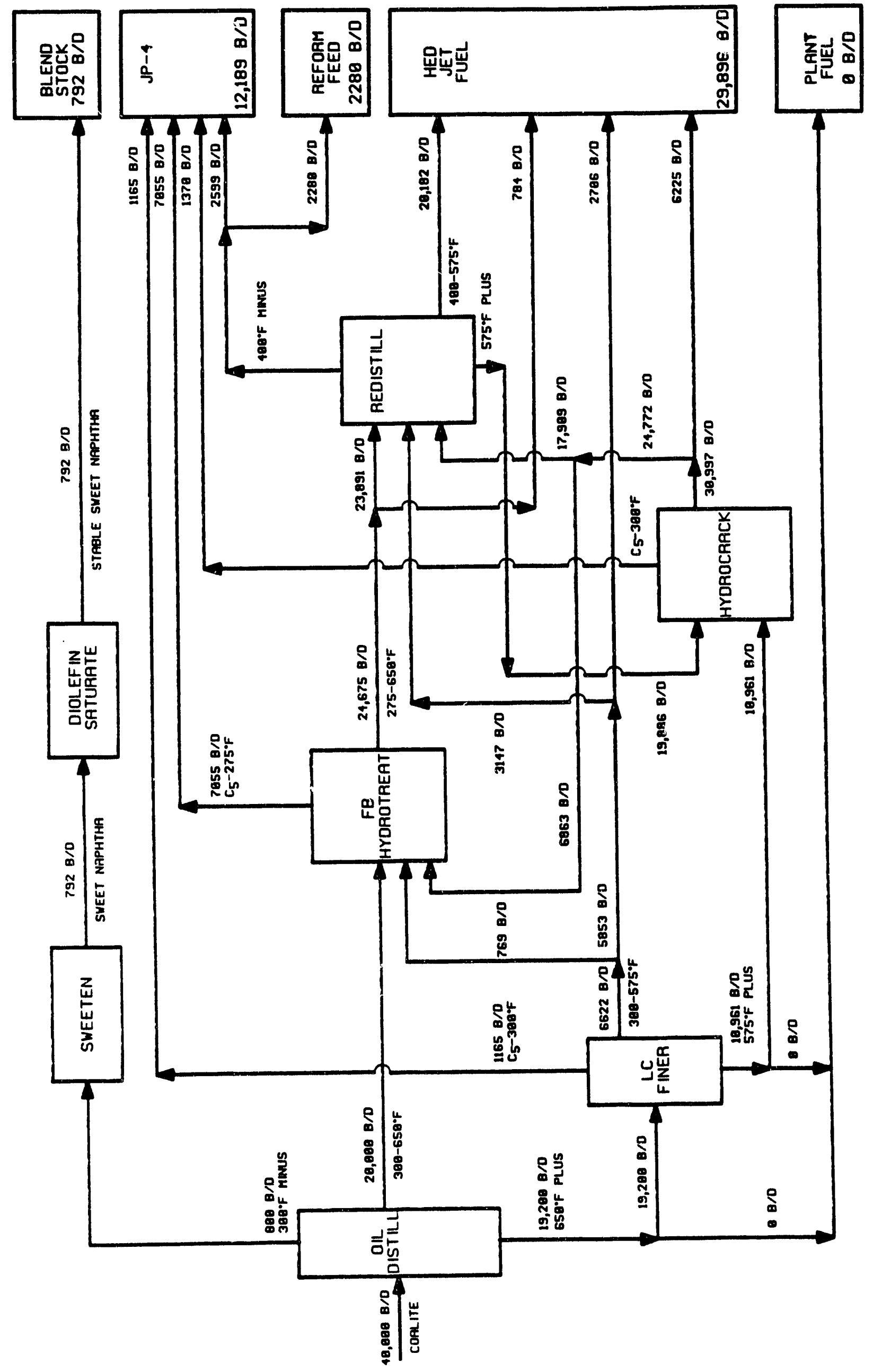

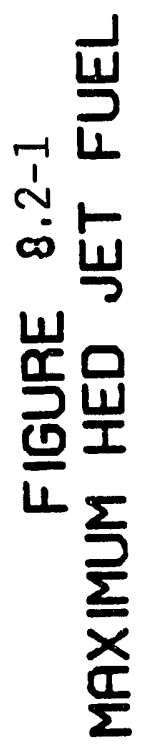


HEDF jet fuel. In total, almost 30 MBCD of HEDF jet fuel could be produced from 40 MBCD COALITE, for a $75 \%$ yield. Table $8.2-1$ gives the properties of the HEDF jet fuel produced in the maximum HEDF case column, and compares those properties with the specifications. The product slightly exceeded the desired minimum volumetric energy density. The limiting specifications were maximum aromatics content, minimum viscosity, and distillation endpoint.

Table 8.2-2 shows the process unit sizes that hac to be constructed for this case, along with the corresponding investment costs. The capital total of 439 MMS includes 12.7 MMS for initial catalyst fills and 46 MMS for allocated costs of utilities and OSBL.

Table 8.2-3 summarizes the economics for the maximum HEDF jet fuel case, as well as the volume of feed, product, and utilities required. The sum of raw material and utilities costs is about equal to the profit from sales of HEDF jet fuel and co-products. The added costs for fixed items and capital recovery leave a net cost (10ss) of 315 $M \$ / C D$. This is equivalent to a loss of $\$ 10.53$ per barrel of HEDF above its assumed $\$ 21.84$ selling price. Thus, the HEDF jet fuel must sell for about $\$ 32.37 / B$ in order to break-even with all the costs necessary for its production.

Because the maximum HEDF jet fuel processing scheme had so many branches and recycles, another case was investigated that produced about half of this maximum production of HEDF jet fuel. Figure 8.2-2 shows that the same process units are required but the processing scheme is indeed simpler, as many of the branches and recycles have zero flow rates. Much of the raw 650F+ COALITE liquid and the heavy LC-Finer bottoms is diverted to plant fuel needs instead of finished product sales. These high boiling streams are obviously the most expensive to convert to HEDF or any other salable product, although they provide somie of the desirable properties for HEDF. Table 8.2-1 shows that the 40\% HEDF yield jet fuel product is lower in specific gravity and volumetric heating value than the maximum HEDF product. The viscosity and distillation specifications are still limiting, but the aromatics content has been reduced to $12 \%$.

Although Figures 8.2-1 and 8.2-2 do not show by-product gas streams (because gases are treated as fuel gas utilities), the high production of liquid plant fuel in the $40 \%$ yield HEDF case allows the plant to sell some by-product gases for fuel. Thus this case is a net exporter rather than importer of fuel gas as indicated in Table 8.2-3.

Table 8.2-4 shows that the capital requirement has been reduced to 305 MMS, or about $70 \%$ of that of the maximum HEDF yield case requirement. Since it produces only about $55 \%$ of the amount of HEDF, the capital and fixed costs per barrel of HEDF are higher. Since the feed is the same amount of COALITE liquid, the cost of raw material per barrel of HEDF has also increased as indicated in Table 8.2-3. On the other hand, relatively more of the COALITE is sold as co-product and as by-product fuel, so these cost elements are more favorable than in the maximum HEDF yield case. Overall, the losses are reduced to $274 \mathrm{M} \$ / C D$, although the loss per barrel of HEDF is increased to $\$ 17.11$ per barrel. 
TABLE $8.2-1$

PRODUCT COMPARISON WITH SPECIFICATIONS

$40 \mathrm{MBCD} \$ 18 / \mathrm{B}$ Coalite

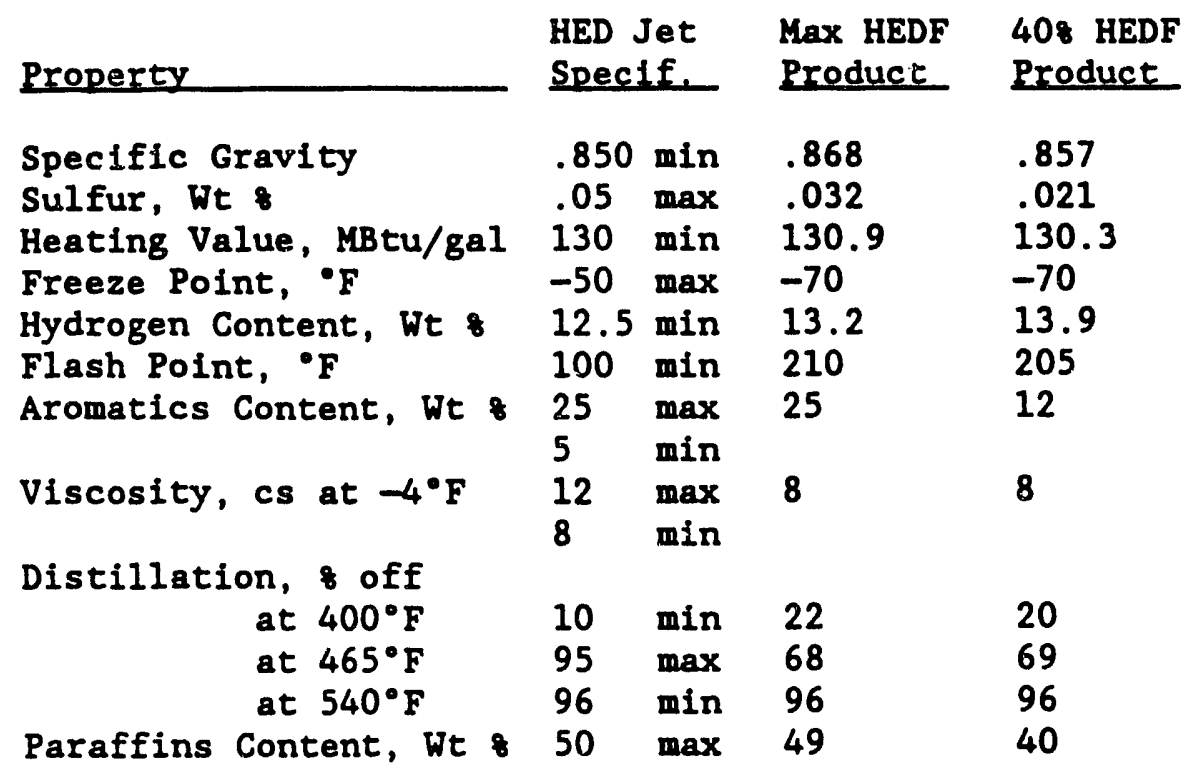


TABLE 8.2-2

INVESTMENT SUMMARY - MAXIMUM HEDF JET FUEL

40 MBCD $\$ 18 / B$ Coalite

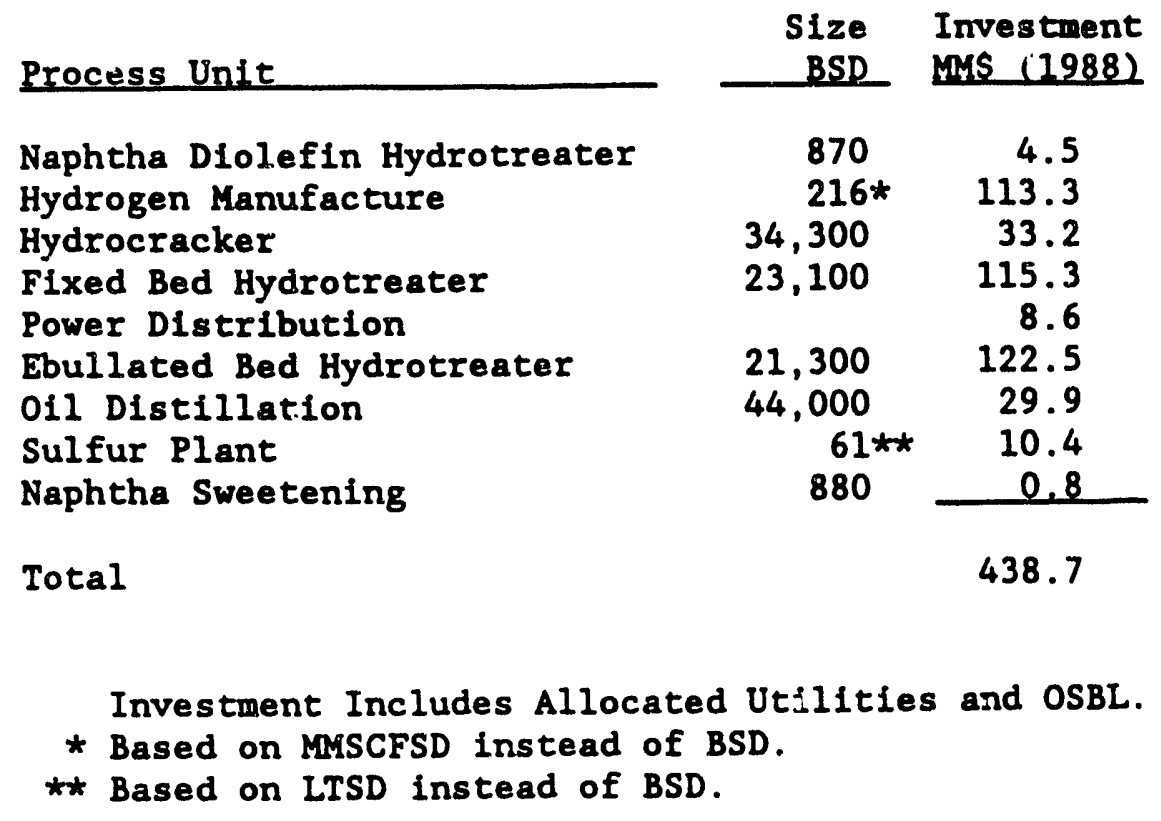


TABLE $8.2-3$

BASELINE CASES ECONOMIC BREAKDOWN SUMMARY

40 MBCD $\$ 18 / B$ Coalite

\begin{tabular}{|c|c|c|c|c|}
\hline \multirow[b]{2}{*}{ Cost Component } & \multicolumn{2}{|c|}{ Maximum HEDF Jet } & \multicolumn{2}{|c|}{ 408 Yield HEDF Jet } \\
\hline & $\begin{array}{l}\text { Costs, } \\
M S / C D\end{array}$ & $\begin{array}{l}\text { HEDF Cost } \\
\mathbf{S} / \mathrm{Bb} 1\end{array}$ & $\begin{array}{l}\text { Costs, } \\
\text { MS/CD }\end{array}$ & $\begin{array}{l}\text { HEDF Cost } \\
\mathrm{S} / \mathrm{Bbl}\end{array}$ \\
\hline $\begin{array}{l}\text { Raw Materials Cost } \\
\text { HEDF Sales } \\
\text { Co-Product Sales } \\
\text { Utilities } \\
\text { Fixed Costs } \\
\text { Capital Recovery }\end{array}$ & $\begin{array}{r}794.2 \\
-652.9 \\
-388.0 \\
250.8 \\
54.0 \\
256.6 \\
\end{array}$ & $\begin{array}{r}26.56 \\
-21.84 \\
-12.97 \\
8.39 \\
1.81 \\
8.58 \\
\end{array}$ & $\begin{array}{r}762.2 \\
-349.4 \\
-265.0 \\
-92.1 \\
39.4 \\
178.6 \\
\end{array}$ & $\begin{array}{r}47.64 \\
-21.83 \\
-16.56 \\
-5.76 \\
2.46 \\
11.16 \\
\end{array}$ \\
\hline Total Costs & 314.7 & 10.53 & 273.7 & 17.11 \\
\hline
\end{tabular}

Purchases

Coalite

Natural Gas

Catalyst \& Chemical

Cooling Water

Process Water

Power

Sales

HEDF Jet Fuel

Sweetened Naphtha

Reformer Feed

JP-4 Jet Fuel

Fuel Gas

Propane

Sulfur
Quantity Unit

$\begin{array}{rl}40.0 & \text { MBCD } \\ 12.4 & \text { MFOEBCD } \\ 72.2 & \text { MS/CD } \\ 105.7 & \mathrm{Mgal} / \mathrm{CD} \\ 3.7 & \mathrm{Mgal} / \mathrm{CD} \\ 50.9 & \mathrm{MW}\end{array}$

$\begin{aligned} 29.9 & \text { MBCD } \\ 0.8 & \text { MBCD } \\ 2.3 & \text { MBCD } \\ 12.2 & \text { MBCD } \\ 0 & \text { MFOEBCD } \\ 1.7 & \text { MBCD } \\ 58 . & \text { LTCD }\end{aligned}$

Quantity Unit

40.0 MBCD

0 MFOEBCD

$27.7 \mathrm{MS} / \mathrm{CD}$

$41.2 \mathrm{Mgal} / \mathrm{CD}$

$1.7 \mathrm{Mgal} / \mathrm{CD}$

$21.3 \mathrm{Mk}$

$16.0 \quad \mathrm{MBCD}$

0.8 MBCD

1.0 MBCD

8.9 MBCD

9.3 MFOEBCD

0.5 MBCD

31. LTCD 

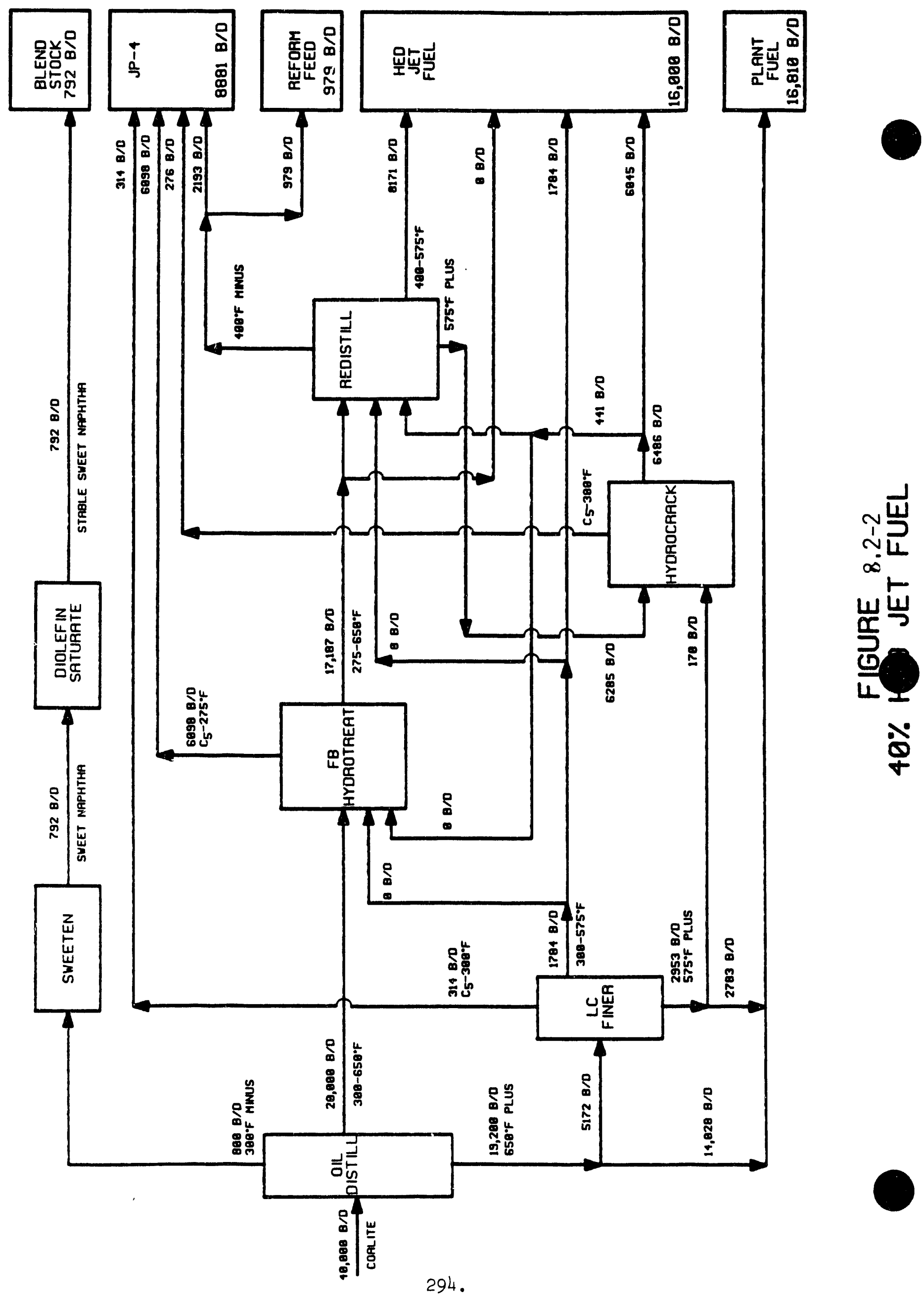


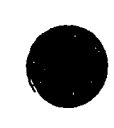

TABLE $8,2-4$

ECONOMIC SUMMARY

$\$ 18 /$ B Feedstock Price Basis

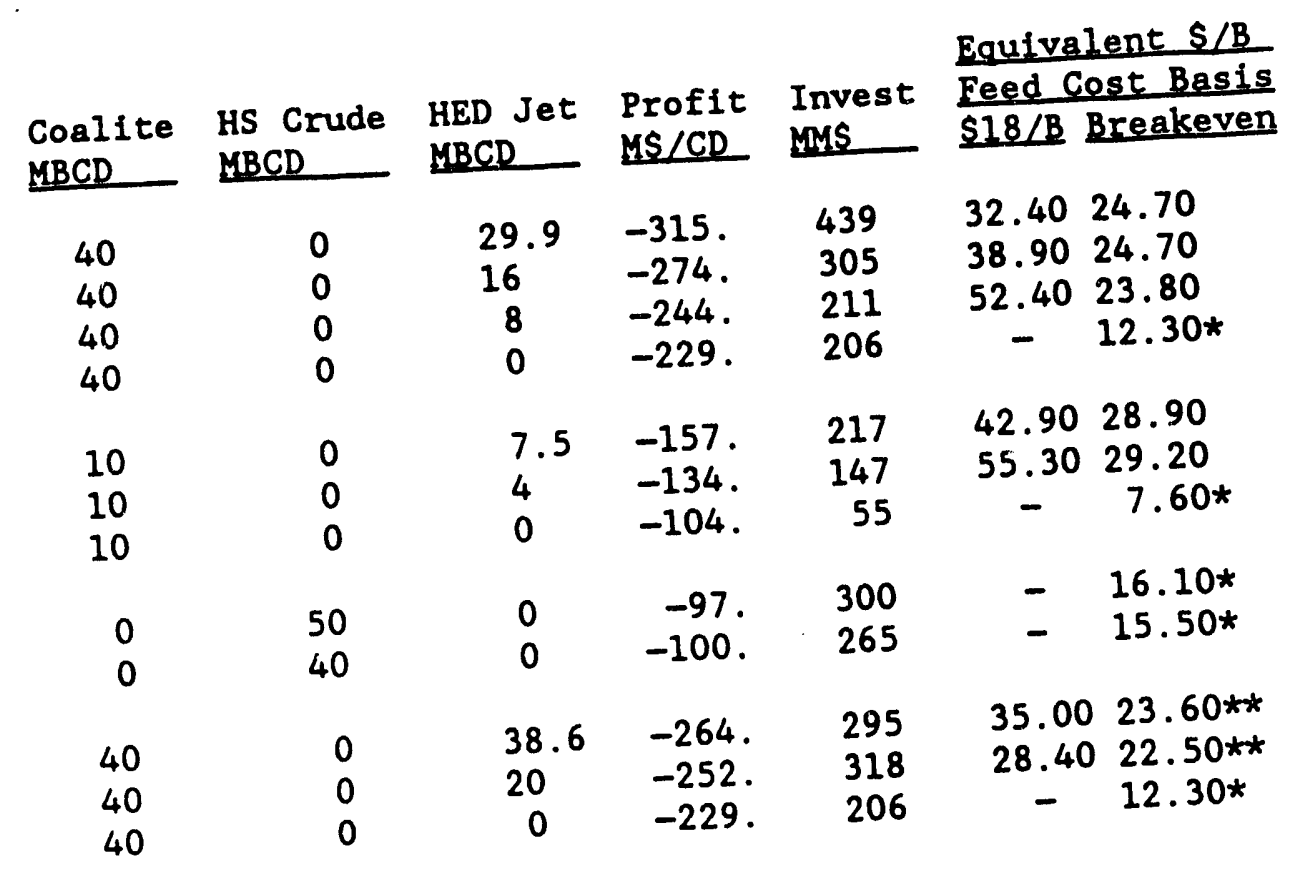

* Based on feed rather than jet fuel.
* All HEDF specs waived, see Figure 12 and Table IX. 
TABLE $8,2-4$

ECONOMIC SUMMARY

$\$ 18 /$ B Feedstock Price Basis

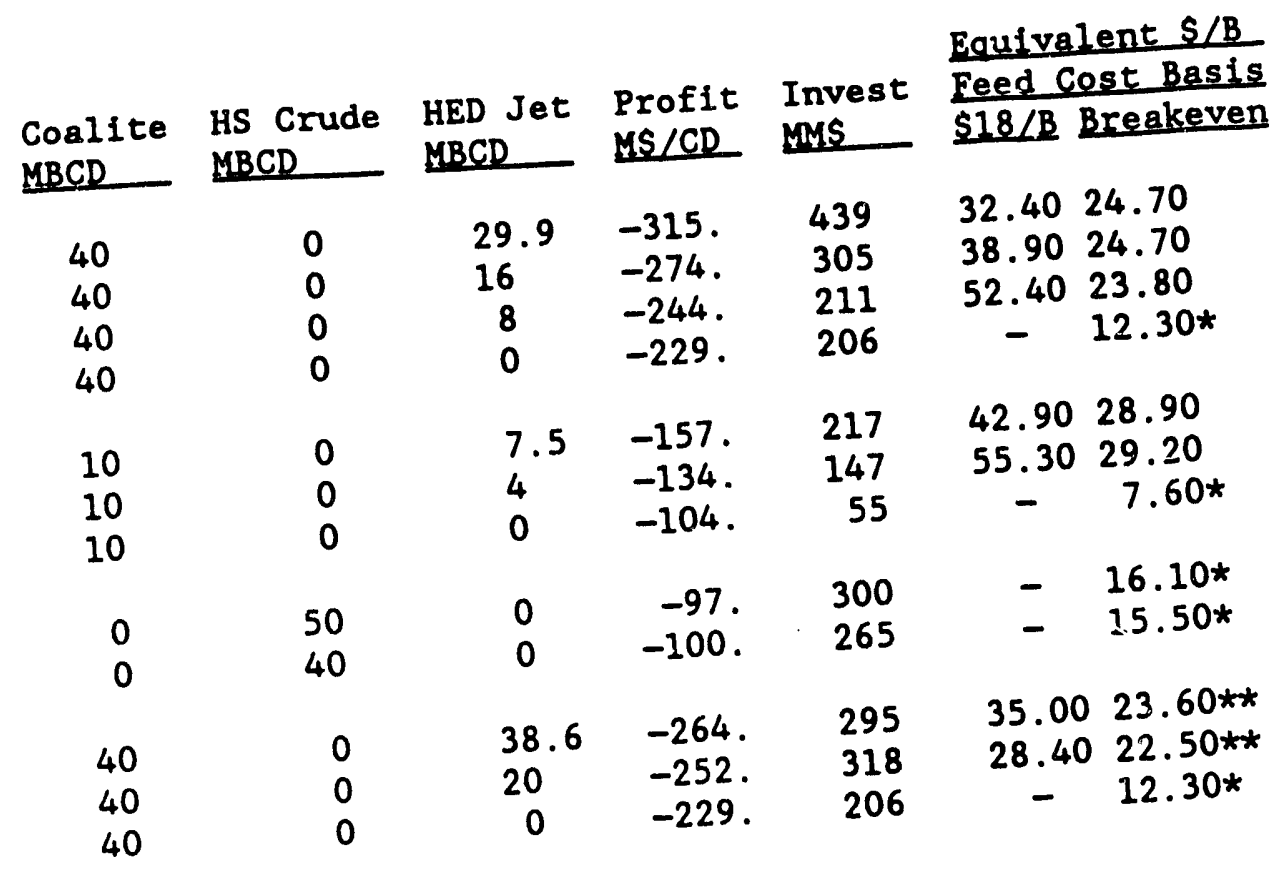

* Based on feed rather than jet fuel.
* All HEDF specs waived, see Figure 12 and Table IX. 
Table 8.2-4 summarizes the investment costs, net losses of cash flow (negative profit), and break-even HEDF costs when feeding 10 MBCD of COALITE instead of $40 \mathrm{MBCD}$. Similar processing routes were chosen as for the $40 \mathrm{MBCD}$ cases. but the economics are less favorable because of decreased economies of scale.

Table 8.2-4 and Figure 8.2-3 show the economics when no HEDF jet fuel is produced, and only co-products (chiefly JP-4 and normal diesel fuel) and by-products are sold. Obviously, the economic parameters per barrel of HEDF are undefined in these cases. Figure 8.2-3 shows that, in all cases studied, increased HEDF production for sale at $\$ 21.84$ per barrel results in lowered profits. The break-even cost calculations already discussed confirm that the cost of HEVF from CQALITE is higher than this current jet fuel price.

To provide an alternative way to evaluate these economics, the linear program model was run feeding petroleum crude oil and no COALITE, at rates of 40 and $50 \mathrm{MBCD}$, respectively. The LP model chose typical refinery process units and produced no HEDF. Table 8.2-4 and Figure 8.2-3 show the economics of these cases. The small refineries produced in these crude oil cases lost money, confirming the industry-wide lack of current and scheduled refinery construction plans. Since even crude oil processing loses money with the economic bases assumed here, the small economies of scale and pricing assumptions used in this study also bias the above HEDF cases. Another way to state this is that the above HEDF costs include the losses that any small grass-roots processing plant would incur, and are not related to the true inherent or incremental HEDF costs.

To look at the economics without these small plant inefficiency costs, we will price the feedstock at its break-even cost, and determine true product costs from that base point. The break-even costs per barrel of feedstock for these crude oil cases, and also the no HEDF cases, are shown in Table 8.2-4 and as the lower points in Figure 8.2-4. The difference between the crude oil and COALITE lines implies that COALITE liquid is worth only about \$3/B less than crude oil for making conventional products. This might be expected from the lower hydrogen and higher aromatics content of COALITE and its more severe refining processing requirements compared with crude 0 il.

If COALITE were priced at this break-even cost $(\$ 7.60 / \mathrm{B}$ at $10 \mathrm{MBCD}$ and $\$ 12.30 / B$ \& $40 \mathrm{MBCD})$, we get a different picture of the incremental cost of producing HEDF. The costs for the $40 \%$ HEDF yield case are shown in Table 8.2-4 under the break-even feedstock cost column and as the center points in Figure 8.2-4. These HEDF costs are in the mid- to high- twenty dollar per barrel range, and are not that far from the current jet fuel price $(\$ 21.84 / B)$. Table 8:3-1shows that the trends in the $\$ / B$ costs for the maximum HEDF yield cases are very similar to the $40 \%$ HEDF yield cases. Thus, if processing units were available that could process COALITE to conventional products, the incremental costs for making high energy density analogs would not be very much higher. 

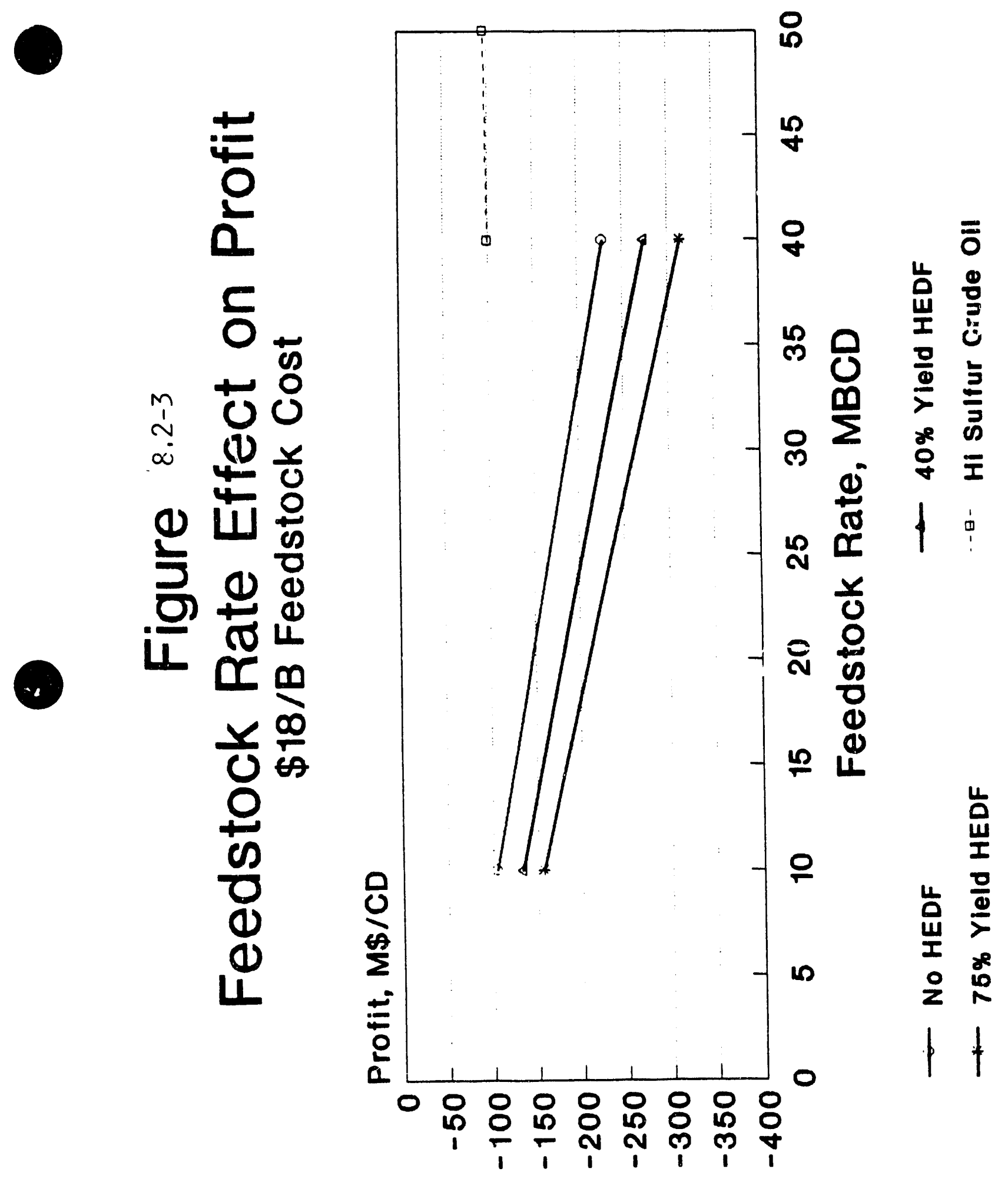


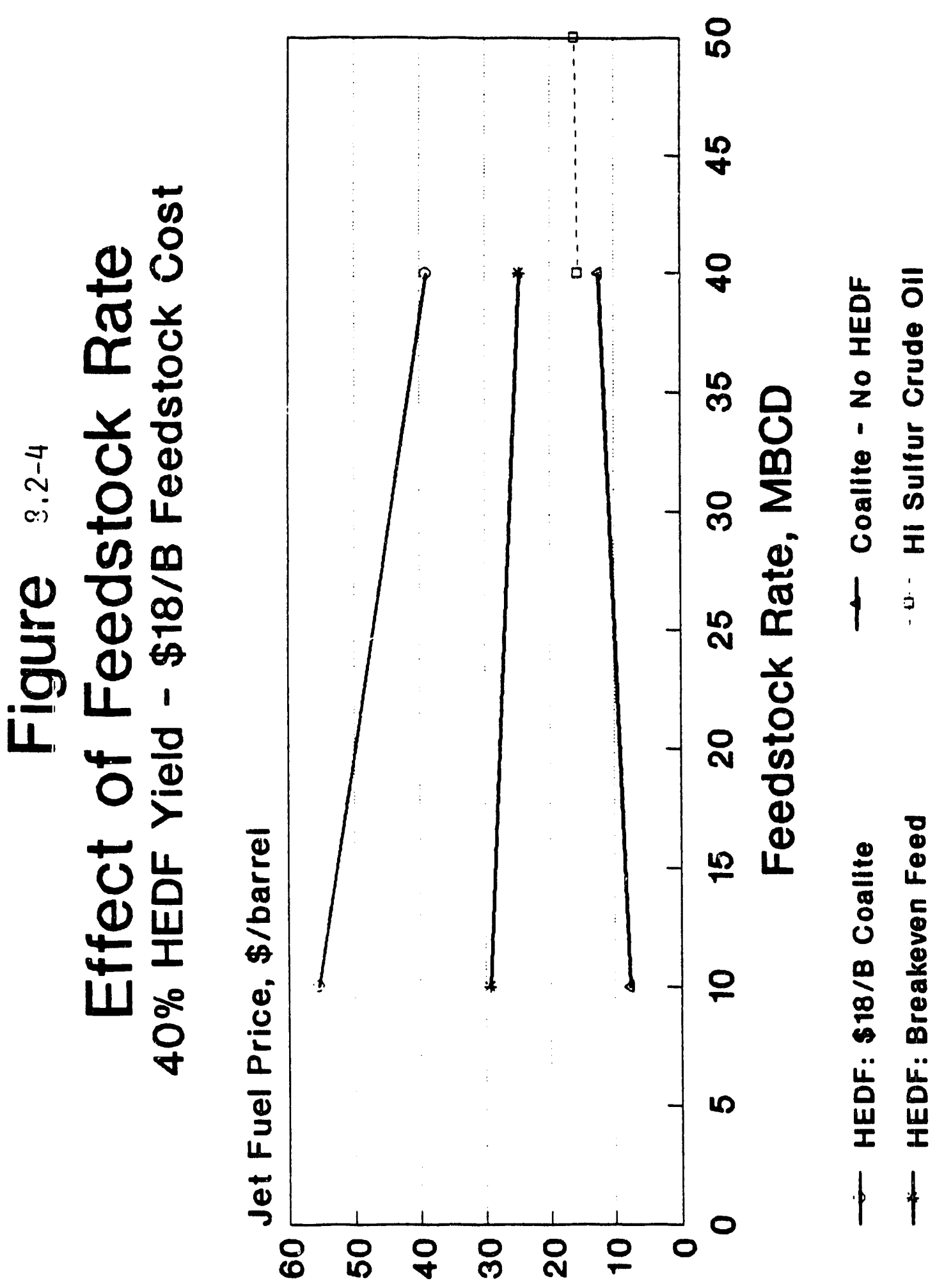




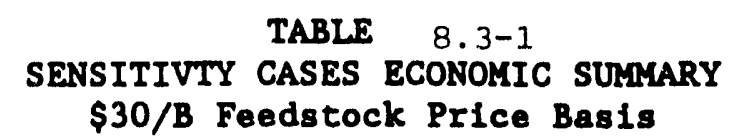

\begin{tabular}{|c|c|c|c|c|c|c|}
\hline $\begin{array}{l}\text { Coalite } \\
\text { MBCD }\end{array}$ & $\begin{array}{l}\text { HS Crude } \\
\text { MBCD }\end{array}$ & $\begin{array}{l}\text { HED Jet } \\
\text { MBCD }\end{array}$ & $\begin{array}{l}\text { Profit } \\
M S / C D\end{array}$ & $\begin{array}{l}\text { Invest } \\
\text { MS }\end{array}$ & $\frac{\text { Equivg }}{\text { Eeed } C}$ & $\frac{\text { alent } S / B}{\text { Cost Basis }}$ \\
\hline $\begin{array}{l}40 \\
40 \\
40 \\
40\end{array}$ & $\begin{array}{l}0 \\
0 \\
0 \\
0\end{array}$ & $\begin{array}{c}30.0 \\
16.0 \\
13.1 \\
0\end{array}$ & $\begin{array}{l}-216 \\
-173 \\
-195 \\
-196\end{array}$ & $\begin{array}{l}443 \\
420 \\
387 \\
398\end{array}$ & $\begin{array}{l}43.60 \\
47.20 \\
51.20 \\
-\end{array}$ & $\begin{array}{l}37.10 \\
35.00 \\
36.30 \\
25.10 *\end{array}$ \\
\hline $\begin{array}{l}10 \\
10 \\
10\end{array}$ & $\begin{array}{l}0 \\
0 \\
0\end{array}$ & $\begin{array}{l}7.5 \\
4.0 \\
0\end{array}$ & $\begin{array}{l}-130 \\
-122 \\
-111\end{array}$ & $\begin{array}{l}217 \\
150 \\
120\end{array}$ & $\begin{array}{c}53.80 \\
66.80 \\
-\end{array}$ & $\begin{array}{l}39.00 \\
39.00 \\
11.10 \star\end{array}$ \\
\hline 0 & 40 & 0 & 7. & 310 & - & $30.20 *$ \\
\hline $\begin{array}{l}40 \\
40\end{array}$ & $\begin{array}{l}0 \\
0\end{array}$ & $\begin{array}{c}22.3 \\
0\end{array}$ & $\begin{array}{l}-326 \\
-196\end{array}$ & $\begin{array}{l}499 \\
398\end{array}$ & $\begin{array}{c}51.10 \\
-\end{array}$ & $\begin{array}{l}42.30 \star \star \\
25.10 \star\end{array}$ \\
\hline
\end{tabular}




\subsection{Economics Sensitivity Studies}

Since Table 8.2-1 shows that the HEDF jet fuels produced in the cases discussed above slightly exceeded the 130,000 Btu/gallon specification, a question might be asked of how high an energy density could be produced with the techno!ogies currently known as a result of this project. To answer that question, the energy density specification was incrementally increased and the volume and cost of the resultant HEDF was calculated. Figure 8.3-1 shows that the volume of HEDF that can be produced at $132,500 \mathrm{Btu} / \mathrm{gall}$ in is about half of the baseline volume. The fully loaded cost for this higher heating value product is about $\$ 6 / B$ higher with $\$ 18 / B$ feedstock costs, while the cost using the break-even feedstock cost is only about $\$ 3 / B$ higher. It was not possible to produce a HEDF with a heating value of 133,000 Btu/gallon using the current database generated from the Task 3 screening program. Figure 8.3-2 shows how these higher energy density costs compare to the current jet fuel cost as a function of feedstock price. Further $\$ 30 / B$ feedstock cost cases are discussed in the following sections.

Figure 8.3.3 shows the componential break down of HEDF dollar per barrel transfer costs for the \$18/B feedstock cost, 40 MBCD cases into component areas. Figure 8.3-3 shows that net raw material cost (feedstock minus by- and co-products) is the major cost component. Capital costs account for about a quarter of the total HEDF costs. Hydrogen costs, taken as the sum of hydrogen plant capital, fixed, and operating costs, amount to just over $\$ 8 / B$, so 1 mprovements in the cnsts of hydrogen generation might leac to reductions in the cost of HEDF manufacture. Not much improvement could be expected from reduction of the fixed expense components since these represent a small fraction of the total HEDF costs. The net variable oferating costs for catalyst, chemicals, and utilities are the next smallest component over fixed expenses.

To provide a sensitivity to feedstock and product prices, the crude 0 il and COALITE price was increased to $\$ 30 / B$ from $\$ 18 / B$. The by-product, co-product, and utility prices in Table 8.1-3 were also increased by the same proportion. Since hydrogen is made from either natural gas or a fuel gas which is a byproduct of these feedstocks, the hydrogen cost will roughly escalate with these prices also. Capital related costs remained constant in these sensitivity studies.

Table 8.3-1 and Figure 8.3-4 show the economic trends for the cases with these higher feed and product prices. These data can be compared with Table 8.2-4 and Figure 8.2-3 that use the $\$ 18 / \mathrm{B}$ price basis. The LP model predicts a small profit for the crude $0 i 1$ only case. Table 8.3-1 shows that the profit for the 40 MBCD COALITE feedstock cases shows an optimum in the intermediate range of Jet fuel production, athough the overall profit for the plant is still in the negative range. This optimum is confirmed by a break-even cost in that range that falls below the $\$ 36.40 / \mathrm{B}$ base jet fuel price that is consistent with the $\$ 30 / B$ feedstock cost. Since it is known that the hydroprocessing routes selected by the LP are capital intensive, 


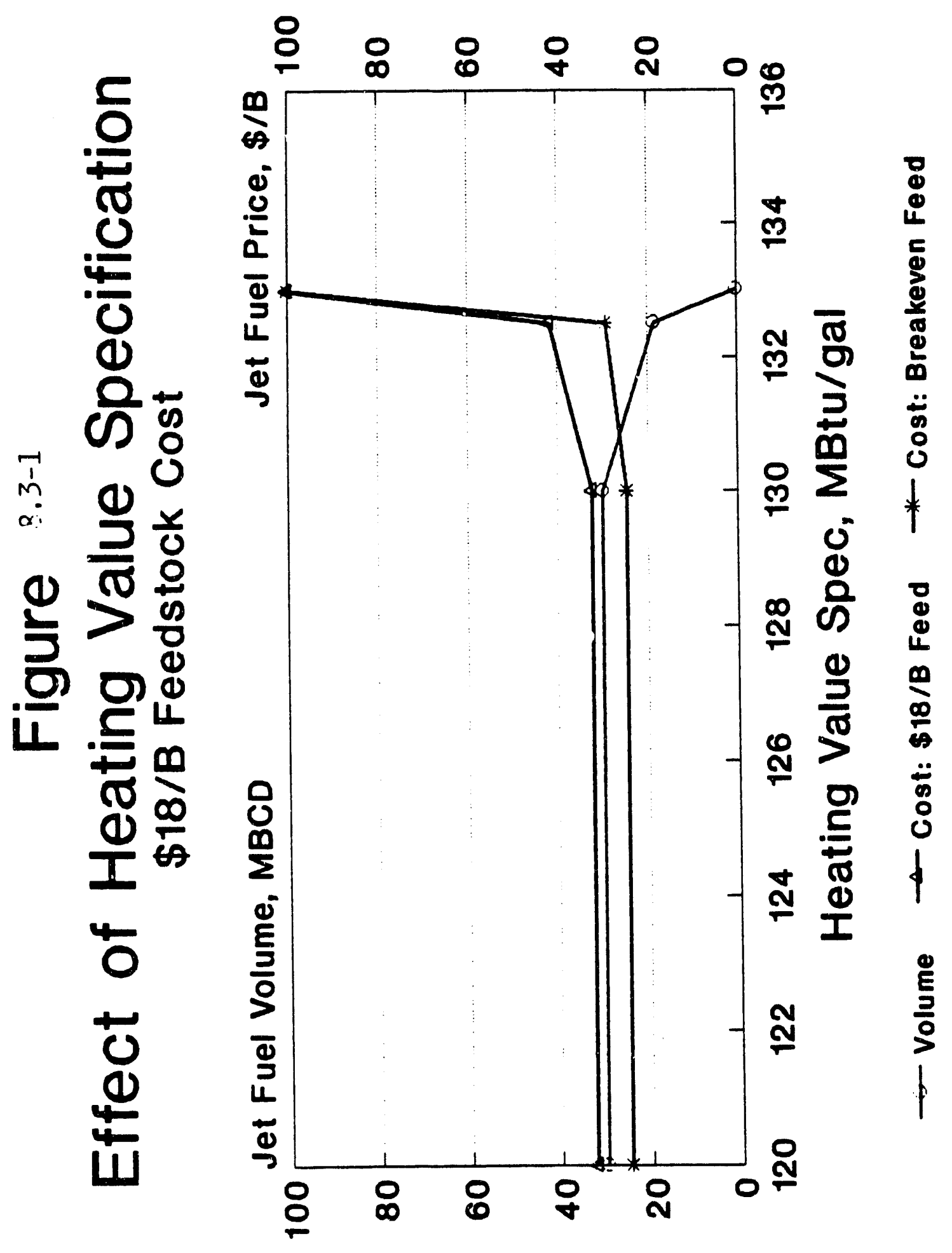




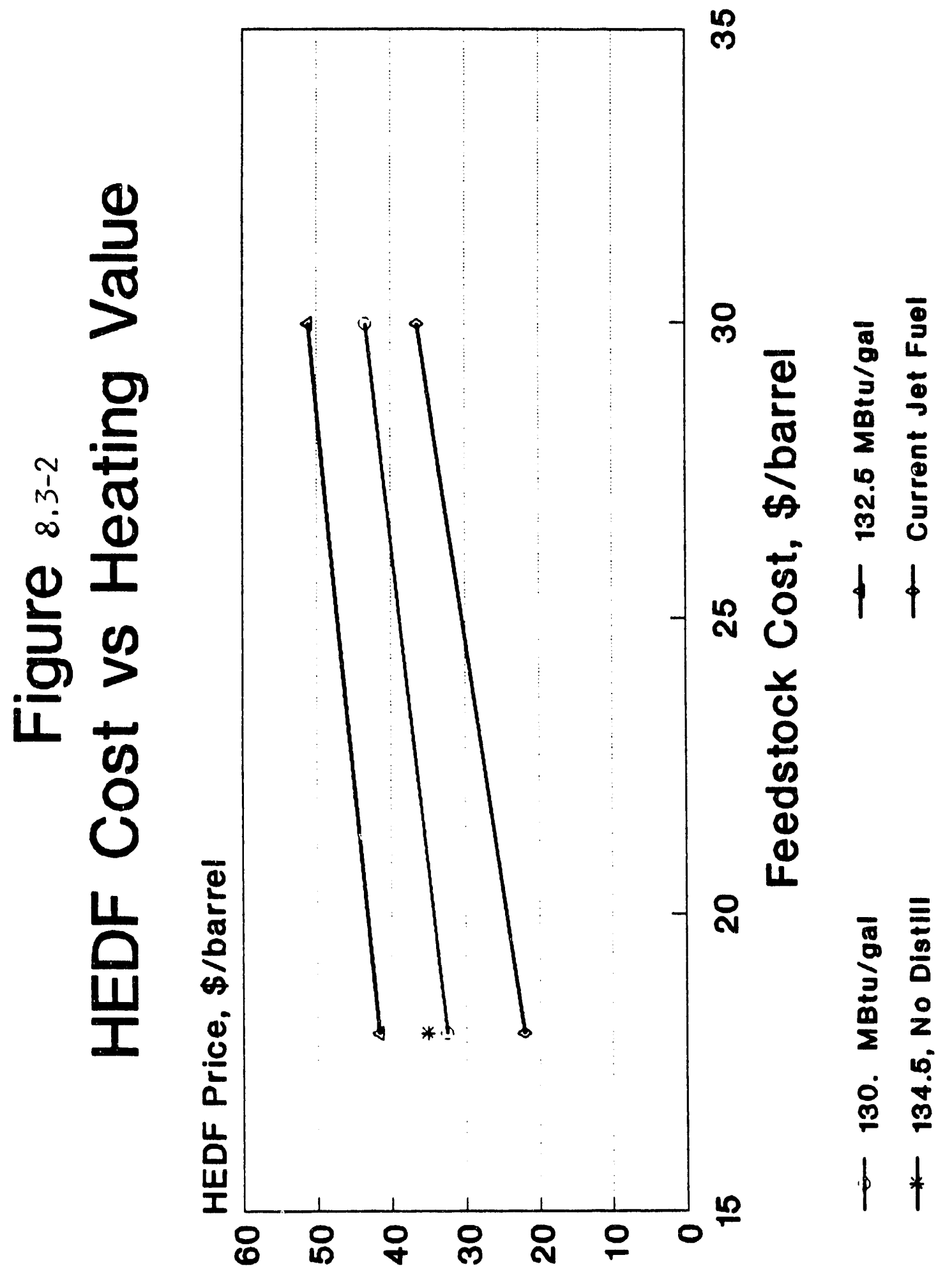




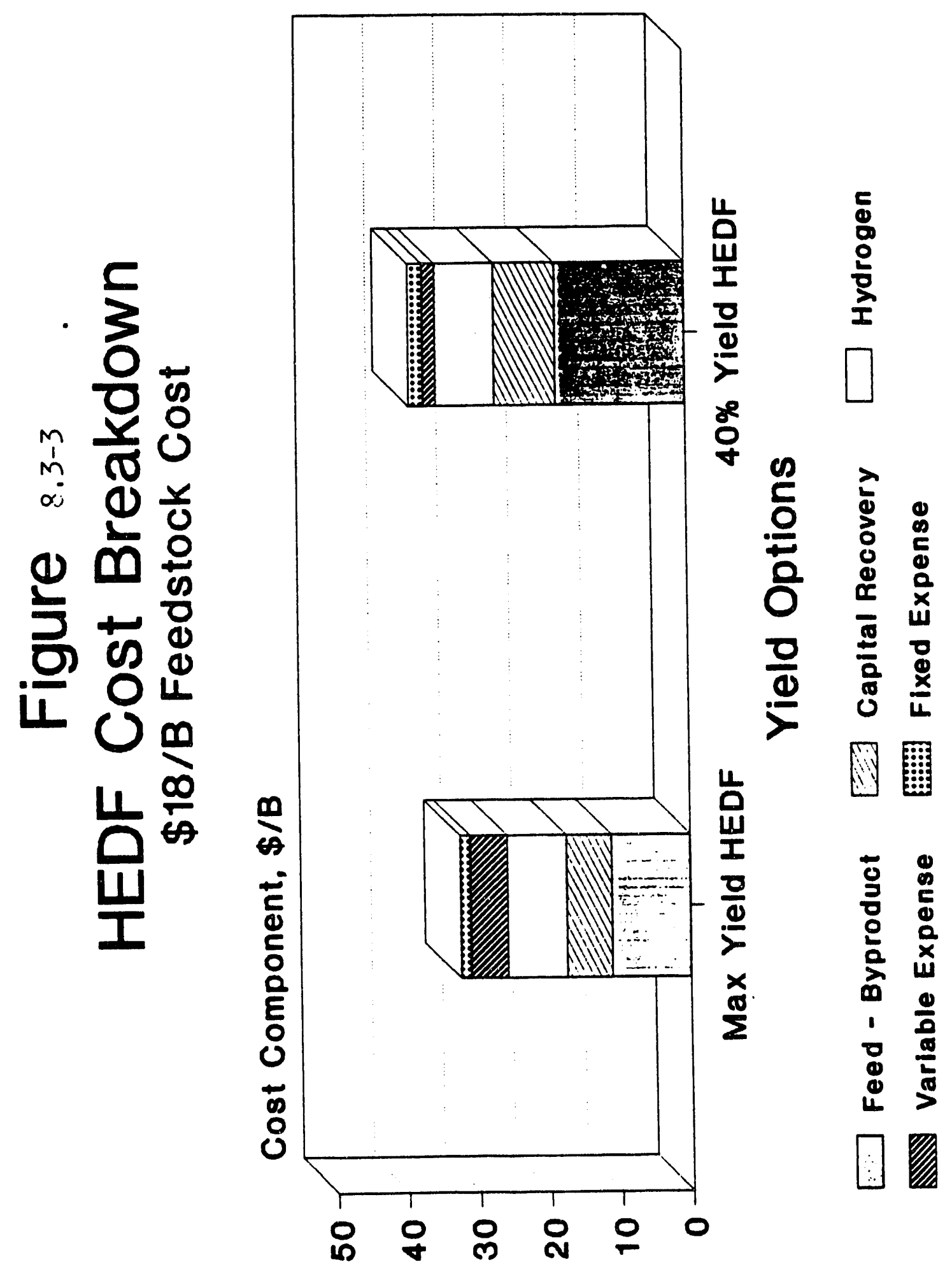




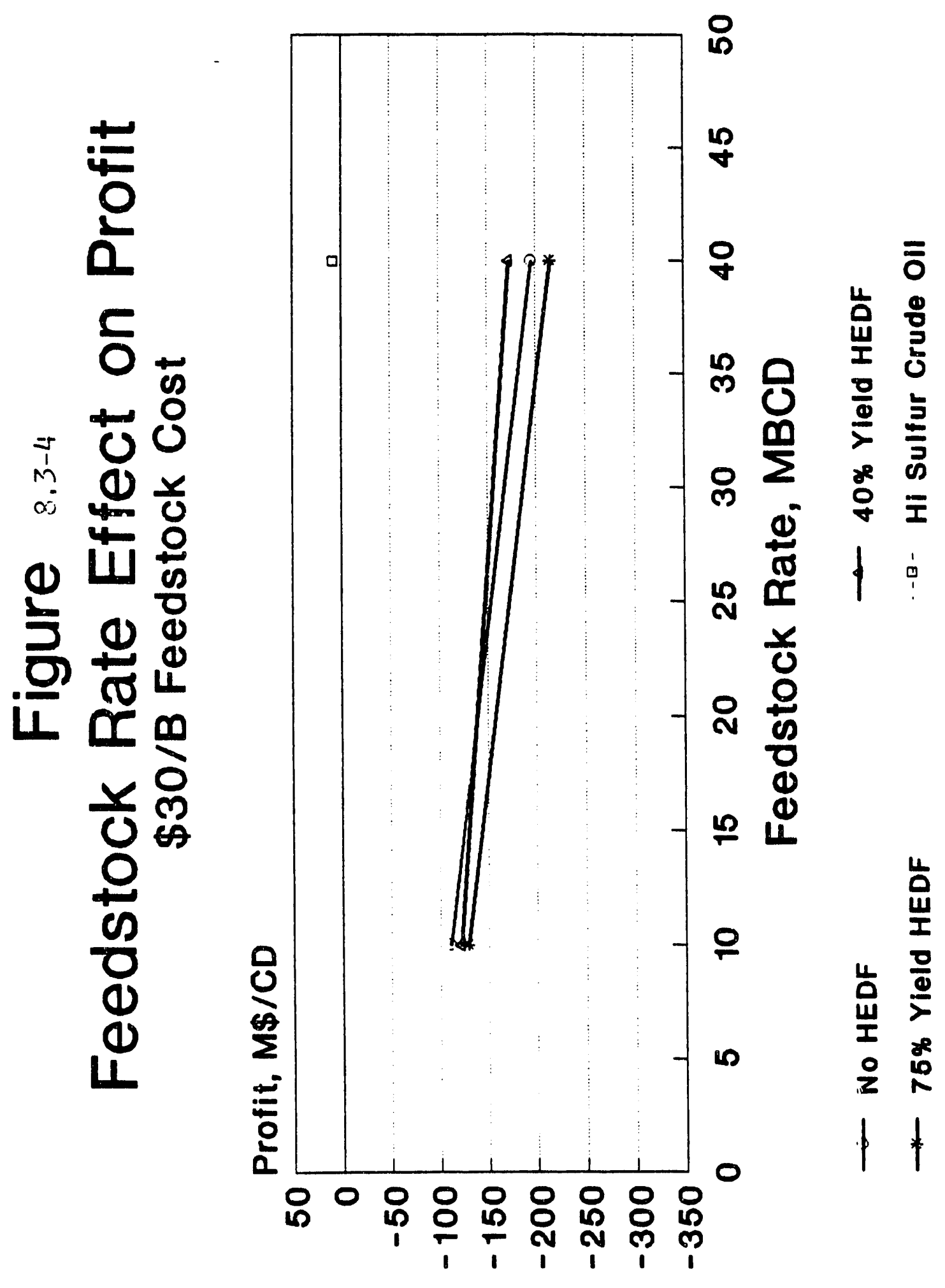


raising product prices helps to encourage the more severe processing needed to produce HEDF by providing more net sales margin to cover capital recovery costs. However, as more HEDF production is required with a fixed COALITE feedrate, costs eventually rise because ultimately stocks are selected for which the incremental processing costs are higher than the let fuel selling price.

The \$/B analysis of these cases is shown in Table 8.3-1 and Figure 8.3-5 for comparison with Table 8.2-4 and Figure 8.2-4. Because the crude oil only case shows a slight profit, the breakeven $\$ / B$ for this case is above, rather than below, the $\$ 30 / B$ starting basis. COALITE is worth about $\$ 5 / B$ less than crude oil at this price level. This is about $17 \%$ below the crude oil price, as in the $\$ 18 / \mathrm{B}$ cases.

It was recognized that the HEDF specifications listed in Table 8.1-1 were somewhat arbitrary. Experience with petroleum based fuels and current fuel delivery systems was used to set their levels. If a HEDF was needed for some specialized application, a hardware solution could be found for most cases of non-compliance with the specifications listed. For example, if the new HEDF was produced that was more viscous than current specifications, a higher power fuel pump might be specified in the target engine instead. A case was run to see what HEDF would be produced if all specifications in Table 8.1-1 were waived except energy density.

Figure 8.3-6 shows that over 95\% Yield of HEDF could be obtained from the COALITE starting material. The processing options selected include the same sweetening and diolefin hydrotreating for the COALITE naphtha as in the baseline cases. The whole 300F+ COALITE stream is treated in an expanded-bed LC-Finer. The light LC-Finer naphtha is blended to gasoline, while the heavy LC-Finer naphtha is sold as reformer feed. The LC-Finer distillate is blended directly to HEDF. The LC-Finer bottoms stream is hydrocracked, and the hydrocracked products are blended in the same manner as the corresponding LC-Finer streams.

The properties of the HEDF produced are shown in Table 8.3-2. This HEDF exceeds the energy density specification and is much heavier than conventional jet fuel as the high viscosity and the $50 \%$ off at $540 \mathrm{~F}$ shows. The viscosity is probably equivalent to around $5 \mathrm{cs}$ at $68 \mathrm{~F}$, and would be slightly lower than diesel fuel. The high aromatics and low hydrogen contents suggest a fuel that would require major jet engine modifications. However, some intermediate processing between this case and those previously discussed may be worth pursuing to improve yields and energy density.

Figure 8.3-7 shows how the HEDF jet fuel cost from the 40 MBCD plant size varies as a function of HEDF yield for both feedstock costs. The HEDF cost falls as the yield increases. However, at best, the HEDF cost remains some $\$ 8-10 / B$ above the conventional jet fuel cost when the feedstock is priced at $\$ 18 / B$. Figure $8.3-8$ shows the same trends for the $10 \mathrm{MBCD}$ size plant with some of the $40 \mathrm{MBCD}$ points shown for reference as dashed lines. The smaller scale of the 10 MBCD plant always leads to higher HEDF costs. 


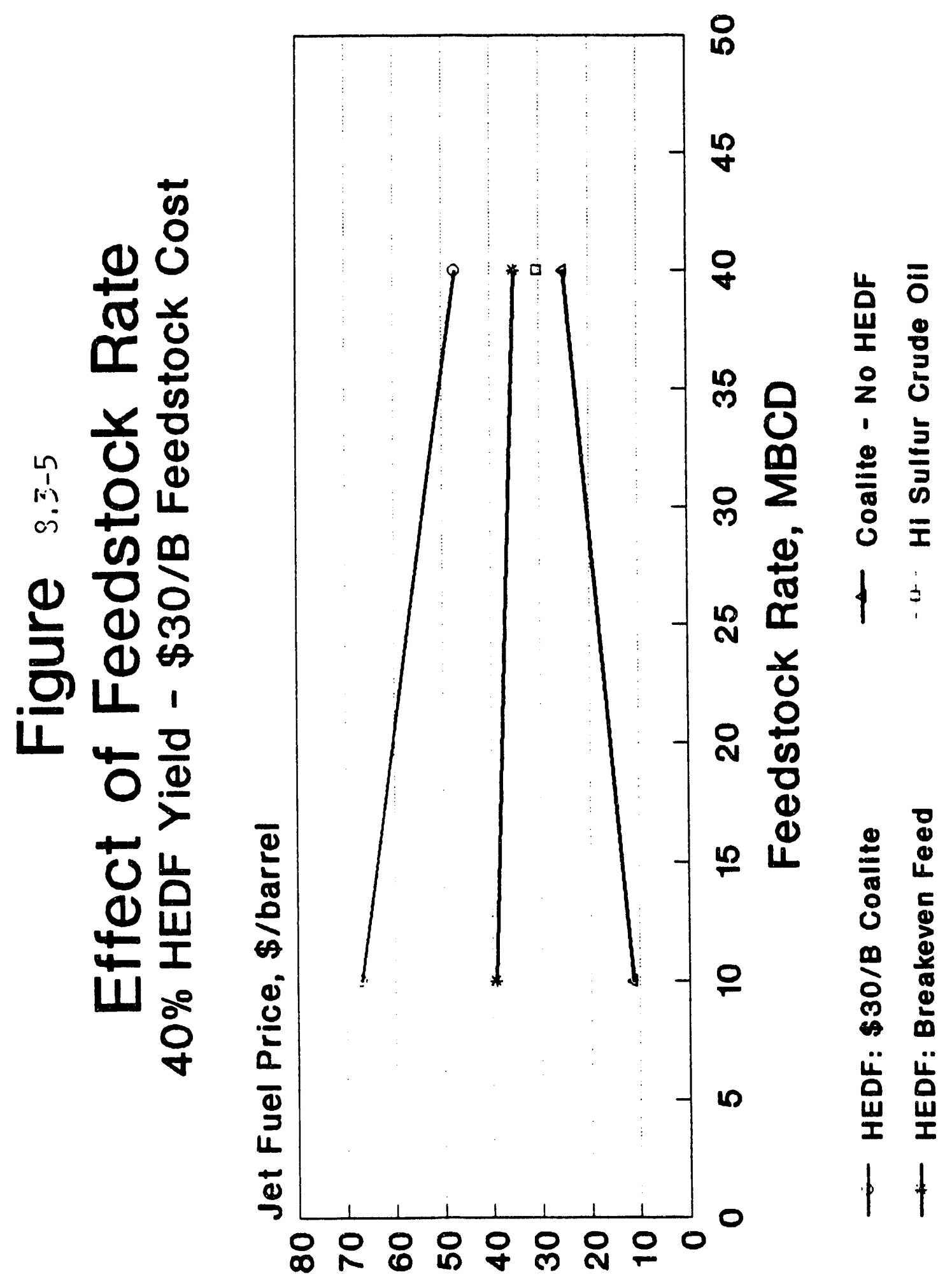

306. 


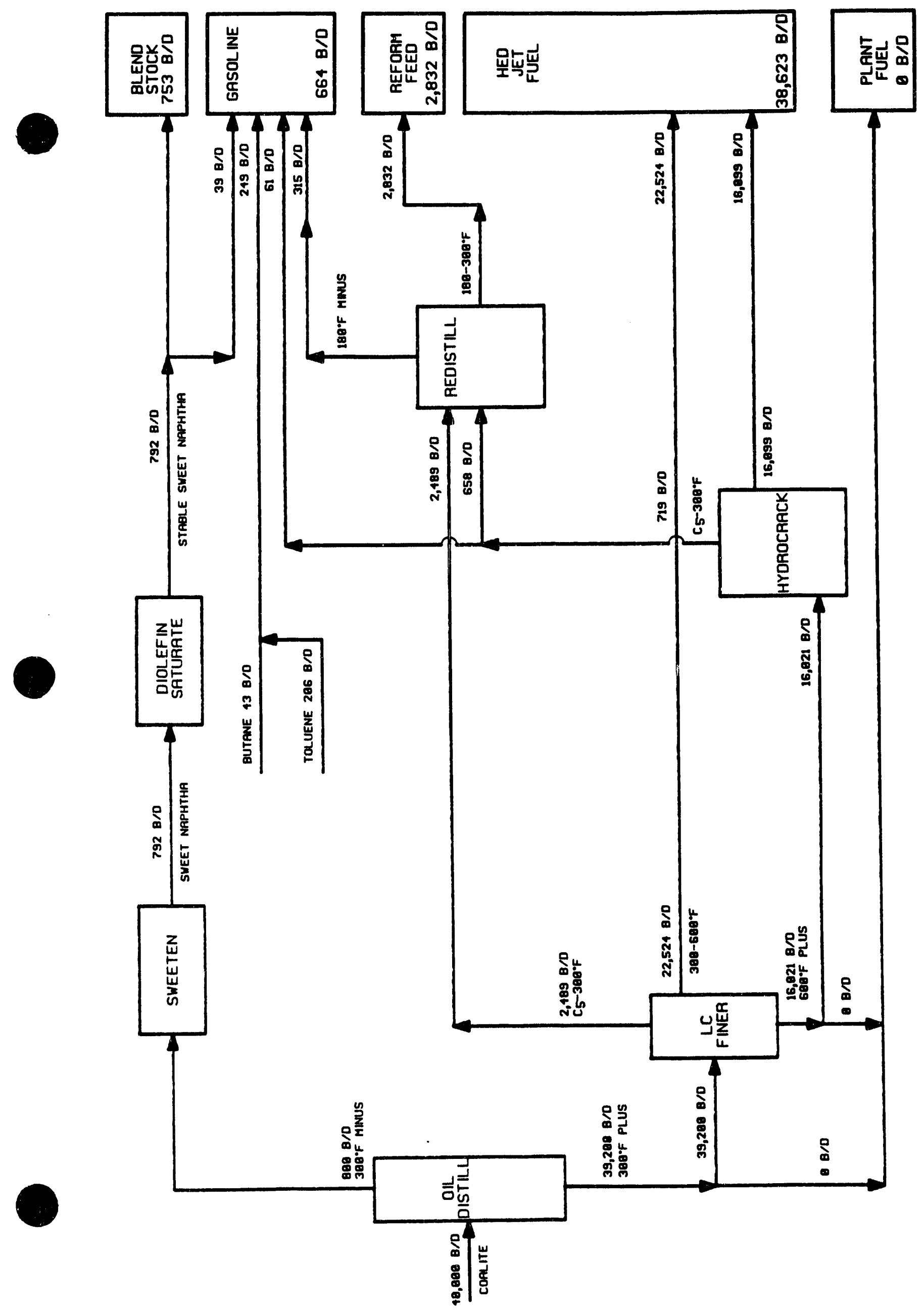

U
$w$
os
을

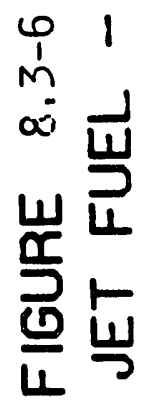

포

$\frac{\sum}{\frac{\Sigma}{\Sigma}}$

307. 


$$
\text { IABLE } 8.3-2
$$

PRODUCT COMPARISON WITH SPECIFICATIONS

40 MBCD $\$ 18 / B$ Coalite

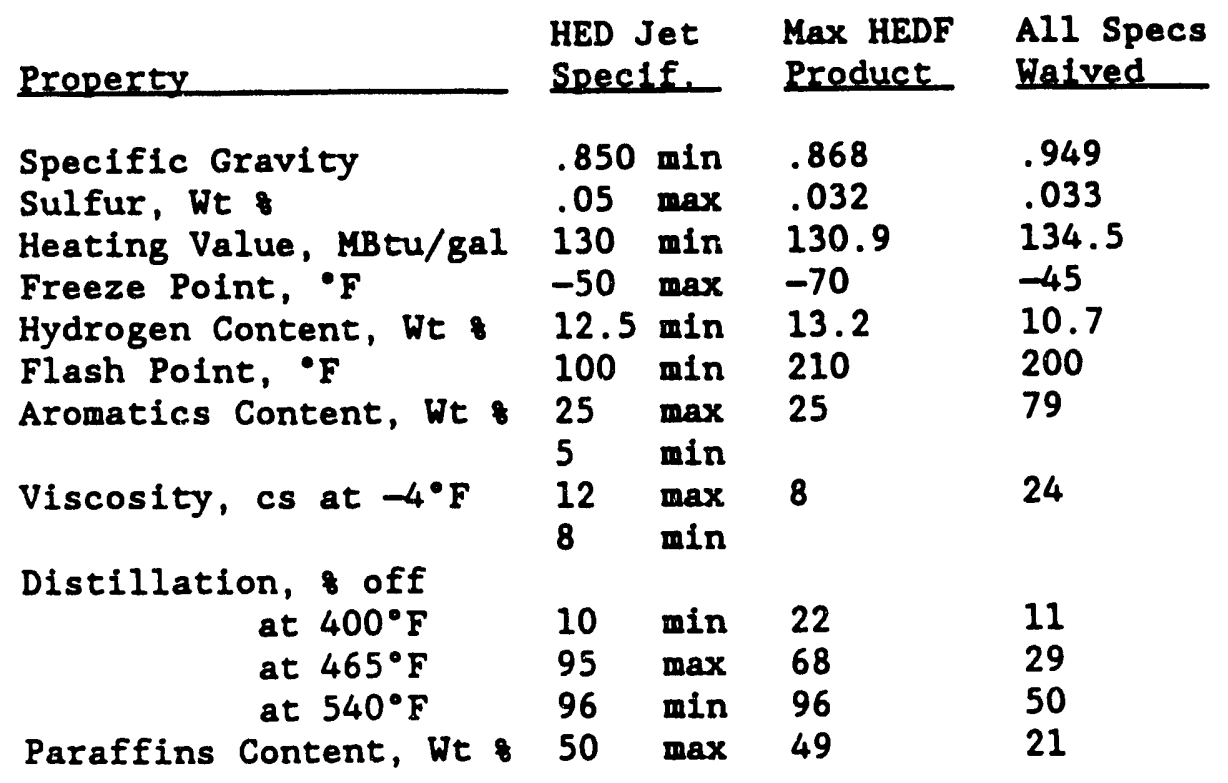




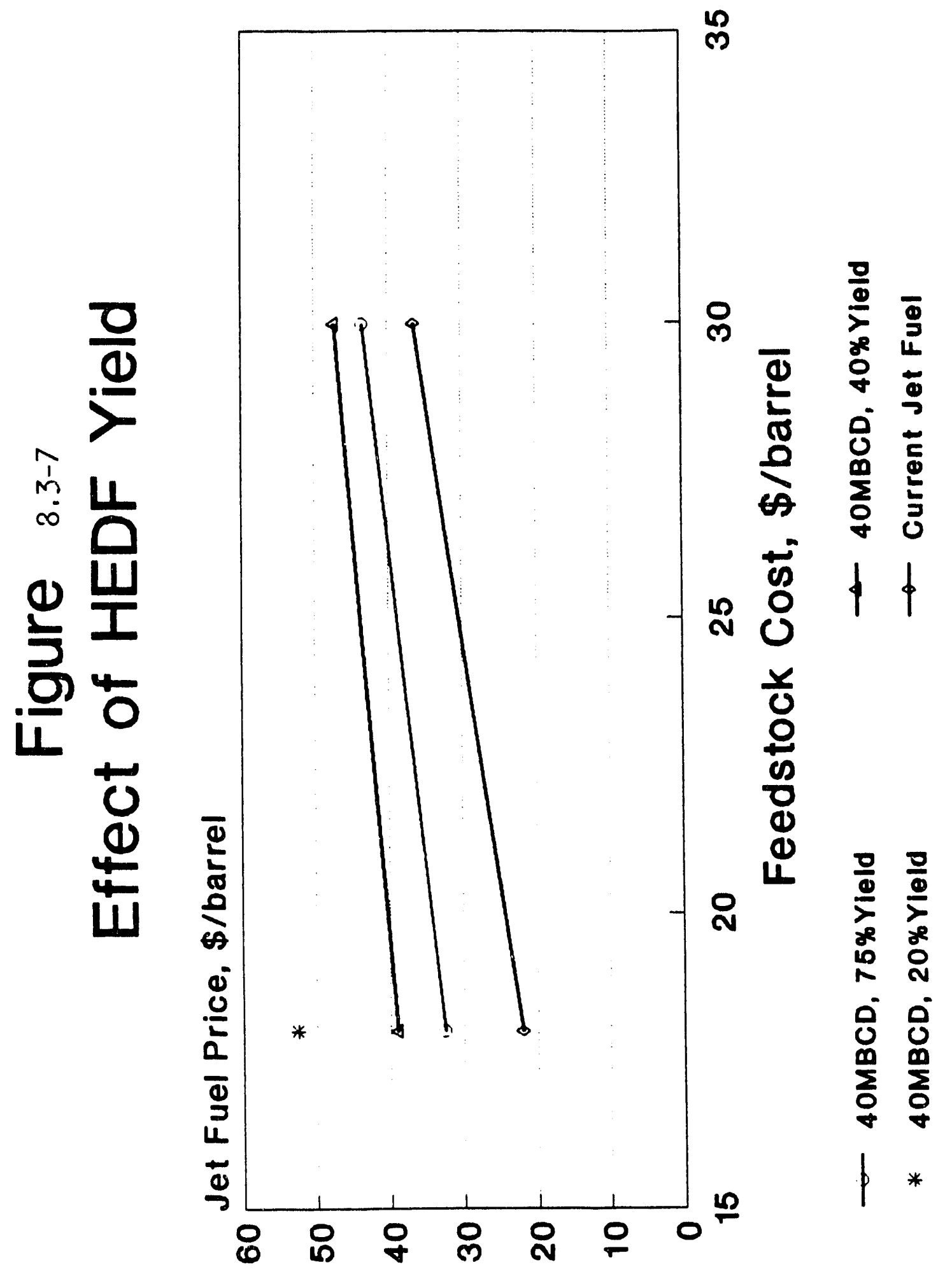




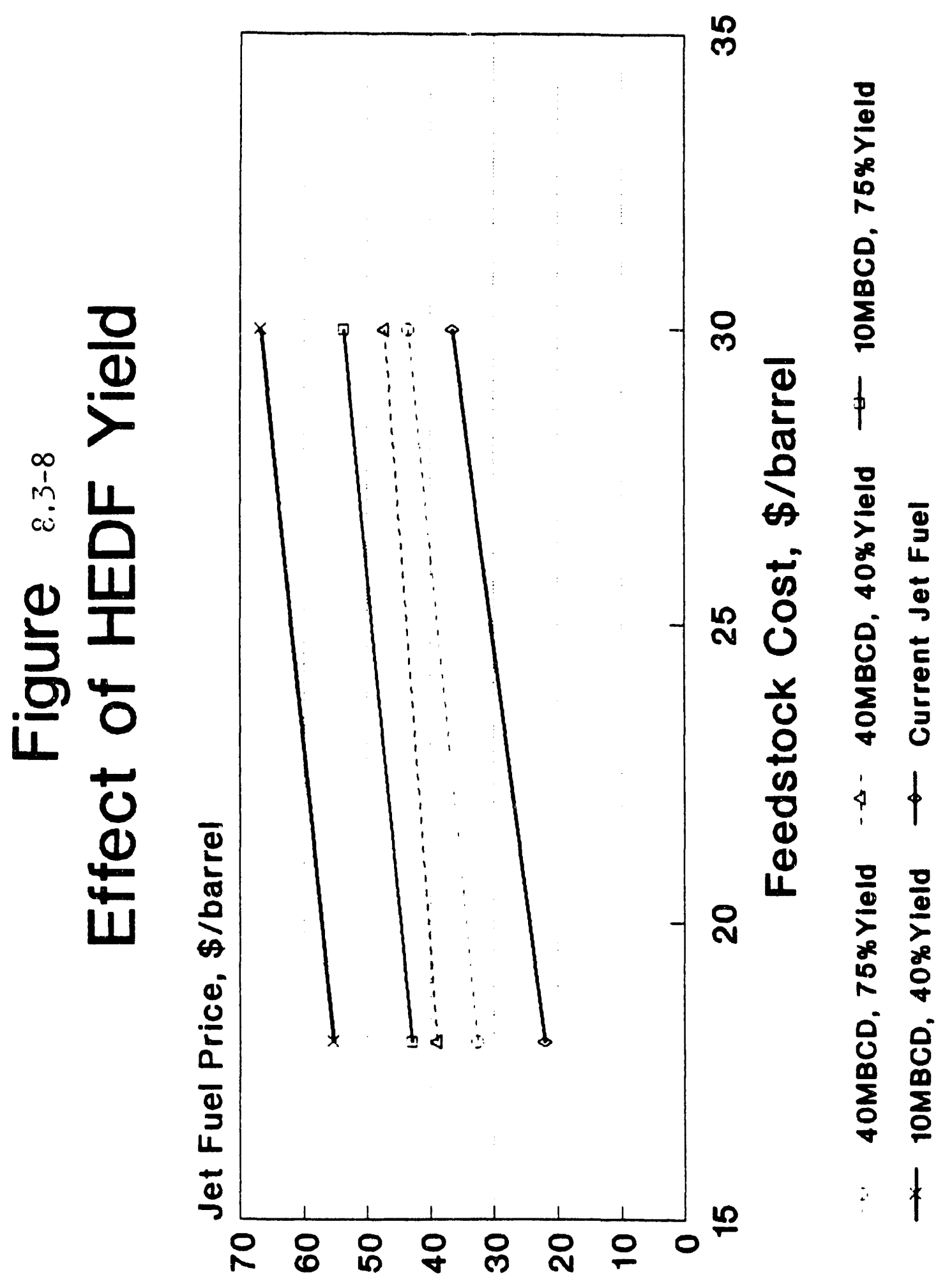




\subsection{Conclusions/Recommendations}

The major conclusions of the LP study when applied to refining COALITE fluids utilizing the current database obtained during the Task 3 screening efforts are as follows:

- The COALITE (MCG) liquid feedstock cost is a major component of the HEDF transfer price. For a 40,000 bpcd refinery operated under the constraints of an $\$ 18 / \mathrm{bbl}$ petroleum crude-based economy, the allowable COALITE cost with conventional products is estimated at $\$ 12.30$ per barrel. This represents only a $\$ 3$ per barrel disadvantage relative to high sulfur petroleum crude. When the refinery is allowed to produce HEDF products, the al lowable COALITE cost decreases only to about \$10-11 per barrel.

- Refining of COALITE to HEDF products is capital intensive and capital recovery costs can amount up to $25 \%$ of the HEDF transfer price.

- Hydrogen-related costs, operating as well as capital costs, can represent up to $15-25 \%$ of the HEDF transfer costs suggesting the importance for development of catalysts to improve hydrogen utilization.

- The economy of scale also has a great effect on HEDF transfer prices and refining capacities on the order of a hundred thousand barrels per day or greater should significantly reduce the per barrel cost of upgrading COALITE.

- Determining the use value of a high density iet fuel could have a great impact on the processing alternatives and the allowable production costs of MCG liquids via Mild Coal Gasification. In this study, the baseline case assumed the HEDF product would have a value equivalent to that of conventional JP-8 fuel, namely, $\$ 21.84 / \mathrm{bbl}$. Raising product prices helps to encourage the more severe processing needed to produce HEDF by providing more net sales margin to cover capital recovery costs.

$0 \quad$ While Task 3 and 5 efforts did not achieve the $135,000 \mathrm{Btu} / \mathrm{gal}$ energy density target, values in the vicinity of 133,000 were achieved. If the proper premium is placed on this type of fuel, when used either for military or commercial applications, and assuming the MCG char can be sold at some premium value over that of the feed coal (on an energy value basis), an LP model study would probably indicate that the MCG to HEDF route would be economically viable for a petroleum pricing scenario of $\$ 20-25 / \mathrm{bbl}$. 


\subsection{REFERENCES}

1. Pound, G.S., "The Production of Chemicals From Low Temperature Tar", J. Inst. Fuels, Coke \& Gas (October 1952)

2. Char 0il Energy Development (COED), Vol I Final Report, FE-1212-F, ERDA Contract E(49-18)-1212, September 1975.

3. M.R. Khan, "Correlations Between Physical and Chemical Properties of Pyrolysis Liquids Derived from Coal, Oil Shale and Tar Sand, Energy \& Fuels, 1988, 2, 834-842

4. "Development of High Energy Density Fuels from Mild GAsification of Coal - Task 3 Topical Report: Screening of Processing and Upgrading Schemes", DOE Contract DE-AC21-MC25020, ABB Lummus Crest contractor, Report MC25020-T3 (October 1991)

5. "Development of High Energy Density Fuels from Mild GAsification of Coal - Task 4 Topical Report: Proposed Upgrading Schemes for Advanced Fuels", DOE Contract DE-AC21-MC25020, ABB Lummus Crest contractor, Report MC25020-T4 (October 1990) 


\subsection{INVENTION DISCLOSURES}

No invention disclosures were filed as a result of performance of work under this contract.

313. 


\subsection{ACKNOWLEDGEMENTS}

Lummus would like to acknowledge the following individuals for their guidance and assistance in facilitating the efforts on this HEDF technology screening program:

Charles Byrer

Jim Burchfield (retired)

Joe Masin
DOE-METC COTR

DOE-METC Extraction Projects

Management Division

AOC Subcontractor, Lead LP Modeling Process Engineer

We would also like to acknowledge the following Lummus personnel for their contributions on the screening program:

Marvin Greene

Steven Huang

Sam Mikhail

Louis Senario

Vincent Strangio

Robert Valente
Project Manager/Principal

Investigator

Pilot Plant Engineer

Analytical Chemistry Supervisor

Pilot Plant Operations Supervisor

Pilot Plant Operations Manager

Pilot Plant Engineer 

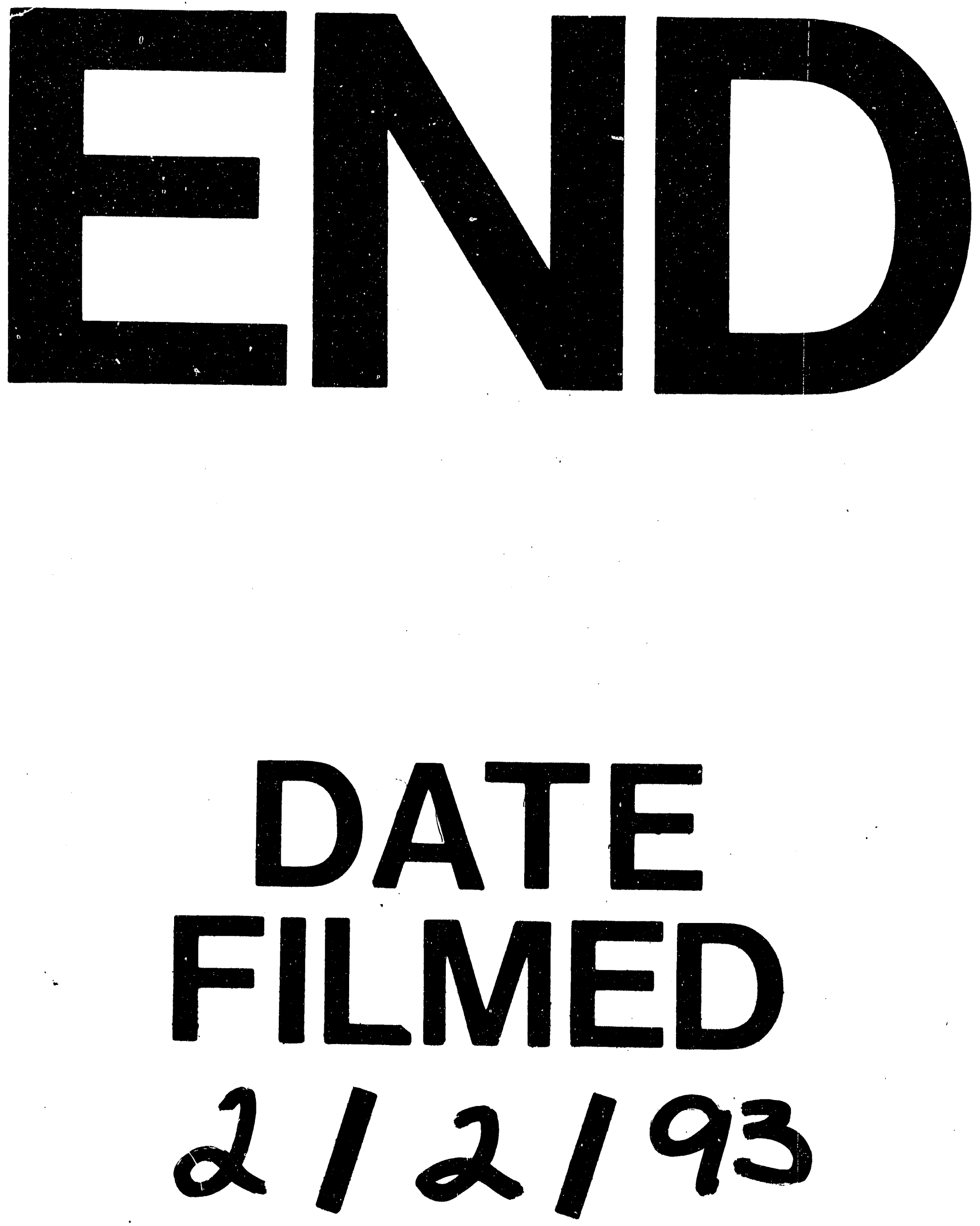
